
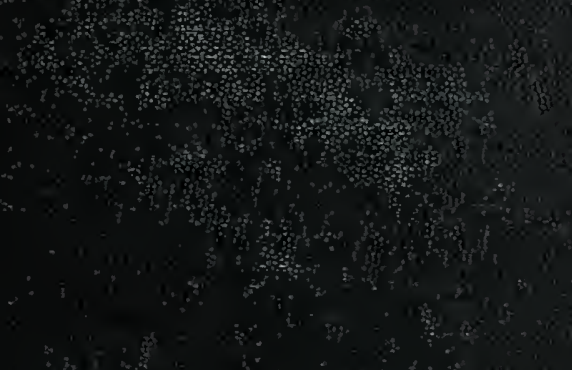

器: -
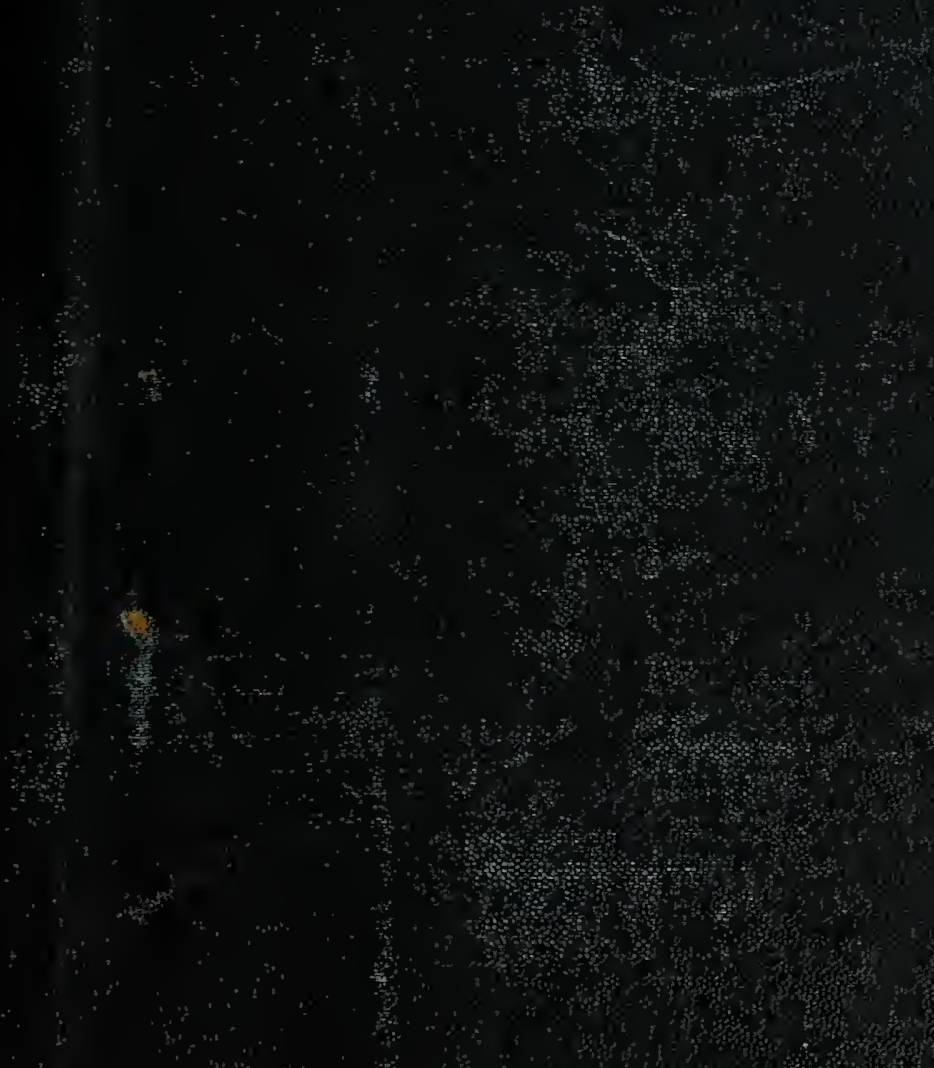

A

soth

椟

$\therefore \%$
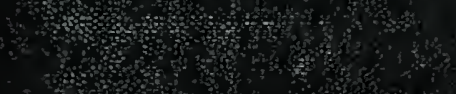


\section{STATE COLLEGE}

\section{OF}

WASHINGTON

\section{LIBRARY}

class..58.9. No..8?h Act. No.t375.4 Cop... 
Digitized by the Internet Archive in 2007 with funding from Microsoft Corporation 



\section{A \\ HISTORY OF BOTANY I 860-I 900}

BEING A CONTINUATION OF SACHS

'HISTORY OF BOTANY, I530-1860'

BY

\section{J. REYNOLDS GREEN}

Sc.D., F.R.S., F.L.S.

FELLOW OF DOWNING COLLEGE, CANBRIDGE; HARTLEY LECTURER IN VEGETABLE PHYSIOLOGY IN THE UNIVERSITY OF LIVERPOOL; FORMERLY PROFESSOR OF BOTANY TO THE PHARMACEUTICAL, SOCIETY OF GREAT BRITAIN; SOMETIME SCHOLAR OF TRINITY COLLEGE, CAMBRIDGE AND SENIOR DEMONSTRATOR OF PHYSIOLOGY IN THE UNIVERSITY

\section{OXFORD}

AT THE CLARENDON PRESS 
HENRY FROWDE, M.A. PUBLISHER TO THE UNIVERSITY OF OXFORD LONDON, EDINBURGH, NEW YORK TORONTO AND MELBOURNE
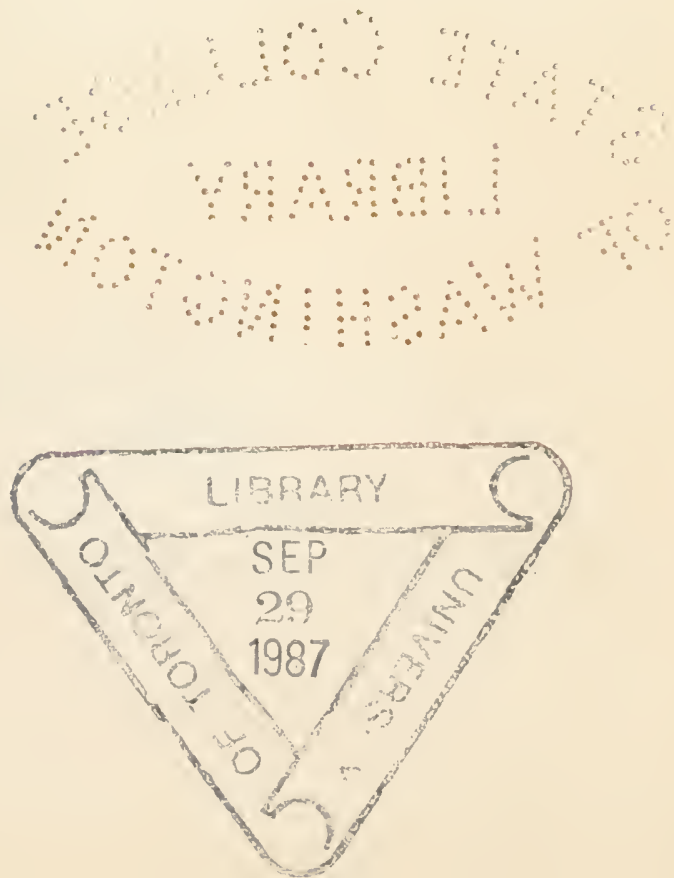


\section{PREFACE}

THE task of writing a continuation of Sachs' History of Botany, which was three years ago entrusted to me by the Delegates of the Clarendon Press, has been a particularly onerous though very agreeable one, and it is with considerable diffidence that I submit this supplementary volume to the criticism of my colleagues and fellow workers in botanical science. The difficulties attending its production have not been minimized by the reflection that no doubt each of them has his own conception of what such a continuation ought to be, and of the manner in which it should be planned. I have thought it best to adhere as closely as I could to the lines on which Sachs founded the original work, though I cannot but feel that I have no right to claim that this is undeniably the best method. The difficulty of dealing with an almost innumerable number of memoirs instead of with a few great works, may well in the opinion of many have called for different handling. On such a point I do not wish to dogmatize. I have tried, while adhering to Sachs' main lines of treatment, to show what has been the trend of thought in the different sections into which he divided the subject, and have been compelled by the great amount of literature to select for notice what have seemed to me the leading memoirs. There may be differences of 
opinion as to the justice of such selection as I have made and as to the omissions I have felt necessary. On such points I shall welcome the criticism of my readers with great cordiality, recognizing fully what variety of opinion may exist on the details of every subject. I claim, however, to have made a sincere attempt to give credit where it is due and to judge no one unfairly.

In one respect I have departed from the plan of Sachs' volume; I have given a bibliography as full and as complete as I have been able to compile of the works to which I have found occasion to refer.

I wish to express my acknowledgements of the kind assistance of Dr. Francis Darwin, of Dr. D.H.Scott, and of Dr. A. B. Rendle, who have read certain chapters of the manuscript, and to thank Professor Harvey Gibson, and especially Professor S. H. Vines, for much kindly help and criticism as the work was passing through the press.

Cambridge, I909. 


\section{CONTENTS}

PAGE

General Introduction $\quad$ • $\quad$ • $\quad$ • 7

\section{BOOK I. MORPHOLOGY}

INTRODUCTION • . • . . . 43 CHAPTER

I. The Nature of Alternation of Generations 46

II. The Theory of Metamorphosis . . . 65

III. The Morphology of the Flower • • • 85

IV. TAXоNomy . . . . . . . . . IIO

V. Palaeobotany, I860-I900 . . . . I 33

BOOK II. THE ANATOMY OF PLANTS

INTRODUCTION . . . . . . . I57

I. The Cell . . . . . . . . 166

II. The Differentiation of the Tissues . . 194

III. The Study of the Cryptogams a • . 226

BOOK III. THE PHYSIOL.OGY OF PLANTS

INTRODUCTION • • • • • • • 245

I. The Developaent of KNowledge of the Processes of Absorption of Water AND its Subsequent Transport in the Body of the Green Plant • • . . . 247

II. The Development of Knowledge of the Approprtation of Carbon Dioxide by the Plant . . . . . . . , 278 
CHAPTER

PAGE

III. The Absorption of Nitrogen aNd the Construction of Nitrogenous Substance • 323

IV. ThE PRogress oF OUR KNOWLEdge OF THE Róle of the Constituents of the Ash of Plants

V. The Discovery of Chemosynthesis • • 368

VI. The Development of KNowledge of the Metabolic Processes . . • . 372

VII. ThE DEVElopment oF KNOWLEdGe OF THE Metabolic Processes (continued): Digestion. The Nature of Nutrition • • 400 VIII. The Development of the Modern Idea of the Catabolic Processes and the INTERnaL Energy Relations of Plants. • . 4 I9

IX. The Influence of the Study of the Nutrition of Heterotrophic Plants on the Progress of KNowledge of the True Nature of the Food of Plants . . . $43 \mathrm{I}$

X. The Problems of Growth and its Associated Conditions • • • . . . . . 442

XI. The Development of the Theory of Special SENSITIVENESS UNDER THE INFLUENCE OF THE 'Origin of Species' . . . . 458

General Conclusion . $\quad . \quad$. $\quad . \quad$. 50 . BIBLIOGRAPHY . . . . . . . . . 508 INDEX . . . . . . . . . . . 539 


\section{GENERAL INTRODUCTION \\ 43724}

SACHS has pointed out in his History of Botany how great was the change in the position of investigation and study which took place towards the middle of the last century. After 1840 there set in a great modification of botanical literature; instead of weighty presentations from the hands of a succession of great masters appearing at long intervals, the subject was developed by single monographs or isolated memoirs coming from the pens of numerous writers from various centres of study. These were naturally of very unequal merit, and needed a careful and independent scrutiny from their readers. The weight of authority was thus disturbed and the critic rather than the student grew in apparent importance. This change in the history of the development of the science became more and more pronounced as the century advanced; a period of confusion arose, which was perhaps inseparable from the accumulation of masses of detail concerning intricacies of form and structure. Out of such accumulations, however, though they were marked for the most part by no plan and no orderly arrangement, definite principles slowly emerged and made clear the way for the observers from I860 onwards. At the outset, we find the researches of that time failed especially to recognize the fundamental importance of the study of the living processes of the plant, of the bearing of anatomy on physiology and of physiology in its turn on anatomy: structure and function were only partially correlated and there was little recognition of the fact that the clue to the meaning of 
differentiation of structure must be sought in division of labour.

Two theories of fundamental importance were still held by most botanists: the one, that of the constancy of species; the other, that of metamorphosis. Of these, the first was destined to disappear almost at the beginning of the period I860-Igoo, which forms the subject of this volume ; the second was to give rise to considerable discussion and to obtain a presentation from an altogether different point of view.

These changes and the great development of the science that marked the period under review were in large measure the result of the appearance of two epoch-making works, each of the profoundest importance. It is difficult to compare them, for though they had certain features in common these did not appear upon the surface. The one appealed to botanists in particular, the other to the world in general. They were Hofmeister's researches on the Cryptogams and their affinities, and Darwin's Origin of Species. Appearing as both did just on the threshold of our period, and appealing to the whole biological world, they marked the commencement of the period as a starting point of generalizations, wider and of importance further reaching than any of the great generalizations of the past.

Hofmeister's illuminating investigations established the recognition of a more or less uniform plan of organization running throughout the whole vegetable kingdom, and overthrew what had till his time been considered to be the fundamental difference between the Cryptogams and the Phanerogams. He showed that, when co-ordinated and arranged, the structures of the reproductive mechanisms in both groups point to a progressive development or evolution throughout the vegetable kingdom, and that consequently a consistent phylogeny may ultimately be demonstrated connecting all the forms in one great 


\section{General Introduction}

sequence of relationship. By careful comparison of the life-histories of the plants comprised in the four now familiar principal divisions, he demonstrated a unity of plan appearing through great differences of structure and development - a uniformity based upon the curious life-cycle known to-day as the alternation of generations. Researches made thenceforward till near the end of the period under review showed that this uniformity and plan goes even further than Hofmeister taught, and vindicated the attitude he took and the great generalization associated with his name.

The bearing of his work was thus twofold; its morphological importance in pointing out the homologies of the reproductive organs of Cryptogam and Phanerogam, and its consequent explanation of the occurrence of that feature forming a distinction between the two groupsthe seed-was perhaps even of less consequence than its influence in emphasizing the new principle in classification that resemblance in particular characters indicates affinity based upon descent. Hofmeister developed the idea of the descent of the highest plants from primitive simple ancestors, and so struck a heavy blow at the dogma of the constancy of species.

The work of Hofmeister did not stand alone during those years of patient inquiry. The researches of many others, working on other lines, were similarly preparing the way for that recognition of evolution in the organic world which found its definite presentation in the writings of Darwin and Wallace. A little prior to 1860 morphology was studied in the light of theories of development and met therein with a certain explanation. The_cell was recognized as the unit of construction of all organized bodies, and the study of its multiplication and development was a feature of the time. The cell theory of Schleiden and Schwann had obtained general acceptance, the work of Von Mohl was exciting much interest and controversy, and the 
researches and theories of Unger and Naegeli were cooperating to direct the current of thought towards an evolutionary process capable of recognition in anatomy. The study of the ancient forms of plants was not without its influence on the same idea. Researches on fossil plants had not then reached a very advanced state of development, but even at that early period in their investigation the results obtained led Unger to make a definite pronouncement against the constancy of species and in favour of the view of evolutionary development. Naegeli gave the support of his opinion to the same idea, based upon similar considerations.

While these ideas were slowly and from several points of departure making their way into the stream of scientific thought, the position of the systematists, under the influence of the doctrine of the constancy of species, was becoming continually more hopeless and their outlook less cheerful. Their position was very clearly stated by Bentham in the following words: "There were no means of estimating the importance or value of characters except by such vague standards as the number of species in which they had been observed to prevail, no means of determining what degree of variation and persistence actually distinguished the species from the variety. The botanist who affirmed that Rubus fruticosus, Draba verna, or Sphagnum palustre were each one very variable species, and he who maintained that they were collective names for nearly 400, for at least 200, or for some twenty separately created and invariably propagated species, had each arguments in their favour to which no definite reply could be given, and systematic botany was in too many cases beginning to merit the reproach of German physiologists, that it was degenerating into an arbitrary multiplication and cataloguing of names and specimens of use to collectors only, and serving as impediments instead of aids to the 
extension of our scientific knowledge of the vegetation of the globe.' 1

The trend of the main line of thought, then, in the years immediately preceding $\mathrm{I} 860$, was clearly if not very emphatically, in the direction of the rejection of the old dogma of the constancy of species and the substitution of something more plastic and more in harmony with current discoveries. The way was thus in some sense prepared for the work which, from its bold generalization based on years of skilful research and matured reflection, made the years I859 and I860 a most prominently marked epoch in botanical research. On July I, I858, papers were communicated to the Linnean Society of London, ' On the tendency of species to form varieties and on the perpetuation of varieties and species by natural means of selection,' submitted jointly by Charles Darwin and A. R. Wallace, which embodied the first statement of the new views, and, in the next year appeared the monumental work of the former-The Origin of Species by Natural Selectionwhich was destined almost at once to revolutionize the methods and direction of biological research, substituting finally a definite plan of investigation for what had been up to that time almost purely empirical. At once Phylogeny as a definite line of inquiry, stood out before the thinker, and a new principle appeared established. Physiological problems assumed pre-eminence almost at a bound; the inquirer saw before him living individuals engaged in the struggle for existence and the propagation of their kind, contending partly with each other, partly with their surroundings, and almost for the first time he recognized the needs of life as the central point of interest, while details of structure acquired a new importance as they were interpreted in the light of this inevitable contest and turmoil. Physiological needs in the presence of environ${ }^{1}$ British Association Reports, Belfast, 1874. 
mental difficulties brought to light the processes of adaptation, and showed how the living organism assumed its peculiarities of form and structure in accordance with the nature of the life it had to lead.

In this way the final blow was given to the dogma of the constancy of species, and evolution through natural selection in the struggle for existence took its place. How great a change was this the researches of the remainder of the century will serve to show. At the outset it opened the way for new investigations, offering them the stimulus of more illuminating ideas and compelling them to new methods, and it succeeded in bringing about a great enthusiasm for all branches of inquiry.

The other almost fundamental dogma of the time, Goethe's theory of metamorphosis, also came under review. This doctrine, the outcome mainly of a poetic mind, was, as stated by Goethe himself, difficult to grasp and harder fully to appreciate. As expounded by others it became rigid and exacting. The introduction of the new ideas modified it sensibly, emphasizing the view that the changes in the different parts of the body of the plant, which were described as metamorphoses, are mainly adaptive and consequently traceable to the influence of the environment. Though the theory of metamorphosis gave rise in the later years of the century to considerable controversy, the change in the point of view led to greater clearness of conception and to the abandonment of the somewhat fanciful or ideal attitude with which Goethe's early pronouncements were associated.

To ascertain the position of the science in I860 it is well to turn to the textbooks of the time, as, though not abreast with the then most recent inquiries, they presented to their readers what were the established opinions among the botanists of the countries of their publication. Germany had produced the majority of the workers on intimate 
structure, and, as may well be imagined, was in possession of the most advanced knowledge. The labours of Schleiden, Von Mohl, Unger, and Naegeli had been sedulous and protracted, and had led to the recognition of the part played by the cell in the construction of plants, and consequently to the establishment of the cell theory. But though the cell as a unit was attracting attention its parts were not clearly appreciated. By many the importance of the protoplasm was not grasped, nor its identity as the living part of the cell realized. It was frequently spoken of as merely a part of the cell contents. Nothing was known about its differentiation except the existence of a nucleus, and the fact that in some cases its surfaces are not exactly like its more internal part. The continuity of the protoplasm between cell and cell had not been discovered, though it was suspected in such cases as the segments of sieve tubes. The differentiation of the tissues had not been very fully studied, though some progress had been made by the investigations of Unger and of Naegeli. The knowledge of the vascular system was very imperfect and no information of any value was forthcoming as to the tissues of nutrition or secretion. The lines of investigation and research were based chiefly upon the formation and character of the cells of the tissues, and there was consequently a lack of proper interpretation of their purposes. Their inter-relations had not come into question, and therefore the study of anatomy could not have its proper perspective. A special weakness was the absence of a realization that the differentiation of structure is the outcome, more or less immediate, of physiological division of labour. The influence of the environment on structure, one of the great lessons to be drawn from Darwin's teaching, was still unexamined. At the same time much sound knowledge had been obtained. The researches carried out by Naegeli on the various bodies found in cells and on the membranes 
which separate them had led him to formulate his wellknown theory of the micellar constitution of all organized structures and of growth by intussusception, the most notable generalization of the time. It had been received with enthusiasm by the leading workers in both anatomy and physiology, and it played a great part in the investigations of the earlier years of the period with which this book proposes to deal.

In France and in Great Britain the condition of knowledge was not so far advanced as in Germany. Even the mechanics of the stem were wrongly apprehended and gross errors still remained uncorrected. By some of the leading botanists of the day in those countries, cambium was still held to be a jelly-like, mucilaginous substance, out of which new cells were formed by a process something like condensation or crystallization; the laticiferous vessels of the stem were held to be the path of the descending sap, communicating with the other vessels, and acting as venous reservoirs for the circulating fluid.

The conception of the vegetable cell which was current in England is especially noteworthy. Cells were said to be formed from a thickened fluid in the interior of cells, or elaborated by their agency, the thickened fluid being called protoplasm. There was no recognition that protoplasm is the living substance-indeed there seemed a strange indifference to the existence of anything living in the plant at all. In an edition of I86I, Bentley's textbook gave the following presentation of free cell-formation : 'A portion of the protoplasm collects into a more or less rounded or somewhat oval form, with a defined outer border, thus forming the nucleus of the cell; upon this a layer of protoplasm is deposited, which assumes the form of a membrane, and expands so as to form a vesicle ; on the outside of this a cellulose membrane is secreted and the formation of the cell is completed. The proto- 
plasmic vesicle in this case forms the subsequent lining of the young cells, and constitutes the "primordial utricle" of von Mohl.'... 'In some cases no nucleus can be detected in a cell previous to the formation of other cells free in its cavity; hence it is quite clear that the presence of the nucleus cannot be regarded as essential, but that the separation of a portion of the protoplasm from the general mass must be capable of acting as one, and thus to cover itself with a membrane and form a cell.' Henfrey's textbook contained a very similar account, but ignored the nucleus altogether.

It is hardly necessary to go into further details; it is only too clear that the need for new investigations was pressing, and that especially new points of view and new lines of research were imperatively required.

The state of knowledge of physiology was still less satisfactory-indeed it may almost be said that vegetable physiology as a science had not yet come into existence. Since the early researches of Senebier, Ingenhousz and de Saussure no physiologist of eminence save Dutrochet had appeared. Liebig had done great service in disposing of the 'humus' theory of nutrition, but the confusion he introduced into the consideration of the important question of respiration can only be called deplorable. Boussingault, like Liebig an agricultural chemist rather than a botanist, had made important investigations into the same range of problems, connected with the supply of nitrogen to the plant. But on the whole little progress had been made; it is indeed doubtful whether knowledge had not gone backward rather than forward during the two decades prior to 1860 .

The absorption and transport of water, the relation which it bears towards the problems of nutrition, the nature and meaning of the gaseous interchanges between the plant and the atmosphere, the meaning of the presence of chlorophyll-all problems of the highest importance- 
had not been the subjects of study in any detail-indeed no methods had been devised for dealing with them. The appropriation of carbon dioxide was held to be a form of respiration quite as much as the true respiratory processes; the nature of the latter was not understood, and it was held to be nocturnal only in its occurrence. True, speculation had begun to be rife and inquiry was in the air, but botanists stood on the threshold of an unknown territory illuminated by hardly a single ray of light.

By many others a still less satisfactory position was taken up. Anatomical or histological conceptions were made primary, and functions sought or imagined for each. For instance, parenchyma was thought to have some definite function as such, and consequently this hypothetical function was suspected wherever parenchyma occurs. The same sort of conception was applied to the stem-it was thought necessary to assign separate functions to the pith, the wood, the medullary rays, the bark, all of which were held to be definite organs. No doubt it is possible to see a relation in these structures to a division of labour, but a severe allocation of each to some particular duty went much further than was justified by the state of knowledge. The fundamental error in conception was a failure to recognize the plant as an individual exhibiting unity of purpose in its working. Instead, the cell was made the unit, and inaccurate conceptions followed. It is rather strange also to notice in the textbooks of the time what a lack of proportion was shown in the treatment of physiological subjects. It was not uncommon, for instance, to find that descriptions of the 'rotation of sap' in the cell had as much space allotted to them as the whole story of absorption and transmission of fluid!

The progress of classification was almost at a standstill. The system of de Candolle was almost universally accepted as a basis, and though Lindley in England, and Brongniart 
in France had attempted to bring about advances in a truly natural direction, they had not been very successful -indeed Lindley's system was rather retrograde than otherwise. A certain progress, springing from Hofmeister's researches, had been made with the Cryptogams, but the details of their life-history in many important groups were altogether lacking, and hence no data for accurate classification were forthcoming. The terminology employed was confused and often inexact, making correct ideas on homology difficult, if not impossible. The last two considerations bore with especial weight upon the Algae and the Fungi.

In the year I860 we see that botanical research was entering upon a period of renewed activity. With the coming of the new epoch brought in by the appearance of Darwin's work, investigation ceased to be empirical, and became dominated by a new and stimulating idea. The days of almost purposeless collection of new facts were over, and definite problems presented themselves in great profusion, developing and illustrating the theory that Darwin had put forward. The definite directing of the new series of researches towards special problems led with certainty to the widening of ideas and to the spreading of the paths of investigation in almost every direction.

Just at this crisis there appeared upon the scene another worker to whom may be attributed in a remarkable degree the immense progress of investigation which marked the years I860-I900. This was Julius von Sachs, who may almost be spoken of as the father of modern botany. Great as was the part he played in the researches of his time, his influence extended far beyond the limits of his own laboratory. He co-ordinated the work of those who had preceded him with that of his contemporaries, and by his lucid writings he was largely instrumental in directing the stream of thought. He illuminated all departments of 
the science by his keen insight, while his attractive style and clear modes of expression made him at once the most able and most popular of teachers. His strong personality attracted to his lecture-room and laboratory a crowd of enthusiastic and able pupils, by whose efforts research was advanced to an extent almost unprecedented. Men of all nationalities flocked to him, and after a longer or shorter period of intimate association with him they carried to their own countries the spirit which animated him, and which they had caught while under his immediate influence. In England especially his works aroused the greatest enthusiasm. Research had been effectively pursued by few since the time of the activity of Knight and of Robert Brown. Indeed, if we exclude these two, Sachs himself showed that England had done little for the advancement of botanical science since the days of Nehemiah Grew and Stephen Hales. This reproach, however, was speedily removed, and the English school of botany, inspired by his spirit transmitted by his pupils, Vines, Scott, Bower, F. Darwin, Marshall Ward, and Gardiner, has been able to hold its own with those of the continental nations. In Germany, naturally, his influence was paramount; schools sprang up under the leadership of Pfeffer, Goebel, and others of his distinguished students and colleagues, in which the traditions of Würzburg are still potent factors. It was perhaps even more by his writings, especially his great textbooks, giving as they did such an impetus to physiological problems, that his influence has been felt.

Great, however, as must be the position accorded to Sachs in the history of the science, his work was not so epoch-making as that of Darwin. Taking up investigation and research at the level on which the subject stood in I860, Sachs carried many problems certain stages forward, but he did not reach finality with any of them, and subsequent observers have found it necessary to modify his 
conclusions. His theories were not always sound, and his judgement was sometimes subordinated to his enthusiasm. For example, he gave in his adhesion unreservedly and prematurely to Naegeli's theory of the constitution of organized structures, and attributed finality to it. But its downfall, or at any rate its very drastic modification, was only distant about twenty years. Sachs' theories have already passed out of the normal field of view, while Darwin's grand generalization stands unchallenged. Darwin had the philosophic mind, combined with the unwearied patience of the true student of Nature and the explorer of her secrets.

Still the two great figures stand as dominating botanical science at the opening of our period, and under the great influence of both the stream of thought has been widened and deepened, and from the semi-obscurity of the first half of the century we have advanced to the relatively brilliant light of the present day.

It has been especially in the study of physiology that the greatest progress has been made, though incidentally all sections of the science have been materially advanced. The idea of the struggle for existence carried on continuously by the plant, directed attention to its equipment and led at once to the recognition of its power of appreciating changes in its environment. Linnaeus had denied the existence of the power of feeling in the vegetable organism, making it one of the points of difference between animal and plant. Already a certain hesitation in accepting that dictum had been felt by many botanists; from this period it disappeared. The nature of living substance was and had been only imperfectly appreciated, though von Mohl had made some investigations in that direction. Now the protoplasm, to use the name he gave it, assumed at once its proper importance, and its peculiarities formed the basis of the physiological investigations at once initiated. The rôle played 
in the plant by the living substance was difficult to understand till botanists-Sachs especially-put forward the great generalization of the continuity of the protoplasm through the cell-walls, a theory which passed from the realm of hypothesis to that of fact under the careful investigations of Gardiner and of Russow. The similarity of the principles underlying the construction of animals and plants followed this demonstration, and researches carried out in the later years of the century established the fact of the essential identity of all living substance. Nothing did more than this discovery to clear up all the old confusion as to the true nature of the respiration of plants. It led, moreover, to the important elucidation of the true nature of the food of plants, and the recognition that the action of chlorophyll is not the digestive process of the vegetable organism, but that the chloroplast is a distinct mechanism for the primary construction of organic material destined to become the food of animal and plant alike. The details of the metabolic processes in both kingdoms of Nature have since been ascertained to be fundamentally the same, and the action alike of the protoplasm itself and the enzymes it secretes has been shown to be strictly comparable in the two cases.

In the field of what has been very generally called irritability, but which many physiologists are coming to speak of preferably as sensitivity, perhaps the greatest advances have been made. Prior to I860, but little accurate knowledge of this subject had been acquired. The old Aristotelian dogma of the soul of plants, and the naturephilosophy associated therewith, was abandoned nearly twenty years before. De Candolle recognized something of the power of appreciation of the surroundings when he wrote of excitability, though the term hardly expresses the ideas held to-day. Meyen also observed what he called voluntary movements in Hedysarum, and noted 
instances of sensation in plants. Few conclusive results, however, attended the desultory researches carried out before I860. The mode of regarding the whole problem gradually underwent a change after the appearance of Darwin's work. The phenomena observed were held to be of interest chiefly as helping to explain certain movements of plants, which nevertheless remained to some extent meaningless. Movement was thought to be the principal subject for investigation in this direction, and irritability was studied for the most part only in its bearing upon movement. This idea by somewhat slow degrees gave way to a broader view, and sensitivity, or the power of appreciating changes in the environment was ascertained to play a far wider part than the causation of movementto be indeed the clue to many so far obscure changes in the interior of plants, which had hardly received observation or recognition.

Later in the century arose a development of physiology which now bids fair to assume a very high degree of importance. The study of the individual plant gave way to some extent to the investigation of the mutual relations of plants growing together in some kind of association, and to the study of the vegetation of some particular environment as a whole. This was a departure at once novel and fascinating. It attracted the attention of many of the younger school of botanists and was pursued with much diligence under the name of oecology. Many of the more obscure problems of physiology needed approaching from this standpoint.

One of the most interesting results of this new field of inquiry was the demonstration of the fact that the main differences between animals and plants are attributable to the one being incapable of movement from place to place, while the other is constructed with a view to locomotion.

Another very important development of the physio- 
logical side of botany was the new science of vegetable pathology. The study of disease itself was largely associated with researches upon the Fungi, but towards the end of the century it went further and occupied itself with questions of remedy, prevention, and immunity. This latter aspect, however, was still in its infancy at the end of the century.

The recognition of the association of disease with parasitic infection by bacteria or by true fungi spread very widely between I860 and I900. The study of bacteria in the widest sense, mainly under the inspiration of Pasteur, became elevated to the rank of a separate science, and under the name of Bacteriology soon developed its own periodical and permanent literature. Laboratories were founded for its pursuit, and teaching and research were very widely extended. The separation of the study of these organisms from other plants, and the organization of the new science removes it, however, from detailed consideration here.

The new science reacted to a very important extent upon the older studies, and new methods of research followed. The practice of cultivating organisms in fluid or gelatinous media, a modification of Sachs' water-culture of the higher plants, came into general use, and by its aid the life-histories of many forms of both lower and higher fungi were unravelled.

The study of anatomy was, perhaps, the branch most generally pursued at the beginning of the period under review. The work of Hofmeister and of Unger had stimulated investigation in this field, and the new theories of Naegeli had excited great attention to the scope which anatomical research afforded. Almost immediately, we had the very important contribution of Sanio to the knowledge of the stem, followed by many memoirs from other pens, which we shall consider in their place. The direction of research 
during our period led to the development of a third science, springing very largely from the work of botanists, viz. Cytology, the science of the cell. The cell theory itself may be attributed to the work of a botanist, Schleiden, as much as to that of a zoologist, Schwann; and its development fell into the hands of workers in the vegetable as well as the animal kingdom. The direction of research into the peculiarities of the tissues was slightly modified, inquiry being made into their actual structure and composition as well as into their special distribution and relations. As the century drew towards its close a closer alliance was brought about between the anatomists and the physiologists, under the influence of the writings of Schwendener and later of Haberlandt. Another movement which arose in Germany under the influence of Radlkofer also calls for mention as a feature of the period. This was the development of research having for its object the elucidation of anatomical relationships between species and genera, with a view to finding therein characters of value for taxonomic purposes.

When we turn to the field of systematic botany, we find it difficult to trace so clearly the influence of the new current of thought upon the classification of the flowering plants. The period saw, however, a gradual withdrawal of the system of de Candolle and his successors. The points of structure on which the larger divisions of this scheme rested became recognized to a certain extent as rather artificial than natural in many respects, and various modifications of the system were suggested by more than one botanist. Instead of basing distinctions on the peculiarities of union or freedom of the floral leaves, and the relative positions of androecium and gynaecium, characters indicating more general affinity came to be more insisted upon. This was recognized more especially abroad than in England; in Germany in particular we find 
that the work of Eichler and of Engler almost universally replaced the older proposals of de Candolle. In 1860 the classification of the lower plants was almost entirely empirical. Hardly anything was known as to either lifehistory or structure of many of the Thallophytes, so that classification of them was little more than guesswork. The Vascular Cryptogams were the subject of much research during the period we are dealing with, and after many efforts at obtaining a satisfactory scheme the gradual adoption of phylogeny as the clue to classification led to at least an approximation to a satisfactory grouping. This very desirable result was due in some measure to the discoveries made during the study and investigation of the fossil remains of the vegetation of past ages, which received a great impetus from the labours of Williamson and of Renault.

The classification of the Thallophytes gradually took shape as the elucidation of life-histories progressed. For the Algae, through the researches of many workers, a scheme was arrived at which met with general support towards the end of the century, and which though not altogether satisfactory may serve as a sufficient basis for a more complete system in the future.

The Fungi were studied in the same way and perhaps to more purpose. Classification of them was in the first instance made by De Bary, to whom, perhaps more than to any one else, the progress of scientific and accurate knowledge in this field is due. Following De Bary after some years, a rival system was proposed by Brefeld, which enjoyed a somewhat ephemeral success. Towards the end of the century De Bary's views again came into favour.

The last few decades of the century were noteworthy for the prevalence of exploration and the elucidation of the floras of many regions of the world. Researches 
in this direction were not confined to any nationality, though perhaps English investigators were the most prominent.

The whole period from I86o onwards, under the various influences which have been mentioned, was marked by a more thorough organization of research. Instead of individual professors engaged in solitary investigation, as in the early part of the century, well organized schools of work arose which were carried on under capable direction and which received and communicated mutual stimulus. The personal influence of Sachs in founding a school of investigation did not stand alone. His immediate pupils, imbued with the spirit which he was so successful in inspiring, became in turn the heads of schools, so that his example was widely followed. Nor was this development confined to his followers; it was helped by many independent enterprises both in Germany and other countries. The wave of scientific enthusiasm of the time was naturally not confined to botanists, though they were widely and deeply affected by it. One of its most important results was the inclusion of science in the curriculum of general university education. Taken up in the universities of Europe by the most enlightened pioneers of education of the time, the members of the newer school of science were sent out into the world with better training and with better equipment than their predecessors, while the resources of the universities were with greater or less freedom placed at the disposal of scientific teachers. Of those who conduced to the development of botanical science in England by bringing about this development and by cultivating the scientific attitude of mind, mention should be made in most appreciative terms of Huxley, Foster, and Thiselton-Dyer. They were quick to perceive the magnitude of the movement of the early sixties, the wonderful possibilities it presented and the importance of 
its issues, and it was in no small degree to their influence and effort that its success must be attributed.

With the inclusion of botany among other sciences in the curriculum of university study, and the coincident extension of facilities for research in the establishment of well-equipped laboratories, there came a thorough reorganization of methods. Micro-chemical analysis was carefully studied; new reagents were discovered, which enabled determinations of composition to be made on amounts of material till then held to be far too small for accurate observation. The application of staining reagents was very carefully studied; the somewhat empirical methods of using them which marked their introduction gave place to others which combined colour-differentiation with demonstration of chemical composition. The whole art of microscopic technique was carried to a pitch of perfection which seemed utterly visionary before I860. The introduction of mechanical appliances was attended with great success; the perfection of the microtome for cutting thin sections had an importance hardly surpassed by the coincident improvements brought about in the microscope. The introduction of other instruments, particularly into physiological research, was another very important feature of the inquiries of the period.

During the early years of the time under review the great amount of attention directed to laboratory and lecture-room seemed to crowd into the background the older modes of study associated with the botanic garden. Indeed some thought the days of the latter as part of the educational mechanism were over. Possibly enthusiasm for the new studies was allowed to go too far; happily, towards the end of the century, wiser counsels prevailed and garden and laboratory were united closely in the prosecution of study and research. Indeed the greater utilization of the resources of the garden was one of the 
most marked features of the later decades of the century. Not only were the older gardens of Europe and America maintained and developed, but similar stations were opened up in the tropics for purposes of research. The superior opportunities which these institutions afford-in that plants can be kept under constant observation while growing normally under their natural conditions-were at once recognized. To such institutions, now spread almost over the world, we owe much of the knowledge which was obtained of the plants of particular regions, as to not only their scientific interest, but their economic importance.

The great development of university teaching to which reference has been made, which was the outcome of the Würzburg influence of the early sixties, was felt almost at once throughout Europe. Nor was it long in spreading over a much wider field. Schools of study started to life in the universities of America, and a new and vigorous race of botanists soon recruited the ranks of the transatlantic systematists. Though much younger than the schools of Europe they showed no lack of vitality, and the development of botanical research, at any rate in the United States and in Canada, became as vigorous as in the older countries. Alike in the fields of Anatomy, Physiology and Taxonomy, workers appeared who made contributions to science which were of the highest value.

Still younger was the school which at the end of the century bulked large in Japan. Throughout the whole of our period, students of Japanese nationality were to be encountered in almost all the laboratories of Europe, and as the years passed on, their return to Tokyo was marked by the establishment of schools of teaching and research of no mean reputation.

South Africa, too, became in the closing years animated with the same spirit, and developments began which gave great promise of distinction during the coming century. 
The literature of the period embraces many important works, the most prominent of which had their origin in Germany. The first and, in many respects, the most ambitious of these was the series of volumes projected by Hofmeister, which was to appear under the title of the Handbuch der physiologischen Botanik. The proposals were initiated in I86I, but various circumstances prevented the appearance of any part of it for four years. Difficulties and disappointments attended it throughout; some of the contributors retired from active co-operation almost at the commencement, and many causes of delay appeared as time went on, so that it never reached publication in the form originally projected. Hofmeister's own contribution to it was to be the first volume, of which the first part, Die Lehre von der Pflanzenzelle, appeared in I867. The wellknown volume of Sachs' Experimentalphysiologie der Pflanzen was issued in 1866 , and was followed in the same year by De Bary's Morphologie und Physiologie der Pilze, Flechten, und Myxomyceten, so long the standard textbook on the subject. Many years elapsed before another volume was published, and the great development of certain sections of botany compelled a complete revision of the scheme. Not long afterwards Hofmeister died, early in 1877 , and it was decided to wind up the enterprise with the publication of De Bary's Vergleichende Anatomie der Vegetationsorgane der Gefässpflanzen, which was then nearly ready for press. This final volume accordingly appeared in 1877 .

A work which exercised a wider influence than the Handbuch was the Lehrbuch of Sachs. Originally published in I868, it passed rapidly through four editions, of which the second and the fourth made their appearance in an English translation, to the great benefit of botanical science in Great Britain. As the subject developed and the mass of detail multiplied, Sachs divided the work into two sections, the first of which, on Morphology and Anatomy, 
passed into the care of Goebel, while Sachs himself re-ivrote the second, publishing it in the form of the Vorlesungen iiber Pflanzenphysiologie in 1882 .

Goebel's volume appeared in I882 and was followed by his independent works on Organography in and after I897.

Another of the most distinguished of the pupils of Sachs became his rival, and in a sense his successor, as an exponent of physiology. This was Pfeffer, who while professor at Tübingen brought out in I880 the first edition of his Pflanzenphysiologie. Though he took perhaps a more mechanical view of things than Sachs, his textbook was a work of great learning, and exercised a very important influence on current thought. A second edition revised and enlarged appeared in 1897.

Another important volume which appeared in I880, I882, and I884 was Schenk's great textbook, the Handbuch der Botanik, in the production of which most of the leading botanists in Germany collaborated.

A second edition of De Bary's great work on the Fungi appeared in I884. It was almost a new treatise, though based upon the book of 1866 .

Besides the works of De Bary on the Fungi, the literature of these plants was greatly extended by the numerous memoirs and writings of Brefeld, which extended over the years $I 872$ to $I 884$. These, which were altogether admirable, covered nearly all the families of the group, and elucidated with great completeness the life-histories of many forms.

As a result of his work on the group, Brefeld put forward a new scheme of classification for the Fungi, in which, while he recognized the chief families of De Bary he arranged them differently, seeking to finally settle their affinities. Though a certain success attended his efforts his classification did not displace De Bary's. Indeed, sufficient data were not forthcoming. 
Zopf's treatise on the Fungi was another noteworthy volume which appeared in I890. Von Tafel contributed a work on Brefeld's lines in the Vergleichende Morphologie der Pilze, I892. We must also mention Istvanffy's Untersuchungen über die physiologische Anatomie der Pilze, I896.

Haberlandt's Physiologische Pfanzenanatomie was one of the remarkable books of the period. It was published in I884 and was received with great favour. It aimed, as its title suggests, at interpreting anatomical detail by physiological need, and discussed the classification of the tissues from this point of view.

The indefatigable industry and the clear insight of Strasburger led to the enrichment of literature by the addition of many classical memoirs and treaties. Of these the following were the chief:-Die Befruchtung bei den Coniferen, I869; Die Coniferen und die Gnetaceen, I872; Ueber Befruchtung und Zelltheilung, I878; Die Angiospermen und die Gymnospermen, I879; Ueber Zellbildung und Zelltheilung, I880 ; Bau und Wachsthum der Zellhäute, I882 ; and Bau und Verrichtungen der Leitungsbahnen, I89I. These enshrine the results of those magnificent investigations associated with his name.

The end of the century (I899) witnessed the appearance of Solereder's Systematic Anatomy of the Dicotyledons: an attempt to utilize anatomical characters for purposes of classification.

Neither French nor English literature can compare with German writings of the time. Of contributions to the former the most important were Le Maout and Decaisne's great work of I868 on Classification, and Van Tieghem's Treatise of I8gI, which was memorable as presenting to the scientific world his now well-known theory of the stele.

In England the Genera Plantarum was almost the only really notable publication which appeared. Brought out by Bentham and Hooker in the years I862-I888 it stands 
alone for the minuteness, completeness and accuracy of its description of the genera. It is a monument to the greatest of British systematists.

Mention should be made also of two books which were the earliest efforts that attempted to deal with the pathology of plants. They were Frank's Krankheiten der Pfanzen, published in I880, and as a second edition in I884, and Sorauer's Pfanzenkrankheiten, which appeared in I886.

The period I860-I900 witnessed the deaths of many botanists of the first rank, to whose labours in the laboratory the science owes its new revival, and to whose writings the great movements of the new century are deeply indebted.

Von Mohl passed away in I872. It is difficult to speak with sufficient admiration of his work, which extended over so many years and did so much to establish the new views. His researches were mainly histological ; he may be said to have utilized to the utmost the development of microscopic appliances in their application to the minute internal structure of the plant. His name will always be associated with the term protoplasm, which though not originally due to him was applied by him to the living substance of the plant. $\mathrm{He}$ was one of the pioneers who insisted on its study. Von Mohl's writings show him to us as a model of clearness and especially of fairness in controversy; they always carefully review the contributions of others while setting out the problems under examination from his own point of view.

The year 1887 was marked by the death of Boussingault. Though not strictly speaking a botanist, he contributed very largely to the development of the physiological side of the science. His agricultural papers were of the greatest importance, especially those dealing with the supply of nitrogen to the green plant.

De Bary survived Boussingault only a year, passing away prematurely in 1888 . His work was very varied, but it 
was in connexion with the Fungi that he was best known. From I86o onwards he contributed memoirs and books to the literature of this subject, and built up a coherent superstructure on the foundation of painstaking and elaborate research. He was particularly skilful in cultivating different species and tracing their life-histories. Among the most memorable of his contributions to science were his investigations of the potato disease in $I 86 I$ and of the development of fungal parasitism in 1865 , wherein he laid the foundation of scientific vegetable pathology. His researches on the red rust and its relation to Berberis opened up the story of heteroecism. In I878 and I879 he published valuable contributions on Apogamy and Symbiosis, while his investigation of the Peronosporeae appeared in I88I.

De Bary's literary work was of the highest order. $\mathrm{He}$ edited the Botanische Zeitung from I867 to I888; he founded the Beiträge zur Morphologie und Physiologie der Pilze in I864. In I866 there appeared from his pen the Morphologie und Physiologie der Pilze, Flechten und Myxomyceten, a work which, while it brought together the scattered facts that had been ascertained about those organisms, showed marvellous grasp of details and power of logical generalization. In 1867 he published a volume of his lectures on Bacteria, an admirable presentation of the subject at the time. In 1877 appeared the Vergleichende Anatomie, and in I884 a greatly extended edition of the Vergleichende Morphologie und Biologie der Pilze u.s.w.

In I89I died Carl Naegeli, one of the most distinguished men of science of the time, after a long life devoted with great earnestness to study and research. It is impossible, in the space at our disposal, to do more than bear testimony to his eminence in every field of botany and to call attention to a few of the more important of his contributions.

$\mathrm{He}$, von Mohl, and Schleiden practically made possible the great advance of scientific botany which is still in 
progress to-day. In his earlier writings the influence of Schleiden appears perhaps somewhat prominent, but Naegeli soon showed himself a leader of thought. Among his contributions to science may be mentioned his Zellenkerne, Zellenbildung and Zellenwachstum, which was his first great memoir; in it we find the demonstration of the nucleus as a structure occurring in the leading families of the Cryptogams as well as in the flowering plants, where it had been seen by Robert Brown. His name may be associated with that of von Mohl in the discovery of protoplasm, though he called it 'Schleimschicht' from its appearance and apparent distribution. He carried out researches on the Cryptogams, discovering the archegonia and antheridia of Ferns, and making very important observations on the Siphoneae and on the Florideae, in which group he discovered the apical cell. It was perhaps by his theory of the micellar structure of organized substances and of growth by intussusception that he is best known to the younger generation of botanists. It was a wonderful conception, giving for the first time a theory in any way satisfactory to the philosophic thinker. It received rapid recognition and acceptance everywhere, and for some twenty years was considered as the last possible word on the subject.

Naegeli was a philosopher as well as an observer. He took an active part in the controversy that followed the appearance of the Origin of Species, opposing Darwin's views for the most part and supporting those of Lamarck. He held, in opposition to Darwin, that utility is a principle which is quite inadequate to explain phylogeny. In later years (1884) he published his views on evolution in the Abstammingslehre, and showed therein a certain approximation to the opinions of Darwin in postulating a potentiality of complex differentiation of the soma. He introduced the idea of a material basis for heredity in the form of an 'idioplasm,' to which he attributed the transGREEN 
mission of the characters which an organism inherits from its parent. He held this idioplasm to be the seat of the potentiality alluded to, and generation by generation to make advances in complexity. He admitted that this plasticity can be moulded more or less by external conditions and that if these act in a particular direction for a lengthened period considerable adaptive modification of form and structure may result. He differed from Darwin in particular by denying that all organization is essentially adaptive, laying stress on the potentiality of spontaneous evolution of the idioplasm.

A great Algologist passed away in I894 in the person of Pringsheim, who made a special study of these organisms from I855 onwards. His work was not, however, confined to them; in his later years he gave a good deal of attention to vegetable physiology, and in particular to the nutritive processes of the green plant. In this department he was much less successful, for his name is associated in particular with his theory of hypochlorin as one of the early products of chlorophyll activity, and of the famous hypothesis of the screening action of chlorophyll in carbon appropriationneither of which stood the test of examination.

A good deal of Pringsheim's work falls into our period; his studies prior to I86o had, however, earned for him a very high reputation. He investigated the Coleochetaceae in I8 58 and discovered the much-discussed alternation of generations in the group. He showed in the same year that in fertilization or conjugation an actual fusion of the sexual cells takes place, and not as Thuret had said, a mere dynamical reaction.

He investigated various groups of Algae during the next ten years, and contributed many important discoveries to science. One of his most interesting publications was his memoir on the morphological differentiation of the Sphacelariae, published in I87I. On other groups the 
work he did was of less importance. Mention should be made, however, of his paper on the morphology and development of Salvinia, in I863, when for the first time the life-history of the plant was traced; also of his great investigation of the Saprolegnieae, in which he discovered the sexual reproduction.

One of Pringsheim's most noteworthy services to science was the founding of the Journal which is commonly called by his name. The Jahrbiicher fïr wissenschaftliche Botanik was started in 1858 , and has been one of the leading botanical periodicals ever since.

Pringsheim was the principal advocate of the so-called homologous theory of the alternation of generations, appearing as a vigorous opponent of Celakowski. He published his views on the subject in 1876 . Reference will be made in more detail to them in a subsequent chapter.

In his views on evolution Pringsheim was a supporter of Naegeli.

The death of Sachs in 1897 terminated a career remarkable for the influence it had on the progress and development of botanical science. Alike as philosopher, investigator, writer, and teacher, Sachs stood out conspicuous as one of the foremost botanists of the century.

The next year, I898, saw the death of Cohn, in an old and honoured age. He was not well known to the younger generation of botanists, for most of his work was done before the opening of, or early in, our period. In his younger days he investigated with great thoroughness the lower members of the vegetable kingdom, and to the end of his life they formed the chief centre of his interest. Cohn was the original editor of the Beiträge zur wissenschaftliche Botanik.

The century had hardly ended when botany was called upon to suffer the loss of one of the most enthusiastic and able of its younger votaries, in the person of A. F. W. Schimper, who died in I9oI. He gained a reputation 
at the outset as a histologist by his remarkable paper on starch formation, which he published in I880. Herein he traced the formation of the highly organized starch grain in all cases through the agency of plastids, and showed that the action of the chloroplast is twofold, the original construction of carbohydrate depending on the chlorophyll, but the elaboration of the starch grain as such being independent of the pigment. He pointed out the existence of similar though colourless plastids in the non-illuminated parts of plants, and showed that in certain cases they develop pigment when exposed to light.

In this work Schimper was compelled to oppose the intussusception theory of the growth of organized structures advanced more than twenty years before by Naegeli, which is not in accordance with the action of the plastid in secreting successively layer after layer of starch. Schimper's work thus prepared the way for Strasburger's generalization shortly to follow.

Schimper's later work was to a large extent in the field of oecology. He published memoirs on Epiphytes in I884 and I89I, on the mechanism of transpiration in I890, and on the littoral vegetation of the Indo-Malayan region in I89I. During his later years he was engaged on his most fascinating work, the great volume on Geographical Distribution considered from a physiological standpoint, which appeared in 1898 .

The death of Brongniart in 1876 robbed France of one of her greatest botanists, one who may indeed be regarded as the founder of the department of Palaeobotany, for he certainly made possible the researches of the later time. He devoted a long life in the main to investigations in this field, commencing in his twenty-first year with a paper on the classification and distribution of fossil plants. This paper had of course to deal with but a small part of the material now known, but it was memorable for its time, serving 
indeed as the starting place for an intelligent study of the subject. Brongniart had to carry on his researches in his early years for the most part unaided; it was only later that he found as colleagues Renault and Grand'Eury. He was, however, especially well-equipped for the study of the fossils by reason of his attainments as a skilled vegetable anatomist. One of his principal memoirs was on Sigillaria elegans, the first member of a very important family to be described. Of his larger writings the most important was the Prodrome d'une Histoire des Vigetaux fossiles, published in $I 828$. This was intended to be only preparatory to the appearance of a more comprehensive work of the same kind, but the latter was never completed, in consequence of his ill-health. Even in the production of the Prodrome there was a gap of nine years between the twelfth and thirteenth parts, and only three parts appeared after its resumption.

Brongniart's work, great as was its influence at the time, was rather that of the systematizer than of the discoverer, though he added considerably to the sum of knowledge by observation and research. He was more remarkable, however, as introducing order and clearness into the study of materials which had been already collected. He was eminent for accuracy and judgment, as well as for the clearness and neatness of his scientific writings.

Another botanist of world-wide fame was lost to France in 1893 when Alphonse de Candolle passed away. In the earlier part of the century no names were more conspicuous in the study of taxonomic problems than those of the de Candolles, father and son. Nor were they without great reputations in all the other departments of botany which occupied the student and the investigator. It would be idle to attempt to recount here all the services which the younger of the two rendered to botanical science,--a few of the most prominent only can be mentioned. His botanical career commenced at the age of eighteen, and at twenty-four 
he was co-operating with his father in the production of the Prodromus, the editorship of which passed into his hands at his father's death in I84I. He was occupied with it subsequently for a period of more than fifty years. Among his own contributions to it were the monographs on the Campanulaceae, Myrsinaceae, Apocynaceae, Begoniaceae, and Cupuliferae, besides several other orders, genera, and species. The monograph on the Cupuliferae was especially remarkable, containing some very fine work on the oaks, a subject that had never till then been properly treated. De Candolle wrote several less technical, more philosophical works, the greatest of which was his Giographie botanique raisonnie, conspicuous for its search for general principles and laws, and containing exhaustive chapters on the influence of heat and light on the development of individual species and on the distribution of the higher groups of plants. He was a most prolific writer ; the Royal Society's Catalogue contains the titles of seventy-eight of his papers-not more, however, than a quarter of what he wrote.

During the years I860-I90o Englishmen were called upon to part with several of the most prominent taxonomists that the country had seen. Not since the time of Ray and Morison had such figures appeared among them as Lindley, the two Hookers, and George Bentham. Of this group Sir Joseph Hooker was the only survivor in I9oo. His father, Sir W. J. Hooker, who died in I867, left a conspicuous mark on English botany as an administrator. One of the most successful directors of Kew Gardens, he was also distinguished by his writings, which included several floras and descriptions of the botanical discoveries of several exploration expeditions. In his younger days he had contributed to the knowledge of the Bryophyta, his work on the Jungermanniae and on the Mosses appearing in I8I6 and I8I7.

Lindley died in the same year. It is to his efforts that we in England owe very largely the development of the Natural 
System of Classification. When he began his career the Linnean system was universally taught here, and he brought at once to its replacement by a better one all the weight of his teaching and his personal influence. Consequently, his best known writings are those tending to develop the Natural System. He published a Synopsis of the British Flora in I829, and an Introduction to a Natural System of Classification in 1830 . This was the basis of the great work, The Vegetable Kingdom, which appeared in I846, after many years of laborious investigation.

Besides these and other books Lindley contributed a long series of monographs and isolated descriptions of plants to many journals. His researches were especially directed towards the Orchidaceae, many new genera and species of which he described. He wrote several works upon the group, the latest of which, Folia Orchidacea, was unfinished at his death.

Bentham passed away in I884. In his young days he was a close friend of de Candolle, to whose influence in a large measure his own career may be traced. During a long life devoted to botany he contributed very largely to literature and to exploration. He worked up the Labiatae and the Indian Scrophulariaceae, and was responsible for the accounts of these groups in de Candolle's Prodromus. He investigated the Leguminosae in $\mathrm{r} 840$. His floras included that of the Pyrenees, based largely on his own explorations, and that of Hong Kong, published in I86r. Two years later he started the publication of the Flora Australiensis, which was completed in seven annual volumes. His greatest work, the Genera Plantarum, was done in collaboration with Sir Joseph Hooker. It is impossible here to do more than mention the chief contributions he made to botany, for there is hardly a temperate or tropical region of the world with the flora of which he was not familiar. He had made substantial contributions to most of them. 
A great fungologist, Berkeley, died in $188 \mathrm{~g}$. He was mainly a systematist for most of his time, but he contributed to other fields of study. It is to him that we owe the first complete account of the Peronosporeae, published in 1846 , in which he anticipated De Bary by about fifteen years. He was a prolific writer in various journals, chiefly upon fungi.

America lost her greatest botanist of the time in I888, when Asa Gray passed away. It is to him that we trace our knowledge of the flora of the northern continent, which he knew from the Arctic Islands to Mexico, and from the Atlantic to the Pacific Ocean. His chief earlier works were the Synoptical Flora and the Manual of Botany of the Northern States. He projected a larger work, the Genera Florae Boreali-Americana Orientalis, but only two volumes of it appeared. Gray's most original contribution to science took the form of a Memoir of the Flora of Japan, in which he compared the vegetation of Japan with that characterising the eastern and the western regions of America, and those with one another, and the whole with the tertiary flora, so that he sketched the history of the vegetation of the north temperate hemisphere in relation to its geography, from the cretaceous period to the present time. In his teaching Gray was an ardent supporter of Darwin's views, which he helped materially to spread in America. 


\section{BOOK I \\ MORPHOLOGY}





\section{INTRODUCTION}

THE study of morphology received a new impetus from the works of Hofmeister and of Darwin, which appeared just before the opening of the period under review. They altered very materially the points of view from which such study was undertaken, bringing two new principles prominently forward. The researches of Hofmeister led immediately to a conception of one uniform plan underlying the whole of the vegetable kingdom and so modifying the old distinction between Cryptogams and Phanerogams. The modifications of such a fundamental unity which could be traced in the several groups had, further, necessarily to be studied in the light of Darwin's theory, and adaptation came to be recognized as playing a very prominent part in morphological problems. The alternation of generations traced by him in the vascular Cryptogams bulked large in the study of the time, and efforts, which became gradually successful, were applied to tracing it in the life-histories of the Gymnosperms and Angiosperms. The study and comparison of numerous forms brought to light the curious continuous retrogression in importance of the gametophyte and the corresponding advances in magnitude and complexity of the sporophyte, up to their culmination in the Angiosperms. A still further development of this line of research raised the question of the origin of the terrestrial flora and its relation to the aquatic organisms from which its descent became gradually more and more apparent.

The theory of metamorphosis was shaken to some extent by these studies, and especially by the pronouncement of morphologists whose researches led them to the opinion 
that besides root, stem, and leaf, other members can be recognized which claim equal morphological value, conspicuous among them being the sporangium, pronounced as a member sui generis by Goebel, and the sporangiophore, claimed as such by Bower. The leaves of mosses and those of plants higher in the scale were seen not to be homologous structures, originating as they do on alternate phases of the plant-body.

Mention may be made of the investigations of several botanists in this wide field. Especially important were the researches of Goebel on the sporangia of the Pteridophyta, published in I880 and I88I, and the still more elaborate investigations by Bower of the spore-producing members of archegoniate plants, which appeared at intervals during the last seven years of the century. These are worthy of comparison with the discoveries of Hofmeister fifty years before, leading as they did in the new century to his masterly treatise on the origin of a land flora. Leitgeb's great work on the liverworts was a feature of the middle of the period, appearing between I874 and I882. Campbell's researches on the Bryophyta and Pteridophyta towards the end of the century led to the production of his well-known volume on the Mosses and Ferns.

Results of the very greatest importance attended the study of the fossils, especially those of the coal measures. Williamson and Scott in England, Renault and Zeiller in France, Solms-Laubach in Germany, stood out conspicuously among a crowd of other workers. These results included the elucidation of many points of affinity among the still existing forms and of several obscure relations of phylogeny.

Taxonomists were little by little successful in framing more satisfactorily the natural system of classification which had been so long desired, though much still remained to be done when the century closed. The period was marked by a great extension of knowledge of the floras of 
different regions of the earth's surface, furnishing more and more data for the pure systematists. A further feature of the time was the succession of efforts made to bridge over the gaps between the great divisions of the vegetable kingdom, which, however, till the end of the century, remained questions of speculation and of hypothesis rather than of fact. 


\section{CHAPTER I \\ THE NATURE OF ALTERNATION OF GENERATIONS}

THOUGH this term was in use among morphologists prior to I860, its interpretation was altogether different from that which is at present in vogue. Introduced by Steenstrup as long ago as I845, it only carried the idea of a succession of vegetative shoots culminating in the production of the flower. Though it was discussed at some length by other writers; during the next decade, no material expansion of the idea took place.

The exhaustive researches of Hofmeister, published in I85I and I862, placed the study of morphology upon a new plane. In them for the first time a unity of plan was shown to run through all the archegoniate plants, and the old distinction between Cryptogams and Phanerogams based upon the methods of reproduction had to be abandoned, though the full realization of all that his discoveries involved was only slow. In his treatment of the Mosses and Liverworts, the Vascular Cryptogams and the Gymnosperms, Hofmeister showed clearly the two forms or phases of which their life-cycle consists, and distinguished between a spore-bearing generation and another which exhibits sexual reproduction. The Thallophytes, however, were not included in his scheme.

Though Hofmeister, with his unequalled skill and patience, established the facts of structure and life-history, he left it to later writers to discuss their bearing, and to formulate what came to be known as the law of alternation of generations. 
At about the time at which our period opens, and while Hofmeister was still engaged on the Vascular Cryptogams, Pringsheim was at work upon the Algae, publishing a series of papers in 1856 and 1858 , in the course of which he established that both Oedogonium and Coleochaete show a curious behaviour on the part of the fertilized cell, in that it does not at once produce a plant like the parent, but that it gives rise either at once (Oedogonium), or with but little vegetative development (Coleochaete), to asexual reproductive cells. Pringsheim saw indeed in the body proceeding from the zygote of the latter an approximation to the sporogonium of the simplest of the Liverworts. He established, too, that these phenomena are rare among the Algae, and showed that the latter are often polymorphic; there is not a regular alternation of sexual and non-sexual forms in their life-histories.

Though the question seemed ripe for discussion about I860, the subject was only occasionally pursued for some years. The earlier writers did not shake themselves clear from the doctrine of the alternation of vegetative and floral shoots, which they tried to make the basis of a scheme into which the new discoveries should fit. Moreover, the true homologies of the stages in development were only slowly recognized.

In contradistinction to these somewhat nebulous views, we find an important pronouncement made by Celakowsky in I868. He cleared the way for the discussion of the whole problem by showing that the old alternation of shoots stood quite apart from the new question, and however varied might be the forms involved, and whatever its own intrinsic importance, it must be put quite on one side when discussing the more far-reaching problem.

Celakowsky accepted the discoveries of Hofmeister and Pringsheim and their results as to the structure of the archegoniate plants and the Thallophytes, and made them 
the basis of his argument. It followed at once that he was compelled to distinguish between two different kinds of life-cycle. In the Thallophyta asexual forms follow in succession for several generations; then a sexual form occurs, to be followed again by several asexual generations. In the archegoniate plants, from the liverworts upwards, the alternation of sexual and asexual forms is constant, and the two phases are apparently fundamentally distinct. Celakowsky applied the terms protophyt and antiphyt to the two phases, names replaced later by gametophyte and sporophyte in use to-day. He was clear as to the distinction:'The protophyt is never able to produce spores as well as sexual cells, the antiphyt never sexual cells besides spores.' Here is a clear pronouncement of a difference from the thallophytic plants, where the separation of the sexual and asexual reproductive cells is not so absolute. The alternation shown by these latter Celakowsky called homologous, basing the term upon the similarity of organization of the two alternating forms, in which the question of the nature of the reproductive cells arising on them is determined in great measure by variation of internal or possibly external conditions. This aspect of the subject, as we shall see, was very closely investigated later in the century by Klebs. The similarity of organization is emphasized by the fact that individuals bearing the sexual organs may, and often do, produce asexual reproductive cells as well.

The other kind of alternation, in which the asexual phase invariably gives rise to the sexual, and vice versa, indicating that the life-cycle is cast in a very definitely settled mould, Celakowsky called antithetic, suggesting that the one form is the natural complement of the other, and that a single life-cycle necessarily embraces both.

Celakowsky does not appear to have held the view that the processes, already alluded to as discovered by Pringsheim in Oedogonium and Coleochaete; correspond to the 
Chap. I

alternations in the Archegoniatae, as he attributes to the seaweeds mentioned the possession of three generations.

A few years later, as knowledge of life-histories of various forms increased, the subject again attracted a great deal of attention and controversy became keen. A. Braun made a contribution to the discussion in 1875 , but though he took a wider and more philosophical view than his predecessors, examining anew the possible correspondence of the alternation with similar phenomena in the animal world, he did not make matters clearer, or bring to light new facts. On the whole his reasoning agreed with that of Celakowsky, but he introduced a new factor into the problem by directing attention to the importance of taking into account considerations of phylogeny. He definitely stated the opinion that the sporophyte is a later generation than the gametophyte.

In the first edition of his Lehrbuch, Sachs treated of the subject with a certain caution, though he supported on the whole the views held by Celakowsky. He held that the essential condition for the passage from one alternate generation to the other is a change in the law of growth, though he admitted that it bears an intimate relation to, the production of sexual and asexual cells. In I874, however, he took up a much stronger attitude. He added many other plants to Oedogonium and Coleochaete as exhibiting an alternation similar to that in the Mosses and Vascular Cryptogams, specifying Mucor, Penicillium, and other fungi, and the majority of the group he called the Carposporeae, including here both the Ascomycetes and the Rhodophyceae. In the latter group, then generally called the Florideae, he said that there is a true alternation of generations which may be considered rudimentary or fully developed, according as the structure of the sporocarp is simpler or more complicated; in the latter case he held it to. constitute an alternating generation comparable with that of 
a fern. In the case of the Ascomycetes also, he identified the fructification with what we now call the sporophyte.

Sachs made much more clear than before the limitation of the two phases in these Thallophytes by defining very lucidly the term spore, which till the time he wrote had been applied loosely to all asexual reproductive cells. He says, 'For the purpose of a scientific nomenclature the term Spore (if used in the same sense as in Muscineae and Vascular Cryptogams) must be applied in Thallophytes only to those reproductive cells which are the result of an act of impregnation, whether direct, or indirect through the production of a vegetative body which constitutes a second generation and closes the entire course of development of the plant. All other unicellular and non-sexual organs of reproduction we shall not term spores, but gonidia or conidia.' He classed the latter with bulbils or gemmae. He left, however, room for some confusion, as the zygote or fertilized cell is a direct result of an act of impregnation. His explanation of this inclusion is found in his view that, "if the act of fertilization did not result in the production of any vegetative structure, or the second generation be altogether suppressed, the fertilized oosphere would then itself become a spore, as in the Coleochaeteae, Oedogonieae, and Vaucheria. In this case the spore is an equivalent for the whole of the second generation, it stands for the entire fructification of the Ascomycetes, the entire spore-capsule of a Moss, \&c.'

Sachs' position was clearly that of Celakowsky, but he carried his reasoning further, seeing an identity of procedure through the whole vegetable kingdom. Impressed with this view he interpreted various appearances among the Thallophytes somewhat arbitrarily, and saw homologies the propriety of which are, at any rate, possible subjects of discussion. He saw, however, more clearly than most of his predecessors and carried the controversy much further. 
He did service, too, in emphasizing the progressive advance in organization of the spore-bearing form, and in finally removing from the controversy the alternation of shoots.

It is thus seen that to Sachs we owe the first clear presentation of the idea that there is a regular alternation of generations in the Thallophytes, based as we have seen upon his conception of the course of development of the Algae and the Fungi, and of the homologies of the structures occurring in their life-history. As we look back upon his views to-day, we seem to see him basing them upon the undoubted sequence of events in the archegoniate plants, and with some ingenuity, perhaps even with some straining of interpretation of appearances to make them fit into his scheme, finding that a single law runs through the whole vegetable kingdom-an instance of somewhat hasty generalization, though supported by many life-histories. His writings suggest that very little doubt remained in his own mind and that he held there was little room for discussion.

At about the time when Sachs was thus presenting the subject to his numerous readers, a discovery was made which led a little later to the revival of the homologous view and to its restatement and elaboration by Pringsheim. This was the observation made by Farlow in I874 that it is possible for a fern plant to grow altogether vegetatively from a prothallus, without the intervention of the sexual organs. It seemed not unfair to argue consequently that the two forms are homologous. Pringsheim, to whose work on the Algae the controversy up to that date owed so much, gave immediate attention to the study of the phenomenon, which its discoverer called apogamy, and especially to the possibility of obtaining the similar and supplementary production of the sexual phase vegetatively from the asexual. In this, after many experiments, he succeeded, cultivating protonemata from the divided seta of the capsule of a moss. These two phenomena, Apogamy and Apospory, naturally 
attracted a good deal of attention, and though at first only these two isolated cases were known, the discovery led to a re-examination of the question of the relation of the sexual to the asexual forms of archegoniate plants.

The view which has since this date always been associated with the name of Pringsheim was advanced by him in 1877 , on the basis of his former investigations, supplemented by these new discoveries. He claimed that there is a fundamental agreement between the irregular but homologous alternation in the Thallophytes and the regular sequence in the Mosses and Vascular Cryptogams, recognizing only a difference of degree between them. The two phases in the latter groups are according to him homologous with one another, and the same homology exists between the sporangia of the one and the antheridia and archegonia of the other. Indeed he went so far as to claim that the seta of a moss capsule is homologous with the axis of the plant which bears the leaves. He put his position very clearly as to the condition in the Mosses, claiming that the alternation is due to the reduction of the series of asexual forms of the Thallophytes to a single one, which remains in inseparable connexion with the sexual one which originates it. He said further, emphatically, that the moss sporogonium stands in about the same relation to the moss plant as the sporangium-bearing individuals of Saprolegnia stand in to those which bear oogonia, or as among the Florideae the specimens with tetraspores are related to those with sporocarps.

Dealing with the Thallophytes, Pringsheim called attention to the great diversities which exist in the relations of the sexual and the asexual individuals to one another. Some bear only one form of reproductive cell ; others may bear both. Most frequently numbers of individuals bearing asexual cells are developed in a long sequence, and a sexual plant only occurs at intervals. The sexual individual never 
gives rise directly to any but an asexual form. All these forms, therefore, are clearly homologous with one another. In the cases of Oedogonium and Coleochaete, to which the origin of the intercalated generation was traced by the advocates of the antithetic theory, Pringsheim saw in the production of the zoospores of the former and the fruitbody of the latter only the first asexual generation, the difference in its development being due merely to reduction. In Sphaeroplea the alternation is simpler, taking the form of an alternation between a single sexual and a single asexual generation.

Pringsheim disputed also the propriety of regarding the sporocarp of the Florideae as corresponding to the sporophyte of either Coleochaete or the Moss or Fern, as had been suggested by Sachs. He claimed that it was palpably a part of the thallus on which it arises and has none of the marks of a distinct organization. Yet we may notice that it presents very distinctly one of the features claimed by the advocates of the antithetic theory as a step in the development of an intercalated sporophyte, that of securing by a single act of impregnation the development of a number of reproductive cells.

It thus appears that Sachs and Pringsheim were exponents of fundamentally different views. Sachs argued from the very different phases or generations in the Mosses and Ferns, traced these phases up to the Phanerogams, and then claimed to show their existence among the lowlier forms, explaining away what appeared in the latter group to be conflicting with his views. Thus he arrived at a conception of a uniform process throughout the vegetable kingdom. Pringsheim, on the other hand, though he also claimed the uniformity of the ultimate result, sav it brought about in quite a different way. Recognizing in the lowly Thallophytes homologous forms bearing sexual and asexual organs, he carried the idea of such homology upwards and held it 
to cover also the gametophytes and sporophytes of the highest as well as of the lowliest plants.

A reply to Pringsheim was made by Celakowsky in the following year. In this he set himself to combat again the central position of his opponent by showing how the new discoveries were easily reconcilable with his own views. He pointed out that the normal sequence of alternation is not lost in the occurrence of apogamy and apospory, but that all that happens is the omission of a particular stage. His explanation of the two phenomena seems a little forced; he claimed that apospory is explicable if we admit the origin of all the vegetative cells of the sporophyte from primitively reproductive cells, and that apogamy proves nothing further than that the sporophyte can arise from an indifferent cell of the prothallus instead of from a special sexual cell by a sexual process.

Celakowsky found himself partially in accord with Pringsheim on the position in the cycle of the cystocarp of the Florideae and the sporocarp of Coleochaete. He conceded that the former need not be regarded as a definite generation, but he laid much stress on the similarity of Coleochaete with the liverwort Riccia. The sporocarp of Coleochaete is so far homogeneous that all its cells produce spores, while the sporogonium of Riccia shows so much differentiation as to have the sporogenous cells covered in by a protecting layer or membrane. The difference between the two is really the sterilization of certain cells of an originally sporogenous body. As we shall see later, this forms the starting-point of a theory of the sporophyte elaborated subsequently by Bower.

A new feature was added to the controversy by Celakowsky's suggestion that the sporogonium in the Muscineae is not only antithetic to the gametophyte in completing the life-cycle, but is a third newly-arrived generation interpolated between the sexual and the first neutral or asexual 
generations of a Thallophyte. This idea of the intercalation of the sporophyte as a new and later generation is hinted at in the writings of Braun and was again presented by Bower some years later, though in a different position in the life-cycle.

From this time onward we can trace a change in the nature of the controversy. It was realized that attention had been paid too exclusively to morphological considerations only, and that physiological influences need to be taken into account, while it is of the highest importance to obtain if possible correct views of the descent of the higher plants from the Thallophyta. Two questions were thus forced to the front-What determined the origin of the sporophyte? and, Has the evolution of the sporophyte of the higher vascular plants passed through a stage corresponding to the sporogonium of a Liverwort or Moss ?

After some years during which controversy was almost hushed, and investigation into structure was resumed in many laboratories, the antithetic theory was strongly supported and amplified in the effort to find answers to these questions. It had gained in the interval many adherents in England and on the continents of Europe and America.

The position in I890 was very forcibly expressed by Bower, who stood out prominently as the leading advocate of the antithetic theory, and the man who more than any one since Celakowsky supplied evidence in its favour. It was in this year that he set himself the task of making a careful examination of the spore-producing members of the lower vascular plants with special regard to their development, in the hope that such an investigation might lead to an opinion as to the way in which a transition from the typical Bryophyte sporogonium to a sporophyte of the vascular plant may have taken place, and continued the work up to and beyond the expiration of the century, producing a monumental work, accumulating a mass of 
evidence, and clearing up so fully many difficult points of structure, that his investigations are fully worthy of being placed side by side with those of Hofmeister fifty years before. It may be added, parenthetically, that his later work did not lead him to modify in any material point the views he expressed in 1890 , to which we must now turn.

Bower's views may be summarized as follows: He set out by restating the conclusions of Braun and of Celakowsky that the gametophyte of the antithetic phase is the original form of the plant, and claimed that the sporophyte is a stage that has been gradually intercalated between two successive sexual generations. The development of the sporophyte has been produced by amplification of the zygote. The subdivision of the latter into numerous cells has brought about, as the effect of a single sexual fusion, the possibility of a large number of offspring. This practically amounts to a kind of polyembryony, as was suggested in 1887 by Vaizey. The cells when isolated are the structures we recognise as spores or carpospores. The sporeproducing multicellular body-so made by the subdivision of the zygote-was all sporogenous at first, but as its size has increased a progressive sterilization of its tissues has followed, so that the production of spores has become confined to part of it, the rest being sterile or vegetative. No doubt the formation of a wall to the mass, seen in Riccia as already noted, was the beginning of this process. The group of the Bryophyta shows us a series of plants in which progressive sterilization is closely connected with increasing size and structural complexity. Starting with the condition in Riccia we find sterile cells, elaters, \&c., making their appearance in the mass of sporogenous cells, the gradual formation of a central columella, and the differentiation of a more actively vegetative part, the apophysis, at the base of the whole sporogonium, together with the further 
differentiation of its whole mass into seta and capsule. The whole group is, however, characterized by the fact that the sporogenous tissue of each individual is normally a continuous mass.

Turning to the Pteridophyta or Vascular Cryptogams, there is not any doubt that progressive sterilization will account for many stages in their evolution. They differ in degree from the Bryophyta, for the proportion of sporogenous to vegetative tissue is but small and the sporogenous cells are either separated into small masses or are distributed singly. There has been a great development of the external form, which, originating in a relatively simple strobiloid structure, derived from a simpler sporogonium-like fructification, has become more complex through the putting out of appendicular organs. This was no doubt at the outset a physiological rather than a morphological development, for the adoption of the foliar habit in the group, correlated further with the acquirement of a subterranean absorbing system, brought with it great advantages, ensuring the physiological independence of the sporophyte.

Passing then to the question of the suggested intercalation of the sporophyte, Bower examined the question from the broader point of view of the relations of the two forms to environment, pointing out that physiological relationships were most probably determining factors, though he admitted that the conclusions reached must be checked by considerations of phylogeny. Taking the fern as his starting point, he pointed out the evident adaptation of its gametophyte, the prothallus, to a watery or at any rate moist environment, showing as it does relationship to the Algae in its simple structure and in the mode of fertilization of its ova. It is indeed semi-aquatic. The sporophyte, the fern plant, is on the other hand robust, with well differentiated tissues, adapted to the more exacting conditions of life in air. 
Phylogenetic considerations confirm the conclusion to which these facts lead, showing that the gametophyte is the older generation, corresponding closely with the gametophyte of the Liverworts if not so evidently with that of the green Algae. The sporophyte is younger and does not correspond with any structure in the latter group. Viewing a large number of forms, a comparison of them shows the progress of the sporophyte from small beginnings in the lower Bryophyta to large size and great complexity of form and structure in the Vascular Cryptogams and Gymnosperms.

The whole advance is accompanied by a corresponding reduction of the gametophyte. Bower concluded from these facts that the establishment of the alternation is the result of the adaptation which followed the change from conditions originally aquatic to a sub-aerial habitat. $\mathrm{He}$ went so far as to say that the alternation might be distinguished physiologically as an amphibious alternation, which finds its morphological expression in the differences of external form and internal structure observable between the more ancient gametophyte and the more recent sporophyte.

It is quite in harmony with this position that Bower refused to see as definitely as Sachs did the origin of the sporophyte among the Algae. Neither in the case of Oedogonium nor in that of the Florideae did he admit any true homology. He pointed out with some emphasis that the circumstances of formation are different in the two cases, while the bodies produced from the spores or carpospores of Oedogonium are motile and not fixed plant forms. Bower accordingly held there was in these Algae only a parallel development, not leading on to the establishment of the sporophyte of the archegoniate plants.

Bower's views so far were supported by Atkinson some years later, and the additional argument was adduced by the latter writer, that the disturbance of the new terrestrial 
habitat and the difficulty of establishing itself must almost necessarily be attended by a lessening of its powers of obtaining nutriment, thus enforcing on the sporophyte the development of vegetative powers, while the same necessity was most likely to result in the disturbance of its sporogenous tissue, leading to partial sterilization.

Bower summed up his views in 1890 as follows: 'The archegoniate series is undoubtedly of Algal origin, and this their gametophytes amply bear out : they probably sprang from filamentous green aquatic forms, inhabiting shallow fresh water or the higher levels between the marine tidemarks. . . . Certain forms spread to the land where access of water was only an occasional occurrence; in these the sexual progress could only be effected at time of rains, or floods, or copious dews, and even then might not take place unless the sexual organs were fully mature; thus less dependence could be placed upon sexualty for propagation and an alternative method of increase of individuals had to be substituted. This was done by the production of the sporophyte from the zygote; once fertilized, a zygote might in these plants divide up into a number of portions (carpospores) each of which would then serve as a starting point for a new individual, and dry circumstances under which they would be powdery, would favour their dispersion. In proportion as these plants spread to higher and drier levels (in accordance with the advantage which they gained from escape from competition and more free exposure to light for assimilation) the chance of a frequent recurrence of the circumstances necessary for sexual reproduction would be diminished and the dependence upon carpospores for propagation would increase; consequently the number of spores produced by each sexually-formed sporophyte must be larger, if the race is to survive and be in a position to compete. Any increase in the number of spores entails greater supply of external nourishment during their forma- 
tion; this in the phylum of the Bryophytes is chiefly supplied from the gametophyte which shows distinct adaptation to sub-aerial habit, while the means of nutrition on the part of the sporophyte itself are in these plants very limited and the external morphology of it very slight. In other distinct phyla, however, such as the Filicinae, Lycopodinae, and Equisetinae, the sporophyte itself assumed the function of nutrition ; a higher morphological differentiation of parts followed, and a more clear distinction between the organs which were to supply the nutriment (stems, leaves, roots), and the parts devoted to the formation of spores (sporangia), this for the first time stamped the sporophyte with a character of independence and permanence.'

The second question raised as to the necessity of assuming that a sporogonium stage must have occurred during the evolution of the sporophyte of the fern was not emphasised so strongly. Most writers agreed that the great gap existing between the surviving Bryophyta and Pteridophyta, with the complete absence of any evidence on the point arising from fossil forms, takes it out of the region of profitable discussion. Lang, whose work came nearer to the end of the century, held that the passage from the one group to the other is quite conceivable, and said that the comparison has been facilitated by fuller knowledge of the structure of the simpler sporophytes of the Pteridophyta, especially that of Phylloglossum, but he did not go so far as to endorse the view of direct descent. A similar cautious reserve is noticeable in the writings of Bower already quoted. Klebs, writing in I8g8, seems to have said the last word of the century on the point: "Though we have gained certain connecting points for the phylogeny of the Mosses, the question as regards the Ferns, in which the fertilized ovum develops into the leafy plant, is in quite another position ... The spot where the first indication of 


\section{Снар. I The Nature of Alternation of Generations 6I}

a Fern sporophyte appeared was the birthplace of the vastly developed series of the Phanerogams. The Thallophytes hitherto known do not give the least clue to the discovery of that spot.'

Another factor was brought into the discussion in IS93, which, when followed up, pointed to structural difference between the gametophyte and the sporophyte which was not traceable lower than the Hepaticae. This was the discovery by Overton that the nuclei of the cells of the prothallus of Ceratozamia have only half the number of chromosomes which are possessed by those of the sporophyte. The subject was discussed by Strasburger at the meeting of the British Association for the Advancement of Science at Oxford in I894, when, after dealing with the cells of gametophytes and sporophytes generally, he gave it as his opinion that the facts then known justified the belief that there is a definite difference between the number of chromosomes of the two generations in archegoniate plants, the sexual generation exhibiting half the number of the asexual phase. Strasburger further showed that in most cases the reduction or halving of the larger number takes place in the spore mother-cells. He stated that, in his opinion, this difference is fundamental and phylogenetic, and that the reduction-division implies a return to the original generation, from which, after it has attained sexual differentiation, offspring is developed having a double number of chromosomes. Strasburger restated the position in r 897 , his views closely resembling Bower's, though led up to by a study of nuclear detail.

The very strong position which was thus taken by the upholders of the antithetic theory was not, however, allowed to remain unchallenged, though but little impression was made upon it before the close of the century. It was attacked with some vigour and no little ingenuity by Scott in I896. He restated Pringsheim's views, and showed that 
they are not inconsistent with reasonable interpretation of the facts recently observed. In particular, he objected to the view of an intercalation of a new generation (the sporophyte) in the course of a series. He said, 'If we are to apply the antithetic theory of alternation to these cases (Oedogonium and Coleochaete) we must assume that the zoospores produced on germination in the oospore are a new formation intercalated at this point of the life-cycle. But is this assumption borne out by the facts? I think not. In reality nothing new is intercalated at all. The zoospores formed from the oospore on germination are identical with the so-called zoogonidia formed on the vegetative plant at all stages of its growth ... To my mind the point seems to be this-an Oedogonium can form zoospores at any stage of its development; there is one particular stage, however, at which they are always formed, viz. on the germination of the oospore. Nothing new is intercalated, but the irregular and indefinite succession of sexual and asexual acts of reproduction is here tending to become regular and definite.'

The homologous theory received some support in I896, and later in I898, by Lang's discovery of the occurrence of well-developed sporangia on the prothallus of a species of Lastrea. This was interpreted, as had previously been the phenomena of apospory and apogamy, as indicating that the prothallus and the fern plant are fundamentally homologous.

It was contended, on the other hand, by the advocates of antithetic alternation that all these phenomena are teratological, and therefore no conclusions on an important question of this kind can fairly be drawn from them.

Towards the end of the century Klebs published the results of his experiments on the influence of the environment in modifying the reproductive processes. His work was carried out mainly on the green Algae, and went to 
prove that the sexual and asexual methods of reproduction can be brought about at will by varying the conditions under which the plants are kept. It follows necessarily that the forms are all homologous. This, at first sight, seemed to be strong evidence against the antithetic theory, but reflection shows that it is not necessarily so. The advocates of the theory are not and have not been unanimous in trying to include the Thallophyta in their scheme at all, Bower, especially, holding that any regular alternation of sexual and asexual forms in that group indicate parallel development rather than stages in phylogenetic sequence. Nor can the varying behaviour of the nuclei in the Thallophyta be held more pertinent to the inquiry, on account of the plastic nature of the whole group.

No further discovery of importance fell within our period. The controversy which was being conducted with so much warmth extended over the remaining years of the century, both theories attracting supporters, who, however, did little if anything more than re-state the old arguments, based upon the long-known facts. With the dawn of the new century, further research led to the elucidation of certain points bearing on the theories, and opening the way to their further discussion from slightly different points of view. The year I9oo, then, saw several different views in favour. One school found antithetic alternation regular and constant throughout the archegoniate plants, but not represented with any certainty among the Thallophyta. Another held that its inception can be traced there in such forms as Oedogonium and Coleochaete, and among the Florideae and the Ascomycetes. Yet a third claimed that all the forms are homologous, and that the differentiation in the Archegoniatae is but the evolution of a differentiation commencing in and perhaps extending throughout the lower group. All agreed that in the Thallophyta there exists an alternation of an irregular and intermittent character, of 
actual and potential gametophytes, or of sexual and neutral forms. The relation of this alternation to the regular sequence of the Archegoniatae and the place in it of the fruit bodies of Coleochaete, the Florideae, and the Ascomycetes, were, as we have seen, subjects of controversy. Similarly, the origin of the sporophyte of the terrestrial form was held by some to be the differentiation of a vegetative form, fundamental to gametophyte and sporophyte alike ; by others to be the intercalation of a new plant-body derived entirely from the fertilized sexual cell. 


\section{CHAPTER II}

\section{THE THEORY OF METAMORPHOSIS}

THE controversy which occupied us in the last chapter was not unnaturally accompanied by a re-examination of the theory of metamorphosis, which had become very generally accepted since the days of Goethe and of Wolff. By both these writers it was held to be concerned almost entirely with the leaves and stem. Wolff presented it in the following terms: 'In the entire plant, whose parts we wonder at as being at the first glance so extraordinarily diverse, I finally perceive after mature consideration, and recognize nothing beyond leaves and stem (for the root may be regarded as a stem). Consequently, all parts of the plant except the stem are modified leaves.' Goethe about thirty years later spoke of certain exterior parts of plants passing into the form of adjacent parts either wholly or in a greater or less degree, so that it is possible to look upon a stamen as a folded petal, or a petal as an expanded stamen. His ideas were not put before his readers very clearly, and left them sometimes uncertain whether he considered all leaves modifications of some ideal or theoretical form, or whether he held that a structure commencing its development in some particular direction might be actually diverted into another, and become something quite different from what it would have become, had its development not been interfered with. The former view, on the whole, met with more general support at the outset. Many years nearer the opening of our period we find it supported and interpreted by Alex. Braun, who recognized as modifications of the hypothetical leaf, cotyledons, cataphylls or scales, foliage leaves, the leaves of the perianth of the flower, GREEN 
and sporophylls. We do not find, however, a satisfactory conception of the theoretical or ideal leaf of which all these are modifications. Nor do we find it stated clearly in what direction the modification proceeded-whether the order of approximation to the ideal was from foliage leaf to sporophyll, or in the opposite direction, though for purposes of convenience of description, rather than any other, progressive metamorphosis was the term associated with the former, regressive with the latter, change.

Opinion was not however fixed, for the view of a very definite actual change during development was entertained by many botanists.

One thing is, however, very clearly seen to have been held as underlying the theory of form. The plant was understood to consist of a few fundamental parts or members which are essentially different from each other, and whose modifications, however interpreted, make up the various forms of plant-body which exist. These fundamental members were held by Wolff to be leaves and stem, the root being included in the latter. The leaf was held to be subject to metamorphosis more freely than the stem.

The dignity of these parts as morphological members was emphasized in I867 by Naegeli and Schwendener, ${ }^{1}$ who gave to them the names caulome and phyllome, by which they continued to be known till the end of the century.

At the commencement of our period the clearness of this conception of metamorphosis had begun to be obscured. The wider survey of the vegetable kingdom that had been progressing since the time of Goethe, and which had been prosecuted in the late forties especially by Naegeli, had been directed to a great number of forms of lowlier plants in the construction of whose body the distinction between leaf and stem is not apparent. Naegeli's researches on the Cryptogams had been followed by many other observers,

1 Das Mikroskop, 1867. 
and the study of them became greatly developed and extended after I860. Naegeli himself never appears as a very prominent supporter of the theory of metamorphosis, and his work of 1867 , in conjunction with Schwendener, eads to criticisms which appear certainly as damaging to the dogma, if not subversive of it in its earlier form. The light amount of differentiation of form recognizable in the lowlier, if not in all, Thallophytes, was shown to be net with also in the higher plants-cases like Wolffia and Lemna appearing among the Phanerogams. To describe uch forms Naegeli and Schwendener introduced the term hallome to designate the undifferentiated body of the lant. They suggested a further category of parts or nembers, consisting of the hairs or outgrowths from the yeneral surface of either phyllome or caulome, to which hey applied the name trichome. There thus stood out our categories of members which were considered co-ordinate, thallome, caulome, phyllome, and trichome.

These suggestions of Naegeli and Schwendener, though hey seem at first sight only to make the morphological conception of the plant comprehensive and complete, are ound on examination to be antagonistic to the theory f metamorphosis, as propounded by Wolff and Goethe. The conception of the thallome implies that the differentiaion of the plant body into leaf and axis is not fundamenal. It is agreed on all hands that the archegoniate plants nave been derived or evolved from the lowlier forms and as at any rate the simpler of these hardly show a lifference between stem and leaf, such difference must ave been acquired during the course of development. if so, a differentiated stem and leaf cannot form the foundaion on which the form of the plant-body has depended. From the point of view of those who do not accept the cosition of Wolff the course adopted by Naegeli does not io much solve as evade the difficulty of bringing the theory 
of metamorphosis into harmony with the whole of the vegetable kingdom. The alternative, to admit that the conception of leaf and stem as different, but equally essential, members, only became evident after a certain course of evolution, and that consequently the metamorphosis of a member could only be conceived of as taking place in a certain section of the vegetable kingdom, destroys its fundamental character, and therefore reduces, or even minimizes the importance of the theory.

The idea that the so-called trichomes are morphologically co-ordinate with the phyllome and the caulome is also open to serious criticism. Trichomes arise indifferently and irregularly from both the others, and their identification depends upon anatomical and not morphological features.

The position of the sporangium in the scheme of members was again a difficulty. Its true homologies were only gradually brought to light: in some cases it appears to be an epidermal outgrowth, and hence a trichome. In others, arising on a leaf, it seems to be a part of the latter; springing from a stem the theory of metamorphosis pronounces it to be a phyllome. It was not till I88I that it was recognized as an independent member, corresponding to none of the others, but being sui generis. Its identification as such was made by Goebel in a paper published in the Botanische Zeitung in I88I, and it met immediately with general acceptance. The recognition need not, however, be taken as necessarily antagonistic to the theory of metamorphosis, as it may be said only to add another member to Wolff's list. On the other hand it can hardly be fundamental, as its occurrence is restricted.

Bower carried this idea still further, when he suggested in I894 that the sporangiophore also should be regarded as a member sui generis.

The study of the Cryptogams was soon found to involve the recognition of adaptation to environment to a greater 
degree than had been formerly held. As we have seen, the work of Darwin had given a special prominence to this aspect of the subject, and its spirit dominated to a greater or less degree almost all the research of the time. As we trace the course of opinion on the theory of metamorphosis it is important to bear this in mind. Morphology alone, morphology allied to phylogeny and ontogeny, were alike seen to furnish insufficient answers to the problems of development, and physiological considerations came very prominently into the field. It is impossible to avoid recognizing how these considerations modified the current views on metamorphosis.

Another line of investigation was not without its influence in a similar direction. The alternation of generations, whose development we have just discussed, drew attention to and excited inquiry about the origin of the terrestrial plant. As we have seen, the advocates of the antithetic theory supposed the latter to have arisen from a structure originating as little else than a mass of spores, and to have begun its evolution from such a stage by sterilization of sporogenous tissue, possibly passing through such a stage as the sporogonium of a liverwort, or the strobilus of a Lycopodium. In such a mode of origin there is no room for the stem and leaf as fundamental or primitive structures. The differentiation into members of these categories must have been later in the course of evolution, and again, adaptation to environment-a physiological conception-must have been one at least of the causes which led to the attainment of definite form.

The difficulty which appeared in the writings of Goethe, and later in those of Braun, in that neither puts forward a definite conception of the ideal leaf, was reflected in the writers who followed them, and was felt the more seriously as the necessity for making a clear distinction between stem and leaf was realized. Many attempts were 
made, but none withstood examination. The first idea was that they might be regarded respectively as axial and appendicular members, the leaf being an outgrowth from the stem. But as branches of the stem must be morphologically stems, and as they are appendages of the stem, this distinction proves insufficient. The young twig is axial as far as its relations to its leaves are concerned, while it is appendicular as regards the stem of which it is a branch. Again, a compound leaf has an axis on which leaf-branches-the leaflets-arise, while it is an appendage on a stem. A recognition of two classes of appendicular organs, the branch arising in the axil of the leaf, seemed to indicate a more fundamental difference, that of relative position. This view received considerable support, but there are so many exceptions to the arrangement, that standing alone it, in its turn, is insufficient. The outer leaves or scales of the leaf-bud, as well as the leaves of the flower bear no branches in their axils. A third attempt at a conception was more generally accepted than either-that the leaf is an outgrowth from an axis, from which it differs in its organization and its structure. This seemed, at first, more satisfactory, but it does not seem decisive in the cases of the rachis of many compound leaves, whose structure, at any rate, is fundamentally similar to that of the stem which bears them. Moreover, the organization of leaves and of winged stems is not essentially dissimilar. If we apply the conception to the Mosses we find the foliar expansions of the latter comply with the conception, but no morphologist who holds the antithetic theory admits that there is a true homology between them (arising as they do on the gametophyte), and the leaves of the higher plants, which are all developed on the sporophyte. The sporangia of Selaginella present another difficulty. They arise on the stem, and they differ from it in organization-but they 
are not to be regarded as leaves according to the conception based on relative position. According to Goebel they are members sui generis.

Nor do anatomical details afford us a criterion. Though the bilateral leaf and the radially symmetrical stem seem to have little in common, Bower has shown how inadequate is internal structure to supply grounds of identification, which shall be indisputable or conclusive.

These and other considerations show us that the conception of leaf and stem, even in the groups of plants in which we find it convenient and even necessary to recognise them, must remain arbitrary, and their individualities in many cases almost impossible to define.

The essential or fundamental character of the leaf as a distinct conception was discussed by Eichler in I86r. In the Entwickelungsgeschichte des Blätter, published in that year, he claimed that there is a primordial leaf that is distinguishable from the stem. It exists as such before internal or external differentiation, and becomes differentiated later into two chief parts, a stationary zone, or foliar base-which takes no further share in the formation of the leaf-and a vegetative part, which forms the petiole and the lamina and its branches. He laid great stress on the existence of a radical difference of these two parts from one another.

The difficulty of forming an adequate conception of the leaf presented itself very forcibly to the mind of Sachs, who discussed the matter with some completeness in the Lehrbuch. He claimed that absolute distinction between stem and leaf, and between thallome and leafy shoot, cannot be maintained. He said 'the expressions stem and leaf denote only certain relationships of the parts of a whole-the shoot; the greater the differentiation the more clearly are stem and leaf distinguished', and again, ' certain lateral outgrowths in some Algae may be termed 
leaves, and the axial structures which produce them stems (Characeae, Sargassum) ... When the difference between the outgrowths and the structures which produce them is less . . . it becomes doubtful whether the expressions leaf and stem ought still to be used, and when finally the similarity preponderates, the whole shoot is no longer called a leafy stem, but a thallome.' Still further, he said that the external differentiation of the members of the shoot into stem and leaf does not depend on internal differentiation, and instanced Caulerpa, in which such internal differentiation does not exist.

Sachs' views, therefore, were opposed to those of Wolff, and his conception of the form of the plant was that the fundamental differentiation of its body is into root and shoot.

As we examine Sachs' position more fully, his pronounced physiological bias becomes more and more evident. His conception of the leaf included its exogenous formation from the apical meristem, and the absolute continuity of the tissues there. The meristem producing stem and leaf jointly is uniform. He said the leaves and the shoot axis are essentially portions of one organ, the leaves being nothing more than protuberances of the shoot axis, developed to present the chlorophyll contained in them to the light and air. He did not recognize in the veins, ribs, \&c., anything fundamental, like branching of an axis, as we shall see some of his successors did; he made everything adaptive; and discussed very fully the adaptations and mechanical arrangements which they show. $\mathrm{He}$ recognized in a typical leaf as definite regions, the lamina, petiole, and sheath.

Gcebel criticized Eichler's views in papers in the Botanische Zeitung in I880 and I882, and modified his terminology. He insisted that the two parts into which his primordial leaf becomes differentiated are not sharply marked off 
from each other, but are only to be distinguished by the part they play in the further growth of the young leaf.

The relationship between stem and leaf was examined very closely by Bower in I884, and a new view of the morphology of the latter was advanced. At the outset he drew attention to the undesirability of confining the study of these forms to the higher plants, as Sachs had done some years earlier, and insisted on comparing them with the more lowly ones, to test the validity of the distinctions that had been drawn. Criticizing Eichler's theory, he showed that the separation of the leaf into foliar base and upper leaf divides the leaf into two parts that are not co-ordinate, a plan which is unlikely to lead to true insight into its morphology. He said, 'The most important point in the morphological study of a shoot or branch system is to ascertain the mode of origin and sequence of appearance of the various parts, and their relations in these respects to each other. In dealing with the leaf this principle is not kept so clearly before the mind. Current morphology still retains those obvious distinctions of sheath, petiole, and blade, as co-ordinate structures, ignoring the fact that the distinctive marks between them depend on processes of growth in various directions'. Hence, he concluded that Eichler's two categories are misleading. Bower substituted the idea that the leaf is a podium, which may or may not branch, and may develop in different ways at different points. He proposed the term phyllopodium to designate it, and showed how greatly it may vary. It may be cylindrical as in Pilularia, flattened, without wings or midrib, as in Welwitschia, winged throughout part or the whole of its length as in Gnetum. It may branch, the branches appearing in acropetal or basipetal order, sometimes merely as teeth at the margins of the wings, at others as distinct pinnae which may branch in turn. Differences in the distribution of its growth may lead to the appearance 
of sheath, petiole, and blade, or, to use his own terminology, of hypo-, meso-, and epi-podium.

Bower's theory differed considerably from that of Eichler. According to the latter the leaf is a member which may, or may not, branch in its upper region. Bower held it to be a potential branch-system. Eichler distinguished between the basal part of the leaf and the upper part, with its potentiality of branching; Bower distinguished between the podium itself and its branches, if any.

Bower's theory of the morphology of the leaf and stem implied a much greater similarity between the two than did the older ideas; instead of a fundamental difference in organization it suggested a tolerably close and detailed resemblance; both are branch systems, showing alike axial and appendicular parts ; both are capable of flattening or winging, the process in each being adaptive, or functional.

Bower applied his theory only to the Pteridophytes and the Gymnosperms, and supported it by anatomical researches carried out on the growing points, and by the history of the development of the individual leaf and of the separate pinnae.

The present writer in 1895 advanced the view that this theory is applicable also to the Dicotyledons, and applied it to leaves generally. Bower indicated that his opinion ran in that direction, but he did not amplify it. The writer showed that all cases can be explained by the theory of a branching podium or axis, with a capacity for developing wings, and pointed out the laws of branching are practically the same as those affecting the stem. Also that the capacity for winging is not peculiar to the leaf, but is shared by the stem, and is therefore not a distinctive, or inherent indication of difference of organization. On this view the midrib and the other prominent ribs are axial parts, branches whose wings have congenitally fused to varying 
extent. The anatomy of the ribs bears out the idea, the structure of the petiole being traceable with sufficient clearness through the length of the midrib. There is a fundamental similarity in anatomy between the leaf-axis and the stem-axis, though this is modified in the region of the epipodium by the flattening associated with the development of wings.

The leaves of the higher plants, therefore, may be compared with the flattened appendicular outgrowths in the Algae ; both resemble at first the main axis in organization and structure, only later showing specialization for functional purposes, both in form and construction. The degree of specialization is greater in the higher plants, and is mainly dependent on the need for an appropriate relation between surface and bulk. The need of proper communication between the atmosphere and the interior of the plant is imperative, and is met by subdivision, with subsequent flattening or winging.

This view of the morphology of stem and leaf harmonizes completely with Sachs' claim that the differentiation of form is fundamentally into root and shoot; indeed, it is only a development of his theory.

With a certain school of thinkers the entrance of physiological or adaptive considerations led to a still greater departure from the Wolffian theory, which was making itself known in the closing years of the century, and which may be traced back to the Darwinian position of the struggle for existence. This was the view that the determination of form does not depend on fundamental categories of members, but may be traced back to physiological influences combined with, or superposed upon hereditary tendencies in minor directions. If the primitive or original plant was a unicellular organism, possessing a power of, or tendency to the acquirement of, increasing complexity, its gradual development can be traced by studying the existing 
forms of the simpler plants. The cell increased in size; at a certain stage the ratio between bulk and surface was found insufficient, and the cell divided. If the two resulting cells failed to separate, the cell-filament was initiated; later, for similar reasons, the cell-plate was formed, and later still the cell-mass. Increase of size of the latter could not now be adjusted by separation into two, and hence the operation of branching came into being. Internal differentiation, which was unnecessary so long as the body remained small, became imperative as size increased. Among the Algae of the present day this process can be traced, and the beginning of such differentiation is visible in such plants as Fucus, where we have a protective outer layer and a rudimentary conducting-system in the centre. Though much branched, the general anatomy is alike in both axis and appendages. In the larger forms the differentiation of the axis has become more conspicuous, but all stages can be traced. The determining need seems to have been to maintain an adequate ratio between surface and bulk, a matter of increasing difficulty as the dimensions of the plant increased. The form attained has therefore depended on the division of labour which the larger size has involved, so that all parts of the plant may partake of the advantages offered by the environment. When migration to the land took place physiological conditions determined the form assumed. The plant, originally a flat thallus, gradually assumed permanently what had before been only occasionally attained-the upright position, and the subdivision of its form increased as the environment became air instead of water. The so-called leaves of the Liverworts and Mosses, though little more than emphasized subdivisions of the original flat thallus, began to show a rudimentary differentiation, while the initiation of a root system is indicated by the differentiated rhizoids which mark the bases of the higher mosses. The physio- 
logical nature of the cause of their origin is emphasized by Goebel's discovery that leaf-formation in the Liverworts has arisen in quite a number of series independently of one another (Organographie, p. 26I).

The same cause was suggested by Bower for the sporophyte phase of the plant. Originating as a zygote, giving rise to a large number of spores, a sporangium in fact, the needs of the structure under open-air conditions were primarily those of nutrition. The small supply of food that could be derived from the gametophyte caused an independent development of vegetative organs which was initiated by a sterilization of part of the sporogenous tissue. Whether the evolutionary process went on in one or in several phyla is not of much importance to the question before us. In any case the sterilization of the sporogenous tissue led to the acquirement of vegetative features by the sterilized cell-aggregates. The output of special protuberances by these postulates nothing improbable, though no evidence is forthcoming on this point. Granted that outgrowths did appear, the gradual differentiation of both form and structure under functional necessity must have followed.

According to this theory, form has been determined by physiological rather than morphological conditions, and has been almost entirely traceable to the action of the environment upon originally undifferentiated organisms. It postulates, however, an inherent capacity for increasing complexity of structure, together with a potentiality of development in response to such stimulation as a widely varying environment may present in different cases. The individual qualitative differences in such capacity must have been considerable, as the same external surroundings have not produced uniformity of form or substance in detail. Such differences, further, must have been deepseated in the organism, as the forms of the plants of to-day 
are hereditary though still capable of varying under changes of conditions.

It remains an interesting question how far the heredity of these forms in detail is the result of long acting conditions affecting in succession the protoplasm of countless generations, and how far of inherent tendencysuperior to their action.

The advocates of these physiological speculations found themselves obliged, however, to accept the categories of stem and leaf as existing in the higher plants. Though they differed from the morphologists in their conception of them, and denied that they are fundamental, they admitted their convenience for descriptive purposes and made no attempt to introduce new terms which should indicate dissent from the position of the older writers. Their position was consequently not so different as at first it seemed to be from that of the advocates of metamorphosis as stated by Wolff and Goethe. The difference was rather as to the origin of, than as to the changes possible in, the outgrowths universally called leaves. It was possible to accept a physiological basis of form, and yet to admit that these, or any outgrowths, could be made to assume different forms under the stress of physiological need. This aspect of the theory of metamorphosis differs but slightly from that put forward by Sachs in the Lehrbuch, in the words, "Metamorphosis is the varied development of members of the same morphological significance resulting from their adaptation to definite functions.' It does not seem very clear what importance Sachs attached to the words 'morphological significance', for he goes on to say 'The conceptions of stem, leaf, root, trichome, as at present employed in botany, result from the consideration of highlydeveloped plants, the different members of which actually present considerable diversities, from a purely formal point of viere; 1 ... absolute distinctions between thallomes and

1 The italics are the Author's. 
eaf-bearing axes are not to be found. It is therefore a matter of convenience where the boundary-line is drawn '; and again, 'The expressions thallome, caulome, phyllome, trichome, root, designate, as has been said, several ideas ${ }^{1 . '}$ The development of the idea of metamorphosis, taken $\mathrm{n}$ the sense in which Sachs used it, itself proceeded on the ines of adaptation. Its most eminent exponent was Goebel, who may in many respects be looked upon as Sachs' uccessor. It was, as interpreted by him, fundamentally morphological rather than physiological, though it recognized the direct influence of the environment as a factor n determining form. Writing in I895, Goebel interpreted netamorphosis as implying the perception that the variety n external form exhibited by plants is to be traced back io the diverse modifications of a very few fundamental ypes. He said that its study is very closely bound up vith that of adaptation, and it might almost be asserted hat a metamorphosed structure owes its existence to an daptive modification of a relatively primitive type form.

Goebel admitted that in certain cases it is not possible o differentiate the members of the plant definitely into eaf-stem-root, but he opposed the idea that this negatives he metamorphosis of one of these into another or of netamorphosis within the limits of each category. He set ut with fairness the impossibility of drawing a definite ine of demarcation in all cases between leaf and stem, nstancing the various shoot-like members of certain species f Utricularia, which he claimed to have the morphological zalue of leaves. He held, however, that though such a lefinite separation of the two, of universal application, annot be found, yet such becomes practicable when we imit our consideration to single groups of tolerably closely llied forms, and that this is sufficient for the purpose of he theory of metamorphosis. The leaf and shoot rudi-

1 The italics are the Author's. 
ments differ $a b$ initio, although the lines of demarcation between the two series of organs as distinct categories may vanish.

The morphological conception of leaf and stem being taken as a starting-point, two different theories were advanced to explain the facts of metamorphosis in the several categories. Of these the first was put forward by Frank in 1892 and was known as the theory of differentiation. His position was that when we see the rudiment of a leaf or a leaf segment, which would normally become a foliage leaf, developed instead as a scale leaf or a sporophyll in consequence of some change in the conditions of its life, we are face to face only with a possibility of varied development in it, and need not hold that we are encountering an actual transformation of one organ into another one. The rudiments which are capable of going through various developments are composed of undifferentiated embryonic tissue, but when they have assumed the form of one definite structure they are incapable of changing into any others.

Goebel, writing in I895, rejected this hypothesis of Frank. He said that this differentiation theory assumes that at the vegetative point of the shoot indifferent primordia arise which are capable of development in various ways according to the need of the plant, but that they have in common the fact that they are leaves. He objected to this assumption and pointed out that the idea of 'leaf' is a purely abstract one, 'an artificially constructed category which has no concrete existence. What these organs have in common, which we endeavour to fix by a general idea, must be something else than their origin from leaf primordia.'

Goebel claimed, in opposition to Frank, that in such cases we are face to face with such a change in the progress of development that the rudiment of a particular organ 
becomes actually transformed into another-that metamorphosis is real and not a mere modification of the course of potential development. He said, "The primordia of the organs at the vegetative point are not of an indifferent nature, and do not consist of embryonal tissue capable of developing in any direction. . . . We must assume for the primordia of leaves the possession from their outset of a definite, not an indifferent, material nature, which conditions their further development.' He went on to argue that the fate of a primordium may be entirely changed by altering conditions-' If now all the foliage leaves be removed from a plant of Onoclea, the development of sporophylls is hindered-the primordia of the sporophylls, which are nothing else than primordia of foliage leaves, are then forced to develop into foliage leaves and the production of sporangia is either partially or entirely suppressed'.

Goebel did not attach so much importance as many other writers to phylogenetic considerations. He said that the causes of metamorphosis are mainly internal and belonging to the capacity of the individual plant, making his idea of the process thus mainly an ontogenetic one, though he held that the transformations actually seen in organs are conditioned by a change of function. His leaning to the side of the physiologists was clear. $\mathrm{He}$ said, "Metamorphosis is an actual objective fact; the rudiment which is normally destined to develop into a definite organ may change its ordinary proportions during development and thus give rise to another organ, and this change of form is constantly associated with an alteration of function. . . . It is true that division of labour does not necessarily involve metamorphosis, but it is a condition of its manifestation. Hence not morphology, but physiological requirement is the main factor, teleologically speaking, in effecting structural differentiation.' 
It would, however, be altogether inexact to say that these movements of opinion were universal among botanists. The old views were maintained with equal vigour by many of the first rank, and the new considerations advanced by the organographists were carefully examined and discussed, conceptions of them being advanced which harmonized with the older theory. The controversy cannot well be followed in full detail, but the position can be stated as it was left at the end of the century.

First place here should be given to Naegeli's great work, Die phys.-mech. Abstammungslehre, published in I884, which contains a most admirable presentation of the subject from this standpoint. For the English reader, however, it was insisted upon by Vines, who may be quoted as a leading exponent of the view, that the standpoint of pure organography is utterly subversive of morphology, destroying all homologies. He argued that if in the development of the plant a leaf be regarded as merely the expression of a tendency to increase the plant's body, this tendency would have been satisfied by the acquirement of a flat, branched, thallus, and that further progress to such distinct structures as stem and leaf would have been unnecessary. In his view the gradual evolution of stem and leaf from a primitive thallus has essentially nothing to do with the adaptation of the organism to external conditions; the differentiation of the plant body into members is the expression of the inherent tendency of the protoplasm of the living organism to develop into ever more complex ' aggregates ' of members. This was almost the old Wolffian position, but interpreted in the light of the evolutionary spirit which had appeared since Wolff's own time. It gave us the organism endowed with inherent possibilities of variation controlled by being confined to definite lines by the inherent constitution of protoplasm. The ultimate members, root, stem, leaf, may in this view be looked upon as potentially 
present even in the unicellular plant, just as Man is potentially in the Amoeba; and their gradual unfolding is but a matter of time and the realisation of their inherent tendency to complexity, much as we have in the spore or the ovum, the potentialities which we see realised as it grows into a plant.

Vines laid special stress on this inherent tendency of protoplasm. He asked why the course of development or evolution has been in fairly uniform directions in large groups of plants. The influence of environment appeared to him insufficient, unless it were conceded that something in the plant presented the material or tendency to work upon. Something of the kind had been advanced much earlier by Darwin in the Origin of Species, where he said, ' In all cases there are two factors, the nature of the organism, which is the most important of the two, and the nature of the conditions. The direct action of changed conditions leads to definite or indefinite results. In the latter case the organization seems to become plastic, and we have much fluctuating variability. In the former case the nature of the organism is such that it yields readily when subjected to certain conditions, and all, or nearly all, the individuals become modified in the same way '. 1

Vines compared the inherent tendency to complexity of development, which ultimately results in the revealing of stem, root, and leaf as the plant's constituent members, with the formation of crystals in the inorganic world. As the assumption of a definite and constant crystalline form is the expression of the special property of the substance, so every living organism, whether plant or animal, possesses a characteristic form which is the outcome of the properties of its protoplasm. The latter differs from the former in being unstable and subject to change.

The morphologists of this school did not controvert the 1 Origin of Species, ed. 6, p. 106. 
view that physiological need largely determines form. They limited the direction and the extent to which that determination can occur, insisting that it must fall within the limits of the members of which they held the plant to consist. In other words, they considered organography subsidiary in every respect to morphology.

Adhering in this way to the view that the plant is built up by modifications or metamorphoses of a few fundamental members, Vines, agreeing with Bower, rejected the suggestion of Goethe that the foliage leaf is the most primitive, and that in an ascending series, bracts, perianth leaves, and sporophylls represent more and more complete metamorphoses of it; he adhered to the theory of Celakowsky and of Bower that the sporophyll is the earlier, accepting the view that progressive sterilization of originally sporogenous tissue has played a great part in the metamorphosis. The phylogeny of the leaf on this theory supports the view of the descending or regressive metamorphosis of Goethe.

The fundamental difference between the strict morphologists and the organographists appears, then, to lie in the importance attached by the former to the power claimed by them to be inherent in the living substance to develop in the direction of increasing complexity of form apart from the influence of external conditions. Adaptation to environment in the absence of such tendency is not sufficient ; it does not necessarily involve complexity or higher organization at all, for the more lowly organisms are as perfectly adapted to their environment as are the highest.

Such was the position of the controversy when the century closed. Both views had their supporters, and neither could be said to be indisputably established. 


\section{CHAPTER III}

\section{THE MORPHOLOGY OF THE FLOWER}

THE conception of the flower which was almost universally held in 1860 was the direct outcome of the dogma of metamorphosis. On this view the modifications of the leaf occur in orderly sequence, and the development takes the order, foliage leaf, bract, sepal, petal, stamen, carpel, this being termed progressive metamorphosis. The fundamental idea of the flower was that of a branch or shoot, whose leaves were progressively modified in that direction, the metamorphosis culminating in the carpel.

With the full realization of Hofmeister's discoveries a little change came about, the stamen and carpel being recognized as being concerned in spore-production, and not forming truly sexual organs. The term sporophyll came into use as applicable to them as well as to the sporebearing leaves of the Ferns and their allies. The conception of the flower became, under Goebel's guidance, that of a shoot bearing sporophylls, a view associated many years earlier with Schleiden.

The morphology of the flower on such a basis had been the subject of an exhaustive work by Payer in I857, and his researches excited much discussion and research. Chief among the writers of the period were Döll in 1870 , Eichler in $1875^{-8}$, Celakowsky in I875, and Goebel in I 884 . Eichler's contribution to the science took the form of the Blïthendiagramme, which was the most important publication of the period dealing with floral morphology. It contained a full exposition of the floral type of each natural order, and the more important of its modifications, showing 
the range of floral structures within each group. Eichler gathered together by way of preface to each order all the most important works of different writers upon it, including references to anatomical and histological detail, and discussed the peculiarities of morphology from the standpoint of the evolutionist.

The view at first held of the nature of metamorphosis, as we have already seen in another connexion, was gradually modified as time went on. The view of the differentiation of an original type under the influence of adaptation was set out by Hanstein, and the actual metamorphosis of one specialized organ into another was denied, to be re-asserted however, by Goebel in I88o. In his paper in the Botanische Zeitung of that date he concluded that sporophylls are metamorphosed foliage leaves, for he observed that sporangia are met with sometimes on what appear to be normal green leaves of Botrychium, and that where they occur the vegetative development is reduced. Hence the gradual change from the foliage condition by reduction to the spore-bearing condition.

In I893 a theory radically opposed to that of Goebel was put forward by Bower. Reference has already been made to his elaborate researches on the spore-bearing members of the whole group of the Pteridophyta. The first series of these, which dealt with the Equisetinae and the Lycopodinae were then completed, and the relations of the leaves to the sporangia in these groups were under consideration. They led to the conception of the sporophyll as originating from a sporangial or strobiloid form in which the adequate development and distribution of sporangia were the primary considerations. Hence Bower came to the conclusion that the sporophyll occurred earlier than the foliage leaf in such a strobiloid form, and therefore if metamorphosis has played a part in the development at all, its order has been from sporophyll to foliage leaf and not in 
the contrary direction as the older dogma claimed. From this view it was no great step to regard the flower as primarily composed of sporophylls, by sterilization of which the members of the perianth became differentiated.

A somewhat similar idea, but one of much less general application, had already been advanced by Prantl, when he made the suggestion that the petals in certain Ranunculaceous flowers have been derived from abortive stamens. It was left, however, to Bower to put forward the great generalization on which the study of floral morphology depended during the remaining years of the century.

Among contemporary writers Goebel gave a modified adhesion to Bower's view, but denied that its application was so general as had been claimed. Hé argued that the converse metamorphosis must not be excluded, for that in such flowers as those of the Nymphaeaceae the leaves of the flower are demonstrably derived from bracts. In certain anemones he claimed to be able to trace the transformation of the involucre to the calyx, and its gradual assumption of petaloid characters subsequently.

The question of the nature of the metamorphosiswhether it had been progressive or regressive-led to considerable discussion as to the nature of the primitive flower of the Angiosperms, and the controversy was maintained long after the close of the century. There were two main schools of thought: the first saw with Engler such a primitive flower in the forms with one or more free sporophylls without any perianth, and traced its development by modification of this type, by such steps as the gradual differentiation of a perianth, by the further differentiation of the sporophylls into stamens and carpels, and by modifications of the arrangement of all, together with congenital unions between the members of the whorls of each and between them and the floral axis: the other school, on the whole under the inspiration of 
Bower's views, saw the primitive flower initiated somewhere among the strobili of the Pteridophyta, such as those of Equisetum or the Lycopodinae, traced it through the cones of the Gymnosperms, and found it appearing in the Angiosperms already complex and showing a high degree of differentiation, provided with a perianth of at least one series of members and with modified sporophylls, and though showing its strobiloid character by the spiral arrangement of its members, approximating to what the adherents of the other school held to be a highly specialized type. On such a hypothesis as this the so-called primitive flowers of Engler were held to be due to reduction. Bower himself suggested in 1894 the comparison of the flower of the Phanerogams with the strobilus of Pteridophyta, but he refrained from definitely claiming them as homologous; indeed, he pointed out a difficulty in accepting such a position, in that the homosporous strobili are entirely nonsexual, while this is not the case with the flowers of Angiosperms. At the same time it will be remembered that the strobili of Selaginella contain both micro- and mega-sporangia. Bower was quite emphatic in opposing the old view ; he said, 'in any case there seems no sufficient reason to think that . . the Phanerogamic flower ever was a foliage shoot.'

Though there seems reason from Bower's work to look for the primitive flowers among the strobiloid structures of the Pteridophyta, it must not be supposed that they are necessarily homologous. Indeed, in his studies on the spore-producing members, Bower gave reasons for hesitating to adopt the view without reserve. He held that the so-called sporophylls of many of the latter are not necessarily foliar structures, but may be traced to development from outgrowths similar to the sporangiophores of Helminthostachys. He said, "the practice of referring every part of the shoot to some modification of axis or leaf, emergence or hair, has already been broken down in the 
case of sporangia (Goebel, Bot. Zeit., I88I), and there is just reason to be prepared for its being broken down also as regards the parts which bear the sporangia . . . it is, in fact, suggested that the sporangiophores are simply placental growths, and not the result of any metamorphosis of parts or appendages of prior existence.'

The same idea was stated by Scott in his discussion of the morphology of certain fossil forms, in the words, "The difficulty is perhaps met by regarding the sporangiophore (like the sporangium itself), as an organ sui generis, which often occupies the position of the ventral lobe of a bract, but may also arise independently, and may so far resemble an entire leaf.'

Bower did not go so far as to suggest that the stamen and carpel of the Phanerogams are modified sporangiophores. He concluded his general discussion of the morphology of the latter by saying: 'But a warning is necessary that mere form is not a sufficient characterization of any given part as a non-foliar sporangiophore; for in some cases a clear line of evidence shows that certain parts which have the form of stalk with vascular supply, enlarged distal end, and pendent sporangia common for sporangiophores are truly of foliar nature; I mean the female sporophylls of the Cycads. The argument for reduction from some more elaborate sporophyll is for them firmly established on a comparative basis, and it seems hardly open to doubt that they are foliar structures reduced from some more elaborate Cycado-Filicinean leaves. But though this may be true for the Cycads, it does not invalidate our hypothesis for sporangiophores generally; it merely suggests that similar results, of which the biological advantages are obvious, may be arrived at along different evolutionary routes. It will also make caution especially necessary in treating similar cases among seed plants.'

The domination of the idea of metamorphosis led to 
much theorizing as to the structure and homologies of the so-called female cone of the Coniferae. A good deal of the speculation was based upon abnormal cones or monstrosities which were investigated during our period by various workers, and the views put forward show in many cases an almost perverse ingenuity in attempting to force the recognition of homologies, and to explain in terms of metamorphosis every abnormality that was found Frequently one monstrosity was interpreted only by the light of another, and it is not to be wondered at that the literature of the period presents us with explanations whose ingenuity constitutes their chief value. Among them, however, certain theories stand out as having attracted the support of leading botanists.

At the opening of our period the theory of Alexander Braun, put forward in 1853 , was generally accepted. This hypothesis stated that the seminiferous scale of Pims is formed by the fusion of the contiguous margins of the first two leaves of a bud which is in the axil of the bract or carpellary scale, but which undergoes no further development. This view was opposed by many, but as often as it appeared controverted it came up again into notice, brought forward by new advocates. With various small modifications we find it advanced by Caspary in I860, Parlatoré in I864, Oersted in the same year, von Mohl in I87I, Stenzel in I876, and Willkomm in I879. It was finally defended with much elaboration by Celakowsky, whose writings on the subject extend from I879 to I897.

Another theory was advanced by Baillon in I860, which he based on the study of the mode of development of the parts. He said the flower, i.e. the seminiferous scale, is either terminal or axillary, but always arises on an axis and not on an appendage, and is itself an axial structure. It consists of an ovary of two carpels surrounded by a cupular structure, which in several genera is known as an 
aril. The ovaries are naked, and each contains a single orthotropous ovule on a basal placenta, the ovary wall being adherent to the ovule. This hypothesis was supported in I869 by Sperk, and in his earlier writings of 1872 by Strasburger, though later (1879) he came to consider the so-called ovary to be an ovule.

The view which on the whole met with the most general acceptance was put forward by Sachs in the first edition of the Lehrbuch in I868, and was in I88I endorsed and amplified by Eichler. In their opinion the cone of Pinus is a single flower consisting of an axis with numerous seminiferous scales arranged spirally along it; each scale is a carpel, from the face of which an outgrowth of the nature of a placenta is developed, and on this placental scale or ligule, two naked ovules are seated. Eichler said that this structure occurs in the Araucariae, the Abietineae and the Taxodineae. The Cupressineae bear their ovules in the axils of the carpellary scales. Taxus and Torreya bear them at the apices of lateral shoots, the apex becoming modified into the ovule, and carpels being absent. They are surrounded by an aril. In these two genera consequently the flower is represented by a solitary ovule.

A theory in many respects resembling the views of Braun was advanced in 1869 by Van Tieghem. The scale is a foliar organ, the first and only leaf of an axis which arises in the axil of the carpellary scale or primary bract, and undergoes no further development. Arising from this suppressed axis its face is turned towards the primary bract and it bears the two ovules usually on its dorsal surface, just as the microsporangia are borne upon the dorsal surface of the leaf-like stamens in the male flowers. In the Taxineae the ovules terminate the carpellary leaf; they result from the transformation of its whole entire limb, or as in Ginkgo and Cephalotaxus, from a similar transformation of each half of the limb. In other words, the carpellary 
leaf is reduced to a sessile limb completely converted into either one or two ovules.

Yet another theory was due to Penzig in I894, which was that the seminiferous scale is formed by the two lateral lobes of the carpellary scale turning inwards till they meet, fusion of the margins then taking place.

Like all the floral members, the stamen in I86o was held to be a metamorphosed leaf, and its various parts were accordingly attributed to particular foliar regions. Cassini and Roeper put forward the view that the two anther lobes are the swollen lateral halves of the blade. The pollen sacs must consequently be excavations in the tissue of the leaf; the furrow between the two anther lobes must represent the leaf margin, and the two pollen sacs of each lobe must be on different faces of the blade. Sachs combated this view, bringing forward the researches of von Mohl on certain abnormal developments. He suggested as preferable the theory that the whole structure is of a sporangial nature. Reviewing, too, the facts of histological development, he said, 'The origin of the pollen mothercells and the development of the wall of the separate pollen sacs call to mind so vividly in all essential features the corresponding phenomena in the sporangium of Lycopodiaceae and even of Equisetaceae, that it may be assumed, until more exact observations bring something different to light, that each pollen sac (i.e. each loculus with its wall) corresponds to a sporangium, and hence also to a single pollen sac of Cycadeae and Cupressineae.'

Here we have the first presentation of the views now current, which only waited for the work of Goebel to give a satisfactory exposition of the morphology of the stamen.

The theory of the stamen as essentially a modified leaf was contested on other grounds, particularly on certain anatomical researches carried out by many investigators. The first of these and the most important were made by 
Kauffmann in I868 on Casuarina, and their outcome was to prove that the pollen sac in that genus is cauline and not foliar, being developed from the tissue of the axis. In I869 Magnus made the same discovery in the case of Naias, and in 1873 Warming observed a similar origin for that of Cyclanthera, which was confirmed by Engler in 1876 . In the later years of the century Campbell found other cases in Zannichellia, and Lilaea, and confirmed Magnus's observations on Naias.

In spite of these observations, the idea that the stamen is a metamorphosed leaf had not disappeared at the end of the century. It was being assailed, horvever, in consequence of the recognition accorded to the sporangiophore as an organ as much sui generis as Goebel had claimed the sporangium itself to be. The view was tentatively entertained in some quarters that whether arising from axial or appendicular tissue it is essentially a sporangiophore.

The first account of its anatomical development appears to have been given by Warming in 1873 .

In the story of the investigation of the morphology of the ovule two features especially stand out prominently. The first is the domination of the earlier speculations by the old theory of metamorphosis, which in this connexion, as well as in so many others, acted as a hindrance rather than a help to the conception of correct morphological ideas, and led botanists to frame hypotheses which seem almost gratuitous, to make structures fall in with preconceived and unnatural theories of so-called laws which were based on no secure foundation. The second feature of primary importance was the change in the conception of the morphological value of the ovule which followed the gradual recognition of the importance of the sporangium in the category of the members of the plant. The acceptance of the contention of Goebel that the sporangium is an organ sui generis freed morphologists from the neces- 
sity of looking for its homologues among stems and leaves, and opened the way to the comparison of the ovule and the structures which it contains with other structures occupying similar positions in the life-history of the Pteridophyta, and so to the establishment of true homologies extending through the range of vascular plants, both recent and extinct.

In $\mathrm{I} 860$, and for some years subsequently, the accepted view of the morphology of the ovule was the pronouncement of Schleiden and Braun that the placenta is an axial structure, and the ovule arises as a bud upon it. The integuments of the ovule thus correspond to the fused leaves of such bud.

Though this was the opinion of most botanists of the time, it was not felt to be satisfactory, and two other hypotheses were developed in the course of the next decade. In I869 a theory which had been held by a few morphologists even before I 860 was restated by Cramer. It was that the ovule is a metamorphosed leaf or part of a leaf, either a tooth or an outgrowth of the upper surface. Sachs states Cramer's position in the Lehrbuch in the following terms :' The ovule of Primulaceae and Compositae he considered to be a whole leaf, and he supposed that closer observation would show the same to be the case in other flowers also, especially in those where the flower is said to possess a solitary 'reputed terminal ovule' as Urtica (and Taxus) and perhaps also the Dipsaceae and others. The nucleus (nucellus) would in this case be a new formation on the surface of the ovular leaf, the funiculus would correspond to the base of this leaf, and the integuments to its upper part, which is folded once or twice in the form of a cup or hood round the nucellus. On the other hand, he would consider as only portions of the leaf (teeth or outgrowths of the upper surface) all those ovules which spring singly or in numbers from the margin or upper surface of carpellary 
leares, such as those of Cycadeae, Liliaceae, Ranunculaceae, $\&$ c. In these cases the nucleus would be a new formation on the surface of the lobe, the funiculus would correspond to its base, and the integuments to its upper part folded once or twice round the nucleus in the form of a cup. Only in those few plants in which the orule has no integument would the naked nucleus or entire ovule correspond to this lobe of the carpellary leaf,' and further, 'When the ovule appears to be the equivalent of a lateral branch or of the whole of a leaf, the funiculus and the integuments together correspond to the foliar structure in each case; the nucleus arises from it as a lateral outgrowth, while the integuments correspond to the hood-shaped lamina of the leaf, growing over the nucleus.'

To such straits did the domination of a so-called 'law'the theory of metamorphosis-drive its votaries, some of them among the most brilliant intellects of the time!

Sachs says in the fourth edition of the Lehrouch that when writing the first edition he agreed with Cramer's view, but that he had come subsequently to reject it in favour of ascribing different morphological significations to the ovules, according to their mode of origin and their position ; terminal ovules must be regarded as the terminal portions of the axis, lateral ones as equivalents of whole leaves, marginal as branches of leaves, while superficial ones might be included 'in the category of such foliar outgrowths as we have already found to occur in the form of sporangia among the Lycopodiaceae. The ovules of Orchideae must, however, be included under the category of trichomes, inasmuch as they owe their origin to simple superficial cells of the parietal placentae.'

We find here the dawn of the idea of the sporangial theory of the ovule, but it was little more. The tenacity with which Sachs adhered to the view of the metamorphosed leaf is but a mark of the difficulty with which men parted 
with old traditional views which had been held to be fundamental. It is strange that while we find him putting forward these views, we meet in the same edition of the Lehrbuch with the statement that the embryo-sac is the representative of the 'macrospore' of Selaginella, and the nucleus (nucellus) of the ovule must be considered the equivalent of the 'macrosporangium' (Eng. Ed., i, p. 422). The far-reaching importance of this recognition in the light of morphology does not seem at that time to have impressed him. Indeed it apparently escaped a proper appreciation till Goebel promulgated the true morphological conception of the sporangium.

Other botanists were more conservative than Sachs. The modified leaf theory was supported by Celakowsky in I874 and 1877 , and by Eichler in the second volume of the Blïthendiagramme. On the other hand, Strasburger in I872 appeared as an advocate of the older view of Schleiden and Braun, and particularly opposed the idea that the morphological value of the ovule can be different in different cases. Making descent the foundation of morphology he pointed out the uniformity of its construction, wherever arising, and denied therefore that ovules can have arisen at different times and in different ways. He attributed to them the morphological value of a bud, the nucellus being the axis and the integuments leaves.

The supporters of the leaf theory denied the resemblance to a bud on the ground that the development of the parts of the latter is always acropetal, while the nucellus and integuments arise basipetally. They supported their own views by urging that the ovule as a leaf outgrowth becomes homologous with the sporangium of a fern. Again we find opinion advancing in the direction of the sporangial theory.

This view, which is the second of the two to which we have alluded, while gradually taking shape did not assume its true importance till Goebel's famous pronouncement in 
I88I : 'As a shoot remains a shoot, and does not lose its morphological dignity, whether it arise as a lateral shoot on the growing point of a stem, or from the embryonic tissue of a foliage leaf (as in many Ferns), or is adventitious on a root, \&c., so also a sporangium remains a sporangium and nothing else, whatever its position ; sporangia are just as much organs sui generis as are shoots, roots, \&c.'

Goebel's views led to the reconsideration of the older theories, and though the latter did not altogether disappear they gained no ground up to the end of the century. The sporangial nature of the ovule on the other hand was almost universally accepted; its integuments were interpreted by some as homologous with the indusium of the unisporangiate sorus of Azolla, and by others were regarded as purely adaptive.

The morphology of the placenta was in its turn the subject of dispute. Schleiden, as we have seen, held it to be axial, apparently because ovules, if they are buds as he said, can only arise on axes. From I87r for some years onwards, the view of Van Tieghem that the placenta is a portion of the carpel, usually of its margin, met with general acceptance. Among its supporters were Celakowsky and Eichler. Huisgen in 1873 suggested that its morphological value is not the same in all cases; in the Primulaceae it seems to be a direct prolongation of the stem, and many other orders point, though less strikingly, to the same origin. Though many ingenious theories were advanced to explain away these exceptions to the carpellary theory, they were not very satisfactory, and as the century drew to its close Huisgen's views gained considerable support.

The details of the development of the ovule were accumuating during the latter part of the century. Hofmeister admittedly left them incompletely investigated, though his contributions to the knowledge of them were of the first 
importance. It is impossible to give an account of the work of the numerous observers who helped to elucidate the structure and development of the ovule, and to show its various modifications. Place must be found, however, for Warming's great memoir of 1877 , and for the work of Strasburger in 1877 and 1879 , prior to which the embryosac was thought to be produced by the simple enlargement of a cell of the nucellus of the ovule, as stated by Sachs.

The elucidation of the exact nature of the homologies of the pollen tube and its contents was gradually accomplished, but was not complete till near the end of the century. Soon after the opening of our period Millardet and Pfeffer showed that they could recognize indications of a male prothallium and an antheridium in a very simple condition in the pollen grain of Gymnosperms, when comparing the latter with the microspores of Selaginella and Isoëtes, but the nature of the agent of fertilization was not known to them. Sachs spoke of it in the early editions of the Lehrbuch as "the male fertilizing principle which, passing into the oosphere or embryonic vesicle, causes it to develop the embryo'. He considered the pollen grains to be male sexual cells, and was either not aware of the nuclear divisions taking place in them after maturity, or he attached no importance to them.

The two nuclei which mark the commencement of germination in the pollen of the Angiosperms were first observed by Hartig in I866, but their importance was not realized.

The first real advances of knowledge in this direction appeared in Strasburger's Befruchtung und Zelltheilung, published in 1877 , where the tube and its nuclei were discussed. Strasburger showed that the microspores of the Angiosperms can be compared in detail with those of the Gymnosperms so far as their contents are concerned. In this work he erroneously attributed to the vegetative 
nucleus the sexual function, while the true sexual nucleus was thought to break up and disappear, but he elucidated the true relations in his memoir of $\mathrm{I} 884$.

In this work he suggested also that the products of the germination of the angiospermous pollen grain represent only an antheridium, and that the prothallial tissue, reduced continuously throughout the Pteridophyta, is met with for the last time in the few cells cut off in the pollen grain of the Gymnosperms, before the protrusion of the tube. This view received very general support, and the pollen tube of the Angiosperms gradually ceased to be recognized as the male gametophyte, though the exact nature of its homologies was in dispute at the end of the century.

The more completely differentiated antheridium of the Conifers was discovered in I8gI by Belajeff, in his researches on Taxus. The homology of the structures resulting from the division of the antheridial cell with the antherozoids of the Pteridophyta was established, if proof were needed, by the discovery of ciliated male cells in Ginkgo by Hirasé in I895, in Cycas by Ikeno in I896, and in Zamia, by Webber in 1897 .

Though in the Lehrbuch the embryo sac was recognized by Sachs to be the representative of the megaspore of Selaginella, he did not find in its contents the homologues of the prothallus. In the fourth edition of the Lehrbuch he spoke of embryonic or germinal vesicles formed in it by free-cell-formation, and of one of them, a primordial cell with a large nucleus, as homologous with the oosphere among Cryptogams. He said there were usually two embryonic vesicles side by side in the embryo-sac, which in some genera were very long and peculiarly organized, the upper end projecting as a long slender tube into or even beyond the micropyle. This appearance had been seen also by Schacht, and by him named the 'Filiform Apparatus'; it was considered to receive the pollen tube 
as it approached the embryo sac. Pringsheim and Strasburger compared it to the canal-cell in the archegonium of the Cryptogams. Sachs held as they did, that the two germinal vesicles corresponded to two archegonia, the basal rounded part of each being the oosphere, and the elongated apex the canal-cell, which became separated from the other only after impregnation.

The antipodal cells were recognized quite early, but no account of the method of their formation was given for some years. Pfeffer held them to be a rudiment of the true prothallium.

More exact knowledge of the true condition of things came to light in the years $1877-8 \mathrm{I}$, when, through the concurrent investigations of several workers, the progress of the development of the sexual apparatus was ascertained. Among the many writers who treated of the subject may be mentioned Warming (I877), Vesque (I878-9), Strasburger (I879), Fischer (I880), Marshall WVard (I880), Treub and Mellink (I880), and Guignard (I88I). Their accounts agreed in all essentials, and were confirmed and extended by many researches in more recent years.

The homologies of the egg apparatus and the antipodal cells in the light of the new discoveries were sought for in two directions. Warming and Vesque considered that the cell which develops into the embryo-sac is equivalent to one of the spore mother-cells in the sporangium of a Pteridophyte, and without regarding the probability of a prothallial development, held that the early accumulation of four nuclei at each end indicated a tetrad of spores. How fertilization of one of them was possible, if such was their nature, remained unexplained.

Strasburger put forward the other hypothesis: he considered the embryo-sac to be a spore mother-cell which develops into a single megaspore, and the structures arising later to be its prothallium. He held these to 
constitute the primary endosperm and to be partly sexual, and partly vegetative. The sexuality of the oosphere is certain; the synergidae have, in his opinion, been modified to perform a secondary office in the process of fertilization. He taught further that the archegonia of the Pteridophyta and of the Gymnosperms are reduced in the Angiosperms to a single one, which is represented only by its oosphere.

His anatomical researches explained the nature of the filiform apparatus of Schacht, which was seen to be the elongated ends of the synergidae.

Strasburger's hypothesis of the nature of the prothallium in the Angiosperms was completed by the suggestion that its development is arrested at the stage described, and resumed after fertilization of the oosphere, by the development of a secondary portion, the so-called endosperm, from the definitive nucleus, itself the result of the fusion of the polar nuclei.

Goebel held the epinion in I 880 that th antipodal cells correspond to the laige-celled endosperm, selaginella.

The synergidxe were recognized to be potential-sexual cells by Dodel in I891. He cescribed their fertizization in Iris sibirica:. Simlar observation's were made by Chauveaud in I892, when investigating some, cases of polyembryony in Vincetoxisum: The jertilization of one of them was observed by Scrivere in Taraxacum four years later. Guignard, as long ago as I88I, found in a species of Mimosa three embryos side by side, suggesting a development of one from each of the synergidae as well as from the oosphere. At the time he did not suggest this order of development as certain, holding it to be possible that they might be due to budding from the early segments of the zygote. He observed a similar occurrence of two embryos in Naias in Igor, but again he admitted the possibility of a similar explanation. 
Various curious appearances of the development of different parts of the embryo-sac, and particularly of its antipodal contents, suggested that haustoria are often developed, generally after fertilization. Cases were observed by Guignard in I885, and by Johnson in I889. Other instances have been noted since the close of the century.

The prothallus of the Gymnosperms and its homology with the endosperm of Selaginella and Isoëtes were known to Hofmeister. It is interesting, in the light of the possible sexuality of the synergidae, to find that in $1898 \mathrm{~V}$. H. Blackman determined the ventral canal cell of Pinus sylvestris to be an arrested gamete. Chamberlain came to the same conclusion in I899, as the result of a study of Pinus Laricio. The details of the development of the archegonia and the separation of the ventral canal cell from the oosphere were studied in I 879 by Strasburger.

The details of the process of fertilization were not known with any accuracy in I85o. The fusion of the cells had been observed, "bu there "was no clear idea of what the fertilizing "súbtance "consisted." Sachs said in the Lehwbuck "às 'ate as 1874 , that fertilization corsplsts of a union of the fertilizirg sulistanc of the male cell with the protoplasm of the fernate "The entrance of the antherozoids of the crypogams into the archegonium was observed by Hofmeister, but "their penetration" as far as the oosphere was first observed by straburger. The penetration of the embryo-sac by the pollen tube not having been seen, except in the solitary instance of Canna, Sachs suggested that in Phanerogams a union by diffusion takes place of some substance contained in the pollen tube with the germ cell, and that the contact of the tube with the apex of the embryo-sac is sufficient for its transmission.

The part played by the nuclei was first observed by Sclimitz in studying the conjugating cells of Spirogyra in I879, and their fusion in Angiosperms was discovered by 
Strasburger in I884. Details of their behaviour in different cases were the subject of numerous memoirs from that date onwards.

The approach of the pollen tube to the embryo-sac was thought to be uniformly by way of the micropyle till I89I, when the curious process of chalazogamy was discovered by Treub in Casuarina. This discovery excited great attention and was at first held to indicate a new basis of classification of Angiosperms. It was observed again by Nawaschin in Betula, in I892, by Miss Benson in several families of the Amentiferae in I894, and by Nawaschin in Juglans in $\mathrm{x} 895$. Further investigations by the last-named writer in 1898 led to the discovery that in two species of Ulmus the mode of entry of the tube into the embryo-sac is varied and irregular, an observation confirmed by Zinger's researches on the Cannabineae; hence the idea that it is of classificatory value was abandoned.

Towards the close of the century, in 1898 , another discovery of great interest was made by Nawaschin-one which had an important bearing on morphological speculation. This was the fact that in Lilium and Fritillaria both the generative nuclei of the pollen tube are concerned in fertilization, and that while one fuses with the nucleus of the oosphere, the other either unites with the definitive nucleus of the embryo-sac,- the latter being itself the result of the fusion of the polar nuclei,-or it fuses with one of the polar nuclei. This phenomenon has been indifferently spoken of as double fertilization, or triple fusion. . It attracted great attention, and many investigations were proceeding as the century closed, with the result that the occurrence was seen to be so wide-spread as to justify the conclusion that it is universal.

The chief result of the discovery was a re-consideration of the morphology of the so-called endosperm of Angiosperms. As we have seen, Strasburger included this struc- 
ture in the prothallus, of which he held it to be a part, whose formation, taking place after fertilization of the oosphere, is due to a resumption of vegetative activity by a certain constituent of the primary prothallium under the stimulus of the fertilizing fusion. Such resumption of vegetative activity is illustrated in other directions, particularly by the carpellary structures, causing them to develop into the fruit.

Another view of the formation, however, was advanced in I887, by Le Monnier, long before Nawaschin's discovery. He suggested that the polar nuclei are both sexual, and that their fusion is comparable to that of the gamete of the pollen tube with the oosphere. In consequence of this fusion he held that a second embryo is developed, and that polyembryony is the normal state of things in the embryo-sac. As usual, in cases of polyembryony, only one embryo matures, and Le Monnier suggested that the second was from a very early stage modified for physiological reasons, in fact, was altogether subservient to the nutrition of the first.

Nawaschin's discovery brought Le Monnier's theory again into prominence. It was supported in I900 by Miss Sargant, who suggested that the reason for its abnormal development is perhaps to be looked for in the fact that the antipodal polar nucleus is a vegetative and not a sexual structure, and hence not unlikely to cause an abnormal development. An argument in favour of the process being one of sexual fusion is derived from the observations on xenia which have been made by various writers since I86o. Xenia may be defined as an effect produced on the endosperm in consequence of fertilization by alien pollen, and is consequently noticeable in connexion with hybridization. It implies that the endosperm shows the characteristic features, not only of the plant in which it is formed, but also of that from which was derived the pollen the pistil received. It was first noticed by Hilde- 
brandt in $\mathbf{I} 867$, as the result of crossing a yellow and a dark-brown race of maize. Not only was the embryo a hybrid, but the endosperm showed characters proper to each of the parents. The phenomenon was observed again in 1872 by Körnecke, and subsequently in I $88 \mathrm{I}$ by Focke, who introduced the term xenia for it. Many subsequent observers confirmed these early results. Xenia remained unexplained until Nawaschin's observations were announced, but was then seen to be readily accounted for, indeed, was only what might be expected on the assumption that the fusion of the pollen nucleus with that of the embryo-sac constitutes a sexual union. This view was at once put forward and supported by experimental evidence by De Vries, Correns, and especially by Webber, who carried out a long series of researches at the Nebraska Agricultural Experiment Station in I898, I899, and I9oo.

The pursuit of the subject of the pollination of the flower received an additional stimulus from the publication of the Origin of Species, and of Darwin's investigations into the cross and self-fertilization of flowers, which followed after a short interval. Darwin's work extended over the first twenty years of the period under review, and marked by his wonderful patience and careful observation, contributed materially to the elucidation of the structure of many of the most complex floral mechanisms. His observations on heterostylism in dimorphic and trimorphic flowers, published in I869, were especially important. Other workers in the same field were Hildebrand, Delpino, the brothers Fritz and Hermann Müller, and Axell, all of whom made valuable contributions to this branch of knowledge from I860 to I870. Hermann Müller's presentation of the subject in his great work Die Befruchtung der Blumen in I873, was one of the most noteworthy features of the study of Natural History of the time, and was for long the standard authority on the subject. 
The passage of the pollen tube down the tissue of the style was first shown to be the expression of a true process of germination by Van Tieghem in I87r. He pointed out that the pollen grain contains small stores of nutritive materials, and that the tissue of the style is similarly supplied. Mangin showed in I886 that the germination of the pollen grain is accompanied by very active respiratory changes. In 1893 the present writer was successful in showing that the progress of the growth of the tube is due to digestive changes set up and maintained by enzymes secreted both by the pollen grain and by the tissue of the style.

The mode of passage of the contents of the pollen tube into the embryo-sac was held by Sachs, as we have seen, to be a process of diffusion. When further details of the behaviour of the synergidae had been obtained, it was evident that the fertilizing substance is not liquid, and that, therefore, bodily entry into the embryo-sac must be effected. Van Tieghem, in his paper already referred to, claimed to have seen a perforation of the pollen tube, sometimes single, sometimes occurring at many points just behind the apex, with small drops of viscid matter exuding.

The writer observed in the pollen tube of Narcissus a well-defined aperture in a particular position on one side of the tip. Similar appearances were observed by Ewart in I895, but he concluded they were temporary rather than permanent openings. They were apparently not due to accidental rupture. In I897 Schaffner studied the pollen tubes of Sagittaria, and observed a thin area at their tips, which became ruptured after the tube had penetrated the embryo sac, so that the two nuclei were discharged from it. V.H. Blackman showed in I898 that in the Gymnosperms the tip of the tube becomes fused with the egg membrane and does not enter it.

The first description of the structure and mode of develop- 
ment of the embryo in Monocotyledons was given by Hanstein in I869, in his account of his researches on Alisma. He was confirmed by Famintzin in IS79. A somewhat different type was described in I874 as seen in Pistia; it is remarkable for the absence of a suspensor. A third form, which is characteristic of many of the Orchidaceae, was investigated in I879 by Treub. It is remarkable for the development of the suspensor into a haustorial organ. Yet a fourth type was found to exist in many of the Liliaceae in I 894 by Coulter, characterized by the irregularity of its segmentation, and by the development of a massive suspensor.

The exact nature of the so-called cotyledon of this embryo has been disputed. Solms-Laubach showed in I 878 that in certain cases its origin is lateral, and the apex of the stem terminal. Other variations in embryos of the Alisma type were noted by Campbell at the end of the century. The normally terminal position of the cotyledon and its physiological function as an absorbing organ were suggested by Bayley Balfour to show that its true homologies should be looked for in the foot of the Pteridophytic embryo.

For our knowledge of the Dicotyledonous embryo we are again indebted to the researches of Hanstein in I869, and those of Famintzin ten years later. The form first investigated was Capsella, which has maintained its position as a kind of standard or typical embryo, though many small varieties in the details of development were noticed during the later years of the century. Guignard showed that a different type exists among the Leguminosae, nearly forty species of which he examined. The chief feature they present is the extremely massive suspensor, which in some species is coenocytic in structure. Guignard's researches were published in I88I. In some of the Mimoseae and Hedysareae he observed another variation, 
in that both the cells resulting from the first division of the zygote take part in the formation of the true embryo.

The first satisfactory account of the development of the embryo in the Coniferae was given by Strasburger in 1872 and I879. In the other groups of the Gymnosperms its development had not been traced before the end of the century.

Polyembryony, or the occurrence of more than one embryo in the embryo-sac in Angiosperms has already been spoken of as arising from fertilization of the synergidae. This is not, however, the only cause of its origination. Strasburger, in I878, observed the formation of embryos by budding from various cells of the nucellus, some of them situated some little way from the embryo-sac. The young bud-like body pushed its way into the embryo-sac and developed into an embryo. The plants in which this occurred were Funkia ovata, Coelebogyne ilicifolia, Nothoscordon fragrans and Citrus Aurantium. In I897 Hegelmaier observed a similar formation in Allium odorum, from the inner integument. Ganong, in 1898 , found polyembryony caused in the same way in Opuntia. These cases were called 'sporophytic budding'.

Apogamy or oophytic budding, the development of an embryo from a vegetative cell of the prothallus, was observed in I895, by Tretjakow in the same species of Allium, the antipodal cells being those concerned. Hegelmaier made a similar observation two years later. These cases can only be explained as occurrences of apogamy, comparable to what we have noted in the Cryptogams, or as giving evidence that the antipodals like the synergidae are potential sexual cells. In this case, on that hypothesis the embryo developed parthenogenetically.

Another abnormal case of embryo formation was noticed 111 I895 by Jeffrey in Erythronium. The embryo arises 
from the zygote, but from the suspensor instead of the normal segment.

A case in which an embryo of very doubtful morphological value occurs was described in I 898 by Treub, and in I899 by Lotsy. This is the genus Balanophora. Fertilization does not occur; the embryo is formed by the upper polar nucleus, a case presumably of parthenogenesis, if we recognize this nucleus as sexual and the sister nucleus of that of the oosphere. But in addition both observers found that a cell in the midst of the endosperm started the formation of a second embryo, though it did not develop very far.

True parthenogenesis, the development of the oosphere into an embryo without any sexual fusion, was observed by Juel in I898 in Antennaria alpina. He noted further that its chromosomes do not vary from the haploid to the diploid condition, but are constant during the whole of the life-history of the plant, and that no divisions of the heterotypic kind occur. Just at the close of the century Murbeck observed almost exactly the same phenomena in several species of Alchemilla. 


\section{CHAPTER IV}

\section{TAXONOMY I860-I900}

AT the opening of the period under consideration the classification of the vegetable kingdom was in a very imperfect condition. Under the influence partly of Hofmeister's brilliant researches on the Vascular Cryptogams, and of those of Thuret, Pringsheim, Naegeli, De Bary, and others on the Thallophytes, the inordinate importance that had been attached to the Phanerogams was disappearing, and inquiry was being directed for the most part to the relationships existing among the lower plants. The main outlines of the principal groups of these were gradually taking shape, but the details of structure presented by the numerous types had not been ascertained with sufficient clearness to enable any satisfactory subdivisions of the larger groups to be arrived at. Though the great class of the Thallophyta was recognized, and was seen to differ in important respects from the more highly organized Mosses, the line between them was not drawn with precision and certainty. The cleavages between the Mosses and the Pteridophyta, and between these and the Phanerogams were seen more distinctly, and general conclusions had been arrived at as to the range of forms to be allotted to certain main divisions. The system of de Candolle, with various modifications suggested by different systematists, was still the basis of classification for the flowering plants.

The early part of the period was characterized by great activity in the unravelling of the problems presented by the lowlier forms; the structure, modes of reproduction, and general life-history of almost innumerable species of 
Algae and Fungi were determined, and gradually a basis for a truer classification, and one founded on fact and not on hypothesis was established. Among so great a crowd of workers it is difficult to distinguish individuals, but the names of Pringsheim, Bornet and Thuret, Naegeli, J. G. Agardh, Harvey, Kützing, Schmitz, among algologists; and of De Bary, Woronin, Tulasne, Brefeld, Van Tieghem, Le Monnier, Cohn, and Fries, among fungologists, claim particular mention.

Meantime, though satisfactory data for the work were not forthcoming, efforts at the formation of a more truly natural scheme of classification were not wanting.

The first of them were put forward by A. Braun in I864, and are noteworthy as suggesting co-ordinate divisions for the higher and lowlier plants. Braun made three great classes-Bryophyta, which, with two subdivisions included the Algae, Fungi, and Moss-like plants; Cormophyta, comprising the Vascular Cryptogams, and Anthophyta, or lowering plants. His treatment of the latter was characerized by a recognition of the very unsatisfactory nature of de Candolle's Monochlamydeae, or Apetalae, the families ncluded in which, or at any rate the greater part of them, ne distributed among the Thalamiflorae and Calyciflorae.

A more detailed scheme was adopted by Sachs in the irst edition of the Lehrouch in I868. He recognized five orincipal groups, which he held to be readily distinguishable rom each other by characters of the first importance. These were (i) Thallophyta, comprising the Fungi, and he Algae with the exception of the Characeae; (ii) Charaeae; (iii) Muscineae, comprising the Liverworts and Mosses; iv) Vascular Cryptogams ; (v) Phanerogams. The system vas in great part based upon Bartling's proposals of $I 830$, ut it differed in the rank assigned to the Characeae. achs held these plants to be nearer to the Mosses than o the Algae, mainly on account of the form of their sperma- 
tozoids, and, while not admitting them to the more highly differentiated group, felt justified in assigning them an intermediate position, a view which, however, he abandoned a few years later.

The numerous forms at that time known among the Algae presented great difficulties to the searchers after systematic relationship. Sachs spoke of the classification of the group as being in the utmost confusion, and said that the older divisions of its members into large groups and families was inconsistent with the discoveries then continuously coming to light, and that no satisfactory substitute could be devised. He was so impressed with this feeling that in the Lehrbuch he merely described seriatim the forms which were known, making little effort to indicate affinities.

The Fungi were a little better known. De Bary classified them into four groups, Phycomycetes, Hypodermii (including the Uredineae and the Ustilagineae), Basidiomycetes, and Ascomycetes-broadly the lines on which present day classification runs, though certain modifications and expansions have been adopted.

The discoveries by Schwendener of the true nature of the Lichens mark the years I860 and I862, though the full statement of them was not made till I868. He showed that they are plant associations, an Alga and a Fungus living together to their mutual benefit. His views were bitterly opposed by many botanists of the older school, and made their way at first but slowly. They received confirmation, however, at the hands of other workers, who subjected the lichen thallus to a species of analysis. Baranetzky, though he did not see the meaning of his observations, showed in IS67 that the algal constituents, or gonidia as they were called, are capable of an independent existence if separated from the lichen, and are none the worse for the separation when properly nourished. 
Baranetzky's results were confirmed and extended by Treub in I873 and by A. Möller in I887. Reess, in I87I, found it possible to start the formation of a Collema thallus by germinating some spores of the lichen among cells of Nostoc lichenoides, and Bornet afforded further proof in I873 by obtaining a lichen in consequence of sowing spores of Parmelia among cells of Protococcus. Bonnier in I889 extended these results by many careful synthetic cultures. The fact that fungi of quite different families may be concerned in the formation of a lichen was proved in I88I by Mattirolo, who showed that the fungus of Cora is one of the Basidiomycetes, while all previously noticed belong undoubtedly to the Ascomycetes. The fructiication till then associated with the Lichen as an organism was exactly similar to those of the latter group.

The nature of the relationship was at first, and naturally, ield to be one of parasitism, in consequence of the known ncapacity of fungi to lead an independent life. Later investiyations, however, revealed its true nature to be symbiotic. Stahl made a very complete investigation into the tructures concerned in the reproduction of lichens in I877.

In his classification of the Vascular Cryptogams Sachs aid stress on heterospory as a diagnostic feature of what ne held to be natural groups. He distinguished three wholly isosporous divisions, Filices, Equisetaceae, and Ophioglossaceae; while he recognized two groups which are artly heterosporous, Rhizocarpeae and Lycopodiaceae. He was inclined to class the Marattiaceae with the Ophiolossaceae, on account of the resemblances between the porangia of both. In further subdivision of the Filices e followed in the main the classification of Mettenius n I856, recognizing as subdivisions: Hymenophyllaceae, tleicheniaceae, Schizaeaceae, Osmundaceae, Cyatheaceae, nd Polypodiaceae, but relegating as we have seen the Iarattiaceae to another division. 
In the fourth edition of the Lehrbuch important changes were introduced, in the light of the knowledge of the reproductive processes which had been obtained. Sachs proposed four classes of Thallophytes, and included in each forms with and without chlorophyll, thus abandoning the idea that a fundamental division exists between Algae and Fungi. In this he followed Cohn, who had made a similar proposal in 1872 . His classes were based upon the manner of the reproduction prevalent in each. The first was Protophyta, in which he included the blue-green Algae and the two groups of the Bacteria and the Yeasts, in which no sexual fusions had been observed. The second class included all the forms in which sexual reproduction was found to take the form of the fusion of similar gametes or sexual cells, no difference of sex being noticeable. He called it $Z$ ygosporeae-from the zygospore, the product of such fusion. His third class, Oosporeae, included the forms which showed the fertilization of a female cell, or oosphere by a motile antherozoid; and the fourth, Carposporeae, those in which the product of fertilization is a complex fruit-like body. Among these he recognized an alternation of generations comparable to that which is presented by the higher plants.

This separation of the Algae and Fungi into two parallel series, though indicating the affinities existing between the two groups, did not obtain permanent acceptance by botanists. The classification of the Fungi which we owe to the writings and work of De Bary was more satisfactory, and has remained, with some inevitable modifications, practically unchallenged, though a certain re-arrangement of his main groups was suggested by Brefeld many years later.

- The recognition of Bacteria as vegetable organisms was due to Cohn, in I853. At first they were held to belong to the fungi, and were long known as Schizomycetes. The 
discovery of chlorophyll in some forms rendered this unsatisfactory, and they then seemed to be a class by themselves, most nearly allied to the Cyanophyceae or blue-green Algae. Since the early work of Cohn they have attracted much attention, and when, through the labours of Pasteur, the part they play in causing disease became understood, the study of them led to the recognition of the science of Bacteriology. This aspect, however, does not come within the scope of the present volume. From the standpoint of the botanist they are still regarded as members of Protophyta, in accordance with the opinions of Cohn and Sachs.

In the fourth edition of the Lehrbuch Sachs gave up the view that the Characeae are of sufficient importance to be regarded as a class intermediate between Algae and Muscineae, and relegated them to the Carposporeae. This inclusion, together with that of the Coleochaeteae rendered this group a not altogether natural one, and its individuality was not long maintained.

Sachs modified at the same time his original classification of the Vascular Cryptogams. Fankhauser's discovery of the monoecious prothallium of Lycopodium led him to abandon the division into Isosporeae and Heterosporeae, and to regard heterospory as a phenomenon that has taken place in two distinct groups, the one a developmental series beginning with the true Ferns, and the other a similar series beginning with Lycopodieae. He substituted for his original scheme the recognition of three main groups, which he called Equisetineae, Filicineae and Dichotomeae. The second of these included (I), under the name Stipulatae, the Ophioglossaceae, Marattiaceae, Osmundaceae, and Schizaeaceae; (2), the Filices proper, comprising the Gleicheniaceae, Hymenophyllaceae, Cyatheaceae, and Polypodiaceae, and (3), Rhizocarpeae, consisting of the Salviniaceae and Marsiliaceae. The Dichotomeae, so called 
from the habit of their branching, were divided into the Lycopodiaceae and the Ligulatae. The Lycopodiaceae comprised the Lycopodieae, Psilotaceae, and Phylloglosseae; while the Ligulatae, so called from the development of a ligule in connexion with their leaves, included the Selaginelleae and Isoëtes.

Though Sachs included the Osmundaceae and Schizaeaceae in the Stipulatae he did not appear to be satisfied with their position there, as he discussed them, in the detailed examination of their structure, with the Filices proper. The association of the Marattiaceae with the Ophioglossaceae was based upon similarity of their stems and roots, and the complexity of their sporangia. Further knowledge of the life-history of the members of both groups has shown their affinities to be hardly so close as Sachs supposed.

The very distinctive group of the Rhizocarpeae was found to be possessed of characters so nearly resembling the true Ferns that with the recognition that heterospory alone did not form a sufficiently differentiating characteristic, the desirability of keeping them as a separate group of the Vascular Cryptogams, co-ordinate with the Ferns, was no longer great, and like the Ophioglossaceae Sachs included them in the more comprehensive group of the Filicineae.

Sachs' classification stood the test of examination, and its satisfactory character was, on the whole, emphasized by the detailed anatomical researches which were carried out by various observers during the later years of the century. With certain modifications rendered necessary by these and by the gradually accumulating evidence derived from fossils it held its position till the end of the period under review.

In I880-I Goebel suggested a classification of vascular plants on the lines of the character of the development of their sporangia. The Ferns and Rhizocarps, in which 
each of these organs arises from a single cell, were grouped together as Leptosporangiatae; the rest, in which the origin of the sporangium is multicellular, he called Eusporangiatae.

Little further advance in classification of the lower plants was made until the appearance of Eichler's system in $188_{3}$. In this for the first time we find the recognition of three of the four great groups which are generally recognized to-day, the Thallophyta, Bryophyta, and Pteridophyta. Eichler, however, grouped these together as Cryptogamae, and regarded the latter as co-ordinate with the Phanerogamae. He abandoned Sachs' arrangement of the Fungi and Algae as parallel series, and restored their rank as separate classes, into which he divided his Thallophyta, while he did not recognize the division Protophyta. It is in his treatment of the Algae that we find perhaps the greatest advance that his system presented. In it they were divided into groups which were named according to their colour-Cyanophyceae, Chlorophyceae, Phaeophyceae, and Rhodophyceae. It was not, however, his intention to indicate that in their colouring matter he found their most characteristic feature. They fell into four natural groups, each marked by very special features connected with both their vegetative and their reproductive habit. Each separate group was found, however, to possess a distinguishing colour in addition to its other peculiarities, and Eichler adopted this feature as a convenient one on which to base its name. A fifth group, the Diatomeae, was made by Eichler in his first scheme, but in the revised proposals of I89I it was united to the Phaeophyceae.

Eichler's system was modified only slightly by Engler, whose proposals were the latest that obtained acceptance before the close of the century. He adopted in the main the divisions of Eichler, though his subdivisions were not quite the same. He made two divisions of the Thallophyta, 
separating the Mrxomycetes irom the rest; a third division - the Embrtophrta Zoidiogama, or Archegoniataeincluded Eichler's Brophrta and Pteridophrta, and a fourth-the Embrrophrta Siphonogama-comprised the Phanerogams. which he arranged in two subdivisions, each co-ordinate with Bryophrta and Pteridophrta-riz. the Grmmospermae and the Angiospermae.

Though Engler's ststem was adopted largely on the continent of Europe, it did not at first obtain acceptance in England, where Eichler's main divisions were adhered to up to the end of the century:

The acceptance of these four main groups and the discussion of their relationship to each other directed inquirs into the question of phrlogens, which gradually assumed a great importance in the literature of the period, and maintained its interest throughout the closing rears of the century. The inquiry received considerable support from the renewed activity that was displayed in the in. restigation of the fossil remains of plants from the different geological strata, interest perhaps being greatest in the question of the origin of the Phanerogamic Flora. To this branch of study reference will be made in a later chapter.

The difficulty of tracing the descent of the Bryophyta from the Algae was recognized by all. As we have seen, it assumed great prominence in connexion with the discussion of the homologous and antithetic theories of alternation of generations, and while no writer claimed to have solved the problem, there was a general agreement that the explanation must be looked for in connexion with the migration of plants from an aquatic to a terrestrial environment, and the consequent upsetting of their physiological equilibrium. That it was due to some far reaching cause tras obvious, when the course of erolution in the group of the Algae was studied and compared with that 
which had been developed in the Bryophta. Buth vegetative and reproductive mechanisms had undergone a fundamental modification which was inexplicable except upon some such hrpothesis.

More active speculutions were induiged in as to the crisin of the Pteridophyta, but in the absence of evidence derived from the preservation of fossil remains they remaired speculations only. Some morphologists. perticularly Campbell, suggested the origination of some stch form as Ophioglossum from a hepatic ancestor of the type of Anthoceros. Bower, with perhaps more reason. इug. gested the origin of the group irum a primitive $\$:-0$ biloid form oi which Phylloglossum may te the nearest living ally. The original type be pictured as an trbranched upright strobilus. in which all the leares were sporophylls, and the sporangia of moderate size. Erch a form he held might be traced back to a body of the nature of a sporogonial head. develupmeni proceeding on the lines of $(i)$ sterilization of the potentialit sporogenous tissue; (ii) formation of septa; iii relegation cf the spore-producing cells to a supericial position; ; iv eruption of outgrowths sporangiophores on which the sporangia are supported.

Both Camphell and Bower agreed that in the series of Pteridophyta the three existing classes have been developed along parallel lines, having diverged separately from the original ancestral type at eariy periods of their erolutionan opinion that commanded general assent.

The inter-relationships of the sroup gave rise to a great deal of controversy. much of which centred round the different iamilies of the Ferns. Prior to ISgo, Iargely owing to the researches of Mettenius in Isó sidered that the Leptosporangiate forms were the more primitive of these. and that they are consequently related the most closely to the Algal or Brycphytic ancesturs. 
In that year, however, Bower advanced reasons for the view that that position must be assigned to the Eusporangiate forms, and the opinion obtained general acceptance.

The position of Isoëtes as closely allied to Selaginella, and properly included with the latter in the Ligulatae, was challenged by Vines in I888. He pointed out that the chief resemblance is the development of the ligule, and that the general features of its embryogeny-especially the absence of a suspensor,-its general habit, the absence of any cone-like fructification, the form of its antherozoids, and some of its anatomical features, indicate a relationship to the Ferns. Vines's view was endorsed by Campbell in I895, although with a certain amount of reserve. Opinion in Germany continued in favour of regarding it as akin to the Lycopodiaceae, though apparently but little evidence was forthcoming in favour of such position.

The propriety of grouping together the Salviniaceae and the Marsiliaceae was called into question by Campbell, who pointed out that, regarding them as Ferns, the two groups have little in common but their heterospory. The Salviniaceae show certain resemblances to the Hymenophyllaceae, while the Marsiliaceae are more like the Polypodiaceae.

Several objections were raised with regard to the position of Ophioglossaceae among the more primitive Ferns, and many botanists towards the end of the century were inclined to place the group near, if not among, the Lycopodinae. Celakowsky, in $\mathrm{I} 884$, held that some ancestral form gave rise to both the Ophioglossaceae and the Lycopodiaceae, and that it probably possessed the simple sporophylls of the latter ; he therefore considered that of all living plants they were the nearest prototypes of the Ophioglossaceae. From a comparison of their respective sporangia, Bower, in $189 \mathrm{I}$, and again in 1895 , concluded that the two groups are closely allied, and that the Psilotaceae are intermediate between them. 
When we turn to the systematic position of the Gymnosperms we see that, while in I860 they were considered to be a subdivision of the Phanerogams, and hence not on the same plane as the Vascular Cryptogams, opinion gradually changed as the century closed, and they came to be regarded as co-ordinate with the Pteridophyta, and on the whole more nearly allied to them than to the Angiosperms. Their relationship to the former group was supported by Belajeff's researches on the germination of their pollen in I89I-93, in the course of which he was led to the recognition of an antheridium of a higher type than had been previously observed. A more striking indication of affinity was afforded by the discovery of ciliated antherozoids in Ginkgo by Hirasé in I895, in Cycas, by Ikeno, in I896, and in Zamia, by Webber, in 1897 .

In studying the phylogeny of the group a safe startingpoint was afforded by Hofmeister's classical researches, which clearly indicated a descent from some form of Pteridophytic stock. From the similarity between the gametophytes of the Conifers and of Selaginella, as well as from the similarity of the general habit of the sporophyll in the Coniferae and the Lycopodinae, it was considered that theGymnosperms descended from Lycopodiaceous ancestors. The relationship was considered to be supported by the presence of gigantic members of the latter group in the carboniferous rocks. The idea, however, of a monophyletic descent was gradually abandoned as more and more information was obtained from fossil forms. The study of the latter was prosecuted with considerable energy during the last decade of the century, and brought to light many considerations bearing upon affinity and descent.

The careful scrutiny of the structure of Heterangium and Lyginodendron by Williamson and Scott pointed to a relationship with both the Cycads and the Ferns, an idea supported by the study of the members of the Lygino- 
dendreae. The question was investigated almost at the same time by Potonié. In consequence of these researches a new group came to be recognized, the Cycadofilices, a name suggested by Potonié in IS97. Scott held that the two forms he particularly studied were derivatives of an ancient non-specialized Fern-stock, and in 1899 he expressed the opinion that this common stock is to be sought among simple Ferns or fern-like plants.

From this stock we are led, therefore, to derive the existing Ferns, and, at any rate, one phylum of the Gymnosperms. In the speculations which followed, supported it is true by hardly any evidence, the Cycadofilices were suggested as ancestors of the Ginkgoales and of the Coniferae through the extinct Cordaiteae, as well as of the Cycads. The Bennettiteae were also spoken of as probably intermediate between Cycadofilices and Cycads. Other workers declined to abandon the theory of the descent of the Conifers, or some of them, from the hypothetical Lycopodiaceous ancestor, a theory supported by Seward as a result of his examination of the Araucarieae. It was a time of speculative ideas, when the task of drawing up hypothetical genealogical tables exerted a strange fascination on the minds of many, carried away by the startling discoveries obtained from the records of the rocks.

The last theory of the classification of the vascular plants put forward prior to the close of the century was Jeffrey's scheme of Igoo. He based it on anatomical considerations, making two large groups-the Lycopsida, possessing a cladosiphonic stele and bearing small leaves, and the Pteropsida, with a phyllosiphonic stele and usually developing large leaves. Lycopsida included the Lycopodiales and the Equisetales, among the latter of which he put the Sphenophyllales, while Pteropsida comprised the Filicales, Gymnospermae, and Angiospermae.

Jeffrey claimed that the anatomical structure of the 
skeleton ought to receive recognition as of great importance in the delimitation of the larger groups. He therefore adopted it as the basis of his proposals.

An observation made by Scott just before the close of the century calls for special notice, not only on account of its intrinsic importance, but as bearing on the startling discovery, by Oliver and Scott, of seeds borne by Cycadofilicinean plants, which was announced in I903. This was the occurrence of a curious seed-like fructification in certain palaeozoic Lycopodinae-the first intimation of any such structure in plants not then included in the Phanerogams.

During the early years of our period comparatively little advance was made in the elucidation of a natural system of classification of the Phanerogams. The de Candollean scheme formed the basis of most of the systems which were in use in I860. Certain modifications of it were proposed by Bentham and Hooker in I863, when the introduction of the disc as a character mark was introduced, and the large sub-class of Dicotyledons, known as the Disciflorae, was constituted by combining several natural orders on the border-line between Thalamiflorae and Calyciflorae. This change had but little importance, for the characteristic features of the disc in the orders selected were not at all uniform, nor of the same relative magnitude.

Bentham and Hooker also modified the arrangement of the Monocotyledons, and they retained the heterogenous group of the Monochlamydeae, into which they endeavoured to introduce some kind of order, but without much success.

The work of Bentham and Hooker culminated in the publication of the Genera Plantarum, a work describing in great detail and with marvellous accuracy all the genera of flowering plants then known. It was commenced in I862, and its publication was continued during the next twenty years. The importance of this work cannot well be overestimated; whatever system of classification may 
ultimately be adopted, the need of an authoritative description of the genera is imperative. Nor could it have been carried out by more competent workers than the great Kew authorities, who commanded the confidence of botanists all over the world. So far as England is concerned, the appearance of this great work was epochmaking.

But it was felt on all hands that the de Candollean system was unsatisfactory. Its divisions were eminently artificial, and though it professed to be based upon natural relationships and affinities, its main lines had been drawn when those affinities had not been properly investigated, and were in many cases seriously misunderstood. The grouping together of a series of families, hardly if at all related, under the head of Monochlamydeae or Incompletae was rather a confession of ignorance than a serious effort at classification. It is not a matter of surprise that systematists made repeated efforts to abolish the group, as we have already seen.

Sachs abandoned the scheme of de Candolle altogether, and substituted in the Lehrbuch of I868 a system based, so far as the Monocotyledons were concerned, on that of Braun of 1864 , but almost identical in the case of the Dicotyledons with an arrangement proposed by Hanstein in I867. It did not, however, make its way into favour, though it was based more closely than its predecessor upon natural relationships, indicated by general structural features rather than arbitrarily selected characters.

The system devised by Eichler in I 883 gradually replaced that of de Candolle in general botanical circles. It made but little way in England, a circumstance due no doubt to the dominating influence of the names of Bentham and Hooker, and to the appearance of the Genera Plantarum. It showed, however, a great advance upon those which had preceded it in the importance it attached to questions 
of phylogeny, and to the recognition of the fact that problems of affinity are bound up with actual descent.

Eichler's system served as the basis of the arrangement proposed a little later by Warming in Denmark, and was followed in the main by Engler, whose classification appeared in 1892 and was very generally adopted by the end of the century. His arrangement of the lower groups has already been alluded to. In classifying the Phanerogams, which he called Embryophyta Siphonogama, he followed his predecessors in recognizing the Gymnosperms and the Angiosperms as co-ordinate subdivisions. His selection of the terms Embryophyta Zoidiogama and Embryophyta Siphonogama was unfortunate, as they were shown to be quite inappropriate by the discovery of antherozoids in certain Gymnosperms in $\mathbf{I 8 9 5}$. He introduced among the Gymnosperms the extinct groups Cordaitales and Bennettitales, which had not been recognized by any previous taxonomist. In subdividing the Angiosperms he made two very unequal classes, the Chalazogamae, in which the pollen tube reaches the embryo-sac by way of the chalaza, being made co-ordinate with the Acrogamae, which comprise the rest of the group. The necessity of this is open to question, as it may be taken to be at least doubtful if so purely a physiological character as the mode of fertilization is of very great diagnostic value. The Acrogamae were then divided into Monocotyledons and Dicotyledons. Of the former Engler made ten series, commencing with the Pandanales, which he held to be the most primitive forms.

In the arrangement of the Dicotyledons he abolished the large inchoate group of the Monochlamydeae, and distributed its members among the forms with free petals, so constituting a large series, the Archichlamydeae. He made but one other group, the Sympetalae, which included all with united petals. Here he had a considerable follow- 
ing among botanists, for there was a somewhat widespread opinion that the plants whose flower exhibits this feature are a group which is truly monophyletic, and which represents the highest development among Dicotyledons. The sympetaly of the corolla is but one peculiarity of a large division of plants which show important marks of relationship in other respects.

In the subdivision of the Archichlamydeae Engler took the view that the primitive form of the flower consisted primarily of sporophylls which had mainly bracteal protection, or perhaps, rudimentary perianths. Advance therefrom he traced through such families as the Amentiferae and other plants with naked flowers to those possessing sepaloid perianths, and thence to the biseriate flowers, among which he followed the gradual differentiation of the most highly coloured petals, and most highly organized flowers. Hence, the series started with the Piperales and led up to the Umbelliflorae.

It will be observed that in this arrangement Engler departed from the view generally accepted by the followers of the de Candollean tradition, that the flowers of the simpler Ranunculaceae represent the primitive Angiospermous type. The supporters of this view concluded that the evolution of the flower had proceeded very far before the Angiosperms appeared, and that the gradual development of a perianth took place among the lower groups, appearing, however, with a certain irregularity, and consequently not being recognizable in every family. The flowers which Engler claimed as primitive were held to have been derived from forms with a perianth by a process of reduction, or abortion of parts.

To discuss the positions taken by these two schools of thought would take us beyond the limits of this book. Whether we accept Engler's view or not, it cannot be denied that his arrangement presents a striking advance 
in the direction of a natural system when it is compared with its predecessors, as Schleiden's had done in his time so many years earlier. Not only in its broad outlines but in the grouping of the Natural Orders, it shows an appreciation of possible or probable lines of development, which justify a remodelling of their mode of presentation. In the different phyla put forward, we can recognize certain features which may be accepted freely, although the complete sketch may fail to secure approval. For the successful presentation of even a plausible theory of descent which shall be comprehensive we must be willing to wait.

A feature of the last thirteen years of the century was the issue of Engler and Prantl's great work, Die natürlichen Pflanzenfamilien, which began to appear in $x 887$, and was still in course of publication in Igoo. Though not embodying the results of such careful research and observation as the Genera Plantarum, it has been of the greatest value to systematists all over the world.

Taxonomy on the whole excited less attention in France than in England or Germany during the period I860-I900. At its commencement the systems of A. I. de Jussieu and of Brongniart, dating back to $x 843$, were the basis of classification there. For the time, research rather on the lines of Payer's Organogénie de la fleur was more popular than the severer work of Taxonomy in the strict sense. In I867 Baillon commenced his well-known Histoire des Plantes, which was a series of notes on the principal genera of various Natural Orders, based on and intended to illustrate Payer's views.

More strictly systematic work was attempted by Adrien de Jussieu about the same time, when he proposed certain modifications in Brongniart's scheme. How feeble the effort was, may be judged from the fact that he retained the Gymnosperms as a subdivision of the Dicotyledons. 
The treatise of Le Maout and Decaisne which appeared in I 868 became the textbook of the time. It gave a much better presentation of the subject and was beautifully illustrated. Bentham however criticized it severely as teaching that 'affinities are to be determined by a calculation of resemblances estimated according to a fixed scale of the relative value of characters '. It took too little account of the new current of thought with regard to evolution.

A classification of the Phanerogams of a totally different nature appeared in 1898 from the pen of the veteran botanist Van Tieghem. He applied anatomical characters as marks of relationship, and laid stress on many which had not previously attracted attention in that connexion; one especially was the development of the growing point of the root, and the morphology of its piliferous layer. On this line he separated the Nymphaeaceae from the rest of the Dicotyledons, and the grasses from the Monocotyledons and united them into a third great group, co-ordinate with Monocotyledons and Dicotyledons, calling them Liorhizeae Dicotyleae. He held the grasses to be really dicotyledonous, an assumption which was clearly open to criticism. His divisions of Monocotyledons were based on the character of the corolla and the position of the ovary. Those of the Dicotyledons were founded on the presence or absence of perfect seeds. Those with seeds were further subdivided on the lines of the number of the integuments of their ovules, and further again on the characters of the corolla.

This system met with little favour outside France. It was criticized with some severity by Bayley Balfour, who disputed the interpretation of the anatomical structure of the embryo of the grasses, and denied the existence of any metamorphosed second cotyledon. Balfour's views were accepted generally in England.

1 Belfast Address, I874. 
The other points on which Van Tieghem laid stress seem to be artificial when an examination is made of the whole flora. They link together families which have never hitherto been held to be allied, and they separate others whose affinities have been generally recognized. IVe can hardly imagine either that such a feature as the mode of differentiation of the root-apex is likely to be a character of diagnostic value on so large a scale as Van Tieghem claimed.

One very important duty which was discharged in large measure in these years by systematic botanists was the promulgation of the importance of the study of the geographical distribution of plants. It was especially recognized and taught by the Kew authorities, who embodied what was known in their treatises on Taxonomy. Bentham, in particular, was very much in earnest on this point, calling attention to it in several of his addresses given as President of the Linnean Society of London, as well as in articles in the contemporary reviews. The result was a great extension of activity in the compilation of Floras, many of them giving the records of large tracts of country, while others dealt with smaller subdivisions. During the later years of the century botanical, exploration was being pursued with great zest all over the world, the results appearing sometimes in the form of Floras of particular districts, sometimes in that of chapters in the record of travels whose scientific objects were on a wider scale.

The most important work of this kind in Europe was de Candolle's Prodromus. Originally projected in IS24 it continued to appear till I873, when the seventeenth and last volume was published. Of it Bentham said "the Prodromus has been gradually extended into a series of concise monographs by different authors, differing much in merit, but drawn up as nearly as could be according to 
one plan, and uniformly printed in the successive volumes of a single work-the younger de Candolle, besides working up many of the Orders himself, having gone through the tedious labour of editing them, giving to the botanical world a splendid monument of industry and perseverance, which will long be of great practical utility '.1

Other works dealing with various European Floras were Willkomm and Lange's Prodromus Florae Hispanicae, I86I93; Nyman's Conspectus Florae Europaeae, I978-84, with two supplements; Gremli's Flore analytique de la Suisse, of which an English edition was published in r889; and, most recent of all; Ascherson and Graebner's Synopsis der Mittel-Europäischen Flora, which was commenced in I896. Besides these, Parlatoré's Flora Italiana was appearing during the earlier part of the period, but the publication was slow and irregular. The vegetation of Eastern Russia was being carefully studied by Maximowitsch.

Passing on to the Asiatic Floras the most noteworthy was the magnificent work of Dr., afterwards Sir, Joseph Hooker, The Flora of British India, I872-97, in which he had the assistance of C. B. Clarke, J. G. Baker, W. P. Hiern, M. T. Masters, J. F. Duthie, and other botanists. It would be difficult to speak in terms of too great praise of the labours of the veteran botanist in this connexion; the work will ever constitute an imperishable monument to his fame. As offshoots of the Flora Indica, we may perhaps regard Trimen's Flora of Ceylon, I893-I9oo, and Cooke's Flora of Bombay, begun as the century was closing.

The Linnean Society of London published in their Journal a Flora of China Proper, Formosa, Hainan, Corea, the Luchu Archipelago, and Hong Kong, which was compiled by Messrs. Forbes and Hemsley. The different numbers describing the plants appeared as vols. xxiii and

$$
1 \text { Loc. cit. }
$$


xxvi, and were published between the years I886 and I902. Boissier's Flora Orientalis, which dealt chiefly with Persia and Greece, ranged from I867 to I888.

Besides these more prominent works, a useful series of monographs of Indian genera and families appeared with a certain intermittence in the Annals of the Royal Botanical Gardens of Calcutta, which were started by Sir George King in 1887 , and in other serial publications.

Botanical exploration in Africa has always been diffcult, on account of the climate, want of information about the country, and the character of its inhabitants. Still some progress was made. Harvey and Sonder began the issue of the Flora Capensis in 1859 and continued it till I865, when circumstances compelled them to stop its publication; it was resumed, however, in I896. Oliver's Flora of Tropical Africa was commenced in I868, and is still appearing; Engler's Pflanzenwelt Ost-Afrikas dates from 1895 .

The great Flora Australiensis was published under the editorship of Bentham between I 863 and I878. This was a work of great difficulty, the country being so little known and presenting such apparently insurmountable obstacles to travellers. It owed much to the labours of Ferdinand von Mueller, who madesubstantial contributions to it, based on his personal explorations.

Martius' Flora Brasiliensis, which Bentham spoke of as a splendid monument of systematic botany, was begun in I840. Its publication was associated with many of the most distinguished systematists of our period: J.G. Baker contributed substantially to it, as did A. W. Bennett, and Maxwell T. Masters. It was for a long time under the editorship of Eichler.

A very important essay from the pen of Dr. J. Hooker on the distribution of Arctic plants appeared in I860.

The North American Flora was expounded very fully 
by Asa Gray, to whose unwearied efforts we owe much of our knowledge of it. He began his labours in I848 and continued them till his death in I888. They were presented to the world in his Manual of Botany, the first edition of which included a Flora of the North-Eastern United States. Many editions appeared as time advanced, and each extended the range of vegetation under his consideration till information as to the Flora of nearly the whole of the United States was afforded by his work.

The Flora of California was treated of in 1876 by Brewer and Watson. Hemsley presented that of Central America in his contribution to Godman and Salvin's Biologia Centrali-Americana, published I879-88. A more special work dealing with trees only was the Sylva of North America, published by Sargent during the years I89I-I902. Finally. Britton and Brown brought out in I896-8, the Illustrated Flora of the Northern United States and Canada.

The more careful study of the vegetation of the British Isles led to the production at frequent intervals of local catalogues of plants. This was no new feature, as many such works were in existence long before I86o. Nor was their importance great from the point of view of geographical distribution and its causes, which had been very prominent in the larger works. Attention should be called to Watson's Cybele Britannica published in I870 and to his Topographical Botany of I873. Of the local Floras appearing from 1860 onwards, the chief were those of Kent by Hanbury and Marshall, Middlesex by Trimen and Dyer, IViltshire by Preston, Oxfordshire by Druce, Plymouth and district by Archer Briggs, Berkshire by Druce, Somersetshire by R. P. Murray, Hampshire by Townsend, Cheshire by Lord De Tabley, and IVest Yorkshire by Arnold Lees. The flora of Perthshire was investigated by Buchanan White ;-Colang and Scully published in I8g8 a second edition of Moore and More's Cybele Hibernica. 


\section{CHAPTER V \\ PALAEOBOTANY, I860-I900}

THE opening years of the period under review were not marked by great activity in the study of the fossil flora, and discovery remained for a time almost at a standstill. The long series of researches conducted by Brongniart and by Goeppert had drawn almost to a close, and no investigator of similar calibre to either had appeared. The publication of Hofmeister's wonderful researches had directed the attention of anatomists to the study of the Cryptogamia and to the relationships between them and the flowering plants, and though the clue to such relationships came to be recognized as lying hidden in the rocks, the search for it there was not prosecuted with much energy, while the problems presented by living forms remained rather suggested than unravelled. Darwin's great masterpiece, even newer than the work of Hofmeister, and equally epoch-making, was drawing men's minds to the great physiological problems connected with the life of the individual as well as the evolution of the race, and the more ardent of the younger botanists were led to researches of a physiological rather than an anatomical character.

Still in the early sixties there were some who were concerning themselves with the solution of the problems raised by the fossils. Little was known with certainty as to affinities either among the fossil plants, or remains of plants, themselves, or between them and their living successors. The pioneer work of minute description of the forms as they were discovered was what was at the time the only possible line of research. A few scattered 
papers from the pens of Brongniart and Goeppert, and the memoirs of Binney and of Carruthers on the Calamariae were the most noteworthy.

Towards the end of this decade two men appeared who brought about a total change in the position of the study and who revived its palmiest days, giving it, indeed, a prominence and importance which it could not claim even when Brongniart was at his best. These were Williamson in England, and Renault in France.

It is hardly too much to say that Williamson founded modern palaeobotany, particularly the section that dealt with the flora of the Coal-measures. His first memoir appeared in I868, in the form of a description of the woodyzone of a specimen of a Calamite then new to science. From that time onward till I893, no fewer than nineteen papers, of the highest importance, were published from his pen by the Royal Society of London. In them we find a masterly treatment of the most important types of the Carboniferous period. It was, perhaps, in connexion with the Lepidodendron group that he did his greatest work, but he carried out noteworthy researches on the Sphenophylleae, being the first to describe a fructification exhibiting anatomical structure. He also described the fructifications of the Calamariae and of the Lepidodendreae. A further important memoir was one dealing with Lyginodendron, which had been previously discovered by Binney and referred by him to Dadoxylon.

The feature of perhaps the greatest interest of the life of Williamson during these years was the claim which he advanced, based upon the study of the fossils, that secondary thickening of the trunks of trees is not exclusively a mark of the Phanerogamic type. The controversy between him and the French school, headed by Renault, was acute upon this point. Brongniart had divided the Calamarian plants into two classes, according as they showed or did 
not show secondary thickening in their structure, and, claiming that secondary thickening was peculiar to the flowering plants, referred the section of the Calamodendreae to the Gymnosperms. His followers accepted this position and extended it to the Lycopodiaceous types as well. IVilliamson showed by many researches that secondary thickening is only a subordinate character, and that the general affinities of form and structure in the several groups are much too complete for Brongniart's separation to be scientific. His opinions gradually obtained acceptance, even Renault at last acquiescing in the correctness of his views.

The position IVilliamson assumed in England was taken in France by Renault. A pupil and collaborator of Brongniart, he succeeded him as the leading authority on palaeobotany on the continent of Europe. It is difficult to say whether he or Williamson exercised more influence on the study of the time.

Renault was especially known in connexion with the microscopical investigation of the structure of fossil plants-a field which, at the time of his appearance, had not been very greatly cultivated. His work was so extensive and ranged over so much ground that it is impossible in the space available to do justice to it. A brief reference to his more important contributions is all that is possible. One of his earliest papers contains his discovery of the anatomical structure of Sphenophyllum, which he communicated to the French Academy in I870. In I874, in collaboration with Grand'Eury, he described the anatomy of a Sigillaria, a fossil which had been discovered in I839 by Brongniart, who then gave the world for the first time an account of a member of this group. In I875 Renault discovered Botryopteris, and published a description of the internal structure of the stem, the petiole, and the fructification. In the next year he described the fructifica- 
tion of Zygopteris, and grouped the two genera together in one family, so founding the Botryopterideae, a group of primitive ferns, to which he assigned a position between the existing Filices and the Ophioglossaceae. This was, perhaps, the most important of his early work. About the same time, or a little earlier, he made contributions to the knowledge of the group known a little later as the Cycadofilices, showing that the fronds of Neuropteris and Alethopteris were borne on petioles of the type of Brongniart's Myeloxylon. These were some years later found to be the petioles of Cotta's Medullosa stems, and were included in the Cycadofilices towards the close of the century. Renault, at the time, held them to be ferns showing affinities with the Marattiaceae.

The next important work calling for mention was his wonderful account of the minute structure of the Cordaiteae, which he undertook in collaboration with Grand'Eury, in I879. The details of the work are given in the memoir Sur la structure comparée de quelques tiges de la Flore Carbonifère.

Renault was fortunate in his collaborators. Not only did he work with Grand 'Eury, in the researches already mentioned, but he had in turn the help of Zeiller and of Bertrand. In 1889 he published with the assistance of the former, a complete account of a rich flora of Upper Coal-measure age, under the title Etude sur le terrain houiller de Commentry, which was followed a few years later by his last great work, Flore fossile du bassin houiller et permien d'Autun et d'Epinac. His own contribution to this was the second volume, published I893-6; it contained descriptions of the internal structure of all groups of the palaeozoic plants. The first volume, which dealt with the Ferns, was written by Zeiller and published in I89o.

With Bertrand he investigated the structure of the Poroxyleae, a group he had discovered in 1879 . The 
joint work did not appear till I886. It showed that the group tends to connect the Cordaitae with lower forms, and contained a wonderfully clear and minute account of their anatomy.

The classical work on the structure of silicified seeds, which was published under Brongniart's name in I88I, was done by him in collaboration with Renault, and owes much of its value to the investigations of the latter.

Other papers of less importance were numerous, and bear testimony to Renault's assiduity and zeal as well as to his wonderful skill.

In the controversy on the question of the secondary wood of Cryptogams, Renault was till the last years of his life an earnest opponent of Williamson. This is hardly to be wondered at, brought up as he was at the feet of Brongniart and working with him for so many years. He finally convinced himself, however, that Macrostachya, one of the Calamarieae, possessed it, and he came to hold the view that this group, together with the Sigillarieae, were transitional between the Cryptogams and the Phanerogams.

Though the work of Williamson and of Renault and his collaborators dwarfed all other investigations from 1870 onwards, many others call for recognition during that time: Hick and Seward in England, Saporta in France, Stur and Ettingshausen in Austria, Solms-Laubach and Feistmantel in Germany, Heer and Lesquereux in Switzerland, Etheridge in Australia, all made important contributions to science. In England a further impetus to the study was given in I 892 by Williamson's association with Scott, which was not only productive of very important results during their collaboration, but led to Scott's own brilliant researches and generalizations at the end of the last century, and in the early years of the present one. It must add to our appreciation of the services of Williamson, and of his 
scientific spirit, that we find him writing after the brilliant career of the years I870-90, 'My morphological inquiries seem to have reached a stage that makes a more minutely careful examination of these questions of development and growth desirable, but before specially undertaking this, I saw clearly the extreme importance of doing so in combination with some younger colleague, whose familiarity with the details of the physiology of living plants was greater than my own.' One of the most important fruits of this new partnership was the reinvestigation of Lyginodendron and Heterangium, which served really as the starting-point of the recognition of the great group of plants which, showing characters allied to both Cycads and Ferns, was called Cycadofilices at the suggestion of Potonié in I897, and one of which, Lyginodendron, through the agency of Oliver and Scott, was found shortly after the close of the century to have borne the seed Eagenostoma, whose relations up to that time were wholly unknown. Following this discovery, succeeded very quickly by others, we have had the recognition of the seed-bearing habit as no longer the distinctive mark of the Phanerogams, but shared by the group in question. These, now renamed the Pteridosperms, were in fact primitive Phanerogams. But these momentous discoveries belong to the next century.

Attention should be called not only to investigators, but to authors who wrote during these years. Probably the first place should be accorded here to Solms-Laubach, whose Fossil Botany had a great influence on contemporary opinion, and was certainly the best textbook that had appeared up to that time. Mention should be made also of Seward's Fossil Plants, I898, Schenk's Palacophytologie, I89I, Zeiller's Éléments de Paléobotanique of Igoo.

The close of Igoo showed in England a scene of considerable activity. Many workers were already in the field, and material had so far accumulated that it was becoming 
possible to classify the members of the fossil Coal-measure Flora, and to indicate with, perhaps, more than probability the positions they should hold in the general scheme of the vegetable kingdom. Mention should be made also of the American school, prominent among whom stood Leslie Ward, Dawson, and Wieland, the latter of whom had done important work upon the group of the Bennettitae.

The researches and investigations so far considered were concerned almost entirely with the Devonian, Carboniferous, and Permian horizons of Europe. The vegetation of the globe, so far as the Devonian and Lower Carboniferous exhibit it, seems to have been on the whole fairly uniform, but in Upper Carboniferous and Permian times two floras prevailed, that in the northern hemisphere exhibiting in the main the old types, which became almost extinct in the southern. The Lower Carboniferous Flora was replaced by a flora, the chief constituents of which were a number of fern-like plants, possibly Ferns, possibly Cycadofilices, together with a few members of other groups, chiefly Equisetaceous, which, however, only here and there included representatives of the northern types. The first trace of this flora was the discovery in 1828 , by Brongniart, of the frond known as Glossopteris, which was found to occur in India and in Australia. Another form, the Equisetaceous Schizoneura, was discovered at about the same time. After the lapse of many years Rubidge found plants of the same type in I859 in South Africa. Bunbury described several new species from Nagpur in I86I, and Carruthers recorded the occurrence of Glossopteris from Queensland in I872. Several species of the same genus were described in 1878 by Feistmantel, who had them from New South Wales. Tracing still further the progress of discovery we find Zeiller describing a Rhaetic flora from Tonquin, in IS82, in which Glossopteris was associated with some plants of the northern types, and a similar 
association was met with in Argentina, and described by him in 1895 . Feistmantel wrote an important memoir of the fossil plants of Cape Colony in r889. In 1898 Amalitzky found indications of this flora intermixed with northern types in beds of the Upper Permian age in Russia.

This flora, which was named by Neumayr in 1887 the Glossopteris Flora, after its most prominent genus, seems, therefore, to have been abundant in Australia, and over the hypothetical continent of Permian times which stretched across from India to South Africa, and South America. This continent was the Gondwana Land of Suess.

Little more than impressions of the fronds of the plants have been found, leaving their exact affinities an open question. In r885 Tenison-IVoods found in the Sarawak coalfield of Borneo the fossil named Vertebraria which Zeiller has shown to be the rhizome of Glossopteris.

A comprehensive account of the fossil flora of the Lower Gondwanas was published by Feistmantel during the years I879-86, and a good account of the Glossopteris flora as a whole was published by Arber a few years after the close of the century.

When we turn to consider the progress of knowledge as to the several groups of plants, it becomes evident that our acquaintance with the Palaeozoic floras of the past was in Igoo still largely confined to the plants of the Upper Devonian and Carboniferous times, though, as we shall see later, the general character of the Mesozoic flora, and its distribution, in recent years received much attention. The majority of the published records of the Algae were proved to be untrustworthy. A fossil discovered by Dawson in 1856 and referred by him to the Gymnosperms under the name Prototaxites, was re-examined by Carruthers in I872, and shown to be an Alga, having affinities with the larger Siphoneae. He renamed it Nematophycus. A doubt- 
ful addition to the group was Hooker's genus Pachytheca, investigated by Barber in I889 and I89I.

Palaeozoic Bacteria were discovered by Van Tieghem in I879. He claimed to have found both the organisms and the products of their activity. They were carefully studied by Renault in his later years.

Allusion has been already made to the controversy that arose in consequence of Brongniart's division of the plants now recognized as forming the group of the Calamarieae. Holding that secondary formation of wood was confined to phanerogamic plants, he separated those which showed it from the others, thus splitting up somewhat arbitrarily groups which showed many marks of relationship. His views, however, met with considerable acceptance, being supported by Goeppert in I864, Grand'Eury in I877, Schenk in I883, and Renault in I885. The opposite view, propounded by Williamson in I87I and supported by Schimper in I874, and Stur in I88I, ultimately prevailed, as we have seen.

The anatomical structure of the Calamites was first studied by IVilliamson, much of whose early work, published in I868, was devoted to them. He described the type of stem now known as Arthrodendron, which he named Calamopitys. Binney also wrote a memoir on the group in the same year. Casts of the stems were examined by Stur in I877, and by J. E. Weiss in I884. In I877 Grand'Eury showed that the fossils known by the name of Asterophylliles were really the leaf-bearing branches of Calamites, and Weiss made a similar claim in I884 for the Annularieae. We owe a good deal of our knowledge of the group to Grand'Eury's work, Géologie et Palcontologie du bassin houiller du Gard, published in I890. The structure of Archaeocalamites was described by Solms-Laubach in I897; casts of its stem and figures of its foliage shoots had been, however, previously figured by Stur in 1875 .

The roots of Calamites were identified by Renault in 
I885 with the fossil known as Astromyelon. He confirmed and extended his observations in a further memoir in I896. Williamson and Scott also published a very complete account of their anatomy in I 894 .

The fructifications which existed in the group were studied by several observers. The first type known, Calamostachys, was first shown to belong to a Calamite by Carruthers in I867. Heterospory was demonstrated in one of these cones, C. Casheana, by Williamson, in I88o. Another genus, Annularia, which was studied by Grand'Eury and Renault, bore cones of the same type, in which heterospory was recognized by Renault, in I873. The fructification was known at that time as Bruckmannia.

The second type was studied by Williamson in I869, and was called by him Palaeostachya. He considered it to be the true representative form of Calamite fructification. Heinvestigated it more fully in 1887 . J. E. Weiss described a third type, Cingularia, in 1876 , but it was associated only with casts and not with petrified specimens. The fourth type, Archacocalamites, which most nearly approaches recent Equisetaceae, was figured by Stur in I875, but his material was imperfect, as he only had badly preserved cones for examination. Kidston studied this form in I883; and at the same time showed that Pothocites, which had been held to be the inflorescences of Monocotyledonous plants, really belonged to the group. Renault also described some fragmentary fructifications belonging to the Calamites in I896.

Two classifications of the Calamarieae have been made. The first was that of $\mathrm{J}$. E. Weiss in I 884 ; it was based mainly on the form of the stem and its medullary casts. A second and more satisfactory one was that of Grand'Eury, to whom we owe so much of our knowledge of the group as far as its vegetative habit is concerned. It was published in I89o. It made three main divisions of the Calamites, Ammlaria, 
Arthropitys or Calamites proper, and Calamodendron. The latter included the forms originally considered Gymnosperms by Brongniart. The affinities of the Calamites with the Equisetaceae were not clearly established till nearly the end of the century.

Our knowledge of Sphenophyllum dates from Renault's work of 1870 , if we except a reference to its anatomy made by Dawson four years earlier. Though Renault communicated his paper to the French Academy in I870 the full publication did not appear till I873. In I874 Williamson described two other species which he then called Asterophyllites sphenophylloides and A.insignis, both of which were subsequently recognized as true Sphenophylla. The first showed certain points of difference from some of Renault's specimens, particularly in the arrangements of the protoxylem groups. Both species were more fully investigated by Williamson and Scott in I893.

The fructification of this plant was known for several years before its relationships were ascertained. The first description of it was given by Binney in 1870, under the name of Bowmanites cambrensis. In the next year IVilliamson described another specimen, which he named Volkmannia Dawosoni, a fuller account of which he published in I873. In I884 Weiss showed them both to belong to a single genus, and Binney's name having priority, Williamson's fossil was named Bormanites Darosoni. Under this name he published a very complete description of its organization and structure in two memoirs dated I89o and I89I. Two years later Zeiller gave to the Geological Society of France a very detailed account of the structure of some very finely preserved strobili of Sphenophyllum from the French and Belgian coal-measures, and showed that they agreed in every essential particular with Williamson's fossils. His conclusions were accepted by the latter, and the strobilus received its final name, 
Sphenophyllum Dawsoni. In the same year, I893, Williamson and Scott made a further study of the specimens, and gave a very full account of their histology.

Another species was described in I895 by Solms-Laubach, and was named by him Bormanites Römeri. In I897 a cone of a higher degree of organization was described by Scott under the name of Cheirostrobus, and was shown to be the fructification of another related genus.

The affinities of the group gave rise at first to much speculation, Schenk, Van Tieghem, and others, relying partly on the similarity of certain points in its structure to the stem of Psilotum, placed it near Lycopodiaceae; Stur held it to belong to the Calamarieae, Renault to Salviniaceae, while Zeiller considered it to show affinities with the Ophioglossaceae and the Marsiliaceae. SolmsLaubach suggested in 1887 that it was sufficiently distinct to form a group co-ordinate with the Lycopodiaceae, but not to be included in them, a view that was advanced again in I89I by Kidston. The investigation of Cheirostrobus led Scott in 1897 to hold that both it and Sphenophyllum ' sprang from a very old stock which existed prior to the divergence of the Lycopods and Calamarians. This common stock survived for a certain time side by side with these two divergent branches-between them as it were. Sphenophyllum is a group which had advanced very far along this third line of descent, so that its common characters with the other lines have become comparatively obscure. Cheirostrobus has retained more of the common character, though reaching a high degree of complexityon itsown lines '.1

The structure of Lepidodendron selaginoides was described by Carruthers in $I 869$, but our recent knowledge of the Lepidodendreae is due chiefly to Williamson, who worked out the anatomy of nine distinct forms in the long series of papers he contributed to the Royal Society of London,

1 Phil. Trans. 189B (1897), p. 26. 
whose publication ranged over the years I872-93. It was in connexion with his examination of this group that he took up the position already attributed to him in opposition to the French school, that secondary wood was developed in the Vascular Cryptogams. Brongniart had studied Lepidodendron Harcourtii and the allied genus Sigillaria, as long ago as I839, and had separated them widely from each other on the ground that the last named, showing secondary thickening, must be phanerogamic. Williamson showed that L. Harcourtii was exceptional in this particular and that most Lepidodendra, like the Sigillarias, increased in thickness through cambial activity. Williamson showed further that the two genera agreed in anatomical structure and must be regarded as members of the same group.

The structure of $L$. selaginoides was investigated later by Hovelacque in 1892 .

The ligule of Lepidodendron was first identified by Stur in $\mathrm{I} 892$; the discovery was confirmed by Solms-Laubach and by Hovelacque in the same year. The complete anatomy of the leaf was worked out by Renault in I 896 .

The anatomy of the non-ribbed Sigillarias, first described by Brongniart in I839, was reinvestigated by Renault and Grand'Eury in 1875 . Bertrand described the ribbed form $S$. elongata in I8g9.

The curious fossils known as Stigmaria, which had been found to occur in conjunction with Sigillaria and were commonly held to be the roots of that genus, were carefully studied by Williamson and were ascertained to occur also on stems of Lepidodendron. Their exact nature remained undetermined at the end of the century.

The character of the fructification of Lepidodendron was thought to have been ascertained in I880, when D'Arcy Thompson showed that the fossils known as Ulodendron, thick shoots bearing cones attached to them laterally, were the flowering branches of the trees. Some doubt, however, 
was cast upon this view by the researches especially of Watson, after the century closed.

The cone described much earlier under the name Lepidostrobus was known to be the actual fructification. Another form of cone was described by Williamson in $\mathrm{x} 878$, named by him two years later Lepidostrobus insignis, and referred to in $\mathrm{I} 893$ as the fructification of Lepidodendron Spenceri. It was examined in greater detail in $\mathrm{I} 897$ by Scott, and on account of differences in the mode of insertion of the sporangia, their form and the form of the sporophylls, and of the general habit of the strobilus, he placed it in a new genus, Spencerites. At the same time Scott described another newly-discovered fossil of the same genus.

The fructification of Sigillaria was found by Zeiller in I884. It consisted of large strobili which, in the case of one species, were not very unlike Williamson's cone. Sigillaria was, however, heterosporous. Other Sigillariostrobi were described by Kidston in 1897 .

General opinion in I860 regarded the Ferns as the dominant type of vegetation of the Carboniferous period, and the view prevailed until late in the century. Detailed investigations into the remains, however, gradually unsettled the opinion. Many descriptions of fern-like forms known as Neuropteris, Alethopteris, and others were from time to time published, but in no case did the frond bear sporangia. Stur in $\mathrm{x} 883$ was on this account led to deny that they were Ferns at all. In I887 Williamson called attention to the possession by some plants of the period of characters intermediate between Ferns and Cycads. Solms-Laubach, in his textbook of the same year, pointed out certain features of Thinnfeldia, a form resembling Neuropteris, which he suggested lay between Ferms and Gymnosperms. Solms-Laubach emphasized the possibility of a common origin to these groups in the same work.

The existence of such a group in Palaeozoic times was 
established by the more thorough examination of several types which on their first discovery had been very difficult to classify. The first of these was Lyginodendron, a fossil whose stem was discovered by Binney in I866. It was described by Williamson in I873, and more fully in later years, but the results of a very much more complete examination were published by IVilliamson and Scott in I895. The disposition of its tissues recalled Cycadean structure, which was confirmed by Scott's investigation in I 897 of the anatomical characters presented by the peduncle of the cones of Stangeria and other recent genera.

Recent investigations have brought to light that the fossil described in 1876 by IVilliamson, under the name of Kaloxylon, was the root of Lyginodendron, that Rachiopteris aspera was its petiole, which bore leaves that were described under the name of Sphenopteris Höninghausii. The whole of the vegetative part of the plant has consequently been reconstructed.

Another plant, showing much in common with Lyginodendron was Heterangium, which was first found by Corda in I 845 ; a species of the genus was described by Williamson in 1873 , and another one in I887. Heterangium, together with Lyginodendron, was dealt with by Williamson and Scott in their memoir of 1895 .

The association of another type with these was the outcome principally of Renault's work. In I874 he made a careful study of the petioles of the so-called ferns Neuropteris and Alethopteris, which he named Myelopteris. It has already been mentioned that in I 883 Stur claimed that these were not properly to be considered Ferns, as no fructification of fern-like character had been detected among the numerous specimens that had been examined. In the same year Renault showed that they had petioles of the type described by Brongniart under the name of Myeloxylon. In the meantime, in I880, Weber and Stenzel proved 
that the Myeloxylon petioles were borne upon the supposed Cycadean stems which Cotta had named Medullosa in I832. They did not, however, publish in full the reasons for their opinion till I896. Medullosa, first described by Cotta, was studied by Goeppert and Stenzel in I88I, and by them referred to the Cycadaceae. The curious structure of the stem was interpreted as polystelic by Zeiller in I890, and his view was endorsed and emphasized by Solms-Laubach in I897. He compared the structure with that of $\mathrm{Cla}^{-}$ doxylon, a plant from the Culm, in which several steles are found each showing secondary thickening, and indicated an affinity between this so-called fern and Medullosa.

Another type of somewhat similar character was described as Protopitys Buchiana by Solms-Laubach in I893. There accumulated thus a considerable body of evidence pointing to the existence in Palaeozoic times of a stock showing such close affinities to both Ferns and Cycads as to warrant the opinion that it might be regarded as the ancestor of both. This group was named Cycadofilices in I897 by Potonié.

Williamson and Scott in their memoir on Lyginodendron and Heterangium suggested that they were derivatives from an ancient and non-specialized Fern-stock from which they showed a marked divergence in the Cycadean direction. Of the two, they held Heterangium to be the most ancient and to stand nearest to the Filicinean ancestry, Lyginodendron having advanced much further on the Cycadean lines.

Further investigations at and immediately after the close of the century led to the view that many of the fronds originally held to be Ferns really belonged to this group, and that the predominance of the Ferns in Palaeozoic times had been overestimated.

It is beyond the scope of the present work to do more than allude to the important discovery, made in the first instance by Oliver and Scott in I903, that these plants 
had advanced beyond the Pteridophytic condition and bore seeds of a fairly high type of organization. They showed that the seed described by Williamson in 1877 and named by him Lagenostoma was borne by Lyginodendron Oldhamium. In consequence of these and subsequent researches, the name Pteridospermeae was with certain reservations applied to the group.

The discovery of the Cycadofilices did not, however, negative the existence of true Ferns among the plants of the Palaeozoicage. The group Botryopterideae was founded by Renault to include certain genera, which he had studied during the years $1868-76$. The first of these was Anachoropteris, the petiole of which was found in the Upper Coal-measures of Autun in I868. He published in I87I an account of the stem and petiole of this plant, and of another which he named $Z y$ gopteris, and this was followed by the discovery of Botryopteris in I875. Renault associated Botryopteris and Zygopteris in the group Botryopterideae from the structure of their fructification, and suggested that they were intermediate between the true Ferns as we now know them, and the Ophioglossaceae. His views met with general acceptance, and they came to be recognized as the most important representatives of the primitive Filicineae.

Another family, the Pecopterideae, which shows relationship to the Marattiaceae, was also the subject of Renault's study, and to him we owe two memoirs, of date I 883 and I 896 respectively, in which he gave a full account of the internal anatomy of the frond.

Though investigated by Carruthers and by Williamson, the Cordaiteae are chiefly known to us by the researches of Renault and Grand'Eury from I875 onwards. Though possessed only of fragmentary remains they studied their structure with great completeness, and gave a wonderfully perfect account of their anatomy, being able indeed to reconstruct their external appearance. They showed them to 
combine the characters of Cycadaceae, Coniferae, and Ginkgoaceae. In 1879 Renault discovered the group Poroxyleae, and with the collaboration of Bertrand published a full account of their structure. They showed that the group was intermediate between the Cordaiteae and lower forms.

In I88I Heer showed that Ginkgo is the surviving representative of a series of allied plants, which are very abundant in the Rhaetic beds.

The mesozoic type Bennettites attracted a good deal of notice during the period we are reviewing. It was originally discovered by Carruthers in $\mathrm{r} 868$, and he founded the genus for certain Cycadean stems occurring in the oölitic and lower cretaceous formations. He described the structure of the stem and gave a very full account of the fructification, or rather what he took to be the female flower. Nothing more was discovered of it for some years, indeed doubt was cast upon the supposed relations between the flowers and the stem. In r 880 Nathorst suggested that the plant bearing the flowers was parasitic on the Bennettites, and made a comparison between it and Lophophyllum. Saporta in I885 suggested that it was a Proangiosperm and classed it with the fossil Williamsonia.

In 1887 Solms-Laubach re-examined Carruthers's fossil and discovered thedicotyledonous embryo and the exalbuminous seed. He contributed a further memoir upon the plant in r8gr, and in the next year in conjunction with Capellini he published descriptions of the specimens which are in the Italian museums. In I894 Lignier described a specimen obtained from the Oxfordian of Normandy.

The true nature of the flower and the minute structure of the plant were investigated at the end of the century by Wieland. Though he did not publish his final results till I9o6, they may be briefly summarized here. The flowers proved to be hermaphrodite and very highly organized, possessing a protective perianth or involucre, 
and suggesting some such composition as Liriodendron. The pollination, however, was that of a Gymnosperm. The genus is most interesting, therefore, as possibly throwing some light on what was the primitive condition of the flower of the Angiosperms.

Apart from Bennettites, the material of the mesozoic flora has been much less satisfactory than that of the older fossils. It attracted the attention of a number of distinguished workers both in the old world and the new. In the earlier part of our period the Marquis de Saporta stood out very prominently in connexion with research into the plant-remains of the Jurassic formations of France, while the writings of Schenk threw considerable light upon the mesozoic vegetation of Germany. A little later Heer investigated the mesozoic flora of the Arctic regions, including not only Gymnospermic types, but also representatives of the Dicotyledons. Nathorst must be mentioned in connexion with similar researches into the fossils of the mesozoic rocks of the south of Sweden. The names of Raciborski, Lignier, and Seward also are associated with these investigations towards the end of the century and during the years that have since elapsed.

Of American botanists who were concerned with the mesozoic flora, special mention must be made of Fontaine, Lester Ward, and Wieland.

Many other workers than those mentioned contributed to our knowledge, but space prevents any detailed presentation of their researches. So numerous were the workers, that it is impossible at present to see their researches and results in a true perspective.

The outcome of these numerous investigations was to establish the predominance of Cycadean forms during the Mesozoic period. The old types of the coal-measures had been replaced by these, probably descended from the Cycadofilicinean ancestors, and new types of Ferns had 
arisen, possibly from the same stock, showing more complete affinities with those now known. Polypodiaceous types were discovered; Fontaine recognized an Aspidium from the Potomac region of America in I889; Renault described a representative of the Osmundaceae, and Schenk spoke of a similar form in I887; Raciborski described a type allied to Danaea in I894. Representatives of the Gleicheniaceae also were discovered, and Seward described some of the Matonideae, allied to the recent form Matonia, in I899.

Nor were the Cycadeae the only Gymnosperms investigated. Many representatives of the Coniferae came to light; Fontaine described a specimen resembling Podocarpus in I889; branches of Pinites, a form allied to Pinus, were found by Nathorst in I897. Cones of Pinus Laricio had been unearthed by him in I896. Many other workers added to the list.

The determination of the remains of the Angiosperms gave rise to much controversy, as they took the form chiefly of leaf casts, and no specimens were forthcoming to show any anatomical details. Though much of such material was accumulated, and though the impressions pointed to outward similarity with many recent types, the study of the Angiosperms of the Mesozoic period was but in its infancy when the century closed.

The period under review thus brought a great extension of our knowledge of the details of structure exhibited by the fossil remains, especially of the plants of the Palaeozoic period. It furnished important results in the classification of the Pteridophyta. The group Sphenophyllales was discovered and its affinities approximately determined. The discovery of the Cycadofilices changed the current views of the dominance of the Ferns in Paleozoic times and showed a great probability of the descent of the Gymnosperms, or part of them, from Filicinean ancestors, a probability which was not lessened by the investigation of the mesozoic 
horizons. At the same time a clearer view of the ancient Ferns was obtained, and it became probable that they were restricted to comparatively few types, while it gradually began to be doubtful if the Ferns of to-day are their direct descendants. Though the knowledge of the Coniferae was not greatly extended by the revelations of the palaeozoic rocks, investigations into the flora of the mesozoic horizons brought to light new forms approximating to those of the present time. In one important particular they helped to explain what long seemed anomalous to some botanists, the appearance of the almost isolated form Ginkgo: the investigations point to its separation from the Coniferae as we now know them, and its recognition as the ultimate survivor of an independent group. 



\section{BOOK II}

\section{THE ANATOMY OF PLANTS}





\section{INTRODUCTION}

THE new currents of thought that set in from the time of the appearance of the Origin of Species, and which, as we have seen, were instigated by it, spread more widely than seemed at first at all probable. The view that adaptation to environment played so important a rôle in the determination of external form commanded almost immediate acceptance, and it needed only a little careful thought to extend the idea to the details of internal structure. Consequently the problems of anatomy began to be studied in a new light, and new series of researches were undertaken from I860 onwards, which were designed not only to ascertain details of structure, but to determine also the relation which these bear to function, and to ascertain how far the action or the influence of the environment becomes apparent in the construction of the tissues which serve to constitute the organ. The members of the plant were becoming rapidly to be recognized as organs, and the importance of studying them from both points of view found a ready acceptance among the anatomists of the time.

Moreover, the work of Hofmeister had prepared the way for investigations on a scale different from any that had prevailed, for he showed that there exists an essential unity of type throughout the vegetable kingdom and opened the way to a comparative study of the anatomy of the vegetative parts which should supplement his own researches on the reproductive structures.

Another epoch-making research dates from about the same time. The identification of the protoplasm of the vegetable cell had been made by a few observers, especially 
A. Braun, Cohn, Unger, and von Mohl, but its importance was not fully realized till Max Schulze, in I863, demonstrated its identity with the sarcode of the animal world, and so placed animals and plants upon the same plane as living organisms, and made possible the researches upon a common physiology which bulked so large towards the end of the century, giving rise indeed to a new scienceCylology, or the study of the cell.

Anatomical researches had been industriously followed by many botanists during the years before I860-indeed, they were being pursued with great assiduity then. A very great advance had been made by Naegeli's magnificent generalization as to the intimate structure of organized substances, a work which explained many till then obscure observations, and threw a great deal of light upon many problems at the moment under consideration. Though Naegeli's conception as he left it did not stand the test of the critical examination brought to bear upon it during the two succeeding decades, it served a most useful purpose in stimulating research. Modified by the results of criticism and in part replaced by other hypotheses, it still stands out as a conception almost of genius, a landmark in the survey of the opinion of the time.

If we turn to examine the general conception of anatomy in I860, we find that there had been a good deal of development of the cell theory since its original promulgation. So far as the vegetable organism was concerned, however, the conception of protoplasm had not reached its proper importance. The cell wall, recognized later as only subordinate, was the central object of investigation. The work of observers still led to views of structure based upon the independence, or, perhaps preferably the isolation, of the cell. The idea of intercommunication of cells at all was confined to sieve tubes, which had been discovered by Hartig long before, but whose perforation was still a subject 
of dispute. The tissues, the conception of which was sadly incomplete being founded upon the view of the isolation of the cells, had been studied by many workers, and a classification of them, admirable for its time, had been promulgated by Unger in 1855 . Still better was the scheme put forward by Naegeli in 1858 , in which we find the recognition of generative and permanent tissues, each being subdivided with some care. The study of the vegetative body of the Dicotyledons and Conifers had led to a correct presentation of the arrangements of the vascular bundles, their courses through the plants, and their general structure. The differences between stem and root were noted and emphasized, though no co-ordination had been made. A certain confusion obtained as to growth in thickness, but the state of knowledige was not the same in all countries, views which had obtained wide acceptance in Germany making their way only slowly in England and France. By many the distribution of the cambium in the axis was confused, and the nature and properties of cambium itself misunderstood. In some of the textbooks of the time cambium was still described as a mucilaginous fluid, from which cells were produced by some process of condensation analogous to the formation of crystals.

The thickening process which occurs in the axis of certain Monocotyledons was still under examination and had not been fully explained.

The structure of the apex of the axis was exciting attention, though no systematic presentation of the variations in it had been made. Naegeli had determined the occurrence of the apical cell in the lower forms.

Von Mohl's view of the thickening of the cell wall by apposition was for the moment under an eclipse. The theory of intussusception promulgated by Naegeli, to which reference has been made, had supplanted it, and in the minds of many had utterly refuted it. It is at the present 
day strange to read how completely the new theory had captured the adherence of the leading minds; no less a thinker than Sachs wrote 'the foundations of von Mohl's theory of growth in thickness were shaken in 1858 by Naegeli's observations, and we may say that on the whole it has been for ever superseded '. 1

The lines of research adopted after 1860 were certainly varied, but among them five features stand out very prominently. The first of these centred about the cell. The study of its protoplasm was pursued with great eagerness, and its constitution, both chemical and physical, gave rise to considerable speculation. The discovery of much more extensive structural differentiation than had been thought possible followed the great improvement of histological methods that were derived to a considerable extent from the laboratories of animal physiologists. The interest which in the earlier time had centred round the cell wall was now transferred to the protoplasm. The nucleus, discovered long before by Robert Brown, had remained almost an unknown quantity, but gave up its secrets so far as structure was concerned to the investigators of the period, among whom Strasburger was pre-eminent. The extension of the idea of intercommunication of cell-substance and so of unity of the protoplasmic basis of the plant, based on the discovery or rather proof of the perforations of the sieve tubes shown by Naegeli in I86r, and more clearly by Hanstein in I864, led to the discoveries of Gardiner and of Russow that protoplasmic threads permeate all cell walls. The mysterious changes of karyokinesis, or mitosis, which mark the division of the nucleus, when brought to light proved but the commencement of researches leading to the establishment of results of the greatest importance concerned with questions of heredity and descent. In this way the study of the cell initiated a movement which

${ }^{1}$ History of Botany, Eng. ed., p. 304. 
culminated, as already stated, in the establishment of the separate science now known as $C y \operatorname{tolog} y$, in the foundation and development of which workers in the fields of animal and vegetable histology have co-operated.

A second line of investigation, perhaps more strictly anatomical, concerned itself with the morphology of the tissues. Originally following the lines of Naegeli, and looking for a morphological basis on which to classify cells and their combinations, we find Hanstein claiming the occurrence of histogenetic layers with a striking similarity to the germinal layers of the animal embryo, and Van Tieghem and his followers promulgating a coherent theory of fundamental unity underlying the vascular structure of the higher plants.

We find, however, a third line diverging from this at an early period. Physiological conceptions were grafted on to the study of anatomy. While they were applied to the cell itself as a dynamical machine, they were extended more widely to the conception of the tissues. The adaptations of the tissues to the environment on the one hand, and the influence of the latter in modifying both their arrangement and their structure on the other, came to alter the direction of the purely anatomical research, in the end no doubt greatly to its advantage. At the outset, however, it introduced an element of confusion, for classification of cell complexes on the lines of function, before the function itself was actually ascertained with certainty, was no easy task. The performance of some particular function by organs derived from different sources added to the difficulty, and helped to obscure clearness of ideas. For a long time there was confusion also between morphological and physiological conceptions, and the limitations of the two were not properly distinguished. The work which first directed attention especially to the physiological interpretation of anatomical structure was Schwendener's GREEN 
great memoir, Das mechanische Prinzip im anat. Bau d. Monocotylen, Leipzig (I874), in which he showed how admirably the skeleton of the plant is adjusted to its relations with the varied features of the environment. The same idea was elaborated and amplified in Haberlandt's Physiologische Pflanzenanatomie of I884, in which the tissues were examined and classified from the same point of view. Another work which treated of anatomical structure from the same standpoint was Tschirch's Angewandte Pflanzenanatomic, published in I888.

Though such a treatment of the anatomy of plants cannot in any sense supersede the more strictly scientific classification based on morphology and phylogenetic relations, it affords a valuable supplement to it, and brings prominently forward the relationship between the life of the organism and the structures which minister to it, and indeed render it possible.

A fourth line of research, having a more direct bearing on the principles of taxonomy, was initiated early in the period under review by Duval-Jouve and continued by him for several years. It was based upon the old idea, propounded somewhat obscurely long before by Linnaeus and by de Candolle, that anatomical structure may be employed for diagnostic purposes in determining systematic relationship. The germ of the idea may be seen indeed in the names Exogens and Endogens employed by de Candolle as alternatives for Dicotyledons and Monocotyledons, and in the subsequent writings of Endlicher, Lindley, and others. Duval-Jouve was followed by Bureau in I872, Bertrand in I874, Engler in I874-all of whom showed a direct connexion between anatomical structure and generic relations in various groups of plants. The founder of the method as one of general application, however, was Radlkofer, who gave a new impetus to it in his great monograph of the Sapindaceous genus Serjania, published in 1875 . 
Radlkofer was followed a little later by Vesque, by whom the elaboration or development of the method was considerably extended. Vesque laid great stress on the structure of the leaf within the limits of the genus as illustrating systematic affinity. Engler and Prantl later gave their support to this mode of treatment. If Radlkofer may be regarded as the founder of this movement, the great importance which came to be attached to it towards the end of the century was in large measure due to his pupil Solereder. Not only did he develop the idea beyond any other writer, but in 1898 he published his encyclopaedic treatise on the systematic anatomy of the Dicotyledons. The value claimed for this rapidly growing method was happily stated by him in the preface to this great work:

"The next Ioo years will be devoted to the anatomical method." These significant words of an illustrious botanist (Radlkofer, I883) are directly responsible for the publication of this work. Repeated earlier attempts had been made to employ the characters afforded by the anatomy of the vegetative and reproductive organs in conjunction with external features, for systematic purposes, and for a long time such characters have been of service to those engaged in applied science as a means of determining vegetable products. Both de Candolle and Endlicher had found anatomical characters useful in the division of the Phanerogams into the Monocotyledons and Dicotyledons. It is only in recent times, however, that certain well-known investigators, and foremost among them Radlkofer, have succeeded in demonstrating in a convincing manner the scientific value of anatomical characters for systematic purposes, and in founding an anatomical method. With the help of this they have been able to solve systematic problems which otherwise could scarcely have been elucidated and to throw an essentially new light on scientific questions relating to the delimitation of species, genera, and orders, as well as to natural affinities. Considering these brilliant results, it is not surprising that small success attended the opposition of systematists of the old school 
who were averse to the unaccustomed use of the microscope in this department of Botany, and feared lest they should have to resign their favourite science to their younger initiated colleagues, and it is not to be wondered at that the new method gained a sound footing. On the other hand, it is not unnatural that a number of botanists of the new school expected too much from the anatomical method, and not only looked for a revival of systematic Botany on a surer basis, but also for an entirely new Natural System.'

While the method no doubt possesses many advantages, it seems clear that it must not be pressed too far. We have seen that a great danger of misinterpretation of relationship of tissues cannot be dissociated from the proposals of Haberlandt and Tschirch to adopt a physiological classification of anatomical structures, and we must therefore scrutinize very carefully suggestions of systematic affinity which rest on adaptive structures. Solereder himself admits as much, for he says, when speaking of anatomical details :

- These features are not always characteristic of large groups of plants. Secretory cavities or cells, though often constant throughout entire orders, tribes, or at least genera, may occasionally occur in isolated species. A definite type of stomatal apparatus is found without exception throughout the Rubiaceae, but is only present in isolated members of the allied orders Umbelliferae and Caprifoliaceae. One or more exceptions may not rarely be found in an Order, the remaining members of which are distinguished by a special phyletic character, e.g. Drapetes is exceptional among Thymelaeaceae in possessing no intraxylary phloem. Such cases are not capable of explanation, for these exceptional members have to be included in the Order concerned on account of the rest of their distinctive characters. All these facts indicate that the value of an anatomical character cannot be definitely predicted.'

Another movement which was gradually increasing in importance up to the close of the century was initiated during 
its last few years, being in a great degree the outcome of the two lines of research which have just been mentioned. The study of the relations between the environment and the structure of the plant had given rise to the conception of a physiological anatomy, and the development of physiological adaptations had been found to be to a certain extent an indication of relationship or affinity. The study of such relationships in the light of physiological need, and the consequent development of anatomical peculiarities running through groups of plants, led to the recognition of a new branch of botanical research, which became known as Oecology. It was not limited, however, to these features, but embraced the study of plant associations and the relative influence of such forms to one another as well as to the general conditions of their environment. This movement, however, was in its infancy at the end of the century. 


\section{CHAPTER I}

\section{THE CELL}

Cytology, or the study of the cell, has taken its place among the sciences almost entirely since I860. Prior to that date the cell theory of Schwann and Schleiden had been formulated, and its importance was becoming more and more recognized each year. So far as plants were concerned, however, the theory was only partially realized ; and the dominance of the protoplasm in the cell had still to be discovered. Many writers of the time apparently had little idea of its importance, for they included it with many other substances under the general term of 'cellcontents'. The cell wall was looked upon as the visible representation of the cell, instead of as a very subordinate part of its organization.

The cell theory was extended in its application and its importance as bearing on the development of the current views on embryology and evolution greatly promoted by the researches (among others) of Hertwig, Strasburger, and Van Beneden from I873 onwards. Of particular consequence was the identification of the cell-nucleus as directly concerned in inheritance, made by these writers and Weismann some ten years later.

During the progress of this research, however, the point of view was wholly changed by the recognition that the living substance of animal and plant is of similar nature, if not absolutely identical. The researches of Max Schulze, especially between I854 and I863, contributed very materially to this result. He was the first to prove that the 'protoplasm' of von Mohl, studied 
by Cohn, Unger, De Bary, and others, is practically the same thing as the 'sarcode' of the animal physiologists, though Unger had suggested it in I855. The term protoplasm was originally used by Purkinje in I840 to designate the formative substance of the animal ovum.

The development of knowledge of the structure and behaviour of protoplasm bulked large in the researches of the first twenty years of our period. It was studied alike by botanists and zoologists, and as the animal and vegetable substance was shown more and more clearly to be the same, the researches calling for mention cannot be confined to either. For our present purpose, however, it will be convenient to put forward most prominently the work of the botanists, though precedence must be given on many points to zoological investigations.

The first idea of the structure or constitution of protoplasm was that of a somewhat viscid, rather slimy fluid, in which variable numbers of granules were present. This was the idea which arose from microscopical examination in days when technique was in its infancy and consequently differentiation by means of staining was hardly possible. Simple observation of such protoplasmic aggregations as the plasmodia of Myxomycetes led to no further discovery. This theory of protoplasm was held by Max Schulze himself, by Haeckel in I862, and by Kühne in I864. These observers saw the streaming movements which many cells present, the flowing together of the pseudopodia of Amoeba, the fusion of the masses of the plasmodium of the Myxomycete, and the tendency of isolated portions of protoplasm to become spherical.

Very soon, however, the consideration of the various complicated processes which even the simplest cell must carry out led Brücke to realize how unsuitable for such purposes must be a single viscid fluid. He suggested that this simple appearance must cover some kind of organiza- 
tion, which he conceived to be a solid cell-body, capable of contractility and containing a fluid streaming through it and carrying the granules. In other words, he held protoplasm to have a firm contractile framework, steeped in fluid.

This position of Brücke's marked a great step in advance, though his conception of the nature of the organization was only rudimentary. It opened the way to more detailed observation, which became more exact as experience was gained of improved methods of technique.

In 1863 Cienkowski, working on the plasmodium of the Myxomycetes, suggested as its composition two fluids of different densities, the one constituting the ground substance being hyaline, and hardly more than semi-fluid, the other more limpid, containing the granules in suspension.

In I864 De Bary suggested the view of a single semifluid, or soft substance, contractile throughout, but exhibiting local differences in its cohesiveness, fluidity and mobility, all depending on variations in its content of water. He was supported by Hanstein in 1870 , and later in 1880 and 1882 . Hanstein distinguished in the protoplasm a hyaline ground substance-hyaloplasm; a more fluid part-the enchylema; and the granules-the microsomes.

The single-fluid theory was held by Naegeli and Schwendener in I865 and indeed up to I877. They considered protoplasm to be mucilaginous in its consistency, and they claimed for it some sort of organization, but they did not accept Brücke's view of its structure. This theory of a viscid fluid was shortly replaced by other views, but was revived later by Schwarz, by Pfeffer, and in a modified form by Berthold, and by Bütschli. To their hypotheses reference will be made later.

The view that protoplasm possesses a fibrillar structure was the next to be advanced, and to find farour among both animal and vegetable physiologists. Of the latter 
the most noteworthy was Velten, who wrote in $1873-6$. He based his views on observation of the streaming movements in the protoplasmic strands crossing the cell in such plants as Tradescantia and Cucurbita; and taught that the substance consists of numberless fine canals filled with fluid, but shut off from the general cell-cavity. The granules which previous observers had associated with the fluid he attributed to the walls. In his first work he denied that his system of canals was a spongy framework, though later he to some extent modified his views on this point.

Among the animal physiologists many claimed to have demonstrated a fibrillar structure in various animal cells. Especially may be mentioned Remak in I844, Max Schulze in I871, Flemming in I882, and Schneider in I89I. Various modes of arrangement of the fibrils were suggested, Schneider holding it possible that the whole cell might be only one long twisted filament.

This theory, though in the main held through a long series of years, soon underwent modification, and another view was advanced side by side with it. This was the reticular hypothesis, which owes much to the researches of Fromman, carried on from I865 to near the end of the century. He formulated in $\mathbf{I} 867$ his theory that protoplasm forms a network or reticulum of solid substance, and that non-living liquid substance occupies the meshes. The nodal points of the network give rise to the appearance of the granules, or, at any rate, of some of them. The theory was supported by a large number of observers, many of whom advanced certain elaboration of Fromman's views. According to some, the substance of the bars of the network can be differentiated into a solid core, covered by a softer substance.

Fromman's theory was endorsed and elaborated with great skill by Heitzmann in 1873 , but while Fromman 
studied both animals and plants, Heitzmann's observations were confined to the former.

If we occupy ourselves mainly with the work of botanists we find among them many cordial supporters of the reticular theory. Foremost among them stood Strasburger, who in I 876 held the structure to be a net-like substance, with coarse vacuolation; he distinguished between the intraprotoplasmic vacuoles and those larger chambers in the cell which are now commonly known by the same name, and which are distinct, of larger size, and filled with an albuminous sap.

Schmitz in I880 carried the theory a little farther. Working on material that had been fixed with picric acid, he held that his preparations justified him in speaking not only of a reticular structure, but of a limiting layer on its exterior or its free surfaces. This he described as constituted by a narrowing, or in some cases by an obliteration, of the meshes of the framevork in these positions. The granular punctations visible in the protoplasm he attributed to the nodal points of the network.

Important contributions to the knowledge of the subject were made in I88I and I882 by Reinke and Rodewald as the result of researches on the plasmodia of Aethalium. In this organism they found a firm ground substance, holding in a kind of spongy framework a fluid which they called the enchylema. The latter could be driven out by pressure, leaving the framework as a hard cake. They believed the framework to be of a plastic and contractile nature, to be permeated by the albuminous enchylema, and to be shut off from the exterior by a thin layer of its substance specially differentiated for that purpose. They were inclined to hold the arrangement of the material or substance of the framework to be alveolar.

Schwarz's work of 1887 , to which reference has been made, was an attempt to reconcile the filamentous or 
reticular appearances with the older fluid theory. He held that the coarser fibrillar appearances are trabeculae of protoplasm of great fineness, while the local reticular structures of which Fromman spoke are only precipitates separating out in certain places. He based his view largely on the fact that he obtained similar appearances of reticulated structure in coagulated drops of white of egg. His view was, broadly, that there are no preformed networks or frameworks, but that certain parts of the protoplasm may under particular conditions become modified to take the form of filaments and strands.

The fluid theory received substantial support in I89o from Pfeffer. He regarded as viscous fluids the streaming protoplasm of the Myxomycetes, and the principal mass of the ordinary protoplasm of vegetable cells, and while he admitted that the cortical layer of the plasmodium possesses a greater degree of cohesion than the inner substance, and that the outer layer of most protoplasts is to be regarded as more or less solid, he denied entirely the existence of a firm, continuous, and permanently rigid framework.

Another hypothesis was advanced in the early eighties, which for a time met with some support. It was based upon the granular character which protoplasm exhibits, the granules assuming a greater prominence than in the theories already alluded to. The granules were explained, as we have seen, by the supposition that they represented the nodular points of the reticulum, or the crossing of the fibrils. Hanstein in I882 considered them to be distinct structures and called them microsomata. In the same year Martin suggested that the fibrillar or network appearances are due to a special arrangement of these granules. Pfitzner held in $\mathbf{I} 883$ that they are viscid or semi-solid structures floating in a fluid ground substance. He accounted for the appearance of filaments by suggesting an attraction 
between them, causing them to range themselves alongside one another.

The most eminent supporter of this view was Altmann, who wrote upon it in I886-90. It led him to reject the reticular theory entirely. He considered that the granules constitute the living part of protoplasm, and that the fluid in which they move is non-living. He called them consequently bioplasts, so that a cell on this hypothesis became not the unit of construction of the organism, but an assemblage or colony of bioplasts.

This theory, though urged with considerable ingenuity, met with but little acceptance.

The views of Berthold have already been spoken of. In I886 he put forward a fresh presentation of the fluid theory, and taught that two fluids are concerned in the structure, their relationship being that of the constituents of an emulsion. He consequently abandoned the fibrillar or reticulate hypothesis, ascribing the appearances described as such to optical rather than physical conditions.

Berthold's work was followed in I 889 by Bütschli's foam theory. On this view the finer reticular appearance of protoplasm which can be observed under high magnification is the optical expression of an extremely finely vacuolated foam structure. Examination of very carefully prepared artificial foams, made by rubbing up oil with potash, or with solution of cane sugar, presented so remarkable a similarity to the structure of protoplasm that they were almost indistinguishable from the latter. Such a structure presents under high powers of the microscope a picture, not of droplets or bubbles pressed tightly together, but of a network, the threads of which are formed by the cross-sections of the thin walls of the droplets as they are looked at in optical section. The optical cross-section of a foam in fact is a network. Suspended in the foam are numerous solid granules, these 
being driven by surface tension forces into the angles formed at the points where the foam droplets come into contact.

The disposition of the protoplasm in the cell cavity and its relation to the vacuolation of the cell, present problems which are mainly physiological and may therefore be deferred. Some discussion took place as to the relations between the external layers of the protoplasm, and the watery contents of the vacuoles on the one side and the cell walls on the other. Hanstein in I870 first recognized that the free surfaces of the living substance, whether bounded by the vacuole or the cell membrane, possess a denser constitution than the rest. The name ectoplasm was applied to these limiting layers as distinct from the endoplasm within them. In all the fibrillar or reticular hypotheses this difference of consistency was explained by relative closeness of mesh or approximation of fibrils on any free surface. This was particularly emphasized by Schmitz in I882 and by Strasburger in I882 and I884. Schneider suggested that they are actually bound together by a special cement substance.

Bütschli explained them differently. He said that the alveoli, which are situated close to the outside of the protoplasm, are always directed vertically to the surface, so that a radially striated, very thin layer of them is formed. It is not apparently a special kind of membrane at all. Bütschli held that such a layer must occur on the outside of a foam-a marginal alveolar layer,-and that it may become solid or nearly so and develop into a firm membrane.

Pfeffer held different views upon the character of the exterior of the protoplasmic unit. He suggested in his Pflanzenphysiologie that definite membranes are produced on the freshly-exposed surfaces of the living substance on their coming into contact with water or some other medium. These are consequently not protoplasmic, but are composed 
of certain substances principally or entirely protein, actually precipitated on the protoplasmic films which bound the free surfaces. These are the well-known 'plasma membranes' associated with this theory.

Pfeffer's theory attracted much attention, and met with general acceptance for a time. It was, however, passing out of favour at the end of the century.

A different view of the external surface of the protoplasm and its relation to the cell wall, was taken by Chodat and Boubier in I898; it was based on actual experiment, but scarcely received as much attention as it deserved. When these observers set up a very gradual plasmolysis of the cell the protoplasm did not wholly leave the walls, but remained attached to them in places by thin plates which extended between the two. The direction of these plates did not always correspond in contiguous cells, so that they were not formed of communicating threads passing through the wall. The plasmolyzed protoplasm remained so for a variable time, united to the wall by more or fewer bands of ectoplasm.

The authors explained the formation of the bands or threads by the suggestion that the ectoplasm is viscous and adheres to the membrane, or else that the external surface or layer of the ectoplasm passes insensibly into the substance of the cell-wall, and so, by this close union and progressive change at the plane of contact, takes part in the formation of the new lamellae of the cell-wall as the latter gradually thickens.

A very different theory of the wall or limiting layer of the vacuole was brought forward in I 886 by De Vries. He advanced the view that the young cell contains among the products of its organization certain structures to which he gave the name of Tonoplasts, small bodies which secrete strongly osmotic substances in their interior, and which consequently swell up very considerably, becoming recog- 
nizable as vacuoles when so swollen. The limiting layer of the vacuole on this hypothesis is the distended wall of the plastid, and is not formed by nor connected with the protoplasmic substance of the cell.

His views were supported in I888 by IVent, but they did not meet with very general acceptance. The hypothetical tonoplast did not apparently behave after the manner of other plastids of the cell, and did not multiply by fission. Nor was it easy to see how the one large vacuole of the cell could be composed by the fusion of smaller ones, each with its own well-defined wall, without showing the existence of the latter or part of it separate from the general protoplasm.

The relations between the protoplasm of contiguous cells were almost unknown in I860. The structure of the sieve tubes had been studied as long ago as I837 by Hartig, and later by von Mohl in I855, and Naegeli in I86I, but though their general features had been observed, it was not satisfactorily shown till the publication of Hanstein's researches in I864 that definite perforations of the walls exist. Nothing further was ascertained till I882, when Russow and Strasburger independently took up the subject, and both made valuable contributions to our knowledge. In his Bau und Wachstum der Zellhäute, I882, Strasburger published a fuller account of their peculiarities, dealing with the formation of the sieve plates and the arrangement of the protoplasmic threads which pass through them. A more exhaustive description of the details of their structure was given by Gardiner and Hill in Igoo.

Vith the exception of the sieve tubes and certain cell complexes in the red seaweeds, observed in $I 88_{3}$ by Hick, there was no evidence of any intercellular protoplasmic continuity, though it was held by many to be extremely probable; Heitzmann put forward the theory in I873, but he failed to produce satisfactory evidence in support of his contention. It was taken up seriously a few years 
later and was made the subject of very careful investigation by several observers, very largely under the influence of Sachs, who laid great stress on the importance of such a relationship. Fromman in 1880 believed he had been able to trace it, while Tangl in I 879 and I880 also occupied himself with the problem. The chief obstacle to the study of the minute histology of the tissues was the inadequacy of the methods which were in use. Those which were applicable to the problem of continuity were confined to swelling up the walls with sulphuric acid and subsequently staining with iodine. Such treatment was moderately successful with the coarse elements of the sieve tube, but was utterly useless with the delicate cell walls of the greater portion of the plant. Gardiner undertook an investigation at the instance of Sachs in I882, and was successful in so far modifying the methods in vogue as to enable him to investigate the more delicate tissues. Russow was engaged in similar investigations simultaneously, his work following his study of the sieve tubes.

Both observers modified the swelling reagent so as to bring the swelling about more gently, and thereby to avoid the destruction of the delicate threads; having it under control they stained the tissue with various aniline dyes. Gardiner treated it with iodine before swelling the wall, and used a further fixing reagent, picric acid, in conjunction with his stains. Both published their researches in $I 883$. Gardiner was successful in demonstrating the continuity of the protoplasm in the cells of the endosperm of various seeds, and in ascertaining many facts about the arrangement of the connecting threads. He was led to the opinion that such communication is general, but he considered he had not satisfactorily demonstrated it.

Russow claimed that he had demonstrated the existence of the threads in a variety of tissues, including such delicate cells as those of the cambium. 
Hick observed continuity between cells of certain Fucaceae in I885. A contribution to the subject was made in I89I by Kienitz-Gerloff, who relied on swelling the wall with sulphuric acid and subsequent staining.

In I893 a new method was introduced by Poirault; he killed pieces of various tissues by soaking them in a dilute solution of iodine. The subsequent treatment differed little from that of his predecessors, but the preliminary fixing of the protoplasm by the iodine was advantageous.

Gardiner took the subject up again a few years later and published some very important results in I897. To kill and fix his tissue he employed a mixture of osmic acid and uranium nitrate, and he stained it subsequently with saffranin. The new reagent enabled the stain to penetrate the tissue much more readily, and so to reach the more delicate of the threads.

He was able to show that in the case of pitted cells the pit-closing membrane is always traversed by threads of protoplasm, and that other threads traverse the general wall. In non-pitted cells the wall is perforated by the threads, though there are no pits. The threads are arranged in bundles in a manner recalling the disposition of the achromatin fibrils which accompany nuclear division. He carried the work out more completely than in his earlier paper, and showed that the structure exhibited by endosperm tissue is in all respects entirely typical of plant tissue generally. In epidermal cells he found that the external walls are penetrated by threads as far as the cuticle, but that the latter blocks their way to the exterior. He claimed to trace the threads to the fibrils of the nuclear spindle which become imprisoned in the newlyformed cell wall.

In a further paper, published in I90o, he showed that in certain cases a dot can be distinguished on the thread GREEN 
in the region of the middle lamella of the cell wall, and he interpreted this dot as the persistent nodal dot of the achromatic fibrils. From this dot the thread appeared to develop through the substance of the wall in both directions.

It is interesting to note that similar swellings or dots were observed by Russow in the middle of the threads or perforating fibrils of the sieve tubes.

Gardiner's view, that the perforations are coeval with the formation of the wall and not produced as it grows older, was borne out by his observations on the distribution of the threads in the walls of such oblong cells as exist in the cortex of young growing stems. The end walls, which undergo but little increase of surface due to stretching, show groups of the threads nearly uniformly distributed over them; on the side walls, however, they are more or less grouped into areas separated by certain distances from each other. Here the influence of stretching can be seen, the separation of group from group being attributed to such a force exerting its influence most strongly on such areas as contain the least number of threads.

The last contribution to the subject made in the century was a very complete account of the structure and distribution of the threads in Pims, made by Gardiner and Hill in I9oo. Though the most elaborate memoir of the time, it only confirmed and extended the observations already described.

The study of the structure and behaviour of the nucleus was the most engrossing feature of research on the cell during nearly the whole of our period. When first discovered by Robert Brown, its importance was not recognized, and it only slowly assumed the preponderance which marked its position after the early seventies.

It was realized some years later, in I884, that it is concerned in the problems of inheritance, a result due to 
the observations and teaching of Hertwig, Strasburger, Kölliker, and Weismann.

For many years after its discovery its general substance was considered to be quite distinct from the general substance of the cell, and the early theories of protoplasm did not include it. It was not till $\mathrm{I} 882$ that we find its true relations taught, when Strasburger included it in the protoplasm of the cell, which he spoke of as differentiated into cytoplasm and nucleoplasm.

The universal occurrence of the nucleus as an integral part of the protoplasm of the cell was not at once admitted. The researches of Schmitz carried out in 1879 and I880 established its existence in many of the lower Thallophyta, including Yeast. Schmitz was inclined to deny its presence in the Cyanophyceae and the Bacteria. A body corresponding to the nucleus, though not possessing the same complicated structure, was found in both these groups independently by Wager and by Zacharias (I890-95).

The researches into the nature of the nucleus, like those relating to the structure of the protoplasm, were conducted by biologists upon both animal and vegetable tissues, with the result that demonstration was forthcoming of the practical identity of the nuclear as well as the cell protoplasm in the animal and vegetable kingdoms. It is difficult therefore to discuss the progress of knowledge from the point of view of the latter only. The work of the two schools of research is in this case mutually supplementary, the leading facts having been supported by both.

The first satisfactory account of the structure of the resting nucleus was derived from the researches of Schmitz, Strasburger, and Flemming, conducted independently in the years 1879 and I880. According to these investigations it consists of a homogeneous ground substance, sometimes, however, having a finely dotted appearance, in which a more solid material is present in the form of a reticulum 
or a much-coiled fibre. In some part of the substance conspicuous granules occur, one of which is usually very conspicuous and constitutes the nucleolus. The network or fibril is composed of a more or less homogeneous ground substance, in which lie granules of a material that stains easily with various dyes. Flemming called the staining substance chromatin ; the non-staining achromatin; Schwarz, in 1887 , called the non-staining basis of the reticulum in which the chromatin is imbedded, linin.

Further researches showed that the chromatin may be present in the thread either in the form of granules, or as a network embedded in the linin, the latter thus itself forming an achromatic network intermingled with the other.

This conception of the structure underwent little change till Heidenhain showed in $1893-4$ that the achromatic network is also granular in composition. He thus distinguished two kinds of granules in the linin thread: the first known, which he called basichromatin, being associated with the other, oxychromatin, in the staining portion, the oxychromatin granules alone being present in the non-staining portion of the linin. He used the names mentioned to indicate differences of reaction to stains ; the basichromatin granules taking up the basic tar-colours such as saffranin, the oxychromatin being stained by acid tar-colours like eosin.

The ground substance of the nucleus was said by Reinke in 1894 to consist of large pale granules of non-staining material, to which he gave the name oedematin.

The nucleus in the cell is delimited by a kind of membrane, which according to Klein, who studied it in 1878 , is a denser portion of the cell protoplasm, much like the limiting layer of the vacuole. Van Beneden endorsed this view in 1883 .

The chemical substance of the nucleus was first investigated by Miescher in $187 \mathrm{I}$, when its great richness in 
phosphorus was first discovered. He named its primary constituent muclein. Altmann showed in 1889 that nuclein is a compound that can be decomposed into nucleinic acid and a kind of albumin. Kossel in I893 identified such compounds of nucleinic acid and albumin with the chromatin of the histologists.

The centrosome was discovered to be an inseparable companion of the nucleus in animal cells by Flemming and by Van Beneden in 1875 and 1876 . Its presence in plants was not recognized till I89I and I892, when Guignard claimed to have discovered it in the sporogeneous tissue of Lilium Martagon. Farmer observed its occurrence in certain liverworts in I895, but he entirely failed to confirm Guignard as to its presence in the flowering plants. A somewhat heated controversy arose, in which Belajeff, Osterhout, and Mottier took part. None of these observers agreed with Guignard, so that the association of centrosomes with nuclei in the higher plants remained entirely hypothetical at the end of the century.

The determination of the behaviour of the nucleus in the process of cell-division was one of the most important discoveries in cytology made prior to I900. Before I860, Remak and others had shown that its own division was an essential part of the process of the division of the cell, but no detailed investigation of the changes was made till I873, when it was observed by Schneider. From this time the study of the phenomenon was undertaken by many biologists, among whom were conspicuous Schleicher, who gave it the name karyokinesis, Van Beneden, Flemming, Schmitz, and Strasburger. Van Beneden distinguished between fragmentation and division in 1876 . The terms indirect, and direct, nuclear division were introduced by Flemming in 1879 , and were long in favour. In I882 the same writer suggested the terms mitosis and amitosis, whicin also came into general use. 
Our knowledge of the details of the process of karyokinesis or mitosis is derived chiefly from the writings of Flemming and Strasburger, who agreed in the main on the course of events occurring, though certain points of difference were observed. They were, however, comparatively unimportant.

The longitudinal fission of the chromosomes was discovered by Flemming in I880. He also first described the heterotype division in $\mathbf{I} 887$.

The reduction division associated more or less directly with the sexual nuclei, was first observed by Van Beneden in I883, and again in I887, occurring in the germ cells of Ascaris. It was discovered in plants by Overton in I893 when studying the endosperm of Ceratozamia, and in the same year by Dixon, who observed the reduced number in the endosperm of Pinus. The great generalization that the nuclei of the gametophyte give rise to only half the number of chromosomes that characterizes those of the sporophyte was made by Strasburger in I894. He was confirmed by Farmer's researches on the liverworts made later in the same year.

The years I858-63 were noteworthy for the elaborate researches of Naegeli on the constitution of cell walls, starch grains, and other organized bodies, on which he based his views of their structure and of their growth by intussusception. These views were stated very fully by Sachs in his History of Botany (English ed., p. 350), so that a summary of them is all that is needed here. They met with his strong approval and support, and indeed led him almost to the view that they represented finality on the subject. They were accepted almost without challenge for more than twenty years.

On Naegeli's hypothesis the cell wall, like the starch grain, consists of crystalline particles between which water penetrates; they are solid and relatively unchangeable, 
and far too small to be visible under the microscope. Each is surrounded by a layer of water, so that adjacent particles are not in direct contact. They may be of different sizes, and the watery layers between them may be of varying thickness, so that the density of the structure will depend on the relative amounts of the solid and liquid constituents. The wall is the scene of action of two forces, the particles being mutually attractive, and the water forcing them apart as more is absorbed by the wall under external pressure, or as it is attracted by the surfaces of the particles owing to surface tension. The particles may be arranged in layers of different degrees of density, watery and more solid laminae alternating. Growth in surface or in thickness depends on the intercalation of new particles among those already existing.

This hypothesis gave what appeared to be a satisfactory explanation of all the facts that had been observed up to that time. It is not surprising, therefore, to find that it met with a very cordial welcome. Sachs spoke of it as " the first successful attempt to apply mechanico-physical considerations to the explanation of the phenomena of organic life '. 1

After about twenty years of supremacy Naegeli's hypothesis was challenged by Schmitz and especially by Strasburger, the latter of whom put forward a view which, while admitting the cell wall to be composed of solid and liquid constituents, opposed the theory that the former are crystalline. The existence of the micellae, as Naegeli called the crystalline particles in 1877 , was altogether a matter of inference, as they were supposed to be far too minute for microscopic demonstration. Strasburger eliminated them entirely from his conception. He held that the forces binding together the solid particles are rather chemical than physical; that their molecules are

1 History of Botany, Eng. ed., p. 315. 
linked together by chemical affinity into a reticular framework, in the meshes of which the water is retained by capillarity or surface tension. Additions to the substance of such cell walls are made by the apposition of new layers to their external surfaces, and the lamellar appearance, known as stratification, is due to such deposition.

Strasburger supported the last part of his hypothesis by actual observation of the deposition of microsomata from the protoplasm in sheets upon the existing walls. The so-called striation he explained by the deposition of the granules in each layer in oblique lines down the longer axis of the cell. He showed further that the lines of such striation are confined to each layer of deposition, though successive layers may be superposed. The appearance of cross striation so often seen is due to the absence of such superposition. Strasburger thus vindicated the view of Wigand in 1856 , that each layer deposited has its own striation marks.

Strasburger's explanation of the growth of surface on this hypothesis was the greater stretching power of a wall after a new lamina has been deposited upon its surface.

For a time, under the inspiration of Strasburger's name, the theory of growth by apposition superseded the older theory of intussusception. In I886, however, another hypothesis was brought forward, which met with considerable acceptance. It was due to Wiesner, and was based upon a conception that had originally been advanced by Hofmeister in 1867 , that the cell wall is a living structure, though in its details it was altogether new. Wiesner suggested that while young and growing the membrane is made up of an aggregation of granules arranged in rows, and surrounded by protoplasm, the granules being connected together by protoplasmic threads. These granules he named dematosomes. On this conception the wall 
is composed of both living and non-living matter, as well as of water.

IViesner supported his view by experiments on dead and old cell walls, in which, under the action of chlorine water and other reagents provoking a gentle decomposition, granular dermatosomes became visible. He brought forward also in its support the presence of protein substances in the cell walls of Fungi. On this hypothesis growth takes place by the formation of new dermatosomes in the protoplasm included in the substance of the wall.

Viesner's views called attention again to the question of intussusception, and again acceptance of the process became general, though not in the original form proposed by Naegeli. Strasburger's observations as to lamination from the exterior were confirmed by Noll's researches of I887, in the course of which he was able to differentiate the successive layers by delicate methods of staining. The reassertion of the intercalation of substance by intussusception was made in the case of structures like root-hairs and fungal hyphae, by Haberlandt in I889, and by Zacharias in I89I. The latter observer succeeded in introducing a stain into the cell-membrane of a growing root-hair, without stopping its growth, and found that the coloured apex lost its stain during surface-growth, while the older portions of the wall retained it. This could not have taken place had the surface-growth been due, as Strasburger suggested, to a stretching of the thickening membrane, but must have been caused by intercalation of new particles. Other writers who supported this view were Leitgeb (I884), Wille (I886), Krabbe (I887), and Cramer (I8go).

Strasburger's views were upheld not only by Noll, but by Klebs in I886, Wortmann in I889, Zimmermann in I887, and Askenasy in I89o.

Pfeffer in 1892 tried to reconcile the opposing schools 
by suggesting that there is no universally applicable method, but that growth, both in surface and thickness, can be brought about in both ways.

Pfeffer showed that the stretching of the cell wall during surface-growth depends to some extent on a softening of its substance by the protoplasm.

Since Pfeffer's work appeared, further contributions have been made to the controversy which seem to justify his suggestion. Correns in $\mathrm{I} 893$ found that intercalation of particles takes place in the walls of Gleocapsa and Apiocystis; Cramer found an increase in the mass and rolume of the walls of Neomeris Kelleri in the absence of any possibility of growth by apposition. In I897 Kolkwitz showed that rapid growth of the cell wall occurs in the pith of certain stems, which are hardly stretched at all during the period of the most active increase in size, confirming thus the observations of Pfeffer four years earlier, that the growth of the walls of certain cells in the root can continue after osmotic pressure in such cells has been almost destroyed. Reinhardt carried out some observations on the growth of certain fungal hyphae in I899, which led to the same conclusion. Strasburger himself accepted the view of different modes of growth of cell wall in different cases in his work of $I 898$.

Strasburger gradually modified his views after the publication of the Bau und Wachstum of I882, in which his hypothesis first appeared. In his Bau und Verrichtungen der Leitungsbahnen (Jena, I 89I), he admitted that the protoplasm of the cell may at times make its way into the wall and become modified to form some of the products which occur there, apart from the normal framework. He admitted that the cell wall is not formed at once and for all, but that the protoplasm abutting on it exhibits a conspicuous power of modifying its constitution. He was thus prepared even then to accept intussusception of a kind; 
though not the infiltration of non-living material on which Naegeli's views were based.

The hypothesis of Wiesner, that the cell wall is at first living and continues for some time at any rate to contain a certain proportion of living matter, was supported by Molisch's investigation on the growth of thyloses, carried out in I888. As the protrusions into the cavity of the vessel enlarge to fill it, they in time touch one another, and their walls thicken and form pits; the latter are formed always opposite to each other in adjacent walls. Molisch pointed out that this almost certainly involves the presence of protoplasm in the cell wall.

The composition of the substance of the cell wall, commonly spoken of as cellulose, was known by the earlier writers from $\mathbf{I} 825$ onwards to be a mixture of several compounds distinguished as cellulose and pectose respectively: Prior to I860 little had been ascertained about their distinguishing characteristics, their relation to each other, or their distribution in the cell-wall substance. The latter was known to show a certain differentiation, its middle region being in many respects unlike the rest. The distinguishing reagent, ammonio-cupric sulphate, which dissolves out the cellulose from the wall, leaving the pectose constituents unaffected, was first employed by Frémy in I859.

Kabsch ascertained certain facts about the relative distribution of the two components in I863. He found that when a cell-membrane is swollen by the action of chlorzinc-iod, the inner layers only take on the blue coloration of cellulose, and that the middle region, or middle lamella of Naegeli and later writers, varies in different cases, sometimes remaining colourless, sometimes appearing yellow, and occasionally taking a pale blue tinge. He consequently located the pectic bodies in the middle lamella, as they are not coloured by the iodine, and claimed that the layers 
on each side of it consist only of cellulose. He noted that the middle lamella thickens as the cells get older, and interpreted this to mean that a transformation of the substance of the cellulose into pectose takes place.

Vogl wrote on the same subject and to much the same effect in the same year. His experiments were made chiefly on the roots of the dandelion and of a species of Podospermum. He found the cellulose compounds to be in greatest evidence on the internal face of the membrane and the middle lamella to be mainly pectosic in nature, the two gradually blending in the intermediate substance of the wall. He, like Kabsch, took the view that the substance gradually changes as it gets older.

In 1864 Wiesner gave the support of his name to the formation of the pectosic component from cellulose, but he went further and said, that while in cortical cells the change goes no further than this, it is different in corky and woody cells where lignin and suberin are the ultimate products of the chemical transformation.

The nature of the middle lamella and its relation to the two constituent substances was the subject of investigation before 1860 , and the earlier views were subsequently the subject of keen scrutiny. At the date mentioned it was held by some writers to be a kind of intercellular substance joining cells together by a kind of agglutination. Other writers, among them Naegeli, held it to be the firstformed layer or primary membrane of the wall. In its composition the pectates were held to take a considerable share, indeed Payen had pronounced it to be a mixture of metallic pectates, principally those of calcium and potassium.

As we have seen, several writers immediately after I 860 tried to show it to be gradually differentiated from the thickening wall, and hence to be quite a different thing from the primary membrane. Sanio, on the other hand, 
revived in 1873 the old view of an agglutinating material of gelatinous nature intercalated between the radial rows of the generating cells. He held, however, that it arises from a decomposition of the original cell wall.

Further light was thrown upon the problem by researches made a little later on the pectosic compounds by Mangin. Published in I892 and I893, these were of the first importance. Before their appearance the whole group of the pectic compounds was ill-defined, and nothing was known very definitely as to the distribution of most of them in the cell wall.

Mangin arranged these substances in two series, the members of the first being bodies of a neutral reaction, while those of the other are weak acids. In each series there are several members, which show among them every stage of physical condition between absolute insolubility and complete solubility in water, the intermediate bodies exhibiting gelatinous stages, characterized by the power of absorbing water in greater or less degree.

Of the neutral series, the two extremes are presented by Pectose and Pectine. The former is insoluble in water and closely associated with cellulose in the substance of the membranes ; the latter is soluble in water and forms a jelly with more or less facility.

In the acid series the two most noteworthy members are Pectic and Metapectic acids. The former generally exists in the membrane in combination with the metals of the alkaline earths, especially calcium; when in the free state it is insoluble in water. Metapectic acid is soluble in water, forming a jelly. The two series are closely related to each other, for by the action of heat, acids, and alkalies the various members of both can be prepared from pectose. The final product of the action of the reagents is the freely soluble metapectic acid.

Their reactions, as given by Mangin, show that these 
pectic substances form a group quite distinct from the celluloses which are known. The ease with which they are altered by the reagents used for their extraction readily marks them off from the latter, as do the products of their oxidation. When warmed with nitric acid they give rise to mucic acid, while the celluloses are oxidized by the same reagent to oxalic acid.

The pectoses are all insoluble in ammonio-sulphate of copper, and are not stained blue by iodine in any combination.

Mangin studied the distribution of celluloses and pectosic bodies in the cell wall by means of differential staining. Cellulose acts as a feeble base, and takes up, therefore, acid stains, particularly those which contain nitrogen. Pectosic compounds on the contrary act as acids and require basic stains.

Mangin supplemented his observations on the staining of the compounds by watching the action of solvents. As just stated, the celluloses dissolve with greater or less readiness in ammonio-sulphate of copper. The treatment must be prolonged and conducted with due precaution, but Mangin found he could free the walls entirely from these substances, leaving a framework staining pale yellow instead of blue with iodine and phosphoric acid, and taking up the basis stains which do not colour cellulose. The pectic compound remaining after the action of the alkaline reagent is not unchanged pectose, but has been partly converted into pectic acid by the treatment.

Mangin succeeded also in dissolving out the pectosic constituent of the wall and leaving the cellulose, by boiling the tissue alternately with dilute acids anḍ dilute alkalies, washing well after each operation.

By means of these methods of procedure Mangin ascertained that in Phanerogams, Pteridophyta, and Bryophyta hardly any soft tissue is devoid of pectosic substances in 
its cell walls. They are conspicuously present in parenchyma, collenchyma, bast, and meristem tissues, pectic acid and pectose being the compounds of most general occurrence. He confirmed an old statement of Payen's, that the middle lamella or 'intercellular substance' consists almost entirely of calcic pectate.

Mangin did not determine the relations between the pectose and the cellulose of the wall, but claimed that there is a very intimate association, probably of a mechanical character, as they can be separated, but only by methods which materially alter one or the other of them.

The formation of the cell wall after the karyokinetic division of the nucleus was described by Strasburger in I882. He held that a transformation of the microsomata or granules of protoplasmic nature into cellulose takes place immediately after their formation in to a plate across the centre of the spindle. This view was clearly only a tentative one, for it did not take into account the phenomena of the separation of the cells of tissues under the action of reagents. The method of maceration in strong oxidizing liquids associated with the name of E. Schulze is applicable to the very young cells of growing points as well as to the older tissues. Mangin held that there is first formed a layer of pectates, upon the surfaces of which laminae of a mixture of cellulosic and pectosic substances are laid down. On this view Strasburger's microsomata are not protoplasmic but pectosic. The view of their protoplasmic nature was based upon their staining yellow instead of blue with chlor-zinc-iod, a reaction which, however, is consistent with Mangin's suggestion of their composition. Mangin suggested, however, another hypothesis to the effect that the wall, formed originally of cellulosic and pectosic constituents, but known generally as cellulose, undergoes at once on its formation differentiation into three layers, of which the middle consists of soluble pectates. 
The first formation of the cell wall observed to take place over the surface of naked masses of protoplasm was attributed by von Mohl and by Naegeli to a process of secretion by the outer layer. Strasburger's observations appeared to be at variance with this view, for he interpreted them to mean the conversion of protoplasm into cell-wall substance. It was not till I 898 that the two theories were reconciled, when he formed the opinion that the cell plate first formed from the microsomata splits into two laminae, between which the true cell wall appears as a secretion product.

The chemical character of the cell wall was studied by many workers after the appearance of Mangin's memoirs. Tollens investigated the pectosic compounds in I895 in connexion with his work on the carbohydrates in general, and determined many points of their relationship with different kinds of sugar. E. Schulze in the previous year greatly extended our knowledge of the celluloses.

The varied character of the cell wall was pointed out by De Bary in I884, when he showed that the membranes of fungi do not give a blue coloration with iodine and sulphuric acid. This so-called fungus-cellulose was proved to consist very largely of chitin by Van Wisselingh in I 898 , a discovery led up to by the observations about four years earlier of Winterstein, Gilson, and other writers, that chitin and cellulose are associated in various animals, while cellulose itself is present in the Tunicata. Van Wisselingh proved the presence of chitin in the cell walls of several species of fungi by heating to $160^{\circ} \mathrm{C}$. in concentrated caustic potash solution for two hours, material that had been preserved in alcohol, and subsequently washing it with strong spirit and staining it with iodine and sulphuric acid. Chitin under such treatment becomes pink, whereas cellulose turns blue.

The laws governing cell divisions and the formation of 
the new cell walls were first investigated by Hofmeister in I867, but received a fuller explanation from Sachs in 1878 . He showed that the new wall is always produced at right angles to the side walls of the dividing cell and distinguished between the periclinal and the anticlinal membranes, the former term being applied to those which arise so as to be parallel with the external surface of the mass of tissue or growing-point, and the latter to those at right angles to the former. The sequence of formation was worked out more completely in $\mathbf{1} 886$ by Errera and by Berthold. They showed that in the majority of cases the process of construction is such that the new walls exhibit the minimum of surface possible. 


\section{CHAPTER II}

\section{THE DIFFERENTIATION OF THE TISSUES}

THE grouping of cells to constitute tissues, and the recognition that the tissues in turn are grouped or associated in various ways to constitute tissue systems, occupied the attention of many anatomists after 1860 . We have seen that just at that time a new impetus had been given to the study, and its main direction materially influenced, if not altogether changed, by the new point of view traceable to the idea of adaptation to environment. In the absence of such an idea morphological conceptions only had prevailed, and they were of but recent introduction. Unger's classification of I855, good as it was for the time, was almost empirical, and Naegeli was really the first to treat the subject on a scientific basis. In his writings we find Morphology taken definitely as underlying and supplying the principles of classification. Promulgated as it was in 1858 , it may be taken to open the period now under review.

A work of a very important nature was published by Sanio in I863. To many present-day readers the name of Sanio is chiefly connected with the discovery of his ' thickening ring '. This, however, constituted but a small part of the work now before us. His treatise was the first to put forward a proper conception of the only partially understood process of the secondary thickening of the axis of the Dicotyledons and Conifers. Sanio showed that it contains a central core surrounded by a circumferential zone, though the delimitation between them varies a good deal in distinctiveness. In the region outside the central core 
he observed a circular band traceable up to near the actual growing point, and found that in the inner portion of this belt the structures originate which ultimately lead to the development of the bulk of the axis. This intermediate zone constitutes the thickening ring spoken of, the structures arising in it being the vascular bundles. Thus he distinguished, what had till then been obscure or not appreciated, that the true cambium is not identical with the zone of origin of the primary bundles; so he made possible the correct view of secondary formations. He showed how the cambium itself is formed later in and between the vascular bundles, and how it produces the secondary layers of both wood and bast.

Sanio made a very thorough investigation into the comparative anatomy of the stems of the groups alluded to, studying the various elements of the wood and their relative distribution. He also inquired into the seat of origin of the foliar structures and the relation of their bundles to those of the axis. He found them to originate in the zone overlying the true thickening ring.

Very little further progress was made for several years, but an effort to place the subject on a satisfactory basis gave us Hanstein's scheme of I868. His proposals were based on the recognition of definite and well-recognizable generative or histogenetic layers of cells in the growing part of the axis in both stem and root of the Angiospermous plants. He claimed to find three such layers alike in the embryo and the axial growing points. These regions were traceable further along the axis in most cases, and gradually led to areas which were characterized by very complete differentiation from each other. He put forward the view that in the meristem also these regions are differentiated and constitute a system consisting of three definite areas, often only one cell in depth, each independent of the others, and giving rise to a par- 
ticular system of tissue. They constitute in fact histogenetic layers, comparable to the germinal layers of the animal embryo. Hanstein named them dermatogen, periblem, and plerome.

This hypothesis proved of considerable value in exciting research. It possesses for us still a great scientific interest, showing us that even then the idea of a single plan of development throughout living organisms was welcomed among biologists.

We find that much of the anatomical work of the next ten years was based upon Hanstein's hypothesis, and many memoirs were published supporting and extending his views. The most important contribution to them was made by Janczewski in I874; it was especially noteworthy, as besides confirming Hanstein on the general distribution of histogenetic layers, he gave descriptions of several variations of their arrangement in the root, which enabled him to classify them, or to arrange them in four differently differentiated groups, as under :-

I. The three layers quite distinct, with the addition of a fourth giving rise to the tissue of the root-cap. This layer, covering the dermatogen and soon disappearing, Janczewski was the first to observe; he termed it the calyptrogen. This complete differentiation is found to exist in only two aquatic Monocotyledons, Hydrocharis and Pistia.

2. Dermatogen and periblem arising from a common group of merismatic cells, only one layer of cells thick. The plerome and the calyptrogen layer quite distinct. This type is the commonest type in the Monocotyledons.

3. Plerome and periblem sharply defined, but a common initial layer for dermatogen and root-cap. The periblem in some cases one cell, in others two cells in depth. This is the prevalent type among the Dicotyledons.

4. A common merismatic zone extending over the apex, 
but not showing differentiation into layers. This is only found in certain Cucurbitaceae and Leguminosae.

Treub published the results of some researches on the same subject in 1876 . He agreed in many points with Janczewski, but found that the second type does not prevail so widely as the latter thought. He accordingly divided the group into two, the latter of them having a well-defined plerome, covered by a group of meristem two layers thick, from which the root-cap, dermatogen, and periblem take their origin.

In I875 Famintzin affirmed that the different adult tissues of the plant are universally derived from definite histogenetic layers; he held the latter to be separated even in the embryo and to develop independently like the germinal layers of the animal body. Fundamentally his histogens were the same as Hanstein's.

Researches generally confirmatory of those of Janczewski were conducted by Eriksson in 1878 , Flahault in 1878 , and Olivier in I88I.

These views obtained general acceptance for several years. Van Tieghem and Douliot, who brought forward a further development of Hanstein's fundamental idea a few years later, adhered to the theory of the histogenetic layers in the root as late as I889. A year later Douliot found in the stems of Dicotyledons in general the three layers of Hanstein, but in those of Monocotyledons only a dermatogen distinct from a common initial group giving rise to both periblem and plerome.

The second and third types of Janczewski, said to be characteristic of the roots of Monocotyledons and Dicotyledons respectively, were interpreted differently by Van Tieghem in I8gI. He held that the outer layer, which he called the epiblema, is the outer layer of the periblem in the former, and that no dermatogen exists there; but that in Dicotyledons it is the result of the tangential 
division of the dermatogen, the inner layer resulting therefrom giving rise to it, while the outer forms the root-cap. He gave up the calyptrogen as a definite histogen.

Passing from these higher plants, it was pointed out by Strasburger in 1872 that the differentiation of the meristem at the growing-point of the root of the Gymnosperms differs in several important particulars from the types then known in the Angiosperms. There is a distinct and well-defined plerome-cylinder showing a small initial group of cells at its apex, and surrounding it a kind of mantle, consisting of many approximately regular and concentric layers of cells, each layer being quite continuous round the apex and having apparently its own group of initial cells, which divide only by radial or anticlinal walls. No layer of dermatogen or calyptrogen is differentiated, and the root-cap consists of only the more loosely arranged cells of the outer part of the periblem.

The meristem at the apex of the stem in this group varies a good deal. In the Araucarieae the three layers are traceable to the apex; in the Abietineae and in Cycas the meristem is not differentiated so far up, a common initial group at the apex separating into three layers some distance further down. Strasburger was able to trace these two types elsewhere in the Gymnosperms, but with no particular regularity. He also confirmed Cramer's conclusions as to the similarity of structure of the Gymnosperms and the Lycopodiaceae as far as the apical meristem is concerned.

The theory of differentiated histogens corresponding to germinal layers was subjected to severe criticism by De Bary in 1877 . He said : ${ }^{1}$

'To the question whether in all cases only definite zones of meristem give rise to definite sorts of tissue, the most

1 Comparative Anatomy of the Phanerogams and Ferns, Eng. ed., p. 22 . 
general answer according to our present knowledge is a distinct negative. To be sure this negative does not hold for all single cases. For instance, for the large majority of roots, not only does each of the layers of meristem correspond to a definite section of a definite system of tissue, but even the separate parts of each of these sections may often be traced back to its separate initial cells in the apical meristem. . . But even in roots exceptions occur. The epidermis, for instance, in the Gymnosperms does not originate from a distinct dermatogen layer. . . The negative of the constant genesis of definite sorts of systems of tissue from definite zones of primary meristem holds to a much greater extent in leaf-forming shoots. Here also it is true there are such relations. The system of vascular bundles of many stems of Phanerogams, for instance, is derived exclusively from the plerome cylinder. But exactly the opposite also occurs. . . And the whole of the tissues and tissue-systems of the leaves, which are continuous with the similar and synonymous tissues of the plerome of the stem are formed, according to the data in hand, outside the plerome, being derived, as is the whole leaf, from the periblem and dermatogen, or from the layers of meristem corresponding in position to these.'

Proceeding to discuss Famintzin's position, then only recently published, we find him saying: 1

' On the share taken by the dermatogen in the development of tissue, there can be no two opinions; the main question is, therefore, whether the system of vascular bundles arises universally, i. e. in the whole plant, from the same primary layer of meristem. If we ignore isolated cases of controversy, the plerome or a certain region of it is in stem or root the initial part for the system of vascular bundles, or for the greater part of them. The question, therefore, is whether the parts of the system of vascular bundles, which pass from the stem system into the leaves, and which belong to the latter, also arise from the plerome at the apex of the stem. This could not be otherwise effected than by outgrowths of the plerome pushing between the other layers of the young forming leaf, and growing

1 loc. cit., p. 23 . 
with these. ... Other investigators do not find this ; they rather say that the vascular bundles in the leaf, like the other inner parts of it, are derived from the primary periblem, since definite bands of the latter show the corresponding differentiation; and that they are connected with the system of the stem by reason of the relative position of the said bands of periblem. Famintzin's researches certainly afford valuable conclusions on certain processes, but no new result on the main question. When he proves that in foliage leaves, especially in the Papilionaceae, the parts of the vascular bundle always arise from quite definite layers of the meristem, he says nothing new; for as the mature vascular bundles in the leaf have a definite position this must hold also for their younger stages. He does not produce proof that these bundle-forming layers arise as branches from the plerome layer in question of the stem, and push themselves among the other tissues of the leaf, and this proof he should have brought in order to establish his view; he communicates, rather, observations which lead to the contrary result. He asserts that the leaf of the Papilionaceae mentioned, e. g. species of Trifolium at a certain age, consists of five layers of meristem; the outermost is dermatogen or epidermis; of the four inner, only the two innermost are points of origin of the vascular bundles. $\mathrm{He}$ further asserts that in an earlier stage, within the dermatogen lies only one layer of meristem cells-which, according to our preceding statement, must be derived from the periblem of the punctum vegetationis; and that the four later layers arise from division of the cells of that one. It is clear that thereby the postulated pushing in is excluded, and on this the theory of germinal layers must be founded.'

A somewhat different scheme of classifying the tissues of the growing-point was proposed by Russow in 1872 . He recognized Sanio's thickening ring, which he called Mesistem, and which he associated with the young cortex termed by him Peristem, to form a layer of tissue surrounding the young pith. He spoke of the latter as Endistem, while he applied the term Existem to the mass of the other two layers lying externally to it. This classification 
described areas of relative importance quite different from Hanstein's. It ignored the plerome as a definite structure, and raised the pith to an altogether fictitious value when its subsequent fate is taken into account.

The structure of the apex of the stem in the Gymnosperms was investigated in 1890 by Douliot, who adopted the view that they possess an apical cell, like most Pteridophytes. A memoir appeared in I89I from the pen of Ludwig Koch, who differed from Douliot entirely on this point. $\mathrm{He}$ declined to support the view of histogenetic layers, finding that even the dermatogen is not constantly distinct in Gymnosperms, the outermost apical layer undergoing periclinal divisions and thus contributing to cortex as well as to epidermis. Nor did he find a distinct initial group for the adult central cylinder; on the contrary, he found that from the meristem of the apparent plerome only the pith is derived, the bundles springing from the intermediate meristem.

Koch returned to the subject in 1893 , when he contributed a memoir dealing with the Angiosperms, which was the most important that had appeared since the theory of Hanstein had been promulgated. He took the line of making a continuous study of a single plant at the successive stages of its development, and obtained new light upon many points of structure. One of the most important of these was the discovery that the histogenetic layers vary in depth at different stages of growth. Taking a Lilac stem, he saw that a single layer of periblem is present during the formation of an internode; but that for a node with its pair of leaves this is insufficient. At such a time of formation the periblen meristem becomes three or four layers of cells deep, and it is not always easy to see the line of demarcation from the plerome. These two conditions continually alternate as the growth of the stem proceeds, showing that the apparent periblem layers are not per- 
manently distinct as histogens. The same layer at one time gives rise to cortex, and at another to the outer region of the plerome. His general conclusions were that the embryonic or merismatic tissue of the apex grows as a whole, and that Hanstein's histogenetic layers have no constant existence.

The writers preceding our period established the fact that in the plants we now know as Bryophyta and Pteridophyta, the meristem is very generally, though not always, dependent on the existence and regular segmentation of an apical cell. The details of the manner and order of the segmentation and of the growth of the apical cell were carefully investigated in $\mathrm{I} 867$ by Naegeli and Leitgeb. Still earlier Hofmeister showed that the segments of the apical cell of the stems of Ferns undergo directly many and repeated divisions, both in directions parallel to the principal walls, and in the radial and tangential planes. By these the growing meristem is cut up into many layers and rows of cells, which are arranged similarly to the segments, but in which the boundaries of the separate segments can be traced only with difficulty. A permanent layer of dermatogen becomes clear only after numerous tangential divisions, and in no case is there a sharp boundary between periblem and plerome.

De Bary pointed out in 1877 that the divisions of the segments come to form masses of meristem consisting of several or many cells, and that the first products of their division form common initial cells for the future layers of meristem, which correspond in their arrangement to dermatogen, periblem, and plerome of the Angiosperms. These layers become defined particularly by tangential divisions, which cut off concentric strata parallel to the surface, and after becoming recognizable undergo a similar development in many cases to that of the similar layers of corresponding members of the Angiosperms. 
The recognition of these layers as histogenetic was opposed by many botanists later in the century, though it received a certain support from Van Tieghem. The weakness of the position was pointed out by Scott in I894 in the following passage :-

' The question is whether the early division walls of the segments mark out the boundaries between the principal systems of tissue. Certainly the mere order of succession of the walls has no constancy. Thus, according to Van Tieghem, while in most Ferns the first tangential septum marks the limits between inner and outer cortex, and the second defines the central cylinder, in Osmunda and Todea the order is reversed. In the former case endodermis and pericycle are more nearly related to each other than are the two layers of the cortex. From this and numerous similar instances it is evident that the order of appearance of the cell walls does not correspond with the relative importance of the subsequent differentiation. In a monostelic stem (e.g. a stolon of Nephrolepis) the first tangential wall corresponds to the outer limit of the central cylinder. In polystelic stems of other Ferns the same wall marks the outer limit of the ring of steles, but here a great part of the tissue to the inside of this wall forms part of the cortex, according to Van Tieghem's use of the term. It is evident that in this case the cortical tissue between the steles is of common origin with the steles themselves, yet the distinction between these regions is, according to Van Tieghem, the most fundamental in anatomy. It may seem trivial to dwell on such minutiae of development, but we must remember that in other cases the most important morphological distinctions have been based on equally slight differences of origin. Thus in the development of the root, the piliferous layer arises in nearly all Dicotyledons from the outermost part of the meristem, and is thus of common origin with the root-cap, while in the Monocotyledons generally, the piliferous layer is derived from the middle meristematic group and is thus of common origin with the cortex. . . We may safely conclude that with the solitary exception of the origin of the root-cap, the first tangential cell walls do not constantly mark out the main histogenetic 
layers from which the principal system of tissues is derived. Such layers arise in different ways in different cases, and at various distances from the apex.' 1

We have discussed Hanstein's proposals at some length on account of the fundamental importance claimed by the scheme he promulgated. It was not a mere classification of tissues but an attempt to give a complete and scientific account of the underlying principles of development. In this respect it had much in common with another hypothesis promulgated later by Van Tieghem, to which considerable attention must be devoted. Before, however, these new views obtained currency, the not very satisfactory nature of Hanstein's position led to the proposal to classify the tissues on another basis, which, if not so scientific, would enable adequate descriptions of their structure to be given. The most noteworthy of such descriptive systems was that put forward by Sachs in the Lehrbuch. It had, however, a distinctly scientific foundation, though of a different character from that of Hanstein. Whereas the latter was mainly ontogenetic, Sachs' classification was chiefly physiological, being based on the function of the different tissues. He distinguished epidermal, fibrovascular, and fundamental tissues, all being derived from a uniform primary tissue or meristem at the apex; the epidermal included the protective layers which bounded the internal mass, the second the conducting strands, while the third formed the remainder of the structure, through which the conducting tissues pass, and which supports them and aids in maintaining their individuality or independence. The epidermal tissues thus comprised more than the epidermis of Hanstein, which was the adult condition of the dermatogen, extending backwards from the growingpoint. They included also the secondary formations making their appearance below the epidermis proper as growth and

1 Science Progress, I 894, p. 473. 
Chap. II

development proceed, viz. the periderms, cork layers with their phellogens, together with so much of the interior as becomes separated from the rest by these corky formations, and with the latter constitute the bark.

Somewhat strangely, the modifications of the parenchyma immediately underlying the external layer, grouped by Sachs under the general term hypoderma, were not included by him in the epidermal system, though they are the seat of origin of the corky layers. We find consequently the strange anomaly that the cells of this region were held to belong at different times of their life to two different systems of tissue.

The fibro-vascular bundles formed a system of their own ; he treated them rather as a number of independent strands than as constituting a uniform tissue system.

Of the fundamental tissue he said :

' The whole course of my description of tissue systems necessitates the introduction of the idea of a fundamental tissue. It has in fact long been required; it was often necessary in anatomical descriptions of tissues which are neither epidermal nor fibro-vascular, to distinguish them by some common term. . . E Epidermal tissue, fibrovascular bundles, and fundamental tissue are conceptions of equal value; in each we find the most various forms of cells ; and secondary meristem may also arise in each.'

The difference between this conception and Hanstein's becomes very strikingly apparent when we find Sachs including in the fundamental tissue of the stem not only the cortex, the adult periblem, but the pith and the medullary rays, both arising from the plerome. In roots, the supporting or conjunctive tissue between the strands of wood and bast, which must correspond in function with the medullary rays so far as it serves to isolate the bundles, was held by him to belong to the fibro-vascular system. 'If the fibro-vascular bundles of an organ form a solid axial 
cylinder, as occurs in some stems and in all roots, the fundamental tissue takes the form of cortex only.'

Sachs criticized Hanstein's theory of the cortex, saying the layer is ' altogether indefinite and indefinable-we speak e. g. of cortex in Thallophytes in quite a different sense to what we do in Vascular plants ; the cortex of Monocotyledons is something different from that of Conifers and Dicotyledons; in the latter the cortex has quite a different signification in young and in older parts of stems.'

The physiological bent of Sachs' mind showed itself further in the subdivision of his several tissue systems. Among others he recognized succulent tissue, "the cells of which during the life of the organ remain filled with the chemical products of the vital activity of the plant'; laticiferous tissue, glandular tissue, \&c., each division being based on function.

Sachs' scheme met with very strong criticism from the pure anatomists. De Bary wrote of it as follows :-

' Sachs, in the exposition of the anatomy of the higher plants, starts from the definition of three systems of tissue, which he terms Dermal, Fascicular, and Fundamental tissue. Under the first term he includes those tissue-forms which limit externally such plants as have their cells aggregated in three dimensions of space, as a matter of fact Epidermis and Periderm. His Fascicular tissue corresponds in the main to the vascular system. The name Fundamental tissue includes what remains after the separation of the other two. However much this distinction may be fitted to guide beginners, still, in my opinion, it does not answer its purpose, which is to serve as a basis for a uniform exposition of the various differentiations of plant tissues. For the names Dermal and Fascicular tissue indicate in vascular plants systems of tissue which are positively characterized by definite tissue-forms; but the name Fundamental tissue implies the remainder, and this may just as much consist of different positively characterized tissueforms and tissue systems, which are equivalent to the dermal and fascicular systems. But if it is necessary, in the 
description of the dermal and fascicular systems to make use of a short general term for the tissues over and above these, the terms Fundamental tissue, or Fundamental mass, or Intercalary mass, are very suitable; just as in Naegeli's treatise on the vascular bundles, or fibro-vascular masses, was his distinction of these from the rest ("Proten ') or as was Schwendener's general term for the parts of the vascular bundle, which in his exposition of the mechanical adaptation, did not bear upon his point. And indeed in describing a form or system of whatever rank, some such method must always be used. I think, however, that the distinction of the forms of tissue must first serve as a foundation for the uniform exposition of the subject which now engages us, and for the choice of terms; then only should follow the investigation how far these forms of tissue take part in the formation of combinations, and systems of higher rank' (loc. cit. p. 6).

De Bary differed fundamentally from Sachs as to the basis of a classification of the tissues, claiming that the latter should be founded on grounds derived from the history of development. He had consequently a distinct leaning to the hypothesis of Hanstein, though he admitted, as we have seen, that it cannot be rigidly applied.

De Bary's great treatise similarly was disappointing as an effort in the direction of grouping the tissues in a natural manner, or of dealing in a comprehensive manner with their morphology. Its great merits were twofold; it gathered together an enormous mass of detail and presented it in orderly sequence to his readers, and it evinced to a wonderful degree the critical acumen of his mind, brought to bear upon many of the problems of development. But to the reader who sought to obtain a coherent and logical conception of general structure, it was far from satisfactory, and succeeded in bewildering him with multiplicity of detail rather than in giving him what he sought. Anything like a satisfactory conception of general anatomy was not forthcoming till Van Tieghem promul- 
gated the stele theory some years later. This claimed to supply something which was entirely absent from De Bary's position, viz. the recognition of a fundamenta unity of plan in the structure of the axis as a whole. De Bary presented the conception of the root-part of the axis with a single large bundle in its centre, sinuous in outline, with a number of projecting points of origin of differentiation of its wood, while an equal number of strands of bast occupied the spaces between them. There was thus a solid core of wood with a number of strands of bast lying along indentations or sinuosities of its periphery. This was called a radial bundle. A totally different plan of construction was recognized in the stem in the shape of a number of conjoint bundles of wood and bast placed separately in the stem in the form of a hollow cylinder.

De Bary recognized that the central cylinder of the root is encircled by a particular limiting layer of special construction, which he called the endodermis, a name previously applied by Oudemans to a particular case. He recognized this layer also in such stems as possess an axial vascular cylinder.

Though these views might represent the structural appearances exhibited by sections, they did not convey the idea that the stem had anything in common with the root as far as the plan of its construction was concerned. Herein lay the weakness of De Bary's presentation of the subject.

The first successful attempt to form a coherent scheme of the anatomy of the axis of vascular plants was made by Van Tieghem in 1870 and the following years. He published first a sketch of the internal structure of the root, and showed that its vascular tissue forms a central cylinder, containing near its periphery strands of phloem which are arranged round the zone alternately with strands of xylem, the whole being united together by conjunctive tissue. The xylem strands meet in the centre when they 
are relatively few in number; when they are more numerous there is left a central pith which becomes lignified. A certain amount of conjunctive tissue surrounds this central vascular core, forming a pericycle. The central mass corresponds to De Bary's radial bundle, and the pericycle is the pericambium of the older writers, especially Naegeli and Leitgeb. This central core, delimited by the layer which later on he termed the pericycle, and abutting on the endodermis, he called the stele. The surrounding tissues Van Tieghem recognized as a distinct cortex, with an external piliferous layer which is not always a morphologically distinct epidermis.

In I872 Van Tieghem postulated a similar plan of construction of the stem, claiming for it a central core delimited by a layer corresponding to the endodermis and clothed like that of the root by a pericycle, which, however, shows certain differences in the two regions. He laid great stress on the point that, alike in stem and root, the fundamental structure is a central cylinder and a circumferential cortex, bounded on the exterior by an epidermis or a layer corresponding to it, and delimited on the side next the stele by a definite endodermis. He admitted, however, that exceptions to this typical structure occur.

In the stem Van Tieghem recognized a differentiation of the stele into conjunctive parenchyma and vascular tissue, the former constituting a central pith from which strands pass radially to the pericycle and separate the vascular tissue into distinct bundles. The parenchyma of the pith, the pericycle, and these medullary rays is of a different morphological origin from that of the cortex.

The delimitation of the tissues in the stem is not so obvious as in the root, on account of the connexions with the vascular system of the leaf, which cause considerable interference with the continuity of the tissues at the nodes. Moreover, the definition of the stele is less accurately made. 
owing to variations in the development of the endodermis and the pericycle.

Exceptions to this suggested typical structure were the subject of further investigations carried out by Van Tieghem and Douliot, which were published in I886. In the first case, in certain medullated axes they said the endodermis and pericycle sometimes bend in between the bundles, separating them completely from one another and becoming broken into segments, which fuse in front of the bundles, completely isolating them. The monostele is in this way broken up into as many pieces as there are bundles, and the parenchyma of the pith appears to be indistinguishable from that of the cortex. The appearance presented is that of a number of steles immersed in and supported by a mass of conjunctive tissue. The outlines of a central cylinder, though an interrupted one, can still be distinguished. Van Tieghem spoke of this condition as Astely. In another type of structure, seen in certain species of Equisetum, these separate steles subsequently fuse laterally, the endodermis and pericycle disappearing between them but forming a continuous ring both within and without the circle which the steles now form. This condition he named Gamostely.

In stems of the genus Auricula another type is found. The cylinder or stele of the hypocotyl is seen to bifurcate, sometimes more than once, giving rise to two or more strands each like the original one. This condition, known as Polystely or Dialystely, is represented also in the Ferns, which were investigated by Leclerc du Sablon in I89o; he showed the structure commonly associated with their stems to be due to the splitting of an original monostele in the hypocotyl, whereby several distinct cylinders are formed.

Van Tieghem included the dialystelic and the gamostelic conditions together under the term Polystely. He recognized, therefore, three main types, the monostelic, astelic, 
and polystelic forms. Where the lateral fusion of the conjunctive tissue round the bundles in the gamostelic type is complete, he spoke of them as gamodesmic.

In I89o Van Tieghem extended his astelic type to include. Equisetum and Ophioglossum, regarding the apparent monostelic condition of some species of the former as deceptive, owing to the differentiation of the cells of the inner endodermis being so slight that the layer has become unrecognizable histologically.

Strasburger discussed Van Tieghem's position in $189 \mathrm{r}$ and showed that on the whole he agreed with his conception. He suggested that as the astelic condition arises from the separation of the bundles of an original monostele, the term schizostely would be a preferable term to designate it. As the endodermis shows so much variety in histological appearance, he proposed the name phleoterma as a substitute for the older name.

Van Tieghem proposed the term meristele for such branches of the stele as can be traced into the petiole. He claimed that they are derived from part only of the stele of the stem. Strasburger suggested schizostele again as preferable to indicate this relationship. He denied that they could appropriately be called monosteles, on the ground that their pith is continuous with the cortical parenchyma of the axis.

In 1893 an important paper was published by Flot, which had a bearing upon the differentiation of the monostele and the nature of gamostely. He investigated a large number of plants, principally Dicotyledons, and claimed to have discovered in them all a special 'perimedullary' zone separating the vascular bundles from the pith, and corresponding in the main to the pericycle on their other side. This zone he found to correspond with the central cylinder in the way in which the divisions of its cells took place, and to differ radically from the pith in this particular. Tracing it upwards to the apex, he found 
that he could distinguish in the meristem of the plerome an outer part giving rise to the vascular bundles, and having the limiting layer on each surface, and an inner part from which the pith alone originated. The association of the perimedullary zone with the bundles was seen in its being visible on the inner side of each bundle when they were separated by wide medullary rays but not being traceable across the latter. It must correspond, therefore, with pericycle and not with endodermis. Flot said, moreover, that it forms the seat of the internal phloem groups or strands characteristic of the Cucurbitaceae and other Natural Orders.

Towards the close of the century the stele theory was minutely studied by Jeffrey in America. In the main, Van Tieghem's results were confirmed by his investigations, but several modifications were proposed on the basis of extended observations.

Jeffrey, who published his results in 1897 and the five or six years which followed, carried his researches throughout the main divisions of vascular plants, and was thereby enabled to generalize. His objections to Van Tieghem's position were stated by himself as follows :-

' The polystelic type of Van Tieghem is not characterized by the repeated bifurcation of the epicotyledonary stele, but there is primitively in the young stem of this type a tubular concentric stele with foliar gaps subtending the points of exit of the leaf-traces. The astelic type of Van Tieghem does not result from the separation of the constituent epicotyledonary stele into its constituent bundles, for in the young so-called astelic axis there are no bundles present at all, but a collateral stelar tube with foliar gaps subtending the leaf traces, through which the internal and external phloeotermal sheaths communicate. The medullated monostelic type of Van Tieghem does not originate, as he states, by the dilatation of the epicotyledonary stele' and the formation of an intrastelar pith, for in favourable cases the so-called medullated monostelic central cylinder 
of the older stem may be seen to be derived from the so-called astelic condition of the young axis by the degeneration of the internal phloeoterma.

'Van Tieghem's three types of central cylinder indicated above are all modifications of a single type, which has been designated by the writer siphonostelic. In this type the central cylinder is primitively a fibro-vascular tube with foliar lacunae opposite the point of exit of the leaftraces. In the so-called polystelic modification the central cylinder has internal as well as external phloem; in the astelic type of axis the internal phloem is absent. The medullated monostelic type of Van Tieghem is derived from the last-named by the degeneration of the internal phloeoterma, or endodermis.

'The siphonostelic type of central cylinder as defined above is probably to be regarded as the result of the mechanical strengthening of the cauline axis to enable it to support the palingenetically large leaves which are characteristic of the Angiospermae, Gymnospermae, and Filicales. In these three groups the siphonostelic fibrovascular cylinder is invariably distinguished by the presence of gaps corresponding to the points of exit of the leaftraces, and in this feature offers a marked contrast to the tubular central cylinder of the Lycopodiales and Equisetales, in which there are no foliar lacunae, but, on the contrary, gaps subtending the branches.' 1

Jeffrey's own conclusions were that vascular plants show two types of cauline central cylinder, protostelic and siphonostelic, of which the former, held by him to be the most primitive, is concentric and without any central medulla. The second type is tubular, the vascular tissue surrounding a pith. The continuity of the tube is interrupted by foliar and ramal gaps, or by the latter only. By the large size of the foliar gaps and their consequent overlapping, the tubular structure may cease to be very obvious in the adult. It is primitively concentric, but in the Phanero-

1 Jeffrey, 'Morphology of the Central Cylinder in the Angiosperms,' Trans. Canad. Inst., vol. vi (1900). 
gams and some other cases it has become collateral by reduction. The pith is to be regarded as an enclosed portion of the fundamental tissue.

Jeffrey used the terms phyllosiphonic and cladosiphonic to indicate the tubular steles with foliar and ramal gaps respectively.

The question of the secondary thickening of the stele does not properly belong to the period under discussion, but there are certain features which call for recognition. The phenomena of the normal cambial activity in both stem and root were known much earlier, and the construction of the annual rings of wood had been observed and studied by many writers before I860. During the years I860-I900, however, many suggestions were made with a view to explaining the different sizes of the cells at the beginning and the closing of the annual thickening period. In the Lehrbuch in I 868 Sachs assumed that the smaller diameter of the autumn wood should be attributed to the great increase of internal pressure brought about by the continuous growth of the ring in so confined a space. In I872 De Vries artificially increased this pressure by binding branches in the spring with ligatures of twine, and found that in the succeeding period of growth the cells underlying the ligatures were smaller than those beyond them, - an experiment which was confirmatory of Sachs' view. Ten years later Krabbe opposed the hypothesis, saying that the pressure spoken of has no existence in the normal condition of the tree. In I880 Hartig, and later in I 887 Wieler, attributed the change to the altered conditions of nutrition that accompany the passing of the summer. In I88I Russow suggested that the greater diameter of the spring wood-cells should be attributed to their greater turgidity during development. Wieler, on the other hand, found the turgidity equal in autumn and spring. Haberlandt (I884), Strasburger (I89I), and Hartig (I894) 
all put forward the view that the anatomical differences are due to and regulated by the transpiration current.

The chief anomalies in the thickening of woody trunks had been discovered prior to I860. A few additions were made to our knowledge afterwards. In I864 Sanio discovered the peculiar occurrence, in the stem of Tecoma radicans, of a second cambium ring, situated within the circle of the wood bundles, and found that it produces bast and wood in order exactly contrary to the order of the normal ring.

In I874 Schmitz found in the rhizome of Rheum the occurrence of several partial cambiums, producing again inverted orientation of their products.

The details of the formation of periderms by phellogen were critically investigated by Sanio in I860. To him are due the foundations of our modern knowledge of the histological facts.

It will be seen that different views of the construction of the stele or steles are possible according to the interpretation that is placed upon the endodermis. Herein may be said to lie a certain weakness of the system, for the endodermis is rather a physiological than a morphological structure. True, as originally propounded by De Bary, it was intended to designate the inner boundary of the cortical area. But certain histological features were combined with this topographical limitation, and by many they came to be regarded as more truly characteristic than the latter. When the cases of polystely and astely came to be examined, difficulty arose in distinguishing the limits of a stele which in many cases seemed to be identical with a fibro-vascular bundle, and if diagnosed by the presence of a layer showing these endodermal histological features, was sometimes represented by nothing more than a mere strand of parenchyma, as shown by Pfitzer in certain species of Equisetum.

The possession of these particular thickenings by the 
walls of its cells seems to mark out the endodermis as especially a physiological layer, the function of which indeed can be readily interpreted in the light of such structure. It seems, however, as if the interpretation of similar structure, seen in layers or sheaths, whose morphological position is not definitely determined from other relationships, should have been made on the lines of adaptation to function rather than on a forced morphological conception. The presence of a sheath with the characteristic marking in the cell walls, delimiting a certain strand of tissue, may well be taken to show that a certain need in connexion with supply or transport of water is its explanation rather than that an interpretation of it must be forthcoming which shall satisfy a demand to associate it with a particular morphological conception, and to bring it into line with an original differentiation into particular systems of tissue.

The pericycle, the layer clothing the stele on the exterior, was shown by many authors to be more constant. This again may be due in a measure to the nature of its functions, which are more definitely associated with the work and relationships of the stele as a whole. Those of the pericycle of the root are mainly three; the development of corky or periderm layers for protective purposes, the origination of lateral roots, and the development of a portion of the ring of meristem necessary for the thickening of the roots. Those of the stem pericycle are more varied, but it is difficult to speak of them freely on account of the ill-defined limits of the layer.

This layer was first defined by Naegeli and Leitgeb in I867, if we except certain references to some isolated cases by Sanio in I863. The recognition of merismatic functions associated with it led to its being called pericambium, a name which was applied to it until the researches of Van Tieghem led to the recognition of the stele. It was 
at that time held to be a special feature of the root. One of its functions was described by Van Tieghem in I872, when he spoke of it as 'membrane rhizogène'. The development of the lateral roots from it was described in much detail in I 874 by Janczewski.

The existence of this special layer in the stem was first shown by Falkenberg in 1876 , when he described the 'Aussenscheide ' occurring in the rhizomes of certain Monocotyledons, and claimed that it corresponded to the pericambium in roots. In I 882 Mangin confirmed Falkenberg and showed that adventitious roots arise from the layer he described.

A more complete identification of the pericycle in stems was made by Van Tieghem in I882; he pointed out not only its individuality as a layer, but showed of what variation of extent and of composition it is capable. Two years later, in I884, one of his pupils, Morot, published the results of very comprehensive and painstaking researches upon it, and made the most complete exposition of its individuality that appeared during the century. Its universality as the seat of origination of lateral roots in the Phanerogams was demonstrated by Van Tieghem and Douliot three years later.

Many details of the structure and composition of the vascular bundles marked the period under review, but they were little more than modifications and extensions of what was known still earlier. It is impossible to write of them at length, for though a more complete knowledge of their elements was gradually gained, the process was a slow and continuous one extending over many years. The occurrence of phloem on the axial side of the woody strand was perhaps the most striking discovery of this nature. It was investigated by Vesque (I875), J. E. Weiss (I880), Petersen (I882), Solereder (I885), and Herail (I885), and was shown to occur in three forms, as a constituent part of the bicol- 
lateral bundles, as distinct strands quite isolated from the wood, or as a constituent of conjoint bundles in the pith.

Phloem was also found to occur as definite islets in woody areas or masses.

The connexion of the very different arrangements of the constituents of the stele in stem and root was the subject of an inaugural dissertation at Zurich in 1876 by Goldsmith. They were shown to be brought together in the hypocotyledonary portion of the axis. Gerard published an important memoir on the same subject in I88I. The corresponding relations in Ferns were investigated by Leclerc du Sablon in $\mathrm{I} 890$.

The classification of the tissues upon a morphological basis occupied, as we have seen, the thoughts of botanists during the whole of the last century, and a certain success was achieved during its later years. There was, however, another movement which had its origin mainly among the writers of Germany, which exercised a great influence upon the current of thought not only there but almost universally.

It originated with Schwendener's great treatise on the physical and mechanical principles involved in the disposition of the hard parts of plants, which appeared in 1874. This was a most fascinating work, expounding and explaining the ways in which the hard, woody, and sclerotized parts of the structure are disposed in view of needs caused by enviromment. It gave us for the first time an adequate view of the skeleton of plants and its purpose, without, however, much regard to its phylogeny or ontogeny. This may be regarded as the first advance towards a physiological view of anatomy, which, whether or no it may claim a scientific foundation, must always possess the greatest importance from the biological point of view.

Schwendener's treatise was followed in 1884 by Haber- 
landt's Physiologische Pflanzenanatomie, which, written on similar lines, went much further, and attempted a classification of all the tissues of plants on a physiological basis. Its aim was to show that the whole anatomical structure and mode of arrangement of tissues, comprising not only the entire plant, but the most minute subdivisions of it, are illustrations of adaptation to physiological needs.

He discussed first cells and their modifications and then their combinations into tissues, of which he distinguished the tegumentary, the mechanical, the assimilative, and the conducting systems. In discussing the mechanical arrangements he followed the lines of Schwendener, but carried them further through the vegetable kingdom, showing that such arrangements can be distinguished even in the larger Fungi.

His treatment of the conducting tissues differed greatly from that of the morphologists. He grouped together under the one name the parenchyma of the cortex, pith, and medullary rays, the vascular tissue, and the laticiferous cells and ressels. Dealing in more detail with the vascular bundles, to which he gave the name Mestom, he renamed the xylem Hadrom and the phloem Leptom, and excluded from his conception of them the mechanical sclerenchymatous or fibrous tissue often abutting on them.

Though there is much to be said for such an arrangement as this when looked at from the physiological point of view, showing as it does no doubt the meaning and importance of many structural peculiarities as adaptations to environment or as ministering in some way to need, it clearly cannot replace a truly morphological conception. It throws no light on the problems of relationship or descent, for physiological modifications frequently affect very different tissues for identical purposes. Function, bearing a definite relation to environment and serving the plant under a particular condition, perhaps permanent. 
perhaps transitory, may cause different changes in different plants or in the same plant at different ages, or under different conditions. The structure, looked at from that standpoint, may disclose a good deal about the conditions of the past life of the race or of the individual, but it is not likely to illustrate, still less to explain, questions of phylogeny and affinity. The latter questions deal with fundamental, the former with fluctuating problems, and the greater importance of relationship must be admitted.

The separate contributions made by authors to the general subject of anatomy were far too numerous even for mention here. The study was so general and so widespread, that communications of greater or less importance were of almost daily occurrence. We cannot, therefore, do more than briefly allude to the more prominent lines of work.

The structure of the vessels of the wood and the nature of the pitting which characterizes them, were the subjects of research by Caspary in I862. He attempted to trace the connexion between the true vessel and the tracheid, but his conclusions were not sound. He denied the existence of vessels altogether in the Pteridophyta and in many Phanerogams. Dippel was more successful in I865; in his memoir he showed how gradual is the passage from one form to the other. His account of pitting was not quite so satisfactory, as he considered the bordered pits to have no pit-closing membrane, a point on which he was at issue with the discoveries of Hartig some years earlier, and with Schacht's work of 1859 . The question was finally settled by the researches of Sachs in 1879 and of Mikosch in $\mathrm{I} 88 \mathrm{I}$, in which the development of the bordered pit was traced. Strasburger confirmed this work in his Ban und Wachstum of $\mathrm{I} 882$.

Schenk contributed a valuable research on lianes in I883.

The occurrence of internal phloem in the central cylinder of certain natural orders was demonstrated byVesque in I875. 
His work was followed and amplified by the researches of Petersen in I882, and of J. E. Weiss in I883. Solereder and Herail independently made important contributions to our knowledge of this distribution two years later.

The occurrence of phloem-strands in the midst of the tissue of the secondary wood was demonstrated and their formation traced by Morot and by Herail in I885. Scott and Brebner in I889, working on Strychnos, showed that these islands, as they called them, are formed like normal phloem, centripetally outside the cambium, and subsequently become enclosed in the wood by means of a new cambial arc completing the normal zone and shutting them in.

Beside the work on sieve tubes already alluded to, which had a bearing mainly on the continuity of protoplasm through the sieve plate, certain observations by IVilhelm call for comment. In I 880 he showed that some sieve-tubes traverse the medullary rays and afford horizontal communication across the tissue. Fischer in I 884 discovered in certain plants of the Cucurbitaceae a transitory system of sieve tubes lying externally to the fibro-vascular bundles.

In 1883 Weiss demonstrated the formation of tertiary bundles in the xylem parenchyma of fleshy roots.

The abnormal thickening of the stems of Yucca and other Monocotyledons, by means of a secondary cambium layer, was elucidated by Millardet in I865. In I89I Kny made a contribution to our knowledge of abnormal bundles occurring in the group. In I893 Scott and Brebner investigated the structure of the vessels of Dracaena and their method of elongation by means of sliding growth.

The details of the formation of cork from a merismatic layer or phellogen were first investigated by Sanio in I860. Later work on the part played by cork in the construction of bark was contributed by Von Höhnel in I877. To him we owe the recognition of the part played by the pericycle in the formation of the bark of roots. Stahl first studied 
the structure and development of the lenticels in 1873 . Haberlandt wrote on the same subject in 1875 .

Investigation of the outer region of the cortex in many monocotyledonous roots led Olivier to the recognition of the exodermis as a definite layer in $\mathrm{I} 88 \mathrm{I}$. He found further that some roots of this group have a true external periderm, especially those of the Aroideae and of some of the Liliaceae. This peculiarity he found shared also by many dicotyledonous roots, those of the Ranunculaceae, Gentianaceae, and Primulaceae affording examples.

The recognition of the fact that the epidermis in many cases acts as a reservoir for water was due to Westermaier in r883. Its power of defence by means of stinging hairs was investigated in r 886 by Haberlandt.

The structure and distribution of the laticiferous tissues were studied by Trécul from 1862 onwards. The true laticiferous vessels were first investigated by Hanstein in I864 and by Dippel in I865, while the laticiferous cells were first distinguished from them in 1872 by David. In 1877 the development of the vessels was described by Schmalhausen, and in r882 Treub and Schmidt independently determined the laticiferous cells to be living elements containing protoplasm and nuclei. Scott described the development of the articulated vessels in $\mathbf{I} 882$.

Researches on the co-ordination of structure and function in leaves were conducted by Stahl in I880 and by Pick in r882. The former showed the adaptation of the palisade tissue to high, and that of the spongy mesophyll to low, intensities of light. Pick pointed out further that the length of the palisade cells varies with the intensity of the incident rays, and with the inclination of the long axes of the cells to the direction of the light. In this connexion he showed that there is a different organization of the chlorophyll-containing tissues on the north and the south sides of photosynthetic stems. 
The anatomy of the leaf of the Angiosperms attracted the attention of Hofmeister in I868, Naegeli and Schwendener in I869, and Leitgeb in I87r. The work of Naegeli and Schwendener dealt partly with the distribution of the tissues according to mechanical requirements. Perhaps the most important memoir on the leaf that appeared after I860 was Chatin's work of 1874 . Goebel also wrote upon it in $\mathbf{r} 880$.

Allusion has been made in a previous chapter to the general elucidation of the problems connected with the morphology of the ovule and the seed. Anatomical research on the same subject was not neglected, though Hanstein's types were for many years the only ones studied. In addition to the work of Famintzin and of Guignard in the early eighties, Treub published a valuable contribution to our knowledge of the ovule and the embryo in I882, and described very fully the development of the former in the Loranthaceae. Campbell in I 898 and I 900 described the development of additional monocotyledonous types of embryo, choosing Lilaea and certain members of the Araceae. The work of many writers on the embryo-sac has already been alluded to.

The Gymnosperms as a group were studied by many botanists from the point of view of anatomy as well as that of morphology. Among the workers on the subject perhaps the first place must be given to Strasburger. Reference has already been made to his earlier work of I869 and I872; his great treatise of I8gr, Ueber den Ban und die Verrichtungen der Leitungsbahnen in den Pflanzen, threw light upon many obscure anatomical points, especially of the Conifers, the completeness of the description of which was very remarkable. He showed that all Conifers that have bordered pits on the tangential surfaces of the latestformed autumn wood are destitute of tracheides in their medullary rays, and vice versâ. Also that intercellular 
spaces containing air occur between the elements of the rays, and that the living cells of the latter communicate by pits with these spaces, which in turn are continuous with the intercellular space-system of the cortex with its lenticels, so that the aeration of the internal wood is secured. He also discovered the special albuminous cells of the phloem medullary rays, and showed that both by their structure and behaviour they replace the companion cells of the sieve tubes of the Angiosperms. He pointed out that these cells are to be met with in the leaves, forming an extension of their bundles, just as the transfusion tissue forms a supplementary tissue to the xylem. He found, too, that the sieve tube has no truly perforated sieve plates; the plugs permit the passage of dissolved substances from segment to segment, though they prevent the continuity of the protoplasm.

Strasburger showed in the same treatise that Pinus at any rate possesses two tissue systems, each extending throughout the whole plant, and being perfectly distinct from the other. They constitute, on the one hand, the region of the stele of the stem, and its communications with the central cylinders of the leaves, and on the other, the tissues of the cortex of the whole, which is preeminently an assimilating system.

In the same work Strasburger showed that in their vegetative structure the Gnetaceae approximate rather to the Dicotyledons than to the other Gymnosperms.

Many other writers elucidated to a greater or less degree the anatomical problems of the group. Von Mohl in I87I explained the curious transfusion tissue of the leaves of Conifers, though the elements composing it had been described seven years earlier by Frank. Worsdell investigated the anatomy of the stems of Cycads in I896 and their sporophylls in 1898 , while Scott carried out researches on their peduncles in 1897 . 
The curious plant Welwitschia or Tumboa was described by Hooker in I862, having been found for the first time in 1860 by Welwitsch in South Africa. Its flowers were carefully investigated by $\mathrm{McNab}$ in 1873 . The anatomy and histology of the plant were the subjects of a careful research by Bower in I88I, but its comparative inaccessibility rendered investigation difficult, and little more was learned about it till the appearance of Pearson's researches early in the present century.

The general embryology of the Gnetaceae was investigated by Bower in $\mathrm{I} 882$, but many points remained undetermined at the end of the century.

Other writers on the anatomy of the Gymnosperms were von Mohl, Geyler, Dippel, Rossmann, and especially Van Tieghem, by all of whom substantial contributions were made to knowledge. The paper of Van Tieghem in 1872 on the secretory system of the Conifers is especially noteworthy. The development of the resin ducts was described by Kreuz in 1877 . 


\section{CHAPTER III}

\section{THE STUDY OF THE CRYPTOGAMS}

IT is necessary to give a résumé of the progress of knowledge and research among this group, but here again space forbids more than a sketch. Each year saw an output of memoirs which became increasingly numerous as the end of the century was approached. Naturally they were very unequal in merit, many of them of scarcely more than transitory interest. The chief works on the Algae that appeared may be classed into those which treated of taxonomy and of life-histories, and of those which were more particularly anatomical. Work on all these lines was only the continuation of what had been already in course of publication in earlier years. In the field of taxonomy mention may be made of the continuation of Agardh's Species, genera, et ordines Algarum, commenced by him in I848, which was only completed at the end of the century; Reinke's Atlas deutscher Meeresalgen, commenced in 1889 ; Falkenberg's Die Algen im weitesten Sinne, in Schenk's Handbuch of 1882, and De Toni's Sylloge Algarum, running from 1889. Special floras were Harvey's Phycologia australica (1858-63), Farlow's Marine Algae of New England (I88I), Kjellman's Algae of the Arctic Sea (I883), and Hauck's Meeresalgen in Rabenhorst's Kryptogamenflora (1885).

The principal researches dealing with the life-history of various forms were Areschoug's Observationes phycologicae (1866-75), Agardh's Till Algernes Systematik (I872-99), Bornet and Thuret's Notes algologiques (1876-80) and their Études phycologiques (1878), and later Kuckuck's Beiträge zur Kenntniss der Meeresalgen (I897-9). 
Special researches on the anatomy of the Algae extended over all the principal groups. The commensalism of Nostoc and similar forms with other plants was investigated by Janczewski and by Leitgeb in the case of Anthoceros, and by Reinke in that of Gummera in 1872 . Klebs described other instances of the same phenomenon in I883. Bornet and Flahault wrote on Nostoc in I887, and Gomont investigated Oscillaria in r893. The question of the constitution of the so-called nucleus in the Cyanophyceae was discussed by Zacharias and by Wager in I 890 and succeeding years, and its structure was determined in several cases.

The Diatomaceae were described very fully by Pfitzer in Schenk's Handbuch of I882. The formation of auxospores and chlamydospores in the group was investigated by Schmitz in 1877 and in I884. Other researches were those of O. Müller in I883 and of Deby and Kitton a year earlier.

An important work on the reproductive processes of the brown seaweeds was Berthold's Die geschlechtliche Fortpflanzung der eigentlichen Phaeosporeen of I88I.

Towards the end of the century several of the problems of the fecundation of the Phaeophyceae were solved. Farmer and IVilliams were successful in observing the details of the fusion of the spermatozoid and ovum of Fucus; Williams followed out the growth and development of Dictyota and Taonia in I897, though many of the cytological features did not appear till after I9oo. Janczewski traced the mode of growth of the thallus of several members of the group in I895. Of more purely anatomical research, mention must be made of the discovery of sieve tubes in the larger species by Parker in I88I, Wille in I885, and Oliver in I887.

Among the researches on the Chlorophyceae may be mentioned the work on Chara of Pringsheim in I864 and of De Bary ten years later. Pringsheim discovered the 
pairing of the swarm spores of the Volvocineae in I869. Rostafinski and Woronin studied the life-history and methods of reproduction of Botrydium in I877. Schmitz observed the coalescence of the nuclei in the conjugation of the cells of Spirogyra. Towards the end of the century appeared the remarkable investigations of Klebs on the reproductive processes of the group and their relation to the conditions of their environment. This work appeared in 1896 and attracted at once the attention of all students of vegetable physiology throughout the world. It was undoubtedly one of the most important researches of the century.

The polymorphism which exists among the members of the group was investigated by Chodat in 1897 .

Considerable progress was made in the elucidation of the peculiar reproductive processes of the Rhodophyceae. The most important researches among these Algae were those of Bornet and Thuret from I860 to I870. They investigated the embryology in 1867 and extended our knowledge of the fructification in much detail. Almost equally important contributions in the same field were made by Schmitz, whose work, Untersuchungen über die Befruchtung der Florideen, appeared in I883. Sirodot published an important paper, Les Batrachospermes, in I884. Later in the century, from I895 to I898, Phillips investigated the group Rhodymeniales, particularly dealing with the structure and development of the cystocarps, and in I8g8 Oltmanns materially increased our knowledge of the developmental processes by his memoir, Entwicklungsgeschichte der Florideen.

Two or three very important features were presented in connexion with the study of the Fungi. Of these, by far the most epoch-making was the rise of the science of bacteriology. Originally only a branch of botany, with a bearing indeed upon pathology, it rapidly enlarged its 
sphere, and by the end of the century its botanical side was of far less importance than its pathological relationships. It was then rapidly spreading into the fields of bio-chemistry, and normal as well as abnormal physiology. Its pathological side, however, was developed almost exclusively in relation to the animal kingdom. Very few cases of bacterial infection of plants were known, so that a very large field of inquiry was about to be opened up. The range of study in this direction was, however, a matter for the new century.

Another feature of considerable interest was the appearance of the new classification of the Fungi, put forward by Brefeld and supported by many of the most eminent botanists, particularly von Tafel, who adopted it in his Vergleichende Morphologie der Pilze of 1892 . Brefeld's work extended over many years, his memoirs appearing from I873 to the late eighties, and elucidating the life-history of many forms. The classification differed fundamentally from that of De Bary, for Brefeld held that the higher Fungi are entirely asexual and have descended from the Phycomycetes through the $Z$ ygomycetes ; while the Oomycetes have given origin to no other group. De Bary on the other hand considered that the Oomycetes were the ancestors of the higher forms, the line of descent leaving the $Z$ ygomycetes on one side. Brefeld's views were to a large extent disproved by Harper's work on the sexual fusions in Sphaerotheca in I895. Though received with considerable favour, his classification did not replace that of De Bary.

The discovery of the true nature of the thallus of the Lichens was another contribution made to the knowledge of the Fungi after r86o. Its symbiotic character needs nothing more than mention here, as it has been spoken of more fully in a previous chapter. Certain anatomical details remain to be described a little later.

The investigations of the earlier times into the Fungi 
and the state of knowledge based upon them form the groundwork of De Bary's great work of I866, to which reference has already been made. This was supplemented by its author in 1884 , in a second edition, greatly extended or rewritten, which was the great textbook of our period. Many important memoirs during the period under review extended knowledge of life-histories, brought to light many facts bearing on pleomorphy, and cleared up many problems connected with sexuality and reproduction. So great was the increase of memoirs and other publications that no satisfactory provision for final classification was arrived at, the mass of detail needing careful scrutiny and discussion when the century closed.

Among the numerous contributions to the literature of the subject, some stand out naturally more prominently than others, either by bringing out new life-histories, or by correcting erroneous views of the nature of various processes.

The Myxomycetes were investigated by De Bary and his pupils from I860 to I870, and their processes of fructification ascertained. A few years later Schmitz showed that the union of the amoeboid masses to form the plasmodium is not a species of conjugation as had been long held, for no fusion of their nuclei takes place. Lister was successful in $I 888$ and 1889 in showing that the nuclei divide karyokinetically. Towards the end of the century the question of their real affinity with the animal rather than the vegetable kingdom was a subject of discussion.

The parasitism of many of the Phycomycetes was studied by various workers, and considerable inquiry was made into their sexuality. De Bary concluded that the Saprolegniae at any rate are always parthenogenetic. The cytology of the group was examined by Pfitzer (I872), De Bary and Woronin (I88I), Hartog ( 1887 and I8g6), Rothert (I887), and Trow (1895). In I889 Wager studied the behaviour 
of the nucleus of Peronospora during the formation of its oospore. He investigated the features of nuclear division in Cystopus, and in certain of the Ascomycetes and Hymenomycetes in the years I894-8.

A great deal of interest centred in the Ascomycetes. Tulasne investigated the structure and habit of the Erysipheae in 1860 , and thenceforward carried out researches throughout the whole group, in the course of which he unravelled the curious life-history of Claviceps purpurea, the Ergot. This was also studied by Kühn in 1863. Janczewski described the reproductive processes of Ascobolus in 187 r. Tulasne's earlier work on Penicillium was confirmed and extended in 1873 by Brefeld, who succeeded in producing artificially its sexual fructifications, which he found took the form of sclerotia. The sexual organs were found to agree in all essentials with those of Eurotium described by De Bary. Further investigations into the sexuality of the higher Ascomycetes were carried out by Harper in 1895. His researches on Sphaerotheca showed the fungus to possess antheridia and oogonia, and to exhibit various nuclear fusions of a sexual character.

Stahl's researches on the structure of the Lichens, carried out in 1877, furnished conclusive proof of the truth of Schwendener's theory of their construction, which has already been spoken of. Stahl produced artificially a lichen by cultivating the spores of Endocarpon amongst green cells or gonidia obtained from the same thallus, and he found it bear both perithecia and spermogonia. $\mathrm{H}$ discovered the carpogonia of Collema and some other forms, which he found to be a coiled hyphal filament projecting upwards from some little depth in the thallus. The coils were low down in the latter, and the projecting part was straight. Stahl called them the ascogonium and the trichogyne respectively. He also claimed to have found the spermogonia with their spermatia, and to have noticed 
the dissemination of the latter over the surface of the thallus by means of water. Further, he said that the contents of a spermatium pass into a trichogyne when the two come into contact, fusion of their respective walls soon taking place. Stahl thus brought the fertilization of the lichens into line with the same process in the Rhodophyceae.

The improvement of methods led to more minute investigation of the cytology of the Ascomycetes and the Uredineae during the later years of the century. The researches, quite at its close, of Dangeard in France and of V. H. Blackman in England threw a good deal of light upon the nature of the sexual processes, and the fusion of nuclei of various origins, bringing into question the views of the older writers upon the sexuality of the members of the group, and at any rate suggesting that the problem is of a much more complicated character than had been supposed. The question was left at a very interesting stage when the century closed.

The work of Brefeld included a very careful study of the biology of many of the fungi and the nature of their dependence upon external conditions, together with the effect of the latter upon their pleomorphy and their reproductive processes. This work appeared in I88I. Klebs's treatise of 1896 , though mainly concerned with the Algae, extended Brefeld's researches on their fungal relatives.

The work on the Bryophyta between I860 and I900 included the exhaustive researches of Leitgeb on the Liverworts. These appeared at intervals between I874 and I882, and formed together a masterly exposition of their structure and development. Leitgeb showed himself to be the greatest specialist on the minute structure of the Hepaticae. Other workers on the same group were Strasburger, who investigated Marchantia in I868, KienitzGerloff, I874-5, Fellner, who studied the germination of the spores of Riccia and the structure of its thallus in 
I875, and Leclerc du Sablon, who investigated especially Aneura in 1885 . The formation of the curious air chambers of the Marchantiaceae was first explained by Leitgeb in the course of his work, the paper appearing in 1880 . Naegeli, in the Abstammungslehre, gave an account of the mode of origin of foliar members in the whole group of the Bryophyta. Remarkable work on the cytology of the Liverworts was done by Farmer in I894 and I895. He investigated the phenomena attending nuclear division in several species and discovered the existence of centrospheres and the part they play in the karyokinetic changes.

Leitgeb contributed also to our knowledge of the Mosses. His paper on Sphagnum appeared in I868, and he returned to the study of the group after he had completed his researches on the Liverworts.

Pringsheim and Stahl both conducted investigations on the Mosses in 1876 , studying especially the protonema and its relation to the moss plant. Kienitz-Gerloff worked out the development of the sporogonium in 1878 . Other researches were conducted by Russow (I887), Waldner (I887), and Vaizey (I887-90). The researches of the latter, though partly anatomical, dealt with the physiological problems presented by the group.

We have already noticed how great an impetus to the study of the Vascular Cryptogams or Pteridophyta was given by the work of Hofmeister. During the years that elapsed between the appearance of his great treatise and the close of the century this subject seemed to fascinate investigators more than any other, and innumerable papers appeared elucidating certain points he had left unsolved, or adding to our knowledge of structure and life-history. The gradually increasing mass of detailed information gave rise to speculation and controversy upon affinities and relationships, which are reflected in the taxonomic writings of the time. As years passed and the records of the rocks 
came to be added to the results of the anatomists, theories of descent of greater or less probability were sedulously worked out. It cannot be said, however, that at the end of the century the leading problems had even approximated to a solution, though, as we have seen, certain foundations were held by many to have been laid for the construction of a true phylogenetic tree at no very remote period. The theories, however, from whatever source derived, failed to supply a plausible view of the origin of the Angiosperms.

Of independent work covering the whole field of the recent or existing Pteridophyta, probably the most important was Bower's Studies in the Morphology of Sporeproducing members. This remarkable work extended over the years I8gI to I903, and contained the record of investigations into the formation, development, and structure of the sporangia of all the groups of the Vascular Cryptogams. It was conceived in support of its writer's views on the sporophyte as an intercalated structure in the life-cycle of the plant, a theory which has been examined in a previous chapter. It claimed to trace, or to render probable, the development of the vegetative system of the sporophyte from originally sporogenous tissue, by a system of progressive sterilization, followed by development of the sterilized tissue, so leading to a gradually increasing segregation of sporangia. Whatever view may be taken of the author's theory, it cannot be denied that the work constituted a wonderful piece of anatomical research and led to more accurate views of the structure of sporangia and their relationships than any other research of the period. It may well claim to be mentioned side by side with the researches of Hofmeister.

Of very great importance here, as elsewhere, was Goebel's great research on the comparative development of sporangia in I880 and I88r.

Another investigation of considerable scope, ranging 
indeed over a very large part of the field, but dwelling more particularly on the Ferns, was the research conducted by Poirault, which was published in 1893 . This was from the laboratory of Van Tieghem, and was carried out partly under his influence. It dealt especially with the anatomy of the vegetative parts, and the structure of the elements of the tissues, throughout the group.

Another book of the period was Douglas Campbell's Mosses and Ferns, published in America in I895. It embraced the results of a large number of investigations into the anatomy of both groups carried out during many many years by himself.

Of all the mass of literature on the different sub-groups of the Pteridophyta, it is only possible here to mention some of the more important memoirs. Naturally, research on the Ferns should receive the first attention.

The last addition to the group of the Ophioglossaceae, Helminthostachys, was first described by Prantl in I883, when he dealt especially with the fertile spike. An investigation of the sporangia was made by Bower in the course of the 'Studies', and its results appeared in I896. The vegetative structure of the plant was described by Farmer and Freeman in 1899 .

The anatomy of Ophioglossum was worked out by Russow in 1872 and by Holle in I875, and symbiosis of its roots with a fungus was demonstrated by both observers. Holle studied the development of the tissues of the whole plant from the apical cell. Further contributions to the same subject were made by Van Tieghem in the Traite de Botanique, by Prantl in I883, Poirault in I892, and Rostowzew in the same year.

The prothallia of several members of this group were discovered and examined. Before I860 Hofmeister had investigated that of Botrychium virginianum, but his material only supplied the older stages of its development. 
The same was the case with that of Ophioglossum pedunculatum, which was described by Mettenius in I856. In I893 the former of the two was investigated again by Campbell, and in 1897 very completely by Jeffrey; the latter described it from its very young condition. Campbell described in 1895 the prothallium of Ophioderma pendulum also. He showed too that a mycorrhiza is present in the prothallium of Botrychium.

The Marattiaceae formed the subject of one of Bower's 'Studies'. Other workers on this family included Mettenius (I864), Tschistiakoff (I874), and Farmer (I892), all of whom carried out researches on Angiopteris. Campbell gave an account of the development of Marattia in 1894, but though this was the first detailed account of the whole fern, its sori had been investigated and described by Russow in $187 \mathrm{r}$, and by Luerssen in 1872 . The germination of the spores and the development of the prothallia of Angiopteris and Marattia were described by Luerssen in 1875 , and Jonkmann in 1878 ; those of Kaulfussia by Jonkmann in I879, and those of Danaea by Brebner in I896. The latter also investigated the embryogeny of Danaea.

Work on the higher Ferns was extensive and varied. Sadebeck investigated the anatomy and development of their leaves in 1874, Van Tieghem made an exhaustive study of their roots in 1883 , which was supplemented by a paper on the lateral roots by Lachmann in I889. A more accurate description of the development of the sporangia than had been given before was published in 1888 by Kundig, who was confirmed by Müller in I893. The structure of the apical meristems was studied exhaustively by Bower in 1889 .

In 1877 Prantl carried out an investigation of the sporangia of the Osmundaceae. Their embryogeny was studied by Kny in 1872 , and by Campbell in 1892 .

Rauwenhoff described the germination of the spores and 
the development of the prothallia of the Gleicheniaceae in I879 and further in I89o. In the latter year Poirault investigated the structure of the stems of various species of this group.

Prantl wrote an account of the structure of the sporangia of the Schizaeaceae in I88I, based upon his own researches. Several years earlier, in 1875 , he gave a complete description of the structure of the mature sporophyte of Hymenophyllum, whose antheridia were investigated by Goebel in I888, together with those of Trichomanes. Bower studied the latter in the same year, and investigated the meristems and resulting structure of the sporophytes of the whole sub-group in 1889 .

The Hydropterideae, or, as they were formerly called, the Rhizocarpeae, attracted much attention. The earliest work of our period was the classical work of Pringsheim on Salvinia in I862, which was an excellent research. In earlier years Hofmeister had studied the germination of the spores and traced out many important points about the female prothallium. Juranyi worked out the processes of development of the sporangia and spores in 1873 , and Prantl reinvestigated the formation of the prothallia in I879. Archangeli also contributed a memoir dealing with Salvinia and Pilularia in 1876.

The structure of the mature sporophyte of Azolla was worked out by Strasburger in I873. This research was as thorough and complete as was that of Pringsheim for Salvinia, and stands now as the basis of our knowledge. In I88I its prothallia were investigated by Berggren and found to correspond in all essential particulars with those of Salvinia. Belajeff traced out the development of the microspores in 1892 and in the next year Campbell investigated the development of the prothallia. Our knowledge of Marsilia is largely due to the researches of Hanstein, carried out in I862 and I865. In a third memoir in I866 
he made a careful comparison between this genus and Pilularia. Russow also studied Marsilia in $187 \mathrm{I}$. In $\mathbf{1} 898$ the development of its leaves and sporocarps were the objects of a research by Johnson.

Besides the researches on Pilularia, incidentally alluded to, mention should be made of Braun's work on the genera Pilularia and Marsilia of I870, and of Campbell's work on the development of the gametophytes of the former, carried out in 1888 .

Descriptions of various features of the anatomy of these plants were given also by Naegeli and Leitgeb in I866 and I867, and by Millardet in I869. The latter was chiefly concerned with the structure of the male prothallia of the whole group of the Pteridophyta.

Hardly second to the Filices in interest as the subjects of research were the Lycopodinae. As in the former case, many works based upon comparative study of the whole group appeared from time to time, while researches upon the several genera and species were numerous. The anatomy of the sporangia forms part of the papers by Goebel and the studies by Bower, which have already been alluded to. The roots were investigated by Naegeli and Leitgeb in I867, and the male prothallia by Millardet in I869.

The anatomy of Lycopodium was the subject of researches by Hegelmaier in 1872 and 1874 , which were chiefly concerned with the vegetative parts. The anatomy of the stem and the constitution of its tissue-elements were more completely investigated by Strasburger in I888-93, while a comprehensive discussion of the structure in the whole group was contributed by Jones in I898. Bruchmann investigated the roots in 1874 . The development of the sporangia was treated of by Goebel and by Bower, as already mentioned. The development and structure of the gametophyte in various species were studied by several botanists. The germination of the spores was first observed 
by De Bary in 1858 , and the first prothallus identified was that of L. annotinum. This was investigated by Fankhauser in 1873 , and held by him to indicate an affinity with Ophioglossum. Bruchmann confirmed Fankhauser's work in I885. Much of our knowledge of this subject is due to the later researches of Treub, which extended from I884 to I 890 ; in the course of them he examined very thoroughly the structure of the prothallium, and the development of the embryo of several species, and in fact laid the foundation of the knowledge of the group. He found that in some cases a mycorrhiza is present. Later in the century, in 1898 , Bruchmann added the elucidation of prothallia of four more species, one of which, L. clavatum, was also found by Lang in the same year and described very completely in 1899 .

Phylloglossum was first investigated by Mettenius in I867, but our knowledge of its structure is mainly due to the researches of Bower, who worked out its anatomy in 1885; he also followed out the germination of the tuber and the formation of the vegetative parts from it. Bertrand in the same year investigated the mature strobilus and the vegetative organs.

Juranyi first carried out researches on Psilotım, dealing with the internal structure of the sporangiophore in $187 \mathrm{I}$; Strasburger made a more complete examination of the anatomy in I873, and was followed by Bertrand in 1885 . In I884 Solms-Laubach investigated the development of the sporophyte, and especially of its sporangiophore. Tmesipteris was the subject of researches by Goebel in I88I, and by Dangéard in I89I.

Millardet's work of 1869 on the male gametes of the Pteridophytes included those of Selaginella, but a more important research was made by Pfeffer in I87I, which was largely concerned with the processes of germination of its spores, the development of its prothallia, and the 
subsequent fertilization and embryogeny. Bruchmann also studied the formation of the embryo in 1874 . In the latter year Braun investigated the arrangement of the leaves and the development of the branches of Selaginella and of Lycopodium. The anatomy of the vegetative organs had not so far received much attention, but about 1872 the subject was taken up by Russow, who was followed in 1873 by Strasburger, in $I 874$ by Hegelmaier, and in 1877 by Treub, all of whom investigated it with more or less completeness in different species. The embryology was further studied by Kienitz-Gerloff in I88I, and in I885 Belajeff took up the investigation of the male gametophyte, antheridia and spermatozoids, a more complete research on the same lines being conducted by Campbell in I895. The most complete and comprehensive study of the anatomy of the genus Selaginella was carried out by Harvey Gibson in the years I893-7. Though all parts of the plant had not been examined by him before the close of the century, his memoirs form a most valuable monograph of the whole genus.

The anatomy of Isoëtes was examined in Russow's great research of 1872 , which has already been alluded to. The development of the spores was studied by Tschistiakoff in I873. Bruchmann investigated the development of the root in I874. The work of Goebel and of Bower on the sporangia forms part of their memoirs on the general subject. In I89o Farmer reinvestigated the structure of the sporophyte and studied the embryogeny. Campbell also conducted a research on the latter subject in the same year.

The early researches of Hofmeister and Cramer on the Equisetaceae were followed in 1867 by the memoir published by Pfitzer on the anatomy of several of the German species of Equisetum. Janczewski and Famintzin independently investigated their structure in 1876 and 
ascertained that the origin of the lateral buds is not endogenous, as it appears to be. Equisetum appears in Goebel's work on sporangia ; it is interesting to find that it was in connexion with the organs of this genus that he introduced the term archesporium to describe the cell or cells from which the spores are finally developed. The development of the prothallium was investigated by Buchtien in I887, though ten years earlier Sadebeck had given an account of the embryology. The anatomy of the stem was investigated by Van Tieghem in I890, and in I899 a very exhaustive account of the anatomy of the whole sporophyte throughout the genus was contributed by Jeffrey. 



\section{BOOK III \\ THE PHYSIOLOGY OF PLANTS}





\section{INTRODUCTION}

THE study of the physiological processes of the plant underwent a great change at about the year I860, a fact which makes the date stand out almost as an epoch in the history of the science. The change can be traced to two especial causes, and can be estimated only by noticing the direction of inquiry before and after their operation.

The first of these was the discovery of the practical identity of the living substance of the two kingdoms of Nature. Protoplasm had been to a certain extent investigated by Von Mohl and other writers, sarcode was well known to many zoologists. When the two were compared and found to be identical, an impetus was given to study and research on the botanical side, which had till then been lacking. The study of animal protoplasm was further advanced, a fact which opened up long lines of inquiry into the extent to which identity could be established. Soon the questions of respiration and nutrition were reexamined, and knowledge slowly grew till they were found to be comparable in all respects and to the smallest details.

The puzzle that was so prominent at the outset, the apparent differences between the methods of supplying food to animals and plants and between the actual nutritive substances in the two cases, opened out under new aspects the old question of the relations involved in the gaseous interchanges between the air and the green plant. The problems of Priestley and his immediate successors turned very largely on such points as the purification or contamination of the air; the effects upon the organization or well-being of the plant were put in quite subordinate positions. All this was changed when the 
problems were regarded from the new standpoint, and by slow degrees the conception of the chlorophyll apparatus as a new factor, a mechanism concerned in the manufacture of organic substance for nutrition of both animal and plant made its way into scientific thought. The absorption of gases from the air came to be recognized as a part of this preliminary work and not necessarily confined to the vegetable organism, though occurring only very exceptionally in the animal world. The chlorophyll apparatus in fact came to be looked on as something sui generis, not necessarily more vegetable than animal, concerned only with the manufacture of food for both, though located for the most part only on one side of the ill-defined border between them. This distribution, moreover, was associated with the stationary as contrasted with the locomotory habit.

While the whole face of this section of physiological study was changed, the second factor alluded to brought about an equally extensive alteration in another. Darwin's great work, the influence of which on morphological speculation we have already examined, was co-operating with the first cause just discussed, and the phenomena of the reaction between organism and environment came into review and received further investigation. The new theory gave the death-blow to all the merely mechanical explanations of vital phenomena that had hitherto held the field and which were little more than gropings in the dark. So the physiology of the period we are considering assumed an importance and obtained a development which would have seemed incredible even to any of the most enthusiastic workers of the time. Research brought in its train literature, discovery succeeded discovery, and by the end of the period the observers of the new century were able to realize that the physiology of plants had ceased to be a subordinate section of botany and had attained to the rank of an independent science. 


\section{CHAPTER I}

\section{THE DEVELOPMENT OF KNOWLEDGE OF THE PROCESSES OF ABSORPTION OF WATER AND ITS SUBSEQUENT TRANSPORT IN THE BODY OF THE GREEN PLANT}

THE mechanisms of the water supply derived from the soil and the functions which are associated with it were the subject of prolonged and exhaustive inquiry during the last half of the nineteenth century, as a result of which an important change came over the minds of vegetable physiologists. The older mechanical ideas, which were advanced by Dutrochet and his successors, and which then marked a distinct advance in thought, were gradually undermined by experiment and discussion, and the probability that the plant itself as a living organism has the largest share in the regulation of the processes of absorption and distribution began to make itself felt. It was not until recently that such views were in any great favour; what was called the selective power of the roots was advanced only tentatively, and was strongly opposed by most physiologists, who preferred to base their opinions on mechanical conceptions of the methods of osmosis and other purely physical processes. To them the plant was a machine, and, like the machines of the commercial world, it had no power apart from the physical forces active in its environment.

The problem which presents itself now for discussion lies at the root of the nutritive processes of plants. It includes the methods of the absorption of water from the soil, the acquirement of the mineral constituents of the latter, 
the distribution of the water with the salts it holds in solution after absorption has been effected, the complicated processes of exhalation of the water in view of the need of a constant and copious renewal, together with the bearing of these processes upon the well-being of the organism.

To find a starting place for its solution we must go back to the time of Dutrochet and recall his researches on the processes of osmosis, which, though admittedly imperfect, laid the foundation on which the modern views are built. He laid down the fundamental proposition that concentrated solutions of various salts, enclosed in organic membranes, apparently exercise an attraction on water in contact with the other side of the membrane, so that a stream of water passes through the latter to mix with the solution. Such increase in volume within the membrane is capable of setting up considerable hydrostatic pressure upon it. His views were not in consonance with the modern conceptions of osmotic phenomena beyond a certain point, for he held that there is always associated with the entry of the water a flow in the opposite direction of a related quantity of the salt solution, which we know now is by no means necessarily the case. The theory of the excretion of various acid substances by the roots, though supported apparently by observations on the corrosion of marble by the root-hairs, is now not at all generally held. Dutrochet's results were based upon the use of very complex membranes, which led rather to the confusion of the processes; the discovery of semi-permeable membranes came much later than his time.

Dutrochet's application of the process of endosmosis to the explanation of the absorption of the mineral matters of the soil, being based solely on mechanical conceptions, failed to explain the variable quantities of different salts which are absorbed by the same plant, or the different amounts of the same salt which are taken up by different 
plants. The view of a selective power of the roots, based upon the older work of De Saussure, remained a difficulty and met with no adequate treatment. The work of Dutrochet, like that of most of the writers of his time, though displacing the old vitalistic theories, led him to too mechanical a conception, which only found correction during the period from I860 onwards, when the doctrine of the independent life and vital functions of protoplasm gradually impressed itself upon the minds of physiologists.

At the commencement of our period another obstacle to progress was in existence, an error in the interpretation of structure, which had laid hold of botanical opinion, and which died hard. This was the spongiole theory of the root, associated with the name of De Candolle. According to the latter, the roots of terrestrial plants are furnished with peculiar spongy absorbent organs, which are developed at their apices. They are capable of active contraction, by means of which they force into the root such water as, by virtue of their hygroscopic qualities and by capillarity, they have been able to accumulate in their substance from outside. It is difficult to reconcile this view of structure with the hypothesis of Dutrochet, but it held its own with great tenacity, though anatomical researches clearly disproved it.

The position as left by Dutrochet was practically unchanged in I86o. Very soon afterwards research was again directed to these fundamental questions, and many exhaustive investigations were made upon the whole subject during the rest of the period under review ; different sections of it fell into the hands of different botanists and were made the subjects of separate inquiries by the most eminent investigators, and of discussion by the ablest critics and thinkers of the time.

These researches into different aspects of the problem were not consecutive, but overlapped considerably in 
various directions, so that it has only gradually become possible to give a co-ordinated account of them. Even now many difficulties remain unexplained and open out the way to further researches, which are still in progress.

The classic investigations of Graham into the phenomena of osmosis were published in I862, and were very quickly taken advantage of by the leading physiologists of the time. The work undertaken by Traube was the first definite application of Graham's researches to the mechanics of the vegetable cell, and particularly to its mode of growth and the part played therein by endosmosis. His work, which appeared in 1867 and in I874, dealt at some length with the structure of the cell wall, which he demonstrated to be very largely colloidal. Starting from Graham's results, Traube prepared artificial cells in which the conditions of the ordinary vegetable cell were reproduced with approximate accuracy. His preparations were made by placing a drop of syrupy solution of a specially prepared gelatine into a solution of tannic acid, when a precipitate of tannate of gelatine immediately formed around it. He obtained thus a colloidal membrane surrounding a solution of a colloid. The osmotic attraction of the gelatine continually drew water through the membrane into the space enclosed in the pellicle of gelatine tannate, setting up hydrostatic tension and continuously diluting the solution of the gelatine inside. Traube held that a pellicle prepared in that way corresponded fairly closely in its behaviour with that of an ordinary cell wall, particularly if a little lead acetate or copper sulphate was added to the gelatine. His experiments led him to support Naegeli's theory of the formation of cell wall by the process of intussusception.

Experiments made with pellicles produced by the reaction of colloidal with crystalloidal substances showed them to be impermeable to the fluids from which they were produced, but to allow certain other chemical compounds to 
pass through them, a peculiarity which Traube attributed to the relative sizes of the molecules of the constituents of the membrane and of the transuding salt; only such being able to pass as had molecules smaller than the micellar interstices of the pellicles.

Whatever the value of Traube's work may be when subsequent researches are taken into account, it was of great importance at the time in directing more careful attention to the part played by the membrane in osmotic action, and in showing that the old view of osmotic equivalence was erroneous, endosmosis being independent of any interchange, and dependent on what is now known as the osmotic pressure of the fluid in contact with the membrane.

While these researches, more or less purely physical in their nature, were being carried on, Sachs was engaged in making contributions to our knowledge of the subject from the point of view of the relations of the plant and the soil. In I859 and I860 he occupied himself with an investigation into the condition of the soil, with special reference to the distribution of air and water in it and to the relationships of the young roots to both. He further inquired into the mode of effecting such contact between the young roots and the particles of which the soil consists, and the water mechanically held by them, as will enable the absorption of the latter to take place. He established the fact that the only water available for the plant is found in the films which surround the particles of rock and other debris, and that water in the interstices of the soil is not only useless, but harmful to the roots, in that it interferes with their supply of air. Sachs discovered also the nature of the relationship of the root-hairs to the particles of soil, and showed that the seat of absorptive activity formerly located in the so-called spongiole consisting practically of the root-cap, really existed in the band of root-hairs just behind the apices 
of the young roots. He went on to show how the water enters the root-hair by the process of osmosis, carrying with it traces of the salts present in the particles of the soil.

Sachs further determined the amounts of water which different kinds of soil can retain with advantage to the plants growing in them, and their content when saturated with it; he showed that saturation is unnecessary by ascertaining how much the soil contains at the moment when the plants growing in it commence to wither, proving thereby that the quantities available for the use of such plants fall far below those which the soil can contain. Incidentally he showed that the available water in a clay soil is to that in a sandy one in the proportion of $44:$ I9.

The osmotic processes received subsequently little detailed attention till 1877 , research during the interval being directed chiefly to the problems connected with the method of conduction of the stream from the roots throughout the plant. In that year appeared two important contributions to our knowledge of the part played by osmosis generally in the movements of liquids in vegetable tissues.

The most noteworthy of these was Pfeffer's Osmotische Untersuchungen, which really forms the foundation of the views of the rôle of osmosis in the vegetable cell held up to the end of the century. The researches on which it is based paved the way to Van 't Hoff's theory of osmotic pressure, advanced by him many years later. Pfeffer directed his attention particularly to the character of the membranes and for the first time pointed out the importance of the part played by the protoplasm. He claimed that the latter, lying as a thin film inside the cell wall, is not homogencous, but that its surfaces, the one abutting on the wall and the other on the vacuole, are permeable with greater difficulty than the softer intermediate substance. This difference of permeability he attributed to what he called 'plasma membranes', which he held to be composed 
of protein substances, thrown out of solution by contact with the water, and so precipitated on the surfaces of the protoplasm. This view enabled him to suggest a hypothesis to explain the varying powers of entry of different substances, and he showed that the membranes are semi-permeable to some substances, and permeable in various degrees to others. Pfeffer suggested that a functional division of labour may exist in the protoplasm with regard to the processes involved in osmosis, but denied that such division of labour disturbs the general principles of the regulation of osmosis and absorption. According to his views the passage of salts in solution through the membrane is mechanical, depending on the relative sizes of the molecules of the salts and the molecular interstices of the membrane, a view held as we have seen by Traube. The action of the protoplasm, so far as vital action is concerned at all, seems, therefore, to be the regulation of the composition of the plasma membranes. Pfeffer did not suggest the more modern view, that the living substance exercises any process of active imbibition or vital filtration of the salts, a view traceable to the researches of Waymouth Reid in I89o.

Pfeffer's work included the investigation of the osmotic pressures exercised by different salts and the consequent tensions existing in the cells. He discussed also the relation between the internal osmotic pressure and the force of imbibition exerted by the cell wall, showing how the two co-operate in setting up and maintaining turgor in the cells, and discussing the conditions of the forces in their interior and the physical principles involved.

In a later paper, published in I886, Pfeffer showed that certain aniline dyes, when in very dilute solution, possess the power of penetrating through protoplasm withont killing it, a discovery which has been of great importance in the conduction of many subsequent researches.

The second work alluded to as marking the year 1877 
was De Vries's paper entitled Untersuchungen über die mechanischen Ursachen der Zellstreckung. Though of less importance than Pfeffer's, it was a very valuable contribution to our knowledge of the subject. It contained a number of determinations of the relative osmotic values of the different substances which are constitutents of the cell sap, in the course of which De Vries established a general relationship between molecular weight and osmotic pressure. He also investigated the phenomenon to which he gave the name of plasmolysis, and showed how it can be applied to ascertain the osmotic pressure of various substances and solutions. Of this work Sachs says, "the relations between turgescence, the protoplasm, and the cell wall, established by Naegeli, Pfeffer, and myself, were first clearly explained by De Vries in I877.'

Subsequent contributions to the subject which appeared at intervals dealt especially with the osmotic pressures in the cells of various plants, both terrestrial and aquatic. The chief were those of Westermaier (I883), De Vries (I884), Krabbe (I884), Jansé (I888), Stange (I892), Pfeffer (1893), Copeland (I896), and Dixon (1896). De Vries determined the osmotic pressure in the cells of the beetroot to range between $\mathrm{I}_{5}$ and $2 \mathrm{I}$ atmospheres. Wieler found almost the same amount in the cells of developing medullary rays of Pinus sylvestris. Dixon determined that of the cells of leaves of $A$ cer to exceed eight atmospheres.

Pfeffer made a further important contribution to the subject in 1890 , when he published his memoir Plasmahaut u. Vacuolen, which was an extension of the former paper and dealt especially with the plasma membranes and their relations to the vacuoles.

The varying permeability of protoplasm by different substances, and its conditions, were investigated very fully by Overton at the end of the century. Without actually endorsing Pfeffer's views, he supported the idea of there 
being a considerable difference in character between the external and the internal layers, which, however, he attributed to a probable impregnation of the former by a large percentage of cholesterin and lecithin. His views remain, however, hypothetical.

Pfeffer's views as to precipitation membranes, or plasma membranes, were accepted by the writers of the time, but more recently they met with much criticism, and by the end of our period they could hardly be said to have maintained their ground in the opinion of many physiologists. Chodat and Boubier, while investigating the phenomena of plasmolysis in 1898 , found that the protoplasmic pellicles cannot be separated from the cell wall as easily as Pfeffer thought. The ectoplasm appears to be adherent to the young growing membrane, and when the protoplasm shrinks towards the centre of the cell, as the water is removed during plasmolysis, the film is actually rent or torn asunder, a very thin part being recognizable adhering in places to the wall. This being the case, there is no possibility of an external precipitation membrane being formed between the protoplasm and the wall during the ordinary process of absorption.

The failure to appreciate the fact that the cell membrane of the root-hair is almost semipermeable led to incorrect views as to the nature of the exudation into the soil which accompanies the absorption of water and mineral salts. This was held to be composed of vegetable acids, a view supported by the well-known corrosive action of roots upon polished marble when they come into contact with its surface. It was disproved by Czapek in I896; he showed that with the exception of carbonic acid, no free acids are excreted by the roots of terrestrial plants, but that there is an exudation of acid potassium phosphate.

Sachs' early work of 1859 and I860 on the mechanism of the root-hairs was followed by further researches pub. 
lished in I865. These showed how the copious absorption of water and its osmotic transference to the cells of the cortex of the root lead to the setting up of a very considerable turgescence in this region, the water passing from cell to cell under the same forces as led to its original absorption from the soil. The turgescence in its turn is accompanied by a very considerable hydrostatic pressure, which is brought to bear upon the cell membranes, and which, not being resisted by any fluid in the vessels of the wood, brings about a filtration into them. This enabled him to associate the processes of absorption with the phenomena of bleeding from cut stems, which had much earlier been observed and to some extent investigated by Hales. To establish this theory of filtration under pressure, Sachs found it necessary to postulate a greater permeability of the membranes on the sides of the cells directed towards the centre of the axis than on the rest of their surface, in order to show how the direction of the stream is secured. Though this has never been disproved, it has never, on the other hand, been satisfactorily established, and it is rather difficult to see why the pressure does not force the water from the cells into the intercellular spaces throughout the cortex, as they are distributed symmetrically through the tissue. Sachs' presentation of the theory is worthy of note, for though he originally illustrated it by a merely mechanical model, with membranous walls of different thicknesses on the two sides of the artificial cell used, he pointed out that the resistance to the filtration is a matter in which the protoplasmic utricle is largely concerned, a view which has come more and more into prominence since his work appeared.

Sachs named the pressure so set up in the cortex, in consequence of the over-distension of the cells, root-pressure, and attributed to it the initiation of the stream of the transpiration current, or ascending sap. A little later he 
showed that a similar pumping action of turgid cells takes place in severed portions of plants, such as grass-haulms, when they are supplied with water, and that the exudation of drops of water by herbaceous plants like Alchemilla has a similar cause. Sachs attributed also the excretion of nectar by flowers to hydrostatic pressure following osmotic absorption, a view which was disproved by Pfeffer in his Osmotische Untersuchungen in 1877 , and replaced by the theory of secretory activity.

Pfeffer found that the feebly-active nectaries of the Cherry-laurel will continue to excrete a syrupy liquid if they are kept in moist air, though the leafy branches may have lost more than a quarter of their water. The process is consequently to be recognized as a vital one, depending on the activity of the gland cells. This is supported by the observation of Darwin in 1877 , that light plays a great part in starting and maintaining the secretory flow. Wilson showed that temperature also is concerned in the mechanics of the exudation.

The amount of root-pressure exhibited by a plant has been shown to undergo daily and annual variations which are irregularly rhythmic. Hofmeister first established the daily periodicity in I862, but it was more carefully studied by subsequent observers, of whom the most prominent was Baranetzky, whose treatise Eine Mittheilung über die Periodicität des Blutens appeared in 1873 . He determined that in any given case a maximum flow can be noticed at some definite time of day, which varies with different plants, and he attributed it ultimately to the alternation of day and night, for he found that any alteration in the periods of illumination causes the daily periodicity to change. Baranetzky observed further that this periodicity is not without exception, not being shown at all by some plants. Brosig followed up the subject in 1876 , and Detmer in I877. A more important contribution to our knowledge was made by GREEN $\mathrm{R}$ 
Wieler in I893, wherein he discussed the phenomena of both daily and annual periodicity, the latter of which he was the first to study. His experiments were based upon plants kept in pots throughout the year under constant external conditions, and they enabled him to show that while the pressure rises to a maximum in spring, it is absent altogether from many trees for some weeks during the winter, being thus clearly associated with the vital activities of the roots.

At the commencement of the period under review, the conception of transpiration as a vital process was only very imperfectly realized. Hales had shown that the exhalation of vapour from the surface of a leaf is less than that from an equal area of free water, so that it was evident the process is not one of ordinary evaporation. A more detailed determination of the fact was made by Unger in I855, but it was reserved for Sachs to point out clearly that the transpiratory process must be included among the vital phenomena of the organism. He carried out a series of researches into the subject in $I 860$, taking up the question of the difference óbserved at the outset by Hales, and showing that such difference is much greater than had been supposed. He pointed out that as cuticular transpiration is but small, and as the greater part of the actual evaporation takes place into the intercellular spaces of the leaf, a comparison must be made between the area of the boundaries of these and that of a free surface of water, and not between the latter and the area of the superficies of the leaf. The ratio so arrived at is at least ten times as great as that based upon the latter. Sachs pointed out that the difference can only be attributed to the living substance of the leaf acting as a powerful restrainer of the evaporation of the water. He showed that if a dead membrane is substituted for a living one, the evaporation becomes greater than that from a free surface of water. 
This inclusion of transpiration among the vital phenomena marks a great development in the explanation of the process and its importance.

Sachs co-ordinated the function of transpiration more closely than had been done before, with the absorptive activities of the roots, by showing that it varies with the temperature of the soil in which the roots are growing and with the nature of the soil itself. The latter observation had been previously made by Sénébier, but his experiments were on a much more limited scale than those of Sachs. The latter found that a Tobacco-plant growing in coarse sand gave off less water than another growing in clay; he investigated the effects of adding various salts to the water to be absorbed, and observed that dilute acids increased, while dilute alkalies restrained transpiration, as did most of the neutral salts with which he experimented.

Sachs' work was followed by that of Bürgerstein in 1876 . This showed that nitric acid and carbonic acid increase the exhalation of vapour, and that so long as very dilute solutions are used, a greater concentration of the salt still further increases the amount. The results of his experiments with various salts showed, in his opinion, that transpiration increases with the concentration of the solution of the salt up to a certain maximum, beyond which it gradually diminishes, becoming gradually less than when the roots are in distilled water.

In I88o Vesque also wrote on the correlation between transpiration and absorption, confirming Sachs, but associating the variations of transpiration with differences of rate of absorption from the various soils, making the dependence on the salts only secondary or indirect.

The observations of Hales on the quantities of water which are transpired by trees were for a long time unchecked. Experiments with a view to a more carefully controlled result were made in 1877 by F. Haberlandt, and 
in 1879 and 1880 by Von Höhnel. The results showed considerable variations, which might well have been expected as plants of very different habits of life were employed for the determination, and the difficulties of computing even the leaf area were almost insuperable. Haberlandt gave 8 o grammes per diem as the amount exhaled by a plant of maize, while a plant of hemp transpired I9I grammes in the same time; a sunflower plant gave off about as much as the hemp. Von Höhnel made more careful observations than Haberlandt, as he made allowance for the varying conditions of different parts of the plant, and for differences of situation. He estimated that a birchtree with 200,000 leaves transpired 30-40 kilogrammes of water during a single hot day.

The relation of stomata to transpiration was treated by the older writers as purely a mechanical one, and was even then only partially understood. Their mechanism was investigated with considerable care and accuracy by Von Mohl in 1856 , and was shown to depend in the first instance on the turgidity of the guard cells. He pointed out that internal hydrostatic pressure made them curve outwards in consequence of the way in which their ends are attached, and tentatively ascribed the variations in their turgor to varying quantities of osmotic substances in their interior.

No material advancement of our knowledge of them was secured until about I88o, when the idea of irritability or response to changes in environment dawned upon botanists in consequence of the writings of Pfeffer, Sachs, and Darwin, to which reference has already been made. We have seen that a conception of the vital character of transpiration had been slowly making its way in scientific opinion since I860, but it had so far been confined to the process of the formation of the vapour. The exhalation of the latter through the openings of the air passages having been shown 
to be accompanied by regulating changes of volume of the guard cells which are situated there, the power of the latter to appreciate the changes of the surrounding air with regard to light and temperature, and perhaps to hygrometric condition, was suggested as a factor in the mechanism that must be taken into account.

In I88I the mode of action of the guard cells was the subject of a very important investigation by Schwendener, who made more complete and minute research into both structure and behaviour than Von Mohl had done. He showed, with very great wealth of illustration, how the distribution of thickening of the walls of the guard cells, and the consequent tensions set up in them, secures definite and purposeful changes of form when the pressure of turgor is increased or diminished.

Sachs supplemented the views of Schwendener by restating the ideas of Von Mohl and suggesting that these variations of turgor are attributable to osmotic interchanges between the guard cells and the other cells of the epidermis abutting on them, under the influence of light; he like Von Mohl pointed to the chloroplasts in the guard cells as indicating a means whereby osmotically active substances can be produced in them as conditions become favourable.

Schwendener's views met with general acceptance for a few years, but in I886 another contribution was made by Leitgeb to the subject which caused some controversy. According to Schwendener, the mechanism is supplied by the guard cells alone; they are independent of pressure of liquid in the other epidermal cells, possessing their own forces of distension and recoil, which suffice for all they have to do. They work under the influence of light and temperature certainly, but these affect them directly.

Leitgeb's hypothesis was very different; according to this, the chief factor in the closing of the stomatal orifice is the action of the other epidermal cells upon the guard 
cells. The latter must be regarded according to this view as passive agents in opening and closure, and not as acting automatically. The force at work is mainly indirect, being the varying turgor of the whole of the epidermal cells, and these working by a kind of traction and not by osmotic changes in the guard cells. Leitgeb was led to this view particularly by observations on the nocturnal closure of stomata. He held that darkness exerts a tonic action on the cells concerned.

A somewhat animated controversy between these two schools of thought was maintained during I 887 and I888, being conducted chiefly by G. Haberlandt and by Schaeffer. It was revived in 1896 by Schellenberger. An important contribution to it, which suggested a basis of agreement, was made in 1898 by F. Darwin, who carried out a number of experiments with great success. He introduced a new instrument for work on the exhalation of vapour, which was found capable of demonstrating extremely small amounts and enabling comparisons to be made with much greater accuracy than before. This was the hygroscope, two varieties of which are described in his paper.

In Darwin's work the idea of the vital character of the action of the guard cells can be seen to have undergone a very great degree of development. He held that the mechanism depends upon correlation between the two factors claimed by the rival schools to be concerned, and that the turgor of the guard cells plays the most prominent part. The action is the autonomic action of the plant as an individual organism, and these variations in turgor are only the machinery by which it works. The changes of illumination, temperature, \&c., act as stimuli, not so much perhaps immediately to the guard cells as to the whole organism.

According to this view, the changes in the turgor of the guard cell are effected by their protoplasm, which can modify 
its own permeability by water in consequence of stimulation, and can under the same influence affect the quantity of osmotic substances in the cells. Darwin suggested indeed that knowledge of the regulation of the production of the latter, in ways not at present capable of explanation, may justify us in expecting that the turgor of the guard cells may be found to be regulated indirectly like other phenomena of irritability.

Darwin supported his view of the co-ordination of the two factors for closing by showing that withering leaves exhibit a gradually increasing closure, which in many plants is preceded by a well-marked rise of transpiration. He explained this as indicating a temporary opening of the stomata due to diminution of epidermal pressure on the guard cells as withering begins. The subsequent closing he was inclined to attribute to the guard cells losing their turgor in response to a possible stimulus caused by the slight flaccidity of the rest of the leaf.

The suggestion made by Von Mohl that the presence of the chloroplasts in the guard cells is correlated with the presence of osmotic substances in larger quantities than in the other epidermal cells met with little or no confirmation. It will be remembered that Von Mohl expressed no opinion as to the nature of these substances, but pointed out that they would probably accompany the increased assimilation or photosynthesis induced by the light, and so secure the opening of the stomata. It follows, therefore, that the withdrawal of the light would, if their closing were due to the same cause, have to be immediately followed by a certain and indeed considerable destruction of these osmotic substances. Quantitative considerations do not support this view of the mechanism, for Darwin showed in the course of the work now under review that half an hour's darkness is not likely to have any great effect in destroying osmotic substances and so 
allowing the cells to become flaccid. A further objection to Von Mohl's hypothesis lies in Darwin's observation that the stomata tend to open again in prolonged darkness, and do not close in air containing no carbon dioxide.

Kohl was the first observer to investigate the action of the different rays of the spectrum on the opening and closing of stomata. He showed in 1895 that the rays absorbed by the chlorophyll, viz. the red and the blue, cause the opening. These observations may be taken to support Von Mohl, but only up to a certain point, for Kohl also failed to identify the substances, the formation of which the theory demands. The activity of the red rays in the process weighs somewhat against the theory of a direct stimulation of the protoplasm by the light, for the most generally efficient rays in stimulation are those of high refrangibility.

F. Darwin suggested that the nutritive changes which are excited by the light may form a stimulus to the protoplasm of the guard cells, and so bring about the varying turgescence of opening and closing. Taking this view, the stimulating action of the light is actually indirect. Darwin admitted that he had no positive evidence in favour of the hypothesis, but he held that the nutritive changes are not of sufficient magnitude to act directly. Darwin also found reason to suppose that the closure of stomata accompanying or preceding flaccidity of the leaf may be its response to the stimulation caused by the commencing reduction of turgor.

An important contribution to our knowledge of the behaviour of the stomata of nyctitropic plants was made by Stahl in I897. In his paper he showed that the stomata of such plants remain open at night so long as temperature conditions remain favourable. F. Darwin agreed that they are more widely open than those of other plants except those of aquatics, which do not close at night at all. 
The phenomenon of nocturnal closing does not, therefore, seem to be one of stimulation entirely. Darwin found evidence that it shows an amount of inherent periodicity in nyctitropic plants, a certain fundamental rhythm existing, comparable with the nyctitropic rhythm, but not so well marked. He found also that though transpiration is checked at night by stomatal action, the closure is not generally so complete as to stop it entirely.

Other evidence of the ultimate dependence of the regulation of transpiration on the behaviour of the protoplasm has been forthcoming. Baranetzky showed, in 1872 , that shaking a branch temporarily increases its loss of water. Wiesner failed to observe this in 1876 , but the phenomenon was again recorded by $\mathrm{Kohl}$ in 1886 and by Eberdt in I889. Both Baranetzky and Kohl said that if the shaking is prolonged the rise of transpiration is followed by a fall. Baranetzky attributed the rise to the rapid expulsion of the saturated air through the stomata at the time of shaking. On the other hand it was ascribed by Vines, in I886, to the effect of the shaking on the protoplasm; acting as a stimulus, it makes the latter modify its permeability and so allows a more rapid evaporation from the cells to take place. F. Darwin (I898) suggested that it may be due to a temporary opening of the stomata, taking place presumably in response to the stimulus.

The vital theory of transpiration received support also from the observation of Von Höhnel in 1876 , that the process is independent of the quantity of water at the moment present in the leaf.

The general effect of light upon the transpiratory processes, apart from its local action on the stomata, was investigated by Wiesner in 1876 . He found that when a plant is kept at a constant temperature, and when the air around it is kept at a definite degree of saturation with moisture, light affects transpiration directly and not through 
changes in the guard cells, causing a considerable increase in the quantity of vapour exhaled. The active rays were determined to be those which correspond to the absorption bands of chlorophyll. Wiesner made his observations on etiolated and normal plants of maize. He arranged such conditions that in his plants the stomata were nearly closed while they were exposed to light, and found that when illuminated the transpiration of the etiolated plants was doubled and that of the normal ones was increased sevenfold. Observations made upon Hartwegia showed that the stomata remained open in the dark, yet the access of light caused the amount of exhaled vapour to be one and a half times as great as before.

Wiesner suggested that the result might be due to the conversion of the light rays into heat rays by the chlorophyll. A similar suggestion as to the influence of the pigment was made by Van Tieghem in 1886 , and it received considerable support in France. The view propounded was that one of the normal functions of chlorophyll is to increase transpiration, a function which was spoken of as chlorovaporization. Dehérain, in 1876 , had stated that he observed that when carbon dioxide was not admitted to the leaf, the incidence of light increased transpiration. The statement was made again by Jumelle as the result of observations carried out in 1889 .

The view has not obtained acceptance in England, and in Germany Pfeffer appears doubtful about it. The results of Dehérain and Jumelle do not receive confirmation from the later work of Kohl and of the Verschaffelts. The increase of transpiration under the influence of light cannot be dependent on the action of chlorophyll, for Bonnier and Mangin determined in $\mathrm{r} 884$ that it is not confined to green plants, but is exhibited also by certain fungi.

The value of the process of transpiration to the plant as a whole has been but gradually recognized. During the 
early part of the period under review the views definitely stated in 1876 by Wiesner were more or less acquiesced in, it being held that such an enormous quantity of water as passes through a tree is necessary for the supply of a sufficient amount of the mineral constituents of the soil, the solutions absorbed being extremely dilute. 'Transpiration was regarded, therefore, as subordinate to, but connected with, the nutritive processes. This view is supported by the fact that such plants as exhibit the most active transpiration are for the most part of considerable bulk, but there is very little direct evidence forthcoming on the point.

The observations of Hales and others of the older writers that the phenomenon of the bleeding of cut stems cannot be observed in summer time received an explanation in connexion with work on transpiration, and a further function of the process came to light. Hales, Meyer, and Sachs all spoke of the evaporation of the water forced by rootpressure into the vessels of the wood, and the last-named writer suggested that such evaporation would lead to the setting up of a negative pressure of the air which gradually replaces the water. Experiment showed Sachs' view to be well-founded, for definite proof was afforded by Von Höhnel in 1876 . He cut under mercury the stem of a transpiring plant and found the metal rise at once to a height of several centimetres in the vessels, particularly those most recently formed. Von Höhnel calculated the force of this negative pressure or suction to be from one-half to one-third of an atmosphere.

This discovery led botanists almost immediately to attribute to the transpiration process a share in the propulsion of water along the axis of the woody plant. Vesque took up the subject in I880, and showed that such suction materially aids the root-pressure in driving water into the cavities of the vessels. $\mathrm{He}$ made the 
observation, also, that a rise in the temperature of the air surrounding a woody plant checks absorption by its roots, a fact which he explained by showing that the gases existing in the vessels at a pressure below that of the air will expand or contract as the temperature rises or falls, so that the negative pressure must vary in amount.

Pappenheim, in I892, ascertained that the gaseous tension in the tracheides of certain Conifers often amounts to not more than one-fourth of an atmosphere. Schwendener, in the same year, found this to be about the same in the vessels of woody stems. Haberlandt found that a similar negative pressure may be detected in the elongated cells of the central cylinder of Mosses.

Von Höhnel not only proved the existence of negative pressure in the experiments described, but he ascertained that it is dependent on transpiration by showing that it gradually disappears as transpiration ceases. Strasburger, in I89I, and Pappenheim, in I892, showed that it is practically the same throughout the whole length of a branch.

When, however, we have attributed these two functions to the process of transpiration, the latter has not received the fullest explanation that can be given. Experiments made at the close of the century by Brown and Escombe suggest a further purpose of the highest importance, so important indeed that it appears strange that emphasis was not laid upon it much earlier. Their views may be expressed in the following quotation from an address given by Dr. Brown at the Dover meeting of the British Association in 1899 :

'The principal factor which determines the amount of transpiration in a plant must be the amount of radiation falling on it. It is essential that the water-bearing mechanism should be able to keep up a good supply of water to the leaf lamina in order to prevent the temperature rising to a dangerously high point. This "safety valve" func- 
tion of the transpiration current is not always sufficiently borne in mind, and we are too apt to think that the plant requires these enormous amounts of water in order to supply itself with the requisite mineral salts. The absolute necessity for the supply as a dissipator of energy will become evident by taking one or two facts into consideration. A square metre of the lamina of the leaf of a sunflower weighs about 250 grammes, and its specific heat is about 0.9. The hourly transpiration in bright sunshine may be as much as 275 c.c. per square metre, requiring the expenditure of 162,800 calorjes, and it therefore follows that if the loss of water were stopped, the temperature of the leaf would rise at the rate of more than $12^{\circ} \mathrm{C}$. per minute. In making our experiments in glazed cases, it has sometimes been very interesting to watch the result of any accidental stoppage of the water-current in the leaf-stalk, and the almost instantaneous effect this has in destroying the leaf when the insolation is of high intensity.'

Brown and Escombe strongly supported their view that the process of transpiration has its greatest bearing on the regulation of the temperature of the leaves by investigations into the proportion of the incident radiant energy which is applied to the constructive processes, to which attention will be directed in a subsequent chapter.

The early ideas of the forces which co-operate in causing the movement of the ascending sap, and of the pathways by which it travels, were purely speculative and failed to stand even the simplest test of experiment. From the time of Hales to about the year I860, the water was thought to move as in capillary tubes, the vessels and the intercellular spaces being spoken of as transmitting it. Quincke, in I863, put forward the view that it travels up the vessels as a thin film on the inner side of their walls, a view which was accepted by Sachs in the first edition of his Lehrbuch in I868. Boehm advanced the hypothesis that the pressure of the air contributes to its ascent. The discoveries of Hartig, at the beginning of our period, that the histological 
elements of the wood of the coniferous trees are not in open communication with each other, and that the bordered pits of the wood cells are not perforated but closed by fine membranes, render both these views impossible. Naegeli showed in I866 that capillarity cannot supply the quantity of water lost by transpiration. In I868 Unger suggested that the current travels in the substance of the walls of the cells in consequence of their power of imbibition. This view was at once subjected to a careful and critical examination by Sachs, who claimed to have made the first definite presentation of it. It is particularly noteworthy as marking an advance in our knowledge, inasmuch as it added to the conception of the action of general physical forces only held up to that time, a recognition of a special mechanism differentiated by the plant itself for the performance of a definite function. This basis of the idea remains substantially unchanged, though Sachs' views of the mechanism are not now considered sufficient or satisfactory.

Sachs' investigations extended over a number of years, and naturally underwent certain modifications during that time. Starting with Hartig's discovery he said that not only are the elements of the wood prevented from free communication with each other, but at the time of the passage of the rapid current supplying transpiration their cavities are not filled with water-the wood cells contain little, while the vessels are empty. He calculated that the wood imbibes and contains more than half its weight of water, of which more than one-third is in the cell walls, they being saturated with it. Investigation into their physical peculiarities showed him that while they can swell very little, they hold the water in a very mobile condition, and consequently he said that the water must move in the substance of the cell walls. He set forth this view as follows in his treatise Ueber Porositït des Holzes, published in 1879 : 
' The wood consists of a framework of lignified lamellae, which enclose cavities (cell cavities). According to circumstances, the cavities may contain water, or air (with aqueous vapour), or both. The walls themselves may be dry, or contain water of imbibition, and their volume or condition of swelling alters with the amount of water contained. The cell cavities of the wood are capillary spaces; the cell walls on the contrary contain no capillaries into which liquid or air could directly penetrate. In order to be able to judge of the movement of water in the wood produced by transpiration and other causes, it is necessary to distinguish sharply between the capillarity of the cavities and the imbibition of the cell walls.'

In his Lectures on the Physiology of Plants, published three years later, he says again :

'The wood owes its significance as the organ for conducting water to a series of most remarkable properties, which are found in no other natural body ... it depends not upon a phenomenon of capillarity, but upon imbibition and swelling. . . . The one point of special importance to be considered here is the facile mobility of the water thus held fast by the cell walls. . . The ascending current of water depends upon the motion of the relatively small number of water molecules which are contained between the micellae of the wood cell walls. This much is established, that this movement can only occur when the wood cell walls at the upper end of this system lose a portion of their water molecules. By this loss its state of saturation with water becomes disturbed, and the equilibrium altered ; the parts of the wood cell walls which have become poorer in water will tend to restore the equilibrium by attracting water from the nearest wood cells, which, in their turn and for the same reason, take it up again from parts of the wood situated lower, until finally this movement, extending backwards, proceeds from the foliage of a land-plant down through the stem into the young roots, which absorb the water out of the earth.'

Sachs' hypothesis thus attributed to the evaporation of transpiration the whole of the force which causes the current 
to flow upwards. He denied that the root-pressure is a contributing factor, calling attention to the fact that when the current is at its maximum owing to vigorous transpiration the vessels of the root contain air at a negative pressure. In this particular, however, his reasoning is clearly fallacious; though the negative pressure in the vessels exists, it does not interfere with the osmotic activity of the cortex of the root and the hydrostatic pressure resulting from it, which we have seen to cause the filtration into the vessels. The suction of the negative pressure no doubt aids the filtration when it is once established, but the root-pressure remains at work, as may be seen by cutting off the top of the stem or branch, when the exudation of water commences after a short time, during which the negative pressure in the vessels of the root-stock becomes gradually extinguished. The force of the root-pressure cannot therefore be ignored, as Sachs supposed, in considering the forces at work in causing the ascent of the stream. His own view, that nothing but evaporation of the water at the head of the columns is necessary, apparently predisposed him to regard it as superfluous when transpiration is established.

The hypothesis of Sachs that the water moves upwards in the walls of the cells in consequence of the evaporation from the leaves, did not long meet with general acceptance. The presence of water in the lumina of the vessels in varying quantity and mixed with air-bubbles of different dimensions forming columns known as Jamin's chains, which had been first determined by Hofmeister in I857, opened up probabilities of other forces at work and other paths than those he postulated. Both Von Höhnel and Boehm, in I878, confirmed Hofmeister's observation that the lumina of the vessels always contain water. Elfving showed in I882 that if the lumina of the vessels of a cut branch are occluded by drawing or forcing cacao butter 
into them, thereby making them impassable by water, the leaves wither very rapidly. Vesque, during the next year, compressed the vessels of a cut branch by a clamp so strongly as to occlude them. They were then unable to conduct water upwards, but regained the power when the clamp was removed and the lumina became re-opened. This observation was repeated by Kohl in I 885 and by Strasburger in I89I.

Sachs' suggestion of the part played by imbibition soon met with vehement opposition, though for some time nothing at all satisfactory took its place. Boehm, in I878, restated the older physical ideas; he said that the movement of water set up by transpiration is a function of the elasticity of the cell walls and the atmospheric pressure in parenchymatous tissues filled with sap; in cells with rigid walls the elasticity of the latter is replaced by that of air shut up in the cells. In another place he said, 'the movement of the water set up in plants by transpiration is a phenomenon of filtration depending on the pressure differences in neighbouring cells.' Though many botanists took part in the controversy, particularly Elfving, Von Höhnel, Russow, and Vesque, no uniformity of opinion was arrived at; indeed we find Vesque writing that of all the theories devised to explain the movement of water in the plant, that of Boehm is the least in agreement with the facts observed. In I889 Boehm came to regard capillarity as a sufficient explanation.

Nothing material was contributed to the elucidation of the problem till about the years $1883-4$, when Westermaier again brought forward the view of a special mechanism set up by the plant, and argued against mere physical agencies being solely concerned in the matter. His view of the nature of the mechanism differed from that of Sachs, inasmuch as he attributed the prominent part in the process to the pumping action of living cells. At the outset he criticized the theory 
of the action of capillarity, pointing out that the sinking of such a water column as is presented by a vessel, would in consequence of evaporation be greater than the raising of the liquid due to the capillary attraction of the cell wall. He then claimed that the imbibition of the cell wall on which Sachs laid so much stress is only a special case of capillary action. His theory of the action of the living cells was based upon the occurrence of such cells in immediate contact with the vessels at intervals along their course. Such cells obtaining water by endosmosis from those abutting on them would cause an infiltration into the vessels in the same way as the original infiltration into the vessels of the root. This infiltration he supposed to be intermittent, so that air and water would pass into the vessel alternately, giving rise to the Jamin's chain. We have thus the view of osmotic forces of some intensity occurring at various heights in a tree, and coming into active play in the living cells in the neighbourhood of vessels and tracheids. These living cells he held to be especially the wood-parenchyma and the medullary rays. This view had been suggested, though in a cruder form, by Grew in his Anatomy of Plants (I682), p. I26.

Godlewski put forward the same views as Westermaier in I884, and they received energetic support from many other writers, and especially from Janse in I887, and Schwendener in 1892 .

On the other hand they were opposed very strongly by Strasburger, who came to diametrically opposite conclusions in consequence of his own researches in I89I. The experiments he carried out present very formidable obstacles to the living-cell theory, for he showed that liquid can be raised to heights greater than that of the barometric column in cut stems, in which the living elements have been killed. Strasburger killed the tissues in the stems he experimented with in some cases by boiling them, and in others by 
causing the absorption of poisons. He thus killed considerable lengths of the structure, in many cases IO-I2 metres. He found that nevertheless water continued to pass up the stems, often to a distance of several metres beyond the injured region.

It is difficult after these experiments to see how the cause of the rise can be dependent on living elements. Strasburger suggested a return to the view that the phenomenon is purely physical, but he admitted that none of the explanations based up to I89I on such a hypothesis account satisfactorily for the facts.

The advocates of the living-cells hypothesis replied with considerable energy to Strasburger's objections, criticizing his experiments and the conclusions he based upon them. The most prominent was Schwendener, whose work appeared in I893. He said that though a continuous column of water cannot be raised by atmospheric pressure to a greater height than the barometric column, this is not the case with a Jamin's chain. He also called into question the statement that in Strasburger's experiments the cells were undoubtedly killed.

It is impossible in the present work to enter fully into the details of the controversy, which was maintained with some vehemence for a considerable time. From the work of Strasburger, however, we may trace new investigations of a physical character which had great weight, and which led the controversy to the position it occupied at the close of the century.

These investigations are based upon a property that water has been shown to possess of resisting tensile stress, so that the columns of liquid may be lifted bodily up the narrow tubes in which they are found. The theory that such is the method by which the water passes up the stem dates from I894 and I895, and was advanced separately by Dixon and Joly in Ireland, and by Askenasy in Germany. 
The cohesive property of water was determined as long ago as 1846 by Donny, but till the appearance of Dixon and Joly's researches it was thought the water must be free from air. These writers proved that this is not essential.

They determined that under the conditions in which the columns of water exist in the wood they will cohere under a tension of about seven atmospheres, which is sufficient to raise the liquid as high as the leaves at the summit of a tall tree.

The forces necessary to exert this traction, naturally sought for in the leaves, were described differently by the Irish and German observers. The former suggested 'surface tension forces, developed in the substance of the walls of the evaporating cells'. Askenasy spoke of imbibition by the cell walls. Both authors claim, however, that a second force can be found in the osmotic suction of the mesophyll cells, which draw water from the tops of the columns as the turgescence of the leaf tends to fall, and they agree further in saying it is probably the more powerful of the two. The relation between the two is put forward very clearly by Askenasy.

A theory so startling to botanists as this one naturally became the subject of much controversy, but was not regarded up to the end of the century as a satisfactory explanation of the phenomena. No complete agreement was arrived at as to the resistance to the flow of the transpiration current, which was very variously estimated. Schwendener computed that the suction power of the leaves is altogether inadequate to exert the necessary force-in fact he held it to be incapable of extending further backwards than 5 inches. Both he and Steinbrink also disputed the ascent of the entire Jamin's chain as a coherent column, basing their objections on the alterations of tension in the air-bubbles during the traction. The movement of the whole column is in antagonism to some observations by 
Vesque in I883, in the course of which he saw the water passing along the vessels between the air-bubbles and the walls. More recently Copeland has repeated Vesque's observations on this point. Strasburger saw the same thing in the tracheides of certain Conifers in I89I.

It is impossible to put forward here the details of the controversy, which extended up to and beyond the end of the century, especially as it has so far not led to a satisfactory elucidation of the phenomena nor to even a general agreement on the part of botanists. Mention may be made of the names of Russow, Nernst, Darwin, Vines, Ewart, as contributing to the discussion, which is still proceeding.

The rate at which the water moves in the wood was first satisfactorily examined by McNab in $187 \mathrm{I}$. He caused plants to take up dilute solutions of a salt of lithium, the salt of which he ascertained to travel at the same rate as the water, and by subsequently making spectroscopic examinations of the wood at different levels he determined the rate at which it penetrated the tissue. Pfitzer, in 1877 , and Sachs, in 1878 , carried out further and more accurate researches on the same lines. 


\section{CHAPTER II}

\section{THE DEVELOPMENT OF KNOWLEDGE OF THE FIXATION AND SUBSEQUENT CHANGES OF CARBON DIOXIDE BY THE PLANT}

THE period I860-I900 was exceptionally rich in investigations into the problems presented by the great question of the nutrition of the vegetable kingdom. They attracted large numbers of workers, among whom may be included many of the keenest and most acute observers of the century; and though we cannot claim that the end of the period found us in possession of all the secrets which are connected with the nutritive processes, a very substantial advance was made in that direction.

At the beginning of the period the outlook was but poor. A few isolated facts were known, but apart from the work of Liebig in the forties, vegetable physiology had made but little progress since the days of Sénébier and De Saussure. The early work of Priestley, Ingenhousz, and De Saussure, had shown that plants take in carbon dioxide from the air and give out oxygen; Sénébier had determined the connexion between these two processes, and had made out that it is in some way concerned in the construction of organic substance. The observation of De Saussure made a little later, that when a green plant is exposed to light in air containing carbon dioxide it gains in weight, had found a place in the literature of the subject. He had also determined that the greater part of the increase of weight of such plants is due to the carbon dioxide, together with water absorbed from the soil. He had not, however, connected the existence of the chlorophyll with these facts ; 
indeed he entertained doubts as to the significance of chlorophyll and even as to the necessity for its presence, for he noticed that the red garden Orache (Atriplex hortensis) behaved like an ordinary green plant, and not knowing that chlorophyll is present with the red pigment, he failed to recognize its importance.

A certain connexion between chlorophyll and nutritive processes had become apparent a little later, when Dutrochet discovered that it was only in cells containing the pigment that the absorption of carbon dioxide and the concomitant exhalation of oxygen were noticeable. Von Mohl had observed the almost universal presence of starch grains in the substance of the chloroplasts, or chlorophyll corpuscles, as they were then called. Naegeli, Cramer, and Boehm had noticed the same appearance. The significance of the observation had, however, eluded the grasp of all, for Naegeli, writing in 1858 , did not associate the construction of the starch in any way with the pigment.

Liebig had reaffirmed De Saussure's statement that the source of the carbon dioxide is the air and not the soil; in opposition to the adherents of the theory of the nutrition of plants entirely from the humus of the latter.

No correlation of these isolated facts had been forthcoming; no one had appeared apparently capable of making the great generalization to which, in the light of subsequent researches, we can see they pointed. It was reserved for Sachs to lead the way, and to bring forward the idea that these isolated and dimly-connected facts are severally parts of one great process, the formation of organic substance from inorganic materials, the fundamental process underlying all organic life, whether animal or vegetable. Sachs' work in this direction gave a new starting-point and a fresh impetus to the series of laborious investigations into these great problems, and directed them into the channels which have to-day brought the story of the con- 
struction of organic substance so far on the way to completeness.

It is to the work of Sachs himself that we are indebted for the establishment of no inconsiderable part of the foundation on which our modern views are resting to-day. He called attention to the part played by chlorophyll; he correlated the growth and nutrition of the organs of the plant with the activity of the chlorophyll corpuscles; he investigated the conditions of the formation of the pigment, and showed its relation to light and its dependence thereon for both its formation and its subsequent activity ; and he for the first time demonstrated what are at any rate some of the products of its activity.

But this is not all the credit that must be rendered to Sachs in the solution of these great problems. By his own illuminating researches he opened the way to the work of others, work very largely carried out under his own inspiration by his many famous pupils. The light he threw upon these questions stimulated enthusiasm in many other quarters than Würzburg, and a great outbreak of research into the chemical and physical problems connected with life became noticeable throughout all Europe.

While Sachs' researches were carried out with great care and exactness for the time, it is not surprising that many of his conclusions, though fundamentally sound, have been found to need considerable modification in later years, as the resources of chemistry and physics have developed and the older, somewhat crude methods of research have given place to others which admit of more exactitude. That was only to be expected and cannot detract from the merit of Sachs' achievements.

The study of the nutritive processes of plants, starting again then from the school of Sachs, has been directed to four main points in connexion with the formation of carbohydrate substance. These have been the gaseous inter- 
changes involved; the nature of the chlorophyll apparatus; the stages of the process of what was till lately known as the assimilation of carbon dioxide, but which is now spoken of as photosynthesis, and the supply and utilization of the energy needed for the latter. These must be examined separately.

The Gaseous Interchanges. The early observations to which attention has already been called afforded proof that a great deal of the substance of the green plant is furnished by the carbon dioxide which the environment affords it. De Saussure indeed concluded that the greater part of this carbon dioxide is derived from the air, though he thought a certain amount may be taken from the soil. $\mathrm{He}$ was acquainted also with the fact that the quantities of carbon dioxide absorbed and of oxygen exhaled by the green plant are approximately equal.

The problem of the mode of absorption of the gas attracted considerable attention during the whole of the period with which we are concerned. The larger question of the whole of the gaseous interchanges between the green plant and the air was in most cases the subject of investigation, but for the present discussion we may conveniently postpone the consideration of respiration.

Two views were prominently before the minds of physiologists during the whole period, and a somewhat vehement controversy was continued down to almost the end of the century. They may be referred to as the stomatal and the cuticular theory respectively.

The stomatal theory followed naturally some observations and deductions made by Dutrochet as long ago as 1832 . He called attention to the continuity of the intercellular spaces in the leaf, and their connexion with its exterior by means of the stomatal apertures, and suggested for them the function of a lung so far as the exhalation of carbon dioxide is concerned. In I850 Garreau also con- 
ducted experiments which led him to trace a connexion between the stomata and gaseous interchange. Though these opinions had their origin more in connexion with respiration than with the appropriation of carbon dioxide, they are noteworthy in that they gave a certain startingpoint for the controversy we are about to discuss, and that they militate against what became for a considerable time the accepted view of the mechanism of gaseous absorption.

The view that the open stomata afford the path for the gaseous interchanges, was put forward in a somewhat tentative fashion by Sachs in $\mathrm{I}^{865}$ in his Experimentalphysiologie. In his Lehrbuch he spoke more decidedly to the same effect, and in the Vorlesungen, in I882, he declared the admission of gases to the interior of the plant to be one of the functions of the stomata. Sachs, however, did not limit this absorption to these organs, for he spoke in the Lehrbuch of diffusion of gases through the cuticle as a certain medium of interchange.

The cuticular hypothesis owed its origin to Boussingault, who was occupied with the problem from I86I to I867. At the outset of his researches he re-examined and re-stated with greater exactness De Saussure's view of the quantitative relations between the two gases concerned, a very important factor in the discussion of the subsequent changes. The experiments on which he based his theory were performed with leaves of Nerium Oleander, which bear stomata only on their lower surfaces. Taking two precisely similar leaves of this plant, he coated the upper side of one and the lower side of the other with lard, which he took to be impermeable to the passage of carbon dioxide. The leaves so prepared were then exposed to bright diffused light for eight hours, in glass tubes containing air to which a known quantity of carbon dioxide had been added. He found that the leaf with the stomata occluded decom. 
posed 17.5 c.c. of carbon dioxide, while the leaf with them open only decomposed Io c.c. The amount of carbon dioxide in the air in the glass tubes was about 30 per cent.

The inference that Boussingault drew was that the mode of entry of the carbon dioxide into the leaf is a process of diffusion through the epidermis into the interior; the upper surface being more actively concerned than the lower.

The more definite suggestion that the cuticle is the part of the epidermis which is the important factor was due to Barthelémy, who brought forward the results of his experiments in support of Boussingault in I868. He held that the constitution of the cuticular layers of the epidermal cell walls shows a special fitness for transmitting carbon dioxide into the leaf, approximating asit does, according to Frémy, to the constitution of caoutchouc.

Barthelémy thought that the function of the stomata is valvular, and that they regulate the exit of gases from the plant, but do not allow them to enter. Like Boussingault, therefore, he denied to them any share in the process of absorption of carbon dioxide.

Barthelémy's views were opposed by N. J. C. Müller in I 870 and I873; the experiments conducted by the latter being upon the same lines but carried out with greater exactness. Another paper by the former author appeared in 1874 , in which he brought forward further evidence in support of his original position, and affirmed it with greater emphasis than before.

He was replied to in 1877 and 1878 by Merget on the basis of experiments made by exposing leaves to the vapour of mercury, which, being incapable of diffusion, can only enter through the stomatal apertures. Merget found the effects of the vapour very speedily noticeable in the interior of the leaf. 
A somewhat animated controversy ensued for a few years, but it cannot be said to have advanced our knowledge of the subject.

The stomatal theory received some support from the work of Wiesner, in I879, on the diffusion of gas through small apertures. He determined the rates at which equal volumes of gases of different densities pass through epidermis bearing stomata, and found that they agreed with the rates required on the theory that they pass by gaseous diffusion through the apertures.

In I880 Pfeffer called attention to the effect of the diminution of turgidity in the guard cells of the stomata, and affirmed that it must render the absorption of carbon dioxide extremely difficult and hence markedly diminish the photosynthetic activity of a subaerial leaf. Pfeffer, however, did not oppose the cuticular theory; on the other hand, he held it to play a certain if subordinate part.

In I884 Haberlandt attacked the view that the intercellular spaces are associated with gaseous interchanges, holding them to be more particularly adapted to direct the outflow of plastic substances from the constructing cells and confine it to the most direct routes. He accordingly favoured the theory of cuticular absorption.

As a result of careful experiments on the diffusion of gases through isolated cuticle, or perhaps epidermis, Mangin, in I887, was led to support the stomatal theory. He calculated the amount of carbon dioxide that passed by osmosis through specially prepared membranes consisting of the outermost layers of certain leaves, isolated by the action of bacilli, and found it to be insufficient to account for the whole of the quantity which he determined in independent experiments to take part in the gaseous interchanges in similar living leaves. He computed further that during the appropriation of carbon dioxide, the tension of that gas 
in the air is too small to produce much osmosis through the cuticle.

After I887 opinion set in steadily in favour of the stomatal theory. Wiesner and Molisch proved in I889 that an epidermis with no stomata does not allow of an appreciable mechanical passage of gas under pressure; Boehm, in his researches on the formation of starch from various substances supplied to the plant, found diffusion possible, but extremely difficult and slow, through the epidermal cells.

Researches carried out by Stahl in I894 were based upon the discovery made by Sachs much earlier, that the appearance of starch in the chloroplastids immediately follows the appropriation of carbon dioxide, a point which will be discussed a little later. Stahl used the appearance of starch as affording, therefore, qualitative evidence of the absorption of the gas. He examined the behaviour of leaves of numerous plants when certain limited areas of each were coated with wax in such a way as to occlude the stomata. $\mathrm{He}$ found a uniform result; abundant starch formation could be observed in all the normal parts of the leaf, but none was formed in the coated areas, even though they were given a prolonged exposure to light.

Experiments carried out in the same year by Meissner on somewhat similar lines gave the same results.

Some researches of Frost Blackman's, carried out at Cambridge, overlapped those of Stahl and Meissner, but were not published till I895. While dealing with the general question they supplemented some observations made by Godlewski in I873, and, together with these, afforded an explanation of the results of Boussingault, on which the cuticular hypothesis was founded.

Blackman's method consisted of enclosing leaves in two specially prepared glass chambers, so arranged that each face communicated with a single chamber and the two chambers were perfectly separated from each other, the 
leaf forming a diaphragm between them. A tube led to each chamber from a reservoir containing air supplied with a known percentage of carbon dioxide, usually about I per cent., and another led from the chamber to a titration apparatus specially devised for the measurement of very small quantities of the gas. Each leaf was carefully examined with a lens to ensure that no perforations in its surface existed. A stream of air was drawn through the apparatus for a definite time by an aspirator under proper precautions to ensure a regular and measurable flow. The light was admitted to the leaves by exposing the apparatus either to direct sunlight or to the reflected light from a heliostat, and was made to fall upon the leaves at right angles to their surface. Measurements were usually taken of the quantities of gas passed over the surfaces of the leaves during fifteen minutes. The leaves used were those of Ampelopsis hederacea, Platanus occidentalis, and Polygonum sachalinense, with stomata on the lower surface only; and Alisma Plantago and Tropaeolum majus, whose surfaces are both stomatiferous. The results showed that the absorption of carbon dioxide follows extremely closely the distribution of the stomata; in fact, in the cases of the leaves of the first three plants mentioned, there is no intake of the gas by the upper surfaces.

Blackman subsequently repeated Boussingault's experiments, using, as he did, the leaves of the Oleander and passing over them a mixture of air and carbon dioxide of the same composition, viz. one containing 30 per cent. of the latter. He found that he confirmed Boussingault's results in all essential particulars. He then used mixtures of the two in different proportions and obtained, with low percentages of carbon dioxide, exactly opposite results. With a high percentage of the gas, then, he determined that a leaf with occluded stomata always decomposes more than a normal leaf, while with low percentages it 
decomposes less. The great amount of carbon dioxide absorbed by the stomata under a high pressure of the gas acts as a poison to the chlorenchymatous cells.

Earlier researches of Godlewski's, made in I873, show that large quantities or high pressures of carbon dioxide in the air prevent the formation of starch, which, as we shall see later, is a sign of the absorption of the gas.

In the light of these researches it is evident that Boussingault's conclusions cannot be accepted as indicating what takes place in a normal leaf. When carbon dioxide is supplied in too concentrated a mixture, and consequently at an altogether abnormal pressure, sufficient can diffuse through the cuticle to give apparently normal appropriation. With approximately normal pressure, no appreciable diffusion takes place.

It remained for Brown and Escombe to show, in I900, that it is possible for carbon dioxide, present in as low a proportion as .026 per cent. in the air, to enter a leaf through such minute apertures as stomata in quantities so great that a sunflower is able to manufacture $\mathrm{I} \cdot 8$ gram of carbohydrate per square metre of surface per hour. In a series of experiments on the passage of carbon dioxide through diaphragms pierced by minute apertures they found, if the latter are sufficiently small, diffusion takes place as rapidly as if there were no separating partition at all. This result was reached when the individual openings were sufficiently far apart to be unable to influence each other's activity, which was the case when the distance between them was at least ten times the diameter of the aperture. Under favourable conditions for subsequent photosynthetic activity, and within certain limits of concentration of the carbon dioxide, the absorption by a leaf proved to be proportional to the partial pressure of the gas. In other words, there is an approximate proportionality between the photosynthetic work a leaf can accomplish 
and the partial pressure of the carbon dioxide in the air bathing the leaf surface. Thus Brown and Escombe, adopting a method slightly different from Blackman's, which enabled them to work with leaves attached to the stems of their plants in the open air, were enabled to confirm his results in all essential particulars.

The close of the century found us thus in possession of evidence proving conclusively that in ordinary green leaves the process of the absorption of the gases concerned in photosynthesis, is one of diffusion through the stomata into the intercellular spaces of the interior, the rate depending on its partial pressure at the moment. We shall see later that the same means of interchange subserves the respiratory processes.

The ultimate absorption of gas by the living protoplasm of the leaf must depend, however, upon a process resembling very closely Boussingault's suggested method of entry. The gas in the intercellular spaces must penetrate the walls of the cells lining them to reach the seats of chemical change. The question of the permeability of the walls by carbon dioxide has been the subject of several researches. Allusion has been made to Barthelémy's views based on Frémy's opinion of the composition of cuticle. Though experiments have proved these to be unfounded, this is not the case with the statements of Wiesner and Molisch. These observers showed that so long as cellulose walls are wet, they are permeable by carbon dioxide, but lose the permeability as they become dry. Leitzmann made a similar observation in $\mathbf{I} 887$.

It is clear that the stomatal method of absorption cannot apply to plants below the Ferns, in which, with rare exceptions, and those very local, stomata do not exist. As a rule these are not strongly cuticularized, so that the properties of ordinary cellulose, such as we find in the intercellular spaces, come into play. Sachsse showed, in I888, that 
aquatic plants not only absorb the free carbon dioxide which is in solution in the water, but obtain a further supply from dissolved carbonates and bicarbonates. The observation was made almost simultaneously by Hassak and was confirmed by Darwin and Pertz in I896.

The exhalation of oxygen accompanying or following the appropriation of carbon dioxide was not made the subject of such close inquiry. The chief experiments made were directed to establishing satisfactory tests for the presence of the gas. In 1879 Hoppe-Seyler introduced haemoglobin as a reagent. This substance absorbs even traces of free oxygen with great avidity and presents distinctive spectra in its presence and its absence. In I89o a further test was devised by Beijerinck, depending on the ready change of colour produced by traces of free oxygen in solution of indigo carmine. Biological methods were devised as well as chemical; in I88I Engelmann showed that Bacterium termo is actively motile in the presence of small quantities of the gas and perfectly quiescent in its absence. In I89I Beijerinck found that the luminosity of certain bacteria may be used to determine whether or no green Algae are exhaling oxygen, the gas causing them to glow with increased intensity.

The Chlorophyll Apparatus. Sachs claimed to be the first to express the opinion that chlorophyll is the organ to which the appropriation of carbon dioxide must be attributed. He put forward the view in his Experimentalphysiologie in 1865 in the following form: 'It is a striking phenomenon in the history of vegetable physiology that the chlorophyll has not long ago been distinguished definitely as the instrument of the separation of oxygen.' He rested his opinion on the facts that only organs containing chlorophyll can effect the decomposition of carbon dioxide and yield oxygen when exposed to light, and that the first recognizable product of the process appears not in any GREEN 
haphazard place in the cell containing chlorophyll, but in the chlorophyll body itself.

Though Sachs was for so many years indefatigable in the prosecution of research, it will be generally admitted that his work upon this particular subject constitutes one of his greatest claims to eminence. During the greater part of the sixties it was engaging his attention, and in the earlier years especially his discoveries were very far-reaching.

During these early years, as we have already seen, Sachs showed that chlorophyll can be formed only in the light, except in rare cases, and he distinguished between the rôle of the light in such formation and the part which it plays in its subsequent activity, showing that the former process is not in any way directly connected with the exhalation of oxygen.

Starting from these discoveries and conclusions of Sachs the trend of thought has been gradually shaping itself through a period of nearly fifty years in the direction of the recognition of the mechanism or, as it is now called, the chlorophyll apparatus, as an independent machine for the performance of certain work, viz. the construction of organic substance from inorganic materials; this mechanism, though present for the most part only in plants, is not an essential feature of the vegetable organism, for it is occasionally and exceptionally present in some members of the animal kingdom, and is, also exceptionally, absent from some plants, and in all the higher ones at any rate appears only after they have reached a certain degree of development. The plants permanently without it are usually held to be degraded forms, but this need not affect the view of its independence. Originally present in the primordial ancestor of both animals and plants, it has come to be localized almost entirely in the latter as evolution and development have proceeded; nearly all animals and some plants ceasing to contain it. The process of parting from 
it took place much earlier in the animal than the vegetable kingdom ; it has almost disappeared from the former, and is still slowly leaving part of the latter. In the remainder, however, it has found its great development and its permanent abode.

The development of knowledge of the chlorophyll mechanism will be seen to afford a basis for the view just stated, which has really gradually come into existence as the result of the researches of the latter half of the century.

The first advance in our knowledge of the mechanism was made by Boussingault in I864 and confirmed by him in 1869 , when he demonstrated that the appropriation of the carbon dioxide is exhibited in full activity only by normal green chloroplastids, or, as they were at first called, chlorophyll corpuscles. Though these plastids had been seen by Von Mohl, up to this time their activity had not been asserted.

In I88I Pfeffer showed that the plastid, whose structure had been meanwhile studied by Pringsheim, is not able to work in the absence of the colouring matter which it normally contains. In his experiments he made use of leaves which did not develop their chlorophyll on account of their not being supplied with iron, a relation which had been discovered much earlier by Gris.

Zimmermann, in I893, confirmed Pfeffer's observation, while in 1897 Kny showed that the chlorophyll without the plastid is equally inefficacious. Kny made use of Engelmann's bacterium method for the detection of oxygen; he exposed to light drops of oil to which the colouring matter had been added; the bacteria were immersed in the solution in air containing carbon dioxide, but no exhalation of oxygen followed. Nor was Czapek more successful at the end of the century. He introduced his coloured oil drops into living cells, but they were without effect. ${ }^{1}$

${ }^{1}$ Since the end of the century Usher and Priestley have claimed to 
The plastid, or chlorophyll corpuscle, appears therefore to be the essential part of the machinery. Its structure was made the subject of study by Pringsheim in 1874 . He treated the plastids of leaves with dilute alcohol, in which the pigment is soluble, and found a colourless stroma left behind. Others he exposed to the action of steam, when he found the chlorophyll exuded in viscid droplets. The stroma which remained he described as a spongy or trabecular structure, whose meshes are normally occupied by the pigment. The latter he held to be only mechanically associated with the framework.

In I883 the subject was further studied by A. Meyer, who agreed with Pringsheim that the stroma is spongy in character. In the colourless stroma he distinguished little specks or 'grana' of green colour, and he described them as filling up the meshes of the network of the corpuscle. He considered the pigment to be oily in its composition.

Reinke in the same year agreed, from the absence of fluorescence of the plastid, that there must be some kind of combination between the latter and the pigment, fluorescence being a property of chlorophyll solutions.

A lacunar structure was suggested by Chodat in I892.

At the end of the century Timiriazeff determined that the colouring matter is limited to a thin layer on the surface of the plastids. IVhen the latter are examined by red light, the so-called 'grana' of Meyer can be seen as small black specks in this layer, whose thickness he estimated at .I of a micron.

Timiriazeff found also that if chlorophyll grains of Phajus, which are rather larger than most, are burst by admitting water to a solution of sugar in which they are mounted, preparations showing this structure can be made with-

be able to show that a strong solution of chlorophyll can decompose carbon dioxide in the absence of the plastid. Their results have not been confirmed. 
out difficulty. The process of disintegration which sets in as the sugar solution becomes dilute must be arrested at the first sign of bursting, which can be done by adding some sulphate of copper. The preparation, if stained then with eosin, shows the pink plastid protruding slightly between the gaping lips of the green outer layerf Timiriazeff said that Naegeli made a similar observation much earlier.

From the thickness of the layer Timiriazeff computed the concentration of the pigment, which he held to be about four thousand times as great as that of a solution of an emerald green colour, such as presents the characteristic spectrum. He said the pigment is nearly solid, and its superficial colour almost black. This very great concentration may explain the absence of fluorescence noticed by Reinke, as fluorescence is only exhibited by solutions of moderate strength.

The nature and relations of the colouring matter attracted considerable attention on the part of chemists as well as botanists; but it cannot be said that the results of their investigations were satisfactory.

In I860 Frémy showed that an alcoholic extract of leaves, if shaken with a mixture of ether and hydrochloric acid, deposits two pigments, one greenish-blue and the other yellow. He was uncertain whether these preexist separately in the chlorophyll, or whether they are formed from a single antecedent by the action of the acid. Frémy called them phyllocyanin and phylloxanthin respectively.

Timiriazeff argued in I869 that they arise from a splitting of the pigment of the leaf.

In I872 Kraus determined the existence of two colouring matters in the plastids; a green one, which he considered the proper chlorophyll, and a yellow one,-to which he gave the name xanthophyll. He traced no relation between 
them. They do not seem to be identical with Frémy's pigments.

In I877 Frémy thought that his phyllocyanin was the potassium salt of a complex acid.

Konrad, in I872, and Pringsheim, in I874, opposed the views of Frémy, maintaining that chlorophyll is a single pigment, though occurring together with others in smaller amounts in the corpuscle.

Gautier made analyses of the matter extracted by alcohol, and in 1876 based upon them a view that the pigment is allied to the colouring matter of the bile of animals-bilirubin. He attributed to the two the formulae $\mathrm{C}_{16} \mathrm{H}_{18} \mathrm{~N}_{2} \mathrm{O}_{3}$ and $\mathrm{C}_{19} \mathrm{H}_{22} \mathrm{~N}_{2} \mathrm{O}_{3}$ respectively. Hoppe-Seyler, in $\mathrm{I} 879$, on the basis of similar analyses of an ether and alcohol extract of leaves, concluded that the pigment, which he found to yield an ash containing magnesium and phosphoric acid, is allied in its composition to lecithin. He did not, however, consider the residue from his extracts consisted of pure chlorophyll. He termed it chlorophyllan.

Tschirch identified this substance with a body described by Pringsheim in 1879 under the name of hypochlorin. an acid derivative of chlorophyll.

In I895 Schunck and Marchlewski described a derivative of chlorophyll, which has apparently much in common with the colouring matter haematoporphyrin or iron-free haematin, itself a derivative of haemoglobin the pigment of blood. This body, to which they give the name phylloporphyrin, exhibits an absorption spectrum almost identical with that of haematoporphyrin, the bands being a little more to the right, but otherwise coinciding. The two pigments therefore appear to be related, though perhaps not closely. They seem both to give rise to pyrrol on dry distillation.

Some observations upon the antecedents of chlorophyll in the leaf were made by Timiriazeff in I886. Acting upon 
a moderately concentrated solution of the pigment with nascent hydrogen he found it transformed into a very pale yellow liquid, which in the presence of traces of air or oxygen resumes very rapidly its green appearance. This yellow colouring matter, when in dilute solutions, is characterized by a total absence of bands in the less refrangible part of the spectrum; in greater concentration it gives bands nearly corresponding to bands 2 and 4 of the chlorophyll spectrum, but no trace of band No. I. He was able to detect the presence of this pigment in etiolated seedlings if he prepared the extracts in the total absence of light. He could not satisfy himself of the presence of this reduced constituent of chlorophyll in an ordinary green leaf, but he pointed out that such demonstration must be extremely difficult, if not impossible, on account of the readiness with which it would be converted into chlorophyll on being exposed to light.

Timiriazeff gave the name protophyllin to this new pigment. He was led by his discovery to the view that we have to admit the existence of at least two states of oxidation of the chlorophyll, which are readily transformed from one to the other by the simple processes of oxidation and reduction. He made use of this observation, as will be pointed out later, in formulating a theory of the mode of action of chlorophyll.

A theory of the derivation of chlorophyll from etiolin was put forward by Gris in $I_{57}$ and supported twenty. years later by Mikosch. It appears to have little to support it except the fact, observed by Pringsheim, Wiesner, and others, that the two pigments are both contained in the green parts of plants and perhaps in the same plastids. The spectra of the two pigments have a general resemblance.

The result of the investigations of the period into the nature and chemical relationships of chlorophyll did not then lead to very concordant results. All that appeared 
certain was that chlorophyll is associated in the plastids with many other pigments, but there was no general agreement as to the nature of these, to their mode of origin, nor to their relation to chlorophyll at all. The pigments described by one author could not be satisfactorily identified with those of another, nor could the immediate source of chlorophyll be identified with accuracy.

In 1859 Sachs called attention to the fact that plants grown in the dark owe their yellow colour to the nondevelopment of chlorophyll in the cells. A little later he showed that in light of moderate intensity, decomposition and recomposition of the pigment continue without cessation. This observation was confirmed by Famintzin in 1867, and by Wiesner in 1876 . The latter writer stated that in strong light the most refrangible rays are those which are most concerned in the development of the pigment. Reinke, in I893, attributed the effect to all the visible rays, but especially to those between the spectrum lines $B$ and $D$, which are the most potent.

The influence of temperature on the development of the colour was first pointed out by Sachs in I864. He said that at the minimum temperature for growth the plastids do not turn green. Wiesner, in 1877 , said that there exists an optimum temperature for the development of the pigment, which, however, is not uniform for all plants. In I880 Elfving showed that when the temperature is too low, the access of light produces a deeper yellow in the plastids, increasing the amount of etiolin, instead of giving rise to chlorophyll.

As a further factor in the development of the latter, we have the free access of oxygen. Correns showed in 1892 that if the partial pressure of this gas is reduced to such a point as almost, but not quite, to inhibit growth, the green colour will not develop.

The idea of the independent nature of the apparatus de- 
veloped gradually from the time when Sachs called attention to the fact that "growth of the organs and assimilation in the chlorophyll are two processes mutually independent in a high degree' (Lectures on the Physiology of Plants, Eng. ed., p. 300). In I88I Engelmann discovered that an isolated plastid can effect a little decomposition of carbon dioxide. In I887 Haberlandt made a still more explicit statement on this point, based on observations of the behaviour of the plastids of Funaria hygrometrica in a 25 per cent. solution of sugar. Ewart also, nine years later, established the accuracy of the observations of his predecessors. He investigated a number of plants, cutting sections of their leaves in sugar solutions of various concentrations. Many plastids escaped from the cut cells, and he placed them on slides in sugar solution and added numbers of the organism Bacterium termo taken from pure cultures. Great precautions were observed in order to exclude all traces of other organisms, such as small unicellular Algae, which are not uncommon on moss leaves. The preparation being made with all due care, Ewart closed the cells hermetically and waited. In some cases movements of the bacteria indicated that oxygen was being given off; in others there was no result. The best results were obtained when the plastids were quite free from any débris of plasma from the cut cells. The plants with which positive results were obtained were Catherinea undulata, Funaria hygrometrica, Dicranum scoparium, Vallisneria spiralis, and Selaginella helvetica.

Engelmann obtained similar results with the green cells or plastids which he was able to isolate from the body of Hydra viridis. Whether or no these are to be regarded as chloroplasts is, however, disputed. Most zoologists regard them as Algae living in some kind of symbiosis with the Hydra.

The balance of evidence is therefore in favour of the view 
that the chlorophyll mechanism is something independent of the general body of both animal and plant. This is supported further by Ewart's observations in I 896 of the conditions under which inhibition can be brought about. Whenever such inhibition was caused by changes in the environment, or by the administration of drugs, the failure could be traced directly to the plastid, the cell in which it was found not being affected, or not to the same extent.

The mechanism seems therefore to have been shown to be an independent apparatus. It is, however, equally certain that it is highly specialized; so much so indeed that its death or destruction slowly or rapidly follows a disturbance of the relations of acclimatization between the plastid and the cell.

Other pigments have been supposed to be concerned under certain conditions in the liberation of oxygen. In some cases they have been associated with the ordinary plastid and appear to have taken the place of chlorophyll in it. Draper showed in 1878 that etiolated plants evolve oxygen, and in I88I Engelmann traced the power to the etiolated plastids. The observation was confirmed in 1897 by Ewart. In both cases the method used was Engelmann's bacterium method. The power according to both observers is very feeble. The observation gives some support to the view already stated, that etiolin is an antecedent of chlorophyll in the plastid. Like the latter it is formed under the influence of light. Elfving's observation on the result of illumination at a low temperature has already been alluded to.

Kohl, in I897, observed that both xanthophyll and carotin exhibit a similar power.

A pigment not associated with a plastid was said by Engelmann in 1888 to be able to cause the exhalation of oxygen. This was a colouring matter found in certain purple bacteria and named by its discoverer bacterio-pur- 
purin accordingly. The matter was explained, however, by Ewart's discovery in 1897 that the bacteria contain a little chlorophyll, which is masked in the normal condition by the purple pigment.

The Processes of Photosynthesis. As has already been mentioned, the first investigations in this direction which led to definite results were those of Sachs, which were undertaken and carried to such conspicuous success in the years I860-5. Not that the work in any way reached finality-on the other hand, but little of its result remains exactly as Sachs left it. It was, however, work on which all the accurate knowledge of more recent times has been based.

Sachs' views based upon these researches were stated by him in the Vorlesungen (Eng. ed., p. 307), in the following terms :

'In a long series of micro-chemical and experimental researches on the growth of starch and sugar, ... I came to the conclusion in I862 that the enclosed starch, which had already been observed in the chlorophyll corpuscles by Naegeli and Von Mohl, is to be regarded as the first evident product of assimilation formed by the decomposition of carbon dioxide. I said to myself, if this view is right, the formation of starch in the chlorophyll corpuscles must cease on the exclusion of light, since the decomposition of carbon dioxide can then no longer take place; and that in like manner renewed access of light to the chlorophyll corpuscles must also bring about a renewal of the formation of starch in them. These and similar deductions were confirmed by appropriate investigations.'

Again he said :

'In the nutrition of plants it is only necessary in the first place to decompose carbon dioxide under the influence of light in the cells containing chlorophyll, with the $\mathrm{co}^{-}$ operation of certain mineral matters absorbed by the roots, and to produce at the cost of its carbon an organic substance-starch-which then represents the starting-point, 
so to speak, from which all the organic substances of the plant proceed by progressive chemical changes.' (Ibid., p. 308.)

The point which thus chiefly attracted Sachs' attention during these researches was the appearance of starch. Holding it to be, as he said, the first evident product of assimilation, he gave his attention primarily to means of demonstrating its formation and to determining the conditions under which it makes its appearance. It was during these researches that he devised his well-known macroscopic test for the presence of the photosynthetic changes. By shading with some opaque covering part of a leaf which was being exposed to sunshine, and later, with proper precautions, staining the contents of its cells with iodine, he showed that starch is only formed in the cells which receive the bright illumination. We must not, however, think that the probable complexity of the formative processes escaped his attention. To this point we shall return.

The next point in the development of knowledge was made by Godlewski, who was repeating and extending Sachs' researches in I873. Sachs quoted him as demonstrating

' By experiments as ingenious as they were simple that in an atmosphere devoid of carbon dioxide no starch is produced in the chlorophyll corpuscles, even in the light. He also found that the starch produced in the chlorophyll disappears not only in the dark, but even in intense light when the surrounding air contains no carbon dioxide.'

This point, that the air, and not the soil, is the source of the appropriated carbon dioxide was further elaborated in I 877 by Moll, who found that unless particular leaves were in contact with the gas, no starch appeared in them, even though all the products of absorption from the soil could reach them and they were adequately illuminated. Sachs himself repeated the demonstration in 1882 and showed 
that it disproved the view that the carbon dioxide can be absorbed either altogether or in part from the soil by the roots.

Sachs summed up his views in the following sentence :

'According to my theory, the basis for the whole of the organic substance of a normal plant is provided by the formation of starch in the chlorophyll of the organs of assimilation, and above all the whole of the carbon, in whatever organic combination it may be found later, occurs originally in the form of starch.' (Vorlesungen, Eng. ed., p. 3I2.)

It is not to be wondered at that the promulgation of this view, which, though not now held, marked a very great advance in the direction of the truth, led many observers to speculate upon the range of chemical change and the probable sequence of events in the passage from the simple substances water and carbon dioxide to the very complex carbohydrate starch, a compound so complex that its constitution was not at the time grasped by chemists themselves. Theories of the stages of construction, at first purely hypothetical, were slowly formed. There was but little to go upon; the substances from which the construction was effected had been determined, but no information further was available except that the appropriation of the carbon of the carbon dioxide is attended by the exhalation of a volume of oxygen approximately equal to that of the carbon dioxide concerned.

In I86I Berthelot and Kekulé suggested that the first stage must consist of the formation of formic acid or some other member of the formyl group, but the credit of devising the first complete hypothesis, covering the whole process, was due to Baeyer in I870. This remarkable hypothesis was in many respects supported by experiment, and was still the most prominent one at the close of the century. It was the following:-the carbon dioxide and 
an adequate quantity of water are split up, the former yielding carbon monoxide and oxygen, the latter oxygen and hydrogen; the oxygen groups unite and are exhaled ; the carbon monoxide and the hydrogen unite to form formaldehyde;-six molecules of the formaldehyde polymerise to form a molecule of sugar; - the sugar by dehydration loses a molecule of water and becomes starch.

This hypothesis was received with acquiescence in most quarters, but not in all. Gerland, in I87I, and Sachsse, in I877, suggested that chlorophyll itself is the primary product of the synthetic process, while Pringsheim in I880 held that hypochlorin fills that place, a view untenable in view of the fact established by Hilburg, that the quantity of hypochlorin obtainable from a leaf does not diminish when no carbon dioxide is supplied to it.

Baeyer's hypothesis was challenged in I 877 by Erlenmeyer, who proposed certain modifications of the early stages in the process. According to him, the first interaction of carbon dioxide and water leads to the formation of formic acid and hydrogen peroxide, and these are subsequently decomposed, yielding formaldehyde, water, and free oxygen. He made no suggestion as to the further changes.

In the later years of the century other hypotheses were advanced, which, like the former, were not at once based upon experimental evidence. Indeed we may say in passing that up to Igoo very little experimental evidence of any kind bearing upon the early stages of construction was forthcoming.

Vines put forward a theory in I 886 which associated the matter more closely with the plastid. Starting with the observation that a carbohydrate substance, cellulose, is produced or secreted by protoplasm in the process of the thickening of cell walls, and noticing the formation of starch grains in the chloroplast as soon as the absorption of carbon dioxide has been established, he argued that the carbo- 
hydrate may perhaps not be formed directly from the simple materials absorbed but may appear as a secretion product from the chloroplast. He suggested that a substance possibly allied to formaldehyde may be first formed according to Baeyer's theory and that this may be used in the construction of protein by combining with the nitrogen and sulphur absorbed in the form of salts from the soil, or with nitrogenous substances derived from previous decompositions of protein. This protein may be then assimilated by the protoplasm of the chloroplast, and from the latter the starch may be secreted.

Six years later, in 1892 , Crato put forward a hypothesis of a different nature from either. He suggested that the carbon dioxide after absorption becomes ortho-carbonic acid, which exists in solution in the cell sap. This acid has the structure of a closed benzene ring in which six molecules are linked together. This becomes decomposed, liberating six molecules of water and six molecules of oxygen, and forming a hexavalent phenol $\mathrm{C}_{6} \mathrm{H}_{6}(\mathrm{OH})_{6}$. This then undergoes a molecular rearrangement and becomes glucose $\mathrm{C}_{6} \mathrm{H}_{12} \mathrm{O}_{6}$.

The last hypothesis of the century which calls for notice is that of Bach, put forward in I893. He pointed out that when sulphurous acid, $\mathrm{H}_{2} \mathrm{SO}_{3}$, is exposed to light, it becomes converted into sulphuric acid, sulphur and water being split off, and he argued that a process analogous with this reaction takes place in a leaf. The carbon dioxide unites with water and forms carbonic acid, which is then split up in the same way as the sulphurous acid, $3 \mathrm{H}_{2} \mathrm{CO}_{33}=$ $2 \mathrm{H}_{2} \mathrm{CO}_{4}+\mathrm{H}_{2} \mathrm{O}+\mathrm{C}$. The carbon and water are not liberated separately, but in combination as formaldehyde. The new acid $\mathrm{H}_{2} \mathrm{CO}_{4}$ splits up into carbon dioxide and hydrogen peroxide, and the latter is decomposed into water and free oxygen.

A work of very great importance appeared in I880. This 
was the classic research of Schimper into the mode of formation of starch grains not only in the chloroplastids, but also throughout the plant, This is scarcely the place to discuss the whole of this investigation, but it raised a very important consideration in view of the theory formulated by Sachs, which has already been quoted. Schimper found that starch grains appear in the interior of plastids situated in the parts of plants not normally exposed to light, and that they are the consequence of a supply of sugar reaching such corpuscles. He also showed that when these colourless corpuscles or plastids are exposed to light, they develop chlorophyll like the plastids of the leaves. A fair deduction follows, viz. that sugar precedes starch in the formative processes, and that in all probability these processes culminate in its construction, starch formation being a subsequent and secondary matter, alike in colourless and coloured plastids. Schimper himself writes on the general question : 1

' It is clear that the starch which appears as the first evident product of assimilation in the true chlorophyll corpuscles does not originate directly from carbon dioxide and water, but that more or less numerous intermediate products still unknown, or at any rate known with less certainty, are interposed.'

These views at first seemed to be opposed to the position of Sachs, and were interpreted in that sense by contemporary writers. They did not appear so to Sachs himself, who, quoting from Schimper in I882, went on to complain of being misrepresented by the writers alluded to, and pointed out the views he propounded were not antagonistic to those of Schimper, whose work he cordially accepted. He reminded his readers ${ }^{2}$ that he stated in his Experimentalphysiologie in 1865 :

i Quoted by Sachs in Vorlesungen, Eng. ed., p. 317.

2 Vorlesungen, Eng. ed., p. 317 . 
'If after all I regard the starch in the chlorophyll as one of the first products of assimilation, it is not, therefore, to be said that carbon dioxide and water unite forthwith to form molecules of starch within the chlorophyll substance ; oxygen being evolved. It is not even necessary that any carbohydrate whatever should arise immediately; it is possible and probable that the process accompanied by the evolution of oxygen is a very complicated one, from which the formation of starch results only by numerous chemical metamorphoses.'

At the same time it must be said that Sachs did not show any great readiness to accept the views of other workers. In the Vorlesungen he said (Eng. ed. p. 3I8) :

'Whether it is right to claim with Berthelot and Kekulé (I86I) formic acid or some other member of the formyl group as the first product of assimilation, I hold as very questionable, and it has been hitherto proved by nothing. I lay still less value on Pringsheim's so-called Hypochlorin. ... . At any rate, even after all the recent researches, the fact which I established twenty years ago, that the starch in the assimilating chlorophyll is to be regarded as the first distinctly recognizable product of assimilation, remains unaltered. Even then I left the way open for further knowledge, since I laid stress on the fact that it was a matter of the first distinctly visible product, and that probably other products hitherto not distinctly visible, however, precede the formation of starch. Hence, even if, as a matter of fact, formyl aldehyde ... were actually an earlier product of assimilation from which the starch is developed in the chlorophyll, which is not the case, there still would not be the smallest item to alter in the statements I have made.'

It is strange that, while he held these opinions, Sachs ignored, or at any rate made no allusion to, the hypothesis of Baeyer, with which he must have been acquainted, published as it was several years earlier.

Sachs said elsewhere, ' I am strongly inclined to assume that both in the assimilating chlorophyll corpuscles and in 
the non-assimilating starch corpuscles, the material for the formation of starch consists of sugar. The question now remains, therefore, how does the sugar itself arise by assimilation? I hold it as probable even now that in this process the proteid substance of the assimilating chlorophyll itself co-operates and undergoes a change.' We have here something akin to Vines's theory of starch formation, to which allusion has been made.

The view that sugar is the immediate forerunner of starch was soon supported by experiment. Boehm, in I883, was the first of a long series of workers who established it. Boehm's researches proved that when green leaves, which have been depleted of starch by being kept in darkness, are put in contact with solutions of cane sugar or of glucose, or when their stalks are immersed in such solutions, starch reappears in the cells. Similar results were obtained in I 885 by Meyer and by Schimper, in I887 by Laurent, in I 888 by Klebs, and in 1890 by Acton. They all showed that starch formation takes place as soon as a plant is supplied with various carbohydrates in appropriate solutions.

Meyer's results proved that during photosynthesis large quantities of soluble carbohydrates are formed in plants without the inevitable appearance of starch, and that these same substances occur in plants together with starch.

Sachs made an observation in the course of his early work to which he did not seem to have attached the importance it deserves in the light of these later researches :

' In some cases it is impossible directly to observe starch as the product of the assimilation in the chlorophyll grains. I found this to be the case in the leaves of our common onion (Allium Cepa), where, however, large quantities of glucose (sugar) are to be recognized as the result of assimilation.' 
With the exception of this statement of Sachs, there seems to be very little evidence, up to the early eighties, that sugar exists in foliage leaves.

After 1880 investigations into the nature of the carbohydrates of the leaf were numerous. In I882 MüllerThurgau showed that the amount of cupric-reducing substance in leaves increases in quantity in the leaf as the starch diminishes. Kayser in the next year proved in the leaves of several plants the presence of cane sugar and the products of its inversion, obtaining the former in a pure condition by crystallizing it from the cell sap. In the paper of I885, to which reference has been made, Meyer gives the first proof of the existence of reducing sugar in the leaf. Taking the expressed sap of 20 kilos of the leaves of Allium porrum he precipitated the sugar by ammonia and acetate of lead. He failed to crystallize it but found it to yield an osazone melting at $204^{\circ} \mathrm{C}$. It had an optical activity $a_{1}-20^{\circ}$. He was not able to identify it further, but its characteristics agreed fairly closely with those of invert sugar. Meyer could not prepare either glucose or levulose from it. In I885 Schimper concluded that the formation of glucose precedes that of starch in the leaf, the latter being constructed from it when it has attained a certain concentration. Meyer found inulin in the leaves of Yucca. In I89I Keim detected cane sugar in the leaves of the cherry.

In I892 Brown and Morris subjected the sugars of the leaves of many plants to an exhaustive examination, in the course of which they identified among them cane sugar, maltose, glucose, and fructose. They came to the unexpected conclusion that 'at any rate in the leaves of Tropocolum cane sugar is the first sugar to be synthesized by the assimilatory process '. Their opinion was based upon quantitative determination of the amounts of the various 
sugars present, and their variations under different conditions of formation and consumption. Brown and Morris admitted that this result was not in accordance with their expectations. They said, 'there seems every reason to believe that this cane sugar, which may be regarded as the starting-point of all the metabolic changes taking place in the leaf, functions in the first place as a temporary reserve material, and accumulates in the cell sap of the leaf parenchyma when the processes of assimilation are proceeding vigorously.' They attributed the glucose and fructose to the hydrolysis of cane sugar, and held that the maltose is the product of a process of digestion of starch.

Their view that cane sugar is the first sugar formed has not been universally accepted. Their own suggestion that it is certainly a temporary reserve product, though less evidently so and less stable than the starch, makes it possible to think that simpler sugars of the glucose and levulose types may precede it in the formative processes, being, however, very rapidly converted into cane sugar as the quantity increases.

At the end of the century the question still remained an open one.

In support of the hypothesis that formaldehyde is a stage in the construction, we had very little direct evidence. In I888 Bokorny made a number of experiments with Spirogyra, feeding the alga with formaldehyde in various ways, to see if it could then form starch. He always failed with the aldehyde itself, which proved poisonous, but he succeeded with sodium oxymethyl sulphonate and with methylal, both of which slowly give it off. His experiments cannot be held to prove its normal occurrence, for many other substances enable the plant to form starch. At the end of the century Pollacci claimed to have shown the presence of formaldehyde in green leaves, and in I897 
Curtius and Reinke noted its appearance in light and its disappearance in darkness. Reinke, in I899, said that it was not present in leaves as formaldehyde, but as a substance having the formula $\mathrm{C}_{8} \mathrm{H}_{2} \mathrm{O}_{2}$.

The process we have been discussing was known till recently as the assimilation of carbon dioxide. The term assimilation, from its usage in another connexion, gradually fell into disuse, being replaced at the end of the century by the word photosynthesis, a term introduced by MacMillan in $1893 .^{1}$

The first investigations conducted with a view to the determination of the quantities of carbohydrate formed by green leaves were undertaken by Weber in I878 in Sachs' laboratory. His methods were not altogether satisfactory, but he succeeded in making an approximate estimate. His figures ranged from 4.446 grammes of starch per square metre per hour for Tropaolum majus, to 5.56 grammes for Helianthus annuus. He computed his quantities from observations on increase of weight of the leaves, and attributed this increase entirely to starch.

More accurate researches were conducted by Sachs himself in 1884 , when he introduced his well-known half-leaf method. Selecting large leaves on plants growing in the open air, he cut out and carefully measured portions of one longitudinal half early in the morning, dried them, and took accurately their dry weight. In the evening corresponding and equal areas were cut from the other half of the leaf and treated similarly. The difference in weight Sachs took as an approximately correct indication of the amount of starch they had formed, which he reduced to amounts per square metre per hour. His figures for Helianthus annums were 0.9r4 gramme, a much smaller amount than Weber had obtained six years earlier. In subsequent

'See Barnes on 'So-called Assimilation', Bot. Centr., 76, i898; No. 47 . 
experiments he used leaves detached from the plant, in order to prevent loss by translocation. Under these conditions he computed the amount to be about I.5 gramme per square metre per hour. He computed the carbon dioxide absorbed during the same time at $\mathrm{I} \cdot 8$ gramme per square metre per hour.

The method does not admit of an accurate determination of the activity of the leaf owing to many causes. Its structure and the necessity of selecting only such parts as can be accurately measured ; the translocation of material to the interior if the leaf is left on the stem; the effect of the accumulation of the products of the photosynthesis if it is severed from it; the fact that respiration is proceeding simultaneously: all militate against more than approximate results. It is noteworthy, however, that Brown and Morris with their improved methods obtained not very different results in 1892 .

In 1885 Kreussler found that using air containing ten times the normal amount of carbon dioxide, about $\cdot 3$ per cent., a square metre of the surface of the leaves of $R u b u s$ fruticosus decomposed 2.5 grammes of the gas, which is equivalent to the manufacture of approximately I.54 gramme of starch. He illuminated his plants with electric light of about the intensity of diffused daylight.

More exact investigations were carried out in I899 by Brown and Escombe. They devised an apparatus by which they could examine and determine the exact quantity of carbon dioxide absorbed by a measured area of a wellilluminated leaf by passing over it a stream of air containing a known percentage of carbon dioxide, the stream flowing at a definite rate and at a constant temperature. The stream of gas was kept passing in each experiment for about six hours, and its carbon dioxide content was examined before and after access to the leaf. They found 
the intake to be directly proportional to the pressure of the carbon dioxide, the light being constant. Their results for Helianthus annums were an absorption of 4I2 c.c. of carbon dioxide and a construction of 8 gramme of carbohydrate (sugar) per square metre per hour.

The rapidity and extent of the formation of sugar, \&c., was thought to depend on the percentage of carbon dioxide in the air. Observations made by Godlewski in 1873 pointed to an optimum of 8-1o per cent. In I 885 Kreussler concluded it to be much lower, finding the greatest activity of construction at a concentration of about I per cent.

Comparisons of this nature have been proved futile unless the standard of illumination is taken into account. This was pointed out by Blackman in I900, who explained the discrepancies in the results of the older writers by showing that the intensity of the light forms a most important factor in the process, and that there is an optimum pressure of carbon dioxide for every degree of illumination.

Brown and Escombe at the end of the century made a very important contribution to our knowledge on this point. They showed that though, as Godlewski had proved, a certain increase in photosynthetic activity could be secured by increasing the proportion of carbon dioxide supplied in the air, yet such a course is attended with very grave dangers to the plants and results in disaster to them. The increased photosynthesis does not to any material extent contribute to the increase of the dry weight of the plants, but exercises a serious disturbing influence on the course of their nutritive processes. It seems to throw them off their balance and results in altogether abnormal development, one symptom of which is a profound modification of the reproductive functions. The extent to which this is seen is the greater as the increased percentage is greater, but it is noticeable if the 
quantity of carbon dioxide is made only two or three times the normal amount.

The ENERgy Relations. While the investigations just discussed were occupying the attention of workers in the domain of biological chemistry, others were being pursued with equal earnestness and perhaps greater or more complete success in the realm of physics. The connexion between light, chlorophyll, and the work of carbohydrate formation was full of suggestiveness from this point of view, and naturally led to the study of the sources of energy for the work together with the methods of its utilization.

As we have seen, the optical properties of chlorophyll had been investigated prior to I860, and its absorption spectrum had been mapped out by Brewster in 1834 and by Draper some ten years later. A belief slowly grew up that the photo-chemical process in the green leaf ought to be considered a function of the total illumination it receives. This was probably largely due to the fact that Draper's results seemed to show that the maximum decomposition of carbon dioxide was brought about by the yellow rays, which are the most luminous-a view which received very strong support from Pfeffer, and was maintained by him many years later.

It was not till about I868-70 that investigations were seriously undertaken with a view to establish the exact relations between the several factors. The first workers in the field were Timiriazeff, Lommel, Müller, and Pfeffer,whose investigations proceeded separately but synchronously for several years. In his first Russian paper, published in I868, Timiriazeff set out the problem which he placed before himself :

' To study the chemical as well as the physical condition of this process ; to follow the solar ray that effects it directly or indirectly, up to the moment when we see it vanish on 
being transformed into internal work; to find out the quantitative relation between the energy absorbed and the work done-here lies the brilliant though perhaps arduous problem, in attacking which modern physiologists ought to unite all their forces.'

The first outcome of the researches was to disprove the view that there is an exact parallel between luminosity and the work effected. Timiriazeff found that the experiments of Draper, on which the idea had been based, had not the value at first attributed to them owing to the fact that the work had been done with a highly impure spectrum. He then proceeded to plot out curves to represent respectively the intensities of decomposition of carbon dioxide, of luminosity, and of energy, and showed that a coincidence of chemical effect with Fraunhofer's luminosity curve is out of the question; but that so far as the visible spectrum is concerned, a relation with the energy curve can be seen. Nor do the results coincide better with the distribution of energy in the complete spectrum, the maximum of which resides in the infra red. Cailletet showed that these rays, which he isolated by passing the light through a solution of iodine in carbon disulphide, have no effect in decomposing carbon dioxide.

These researches directed attention to a law formulated by Sir John Herschel, that a photo-chemical reaction may be produced by those rays only that are absorbed by the substance undergoing a change. The names concerned with the application of this law to the action of chlorophyll are those of Jamin, E. Becquerel, Lommel, and Timiriazeff, though the credit of bringing it forward has been generally given to Lommel. In his paper of I87I (Ueber das Verhalten des Chlorophylls zum Licht), published in Poggendorf's Annalen, he put forward the opinion that the rays which effect the decomposition are those which are absorbed by the chlorophyll, and lays stress particularly on those corre- 
sponding to the band in the red between $\mathrm{B}$ and $\mathrm{C}$, which he said possess a high mechanical intensity. He is thus held to have enunciated the idea that the reduction of the carbon dioxide may be considered a function of the energy of radiation and of the degree of its absorption by chlorophyll.

It must be noticed, however, that as Timiriazeff pointed out, Herschel's law does not quite apply in this case, as the rays are absorbed by the chlorophyll, while the chemical change is concerned with the carbon dioxide which does not absorb the light at all. Timiriazeff suggested that the function of the chlorophyll is really to act as a sensitizer, to absorb the rays, that is, and thus to enable them to do chemical work outside the actual absorbent. With its action in this particular he associated the fact of the existence of the two related pigments, chlorophyll and protophyllin in the plastid, allusion to which has already been made in another connexion.

Lommel's view, that the rays absorbed by the pigment are the effective rays in photosynthesis, which seems to have been accepted at once by other workers, was the starting-point for most of the researches to which attention must now be directed.

Mention, however, must first be made of an alternative hypothesis brought forward by Pringsheim in I874. He urged that the rays absorbed are not those concerned in the decomposition of carbon dioxide, but that they are cut out because they would be deleterious to the constructive mechanism. Chlorophyll, on this hypothesis, is nothing more than a filtering mechanism, sifting the rays of light, and keeping from the plant those which would interfere with its constructive work. This view excited a certain amount of comment when it was put forward, but it was not based upon experiment, and soon fell into the background. It was finally disproved by the observation of Nagamatz in I886 that light which has passed through a leaf has lost its 
power of effecting photosynthesis in another lying below the first. It is clear that the rays which are absorbed by the chloroplasts of the first are the effective and not the deleterious ones.

The earlier methods of investigation of the influence of different rays consisted in cultivating plants or exposing leaves under glass of different colours, or guarded by hollow screens containing definite coloured liquids, the chief of these being chromate or bichromate of potassium and ammonio-cupric sulphate. Such methods are open to criticism, as the light passing through such media will not only differ in quality, but almost certainly vary in intensity, and the medium itself will not give well-isolated portions of the spectrum. It is not very surprising, therefore, that discordant results were obtained. The fact, however, of the association at all was a great advance on previous knowledge.

The method of working with the spectrum which had been introduced by Draper was taken up almost at the same time by N. J. C. Müller and by Timiriazeff. Müller's results lacked precision, on account of his working like Draper with an impure spectrum. The difficulty of working with such a narrow slit as to ensure a pure spectrum was that the light that passed was of too low an intensity to cause enough decomposition of carbon dioxide to be measured by the apparatus then at the disposal of investigators. To meet this difficulty Timiriazeff devised, in I87r, a modification of Bunsen's gasometer of such extreme delicacy as to allow him to estimate so small a quantity of the gas as oor c.c. The leaves were put into small flat tubes of such size as was necessary, and after exposure to the light of the desired part of the spectrum the changes in the air surrounding them ascertained by direct measurement with the modified gasometer.

In other experiments Timiriazeff took living plants of 
Hydrangea, and by keeping them for some time in darkness depleted them of their starch. He then threw upon them a very pure spectrum, as bright as he could obtain, and allowed it to remain upon the healthy leaves for five to six hours. On subsequently treating the leaves with a solution of iodine, starch was found to have been re-formed along the limits of the spectrum, presenting an image of the absorption spectrum in blue. The principal band between $\mathrm{B}$ and $\mathrm{C}$ was very pronounced, and there was a gradual falling off towards the blue end. This method gave no evidence of absorption of carbon dioxide in the blue.

Though Timiriazeff's early experiments gave satisfactory evidence of relation between the absorption bands of the red end of the spectrum, they seemed to indicate that the great number of blue and violet rays absorbed are not concerned in photosynthesis. At the same time his researches proved that the maximum effect is not in the yellow, but is coincident with the band $\mathrm{B}-\mathrm{C}$.

In I88I Engelmann introduced, and in I884 perfected, his bacterium method of testing for traces of oxygen, to which attention has been already drawn. The fact that Bacterium termo is actively motile in the presence of free oxygen and quiescent in its absence, was used to examine the distribution of power in the spectrum. A filament of an alga was mounted in oxygen-free water on a slide and a number of the bacteria introduced. A cover-glass was put over the preparation and its edges closed by a ring of oil or wax, so that no oxygen could gain access from the sutside. A pure spectrum was then thrown upon the algal filament. After a very short interval the bacteria became actively motile and accumulated in the close vicinity of those parts of the filament where oxygen was being exhaled. The greater number were found to swarm in the band B-C, confirming Timiriazeff's observation made by another method. Engelmann claimed to have found a secondary 
maximum about the region F-G, but only a much smaller one than the first-mentioned. He emphasized its occurrence in his paper of I884. Pfeffer, using this method, declared himself unable to convince himself of its existence (Phys., i. 334).

In his early work Timiriazeff investigated chiefly the red end of the spectrum. His starch method seemed to indicate an absence of activity in the blue. A few years later he adopted a method devised by Dubosq to produce a pair of complementary colours from the spectrum. He described the apparatus as consisting of a cylindrical lens and of a wedge-shaped prism fixed in a plate of glass, and said that it gives, instead of a spectrum, two strips of light of equal intensity and complementary colours, each strip comprising the rays of half the spectrum. He could thus compare the effect separately obtained of the two halves. He was enabled to prove a maximum power in the blue equal to about half the maximum in the red-yellow.

Using this instrument, he was able to show a very prominent effect by the iodine method, the amount of starch not being, however, so large in the part illuminated by blue rays as in that by the red and yellow part. of the spectrum.

Reinke's researches in I884 and I885 next call for comment. He devised an instrument which he called a spectrophore, which enabled him to experiment with any part of the spectrum he chose. The light was admitted from a heliostat and conveyed by means of a lens to a prism, and the resulting spectrum thrown upon a glass screen. By means of two adjustable pieces of wood behind the screen forming a kind of shutter, which could be adjusted to give a slit of whatever width was desired, Reinke was able to employ whatever part of the spectrum he wished. Another lens placed in front of the shutter combined the emergent rays into a beam of light which was 
allowed to fall upon the plant. He estimated the photosynthetic value of the rays he blocked out by measuring the decrease in the amount of oxygen exhaled when only part of the spectrum fell upon the leaf. Reinke counteracted the unequal dispersion of the rays by his prism by concentrating different regions of the spectrum to strips of equal size by means of cylindrical lenses. It is very strange to find that Reinke published none of the results he obtained with the apparatus.

Opinion remained divided up to the end of the century on the question of the second maximum in the blue. As we have seen, Engelmann emphasized it strongly in I884. Timiriazeff held it established in I885. In I886 Bonnier and Mangin said that the ultra-violet rays can in some cases cause a small photosynthesis. Kohl supported it in I897. On the other hand, Pfeffer could not convince himself of its existence in I880, and Reinke claimed that only one maximum exists.

The most accurately plotted curves do not show an exact correspondence between the rays of light actually absorbed and those effecting the decomposition of carbon dioxide.

The position of the maximum in the red was differently determined by the various writers whom we have quoted. Timiriazeff said it corresponds to rays of wave-length 685-655 $\mu \mu$, and was confirmed by Engelmann. Pfeffer said 655-590 $\mu \mu$, and Reinke 720-685 $\mu \mu$.

But few investigations were made up to the end of the century to determine accurately the relation of temperature to the activity of the photosynthetic processes. The most accurate ones were those of Kreussler in 1890 ; he showed that a gradual increase of construction goes on as the temperature rises up to about $25^{\circ} \mathrm{C}$. In some plants it rises to a maximum at $40^{\circ} \mathrm{C}$, above which there is invariably a rapid decrease, photosynthesis ceasing generally at $45^{\circ} \mathrm{C}$. 
Kreussler investigated the lower limit in I888 and found a feeble activity in bramble leaves at $-2 \cdot 4^{\circ} \mathrm{C}$. Jumelle confirmed this result in 1892 .

The matter was undetermined with greater accuracy at the end of the century, but Kreussler's work paved the way for the observations of Blackman and Matthaei in I902.

Considerable inquiry was directed to certain collateral questions springing from the information that had been gained as to the absorption of radiant energy. The first of these concerned the relation of intensity to effect. Among the discoveries of Sachs during the course of the researches we have discussed was the important fact that activity does not increase pari passu with the intensity of the light, but that there is an upper linit beyond which increased brilliance of illumination becomes deleterious. There is further a great deal of difference of behaviour among plants as to the maximum intensity. The inquiry into a possible optimum degree of illumination, however, is closely connected with that of a possible optimum percentage of carbon dioxide in the air and the failure to recognize this led to some conflicting results, for the two conditions were studied separately as if they were independent. Different plants again show remarkable differences in the way in which they respond to all these changes. We may almost impute to them personal idiosyncrasies or at any rate peculiarities confined to species.

A series of experiments made with increasing percentages of carbon dioxide led Godlewski in 1873 to conclude that the gas can be very largely increased in quantity, indeed up to Io per cent. of the air supplied, with the result that the activity of the chloroplasts is thereby and up to that point enhanced.

In his Pflanzenphysiologie Pfeffer pointed out that while in $187 \mathrm{I}^{\circ}$ he proved that an excess of carbon dioxide exerts 
a poisonous influence on the plant there is a certain optimal percentage at which photosynthesis is most active, and that this varies not only in different plants, but according to external conditions.

In I885 Kreussler made a number of researches on the subject; in each experiment he kept the air supplied to the plants charged with a measured quantity of the gas, and employed the constant light of an electric lamp. The plants he used were varied, and included Rubus, Carpinus, and Tropoolum. His results showed that the amount of the gas which was used increased with the amount present, but not proportionally. It required the presence of seventeen times the normal amount, or 56 per cent., to make the quantity entering into combination double the normal quantity. He estimated the optimum amount rather higher than Godlewski.

The latest investigations were those of Blackman at the end of the century. These were remarkable in that they correlated closely the two factors of quantity of gas and intensity of illumination and showed that for each degree of the latter there exists an optimum point for the former, which may range as high as Godlewski's figures, but which under ordinary conditions is continually varying. It is, however, much higher than the normal percentage in the atmosphere, so that we find the machine working well within its capacity.

The optimal percentage for photosynthesis is not the same as for the subsequent processes of metabolism. Montemartini found the best percentage for growth did not exceed 4 ; Mangin and other observers proved that though photosynthesis may be very active in air containing 4-I5 per cent. of carbon dioxide, the plants exposed to it are ultimately injured.

For the continuous activity of the chlorophyll apparatus it is necessary that accumulation of the products of photo- 
synthesis shall not be allowed to take place. So far back as I 868 Boussingault showed that the power of appropriating carbon dioxide gradually diminishes in a branch removed from a plant, before any ill effects of the separation are manifested. A similar observation was made by Saposchnikoff in I890, when he noted that photosynthetic products cannot increase beyond a certain amount in a leaf of Vitis.

The ultimate application of the energy absorbed by the leaf was inquired into by several observers. In I 868 Ed. Becquerel made the first reliable experiments on the point and computed that in the case of the sunflower about one two hundred and fiftieth part of the available solar energy is stored by the plant in the potential form. Two years later Timiriazeff estimated it at I per cent. N. J.C. Müller, using a more exact method in 1876 , came to the conclusion that under the most favourable conditions it reaches 5 per cent. He exposed a pyroheliometer to the sun's rays, side by side with a leaf in a condition to effect photosynthesis. Some experiments made by Detlefsen in I888 are of considerable interest. He placed a thermopyle immediately behind a leaf, which was exposed to sunlight, and registered the difference of temperature which it showed when photosynthesis was prevented by absence of carbon dioxide and when it took place in air containing Io per cent. of that gas. He found that in the former case there was a slight rise of temperature, but only enough to indicate that the leaf had used a fraction of the incident light, the amount varying from 3 to I. I per cent.

Detlefsen's method was ingenious, but the possible sources of error caused his results to be received with a certain reserve.

In I894 Timiriazeff, using a similar arrangement to that employed by Müller, computed the amount used to be as much as 3.5 per cent. of the total.

Very careful estimations of the radiant energy absorbed GREEN 
and its subsequent fate were made by Brown and Escombe in 1898 and 1899 in connexion with their work which has been already alluded to. 'They measured simultaneously the total energy falling on a leaf by means of a Callendar's recording radiometer, the amount of carbon dioxide absorbed during the time of experiment, and the amount of water transpired From the data thus obtained they determined that the leaf absorbed and converted into internal work about 28 per cent. of the total radiant energy incident on it when exposed to the strong sunlight of a brilliant day in August; of this 28 per cent., 27.5 per cent. was used up in the vaporization of the water of transpiration, and only 5 per cent. was employed in the processes of photosynthesis. In strong diffuse light, instead of bright sunshine, the leaf absorbed about 95 per cent. of the incident energy, and employed in the processes of photosynthesis $2 \cdot 7$ per cent.

These results to some extent explain the great discrepancies noticeable in the figures of the earlier observers, showing that the percentage used varies according to the absolute intensities of the light received in different cases. The total amount of light absorbed by the leaf may be fairly constant, but yet bear a very different proportion to the total incident amount, as appears in the figures given under the two conditions by Brown and Escombe.

Earlier quantitative experiments on the absorption of light were made by Timiriazeff in 1870 . Using an instrument known as a phyto-actinometer, he found that when bright sunlight fell upon a single leaf of the maple, the latter absorbed 27 per cent. of the incident amount; when three leaves superposed were exposed to it, 3 I per cent. was absorbed. With the lime instead of the maple the figures were 29 and 35 respectively. A single thickness of maple leaf absorbed 13.8 per cent. of yellow and Io per cent. of red light when incident upon it. 


\section{CHAPTER III}

\section{THE ABSORPTION OF NITROGEN AND THE CON- STRUCTION OF NITROGENOUS SUBSTANCE}

THE final abandonment of the theory of the humus as the source of the nitrogen of plants was brought about during the years $1840-60$; the idea that the nitrates and the ammonia compounds of the soil only serve to dissolve it and enable absorption to take place having been advanced and again set aside during that interval. The older writers, to whose advocacy the theory was due, were gradually retiring from the field and new workers were beginning to make their influence felt. Of the latter, the man who stood out most prominently in the field of vegetable physiology was Boussingault, to whose work upon the methods of carbon dioxide absorption reference was made in the last chapter, and to whom we owe most important contributions to the solution of the problems associated with the appropriation of nitrogen. Even before 1840 he had carried out investigations on vegetation, but it was not till towards the end of the twenty years that he succeeded in establishing the important fact that the normal green plant can make no use of the free nitrogen of the atmosphere, but that it obtains its supplies from the soil, and that these supplies are furnished not in the shape of the humus, an ill-defined accumulation of heterogeneous materials, but in that of the nitrates and ammonia compounds it contains.

In his History of Botany Sachs bore eloquent testimony to the services rendered by him in this field of research, attributing to him the credit of being the founder of modern methods of conducting experiments on vegetation.

Boussingault was engaged on these researches at the 
time of the opening of the period with which the present volume is concerned. The results which we have already quoted were arrived at and published a few years before; so that in I860 the new ideas had begun to take hold of men's minds and were finding general acceptance. In I860 and I86I we find him giving exact evidence, based on quantitative estimations, that the green plant needs nitrates in the soil if it is to flourish. The experiments, very striking ones, may be quoted as setting out the position at the opening of our period.

Boussingault made three series of cultures of Helianthus argophyllus; the first in sand without any minerals containing combined nitrogen; the second in sand, to which were added the materials of the ash of the plant and some nitrate of potassium; the third differing from the second only in that carbonate of potassium replaced the nitrate. After eighty-six days the plants of the first and third series showed no increase in nitrogen beyond a trace that might well have been derived from a little ammonia formed in the air, while those of the second series had gained a considerable quantity. The development of the plants of the first and third series was only about one-sixth of that of the second.

While Boussingault was occupied with these problems in France, Lawes and Gilbert were giving them assiduous and careful examination at the Rothamstead experimental station in England. Working on similar lines they arrived at results which were confirmatory of those of the great French physiologist. A very comprehensive paper, in preparing which Pugh was associated with Lawes and Gilbert, was published in I86r.

The question appeared to be definitely settled by these researches, and there seemed no doubt that the atmosphere is to be altogether put on one side as a source of supply of nitrogen. So for several years matters rested, when certain 
new discoveries reopened the whole matter; somewhat heated controversy set in and was maintained till nearly the end of the century. New aspects of the question attracted new workers and several lines of research yielded very unexpected results, results of far-reaching importance, which the end of the century left still far from complete. Indeed these lines of research are bearing promise of richer results to-day than seemed possible in 1900 .

Of the problems which thus presented themselves, the first we may consider was opened out by Berthelot in 1876 and was a subject of examination by him in the midst of his other work till r892. He objected at the outset to the conclusions arrived at by preceding workers as to the atmosphere as a source of nitrogen to vegetation, on the ground that the experiments on which those conclusions were based were not carried out under natural conditions. He did not, however, confine himself to destructive criticism, but carried out long and careful experiments to show that though atmospheric nitrogen may not be appropriated by the ordinary normal green plant directly, yet there is a continual fixation of it taking place in the soil under the influence of certain organisms, so that it is gradually made available for utilization by vegetation in general. Besides the influence of the organic world in this direction, he claimed that certain physical agencies also are at work causing a similar fixation in the air and the absorption of the resulting compounds by the soil.

The latter line of research was the earliest he pursued; in 1876 he showed that free nitrogen can be fixed by various organic compounds in the laboratory under the influence of the silent electric discharge, and suggested that similar reactions probably take place in the air during storms, and at all times when it is charged with electricity. In the statement of his hypothesis he left uncertain what compound of nitrogen may result. In the next year his 
views were strengthened by the discovery that, when he was experimenting with a difference of electrical potential not greater than that which frequently exists between strata of the atmosphere not far from the ground, filter paper which had been moistened with water had its nitrogencontent increased fourfold. On substituting a solution of dextrin for the water the amount of nitrogen fixed increased to sixteen times the original quantity.

These observations stood by themselves till 1885 , when Berthelot became alive to the presence and activity of a new agency, supplementing the purely physical phenomena of his first experiments. He found during that year that certain clay soils fixed atmospheric nitrogen under the influence of the presence of certain microbes or bacteria, which, however, he did not determine, though he stated definitely that he held the process to be rather due to them than to the soil in which they were living. He published further results in 1892 .

This was an important discovery, for though it pointed to the atmosphere as a great source of nitrogenous supply it indicated no less clearly that the utilization of it is in no sense a function of the chlorophyll apparatus, and that therefore we are face to face with some kind of chemosynthetic process; it thus opened up a number of problems as to the relation of the two. Moreover, as the fixation appeared to be due to the protoplasmic activity of the microbe, it emphasized the likelihood that we must discriminate between the function of the colouring matter and that of the living plastid in the process of photosynthesis. Further, it showed how the green plant may be ultimately supplied with nitrogen from the air, though, as Boussingault and other observers had shown, there is no evidence of any direct absorption.

Naturally so striking a pronouncement as this of Berthelot was followed by a long series of experiments which were 
carried on for many years in numerous laboratories and stations for research. The development of the idea continued indeed to be a charge to physiologists till nearly the end of the century, and led the way to research on somewhat similar lines that brought forth results of the highest interest and importance.

Among the workers who were attracted to the subject in France were Dehérain, Joulie, Schloesing, Muntz, and Laurent. Of their researches attention can be called here to only the most important.

Joulie, in I886, led opinion in the direction of the cooperation of the green plant somewhat intimately with the microbe. His experiments were made in the first instance with buckwheat, followed by rye-grass and trefoil. These he cultivated in pots, supplying them with different kinds of soil, and various kinds of manure, and analysing the amounts of initial nitrogen, the nitrogen supplied, and that finally contained in the crop at the conclusion of the experiment. He concluded there is a fixation of atmospheric nitrogen, and that the microbes of the soil probably play an important part in bringing it about, for he thought his results were unfavourable to the idea of the green plants having caused it. He preferred, however, to leave the explanation to the future.

Before the next contribution from French sources was made, Frank, in I886, published some results which led him to the conclusion that while soils lose nitrogen in the free condition as well as in the form of various compounds by drainage and by cropping, there is a greater gain of the gas; while failing to explain it, he held that the fixation of nitrogen from the air takes place in the soil aided by some form of vegetation.

In 1889 Tacke showed that soil containing bacteria may gain as much as $25 \mathrm{mg}$. for every Ioo gms. in a comparatively short time. 
Some experiments made by Schloesing and Laurent in I8gI claim attention next, as they appeared to contradict Boussingault as far as particular plants are concerned. They cultivated certain plants belonging to different natural orders, supplying them with free nitrogen, which was measured at the beginning and at the end of the experiments. They found that in some cases a certain amount was appropriated. In them all they observed that the growth of the plant was associated with the presence of lowly forms of algae and mosses spreading over the surface of the soil. They attributed the fixation to these and not to the culture plants, and showed that it only took place under a free exposure to light and air.

These statements met with some criticism from Armand Gautier and Drouin, who claimed to have noticed the same phenomenon, but who put forward a different interpretation. They attributed the fixation to the microbes in the soil ; they held that aerobic microbes in oxidizing organic matter oxidize and fix a little nitrogen; while anaerobic forms produce from it ammonia and amidogen compounds. These are stored by the algae, so that the lowly green vegetation acts only indirectly, while the microbes fix the nitrogen of the air.

Considerable controversy ensued, maintained during I 892 by Berthelot on the one hand, claiming that the action is exclusively bacterial, and by Schloesing and Laurent on the other, maintaining that it is confined to the surface of the soil and is due to the lowly green vegetation flourishing there.

Passing over the work of Bréal, and some other writers of the time who really added nothing new, some experiments of Kossowitsch in I894 have considerable value as tending to reconcile the apparently discordant results.

He used in his first experiments pure cultures of Cystococcus, which he cultivated in special apparatus and sup- 
plied with air free from compounds of nitrogen. He found they would not grow till a trace of nitrate was mixed with their nutritive medium, and then only in proportion to the amount of nitrate so supplied. Then he used cultures of algae, together with some of the soil bacteria, with no organic compounds. A small increase of the combined nitrogen was observed. Later on cultures of mixtures of several algae, including Nostoc, together with bacteria, resulted in a considerable fixation of nitrogen. In all his series he found the fixation much larger in the presence of sugar.

Kossowitsch concluded that the association of the bacteria with the algae, in a kind of symbiotic union, is the cause, or condition, of the fixation. In this union the algae, supplied with nitrogen by the bacteria, form or construct carbohydrate material, part of which is given to the nutrition of the microbes. This conclusion is supported by the observations that if the mixed culture is placed in the light there is a larger fixation than in darkness, and that if abundant carbon dioxide is supplied still more nitrogen is fixed.

The species of algae which have a mucilaginous envelope wherein the microbes become enveloped, carry out the process of fixation best, and the addition of sugar to such is attended with less effect than it is to forms whose walls are not mucilaginous.

The determination of the non-green member of the symbiosis remained to be made. In I 895 Puriewitsch claimed to have shown that themould fungi Aspergillus and Penicillium are sometimes concerned, but the evidence does not seem conclusive. In the same year, however, light was thrown upon the point by the researches of Winogradsky. He inoculated with arable soil a culture fluid containing no combined nitrogen. Very speedily there was apparent a vigorous butyric-acid fermentation and the organisms con- 
cerned formed a number of masses of zoogloea. He kept the acid neutralized and the fermentation went on so long as any sugar remained in the fluid. IVhen it was finished fungal and algal intruders were able to grow in the culture fluid, proving that combined nitrogen was then present, and consequently that it had been formed in the process of the fermentation. Chemical analysis also showed this to be the case. The zoogloea on examination proved to contain two filamentous bacteria and a species of Clostridium. These were successfully isolated, with, however, very great difficulty, the Clostridium proving far from easy to cultivate. So isolated, their respective activities were determined.

Winogradsky ascertained that the presence of the three organisms is necessary for fixation unless oxygen is excluded from the culture. The actual fixation is carried out by the Clostridium, which is strictly anaerobic. The part played by the other two organisms is the consumption of the free oxygen of the fluid. For this purpose they can be replaced under appropriate conditions by other organisms. Only after the action of these oxygen-consuming microbes can the Clostridium begin to develop. Clostridium has since been carefully examined by its discoverer and its peculiar powers and properties are known. He did not learn, however, anything as to the form of the combination into which the atmospheric nitrogen is made to enter.

Winogradsky claimed to have determined that Clostridium and forms related to it are the only microbes with the capacity for fixing nitrogen. This is in opposition to Berthelot, in whose opinion the power is far more widely spread. Berthelot's views were shared by Beijerinck, who claimed it for a bacterium he called Azotobacter, and for certain Cyanophyceae, including Nostoc and Anabena. He based upon his observations a special class of physiological organism, to which he gave the name 'oligonitrophilous'. 
Beijerinck's work, which appeared at the end of the century, is not so convincing as that of Winogradsky, inasmuch as he did not support it by chemical analysis.

The position at the end of the century, then, was that there is no evidence of appropriation of atmospheric nitrogen by normal green plants, but that circumstances point to a fixation in the soil by a kind of symbiotic association of certain organisms.

Certain other cases of a still more special symbiosis were noted, to which attention will be drawn a little later.

The exact nature of the fixation remained undetermined, but facts pointed clearly to the soil as the chief source of the combined nitrogen absorbed by the normal plant.

During the period under discussion the combined nitrogen of the soil, its sources, forms, and fate, were the subject of much investigation, which proceeded side by side with the study of the problems we have just examined. The questions originated in the effort to determine the form or forms in which the soil supplies combined nitrogen, and the interactions in the soil by which those most advantageous are secured.

The sources which in I860 appeared possible were the compounds of ammonia and of nitrous and nitric acid, together with the heterogeneous complex generally referred to as humus.

The old doctrine of the humus had received its deathblow at the hands of Liebig, but its disappearance from the scene was very gradual. It was in a way resuscitated by De Saussure in his old age and was put forward also by Von Mohl and others, and not finally disposed of till the researches of Boussingault, which were still incomplete in I860. By these, however, we find established the part played especially by the nitrates, which he showed to act by furnishing their combined nitrogen to the plant directly, and not indirectly by dissolving the humus. 
What exactly was included in the term humus was not very clearly defined. Organic matter in various stages of decay exists in the soil, and the number of constituents, many of them in very small traces, is large and varied. It may conveniently be held to have included all such organic nitrogen-containing bodies as are present in the soil, compounds on their way apparently to furnish by further processes of decay the ammonia and ammonia compounds which can be detected there, or by other kinds of decomposition to furnish nitrous or nitric acid. Complex nitrogenous bodies, such as urea, uric acid, glycin, were in I865-7 shown by Hampe to nourish plants in water cultures, and even to carry them to the point of producing seeds. In I 868 Wagner added to the list kreatin and others, and Wolff found tyrosin similarly utilizable.

It seemed at the outset, however, hardly probable that the bulk of the nitrogen of plants is taken from organic combinations, especially in the light of Boussingault's results. Liebig had laid stress in 1840 on ammonia as the chief source of the plants' supply. Boussingault had found that rain carries to the soil nitric acid, formed no doubt in the atmosphere.

It was not, indeed, till the latter part of our period that the compounds of nitrogen we have mentioned were carefully investigated and compared, when certain relations were found to exist between them, and the soil was ascertained to be the scene of considerable chemical and biological activity in order to present the combined nitrogen to the green plant in the most advantageous form.

Certain isolated observations on somewhat collateral points may be mentioned, as having a bearing on the question of determining the latter. In I874 Schloesing showed that the leaves can absorb gaseous ammonia when traces of it are present in the air, and in 1887 Kerner found that under certain conditions this source of supply 
becomes important. In the same year Molisch found that nitrites are absorbed eagerly by the green plant when in so dilute a solution as ' 05 per cent., but that they become poisonous if present in too large amount.

A long series of researches, extending from I 887 to 1896 , was carried out by Pitsch, who showed that as a nutritive material ammonia comes second to nitric acid. In I887 Baumann found that in uncultivated soil the greater part of the combined nitrogen exists in the form of compounds of ammonia, varying much in quantity according to the nature of the soil; nitrates are too small in amount to estimate quantitatively.

In I89o Muntz published the results of a number of experiments arranged to test the value of ammonium compounds by cultivating plants in soil deprived of nitrates, and under conditions which prevented the formation of nitrites or nitrates; he convinced himself that the only source of combined nitrogen was the ammoniacal salts which he supplied. Great care was taken to avoid all possible contamination, and the experiments were rigorously controlled. The plants used were maize, beans, hemp, and barley. He found that they are all able to absorb the nitrogen of ammonia through their roots and that such combined nitrogen is sufficient for them. In Igoo Mazé also stated that in the case of maize and some other grasses, Brassica and a species of Allium, ammonium compounds are about equal in nutritive value to salts of nitric acid.

There has been, however, since the time of Boussingault an opinion which has been widespread and held tenaciously that the normal green plant thrives best when its nitrogen is supplied to it in the form of nitrates. This view has replaced the older view of Liebig that this part is played by ammonia and its compounds, an opinion based chiefly upon the fact that in the decomposition of organic substances such as are presented by natural manures, the 
nitrogen is generally returned to the soil in the form of ammonia. It is clear, therefore, that if Boussingault's views are well-founded, we have to seek in the soil the processes by which nitrates are constructed from such ammonium compounds.

The researches which proceeded on these lines and extended over nearly the whole of the period under review brought to light a certain circulation of nitrogen in nature. In many cases decay of organized matter gives ammonia and in some free nitrogen. From these we have the construction of nitric acid and its compounds, and their absorption by plants with subsequent reconstruction of proteins and their incorporation into living substance. Again we find the round completed by the death and decay of the latter.

The story thus tersely presented was, however, the outcome of many laborious researches, undertaken in a somewhat piecemeal fashion, and only properly collated near the end of the century.

The first researches were those having a bearing on the formation of nitrates in the soil, the search for their antecedents and the agencies by which the transformation is effected.

Among the workers who contributed to the solution of these problems there are two who claim special mention. These are Warington in England and Winogradsky in Russia; their researches were prolonged, and contributions appeared from time to time from both. Though working quite independently, their results in the main agreed and were thus confirmatory of one another. It is owing chiefly to them that an accurate knowledge of the subject was obtained.

In his first series of experiments at the Agricultural Station at Rothamstead, the results of which were published in $\mathbf{I} 879$, Warington found that a solution of ammonium 
chloride containing as well the other mineral constituents required by green plants would not form any compounds of nitric or nitrous acid, unless the germs present in ordinary soil were allowed access to it, and unless an excess of a salifiable base such as calcium carbonate was present. Under these latter conditions nitrification took place after a variable period of incubation. The experiments succeeded best in darkness and at a temperature below $40^{\circ} \mathrm{C}$.

$\mathrm{He}$ found that in successful experiments the products were not uniform; sometimes nitrous acid, sometimes nitric acid, and occasionally both, were produced. The reason for this discrepancy he left undetermined, saying he had not ascertained the conditions leading to the several results. He seems to have regarded the various external factors as playing an important part among those conditions; but he held them in part, at any rate, to depend upon the state of the germ or ferment in the soil employed.

In the same year, 1879, appeared two communications from Schloesing and Muntz, in which they claimed to have isolated the nitrifying organism. They described it, gave an account of their method of separation, of its range of action, and of the temperature under which such action is possible, together with a discussion of the influence of other conditions upon it.

The organism was studied again in 1883 by Duclaux; he described it as varying considerably, and hence suggested that several species possess the property of nitrifying ammonium compounds.

Warington's next paper appeared in I884, and was chiefly devoted to experiments bearing on the character and behaviour of the organism. He started with his old observation of the variation of the nature of the products and the explanation of it which he was then inclined to favour, but showed that his experiments of more recent date led him to think the character of the organism was the 
determining factor and that the influence of the external conditions was at any rate subordinate. He said, 'It is indeed possible to have two similar solutions under identical external conditions, in one of which only nitrites and in the other only nitrates are being produced; the difference being determined by the character of the organisms with which the respective solutions have been seeded.' After giving further proofs of nitrification being due to an organism, and claiming that the idea was completely established, he went on to describe the distribution of the organism in the soil and to show the depth to which it penetrates.

In the course of his memoir of this date Warington said that in $1879-80$ he was able to prepare a culture solution (of course containing microbes), which was incapable of oxidizing ammonia, but was energetic in converting nitrites into nitrates. He held at the time the opinion that this course of action indicated merely a phase in the life history of the nitrifying organism.

In a further paper, published in I89I, he gave special attention to the conditions under which nitrites are formed, and those under which they are reduced to or replaced by nitrates. He started with the observation that in natural soil, in ordinary cases, the nitrites are due to the action of reducing bacteria, working in a deficient supply of oxygen, but that this is not the case when a strong solution of some ammonium salt is treated with a small quantity of soil. Oxidation then takes place, first nitrites, and later nitrates being formed. Then, reverting to the experiments that led him to the conclusion in I 884 already quoted, he described how he had taken one of the cultures that contained only nitrites (in which he had said the nitrifying agent had 'assumed the nitrous character') and continued its cultivation for three years (I879-82), keeping it pure. It never formed nitrates under any conditions. He again interpreted his result by ascribing the behaviour 
to a peculiar condition of attenuation of the organism. At the same time a suspicion began to make itself felt that possibly it might be a question of two organisms rather than one. Further cultures followed, in which he was successful in isolating the organism by which nitrites are formed, and he found it to agree with the description already given by Schloesing and Muntz.

In the same year (I890) in which this work was done, a paper was published by Professor and Mrs. Frankland, in which they claimed to have isolated the microbe.

The complete failure of this organism to produce nitrates when vigorous, or indeed under any conditions, led to a search for a microbe that should be capable of doing this only. But though pursued with great care, the search led to no further result than that of I880. A culture could be obtained which would not act on ammonia but would oxidize nitrites, but no organism possessing the power could be isolated from it. As we shall see later, the discovery of the microbe was reserved for Winogradsky.

It was thus made possible to speak definitely of a nitrous organism. Warington said it could not be cultivated on gelatine or agar-agar, but it would grow slowly in weak broth. It produced nitrites in solutions of asparagin, in milk, in urine, and in solutions of urea, as well as in culture fluids containing inorganic compounds of ammonia. It was incapable of reducing nitrates to nitrites.

We must now turn to the work of Winogradsky; part of this was synchronous with the researches of Warington, but his more important results were obtained after I890. His investigations followed upon his researches into the peculiarities of the sulphur and iron bacteria, to which reference will be made later. He had found in connexion with this research that they are distinguished from the majority of bacteria by their behaviour to organic food materials. His studies of the nitrifying organisms led to one of the 
most important discoveries of the century, that of chemosynthesis, the consideration of which must be deferred till later. It had been established by Warington that the nutrition and growth of the nitrifying organism is injured rather than promoted by good organic nutrients. Starting with this observation, Winogradsky cultivated them in a solution containing only ammonium sulphate, potassium phosphate, and basic magnesium carbonate, and found that when such a solution, properly sterilized, was seeded with a drop of an old culture of the microbe, a strong nitrate reaction was obtained in a few days and in a fortnight all the ammonia contained in the flask was transformed. From the scum which formed on the surface of the culture Winogradsky isolated five micro-organisms which had no nitrifying power. There remained a sediment consisting of a bacterial zoogloea; from this he obtained with much difficulty other organisms which proved to be those of which he was in search. Cultures inoculated with this zoogloea gave rise to vigorous nitrification, the more readily if ammonia was added in small quantities and at once replaced when used up. In the culture solutions, however, he found, as did Warington before him, that both nitrites and nitrates appeared in variable quantity. Further experiments showed him what Warington had failed to find, that the formation of nitrite takes place first, and that only after the ammonia is used up does the formation of nitrate from nitrite take place.

He then attacked the problem with which Warington had grappled with only partial success, viz. to determine whether two organisms are concerned, or whether the whole process is due to one which becomes modified physiologically as it proceeds, and in the course of a series of experiments he obtained conclusive evidence of the existence of two kinds of nitro-bacteria, one of which constructs nitrites from ammonia, the second oxidizes the nitrites to nitrates. 
He showed that their functions are specific, one can attack ammonia only, the other only nitrites.

The two organisms possess the very important peculiarity that they grow freely only on substrata containing no organic carbon, indeed are actually injured by its presence. It follows, therefore, that they can obtain their carbon only from the carbon dioxide of the air or from the carbonates in the solution. By careful quantitative experiments he proved, as Godlewski did later, that the former is the source of supply, and therefore they resemble green plants in this particular, though unlike the latter they contain no chlorophyll. To this subject we shall return.

The two organisms differ in appearance, the nitrous bacteria, of which there are several species, exhibiting two types. Those found in the soils of Europe, Asia, and Africa, are oblong, globular, or oval in shape, and are furnished with a single cilium; they form a cloudy zoogloea, which sinks to the bottom of the liquid. The species found in America and Australia are cocci and have no cilia; they do not form a zoogloea. The nitrate organisms are slender rods, and are among the smallest of all known organisms. They form a kind of mucinous zoogloea in liquid cultures. Neither organism forms spores. The two classes exhibit great differences in their power of oxidizing nitrogen, the nitrite forms being much the more energetic.

Winogradsky succeeded best in cultivating them upon a substratum of gelatinous silica, with no organic material added. In 1899 he published, in collaboration with his pupil Omelianski, the results of some experiments made upon the influence of sundry organic substances on the growth of both organisms. In both cases growth is very greatly impeded by traces of glucose, asparagin, glycerin, and urea, indeed very small quantities inhibit it entirely. A curious exception occurs in the case of bouillon, in 
Io per cent. of which both organisms can thrive. The growth of the nitrous forms is inhibited in culture liquids containing 20-40 per cent., and that of the nitric organisms in liquids containing 60 per cent. of this preparation. The effect of acetate and butyrate of soda is considerable, but both organisms can withstand smaller quantities than 5 per cent. The nitric microbe is impeded by as little as .0005 per cent. of ammonia and its growth is stopped by oI5 per cent. The authors regarded these organic substances as antiseptics towards the organisms.

The question of the simplification of nitrogenous compounds, with the ultimate liberation of ammonia and even of free nitrogen, received considerable attention after I860. About that time there was a certain controversy as to whether free nitrogen is one of the products of the putrefaction of manure, which later was settled in the negative. The main interest of subsequent discussion turned on its liberation by processes of reduction from nitrates. Goppelsröder first pointed out in I 862 that such processes occur in arable soil, and they were first associated with bacteria by Mensel in I875. Apart from soil action we have the observations of Schloesing in I868 to the effect that during the fermentation of putrefying urine or of tobacco juice nitrates disappear, nitrous and nitric oxides and free nitrogen being produced. The same decomposition takes place during the lactic fermentation of sugar. In 1873 he ascertained that a similar course of events can be observed to take place in moist vegetable soil when no change of atmosphere is allowed. In I88I Warington observed that soil can reduce nitrates to nitrites and finally destroy the latter, and in the next year Dehérain and Maquenne confirmed Mensel's observation that the decomposition is a bacterial one. Pure cultures of organisms capable of bringing it about were made by Gayon and Dupetit in $I 882$, by Heraeus in $I 886$, by Warington in 
I887, and by Frankland in I888. These observers, together with several others in later years, showed that many organisms possess these reducing powers, and that the ultimate products of their activity vary considerably.

A third series of researches on the question of the nitrogen supply next claims our attention, one which was carried on during the last twenty years of the century with considerable success, and is probably about to lead to very astonishing results in the future. It embraces questions of symbiotic union between nitrifying organisms and the higher green plants, a method by which at any rate certain of the latter are able to appropriate atmospheric nitrogen. The number of these known to show the symbiosis in some form is continually increasing, and the most recent investigations suggest that the method is very widespread in the vegetable kingdom.

In the early stages of this research, the question was concerned chiefly, if not entirely, with the Leguminosae, but other instances of similar symbiosis are continually coming to light.

Just before the opening years of our period, in 1858 , Lachmann had observed certain tubercular outgrowths on the roots of certain leguminous plants and recognized that they contained certain organisms much like bacteria. He associated them with an increased power to utilize the compounds of nitrogen in the soil. In the next year Boussingault found on growing lupins in rich garden soil, to which sand or quartz had been added, that the soil gained considerably in its content of combined nitrogen, in the forms of both nitrates and ammonium compounds. No other plants than lupins gave the same result. Boussingault put forward no very clear pronouncement as to the cause of this gain; he denied, however, that it could have come from the air, an opinion to which his experiments had led him in the case of the normal green plant, as has already been pointed 
out. He was so firm in holding this opinion that he said he failed to find in these lupin cultures any satisfactory evidence of fixation of atmospheric nitrogen, a denial which he repeated in 1876 and again in I883, though evidence in the opposite direction was slowly accumulating.

In the years I879-8I Dehérain found that under crops of sainfoin the nitrogen of the soil increased in spite of the removal of large amounts in the crops, an observation confirmed later (I883) by Lawes and Gilbert in the case of clover.

That these strange results must be associated definitely with the leguminous plants seems to have been first clearly comprehended by Schultz-Lupitz, after a number of trials which extended over fifteen years. For this period he cultivated lupins on the same soil without supplying them with any combined nitrogen and found the yield about the same year after year, while in other experiments the lupin crop materially improved the soil for a cereal crop following it. Analysis of the soil at the beginning and end of the fifteen years showed a substantial increase of its content of combined nitrogen. He published his results in $I 88 \mathrm{I}$.

It is, however, mainly to the researches of Hellriegel and Wilfarth, and to a less extent to those of Lawes and Gilbert, that we owe the elucidation of the matter.

Hellriegel and Wilfarth published in I886, and more fully in I888, a comprehensive account of the researches they had conducted during several years with peas and other leguminous plants, oats, and barley. They cultivated some of each in pots in washed quartz sand which had been carefully sterilized, and supplied them with a nutritive solution containing no combined nitrogen. Others were supplied also with nitrate of soda in varying quantities. Others were watered with a small quantity of an extract of arable soil. The results showed that with the cereal 
crops the amount of nitrogen in the produce varied according to the amount of nitrate supplied, whether they were watered with the soil extract or not. With the Leguminosae things went differently, those which were allowed to grow in the sterilized soil behaved like the cereals, the nitrogen they contained varied with the nitrate supplied; but those in whose culture the soil extract had played a part showed a remarkable gain. They concluded that 'the Papilionaceae are distinguished from the Gramineae in not being dependent on the soil for their nitrogenous food. The sources of nitrogen which the atmosphere affords have for these plants the highest importance. They alone can suffice to bring them to a normal or full development.'

In a subsequent series of cultures, they found that the growth was as great when the air supplied was freed from nitric acid and ammonia as when no such precaution was taken. Hence they concluded the source to be the free atmospheric nitrogen.

Hellriegel and Wilfarth found by careful observation of their cultures that the apparent power of absorbing nitrogen from the air was associated with the presence of peculiar nodular outgrowths on the roots of the plants concerned, and that there was some correspondence between the amount of the absorption and the luxuriance of the nodules or tubercles.

These nodular outgrowths appear to have been noticed by the older writers; they are alluded to by Malpighi (I687), de Candolle (I825), and Treviranus (I853). They were first examined by Woronin in 1866 , as were certain others resembling them, growing on the roots of the alder. He described them as containing fungoid organisms, differing, however, in the two cases, the lupins containing bacteria, the alder a fungus apparently of the genus Schinzia. The cells in the interior of the tubercles were 
filled with a slimy colourless matrix in which bacteria-like granules were embedded. In I874 Eriksson found these tubercles to be present almost always in all the genera of the Papilionaceae, and regarded them as metamorphosed lateral roots. He found fungal elements in them, existing as hyphal filaments and as forms of Vibrio, but he was not sure whether the two kinds were connected.

In I878 Kny ascertained that these nodules are not developed upon plants cultivated in sterile nutrient fluids, and the next year Frank showed that they do not occur on the roots growing in sterilized soil. We are able, therefore, to connect the presence of the fungus with the occurrence of the tubercle.

In his paper of 1879 Frank confirmed Eriksson as to the presence of the hyphae and the bacteria-like bodies, and was able to connect the two and to show that the latter are budded off from the hyphae.

We owe to Marshall Ward the most complete investigation of the structure of the tubercles, the mode of infection of the plant, and the course of its development. His researches were made in the years $1884-6$, and appear to have been suggested by the remarkable results that were being obtained by Hellriegel and Wilfarth. Ward showed that the nodules are absent from cultures of Vicia faba in sterilized solutions, but can be made to appear with great facility if pieces of chopped nodules are put in contact with their root hairs. The growth is clearly the result of infection by the fungus. The infecting agent is normally in the soil and is taken up from it or from the tubercles with the greatest readiness by water. Infection takes place through the root hair, down which a filamentous growth makes its way as soon as one of the bacterium-like bodies comes into contact with it. After passing through the root hair it traverses the cortex and enters the tissue, which by hypertrophied growth becomes the young tubercle. 
In the cells of the latter after its development the protoplasm is found to become frothy and vacuolated, simulating the appearance of a plasmodium. Corpuscles eventually fill the cells, being budded off from the filamentous part of the fungus in great profusion. On the decay of the tubercle later, some of these corpuscles are discharged into the soil, while the rest are dissolved or disappear in the cells.

Brunchorst investigated the nodules in 1885 , and while generally agreeing with Marshall Ward, he concluded the corpuscles to belong to the root and not to the fungus. He called them bacteroids.

The association of these structures with the process of the fixation of atmospheric nitrogen was made by Hellriegel and Wilfarth, as already shown. In subsequent researches they confirmed the results already quoted. An instructive series threw a good deal of light on the relations of the two organisms. They traced the growth of the pea seedlings from the onset of germination and noticed that they grew regularly till the reserve food material was exhausted. Then followed a period of rest, followed a little later by a second period of growth. This period varied considerably, in some cases being vigorous, in others only limited. They proved that these variations were caused by variations in the luxuriance of the nodular development.

Other results from their experiments led them to conclude that the organism of infection is not the same in different plants, but that probably a specific organism exists for each. They held the view, however, that though the Papilionaceae take atmospheric nitrogen by the aid of the organism they can absorb combined nitrogen, particularly nitrates, from the soil, but they maintained that their development is not normal unless they are aided by the bacterium. Besides the cereals, they obtained negative results with plants of the Chenopodiaceae, Polygonaceae, 
and Cruciferae. Vines showed in I888 that if compounds of nitrogen are present in the soil in which leguminous plants are growing, the development of the root-tubercles is inhibited. He observed a certain approximate inverse proportion between the tubercles and the amount of combined nitrogen present.

Lawes and Gilbert took up the question at Rothamstead in 1887 and conducted their researches for three years. They obtained results confirmatory of Hellriegel and Wilfarth in every particular.

A number of investigations by different observers in different countries at about this period also helped to establish the accuracy of the early results detailed. Among these workers may be mentioned Atwater in America and Bréal in France. Schloesing and Laurent a little later, in I89o, added an additional proof by cultivating some leguminous plants in closed vessels and showing by analysis of the air before and after growth that free nitrogen disappeared in quantity closely corresponding to that gained by the plants.

A discordant voice was raised by Wolff, whose experiments, extending over the years I883-6, were interpreted by him as showing that the fixation is effected by the soil under the influence of its porous and alkaline constituents.

The striking results that had been obtained led Marshall Ward to the view that the phenomenon is one of symbiosis; the organism, possibly a parasite at first, having ultimately modified its behaviour so as to serve as a stimulus to the vegetative processes of the plant. Investigations during the remainder of the century were directed towards obtaining a clearer knowledge of its structure and lifehistory and the part it plays in the symbiosis. They modified Ward's view but slightly, but up to Igoo very little information was forthcoming as to the process of chemical change accompanying the fixation of the gas. 
Prazmowski, in I888, confirmed Ward's account of the structure of the organism, but pronounced it to be a Schizomycete which possesses a filamentous zoogloea. He says that only part of the bacteria become transformed into the bacteroids and that these dissolve to furnish food to the host.

The organism was isolated from the tubercles in I 888 by Beijerinck, who was able to infect plants of Vicia faba from his cultures. He gave it the name Bacillus radicicola ; he thought it a single organism, manifesting, however, special characters in different cases, their determining factor being the influence of the particular host plant.

In I890 Frank published the results of an investigation in the course of which he advanced totally different views. He said the bacteroids are formed by the plant itself through the breaking up of a network of living substance consisting of an intimate mixture of fungal and plant protoplasm, which he called mycoplasm. The bacteroids contain cocci which are the real germs. Frank renamed the organism Rhizobium leguminosarum.

In 1889 Vines showed that poverty of a soil in nitrates acts as a stimulus to the formation of the tubercles.

Passing over a number of papers which were generally confirmatory of some or other of the results just detailed, we come to certain researches by Mazé and by Nobbe and Hiltner, which throw a little light on the position of the organism in the process. In 1897 Mazé found that cultures of it, made quite apart from the leguminous plant, can bring atmospheric nitrogen into combination. The cultures were made in solutions of protein and showed a great gain in the nitrogenous content of the liquid after the culture had been well established.

In I899 Nobbe and Hiltner proved that the nitrogen is appropriated by the organism and is not fixed by the leaves of the leguminous plant. This fact had not before 
been definitely ascertained. Nobbe and Hiltner infected plants of Robinia with the germs of $B$. radicicola, and cultivated them in solutions free from combined nitrogen. When the tubercles were established on the roots it was found that the plant could not appropriate nitrogen so long as they remained submerged; on being brought into the air, the fixation of the atmospheric nitrogen began.

The last contribution of the century to the subject was made by Miss Dawson, who published a very complete investigation into the structure and life-history of the organism in I899 and I900. Confirming in the main the observations of Marshall Ward much earlier, she showed that the hypha-like structures which penetrate to the tubercle are strands of rodlets lying side by side in a homogeneous matrix which contains neither cellulose nor chitin, and which is probably zoogloeal in nature as Prasmowski suggested. The bacteroids budded off from them are of various shapes, often simulating the appearance of a $\mathrm{V}$, an $\mathrm{X}$, or a $\mathrm{Y}$. The authoress left it undecided whether these forms are the results of branching or of the union of two or more individuals. In some cases, in addition to these, certain motile forms were observed.

A very complete investigation of the process of infection possessed by $B$. radicicola was made in the course of Miss Dawson's experiments, and led her to the conclusion that there is only one organism capable of forming nodules on the roots of leguminous plants and working symbiotically with them. She investigated a large number of genera selected from all sections of the Natural Order. She held the view, in opposition to Hellriegel and Wilfarth that the difficulty of inoculating one genus with organisms from another is probably due to special physiological peculiarities of the several hosts and not to the organisms being specific in each case.

The existence of this form of symbiosis and its great 
economic importance led to investigations as to whether it may not be more general. These researches were pursued especially towards the end of our period, and are still in progress.

The observed phenomena led Frank, in r89o, to suggest that free nitrogen may be appropriated from the atmosphere in some such way by all plants, an opinion that has not even now been disproved. True, failures to support it by experiment have been more numerous than successes, but it for the present remains an open question. In I893 Petermann showed that barley cannot fix nitrogen in sterile soil, but that an energetic fixation takes place when it is grown in soil containing algae and bacteria. He made no investigations, however, into these. The experiments of Aeby in I 896 and of Pfeiffer and Franke in I 897 gave only negative results.

Symbioses between other plants have been found to exist, and in certain cases to show appropriation of nitrogen from the air. In I 896 Hiltner proved that the nodules which grow upon the roots of the alder are concerned in such work. When they are absent it can develop only if nitrogenous compounds are supplied, but after they have been formed it can thrive at the expense of atmospheric nitrogen. Nobbe, Schmid, Hiltner, and Hotter described the organism of Elaeagnus nodules, which they held to behave in the same way. They were investigated by Nobbe in 1892 and 1894 .

Nodules growing on the roots of Podocarpus were studied by Nobbe and Hiltner. In I 899 they published the outcome of five years' work upon the subject, in the course of which they were able to cultivate the plant in quartz sand from which nitrogen was entirely absent. In the same year Hiltner investigated Lolium temulentum, with which a fungoid growth was associated, and thought he noted an appropriation of nitrogen. Since the close of the century much investigation has been devoted to the 
subject, but its consideration does not come within our present province.

The processes by which the nitrogen absorbed in these various ways takes part in further chemical changes, or the synthesis of proteins, received much attention during the period under review, but the information which was gained did not at all approach completeness. We have seen that Boussingault, in the course of his researches on the fixation of atmospheric nitrogen, ascertained that for a large number of plants some compound of nitric acid is the most advantageous form of presentation of this element. The subsequent investigations upon nitrification in the soil detailed above bear out this opinion. Still, it must not be concluded that the older writers who said that ammonium compounds are beneficial were altogether wrong. The early part of our period supplies evidence bearing on this point. Sachs in $1860-3$, Schloesing in 1874 , and Mayer in the same year, showed that ammoniacal gases can supply nitrogen. Later, again, Laurent in I889, Pagnioul in I89o, and Muntz in 1896 , showed that some plants can use ammonium compounds as advantageously as nitrates. While, therefore, both classes of compounds are useful, it is interesting to find that some plants prefer the one and others the other form of combination. Lawes and Gilbert, in I862, divided the plants of pastures into nitrate lovers and ammonia lovers, showing clearly that the matter is not so one sided as Boussingault thought.

Muntz showed that the appropriation of ammonia is more vigorous in light than in darkness. That the chlorophyll is not, however, a necessary factor in the process was proved by Laurent, Marchal, and Carpiaux, who ascertained in $\mathrm{r} 896$ that the white leaves of mottled species of various plants appropriate it more easily than the green ones. In both cases they found light to be favourable, but determined the effective rays to be the ultra violet. 
A similar effect of light was noticed in the case of nitrates. In 1875 Sorokine found a smaller percentage of nitrates in the leaves of the buckwheat than in the rest of the plant, while Pagnioul in 1879 went further and demonstrated not only the disappearance of nitrates, but also the formation of organic nitrogenous compounds in the leaves of the beet, when they were exposed to the sun. Emmerling (I880), Molisch (I883), Berthélot and André (I884), and Capus (I886), confirmed Pagnioul.

These researches appeared to point to the importance of light being as great in these processes as in those connected with carbohydrate formation. More exact investigations later brought to light some features which showed the two syntheses to be indirectly connected.

In I896 Laurent, Marchal, and Carpiaux showed that appropriation of nitrate nitrogen by green plants does not occur in darkness, but requires the ultra violet rays; that it is most active in green leaves, and only feeble in etiolated ones, and that it is accompanied by an intermediate production of ammonia. Godlewski, who followed them in the next year, working upon seedlings of wheat, threw more light upon the problem. He supplied some of his seedlings with nitrates, and left others without any ; grew some in light and others in darkness; arranged his experiments so that the plants received no free carbon dioxide, but were compelled to use only the carbohydrates of their endosperms. He found that with access of light the seedlings produced abundant protein, but scarcely any in the dark, a noteworthy quantity of amido-compounds replacing it. The light appears accordingly to be necessary to the synthesis of protein but not of amido-bodies. The process appeared to Godlewski to take place in two stages, light being unnecessary for the first one which terminates with the amides, but being indispensable for the synthesis of protein from the latter. 
Similar conditions appear to attend the utilization of compounds of ammonia. In I895 Kinoshita showed that when germinating in darkness, barley and maize can make use of ammonia, and a large formation of asparagin follows.

Godlewski's suggestion of the two stages of protein construction has received considerable support. The idea in a somewhat more primitive form was not due to him, but, as we shall see later, was advanced at least twenty years earlier. He, however, gave it the force of his support and based it on the evidence of his experiments. It appears to lead to the view of a combination of amido-compounds with carbohydrate to form protein, but many observations are in conflict with so simple a hypothesis. Some experiments made by Suzuki in 1898 showed that the presence of sugar is necessary for the formation even of the amidocompound asparagin from nitrates by etiolated plants. $\mathrm{He}$ found, however, that protein can be formed in darkness when nitrates and sugar are present.

An experiment of Hansteen, made in I896, has some interest as bearing on the relative advantages of ammonia and nitric acid as starting-points in the synthesis. He found that Lemna minor can produce protein in the dark if supplied with sugar and either sulphate or chloride of ammonium, but not if nitrate is substituted for the latter. There is, as we have seen, a good deal of evidence pointing to an action of light during protein construction. As the latter is a very complicated process, and as all its stages are not equally affected, it will be convenient here to consider the progress of research into the synthetic processes and to return afterwards to the influence of light upon them.

Experiment upon the processes in question dates back to about I88I, when Emmerling conducted a number of researches upon Vicia Faba, which led him to the view that the nitrates of the root are decomposed by organic acids 
present in the plant, and that the nitric acid so freed is the next step in the construction of protein. He attributed the decomposition to processes in the leaves, as nitrates could be traced towards them in gradually diminishing quantities, but the leaves themselves contained none. He found that crystallizable nitrogenous organic substances are present in leaves, an observation confirmed by several contemporary writers, particularly Biltz, Kellner, and Borodin.

In 1888 Schimper observed a large formation of calcic oxalate in leaves absorbing much calcium nitrate. $\mathrm{He}$ attributed this to the decomposition of the nitrate by the oxalic acid of the plant, thus agreeing with Emmerling.

Research was followed very soon by speculation, based often upon original observation by the theorists, but sometimes traceable to more general grounds. The idea of a reduction of nitrates in the plant had occurred to a few observers before Emmerling had shown how the nitric acid itself might be set free, and the agents of such reduction had been thought possibly to occur among the products of the action of chlorophyll. In 1872 Gautier attributed it to the formaldehyde, whose presence had just previously been suggested by Baeyer. The reduction of nitric acid in light was first actually observed by Laurent in I890, and later by Berthelot in 1898 , and was found to be accompanied by a production of nitrous acid, nitric peroxide, and oxygen.

In I896 Bach put forward a scheme of decomposition to show what the stages of the early decompositions may be, much as Baeyer hadshadowed forth the stages of photosynthesis nearly twenty years earlier. There was at the time very little evidence in support of his speculation, and indeed till the end of the century the hypothesis remained practically unsubstantiated. It served, however, as did Baeyer's, as a starting-point for research. 
Bach suggested a first reduction of the free nitric acid liberated as Emmerling supposed, in the same way as it is reduced by sulphurous and hydrosulphurous acids, the reducing agent being formaldehyde. Such a reduction would yield in succession nitrous and hyponitrous acids and finally the group $\mathrm{NH}$, which would unite with water to form hydroxylamine. The latter reacting with formaldehyde would give besides water formaldoxine, which is readily convertible into formamide; from this again, by dehydration, hydrocyanic acid can easily arise.

His theory was supported by the observation he made that when formaldehyde reacts with nitric acid, formaldoxine occurs among the products. Bach thought he detected formamide also.

Gautier, in I892, suggested that hydrocyanic acid might form the nucleus of protein, various radicals becoming attached to it. He showed that it polymerizes easily, and in that way lends itself to the production of new complexes. Kossel discovered one of these, adenine $\left(\mathrm{C}_{5} \mathrm{H}_{5} \mathrm{~N}_{5}\right)$, in different plants, so that Bach's hypothesis may very well be regarded as provisionally a working one. It received some support not only from his own researches, but from those of Treub in 1895, in which the latter showed that in Pangium edule cyanides occur at or near the seats of protein construction. From their distribution and manner of appearance Treub concluded that they formed the first product of the appropriation of the nitrogen by the plant. Treub's discovery of the existence of hydrocyanic acid in plants was confirmed by other writers and by his own later researches. So far, however, it does not appear altogether clear that it is a product of the synthetic processes; some observers hold it to be rather derived from protein by decomposition.

Lutz endeavoured to test Bach's hypothesis by searching for hydroxylamine in various species of Phanerogams, Algae, 
and Fungi, but his results were negative. We must remember, however, that at first the search for formaldehyde was similarly fruitless.

The theory already alluded to that protein is constructed in the plant from the more complex of the amido-bodies, together with some form of sugar, has been advocated by many observers since $I 878$, when the fact became known that such amido-bodies are of frequent occurrence in leaves. Borodin found in that year not only that they are formed there, but that a great accumulation of them can be secured by cutting off shoots and keeping them in the dark. Under these conditions no sugar is formed and no protein is made.

Pfeffer said in 1872 that asparagin is regenerated into protein as starch is formed. We owe a good deal of information on the occurrence of amino- and amido-compounds in metabolism to the researches of E. Schulze and his pupils since about that time.

Many observations confirmatory of Borodin's were made later by other botanists, but no one was able to throw any light upon the mode of interaction of the two groups concerned, nor has the way in which the sulphur and phosphorus of protein are incorporated been discovered. Contributions to our knowledge were made by A. Meyer in $I 885$ and by Saposchnikoff ten years later, but neither. furnished proof of any of these points. Saposchnikoff found that protein can be formed in isolated leaves in the presence of light, particularly if they are supplied with nutritive solutions containing combined nitrogen. A diminution of the light retards the formation of carbohydrates as we might expect, but it accelerates that of protein. His experiments led him, however, no further than the conclusion that protein is a secondary product constructed from carbohydrates.

We may now return to the relation of light to the process. In I888 Schimper put forward the view that the 
appropriation of nitrogen by the plant, like that of carbon dioxide, is dependent on chlorophyll and sunlight, basing his opinion on the fact that leaves of Pelargonium, which contain large quantities of nitrate, lose it in strong light in a few days.

In I8go Frank and Otto proved that a synthesis of asparagin takes place in leaves under the action of light. In I 898 Hansteen published the results of a series of experiments, which he made on this question. He found that in darkness protein is produced from urea in the presence of cane or grape sugar; that asparagin and glutamin form protein only when glucose is present; and that glycin or glycocoll needs cane sugar for the purpose. In Igoo some results were published by Maliniak which in the main confirm those of Hansteen. Zaleski showed that a synthesis of protein takes place in the dark in resting or growing bulbs, tubers, and roots, without any increase of nitrogen-content, an observation confirmed by Iwanoff.

Further researches on this point made by Laurent and Marchal were published early in the present century.

This question thus still awaits solution. 


\section{CHAPTER IV}

\section{THE PROGRESS OF OUR KNOIVLEDGE OF THE RÔLE OF THE CONSTITUENTS OF THE ASH OF PLANTS}

PERHAPS there is no department of vegetable physiology in which so little progress has been made as this one,none in which the results of investigation have been so unsatisfactory. It has been found possible to determine what elements can be detected in greater or less quantity in plants; which of them are of widespread occurrence; which only appear occasionally or in special individuals. Within certain limits their distribution in the plant-body has been ascertained, but nearly all attempts to associate particular elements with definite functions have resulted in more or less complete failure to gain any accurate information.

Before discussing these researches and the results to which they have led, we may well remind ourselves of the difficulty of the problem and of the possibility, or even the probability, that a definite association of any of the elements with a particular function does not and cannot exist. Even in the animal body, the study of which is far more complete than that of the plant, such associations have not been found. Each element plays more than one part, and not improbably the part it plays at any moment depends to a very large extent on the condition of the organism. IVe may well conclude that in the organization of the plant also there is no definite devolution of a particular function to a single constituent of its composition. It is probable that the well-being of any organism depends 
on the interaction of many elements with the protoplasm, interaction which may vary from time to time and from place to place according to the changes of the environment or the automatic readjustments going on in the living substance. The influence of varying quantities of the mixture of elements may be considerable. Correlations of the functions of the plant, or the abnormal performance of one or more of them under the influence of disturbances of quantitative relations, may obscure the action of any element or group of elements in whatever combinations it or they may be existing. It is therefore hardly to be expected that much progress will be made in this direction; probably all the essential elements of the ash play many parts, all co-ordinated by the living substance of the organism.

Ve have already examined the development of knowledge of the absorption of water by the roots of plants. This process is associated very closely with the absorption of the elements of the ash, as was established long ago by De Saussure, whose law of absorption expressed the views current up to the opening years of the period under review. Liebig was a little more pronounced than De Saussure in his opinions, for he taught in 1858 that terrestrial plants absorb all their ash constituents from the soil by means of the solvent action of their roots.

De Saussure's law was re-investigated by Wolff in I864, by Knop, in 1859 and $\mathrm{I} 864$, and by Biedermann in $\mathrm{I} 867$. The result of these researches, of which those of Wolff were the most complete, was to establish that De Saussure's law does not hold universally, but deals rather with a special case of a more general rule. The latter, as established in these investigations, is that for every salt capable of being absorbed there is a certain degree of concentration at which the proportion of the amount of salt absorbed to that of the water absorbed with it is the same as that of 
the solution; if the solution presented is of higher concentration than this, relatively more water than salt is absorbed therefrom, so that the solution becomes gradually more concentrated; if it is of lower concentration, the reverse is the case and relatively more salt than water is taken up.

It was known also to the earlier physiologists that when a plant grows in a medium which presents to its root hairs many different salts of various metals it does not absorb them equally and indifferently, or according to the osmotic pressures they exercise. Again, the quantities of each compound taken up by different roots vary considerably. This was attributed to a special property of each root, which was known as its quantitative selective power. The explanation given was not very satisfactory; it was originally attributed by Mulder to the co-operation of osmotic pressure and to metabolic changes following absorption. The fact that deleterious salts are often absorbed in large quantities, established by Phillips in I882, shows that some further explanation is desirable.

. This selective absorption, leading to the accumulation of certain ash constituents by many plants, and to the absorption of unequal amounts by plants growing in the same soil, has been established by numerous more recent analyses. The work of Wolff in I871, Liebig in 1876 , Koenig in 1889 , furnishes details upon this point. Goedechens' analyses of various Algae made in $I 845$ shows that it is equally true of aquatic plants.

The explanation advanced falls short in completeness. No better hypothesis was, however, advanced up to the end of the century. Many physiologists came to the conclusion that there exists in protoplasm a certain directive force, controlling the entry and distribution of metallic salts, and working together with or in antagonism to the ordinary physical force of osmotic pressure. Such a process presents 
certain features which recall the operations of secretion or excretion. The matter was still only the subject of speculation in rgoo.

The view of Liebig, that all absorption of salts is due to the solvent action of the roots, received some apparent confirmation from the observation of Sachs in I865, that roots exert a certain corrosive action on a polished gypsum plate when allowed to grow in contact with its surface. The explanation advanced was that of an exosmotic flow of the vegetable acids of the root hairs, and was in harmony with the views of osmosis that prevailed at the time. Pfeffer's researches on this process, of which mention has already been made, militated against this explanation. Further objections to it were advanced by Czapek in I896. He showed that such acids are not excreted by root hairs, and that their acidity is due to the presence of an acid phosphate of potassium. Czapek said that the only acid which is excreted by the roots of land-plants is carbonic acid.

The variation in nature and amount of the ash, and in the quantities of its several constituents, established by various authors, as we have seen, was the subject of considerable research by Wolff, who greatly amplified the information available on the subject in a memoir published in I87I. In this he showed that such variation depends on the plant as well as on the medium in which it grows. Further proof was adduced by Grandeau and Bouton in 1877 in their work on the ash of the mistletoe and the host on which it was growing. Though the former absorbs its salts directly from the host-plant it does not take them in in the proportions in which the latter supplies them.

Three methods of investigating the problem of the absorption of salts were employed during the latter part of the century. The first was due to Salm-Horstmar in 
I856-60, and consisted in cultivating plants in insoluble artificial soils, to which he added the particular materials whose fate he was endeavouring to trace. By its means he considered he had determined that phosphorus, sulphur, potassium, calcium, magnesium; iron, silicon, and manganese are essential to the wellbeing of all green plants, and especially of the cereal grasses. He was doubtful about chlorine, and denied that sodium is of any utility at all.

This method was modified and improved by Hellriegel in I883; he introduced the use of sand that had been heated to redness and then boiled in sulphuric acid. The salts under observation were added subsequently.

The method of water culture, which had originally been used by Woodward as long ago as I699, was revived in I860 by Sachs, and was used in the same year by Knop. This method, which consists in growing plants in a nutritive solution containing known proportions of various salts, offers many advantages over the others and has been the basis of most of the investigations that have been made since it was again introduced. The results obtained by its employment have established certain facts as to the ash constituents which call for notice, though most of the knowledge that has been obtained has been of the most empirical nature. They have led to little more than speculation, and hardly any accurate knowledge as to the specific functions of any of the ash constituents.

The method of water culture enabled Nobbe to determine in I862 that for one plant at least, the buckwheat, chlorine is essential for full development. He found that with an appropriate solution he was able to cultivate this plant with complete success, indeed, he found it to flourish more luxuriantly than in ordinary soil. Wolff found in I868 that oats behaved similarly.

In I866 Birner and Lucanus found that the elements deemed essential by Salm-Horstmar should not have in- 
cluded either silicon or manganese, but they were in accord with him as to the necessity of the other six. Calcium was shown by Benecke in r894-8 and by Molisch in I895-6 to be unnecessary in the case of Fungi.

The importance of sulphur and phosphorus became evident when it was shown that these enter into the composition of the living substance. Boussingault in I860, and Lawes and Gilbert in the same year, showed that phosphates play a part in the utilization of nitrates. In I898 Macallum showed by micro-chemical methods that phosphorus is an integral constituent of the nucleus, and of the nucleolus.

In I862 Nobbe proved that the buckwheat produces no fruit in the absence of chlorides, an observation confirmed by Leydhecker in I865 and I866. In I89o Aschoff found that when these salts were not supplied to cultures of beans and maize the terminal buds showed themselves incapable of developing, and after a short time perished. He noticed further that the leaves showed a great congestion of starch grains. Aschoff could not, however, assign any specialized function to the chlorine.

Silica was investigated in 1883 by Kreuzhage and Wolff ; they found it to be necessary for the full development of the cereal grasses, aiding in the utilization of the other nutrients and leading to a better production of seed and to an earlier ripening of the grain.

Potassium was the subject of much research. In I87I Nobbe, Schroeder and Erdmann found that in its absence the chloroplasts fail to form starch. They further noticed that unless the form in which it was supplied is the chloride, there is a great congestion of starch grains in the leaf. In the light of Aschoff's work already mentioned the latter peculiarity may be associated with the absence of the chlorine.

In 1887 Lupke found that the absence of potassium does not interfere with the development of any of the different 
parts of the plant, which goes on regularly. It, however, materially reduces the extent of such development, the plants remaining extremely small. Some light was thrown on the importance of this metal for the development of the plant by Schimper's researches in I8go. Starting with a water culture of Tradescantia in which only a minimal quantity of potassium salts was supplied, he found that as it became exhausted the new growth was checked. As it proceeded the older leaves were gradually depleted of the metal; the new leaves formed were smaller and thinner and finally became very minute. As the supply from the older parts slowly failed, the tissues died, and ultimately the growing-point itself perished.

Macallum's observations, made quite at the end of the century, brought further facts to light. He noticed that the walls of the fibro-vascular tissue are saturated with potassium, and that it is present in particular regions of the protoplasm of the green cells, but never in the nucleus. In the cells of the filament of Spirogyra he found a concentration of the metal in an area of the protoplasm near and almost surrounding the chromatophore. In the higher green plants he found a similar disposition of it near the chloroplasts, but it was not so striking as in Spirogyra. From his observations Macallum concluded that potassium is associated especially with photosynthetic processes and possibly also with those of dissimilation, and that it is in some way concerned in the work of the chloroplasts. The prominence of the metal in the structure of the cell walls of the fibro-vascular tissue led him to the view that it is concerned in the growth and formation of the cell wall generally. Tracing the stages of the germination of the spores of Equisetum arvense he found that the cell from which the primary rhizoid arises is from the first very rich in potassium salts, and that these collect at the point from which the rhizoid subsequently springs; as the latter con- 
tinues to grow the inner surface of the membrane remains in close association with the salts. A further observation on the growth of the pollen-tubes of Lilium confirmed this view. Potassium can be detected at the moment the tube emerges from the pollen-grain, and can be observed to accompany its extension as it makes its way down the style. Similar observations were made upon the conjugating processes of Spirogyra, where the reaction of potassium was given close to the terminal walls of the outgrowing tubes. This reaction was found to be much more marked than that of the adjacent cytoplasm, in which, as already mentioned, the metal could be detected.

The influence of calcium still remains obscure. SalmHorstmar proved it to be essential for the development of Phanerogams, and Boehm associated it with the transport of the reserve materials from the seed to the seedling. In I883 Raumer stated that from his observations he concluded that the only special purpose it serves is to help in the construction of the cell wall. Molisch supported this view in I895, by showing that the partial absence of calcium causes an incomplete formation of the transverse cell walls of Spirogyra.

Stohmann found that in the case of maize in water cultures, development ceased as the tissues became exhausted of the metal, and that after several weeks, during which growth was at a standstill, the addition of a calcium salt was immediately followed by the growth of the buds. In I89I Palladin associated its presence with the proper development of the leaves, and ascertained that etiolated leaves contain only one-fifth the amount of the metal that is found in normal ones. Schimper, in I890, said that its function is the neutralization of the oxalic acid and acid oxalate of potassium in the tissues. In I900 Loew advanced the view that it enters into the composition of certain protein compounds which are needed to supply 
material for the construction of nuclei and of chloroplasts. Mangin, in I892, showed that it is a constituent of certain parts of the structure of the cell wall, being in combination with one of the pectic acids.

Magnesium was first shown by Salm-Horstmar to be an essential element for the green plant, but very little has since been discovered as to the part it plays. Schmiedeberg showed in 1877 that the protein crystals of the brazilnut are composed of a magnesium compound of vitellin, and Grübler, in I88I, found that the crystallizable protein of the gourd contains the metal. Like calcium, therefore, it appears to form compounds with protein. In I883 Raumer stated that it is concerned with the transportation of starch from the chloroplast.

Iron has been the subject of much inquiry since Gris, in I843, showed its presence to be necessary for the formation of chlorophyll. Its association with this pigment led to the opinion that it must enter into its molecule, and Hansen, in I889, claimed to have found it there. Schunck, in I89I, said he found it in the ash of phylloxanthin, which is one of the products of the decomposition of chlorophyll. On the other hand, in 1892, Gautier, whose analyses of the pigment were made with great care, failed to find any iron in the ash, and its absence was claimed by Ernich and by Molisch in the same year. Macallum failed to find it in the chloroplasts by micro-chenical methods in I89I. Raulin in I869, and later both Molisch (I892) and Benecke (I895) showed it to be essential to the nutrition of fungi.

Observations as to the disposition of iron in the plant led to its identification as a constituent of the chromatin of the nucleus. This discovery was due to Macallum and his co-workers in America. In I89I Bensley, by microchemical methods devised by Macallum and working with him, found it in the chromatin of the pollen cells of Dianthus, Cucurbita, and Narcissus, both in the mitotic figures 
and in the diffuse chromatin which slowly passes from the nucleus into the cell. Macallum himself observed it in the chromatin of the ovules, while McKenzie found it in the same constituent of the spores of certain Fungi and Algae. In the next year Petit found it combined with nuclein in the tegmen and the embryo of the barley grain, and in I893 in the rootlets protruded by the germinating grain. Bensley, in the same year, obtained a reaction by it in the nuclei of the cells of the ovary of Erythronium.

Macallum noticed its occurrence in a few cases in the cytoplasm, particularly in the cells of the aleurone layer of the wheat grain, and in the spores and hyphae of certain Fungi, in the nuclei of which it was present also. $\mathrm{He}$ did not regard this distribution as indicating that the iron of the chromatin is derived from the cytoplasm.

Physiological observations on the function of iron have led to little. Bracci found that its presence hastened the ripening and increased the yield of oats and wheat. Molisch, in I892, observed a great effect produced by it on the growth of fungi. In I888 Gautier and Drouin found that ferric oxide promotes the fixation of atmospheric nitrogen by the soil bacteria. Pfeffer claimed that the chlorosis due to its absence is not caused by its being directly concerned in the formation of chlorophyll, but is the result of malnutrition.

The last theory of its function was advanced by Saccharoff at the end of the century. Considering the action of oxygen in the cell, and seeking for something universally present therein which is capable of easy oxidation and of yielding compounds which can be reduced again or further decomposed with comparative ease, he held that such processes may be readily carried out by minute traces of iron. He put forward accordingly the hypothesis that the various vital phenomena of protoplasm are set up by the oxidation of a minute trace of iron contained in the 
living substance, with subsequent or concurrent hydrolysis.

The only observations pointing to any special function associated with manganese were those of Bertrand in 1897 . These connected it with processes of oxidation taking place in various plants, especially the lacquer-tree, and to a less extent the leguminous plant lucerne. Bertrand considered it to enter into the constitution of the oxidases. 


\section{CHAPTER V}

\section{THE DISCOVERY OF CHEMOSYNTHESIS}

WE have traced the gradual development of our knowledge of the formation of organic substance during the latter part of the last century, and have seen how the processes taking place under the influence of light have been unravelled by the efforts of a long series of workers in all countries.

Towards the end of the century a very far-reaching discovery was made, in some sense almost inadvertently, in connexion with a research which was directed in the main to the elucidation of certain of the problems connected with the supply of nitrogen. This was the determination of the fact that another process of formation of organic substance from inorganic materials exists in nature, carried out by certain plants, but without the intervention of the chlorophyll apparatus and without the necessity of the access of light.

The process is, of course, found to occur only to a limited extent, and the power to initiate it is confined to certain micro-organisms, some of which have been shown in an earlier section to be concerned in the presentation of combined nitrogen in suitable form to the green plant.

Our information starts with observations made in I 886 upon the nitrifying bacteria, then attracting a good deal of attention. Warington, as we have seen, found great difficulty in cultivating them in the media ordinarily in use, and Munro also noticed that they exhibited a decided distaste for all kinds of organic nutriment. In the same year Heraeus found he obtained very energetic growth when 
he employed a culture fluid containing nothing but inorganic compounds, the most suitable being ammonium sulphate, common salt, and magnesium carbonate. Hueppe made a similar observation in 1887 .

The work of Heraeus and of Hueppe formed the startingpoint of the discovery. It was carried much further by the researches of Winogradsky, who cultivated the organisms with great care in various media, both liquid and solid. Using the former he found they flourished in a solution containing ammonium sulphate, potassium phosphate, and basic magnesium carbonate. $\mathrm{He}$ obtained better results when he used as a basis a preparation of gelatinous silica with which he incorporated a sterilized solution of the sulphates of ammonium, magnesium, and potassium, with some carbonate of sodium. The necessity for the presence of the carbonate was due to the formation of the nitrous and nitric acids by the microbes; this he found was met in the soil by the presence of calcium carbonate.

Winogradsky succeeded in cultivating the organisms on another solid medium containing mineral compounds in a basis of $I .5$ per cent. of agar-agar.

In such media the organisms increased with great rapidity, such multiplication involving, of course, a manufacture of organic substance from the inorganic materials supplied to them. Like his predecessors, Winogradsky found that they were injured by the presence of organic nutrients of even so lowly a form as potassium tartrate. In the absence of all such organic substances the growth was so great that he could estimate the formation of organic material quantitatively.

It was clear that the gain of carbon which his cultures showed could only have taken place at the expense of the carbonates of the nutritive media, or of the carbon dioxide of the air. His quantitative analyses showed that the latter certainly contributed to the process, which, as we have GREEN A a 
seen, was marked by nitrification of ammonia. IVinogradsky's results were published in I89o.

Further and quite conclusive proof was afforded by Godlewski in I895, when he showed that nitrification would not go on and development of the organisms would not occur in cultures containing magnesium carbonate when no carbon dioxide was present in the air supplied to them.

Winogradsky found that the process, which we may call chemosynthesis, can take place as well in darkness as in light, and is not therefore directly dependent upon a supply of solar energy. His experiments showed him that the energy employed in the construction is derived from the oxidation of the ammonia.

Winogradsky left our knowledge of the subject incomplete, and no one has taken it further as yet. Nothing has been ascertained as to the stages of the chemosynthesis. He suggested that possibly urea is one of the products, produced by polymerization of ammonium carbonate. Hueppe, in I887, and Loew, in I89I, suggested that the initial stage may be the formation of formaldehyde from the carbon dioxide and water. The problem still awaits investigation.

Another case of similar character was studied by Winogradsky in 1887 . This was the behaviour of the so-called sulphur bacteria, species of Beggiatoa, which can flourish in water containing sulphuretted hydrogen. He proved that these microbes when supplied with such water flourish luxuriantly and deposit aggregations of particles of sulphur in their cells. These particles are subsequently removed, or dissolved out by some process when the supply of sulphuretted hydrogen fails. As in the case of the nitrifying microbes, Beggiatoa contains no photosynthetic pigment, but gets its energy by the process of oxidizing inorganic substance-in this case sulphur. It grows with great freedom in water containing besides sulphuretted 
hydrogen only traces of ammonia and nitric acid, with as little as 'ooo5 per cent. of organic material. Sugar, peptone, asparagin, and similar compounds rapidly kill the plant, even when present in little more than traces.

There are several genera and species of these sulphur bacteria, some of which were described as long ago as I840, but their chemosynthetic powers were not known till the appearance of Winogradsky's researches.

Winogradsky attributed a similar activity to another group of bacteria, which have the power of utilizing ferrous carbonate, and which are commonly alluded to as the iron bacteria. These were first described by Cohn in I870.

These phenomena leave no doubt that the constructive power of protoplasm is much greater and more varied than was supposed by the writers of the early years of our period. Consideration of them points to the possibility of synthetic processes in the higher green plants without the intervention, or at any rate the immediate influence, of light and chlorophyll. The story of the fixation of nitrogen from various antecedent compounds, which we have already considered, leads to the conception of very extensive chemosynthetic powers in the ordinary green plant, called into action perhaps only after preliminary activity of the chlorophyll apparatus, and not extending to carbohydrate formation, but no less real in the green plant than in the humble organisms in which they seem to set up the only synthetic process. 


\section{CHAPTER VI}

\section{THE DEVELOPMENT OF KNOWLEDGE OF THE METABOLIC PROCESSES}

WE have seen that as late as I860 hardly any accurate knowledge of the constructive processes had been obtained. For several years it had been known that the leaves are the chief seat of formation of what were generally but obscurely called elaborated substances, and it had been inferred that for the growth of the general plant body the formative matter must be conducted thence. The idea of a general correspondence of the streams of material to and from the leaves with the circulation of the blood of the higher animals had seized the imagination of many, and had led to the use of the phrase 'the circulation of the sap'. In some writings of the time we find the view put forward that the raw sap, or as they called it the 'crude' sap, ascends through the cells and vessels of the stem and root, undergoes an elaboration in the leaves under the influence of light and air, and then descends through the bark into the roots again, whence, after losing somewhat by excretion, the rest mixes with the entering stream. The descending stream or 'Elaborated sap' was held by Hartig and by de Candolle, as late as $185^{8}$, to be a kind of mucilage or gum, from which by some process of concentration or evaporation of large quantities of water, solid reserve materials were deposited in various places in the plant.

The problem facing investigation in this direction in I860 was stated by Sachs as being mainly twofold-the nature of the substances produced in the leaves, and the 
manner and path of their transport. The problem included, however, something more than this, viz. the relations between the first-formed substances and the actual constituents of the elaborated sap or formative mucilage of Hartig.

We have already traced the course of investigation into the first of these questions as far as the end of the century. It remains for us to deal with the general inquiry into the phenomena which follow the construction of what we are now able to recognize as the actual food of the vegetable organism, which was known to be transported in some form from the leaves.

In this field Sachs was again a pioneer. $\mathrm{He}$ was the first to subject the old theory of the circulation of the sap to a close scrutiny, gaining extensive knowledge as to the way in which translocation of the different foodstuffs takes place, the exact nature of many of the products concerned, and the means by which such translocation is secured. He ascertained further that such processes of removal or transport are often associated with decompositions and recombinations in the channels through which they pass.

The somewhat vague ideas as to the descending sap were given a little more definiteness in 1860 through some observations of Hanstein. When he removed from a young sapling a ring of cortical tissue extending from the exterior to the cambium, thus cutting away entirely the cortex and the phloëm of the vascular bundles, he found the operation was followed by a formation of adventitious roots above the injury, but not below it, indicating that whatever the descending sap may be, it contains formative material, and that it travels in either the bast or the cortex of a young tree. Hanstein's work was repeated in 1879 by Faivre, and his results confirmed. These observations, however, gave no information on either of the problems 
stated by Sachs. We have seen that he himself contributed not a little to the solution of the first-the question of the process of construction of carbohydrates. In connexion with his researches on this point he made many equally valuable observations on the second of the problems. In I864 he found evidence of the migration of the firstformed starch from the leaves, in that while a leaf may contain a very large amount at night, very little may remain in it in the early morning. The idea of a nocturnal migration following a daylight formation was at once suggested, but further experiments led him to see that the starch is removed in light as well as in darkness, though the observation can be made only with greater difficulty in consequence of the coincident constructive processes. Further light was thrown upon the question of translocation in I873, when Godlewski and Pfeffer independently proved that starch disappears from a leaf when it is kept for a long time in an atmosphere devoid of carbon dioxide. This observation was repeated by Morgen in 1877 . These researches, taken together with those of Sachs, prove that migration of carbohydrate goes on continuously and can be observed readily as soon as its formation stops. Sachs made no statement as to the form in which the starch travels until, in his Vorlesungen, in I882, he said he was inclined to assume it to be some form of sugar.

The relations between starch and sugar had been investigated much earlier. As far back as I8I4 Kirchoff had found that germinating barley grains yield to extraction by water something that is capable of converting the former into the latter, and other writers had incidentally noticed the same thing in connexion with similar researches. This substance, which later came to be recognized as diastase, was not especially studied after Sachs' experiments till I874, when its examination was resumed by Gorup-Besanez. Its relation to the migration of starch from leaves was 
proved by Kosmann in $\mathbf{1 8 7 7}$, Baranetzky in I878, and Krauch in I879. Kosmann and Krauch detected it in the leaves and shoots of the higher plants, and Baranetzky in buds and potato tubers. He found it so widespread that he suggested that it is universally present in vegetable cells. Further researches extending our knowledge of its distribution were made by Brasse in I884.

The existence of diastase in leaves was disputed by Wortmann in I890, and his observations led to further more careful researches by Vines in I89I, and by Brown and Morris in I893. The work of the latter observers was the fullest and most detailed that has at present been carried out on the diastase of foliage leaves, and may be regarded as establishing beyond controversy the existence of the enzyme and the part it plays in the translocation processes.

Sachs, as we have seen, suggested in 1882 that the migration of starch is preceded by its conversion into sugar. It had been known since the early part of the nineteenth century that such a conversion is easily effected, and that Kirchoff's extract is capable of bringing it about. It was not till I87I that the nature of the sugar resulting from the action of diastase on starch was ascertained, when Brücke, O'Sullivan, and Griessmeyer, working independently, came to the conclusion that it is maltose. It was previously known to be able to reduce Fehling's fluid. The discovery of a reducing sugar in the leat was first made by Meyer in 1885 .

In their researches into the sugars of the foliage leaf in I893, Brown and Morris found that the migrating sugar is not maltose alone, but that glucose and fructose may also be detected in the stream. As no means of preparing either of the two latter from starch were then known, it became evident that the translocation of carbohydrates is more complicated than Sachs suspected. It will be 
remembered that ten years earlier cane sugar and the products of its inversion had been discovered in foliage leaves by Kayser. The experiments of Brown and Morris led them, as we have said in a former chapter, to the view that cane sugar is the first-formed sugar of the leaf. Their explanation of the contents of the translocation stream is that the maltose arises from the starch, and the glucose and fructose come from the inversion of cane sugar. They found evidence of the existence in leaves of the enzyme invertase, which effects this change, and which had been known since $\mathrm{I} 860$ to be a factor in the metabolism of yeast.

The transport of proteins has not been the subject of such prolonged inquiry. In 1872 Pfeffer ascertained that the results of their transformation as detected in the travelling stream take the form of some of the amido- or amino-compounds, which we have seen to be probable stages in their formation. An enzyme capable of setting up the decomposition which leads to the production of such compounds was first investigated by Würtz in I879. He found it originally in the fruit of the Papau-tree, but later prepared it also from the sap of the stem and leaves.

The occurrence of proteoclastic enzymes in the leaves remained somewhat doubtful till the end of the century, when the researches of Vines established it satisfactorily and gave us for the first time anything like a clear idea of the nature of the processes involved. To this point we shall return later.

Turning to consider other features of the translocation process we may consider the localization of the paths of transport. The general idea of a stream of sap circulating continually round the plant did not long survive inquiry, but nothing replaced it very definitely for some time. Sachs held the path of sugar and of whatever might be the travelling form of combined nitrogen to be the paren- 
chymatous cortex, but he based his opinion upon the fact that it possesses an acid reaction. He further held that protein as such probably travels by the sieve-tubes, which he thought to be often the places of its production. His views on these points, however, were largely speculative and based on very incomplete observations.

Nothing further transpired till I883, when Haberlandt suggested that the laticiferous tubes are concerned in transport, a view that met with the acquiescence of Schimper in I 885 and of Gaucher in I900. Some observations made by Schimper in 1885 were the first to give definite results. $\mathrm{He}$ found that after he had removed the fibro-vascular bundle of the petiole of Plantago it continued to transport its starch as usual from the leaf-blade. Hence he concluded that the elongated cells of the bundle-sheath form the path for sugar. Von Mohl in I885, 'Lecomte in I889, and Strasburger in I89r, claimed that all plastic substances travel by way of the phloëm. Czapek in I897 argued in favour of the path being both phloëm and bundle-sheath. The theory that the sieve-tubes are the main channel is borne out by Kraus' analysis of the contents of the sieve-tubes of Cucurbita made in $\mathrm{I} 894$. He found that 48 per cent. of their dry weight consisted of carbohydrates.

From some observations of Fischer in I890, which were confirmed by himself and by Strasburger in I89I, it appears that besides the downward stream of organic substance elaborated in the leaves there is in the spring, propelled probably by root-pressure, an upward stream of organic substance derived from the reserves stored all through the winter in the roots and other perennating parts of the plant. This stream supplies the young leaf-buds as they resume their growth ; its path seems to be exclusively in the wood. When we consider the great amount of activity of the metabolic processes which follows the winter rest of vegetation it becomes evident at once that the re- 
searches so far described and their results must be very incomplete.

The forces which cause the movement did not receive so close a study as the transformations concerned. Pfeffer's great work on osmosis was accepted as affording an adequate explanation of the passage from cell to cell till inquiry into the nature of the membranes led to the recognition that they are largely of the nature of semi-permeable membranes and resist the passage of such substances as are undergoing translocation. It was found that the deposition of starch, formed from the translocated sugar, is followed by the passage of more sugar to the cells concerned in the deposition, or, in other words, that there exists in such parenchyma a tendency towards the maintenance of equilibrium with reference to any constituent of the sap in the cells. Osmosis does not conduce to this, for if the concentration of, e.g. sugar in any cell is lessened by its conversion into starch, such cell will give up osmotically more liquid to the adjacent cells than it will receive from them; its turgescence will diminish and the whole process will be disturbed. Diffusion of the sugar was held to be a probable contributor to the motive power till, in 1885 , De Vries showed that its rate is extremely slow, too slow indeed to allow diffusion to be of much practical value.

A theory was advanced by Brown and Escombe in 1900 which may perhaps lead to a fuller elucidation of the problem. Recalling the observations of Gardiner on the protoplasmic communications between contiguous cells, to which we call attention elsewhere, these writers claimed that the very fine passages through the cell wall render the latter a membrane with minute apertures, which may be compared with the membranes on which they based their theory of the mode of entry of gases into plants through the stomata. As we have already noticed this theory in connexion with the absorption of carbon dioxide from the 
air, we need say here only that the authors show that with liquids "the flow of the diffusing substance ... may go on almost as rapidly through the multi-perforate septum, as if no closing membrane were present' (Phil. Trans., B. 193, p. 28I).

It is probable that the protoplasm is more intimately concerned in the matter than these purely physical explanations allow, that, in fact, by a process something like a modified secretion the protoplasm takes up the sugar from the cell sap and passes it on into the contiguous cells, the action starting in the cells abutting on that in which the transformation into starch first occurs. The protoplasmic threads on this hypothesis not only constitute the paths for the translocation, but serve also to transmit a stimulus from the cell in which a weakening of the sugar content is set up to the contiguous ones which contain a greater quantity. The protoplasmic secretory activity is thus a response to the stimulation.

At the end of the century these views remained still in the region of speculation, and but little that was satisfactory was definitely ascertained as to the forces causing the translocation. Very little experimental work bore upon the point, but it was ascertained that translocation from the endosperm of a germinating seed goes on to completeness in the absence of the embryo if the latter is replaced by some absorbing substance such as a plug of gypsum, though it does not progress so rapidly. Hansteen in 1894 and Puriewitsch in 1897 were both able to prove this. Their experiments proved further that this depletion of the endosperm is not due to diffusion only, for it was stopped when the germinating seed was moistened with glycerine or a solution of nitre instead of with water.

Deposition of Reserve Materials. The translocation of the newly-constructed organic substance leads necessarily to two different series of events. The first of these, the 
mode of incorporation of the new material into the living substance, the most intricate of all the problems of nutrition, must be postponed for the present. The second includes the processes of temporary deposit of the translocated substances and their subsequent utilization.

Such temporary deposits or stores have given rise to the recognition of what are now known as reserve materials, and their investigation has been one of the features of the period under consideration.

I. Carbohydrates. (a) Starch. As already mentioned in a previous chapter, the researches of Sachs in I860-4 led to the recognition of starch as the "first visible product of assimilation'. It was observed by him, and by Naegeli at about the same time, to occur as little specks in the body of the chlorophyll corpuscle. The idea that these grains are not necessarily the final stage of a constructive process first appeared in the work of Boehm, published in I874-6, in which he showed that sometimes such starch owes its origin to a transference of some of the carbohydrates of the seed back to the leaf, in the absence of light and of carbon dioxide. More complete recognition, indeed the first definite statement, of the fact that such starch grains are truly reserve materials, was afforded by, and was the consequence of, the researches of A. Meyer in I885 and I886. Still fuller information was derived from the investigations of Brown and Morris in I893, which left no doubt upon the matter.

Perhaps the most noteworthy researches on the deposition of starch made during the nineteenth century were those of Schimper, published in I880. His attention was first given to the relations between the starch grain and the chloroplastid to which, as we have seen, attention had been drawn nearly twenty years earlier by Sachs. He soon extended his inquiries into the conditions of the storage of starch in other parts of plants, and was successful in ascer- 
taining that in this process also, specially differentiated corpuscles or plastids are concerned. He found that in all parts of a green plant in which starch is being deposited, whether for longer or shorter periods, the grains in process of development are associated with peculiar protoplasmic bodies to which he gave the name starch-forming corpuscles, and that those which occur in the non-green parts are analogous to, if not identical with, the chlorophyll bodies. Indeed the presumption of identity is very great, inasmuch as the former can become green under favourable conditions of illumination. Schimper's researches threw a flood of light upon the details of the development of the starch grain in or by the corpuscle, and thus opened the way to more detailed researches into its structure. He also ascertained that the vigour of plastids in different situations is not quite the same, for while those of the bundle-sheaths of the leaves of Tradescantia and those in the cortex of its stem can form starch from the stores of carbohydrate in the plant, thus confirming Boehm, the plastids of its leaf mesophyll can only produce it from atmospheric carbon dioxide. Confirmatory work on this point was published about the same time by Dehnecke.

Schimper said not only that starch grains are always formed by the activity of what we now call a plastid, but also that they arise in its interior. The grains with concentric striation remain always inside it, but those whose markings are excentric break through its substance and, protruding, remain in contact with it on one side only. The plastid absorbs, and is nourished by, the sugar, and subsequently secretes the starch.

Schimper's views were not at once accepted by all botanists, though they met with a very cordial reception in most quarters. Later inquiries have shown them to be in the main correct, though certain exceptions to the process he described have come to light. To these we shall 
refer later. Naturally so important a pronouncement was followed at once by critical examination both of methods and results by many inquirers. His first opponent was Naegeli, who thought he saw the starch grains in process of development in vacuoles in the general protoplasm, being surrounded there by cell sap, at the expense of which they were gradually growing. Naegeli's work appeared in I88I ; his criticisms appeared to be aimed chiefly at the view of the universality of the plastid.

In the same year there appeared the first of a series of writings by A. Meyer, which are almost as noteworthy as those of Schimper, of which indeed they may almost be taken to be the completion. In this first memoir he confirmed Schimper's general conclusions and pointed out that the starch grain grows most strongly on the side which is in contact with the plastid.

A very vigorous opposition to Schimper's position was set up in I887 by Belzung, whose work was chiefly based upon certain leguminous plants. He could find no plastids in the cells of the tissues of the developing embryo of Lupinus albus and L. mutabilis, but saw starch was deposited there. He described the cells in which its formation took place as having vacuolated protoplasm, forming a network with very small meshes containing only cell sap. He was very emphatic in denying the presence of a plastid there, and described the starch grain as originating at some point of the protoplasm and growing subsequently like a crystal. As a result of his researches he suggested that Schimper's plastids were nothing more than cavities in the protoplasm becoming filled up with starch by the action of their limiting layers. In 1892 Eberdt advanced a view which differed from both those quoted. He said that the growth of an excentrically striated starch grain is not due to the action of any unilaterally attached plastid, but that both excentric and concentric grains grow in the cell sap by the action of 
the protoplasm. Grains growing in connexion with chloroplastids sometimes become separated from the latter and are then added to by the general protoplasm wherever the two are in contact. Schimper's leucoplast, according to him, is a formative material which becomes transformed into the substance of the grain.

A paper published by Königsberger in I 893 calls for passing notice, as its author, while admitting the existence of the leucoplasts in certain cases, disputed their universality. He quoted cases of formation by their agency, but claimed to have seen many instances of their appearance without such intervention. In Maranta arundinacea he claimed to have observed cases in which the starch grains originated in contact with a leucoplast, but subsequently became free from it and afterwards grew while embedded in the protoplasm. He controverted Eberdt's statement as to the nature of the leucoplast.

It will be seen that these researches left a little uncertainty as to Schimper's results, chiefly as to the existence of leucoplasts in the regions in which the process of photosynthesis is impossible. The question was, however, finally set at rest by the appearance of the contribution made by A. Meyer in 1895, in the shape of his very complete treatise Untersuchungen ïber die Stärkekörner, in which the whole subject was reviewed and a very large number of new investigations detailed. During the intermediate period several researches supporting Schimper's position appeared, chief among them being the works of Dodel and of Binz, both of which were published in I892.

In one respect the relation of the plastid to the starch grain was not quite accurately stated by Schimper. By the application of delicate methods of staining Meyer found that the grain never ruptures the plastid, though it may stretch it very considerably. Even in the case of the most excentric grains a thin layer of the substance of the plastid 
always invests them. The increase of the thickness of the grain at any point is proportional to the thickness of the enveloping plastid at that point. Meyer was thus the first to show that the starch grain in the leucoplast, as well as in the chloroplast, always arises and remains in its interior. Meyer's work was supplemented in the next year by his pupil Salter.

Schimper was thus the founder of the views at present held as to the deposition of starch in the reservoirs of storage. The relation between the plastid and the starch grain, or the probable process of deposition was investigated with some minuteness. The plastid itself, as described by its discoverer, has a fairly simple structure; Schimper held that these bodies always arise from antecedent plastids by division, while other workers have spoken of them as being differentiated from the protoplasm in the cell. Schimper described them as oval or rod-like pieces of protoplasm, frequently containing a crystalloid of protein nature, which he held to be nutritive for the plastid, and to disappear as the starch grain grows. Meyer confirmed him on these points.

The manner of formation of the starch grain by the plastid was attributed by Strasburger in I 882 to a process similar to that which he had observed in the case of the thickening of the cell wall, where micro-somata existing in the protoplasm are gradually deposited over its surface, the layer so formed slowly ceasing to give the reactions of protoplasm and showing instead those of cellulose. $\mathrm{He}$ held that the starch grain is built up in the same way, each successive layer showing a transition from protoplasm to starch. This mode of formation was also advanced by Noll in I887 in slightly different words. He held that the layer of protoplasm lining the cell wall becomes charged with carbohydrates, and as these increase the protein molecules gradually retreat from the layer, so that ultimately 
the latter consists of carbohydrate alone. Starch, in his opinion, is formed in the same way in the plastid.

Schimper, in I883, developed his view of the action of the plastid in the process, and suggested that such proto. plasmic layers are formed and immediately undergo decomposition, starch being one of the resulting products. This implies that starch appears as a secretion product of the plastid. Schimper's views on this subject were endorsed by Eberdt in the paper already quoted.

Meyer, in I895, attributed the appearance of the grain to a process of crystallization in the outer layer of the plastid.

In 1896 Salter investigated the process of deposition with great completeness, using very delicate methods of staining, which enabled him to differentiate the structures more clearly. He found the successive layers of starch are always quite distinct, and observed that they stain very differently from the plastid. According to him the latter secretes definite starch substance, and in the layer as originally laid down there is no evidence of any transition layer such as was suggested by Strasburger and by Noll. The outermost layer of the grain has always the same composition as the oldest part, from which it differs only in relative density. Salter called the layer most newly formed at any moment the rand.

An appearance of lamination in the grain accompanies its formation. This was known before the year I860 and was the subject of a theory of structure and growth of starch grains formulated by Naegeli in 1858 , a theory formed under the influence of his well known views on the thickening of organized vegetable structures by intussusception. He said the appearance is due to the alternation of watery and dense layers, which arise in consequence of tensions evoked by the mode of deposition of the layers. These tensions increase by unequal nutrition and lead to GREEN $\mathrm{B} \mathrm{b}$ 
separation of the layers, new ones being then intercalated between them.

In a paper published in I88 $\mathrm{I}$, the year following his discovery of the action of the plastids, Schimper discussed the question from the new point of view. He agreed with Naegeli that the formation is accompanied by the setting up of tensions, but he opposed the theory of intussusception and of the intercalation of new layers between the old ones. His explanation was that the tensions are followed by a swelling of the starchy substance along lines formed by the stretching which the tensions cause, the so-called mucleus (kern) of the grain being the first swollen part. The successive watery layers follow in sequence owing to the resumption of the tension after the relaxa. tion which follows the formation of the kern. He saw in the formation consequently a succession of increased and diminished tensions in consequence of repeated swelling.

Strasburger was of opinion that the darker lines of the striation do not indicate bands, but are only the separation surfaces of the successive translucent layers.

Correns, Binz, and Meyer brought forward again in I89I and 1892 the view of Naegeli that the striations indicate the alternation of layers of greater and less density. Acqua, in I894, said that the cell protoplasm invests both plastid and starch grain and deposits layers of starch round both.

The most careful researches that have been published on the subject are those of A. Meyer in I895 and Salter in 1896 , to which allusion has already been made.

Meyer's observations were made on several plants, but his chief results on the point under discussion were derived from observations made on Adoxa and Pellionia. He said that the grains are built up of individual laminae of relatively lax and dense consistency, the former staining most easily. The primary differentiation is induced by variations which affect the course of deposition and particularly 
concern the supply of crystallizable material to the grains. The mode of lamination hence depends on the various influences which have affected their growth. A second factor is a periodically recurring solution of the peripheral layers, followed by a resumption of deposition.

Salter followed with great care the course of development of the grains of a large number of plants. He noted the following stages: (I) the leucoplast with a starch grain beginning to form in its interior; (2) the origin of the mucleus, or kern, inside the grain, followed in the case of excentric grains by an aggregation of the substance of the plastid to one side ; (3) the appearance of a faintly-staining zone round the kern, its marginal part gradually deepening in staining power and constituting the first lax lamina; (4) the succession of a number of laminae, capable of demonstration by staining. In excentric grains the more watery laminae gradually fail to be recognizable the whole way round the kern, causing the grain to become increasingly excentric. Subsequent differentiation in these laminae then causes the striation to be noticeable, but they gradually lose their staining power from the kern outwards. The outer layer $(r a n d)$ generally fails to stain, but appears structureless, and never shows lamination when young. When stains affect it, it always behaves like the dense laminae. Salter held that it always possesses a potential lamination, often containing several layers that later show themselves to be lax or watery. All the laminae are of different density in different parts, but they only become visible as they are covered by new depositions.

Allusion has been made incidentally to a suggestion of A. Meyer that the grain is composed of crystallizable material. This view was originally advanced by Famintzin in I869, when he compared starch grains to sphere crystals of calcium carbonate. It was more fully expounded by Schimper in his paper of I88I; he called B b 2 
attention to many points of resemblance between starch grains and sphere crystals in general, showing that swelling does not change the optical properties of the grains, and thus proving that Naegeli was wrong in attributing their double refraction to internal tensions. Schimper held that their ultimate constitution is one of crystalline fibres arranged across the laminae and resembling protein crystalloids in their properties.

Strasburger agreed that the laminae may be regarded as composed of elongated radially arranged elements, but he held that they are not necessarily crystalline.

In I887 Mikosch said that the grains of the potato are made up of radially placed rodlets, which can be made to break up into a granular mass. He held that the rods consist of a ground substance in which the granules are contained.

Meyer's views of I895 accorded with those of Schimper. He developed the idea in greater detail ; besides showing that their properties agree with a sphaero-crystal constitution, he was able to render the radial trichitic structure visible by suitable means, frequently by inducing a slight swelling of the grain.

As has been already mentioned, although Schimper's discovery of the plastids was the basis of most of the recent work and may be regarded as well-established, there are cases on record which constitute exceptions to it.

Strasburger, in I882, found that in Marsilia and in the medullary rays of Pinus, starch grains arise in cavities of the cytoplasm. Salter offered as an explanation of the observation the suggestion that the grain seen was the staining kern, and the 'vacuole' the colourless layer (rand) surrounding it. In I887 Belzung claimed to have seen them arise in the meshes of reticulated protoplasm. In I893 the present writer found them in pollen grains as shed from the anthers of various plants, and noted a great formation of 
them as the pollen-tubes increased in length during germination. In neither case could a plastid be detected. In the styles of various species of Lilium minute specks of starch appear as the flower matures, extremely small, and in exceedingly large numbers. No plastids can be found in the cells. It appears, therefore, that the ordinary cytoplasm can form starch without such differentiation.

(b) Glycogen. This substance, which appears to play the part of a reserve material in the animal organism, is met with occasionally in plants, but its distribution is almost, if not entirely, confined to thallophytic forms. It was first observed in vegetable protoplasm by Kühne, who, in I868, demonstrated its presence in the plasmodium of Aethalium. It was observed in the same situation in I88I by Reinke and Rodewald, who found 4.7 per cent. of the plasmodium consisted of it. After that period its occurrence in various thallophytic forms, both algal and fungal, was demonstrated by many observers, chief among whom have been Errera and his pupil Clautriau. Their memoirs appeared in I882 and I885, and in I895, respectively. The writings of the last fifteen years of the century showed a very wide distribution of glycogen among the Fungi; among the Algae it was found most prominent in the Cyanophyceae, and apparently absent from the Phaeophyceae and Rhodophyceae. Errera found a substance resembling glycogen in Linum usitatissimum, Mahonia repens, and Solanum tuberosum, but he hesitated to identify it as such.

(c) Inulin. The occurrence of inulin in solution in the cells of the vegetative tissues of a well-known group of the Compositae and their allies was established in the early part of the nineteenth century. Sachs appears to have been the first to observe its separation in the form of sphere crystals after appropriate treatment with alcohol. But little attention to the question of its deposition has 
been paid since. Its discovery in leaves of Yucca by Meyer has already been mentioned. Parkin showed, in 1899, that it occurs in the bulbs and corms of certain Monocotyledons.

(d) Sugar. Of the various forms of sugar existing in the green plant we had little knowledge prior to 1876 . Most of the monosaccharides were grouped together under the name reducing sugar, as distinguishable thus from cane sugar, which does not reduce Fehling's solution. It is probable that these reducing sugars do not constitute reserve materials.

In the study of stored sugars the most interest centres in saccharose, or cane sugar, which has long been known as showing a very wide distribution. The view that it is always a reserve material has been disputed, some authors claiming that it is the first-formed sugar in photosynthesis, as we have already seen.

The evidence against its reserve character is based upon certain observations on the ordinary nutritive processes. It was shown to exist in the ungerminated barley grain by Kühnemann in 1875 , but Brown and Morris ascertained that the quantity increases threefold during germination, instead of decreasing as reserve materials do. In 1882 Lepley showed that the starch of the maize is not formed unless cane sugar is present in the juices of the plant. Balland found the same state of things in I 888 in the wheat, as did Girard in I889 in the case of the potato. Brown and Morris, in 1890 , were able to cultivate young excised barley embryos in a 2 per cent. solution of cane sugar, in which indeed they thrived almost as well as if they had remained in contact with their own endosperms.

(e) Reserve Celluloses, Mucilage. These stores of carbohydrate are treated of in connexion with the composition of the cell wall.

II. Nitrogenous Reserves. (a) Proteins. Little informa- 
tion on the subject of these substances had been obtained prior to $\mathrm{x} 872$, when Pfeffer described the development in the seeds of many plants of the grains which in 1855 Hartig had described under the name of aleurone. These grains are composed of various proteins and are usually associated with some form of mineral matter. Some are small and simple in structure, while others are somewhat complex. Pfeffer attributed their first formation in Lupimus particularly, though not exclusively, to the influence of the mineral constituent associated with them. He said that the latter, usually either minute crystals of oxalate of calcium or amorphous collections of the double phosphate of calcium and magnesium, can first be detected in the cell sap of the vacuole of the cell, and slowly the protein matter accumulates round them and encloses them in its substance. As the seed ripens the sap becomes less and less watery and gradually more protein is deposited by a kind of precipitation, till the complete aleurone grain is formed. To Pfeffer then, particularly in the case of the lupin, the formation was almost entirely mechanical, resembling crystallization, the influence of the protoplasm not appearing important.

Pfeffer's account was not challenged till I888, when Rendle investigated the process as exhibited in the seeds of Lupinus polyphyllus. The result of his researches was to bring it much more closely into line with the work of Schimper on the carbohydrates. Rendle observed the early stages of construction beginning when the development of the cotyledons was sufficiently advanced to swell out the seed coat, by which time the endosperm had been absorbed. At this time the peripheral layer of the protoplasm contained chlorophyll grains, in the substance of which starch was accumulating. Simultaneously the aleurone grains began to appear as, or to be preceded by, small bodies of spherical or ovoid shape which projected from the protoplasm. Little by little these projections increased 
in size, growing inwards as well as outwards, till the grains could be seen as conspicuous masses embedded in the protoplasm, which in consequence of their development assumed the appearance of a coarse network. The vacuole of the cel! became filled up by the continuous formation of aleurone grains, till the cell was swollen up by its own deposits. The growth of the grains in this way was accompanied by gradual chemical change, which was evinced by their behaviour towards solutions of neutral and alkaline salts.

Rendle was consequently of opinion that the process of aleurone grain formation is one of true secretion and not as Pfeffer thought of mere mechanical precipitation. He opposed Pfeffer's view that the formation is determined in any way by the mineral matter, whose presence indeed in the cell he was unable to detect when the formation of the grain began.

A third theory still more fully recalling the work of Schimper was based by Van Tieghem on certain researches conducted in I886 by Werminski, and in I888 by Wakker. Both these authors noticed that in the cells of the endosperm of Ricinus the protoplasm at an early stage exhibited the presence of several distinct vacuoles, and later an aleurone grain was formed in each vacuole, the latter appearing to be gradually filled with protein substance as the seed ripened. Van Tieghem suggested that the apparent vacuoles are really plastids, which, on account of their watery content, he termed hydroplastids. On this hypothesis aleurone grains like starch grains are not formed from the cell protoplasm but by differentiated plastids.

Each of these three theories received support from subsequent writers, and at the close of the century the question remained unsettled. Lüdtke, in I89o, working on Ricinus, came to the conclusion that both crystalloid and globoid originate in the cytoplasm, and that the vacuole has no 
share in the formation. On the whole his researches confirmed the work of Rendle. On the other hand Belzung, in I89I, supported the views of Pfeffer, suggesting that all the appearances may be explained by a process of precipitation of protein existing in soluble combination with alkaline phosphates in consequence of the development of dilute organic acids. Belzung's description of the appearances attending the formation in his material coincided, however, fairly well with Rendle's observations, particularly as to the points of origin of the grains and their final structure. Like Rendle, Belzung worked chiefly on leguminous seeds.

The various proteins which enter into the composition of aleurone grains were investigated by several writers, whose results were very far from concordant. This is not at all surprising, as the whole question of the composition and reactions of protein substances was the object of much inquiry by chemists and physiologists alike during almost the whole of the period with which we are concerned. The progress of knowledge of this very difficult subject was very gradual, and though much advanced cannot be held to be complete at present.

The subject had attracted, in I859, the attention of Denis, who employed successfully as an extracting solvent a Io per cent. solution of common salt, which had been used in the preparation from animal tissues of the proteins known as globulins. His work was extended in $\mathrm{I} 867$ by Hoppe Seyler, who prepared members of this class from the Brazil nut, and from the seeds of several other plants, including oats, maize, peas, almonds, and mustard. He found them to resemble very closely the globulins of animal origin.

The next observations of importance were made by Ritthausen in 1872 . Abandoning the methods of his predecessors, he used as extractive agents water, dilute solutions 
of alkalies, and alcohol. He classified the proteins he prepared into three groups as follows:

I. Albumins: soluble in water; solution coagulating on boiling.

2. Caseins: slightly soluble in water, readily soluble in dilute solutions of potash or of basic potassium phosphate : precipitable from such solutions by addition of dilute acids.

3. Gelatines; soluble in alcohol and in dilute acids.

He described several members of his second and third groups, which differed from each other by exhibiting varying degrees of solubility and by yielding different products of decomposition.

Weyl, who took the matter up in 1877 , returned to the methods of the animal physiologists, holding that the solvents used by Ritthausen led him to overlook the existence of globulins and in many cases altered the composition of the proteins during the process of extraction. He reaffirmed the occurrence of globulins in seeds and identified members of the groups of myosins and vitellins, which were recognized at that time by the animal physiologists. The gluten of flour, which Ritthausen had classed among his gelatines, Weyl held to be derived from globulins, possibly by a species of coagulation akin to the coagulation of blood.

Into the controversy which followed, considerations of space will not allow us to enter. Ritthausen replied at once to the contentions of Weyl and Hoppe Seyler, maintaining his position with some energy in 1877 and again in 1879 . Weyl was supported by Schmiedeberg in 1877 and by Grübler in I88I.

Many observations on the grains of various seeds were made at about the same time as to the solubility of the aleurone in different reagents, especially by Pfeffer in 1872 and Tangl in 1877 , but they threw little light upon the problem.

The observations of Vines, published in $1878-80$, consider- 
ably extended our knowledge. He examined very thoroughly the seeds of a large number of plants selected from a considerable number of the Natural Orders of the vegetable kingdom; his methods were partly micro-chemical, but he also prepared large quantities of many of the proteins and separated them from one another much more completely than had been done previously. While agreeing to a considerable extent with Hoppe Seyler and Weyl, he showed for the first time that in addition to globulins the aleurone grain contains in many cases members of the group known as albumoses, which are soluble in water, but the solution does not coagulate on boiling. In the seed of Sparganium racemosum Vines found a protein soluble only in dilute acids or alkalies, apparently referable to the class known at the time as derived albumins. Martin found globulin and albumose to be associated in the seeds of Abrus precatorius in $\mathrm{I} 887$.

Much more thorough investigations into the proteins of seeds were made during the last ten years of the century in America, first by Chittenden and Osborne, and later by the latter in collaboration with several of his pupils. They showed that the greater number of the proteins of seeds belong to the class of globulins, though albumoses, or preferably proteoses, occur in sensible quantities. In some seeds derived albumins or albuminates exist, but only in small amounts. Albumin is not of frequent occurrence, but a form of it is met with in the cereal grasses.

From these researches it appears that the distinction made by Weyl of myosins and vitellins is not exact, depending upon variation of treatment before and during extraction. These authors showed further that by appropriate methods vegetable globulin can be made to separate in crystalline form. Crystalline bodies were prepared by Maschke.(I859), Schmiedeberg (I877), and Drechsel (I879), 
but these were almost certainly compounds of the protein with magnesium.

The proteins named gelatines by Ritthausen we saw were said by him to be soluble in alcohol. The existence of proteins possessed of this peculiarity was first noticed in I 820 by Taddei, and in I 82 I by Gorham. One of them was investigated more completely by Chittenden and Osborne in I89I and found to compose a considerable part of the proteins of the maize grain. They gave it the name of zein, which had been first employed by Gorham. It seems to have been described by Ritthausen under the name of gluten-fibrin. Osborne and Voorhees found that the gluten of wheat flour is formed by the interaction of two proteins of this class, which they called gliadin and glutenin respectively. These proteins were extracted separately from the flour, but the authors gave no account of their relation to the aleurone grains. It is possible that they exist in amorphous condition in the cells. The name gliadin was used by Taddei, and the protein was described as plantgelatin by Liebig. The proteins of the wheat grain were investigated by Miss O’Brien in I895. A similar substance, named hordein, was found by Osborne to be a constituent of barley. The work done in Osborne's laboratory was not complete in Igoo but has been continued to the present time, indeed is still proceeding.

Reserve proteins have been detected in other places than seeds and in other forms than aleurone grains. Crystalloids had been observed before I86o in the ovule of Lathraea, and in the potato tuber; they were subsequently shown by Vines to consist of vitellin, a form of globulin; they were seen in the Florideae by Cramer in I 862 and by Klein in I88I, also in certain fungi by the last-named author, and by Van Tieghem six years earlier. In the amorphous form, or perhaps in solution in the cell sap, Zöller found a form of globulin in the potato tuber in I8So, and Zacharias 
another in sieve-tubes. This was observed again by Fischer the next year. Martin described an albumin and two albumoses in latex in I885. The latex of several plants was examined by the writer in I886, and several proteins were found to be present. Globulins and albumoses were detected in the succulent cortex of several stems and roots.

(b) Crystalline nitrogenous substances other than proteins. There have been only a few observations on the storage of such substances, and they seem to play rather a subordinate part. We owe a great deal of our knowledge of them to the researches of $\mathrm{E}$. Schulze and his pupils from $\mathrm{I} 878$ onwards. In I870 Scheibler found asparagin and betaïn in beetroots; Schulze and Urich added glutamin to these two in 1878 ; while in the same year Schulze and Barbieri found asparagin, leucin, and tyrosin, in potatoes. In I882 Schulze ascertained that of the nitrogenous reserves in certain of the latter 56 per cent. consisted of these amino- or amido-bodies, and 44 per cent. of proteins. Shorey found glycin or glycocoll in the sugar-cane in I897.

III. FAtty Reserves. While the occurrence of oil and fat as reserve materials in seeds, has long been known in the hyphae of fungi and a few other situations, but little exact information as to the mechanism of its deposition or the stages of its formation was afforded during the period under examination. It attracted the attention of Sachs in connexion with his work on the carbohydrates, and he made some observations upon the transport of oil from the seed to the seedling. As late as I882 he held it to be capable of being formed from, and of giving rise to, starch and sugar, nor did he see any particular difficulty from the chemical point of view in supposing such changes to be direct. He said that it was immaterial how far chemical formulae are able to afford information as to the processes taking place, for there was no doubt that fats 
may be produced from carbohydrates, and that the latter may be formed at their expense.

The process of deposition of fat in starved fungi was observed in 1880 by Cunningham. He noticed that as starvation advanced, the protoplasm gradually disappeared. while drops of fat could be seen to form. The fat indeed seemed to be formed at the expense of the protoplasm. Naegeli came to much the same conclusion in I879, when he determined that its appearance depended but very slightly on the nature of the food supplied to the organism.

Wakker claimed to have found, in the course of some researches on this subject in $\mathbf{I} 888$, that the deposition of fat is in some cases effected by the agency of plastids, to which he gave the name elaioplasts. He observed them especially in the epidermis of young leaves of Vanilla. They were studied again in $\mathbf{1} 893$ by Zimmermann, who described them as being of various shapes, sometimes round or oval, sometimes very irregular, and lying generally near the nucleus of the cell. They have a structure somewhat like that of the chloroplast, consisting of a stroma in the meshes of which the oil is slowly formed. Zimmermann found them in the perianth of Ornithogalum and Funkia, and the leaves of a species of Agave, and in the root of Oncidium.

A passing allusion must be made to the more complex fats and allied bodies lecithin and cholesterin, both of which received considerable attention at the hands of chemists during the last two decades of the century. Lecithin was first found in seeds in I860 by Knop and showed to be of frequent occurrence by Töpler in I86r. It is, however, to E. Schulze and his pupils that we owe most of our knowledge of its distribution and of the varying amounts of it present in different seeds. We may associate most of our knowledge of cholesterin and allied substances 
with the same band of workers, whose researches on both groups have been numerous since 1878 .

Both lecithin and the products of its decomposition have been discovered in other parts of plants than seeds. Lippmann found it in the sugar-beet in r887. Kunz extracted cholin from various roots in $\mathrm{r} 886$ and $\mathrm{r} 888$, while Stoklasa identified lecithin among the reserve materials of pollen in 1896.

IV. Glucosides. A good deal of work during the latter years of the century was concerned with the identification of a large number of members of this group, which in I86o only included relatively few. As, however, they present features of interest rather to the chemist than the botanist, a passing allusion to them must suffice. Researches which concern them were generally conducted rather to determine their rôle in nutrition and the products of their decomposition during digestion. These will be discussed in their appropriate place. Besides this there remains little more than an enumeration of them. with dates of their identification. 


\section{CHAPTER VII}

\section{THE DEVELOPMENT OF KNOWLEDGE OF THE METABOLIC PROCESSES - CONTINUED : DIGESTION. THE NATURE OF NUTRITION}

THERE is perhaps no section of the subject of metabolism that was more closely studied, or which attracted the attention of so many investigators, during the later years of the century, than that which is concerned with the digestive changes that bring reserve materials into active use after their period of quiescence. There are few which were attended by better results. The subject embraces almost all the researches into the existence and the activity of the enzymes or unorganized ferments and the relations between fermentations and putrefactions and the ordinary phenomena of nutrition. One of the chief results that was obtained was the elucidation of the relations of digestive and putrefactive bacteria to the processes associated with the digestive ferments, and the proof that all phenomena of fermentation are to be traced to the vital activity of protoplasm ; while the question of the unicellular or multicellular nature of the organism whose protoplasm is involved, was found to be of very subordinate importance. The distinction between organized and unorganized ferments was shown by the present writer to be unnecessary

At the beginning of the period the researches of Pasteur were throwing a flood of light upon many of the vital processes of the lower organisms, and opinion was tending towards the recognition of a close relationship between the phenomena of fermentation and these digestive changes 
than had been imagined to exist. The progress of thought and of research during the later decades of the century tended more and more in this direction, till at its conclusion the processes of digestion had come to be recognized as altogether fermentative in their character, and the term fermentation had been accorded a much wider meaning than it held in the minds of Pasteur and the workers of his time. The old distinction between organized and unorganized ferments was proved unnecessary and misleading by the numerous researches which showed that all these changes are due to the influence of the living cell, working in most cases by the unorganized ferments or, as they came to be designated, enzymes.

Up to the year I860 but little knowledge of the vegetable enzymes had been obtained. Only a few of them had been discovered, and their distribution in the vegetable kingdom, their mode of action and its conditions were almost entirely unknown.

We have already spoken of the discovery of one of these enzymes, diastase, in connexion with the original translocation of the starch stored temporarily in the chloroplasts of the leaf, and have briefly described the function it discharges. Much more complete information respecting it was derived from investigations made upon germinating seeds, in which a larger amount of material is available for research. Indeed it was from such sources that our first knowledge of it was derived, as our recognition of it as a factor in metabolism only dates back to the researches of Payen and Persoz in I833 upon the germinating barley grain.

It is impossible here, from considerations of space, to do more than call attention to the chief workers in this field and to set out very briefly their several results. The renewed interest in the inquiry dated from the work of von GorupBesanez in 1874 , which resulted in a large addition to our GREEN C C 
knowledge of the number of germinating seeds which yield it, but added little to our acquaintance with the actual process it carries out. Following him we had a large number of workers who studied its distribution in the plant. In I877 Kosmann found it in leaves and shoots, in I878 Baranetzky found it in the tubers of the potato, as Payen and Persoz had done before him, and in the buds and other green parts of so many plants that he suggested it to be universally present in vegetable tissues. Krauch in I879 and Brasse in I884 detected it in leaves and shoots, and the latter writer added materially to the accuracy of our knowledge of its powers. In I889 Kjeldahl, and in I890 Brown and Morris, determined its presence in the barley grain before germination set in. In I893 the writer found it in pollen-grains and showed that it plays a leading part in the nutrition of the pollen-tube. In I883 it was shown by Duclaux to exist in Aspergillus, a distribution which seems strange when we remember that the Fungi contain no starch. Errera's discovery of glycogen in these organisms, made about the same time or a little earlier, removes, however, any difficulty on that account. Bourquelot and Hérissey confirmed Duclaux's observation in I895, and showed that it is not uncommon in this group. Some very important and far-reaching observations were made by Haberlandt and by Brown and Morris in $\mathbf{I} 890$ as to its distribution and its mode of formation in the germinating grains of barley and rye. These observers, working independently, ascertained that during the germinative processes, in addition to a certain small amount in the cells of the endosperm, a considerable quantity is secreted by the cells of the Kleberschicht, or aleurone layer; immediately below the outer coating, and still more by the epithelial cells of the scutellum or absorbing organ, and that the enzyme diffuses thence into the starch-containing tissue. The importance of this discovery lies largely 
in the fact that the seed shows us thus a process of preparation of an enzyme secreted and transported from the place of its secretion to act on material at some distance therefrom, much as is the case in the animal organism. Brown and Morris studied with very considerable success the details of its formation, and showed it to be a definite secretion by the protoplasm. Brown and Morris further made a comparative study of the action of diastase from various sources on the actual starch grains, and proved that two forms of the enzyme exist in plants, which differ in the details of the decomposition they set up.

In I895 some observations made by A. Meyer in the course of the work on starch, to which we have already alluded, led him to the conclusion that in the leaf a certain localization of the enzyme in the cell can be determined. He associated it with the chloroplast rather than the general protoplasm of the cell. In the non-green parts of the plant he held it to be secreted by the leucoplasts, and described many cases in which the starch grains were attacked most energetically where the sheath formed by the stroma of the plastid was thickest. Salter, in the next year, repeated and extended Meyer's observations, and noticed that the starch grains became decomposed so strongly in the region of contact with the plastid as to suggest that the latter practically eats its way into the substance of the grain. Grüss (I894), Hansteen (I894), and Puriewitsch (I896) confirmed Brown and Morris as to the process of secretion.

The progress of the action of diastase upon starch was first investigated by Payen and Persoz, who found that among the products sugar and certain dextrins could be detected. In I860 Musculus recognized that dextrin and sugar are produced simultaneously. About the years I87I-2 Griessmeyer, O'Sullivan, and Brücke, working independently, showed that at least two dextrins are formed, and that the sugar is maltose. It was not, however, until I878 
that a theory of the course of the action was advanced, when Musculus and Grüber suggested that the starch molecule breaks down by a series of hydrations and subsequent decompositions, maltose being formed at each splitting, together with a dextrin of less molecular weight, until finally all is converted into maltose. This view, with certain modifications made by Brown and Morris in I885, was generally accepted.

These observations were all made by means of experiments in vitro. In 1893 the present writer showed by treatment of growing pollen-tubes with iodine that the same general course of action can be observed in the living cell. Leclerc du Sablon obtained similar results in the cells of the bulbs and corms of certain Monocotyledons in I 898 .

The digestion of inulin was ascertained by the present writer in 1887 to be effected by an enzyme, to which he gave the name inulase. It was prepared from the germinating tubers of the artichoke (Helianthus tuberosus). The products of its action upon inulin were shown to be an intermediate crystalline substance and a reducing sugar. Bourquelot detected the enzyme in 1893 in the fungus Aspergillus, in which it occurs mixed with several others, from which, however, he was able to separate it. In the course of his work he was able to prove that the reducing sugar is levulose (fructose). Inulase was detected by the writer in Igoo in the germinating bulbs of Scilla and Leucojum.

The reserves of cellulose, which are met with in thickened cell walls of the endosperms of various Palms and the unchanged membranes of the endosperms of many of the cereal grasses, were the subject of considerable research by many investigators, and were in many cases shown to be utilized through the action of cytase. Several preparations of this enzyme were made, but some uncertainty exists as to their identity with each other. Similar bodies were found to play a part in fungal growth. The 
first indication of the existence of a definite enzyme was afforded by De Bary's work on Peziza in I886, and a more detailed account of its formation and mode of action was given two years later by Marshall IVard, who found it to be the active agent in the destruction of certain species of Lilium by a species of Botrytis. Ward was able to watch the solution of the cell membranes by a secretion poured out by the growing hyphae of the fungus. Kean, in I890, and Grüss, in I896, both found the enzyme in various fungi. It was first observed among the higher plants by Brown and Morris in I89o, when they were. investigating the changes in the barley grain during germination. They noticed the breaking up of the cells in contact with the scutellum of the embryo and saw that this process preceded the digestion of the starch. In subsequent investigations Brown and Escombe ascertained that a greater quantity of the enzyme is furnished by the aleurone layer, and they isolated it from both regions. Action upon the thickened cell walls of the endosperm of Tamus was investigated by Gardiner in 1897 , whose results confirmed those of Brown and his collaborators.

It was suggested by Sachs in $\mathrm{I} 862$ that the utilization of the harder and more resistent endosperms of palms might be due to enzyme action, but he did not succeed in detecting it. Nor did much greater success attend the experiments of the present writer in I887; he determined, however, that the gradual consumption of the thickened walls by the developing absorbing organ of the embryo is attended by the formation of a reducing sugar, and he found that the structure of the epithelium of the absorbing organ is extremely similar in appearance to that of the scutellum of the barley embryo as described by Brown and Morris. The digestive changes were watched in the seeds of Phoenix and Livistonia. In I899, however, the enzyme was extracted from the germinating seeds of Phoenix by 
Newcombe, who discovered it also in germinating seeds of Lupinus albus and in the cotyledons of Pisum and of Fagopyrum.

Enzymes of this class were detected in the germinating carob-bean by Effront in I897, and in various leguminous seeds by Bourquelot and Hérissey in I899. These were named caroubinase and seminase, respectively, by their discoverers. The cytases were studied very carefully by Bourquelot and Hérissey in 1898 and $\mathbf{1} 899$.

The products of the action of cytase were not very satisfactorily ascertained, but the final one is some form of sugar, while the intermediate substances are complex. According to Bourquelot and Hérissey the sugar consists of a mixture of mannose and galactose.

Czapek found in 1899 that the nutrition of certain fungi which attack lignified cell walls is materially aided by an enzyme, which he called hadromase, which dissolves the woody constituents. He found it associated with cytase in the hyphae.

As we have seen, there is no doubt that certain of the sugars found in plants must be regarded as reserve materials. These are especially the polysaccharides cane sugar and maltose, with others of similar constitution. The sugars concerned in actual nutritive processes seem to be the monosaccharides derived from these. The study of the relations of these several classes was conducted with much care after I860, particularly in the later years of the century, and brought to light the existence of several enzymes which are concerned in the formation of the simpler ones by the hydrolysis of the more complex.

Invertase was the first of these to be discovered, and for many years was the only one known. Its first detection does not fall within our period, as it was found in the first instance by the eminent French physiologist Claude Bernard in I849. After proving its presence in the secretion of 
the alimentary canal in mammals he investigated the sugar relations of the beetroot, and not only found evidence of its existence in the cells at the time of the renewal of growth in the second year, but extracted it therefrom. It was next observed by Berthelot in I860, in his researches upon yeast and alcoholic fermentation, in the course of which he showed that it is excreted from the cells of the yeast plant. Berthelot named it 'ferment glucosique'. In 1864 Béchamp proved its existence in several fungi and in the petals of several flowers, especially those of Robinia viscosa. It was named invertin in $\mathrm{I} 875$ by Donath.

The distribution of invertase has been the subject of much inquiry. It was found by Kosmann in buds in 1877 ; in the rootlets of barley grains during germination by Kjeldahl in 1878 ; in pollen-grains by Van Tieghem in $\mathrm{I} 886$, and by the writer in I893; in foliage leaves by Brown and Morris in I893 and by Gonnermann in 1899 .

Invertase was the first of the enzymes whose composition was closely examined. An investigation into its constitution was carried out by C. O'Sullivan and Tompson in 1890. They concluded that it is of a very complex character, composed of carbohydrate and protein substance in particular proportions.

The other enzymes of this group that have been discovered are not so well known as invertase. The next in importance is maltase or glucase, which hydrolyses malt sugar to glucose. Its importance appears when we remember that maltose is the ultimate product of the action of diastase on starch. Maltase was first discovered in I886 by Cuisinier in malt and in certain other cereal grasses, and was again observed in I89I by Geduld in Maize. Bourquelot detected it in Aspergillus in 1893, and in Yeast two years later.

Lactase, which splits milk sugar into glucose and 
galactose, was found in the Kephir organism in $\mathbf{I} 890$ by Beijerinck.

Three other enzymes acting on varieties of sugar of comparatively rare occurrence are trehalase, raffinase, and melizitase. These were all discovered by Bourquelot in 1893 .

Another group of enzymes which includes a continually increasing number was represented in I86o only by emulsin and myrosin. We have already alluded to the widespread occurrence of glucosides in plants and to the large number known to exist. Almost every one of them undergoes digestion through the specific action of some particular enzyme, though such action is not so certainly defined as is that of diastase and inulase. Emulsin was discovered in 1837 by Liebig and Woehler; myrosin by Bussy in I 839 .

Liebig and Woehler described the action of emulsin on amygdalin, the glucoside of the bitter almond ; its distribution was further studied by Thomé in I865, Portes in 1877 , and Johannsen in 1887 . Our knowledge of it was greatly advanced by the researches of Guignard in I890, who first determined its exact situation in the tissues of a number of plants. Myrosin was examined by him with even greater minuteness in the years I890-4. He showed it to be the characteristic enzyme of the Cruciferae and several allied orders.

Our knowledge of this group of enzymes was greatly increased by the investigations of Bourquelot and his pupils, particularly Hérissey, which extended over the last seven or eight years of our period. They discovered a very wide distribution of them among the fungi, and determined that many of these plants contain, either always or under particular circumstances, several of them simultaneously The chief members of the group known in I900, besides emulsin and myrosin, were rhamnase, discovered by Marshall Ward and Dunlop in I887, gamltherase, or betulase, 
first noticed by Schneegans in I894, tannase, found in Aspergillus in Igoo by Pottevin, and lotase, discovered by Dunstan and Henry in the same year.

The study of proteoclasis owes but little to the researches of botanists during the period under discussion. At its commencement the investigations of the animal physiologists had shown that enzymes play the leading part in the process. As far back as 1836 Schwann had discovered pepsin, and in I860 Brücke was engaged in his researches upon its mode of action. Trypsin had been discovered and carefully examined in I 849 by Claude Bernard. The result of investigation so far had been to show that two classes of enzymes could be recognized as possessing proteoclastic powers and that they differed from each other mainly in the extent to which they could carry the decomposition. Based largely upon these researches, Meissner's theory of proteoclasis had been propounded and was slowly finding acceptance. The pioneer work is seen thus to have been due to the investigations and speculations of animal physiologists and physiological chemists.

The study of proteoclasis was considerably advanced by the labours of Kühne and his school, which covered the years I876-86. To them we owe the cleavage theory of the process, which held its own nearly to the end of the century, being, however, modified in certain of its details by the researches of Neumeister in the later eighties, and by those of Kossel and his pupils as the century was closing. These discoveries left still the proteoclastic enzymes as forming the two classes peptic and tryptic, with which the period began. Cohnheim's discovery of erepsin was not yet made.

The work of botanists or vegetable physiologists during this period dealt with details rather than principles. The leading facts of proteoclasis and the current theories of its course of action were laid down by the writers quoted, 
and both animal and vegetable physiologists were submitting them to careful examination and scrutiny, filling in the details of the schemes suggested, or accumulating material for the discussion of their soundness.

Even in this work botanists showed no great activity till the seventies. The search for a proteoclastic enzyme was first undertaken by Von Gorup-Besanez in I874, and such an agent was discovered by him in the seeds of the vetch, hemp, flax, and barley. He described it as having power to convert fibrin into peptone, but his examination was not very detailed.

The enzyme was rediscovered twelve years later by the writer, who detected it in the germinating seeds of the lupin in I886 and in those of the castor-oil plant in I89o. It was referred to the trypsins, as it was found to possess the power of carrying the splitting of the protein as far as the formation of amino-acids. The investigations were made upon fibrin and also on the reserve proteins of the seeds, giving us for the first time some information as to the fate of the latter. Later in the century, in I894, Neumeister found that such an enzyme can be extracted from the seedlings of the poppy, the rape, and several cereal grasses.

These experiments were performed mainly in vitro; it was not till I897 that E. Schulze showed that the course of decomposition is the same in the living plant by his demonstration of the existence in germinating seeds of amino- and amido-acids and characteristic basic bodies, resulting from the digestion of proteins.

Proteoclastic enzymes, whose purpose is not so immediately evident as the trypsin of seeds, were discovered in other parts of plants than seeds by Würz in I879, Bouchut in I880, the present writer in I892, and Chittenden in I894.

IVürz's enzyme is known as papain and was prepared by him from the fruit and juice of Carica papaya. It was investigated with some completeness by Martin in $\mathrm{IS}_{3}$ 
and I884, and was determined by him to be tryptic in character. .It was examined subsequently by many workers, particularly Davis in I893, Sharp in the same year, and Harlay in Igoo.

Bouchut discovered in $I 880$ a proteoclastic enzyme in the juice of the common fig (Ficus Carica). It was investigated in I 883 by Hansen, and more completely in I 890 by Mussi. The latter writer named it cradina. A similar agent was found by the writer in the juice of the fruit of Cucumis utilissimus in I892. Its properties were those of a trypsin.

Chittenden's enzyme, to which he gave the name bromelin, was obtained from the juice of the ripe pineapple. Attention had been called to it in I8gI by Marcano, but it was not completely investigated till it came into the hands of Chittenden and his pupils. It was very completely studied by them, and of its mode and conditions of action more was ascertained than was the case with any other vegetable proteoclast up to the end of the century. Like all the others so far mentioned, bromelin is referable to the trypsin group.

A few other observations of the occurrence of proteoclastic enzymes were recorded, but they added little to the results detailed. Marcano observed proteoclastic power in the juice of the leaves of the Agave and of certain fruits in 1884 , but he did not prepare an enzyme from then.

The occurrence of enzymes of this type will be alluded to later again, in connexion with the nutritive processes of the so-called insectivorous plants.

Among the lower plants they have been described by Krukenberg in I882, Bourquelot and Hérissey in I895, and Hahn in I898, in various groups of fungi, and by Bitter in I887, Lauder Brunton, and McFadyen in I889, Fermi in I89I, and Duclaux in I899, in various species of bacteria. 
It is worthy of mention again, that up to the end of the century no adequate evidence had been obtained in favour of the existence of a peptic as distinguished from a tryptic enzyme in plants.

The decomposition of fat during the digestive processes is most easily studied in germinating seeds and it was to them that attention was principally directed. The course of such decomposition was, however, in many points largely a matter of speculation at the end of the century. The first inquiries made as to the fate of the fat in seeds were due to Sachs, who in I859 noted its disappearance during germination. Observing a simultaneous formation of starch in the tissue of the seedling, he somewhat hastily and with less than his usual caution gave it as his opinion that the oil was changed into the starch. Strange to say, this view was for a time accepted, and prevailed without challenge for some years. Fleury suggested sugar instead of starch in 1865 .

The numerous discoveries of digestive enzymes directed attention to the possibility of a hydrolytic splitting of the fat under such agency, particularly when Muntz in I87I ascertained that fatty acids appear in germinating seeds. Such an enzyme was detected in the animal body by Claude Bernard in 1849, and its action was shown to be the separation of fat into a fatty acid and glycerin. In 1876 Schützenberger observed that when oily seeds were bruised in water and allowed to stand, both fatty acid and glycerin could be recognised in their contents. The discovery of the fatty acid led Detmer to the suggestion that it is the antecedent of the starch observed by Sachs, a view which, however, was not based upon experiment.

The first stages of the decomposition were explained in I 889 by the discovery by the present writer of the enzyme now known as lipase, in the endosperm of germinating seeds of Ricimus. The course of the decomposition which 
it sets up was shown to be exactly the same as that which Claud Bernard had discovered in the animal body. The writer showed that the metabolic changes included a formation of sugar and of crystalline acid substances, all of which passed to the seedling. He was not able to explain in detail their appearance. In the course of the next year the writer's results were confirmed by Sigmund, who found lipase in the seeds of the rape, poppy, hemp, and flax.

The course of the decomposition remained undetermined by these observations. In I895 Leclerc du Sablon ascertained that two sugars occur during germination, one which reduces Fehling's fluid and another which does not. In I899 the writer found that the former is glucose and the latter canesugar. The former is derived from the latter by the action of invertase, present in the seed. Glycerin does not appear in the seedling nor in the digesting endosperm, though it can be detected when the lipase acts on fat in vitro.

A partial explanation of these results was afforded by the observation of Biffen in $\mathbf{I} 898$, that when germination is very little more than started, the protoplasm of the endosperm cells which are quite quiescent during the winter suddenly springs into vigorous activity and increases considerably in amount. The present writer observed it setting up afresh the metabolic activity that had become suspended, and secreting the sugar, which till then had not made its appearance. The remainder of the changes supervening on the decomposition of the fat, viz. the nature of the acids and their fate, remained unknown. Evidence was forthcoming, however, that lecithin is formed in the endosperm during the germination at the expense of the fat, and passes in a state of fine emulsion into the embryo.

The distribution of lipase was not investigated at all fully. Besides its localization in germinating seeds it was shown by Gerard (I897), Camus (I897), and Biffen (I899), to occur in the mycelia of certain fungi. 
The utilization of the products of digestion by the living substance brings us back to the problem which met us at the conclusion of the story of the original construction of organic food material. How, and in what forms, are these various substances incorporated into the living protoplasm? We have here the problem properly named assimilation, which covers accordingly all questions of nutrition in the strict sense.

These problems were the subject of close thought and much speculation during the period we are discussing, but the total outcome of actual knowledge was meagre in the extreme. The study of its progress reminds us of the state of ebb and flow of opinion before I860 upon the questions whose solution has been so greatly advanced since that year.

The range of thought and inquiry was mainly directed to the relation of protein matter to living substance, and naturally so, as evidently the latter demands supplies of nitrogen-containing matter, of which protein most nearly approaches to it in composition.

Here we may first call attention to the writings of Pflüger in 1875 . To him the relations between protein and protoplasm were so close that he regarded the latter as living protein, holding that the difference between the two lies in the power of auto-decomposition of the protoplasm, ordinary protein being a fairly stable substance. He associated this auto-decomposition with the power of fixation of oxygen in some intramolecular combination which forms part of the living molecule, pointing out how the addition of oxygen increases the lability of the body with which it combines. Pflüger held that the fundamental difference between living and dead protein lies in the way in which its nitrogen is attached to the other elements in the molecule, basing his opinion upon a comparison of the decomposition-products of the two. Those which are yielded 
by the living protoplasm comprise for the most part substances in which nitrogen is united to carbon, forming cyanogen compounds, or others which. like urea, are closely allied to them. Hence there arises a probability that in protoplasm the cyanogen group is present. On the other hand, the evidence of the hydrolysis of the non-living protein by acids and alkalies as well as by the digestive enzymes makes it probable that its nitrogen is united to hydrogen, forming amino-, amido-, or ammonia compounds. The incorporation of the latter, or its assimilation by the living substance, therefore involves according to Pflüger a rearrangement of the nitrogen atoms in the molecule, which become freed from hydrogen and united instead with carbon. He held that this change introduces into the living matter energetic internal motion, cyanogen being a radical possessing considerable internal energy.

Pflüger held that the arrangements of the non-nitrogenous part of the protoplasmic molecule probably differs only to a slight extent from that of the protein one, the products of decomposition into which they enter being similar in the two cases.

After an interval of some years, some speculations, based, however, upon certain observations, were put forward by Loew in I892, which are of much interest in connexion with the material incorporation of protein by protoplasm. He took almost the same view of the latter as did Pflüger, but he held that besides the ordinary proteins, some specially labile forms can be demonstrated to exist in the cell. He claimed that researches, carried on by himself in collaboration with Bokorny, showed such labile proteins to be present in at least I20 species of plants chosen almost at random, and that they exist in leaves, petals, stamens, pistils, fruits, roots, and the bark of stems. The labile protein is smaller in amount in leaves in the shade than in those well illuminated, and if the plant be kept in 
darkness it is gradually decomposed with production of amino-compounds.

This labile protein, which is generally stored in the vacuole, is sometimes met with in the cytoplasm also. It can be shown by applying to the living cells certain dilute solutions of organic bases or their salts, or of ammonia. The best reagent is a 0.5 per cent. solution of caffeine or antipyrin, which does not kill the protoplasm. The labile protein separates in the form of little globules, which gradually run together. Loew and Bokorny called these proteosomes; generally they contain traces of tannin or lecithin. If the reagent is at once removed they dissolve again. If the cells are killed, the droplets gradually change their properties and become insoluble and solid. They coagulate on heating. The reagents do not produce the proteosomes in dead cells. Loew gave a fuller description of the labile proteins and the proteosomes in I899, but his views were vigorously opposed by Pfeffer and his pupils, who held that the proteosomes are compounds of ordinary albumin with the caffeine.

The latest speculations that come within our period were those put forward by Verworn in I894. They may be stated here briefly, as they are much on the same lines as the hypothesis of Pflüger. According to Verworn there are in the cell, beside the ordinary reserve store of proteins, carbohydrates and fats, and the products of their decomposition, certain other compounds also, probably protein in nature, which change when the death of the cell occurs. To substantiate this he relied on the facts of metabolism; he called attention to the instability of living and the relative stability of dead material, the living being decomposed and re-formed, giving off certain substances and taking in others. Hence he argued that living substance must contain complexes of atoms that have great tendency toward chemical transformation and auto-decomposition, which may be called 
labile complexes, and are easily worked upon by external stimulation, and that life depends directly upon their existence. He held that the two facts, that living substance demands these labile complexes and that proteins stand at the centre of life, show that living substance must contain certain proteins much more unstable than those which occur in dead substance; that these are present in life only and terminate life with their decomposition. Verworn said furtlier that certain proteins or protein compounds of living substance are continually undergoing spontaneous decomposition, even when the living substance is under wholly normal conditions, while all dead proteins are able to exist for an extraordinarily long time if protected from bacteria. He called this labile protein biogen.

Verworn's views differed but slightly from Pflüger's. He held that the change in the association of the nitrogen with the carbon marks the construction of the biogen rather than incorporation into the general living protoplasm. To quote his own words :

'In these considerations we find a basis for an idea of the manner in which the formation of a biogen molecule takes place in a cell out of the ingested food. By the co-operation of the biogens already present, the atoms of the dead proteid molecule introduced in the food undergo in the cell a rearrangement, in such a manner that an atom of nitrogen always unites with an atom of carbon to form the cyanogen radical with the loss of water. The changes that necessarily appear at the same time in the other groups of the proteid molecule are for the present wholly unknown, but if we may judge from the essential agreement in the nitrogenous decomposition-products of the living and the dead proteid, they do not appear to be of fundamental importance' (General Physiol., Eng. ed., I 899 , p. 483).

A view of a different character was advanced by Sachs in I880 and I882, and somewhat modified ten years later. GREEN 
It can hardly be spoken of as opposing Pflüger's position, as it was not of the same broad general character. It took into account only the vegetable organism, and dealt with hypothetical substances for whose existence there was no chemical evidence. In its final form in I893 Sachs' suggestion was that special stimulating and constructive substances are formed in the metabolic processes in the leaves. He was inclined to hold that one of such special stimulating substances is necessary for, or operative in; the formation of stem, root, and leaf respectively, a particular one indeed for every form of growth. To produce the differentiation of stem and root he considered that two such stimulatory substances, unlike each other, are to be regarded as existing in the axis of the plant, and that the differentiation is brought about owing to their becoming separated by the action of gravity.

Sachs' generalization has no chemical support; he could say nothing of the nature of his hypothetical stimulatory substances, but based his view upon a few specially striking instances of response to chemical stimulation. He originally attributed a great share in the formation of the different stimulating materials to the character of the food.

Vöchting opposed Sachs' position in papers published in I885 and I899-I900, claiming that his observations do not bear the interpretation he gave them. The same view was held by Reinke in I897. Pfeffer also was an opponent of Sachs' hypothesis; in his Pflanzenphysiologie he took the ground that the theory involves a disregard of the mechanism of auto-regulation, whereby any definite result is always due to the co-operation of various factors; and further, that different combinations including the same factor may lead to dissimilar results.

It will be seen that these speculations on the part of the botanists do not carry the question beyond the point at which Pflüger left it in 1875 . 


\section{CHAPTER VIII}

THE DEVELOPMENT OF THE MODERN IDEA OF THE CATABOLIC PROCESSES AND THE INTERNAL ENERGY RELATIONS OF PLANTS

ONE of the most remarkable features of the early part of the period I860-I900 was the confusion that had arisen on the subject of respiration. So far back as the time of Ingenhousz and De Saussure clear ideas of the chief external facts had been obtained and up to a certain point satisfactorily interpreted, while Dutrochet, as late as I837, had put forward a comprehensive statement of its nature and showed that the process is fundamentally the same in animals and plants. But shortly afterwards misconceptions had arisen, the tivo gaseous interchanges associated respectively with respiration and photosynthesis had been confused, and the idea had gained ground that while the latter of these processes was carried on in the light, the former replaced it during darkness. Hence sprang the view that the respiration of plants included them both, so that diurnal and nocturnal respiration were spoken of. Liebig unfortunately went further than this and denied explicitly the existence of respiration in plants in the true sense. The weight attached to his opinion unhappily put back the clock for quite a quarter of a century, in spite of the protests of several observers, particularly of Garreau in $185 \mathrm{I}$.

In I860 the view of a kind of complementary interchange marking diurnal and nocturnal respiration was very generally accepted, and it held its position for a number of years subsequently, as may be seen by the standard $\mathrm{D} \mathrm{d} 2$ 
textbooks of the time. Correct ideas began to make their way again into favour with the appearance of the Experimental-physiologie of Sachs in I865 and the marshalling and interpretation of the facts concerning respiration constitutes by no means the least of his contributions to the physiology of plants. He stated his views more fully in his Lehrbuch (I868), in which he said that respiration consists as in animals of the continual absorption of atmospheric oxygen into the tissues, where it causes oxidation of the assimilated substances, and other chemical changes resulting from this. He pointed out that the formation and exhalation of carbon dioxide may always be observed, and he held that the carbon may be attributed to the decomposition of organic compounds.

Sachs further showed that the activity of growth and of metabolic changes is accompanied by increased activity of the true respiratory processes, and held that the latter take place everywhere so long as life exists. He pointed out that the streaming of protoplasm and the movements of periodically motile and irritable organs are lost in the absence of a supply of oxygen. He also called attention to the loss of weight met with during any suspension of the nutrition and associated it with respiration. Not the least important of his statements was that, while respiration is a source of loss of substance, it is also in addition the perpetual source from which flow the forces necessary to the internal movements. Though he did not state it so explicitly as writers who succeeded him, we can see here an appreciation of the part this process plays in the energy relations of the plant.

Respiration after its re-establishment as a separate vital process came to be regarded as a sort of combustion, in which various constituents of the plant's food or of products of its metabolism, were in a way burnt away with the formation of carbon dioxide. The entering oxygen 
was held to combine directly with carbon to produce this exhaled compound. The idea was not a strange one, as the only facts observed up to that time were the entry of oxygen and the exhalation of the carbon dioxide. At first, indeed, the formation of water was not known, only the gaseous interchange involving oxygen and carbon dioxide having been considered. The time was marked by a vast amount of ill-directed research which was devoted to establishing a ratio between the exhaled carbon dioxide and the absorbed oxygen, and to inquiries into the way this ratio, the so-called respiratory quotient, is influenced by various external conditions, and how it varies in different organs at the different stages of their growth. With such a hypothesis underlying the inquiry, there is little cause for wonder that very contradictory results were reached, and that little accurate knowledge of the respiratory process was obtained.

The identity of respiration with a combustion of some kind was supported by suggestions as to what particular constituents of the food were concerned. Sachs held that it was carried on, at any rate in germinating seeds, exclusively at the expense of the non-nitrogenous reserve materials, a view which was very prevalent among the animal physiologists of the time, and which led them to classify foodstuffs as flesh-forming and heat-giving or respiratory respectively. This view was opposed by some observers, particularly Borodin, who, in 1878 , suggested that the nitrogenous substances constituting the protoplasm become oxidized, and to this oxidation is due the appearance of asparagin in the plant, while the nonnitrogenous materials are used up in supplying plastic material to the protoplasm.

Borodin's views were in a sense a reflection of the hypothesis of Pflüger, which had been stated a few years before and which will be discussed a little later. The idea of 
separate respiratory material, consisting for the most part of carbohydrates and fats, or of groupings of them in the protoplasmic molecule, nevertheless maintained its hold on the opinion of many observers and cannot even now be said to have disappeared, although the view of a direct combustion, apart from the interaction of the living substance, has been to a certain extent modified by those who advocate it.

The weakness of the combustion hypothesis became apparent when the relations of the two gases concerned in the interchange came to be scrutinized. The animal physiologists took the lead in such investigations, but their results were soon supported by the work of botanists. Wolkoff and Mayer showed in 1874 that something more than mere combustion is involved, by the discovery that raising the temperature of the plant at first accelerates the respiratory interchange, but that after a certain temperature, varying with the plant, is reached, further elevation depresses it. Ziegenbein, in I893, also demonstrated the existence of an optimum temperature for respiration; he placed it at about $35^{\circ} \mathrm{C}$. Dehérain and Moissan, in 1874 , investigated the intake of oxygen and the output of carbon dioxide separately, and found that variations of temperature affect them differently; at a low temperature the absorption of oxygen is more active than the exhalation of carbon dioxide, while at a high temperature the contrary is the case. During the early seventies Pfluger and other physiologists showed the independence of the two processes by discovering that frogs kept at a low temperature for several hours in the absence of oxygen continued to exhale carbon dioxide. A somewhat similar observation was made by IVortmann in I88o; he showed that a germinating seed placed in a Torricellian vacuum continually exhales carbon dioxide.

The independence of the two processes became more 
apparent when Laskowski showed in 1874 that water, as well as carbon dioxide, is formed in the respiratory processes, and consequently that the amount of oxygen absorbed is insufficient for the complete combustion which the theory requires.

Another blow to the theory was given by the reinvestigation of some old experiments of De Saussure on Opuntia, in which he found that under certain conditions it exhales no carbon dioxide, though it may be supplied with oxygen. Dehérain confirmed this statement in 1874 , and showed that the plant under these conditions accumulates a large quantity of oxalic acid. Mayer, the next year, showed that certain succulent Crassulaceous plants store a considerable amount of malic acid in their leaves, and that, as in the case of Opuntia, this is attended by the cessation of the exhalation of carbon dioxide. These experiments pointed clearly to such a modification of the respiratory processes as is incompatible with its being a combustion.

Yet the ultimate dependence of the carbon dioxide upon a supply of oxygen appeared from many researches to be undeniable. Broughton, in I870, and Wortmann, in I880, showed that when seedlings are deprived of oxygen, their output of carbon dioxide becomes less. The latter observer confined his seedlings alternately in air and in hydrogen, taking measurements of the carbon dioxide every half-hour under conditions of such an alternation of environment.

Though the idea of respiratory combustion has been proved to be untenable in the form in which it was stated by Sachs and his immediate successors, it has nevertheless not disappeared. Many writers have endeavoured to evade the difficulties it involves and still maintain the essential accuracy of the term by substituting the expression physiological combustion for the older one. It seems, however, rather to introduce fresh difficulties into our conception of the process than to elucidate it. 
It was not difficult to perceive on studying the different items of information yielded by these researches, that a considerable share of protoplasmic activity is indicated. Attention was consequently drawn by the more thoughtful of the physiologists of the time to the living substance of both animals and plants, and a new theory was put forward by Pflüger in 1875 .

Pflüger was at the time advancing the views we have already alluded to as to the constitution of living substance and its relations to dead proteins, coming to the conclusion that in the former the nitrogen is linked directly with carbon, forming cyanogen groupings. His theory of respiration was that the entering oxygen combines or unites in some way with the cyanogen radicals of the living substance. These cyanogen groups already contain a large quantity of internal energy, all their compounds showing a ready tendency to decomposition. The approximation of oxygen to such a labile group, in which already there is active intramolecular vibration of the carbon and nitrogen atoms, brings about a readjustment, carbon dioxide and water appearing, together with more complex substances, among the products of the decomposition.

If we consider this process as proceeding simultaneously with the process of nutrition or repair of the living substance, we see that on Pflüger's hypothesis the protoplasm is the seat of constant changes of building up and breaking down so long as life lasts. The instability of some of the groupings of its constituent atoms causes the decompositions to be of an explosive character. The latter constitute the respiration of the living substance. The entry of the oxygen increases the instability and provokes the explosive decompositions.

Pflüger's hypothesis receives considerable support from observations made before and since it was advanced. Long before, De Saussure had found that when he subjected to the 
action of an air pump a stem into which a quantity of oxygen had been injected, he was unable to extract it again by a diminution of pressure. In I 868 Engelmann brought forward evidence of the existence of intramolecular oxygen in ciliated epithelial cells. Borodin's researches in I878, which have already been alluded to, may be regarded as confirmatory of the hypothesis. In I879, and in I883, Detmer supported it in a slightly modified form, when he suggested that the primary source of the energy developed in living organisms consists in the splitting up of highly complex labile compounds, the decomposition products of which subsequently become oxidized, carbon dioxide and water being the ultimate products. In I894 Maquenne held, as the result of experiments with leaves, that the living substance separates from itself a material which, on contact with fresh oxygen, oxidizes and gives off carbon dioxide.

The views of Pflüger were somewhat modified and extended in 1894 by Verworn, who associated the action with the biogen molecules to which we have referred. $\mathrm{He}$ held that the oxygen entering into the biogen molecule gives it its maximum power of decomposition, "so that only very slight impulses are required to bring about the union of the atoms of oxygen with the carbon in the cyanogen. The material of the non-nitrogenous groups of atoms afforded by the explosive decomposition of the biogen molecule can easily be regenerated by the residue of the biogen molecule from the carbohydrates and fats that are present in the living substance and contain such groups.' He agreed with Pfluger in calling these substances 'the satellites of the proteid molecule', and in thinking this to be probably their essential significance. He said further,

' in contrast to other explosive bodies we must evidently ascribe to the biogens the peculiarity that in decomposition the whole molecule is not destroyed, but that certain groups 
of atoms, which are formed by rearrangement, are split off, while the residue is again built up into a complete biogen molecule at the expense of the materials found in its vicinity, just as in the manufacture of concentrated sulphuric acid the nitrous acid formed from nitric acid by the withdrawal of oxygen is rebuilt into nitric acid with the aid of the oxygen of the air. The substances still present in the living substance in addition to the biogens are merely "satellites" of the biogen molecule, and either serve for its construction or are derived from its transformations'.

This view of respiration presents it then, not as a process of combustion, simple or 'physiological', but as the expression of the dissimilation going on in the living substance of the organism.

At the end of the century the discovery of the oxidases directed speculation towards the possibility of their being concerned in the respiratory processes. These researches, however, had not up to that time led to the formation of a different hypothesis, and a consideration of them does not therefore come within our present province.

We have seen from the experiments of Wortmann and others that respiration continues for a time when the supply of oxygen to a plant is very greatly reduced or even entirely suspended. At any rate, the production of carbon dioxide goes on. Though the observation was made as early as I880, no explanation was for the moment offered.

These observations bring us to the consideration of what has been for many years known as intramolecular respiration, a process which has been considered as supplementary to the true respiratory process and to have the same object, the supply of internal energy to the plant. It is a condition which is associated with the absence of a supply of oxygen, and is hence preferably to be called anaerobic.

It was in I86I that the first observations bearing upon it were made. Pasteur in that year ascertained that yeast and several species of Bacterium are able to live in the 
absence of oxygen, and that such life is associated with the carrying on of the processes of fermentation. In consequence of his researches he put forward the view that fermentation, alcoholic especially, is life in the absence of oxygen. The views that were then obtaining currency on the combustion relations of respiration led him to hold that the object of fermentation is to replace the oxygen of the air, now no longer supplied, by the intramolecular oxygen of the substances undergoing fermentative changes, especially sugar. In this way a supply of oxygen would be made available for the combustion which he held to be essential. All the changes being held to be readjustments of the structure of the molecule of the fermenting body, whether free or in the living asphyxiating substance, the term intramolecular respiration was applied to the process.

The investigations of Pasteur were followed in I869 and I872 by the researches of Lechartier and Bellamy, who studied the behaviour of various succulent fruits, potatoes, and grains of wheat, when kept in closed vessels without access of air. They gradually absorbed all the free oxygen around them and still exhaled carbon dioxide after it had disappeared. Pasteur himself confirmed these observations.

Investigations published by Brefeld in 1876 , and by De Luca in 1878 , showed that similar results were met with in experiments with seeds, leaves, and branches. These researches were confirmed and extended by many observers. So general has the process been ascertained to be, that it is exhibited in the trunks of trees, supervening there on normal respiration, as was shown by Devaux in I899.

This so-called intramolecular respiration was found to be accompanied by the formation of many products which do not occur in the normal respiratory processes. The occurrence of alcohol has long been associated with the process of fermentation by yeast, though the action of yeast may perhaps differ in some particulars from the anaerobic 
respiration of the vegetable cell as it occurs in the substance of a plant. Alcohol was found in the course of their experiments by Lechartier and Bellamy, and by many other observers, particularly by Brefeld, De Luca, Berthelot in I893, Mazé in I899, and Devaux in the same year. De Luca's liberated products included hydrogen and marsh gas, while Boehm in I875 observed the occurrence of ammonia.

The general occurrence of alcohol among the products obtained under the condition of partial or complete asphyxiation led to the opinion that intramolecular respiration is identical with fermentation. Such differences as appear seem to be connected with other peculiarities of the fermenting organism or cell than those connected with the liberation of energy.

The question of the relation between intramolecular or anaerobic and ordinary or aerobic respiration has been differently interpreted. Pfeffer pointed out the genetic relationship between the two in 1878 , and subsequently in I885 put forward the conclusion that the withdrawal of oxygen causes metabolism to assume a different character, the change being gradual as the supply of the gas falls off. The different character of the metabolism becomes evident when we remember the different products which have been found in the two cases, as has already been shown. The gradual nature of the change was investigated by Gerber in 1876 , the material used being the fruit of the Chinese date-plum (Diospyros kaki). The order of events in the ripening of these fruits was found to be the following. In the early stages the respiration showed that they exhaled less carbon dioxide than they absorbed oxygen. The pectose present in the walls of the cells was converted into pectine which produced a softening of the pulp. The swelling characteristic of pectine obstructed the intercellular passages in the pulp, thus interfering very seriously with the trans- 
port of air to the cells of the interior and causing the supply of oxygen to be considerably lessened. When the temperature was maintained at $\mathrm{I}^{\circ} \mathrm{C}$., sufficient oxygen was able to pass along the narrowed intercellular passages to minister to the needs of the cells. When it was raised to $30^{\circ} \mathrm{C}$. this was not the case, and a sort of asphyxiation set in. Fermentation supervened, a considerable additional quantity of carbon dioxide was exhaled and alcohol was produced. The ratio of oxygen to carbon dioxide changed from $I: I \cdot 26$ to $I: 3 \cdot I 2$. The increase of the latter gas resulted from the fermentation of the sugar adding to the quantity proceeding from the respiration of the cells, the latter being the only factor when the lower ratio was observed. This view of the cause of the increase was supported by the observation that when air was admitted more freely by subdividing the tissue into small pieces, the ratio at once fell slightly, though as such subdivision did not completely remedy the obstruction of the intercellular passages, the difference was not very marked.

The view that alcoholic and similar fermentation is concerned in metabolic changes like those of aerobic respiration, involving, that is, explosive decomposition of the living substance, was called into question in consequence of the discovery of Buchner in 1896 that the yeast plant at least causes the production of alcohol by means of the secretion of an enzyme, to which Buchner gave the name zymase. The fact most easiiy ascertained with respect to the action of yeast is that the production of alcohol and the exhalation of carbon dioxide are the result of a decomposition of a sugar which breaks up entirely, though probably by several stages, into those two compounds.

It appears not improbable from Buchner's work that the change in metabolism which diminution of oxygen causes is the secretion of the enzyme, which then brings 
about this decomposition independently of the living substance. This appears the more likely since Effront showed, in $\mathbf{I} 898$, that zymase is produced in fruits and other parts of plants when they are deprived of oxygen. It may be that the decomposition of the sugar is brought about by the direct action of the protoplasm in such cases as do not show the secretion of zymase, and that therefore the decompositions of anaerobic respiration or dissimilation are not so profound as those which they replace. When sugar is not present, it may be that the fermentative changes affect the carbohydrate groups in the protoplasm itself. At the end of the century these views remained still the subjects of discussion.

The discovery of the so-called anaerobic organisms, which cannot live in the presence of oxygen, was made by Pasteur in I86I. These, which are met with among the bacteria, were investigated subsequently by Beijerinck I894, Chudiakow I896, and again by Beijerinck in I899. Little is known about their metabolism except that their energy is derived from chemical decompositions.

Pasteur's view that the purpose of intra-molecular respiration is to obtain oxygen from sugar in order to liberate energy by subsequent oxidation, was replaced at the end of the century by the theory that this object is secured by the liberation of energy during the general fermentative decompositions. 


\section{CHAPTER IX}

\section{THE INFLUENCE OF THE STUDY OF THE NUTRI-}

TION OF HETEROTROPHIC PLANTS ON THE PROGRESS OF KNOWLEDGE OF THE TRUE NATURE OF THE FOOD OF PLANTS

IN the previous chapters we have seen how slowly, and with what difficulty, a correct appreciation of the true nature of the food of plants and its assimilation made its way into the minds of botanists. Even now the terminology which is frequently employed in speaking of the various nutritive processes tends to obscure their actual nature, for by many writers the term assimilation is applied both to the incorporation of food into the living substance and to the absorption or appropriation of the raw materials from which that food is manufactured prior to its incorporation. At the opening of our period in I860, the nutritive processes of the plant were held to be antithetical to those of animals; the plant was considered to be anabolic, building up complex compounds from simple ones, the animal katabolic, breaking them down again. The carbon dioxide absorbed from the air and the mineral compounds taken up from the soil were held to constitute the food of plants, and the constructive changes that follow were thought to correspond to the digestive changes of animals, both being preliminary to actual nutrition. A true conception of the various processes concerned was not reached, indeed was not possible, till the researches of Max Schultze, published in I86r and I863, showed that the living substance, or protoplasm, of both animal and plant, is fundamentally the same. As soon as this was realized it became necessary 
to seek a fuller explanation of the apparent differences in nutrition. Max Schultze's view of the identity of nature of the vegetable and animal protoplasm was demonstrated to be well founded by the various researches to which attention has been drawn in the preceding chapters, and by others to be treated of later which will deal with the problems of sensitiveness or irritability. We consequently gained the idea of nutritive processes which are fundamentally similar in the two cases, and were led to see that the special property of the green plant is to carry on the manufacture of the food material of both animals and plants, a manufacture which precedes the nutritive processes proper, and which is not-shared in by the animal organism, except in a few cases.

The distinction between the two sets of processes, which had not been clear in the current ideas of the nutrition of the plant, was gradually made more evident by the researches of the whole of the period under review, and as this distinction became more and more apparent, considerable light was thrown upon many observations made during the time, which when first noticed received no adequate explanation and were held to be abnormal. Attention has been called to the researches of Boehm, Meyer, Schimper, and others, which showed that plants are capable of absorbing sugar under appropriate conditions, and that this can be taken up so freely as to give rise to the deposition of reserve stores of starch. Hampe as well as Knop and Wolff showed in 1865 that green plants are capable of utilizing the nitrogenous compounds glycocoll, asparagin, leucin, and tyrosin when supplied to their roots. These somewhat complex substances are all associated with the digestion of protein in the animal body and subserve in some way its nutrition. The group of Fungi stood out as differing in an apparently fundamental manner from the green plants, for no true Fungus is capable of utilizing atmospheric carbon dioxide. Obser- 
vations made by Pasteur in 1860 and $\mathbf{1 8 6 2}$, by Naegeli in 1879 and 1882 , by Reinke in I883, showed that Fungi are capable of feeding upon a great variety of carbon compounds, some fairly simple, others extremely complex, and Pasteur especially showed in his classical researches on racemic acid that they exercise a certain selective power. It would take us far beyond the limits of our present studies to attempt to give a résumé of the researches made during the later years of the century into the various food materials Fungi are capable of utilizing. We must, however, call attention to the discovery that they carry out digestive processes in the bodies of their hosts, or in the dead organic matter in which they live, by means of enzymes identical with those which have been found in the higher plants. Much of our knowledge on this point has been due to the work of Bourquelot and his pupils, to which reference has already been made.

This mode of nutrition was ascertained to be characteristic of certain parts of the higher green plants. Van Tieghem called attention to the feeding of the embryo at the expense of the endosperm, and showed that the latter can be replaced by an artificial preparation of carbohydrates and proteins. The nutrition of the pollen-tube in its passage down the style was studied by Correns in 1889 , by Molisch in 1893 , and by the present writer in the same year, and was found to be completely in accord with the nutrition of the Fungi. Beijerinck in 1890 showed that certain lichen-algae prefer peptone to any other form of combined nitrogen.

But some very striking exceptions to the ordinary mode of life gradually became known. Researches, to which we must refer in detail, showed that various green plants living under exceptional conditions, are capable of feeding on the bodies of insects, after a preliminary process of either digestion or putrefaction; while both fungi and bacteria were 
gradually shown to be capable of living and thriving in the juices of the animal body.

Observations like these needed explanation, which was only gradually and slowly obtained. We may appreciate the perplexity which was felt at the apparent impossibility of reconciling them with the old hypothesis when we find the most prominent of British botanists, in an address to the British Association at Belfast in I874, saying that these plants 'seem to invert the order of Nature, and to draw their nutriment in part at least from the animal kingdom, which it is often held to be the function of the vegetable kingdom to sustain '.1 The trend of the thought of the time was indicated in the words, "though the processes of plant nutrition are in general very different from those of animal nutrition and involve very simple compounds, yet the protoplasm of plants is not absoiutely prohibited from availing itself of food such as that by which the protoplasm of animals is nourished.'

As we have seen, further work showed that the old hypothesis was erroneous, and that the processes of nutrition, strictly so called, are alike in animal and plant. Now that the true significance of the observations we have referred to has been realized, they are seen to help materially to the understanding of the actual nature of the nutritive processes of the green plant, and to a discrimination between the manufacture of food and the subsequent processes of its assimilation.

The various aspects of heterotrophic nutrition which came prominently into notice during the years I860-I900 were associated with symbiosis, metabiosis, saprophytism, parasitism, and the capture and digestion of lowly forms of animal life.

The phenomena of symbiosis received a great deal of attention. The part which it plays in connexion with the ${ }^{1}$ Hooker, Brit. Ass. Reports, Belfast, 1874. 
fixation of atmospheric nitrogen in the soil has already been alluded to. The association of a fungus and an alga in a union of this kind to form the organism known as a lichen was first definitely shown by Schwendener in I860, though seven years previously Sachs had advanced the idea of organic interdependence of what were then thought the two tissue elements, the hyphae and the gonidial cells, of the thallus of Collema. Reess put forward identical views of the physiology of Collema in the same year as Schwendener. The term symbiosis was applied to the lichens by De Bary in I879.

Symbiosis in which the higher plants are concerned was shown to be somewhat widespread. The connexion between the roots of many plants growing near each other, which was at first considered to indicate parasitism, was proved to be symbiotic. The structure of the haustoria connecting the Rhinantheae, the Santalaceae and other groups with their so-called host-plants was investigated in 1875 by SolmsLaubach, and the general morphological relationships were studied by Koch in I889 and I89I, and by Heinricher from 1897 onwards.

The tendency of saprophytism of this kind to develop into parasitism was shown in the researches of Wiesner (I87I) and of Koch (I887) on Orobanche, of Koch (I880) and Pierce (1894) on Cuscuta, and of Heinricher (I895) on Lathraea.

The relations of the Loranthaceae with their hosts were studied by Pitra in I86r; he held that a transference of water and inorganic salts from the host-plant was all that takes place. A fuller symbiosis was suggested by Hartig in 1875 and again by Bonnier in I89I.

Symbiotic relations between fungi and the higher plants were shown to be very widespread, the connexion existing mainly in the roots. We have already discussed the peculiarities of the root tubercles of the Leguminosae and other 
plants, and their bearing on nitrogen supply. In many cases filamentous fungi were found associated with roots of various trees and shrubs, in some cases being entirely internal, in others forming a feltwork over the exterior. These associations became known as endotrophic and ectotrophic mycorhiza respectively, the term being introduced by Frank in $\mathbf{I} 888$.

Ectotrophic mycorrhiza was discovered in I88I by Kamienski, in Monotropa, and was observed to exist in a large number of forest trees by Frank in 1887 . Numerous examples have been discovered more recently. Endotrophic mycorrhiza was known long ago by Schleiden, who observed it in Neottia. Its wide distribution, especially among plants of the Natural Orders Ericaceae and Epacridaceae, was pointed out by Frank in I887 and by Schlicht in I889. The way in which the fungus penetrates Neottia and lives in the interior of its cortical cells was investigated fully by Magnus in Igoo. Stahl in the same year made very comprehensive researches into these relationships.

The fact, known long ago, that many fungi live at the expense of non-living organic food, while others infest the living body, led to their being classed into saprophytes and parasites. A certain power of adaptability possessed by them was discovered in $I 884$ by De Bary. He found that by appropriate methods of culture some of the saprophytes can be made to infect living organisms. He therefore introduced the terms facultative and obligate parasites to indicate the possession of this property or its absence.

Marshall Ward, in I899, introduced the term metabiosis to indicate the condition in which one of the higher organisms is infested with two fungi, the first of which, a parasite, kills the tissues of the host, and the second lives on the dead material resulting.

The investigations that were conducted on the so-called 
carnivorous or insectivorous plants between I860 and I900 very considerably extended our knowledge of their modes of life, and the number of species known to possess the power of appropriating animal food was increased. The researches were directed mainly to Nepenthes of the pitcher plants, and to Drosera and Dionaea among those which effect capture by means of movement.

Little accurate information about the pitcher plants had been obtained prior to 1874 , when a comprehensive account of what was known about them was given by Hooker in an address to the British Association at Belfast. Besides describing the arrangements of the pitchers for catching flies, as shown in Sarracenia, Nepenthes, and Darlingtonia, he showed that the liquid in the pitcher of Nepenthes is possessed of digestive power, which is associated with a pepsin-like secretion of its inner wall. About the same time Mellichamp showed that the liquid which the pitchers of Sarracenia contain is not collected from rain, but is exuded from the cells of the pitcher wall.

Von Gorup-Besanez and Will, in I876, made a detailed study of the action of the secretion of Nepenthes on fibrin and found it able to decompose the latter and to produce peptone. They gave attention also to the conditions under which the digestive power appears, and showed it to be due to an enzyme, working in an acid medium. In I877 Vines extracted the enzyme by glycerin from the wall of the pitchers, and proved that in unstimulated pitchers it exists as a zymogen in the cells of the glands the walls contain. In I89o Dubois denied the existence of the enzyme, attributing the digestive action to bacteria. Tischutkin supported him in I89I. Vines, in further researches in I897, showed conclusively that the enzyme is secreted, and carried his discovery further by proving it to be one of the tryptic group.

Sarracenia was shown in 1882 by Schimper to absorb 
animal matter resulting from the putrefaction of its prey. No enzyme appears to be secreted.

Of the plants which capture insects by active movement the most familiar is Drosera, several species of which were very carefully studied. The first important researches which were carried out upon these plants were those of Nitschke, made in I860; they included a complete investigation of their structure and habits. With the exception of Scott's discovery in 1862 , that irritation of the leaf-tentacles causes them to become inflected over the leaf, little more was ascertained about them till after 1870 , when they excited great interest. Three species of Drosera were examined very carefully in 1873 by Mrs. Treat of New Jersey. The minute structure of the tentacles was studied in 1873 by Warming, but the classical researches which revealed the nature of the processes by which they capture and digest their insect visitors were those of Charles Darwin, whose great work upon the whole group of insectivorous plants was published in 1875 . In this book, for the first time, was revealed the story of the mechanism of digestion, carried out in a manner recalling the process of proteolysis in animals, as well as the curious accessory mechanism of stimulus and response, to which attention will be directed in a subsequent chapter. Darwin's researches included a study of the histological changes accompanying the secretion of the digestive fluid, and drew attention to the curious changes in the cells, to which he gave the name of aggregation, showing thereby that the whole process involves special protoplasmic activity. Darwin's explanation of these protoplasmic changes was subsequently modified by Cohn (I876), Pfeffer (I877), Schimper (ISS2), Gardiner (ISS5), and De Vries (ISS6). The intimate association of the cytoplasm and the nucleus in the nutrition of the cells, accompanying and following absorption was the subject of important memoirs by Miss Huie 
in 1896 and $x 899$, and by Rosenberg in the latter year.

A certain reserve was maintained by the earlier writers as to the advantages accruing to the plants, but this was dispelled by the investigations of Francis Darwin in 1878 and of Büsgen in $x 883$. Both writers proved the absorbed products to be nutritive by a detailed comparison of the development of two sets of cultivated specimens, one of which was fed with insects, chiefly aphides, while the other received no other nutriment than was supplied by the air and soil. Similar, though less complete, researches on this point were carried out by Von Raumer in 1878 .

The acid of the digestive secretion was said by Rees and Will, in 1875 , to be formic acid. These authors found that the digestive constituent of the secretion can be extracted from the leaves by glycerin, but that it is not active until it is acidified.

Drosophyllum, another member of the Droseraceae, was examined by C. Darwin and found to agree in all essential respects with Drosera. It was again the subject of a careful research by De Wèvre in I895.

Another allied plant to which considerable attention was directed is Dionaea muscipula, the Venus' fly trap. Its habit of catching flies was known to Ellis in I768 and certain of its peculiarities were mentioned by several writers prior to ISoo, while Curtis in I834 published an account of its behaviour which was very complete for the time at which he wrote. During our period its peculiarities were first examined by Nitschke in I860. Mrs. Treat's researches in $187 \mathrm{I}-3$ were also concerned with Dionaea, but the most accurate information we possess was afforded by the investigations of Charles Darwin, published in I875. Mention should be made also of the work of Canby in I868, in which we have an account of the process of absorption by the leaf following the actual digestion. 
Burdon Sanderson showed in 1873 , and more fully in I882, that electrical phenomena, comparable with those attending muscular contraction, are manifested during the closing of the leaf.

Aldrovanda, a near relative of Dionaea, and possessing a similar mechanism, was investigated by Cohn in 1875 , and by Darwin in the same year. Darwin found that Saxifraga umbrosa possesses the power of absorbing an infusion of raw meat. He proved also that all these heterotrophic plants can absorb dilute solutions of ammonia and of ammonium carbonate, and was inclined to regard this power as bearing on such absorption from the air, and from rain-water, in which traces of these compounds are present.

Another plant which was in the first instance investigated by Darwin was Pinguicula vulgaris; he found it capable of digesting not only the bodies of insects, but such vegetable structures as pollen grains, leaves, and seeds of other plants which may fall upon its leaves. Two other species of the genus gave similar results.

Utricularia, a plant which in some respects resembles the pitcher plants, to which allusion has been made, was the subject of observation by Crouan in 1858 , and by Holland ten years later. Both writers found small aquatic insects imprisoned in its bladders. An important memoir on this plant was published by Cohn in I875, and it figured prominently in Darwin's researches published in the same year. Its operations were carefully watched and explained by Mrs. Treat at about the same time. Further observations upon it were made by Schimper in I882. Neither observer was able to detect with certainty a true digestive process in the bladders, though Darwin held that the appearances justify a suspicion that an enzyme exists. In the absence of such an agent the cause of the disintegration of the captives must be ordinary putrefaction. All these writers agreed that the products of decay or digestion 
are absorbed by the plant, as by Drosera and the other species described. Some other species of Utricularia, which are terrestrial in habit, were described by Darwin and subsequently in 1887 by Schimper. They were found to possess similar mechanisms to the aquatic species.

In 1874 Warming described another insect-catching plant, Genlisea ornata, which resembles Utricularia in its methods of appropriating animal matter. Darwin investigated three other species of Genlisea. 


\section{CHAPTER X}

\section{THE PROBLEMS OF GROWTH AND ITS ASSOCIATED CONDITIONS}

PrIOR to I860 comparatively little attention had been paid to the problems associated with growth. Munter had shown in I842 that the growth of an organ, uninfluenced by external causes, begins slowly, gradually increases till its rate reaches a maximum, and then slowly declines till it ceases. In the same year Harting made some investigations into its dependence upon temperature, which he tried to reduce to a mathematical expression, without achieving, however, any great success. The rhythm which Munter had observed has been recognized by all subsequent observers, and in 1873 was named by Sachs the grand period of growth. It was investigated by him in much detail and shown to be an expression of the behaviour of a single cell as well as of a multicellular organ. Though in its broad outlines inherent in plants, Sachs showed it to be somewhat irregular in its course, autonomic variations of relatively small extent occurring which cannot be explained by changes in the conditions of the enviromment. Baranetzky, keeping the latter constant by artificial means, studied the variations of the grand period in I879, and showed that in some plants they show a fairly regular daily periodicity or rhythm, while in others they are irregular. Drude, in I88I, also showed that the rise and fall of the curve of the grand period does not describe an even line, while conditions are kept constant;- - that indeed the rate of growth does not remain regular for as long as five minutes consecutively.

In a classical paper written by Sachs in I87I he first 
clearly defined the condition of turgor, and showed the intimate relation between this condition and growth. $\mathrm{He}$ examined by careful measurements the gradual elongation of a growing shoot, using for this purpose the auxanometer, an instrument which he invented to record magnified distances of the extension of a growing organ upon a smoked paper surface. He showed also that two definite areas can be distinguished in an apical growing point, the actual punctum vegetationis, in which cell division only is occurring, and a region just behind it in which the cells undergo increase in length. Sachs found that the growing region, as distinguished from that of cell division, is longer than it is in roots, several internodes taking part in it simultaneously. Some years later, in I880, Askenasy showed that in some aquatic plants the region of active growth may extend over as many as thirty to fifty internodes. Sachs measured the growing zones in roots as well as stems, and determined that the second zone is frequently nearly ten times as long as the first.

The auxanometer was employed by Baranetzky in his researches in 1879 , and its form was much improved.

Regions of intercalary growth were examined by Stebler in 1878 , and their distribution in many leaves determined. He showed that in such regions a single zone of cell division lies between two zones of active growth.

The necessity of a supply of water as an antecedent condition of growth was shown by Sorauer in 1873 . He found that the perfect development of the plant has a distinct correlation with the condition of moisture in the soil. De Vries also insisted on this relationship in 1877 , and confirmed Sachs by again drawing attention to the necessity of regular and complete turgor of the cells as an antecedent to growth, a condition which depends upon the moisture of the soil. He showed that the position of greatest turgor and greatest growth coincide. 
The dependence of growth on turgor was shown by Strasburger in $\mathrm{I} 882$ to be sometimes very slight. He pointed out that pollen grains are not turgid when they put out their pollen tubes. In $\mathrm{I} 896$ Copeland showed that in many cases it is turgor that appears to be regulated by growth rather than growth by turgor.

The tensions that come to exist in plants as a consequence of varying distribution of growth and its different rates in different parts were studied by many observers. Hofmeister was occupied with these problems at the opening of our period. He was inclined to attribute these strains to the absorption of water by the cell walls and their consequent swelling, and he attached little importance to the condition of turgor inside them. He added greatly to our knowledge of the development of tensions during the growth of different organs and to their general distribution. Sachs studied the same problems a little later and broadened our knowledge considerably. He showed, in I865, that growing tissues exhibit both longitudinal and transverse tensions, and that they are caused in large measure by the pith growing more rapidly than, and consequently exerting a stretching pull on, the outer tissues. The latter are consequently compressed from within outwards and the more so the nearer they are to the exterior. In 1867 and in 1870 researches on the same subject were published by Kraus, who investigated the longitudinal tensions in turgid stems and petioles and the transverse strains in the epidermis and cortex of various organs. He showed that they are not perceptible in the youngest internode of a stem, but become gradually noticeable as age increases; he attributed them to the gradual differentiation of the adult elements, as they disappear when such differentiation is complete. In 1867 Naegeli and Schwendener investigated and explained the general principles involved in interpreting them. Schwendener also wrote upon the fundamental 
mechanical principles involved in the construction of the plant-body in 1874, as we have noticed in another connection.

An indirect effect of the tensions in plants, resulting from the juxtaposition of turgid cells and pitted vessels, is the formation of thyloses, which result from the bulging of the former through the pits in the walls of the latter, followed by proliferation of the intruding tissue. These thyloses were described in 1868 by Reess. In I882 Strasburger showed that such internal pressures sometimes cause the obliteration of the cavities of the softer vessels which abut on the turgid parenchyma-notably in the case of the older sieve-tubes of Pinus.

Sachs showed in 1879 that the assumption of fixed positions, erect, or inclined at an angle to the vertical, is due to the manner of growth, though frequently such positions are much influenced by the conditions of the environment. He spoke of these two positions as orthotropic and plagiotropic respectively. In 1882 Vöchting showed that when plants are withdrawn from all external influences their axes of growth are nearly or quite straight, whether they are orthotropic or plagiotropic. He said they possess a tendency which he calls rectipetality. F. Darwin, writing in I89I, attributed this apparently straight growth to the continual correction of slight curving departures from the straight line.

Though these fixed positions suggest that growth takes place always in a straight line, this is seldom realized even if conditions are kept constant. The line or direction of the axis generally inclines first to one side and then to the opposite, or else is directed to all points of the compass in regular succession. It exhibits thus a new rhythm, which is known as mutation in the first case and circummutation in the second. Sachs, in I873, restricted the term nutation to the movements of the 
apex produced by growth. Frank had previously (I868) applied it to growth movements which result from external influences. Baranetzky (I883) associated circumnutation with the influence of gravity, saying that, in the absence of the latter force, stems show simple nutation. Darwin, in 1880 , claimed to have shown that circumnutation is universal in all growing organs. He investigated the rate at which the movement progresses and determined it to have a very wide range, a revolution being performed in from two hours thirty minutes to three hours ten minutes by Tamus, but only in from twenty-six hours thirty minutes to forty-eight hours by Adhatoda. Wiesner criticized adversely the wide distribution claimed for circumnutation by Darwin, and said that many stems and leaves grow in straight lines. He held that the movements of growing organs are due mainly to two causes: (I) irregularity of growth, depending on the want of absolute symmetry in structure and on the component cells of the organ not all possessing absolutely similar powers of growth; and (2) the fact that many factors involving opposing growth-tendencies are brought to bear upon the growing organs, so that the bendings are the expression of the resultant of many forces.

Darwin held that though circumnutation is so closely associated with growth, the two are not inseparable. He showed in I875 that though the tendrils of Eccremocarpus and some of the internodes ceased circumnutating in one and one-third hour when cooled to $24^{\circ} \mathrm{C}$. they continued to grow, though very slowly.

A phenomenon akin to simple nutation was examined by De Vries in 1874 . It had long been known that in organs which possess bilateral symmetry, whether anatomical or physiological, the growth of one surface is for considerable periods in excess of that of the other. It can readily be observed in the case of leaves, and occurs also in certain tendrils. De V ries introduced the terms epinasty 
and hyponasty to express these relations. Darwin pointed out in I880 that these phenomena really constitute a very low rhythm of nutation, and Vines in I886 described nany instances of this rhythm; Darwin pointed out that $\mathrm{n}$ the case of the hypocotyledonary axis it is of great ise in the processes of germination, helping the seedling to emerge from the seed coats and to make their way hrough the soil. Wortmann pointed out similar purposes $n$ the case of epicotyls in I882. Wiesner described a nodified form of epinastic growth exhibited by the epicotyl under the term undulating nutation in I883. Sachs, Wortmann, and Vöchting, showed that these modified nutations of the axis of the seedling are spontaneous and not dependent upon gravitation. In I886 Vines reaffirmed the rhythmic character of epi- and hyponastic growth.

The normal conditions of growth and their relation to external stimulation were discussed by Sachs in I863, and at some length by Pfeffer in I893. The influence of light upon them has been the most studied. We have seen that daily periodicity of growth in length was noticed by several observers. A similar rhythm has been detected $\mathrm{n}$ the case of growth in thickness. It was first observed oy Reinke in 1876 , and later by Friedrich in 1897 . Prantl n I873, and Stebler in 1878 , showed that the leaves of many plants show a daily periodicity of growth; Kraus, in 1880, observed the same thing in the case of certain fruits and of various fungi ; while McMillan, in I89I, and Golden, n I894, detected a similar periodicity in the growth of the tuber of the potato.

Pfeffer suggested that these periodicities may have been nduced by the alternation of day and night. A certain correspondence between the two phenomena appeared from the investigations of several botanists. In I866 Duchartre found that the growth in length of various shoots is greater during the night than during the day. 
In the next year Kraus found that the tissue strains in growing organs attain a maximum at sunrise and fall to a minimum at sunset; and in 1880 he observed that the greater growth of fruits and of fungi takes place in the night. Friedrich's observations showed that the maximum growth in thickness of stems takes place at night. Millardet, in 1869, showed a periodicity of the tensions in Mimosa connected with the alternation of day and night.

The induction of this periodic rhythm of growth upon the constitution of the organism is supported by some observations of Sachs in 1872 . He found that induced periodicity is to a certain extent independent of the maintenance of the conditions which set it up, for it persists for some time when the plant is kept in darkness. Baranetzky confirmed and strengthened Sachs' results in I879, when he observed that a plant of Helianthus tuberosus continued to show the rhythm during fourteen days of darkness. He also found that when shoots were grown from tubers of this plant in darkness, so that they did not receive the periodic stimulation, they exhibited no periodicity of growth. Godlewski made similar observations on certain seedlings in I889.

The influence of light on growth extends far beyond its share in inducing this periodicity. The phenomena attending on growth in its absence, known long ago as etiolation, were the subject of much research during the period under review, and our knowledge of the abnormalities which can be noticed in plants so cultivated, was very widely extended. Sachs, in $r 863$, called attention to the changes in relative sizes and position of the stems and leaves and showed that these changes are not so uniform as had been supposed. The hypocotyls of seedlings with hypogeal cotyledons do not elongate in darkness, nor do the stems of the hop, nor the lower internodes of those of Bryonia. Certain obscure changes in the constitution of 
the plant were observed by Janczewski in 1885 ; he found certain aerial roots of orchids tend to become radially organized in darkness, but to be flattened or bilateral in light. Vöchting showed, in I894, that in the phylloclades of Opuntia and Phyllocactus, a radial organization is induced by darkness.

Anatomical changes also occur; Kraus showed in 1870 that in darkness the thickness of cell walls becomes less pronounced, and in 1883 Stahl found that the palisade layer of leaves may remain undeveloped in the absence of light. He pointed out that not only is the development of this layer correlated with the intensity of light, but that in the absence of the latter no internal differentiation of the mesophyll occurs. Haberlandt confirmed Stahl's observation on the palisade layer of leaves in $\mathrm{I} 896$. In $\mathrm{I} 878$ Kraus, Koch, and Rauwenhoff severally showed that the epidermal and parenchymatous cells of elongated etiolated internodes are much longer than those of normal ones. Kraus attributed this to the thinness of the cell walls of such etiolated cells and to the consequent yielding to the longitudinal tensions. Rauwenhoff observed that the fibres of the elongated internodes do not become excessively long if the longitudinal tensions remain small during the whole period of growth.

The effect of darkness upon the growth and development of fungi was examined by several authors. Brefeld, in I889, found both processes were greatly impeded, the sporangia often being either totally suppressed, or only partially developed. Lendner found in 1897 that the sporophore of many Mucorini becomes elongated in darkness. The development of several Algae and Bryophyta has been found to suffer from the same cause. Some more extended investigations into their behaviour were made by Klebs in 1896.

The way in which the absence of light operates in causGREEN $\mathrm{F} \mathrm{f}$ 
ing etiolation was the subject of much speculation, but it cannot so far be said to have been explained. In his Vorlesungen Sachs suggested that the small size of etiolated leaves is due merely to deficiency of food. Kraus and Godlewski also attributed the phenomena to malnutrition and interference with food. Batalin, in I87x, held that the small size of etiolated leaves is due to a suppression of cell division, but Prantl two years later demonstrated the inaccuracy of this view by an actual computation of the number of cells in the leaf under the two conditions of light and darkness. Prantl suggested that the phenomenon is altogether pathological. De Vries, in 1879 , held that the action of light is the result of a direct influence on turgidity, but other writers of the time did not find turgidity increased with any regularity in darkness. In I878 and again in I886 Vines put forward the view that the phenomena are due to a disturbance of the irritability or the motility of the protoplasm of the growing cells, in fact to a pathological condition, as Prantl had suggested five years before. Pfeffer also held it to be not a mechanical but a vital phenomenon, a reaction of the protoplasm to the stimulus. An altogether different view, which has some plausibility, was advanced by Palladin in I893. He associated it with the almost complete cessation of transpiration which is noticeable in darkness, and pointed out that the regions of greatest extension are just those which the reduction of transpiration would cause to be over turgid.

The question, however, seems still to await a solution, for even the hypotheses of Prantl, Vines, and Pfeffer, do little more than restate the problem.

The rays of light which are concerned in restraining growth were ascertained by Sachs in I864 to be those of high refrangibility. He cultivated plants behind screens of ammonio-cupric sulphate and potassium bichromate solutions, and found that the latter cut off the rays con- 
cerned, with the result that the plants showed all the phenomena of etiolation. Sachs' results were confirmed by Kraus, Vines, Wiesner, and others; many researches on the subject being published in the years $1878-93$.

While it is clear that a certain intensity of illumination is necessary for the proper regulation of growth, many researches showed that the results of excessive insolation are as unfavourable as those of darkness. Wiesner showed that exposure to very intense light arrests growth altogether. Pringsheim observed in 1879 that concentrated light kills ordinary green plants if they are exposed to it for a considerable period. Pfeffer, in 1875 , and Darwin, in 1880 , also observed that exposure to very brilliant illumination is attended by fatal results in the case of many leaves, which however protect themselves from excessive insolation by turning their edges instead of their surfaces to the ncident rays. Darwin gave the name paraheliotropism to this phenomenon in I880. It was explained by Pfeffer as lue to the unilateral illumination producing a greater fall of turgor in the more strongly illuminated half of the pulvinus than in the less strongly illuminated half.

The effects of light upon plants are manifested very widely; those which are observable upon growth and growing organs are only part of very far-reaching phenomena, which were the subjects of much study and research. Those effects which have so far been noticed may be taken to be but instances of what are now known as the tonic effects of light.

Certain very curious protective mechanisms were discovered, having for their object the avoidance of injury by the chloroplastids of the leaves, but their discovery dates back to a period just earlier than that under review; Boehm noticed in 1856 that the plastids of the leaves of certain of the Crassulaceae change their position when the light becomes intense. Famintzin and Borodin studied the F f 2 
question in 1865 and $r 867$, and observed the details with greater completeness. Frank took the subject up in $I 872$ and determined that the changes of position are directly referable to the variations in intensity of insolation. His observations showed that in very brilliant sunlight the plastids retreat to the most shaded corners of the cells, while in a moderate light they post themselves in positions favourable to catching the incident rays. Frank termed the two positions apostrophe and epistrophe respectively, and showed that they are taken up in virtue of movements of the protoplasm in which the plastids lie. He noted that the collection of them in any particular position is accompanied by a certain massing of the protoplasm in such spots. In 1876 Micheli stated that the chloroplasts of palisade parenchyma bulge inwards away from the cell wall in moderate light, but flatten themselves against the wall if the light is strong. The subject was studied with more minuteness by Stahl in I880. His results confirmed and extended those of Frank, but he differed from the latter in thinking the changes are made in obedience to the direction rather than the intensity of the light. He found that the cells of the leaves of Oxalis and those of Ricimus exhibit the changes in a very marked manner, but he said that it is not at all a general phenomenon in leaves, that in most plants the palisade cells do not show it. He noticed that the elongated band-like chloroplast of the cell of $\mathrm{Meso}^{-}$ carpus is affected by light in a similar way, twisting on its axis so as to present its edge to very brilliant and its side to moderate illumination.

Haberlandt published researches on the same subject in I886, in which he confirmed and extended Stahl's results.

Light was shown to affect the more lowly plants also. Baranetzky showed in 1876 that the plasmodia of the Myxomycetes move away from it. Deleterious effects of strong insolation were observed by very many botanists. 
In 1892 Marshall Ward found that such exposure is fatal to many species of bacteria, a discovery since confirmed by Flügge in I896, and by Arloing, who ascertained that the vegetative cells have a greater power of resistance than the spores. The present writer found, in I897, that the more refrangible rays of the spectrum, together with the ultra violet, cause the decomposition of diastase. Klemm showed that the more refrangible rays stop the streaming of protoplasm and tend to bleach the chloroplasts, besides destroying various pigments in the cells. On the other hand some plants are quite unaffected by brilliant light; such is the case according to Tammes, (Igoo), with mosses and lichens growing on rocks.

The periodic movements of certain plants, known as nyctitropic movements, which are associated with the alternation of day and night, were studied by many observers after I86o. The assumption of the nocturnal position by the leaves of Mimosa was shown as long ago as I 848 by Brücke, and even earlier by Dutrochet, to be of different origin from the movements carried out by them in response to mechanical stimulation. In I 869 Millardet ascertained that the movement leading to the nocturnal position and recovery therefrom is not a simple rise and fall, but is the expression of a periodicity or rhythm. After its first fall, when it reaches the nocturnal position, the leaf slowly rises to an acute angle with the stem, and then as light dawns it sinks slowly to the day position. He correlated this periodicity with a daily rhythm of tension in the plant, and inferred that the primary petiole is not nyctitropic, the fall being due to the nyctitropic change in position of the secondary petioles and leaflets. Pfeffer investigated the two kinds of movement in 1875 , and showed that the periodic change can be distinguished from the response to stimulation, the mechanism being different in the two cases. 
Batalin, in the year 1873 , associated the rise and fall of certain foliage leaves with the changes of growth, and suggested that pulvini act in the same way. In I875 Pfeffer showed the true nature of the action of pulvini, and gave a full account of their structure. In 1876 he proved that the nocturnal rhythm is induced by the periodicity of stimulation of day and night, and showed that temperature as well as light is concerned in the phenomena. Pfeffer denied that the daily rhythm is hereditary.

Darwin, in I880, added many instances of plants showing this rhythm to those previously examined.

An effect of a similar nature was studied by Cohn in I859, Batalin in I87I, and Pfeffer in I873. They found that if a plant of Oxalis acetosella is brought suddenly from a dull light to brilliant illumination, the leaves fall as they do in darkness.

The influence of temperature on growth and movement was studied by many of the older writers, to whom we owe the discovery of the fact that growth is only possible between certain limits, which range, however, between the freezing-point and about $50^{\circ} \mathrm{C}$. Somewhere between these points an optimum temperature is found, which varies considerably for different plants. The subject of this relationship was investigated very fully by Sachs in I860, and later, in 1870 , it received considerable attention from Köppen and from De Vries. More recently investigations have been made by numerous observers, who from reasons of space cannot be quoted here. A full resume of the literature is given by Pfeffer in his Pfanzenphysiologie, Eng. ed. (1903), vol. ii, p. 83.

Köppen found that frequent and considerable variations of temperature cause retardation of growth ; it was shown however, by Pedersen, in 1874 , that to bring this about the upper limit of these variations must be considerably higher than the optimum temperature for the plant under 
observation. Pfeffer found in $I 873$ that the growth of leaves is not thus affected by varying temperature.

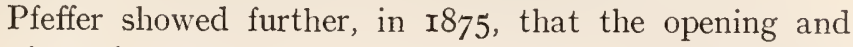
closing of flowers at the onset of day and night is due rather to temperature changes, than to the influence of the varying light. He found that the perianth leaves of the crocus opened when the temperature reached $9^{\circ} \mathrm{C}$, and continued to expand up to $27^{\circ} \mathrm{C}$. ; at $28^{\circ} \mathrm{C}$. closing began, but was incomplete till $36 \cdot 7^{\circ} \mathrm{C}$. was reached; when it was complete. Fall of temperature always caused an open flower to close. Pfeffer held these phenomena to be the accompaniments of growth on alternate sides of a zone of tissue at the base of the perianth leaves. Vines spoke of them as instances of induced epinasty and hyponasty.

This view was combated many years later, just at the close of the century, by Bürgerstein, who attributed the alteration of the position of the perianth leaves to turgor variations, not necessarily accompanying growth. Farmer confirmed him, having found that in the tulip there exists a layer of active cells on the outer face of the young perianth leaf, running longitudinally down its centre, which shows a variation of turgor as the temperature changes. When this layer is isolated and put into water it curves, the curvature being greatest at the base but still extending up to and including the apex, the cells changing their shape more rapidly than those of the internal layers.

The influence of temperature on the movement of the lateral leaflets of Hedysarum was examined by Kabsch in I862. He found that the optimum temperature for them is $35^{\circ} \mathrm{C}$. and that they cease at $22^{\circ} \mathrm{C}$. Sachs, the next year, showed that the leaflets of Mimosa gradually lose their motility if kept at $15^{\circ} \mathrm{C}$. or if merely exposed to $40^{\circ} \mathrm{C}$, the loss taking place more quickly as the temperature of exposure is higher.

The movements of rotation or circulation were shown 
by Velten, in 1876 , to show similar minimum, optimum, and maximum points, the optimum and maximum being very near together, but differing slightly in the case of different plants.

Strasburger, two years later, showed that the zoospores of Haematococcus are motile at temperatures as low as $0^{\circ} \mathrm{C}$. ; their optimum point is from $30^{\circ}-40^{\circ} \mathrm{C}$. and at $50^{\circ}$ they are arrested. In the case of marine algae the maximum point is about $\mathrm{IO}^{\circ} \mathrm{C}$. lower. Kjellman, in $\mathbf{I} 875$, determined the lower limit for the latter forms to be $-\mathrm{I} \cdot 8^{\circ} \mathrm{C}$.

The nyctitropic movements of Oxalis were found by Pfeffer to be only slightly influenced by a fall of as much as $10^{\circ} \mathrm{C}$., and the resulting disturbance largely depended on the point of their daily period at which the stimulation was applied. Millardet, in I869, observed a closer relationship between temperature and movement in the case of Mimosa petioles, which he found to rise with an increase and to sink with a fall of temperature.

The influence of the external conditions was proved to have a powerful effect in some cases in determining certain features of the constitution of particular plants. Zimmermann showed in I882 that the dorsiventrality of the thallus of Marchantia is due to light. Less conspicuous changes were shown by Frank in I870, when he ascertained that shoots of various coniferous trees, normally radially organized, become dorsiventral under the same influence. Two years later De Vries observed that in whatever position a lateral branch of one of these was allowed to develop from the bud, the upper surface became the dorsal and the lower one the ventral. Gravitation seemed to play a part in the matter, as the same change happened in darkness.

We have seen that Pfeffer showed that epinasty and hyponasty can be induced by variation of temperature, as in the opening and closing of flowers. Detmer, in I882, 
claimed to have found that light can play the same part. When he exposed young etiolated seedlings of Phaseolus and Cucurbita to light after a period of darkness, the leaves showed epinastic growth. He applied the term photo-epinasty to the phenomenon. Vines investigated the same subject in I889, and repeated Detmer's experiments, but he failed to confirm his conclusions. Vines denied the existence of photo-epinasty.

Another discovery of great interest was made by Sachs in I863, when he found that plants cannot manifest the power of responding to stimulation unless they have been in a favourable position for some time with regard to both light and temperature. He introduced the terms phototonus and thermotonus to express this condition of a plant with reference to these two features of its environment. 


\section{CHAPTER XI}

\section{THE DEVELOPMENT OF THE THEORY OF SPECIAL SENSITIVENESS UNDER THE INFLUENCE OF THE ORIGIN OF SPECIES}

THE conception of the existence of a close inter-relationship between the plant and its environment, and of varied efforts of the plant to adapt itself to changes in the latter, followed very quickly upon the appearance of the Origin of Species, and was gradually brought more and more into prominence during the period under review. Close observation of many phenomena, which escaped examination till the sixties and later, brought out in numberless cases such evidence of purposeful adaptation that the idea became the dominant one in this section of the field of research. It is true that the purpose of a movement or of some less evident change did not always prove easy of interpretation, but failure in certain instances does not diminish the importance of the point of view.

The recognition of a purposeful change in response to a stimulation led gradually to the coincident recognition of physiological mechanisms, which only slowly became familiar, but which when once appreciated threw great light on certain peculiarities of structure not properly interpreted previously.

In I860 these ideas were somewhat dimly appreciated. It is true that Dutrochet had made important researches into the influence of light and gravity upon various organs, and that Von Mohl had published his classical essay on tendrils and climbing plants ; true, also, that the property described by de Candolle and by Meyen under the names 
of irritability, excitability, and sensation, had been recognized as an existing factor in the plant's life. Still, its exact importance was not properly realized, for the attention that had been given to the subject was directed rather to the movements or changes of position that were observed to take place as conditions changed. These were put in the place of chief importance; indeed most of the explanations of movement that were advanced were based upon a direct and mechanical change or series of changes, set up by the conditions in the cells or areas that carry out the movements. The idea of a response to the environmental change, carried out by an organ as a whole, to secure some advantage thereby, did not find adequate recognition by the botanists of the time.

The whole question of phytodynamics, important as it is, had fallen a good deal into the background since the time of Dutrochet. From about I860 onwards, under the stimulus afforded by a new point of view, it came to occupy a leading place in botanical research at the hands of a new school of workers.

In this departure considerable importance attaches to the appearance of the Origin of Species. True, the latter dealt with many other problems than these, and directed attention to many questions of morphology as well as physiology. The study of structural adaptations, mechanisms of pollination, distribution of seeds, and kindred problems, received from it a great impetus. These, however, ultimately meet explanation only or mainly on the lines of the influence brought to bear upon structure by environment, considered in the widest sense. The idea of action and reaction between the organism and its environment, embodied in the struggle for existence, invested the study of phytodynamics with an importance that had not been realized by the writers of the earlier period, and under the influence of the new view, researches became more numerous and 
more and more light continually manifested itself. The point of view changed rapidly; movement ceased to be the prominent idea and gave place as such to perception of change ; stimulation as a factor came to be recognized; the old idea of sensation as an endowment of vegetable substance, held by the older writers in a mistaken form and subsequently denied even by men like Sachs, gradually grew into favour and became established on a firmer basis. Instead of being regarded as the direct and mechanical result of purely physical influences, movement became realized as a vital phenomenon, a result of a response of the plant to some modification of its surroundings. The idea, in fact, of purpose in movement became established.

The researches which thus led to this result in a term of less than forty years were carried out by many workers in many lands. The earliest, and in some respects the chief place among them must be given to Albert Bernhard Frank, who published two remarkable contributions to the literature of vegetable physiology in the years I 868 and I87o. In the first of these Beiträge zur Pflanzenphysiologie, he demonstrated that the geotropic curvature is an active and not a passive one; that both it and the converse apogeotropic one depend on unequal distribution of longitudinal growth; and that they are not connected at all with passive variations of tensions of tissues in the growing organs. In the second memoir, Die natiirliche wagerechte Richtung der Pflanzentheilen, he showed that horizontal growth proceeds on the same lines as vertical growth, and that it also is influenced by gravity. He proved geotropism to be a similar phenomenon to heliotropism, and set out for the first time definitely the theory that growing organs react to the influences of gravity and of unilateral light by variations in the details of their growth. He showed further that different members or organs respond differently to a uniform force, and that 
the behaviour in any case must be explained by the individual organization or constitution. He thus first indicated the direction that modern thought has taken with regard to the irritability of plants and the part it plays in the active life of the organism. By thus opposing the mechanical theory held by most botanists of the early sixties, under the leadership of Hofmeister, he did much to bring back opinion to the original position of Dutrochet and Treviranus and to prepare the minds of vegetable physiologists to accept the view of the purposeful character of sensitivity.

The researches and writings of Charles Darwin form a very prominent feature of the literature of this time. Apart from the great philosophic work on the Origin of Species, the influence of which on biological science has already been discussed, we find from 1875 to 1880 a continuous output of work on botanical subjects; to which may in the main be attributed the new views the development of which we are trying to trace. In all alike we find sound reasoning, based upon careful and well-controlled experiment, and combined with absolutely impartial criticism of evidence whether derived from his own experiments or from those of other workers. In the last of these magnificent contributions to science, The Power of Movement in Plants (I880), he had the assistance and co-operation of his son, Francis Darwin, to whose subsequent researches the physiology of sensitivity owes so much. In this book we find definitely stated the idea partially led up to by Frank, and suggested for heliotropism and geotropism by Sachs in 1874 and 1875 , that growth curvatures are phenomena of irritability or sensitiveness. Darwin, however, went further than this. In the course of his work he determined that the sensitive mechanism consists of two parts, the one perceptive or sensory, the area of stimulation-the other responsive or motor, the area of movement or secre- 
tion. This was one of the most remarkable discoveries of the period.

Among the writers of the time, one especially must be mentioned who exercised considerable influence on the progress of scientific thought. This was Pfeffer, whose many contributions were of the first importance to the elucidation of the problems arising from the new presentation. Pfeffer carried the subject of stimulation much further than previous writers, discussing the relations between the stimulus and the response, and emphasizing the purposeful character of the latter. He stated clearly the view that light and gravitation act by releasing forces in the interior of the plant, the particular manifestation following being determined by the organization of the part concerned. He laid great stress, in support of his position, on the disproportion between the energy imparted in the stimulation and that released in the movement following.

The purposeful character of the responses to stimulation necessarily drew attention to the protoplasm as dominating them. A recognition of the part it plays in them only slowly made its way into current thought. The appreciation of protoplasm in this matter appeared very clearly in the Vorlesungen of Sachs in I882. In these lectures, after emphasizing the idea of purpose in response, he pointed out that it follows that protoplasm must be the source at once of perception and action, the phenomena being associated with active life. His views on the manifestation of protoplasmic excitation were, however, not so clear. He confused the phenomena presented by the protoplasm with those which are the special characteristics of the mechanisms by which it carries out its purpose.

The special phenomena attending on excitation were first demonstrated by Burdon-Sanderson in his researches on the closing of the leaf of Dionaea, when stimulated. By 
careful electrical measurement he proved that electrical changes of a similar nature to those attending the stimulation of muscle or nerve follow the stimulus administered to the receptive organs of the leaf, preceding by a measurable interval of time the turgor changes leading to its closure.

In a final paper, published in I888, he criticized Sachs' attitude and showed its weakness in that the latter did not distinguish the molecular changes in the stimulated protoplasm from the slow mechanism of growth, turgorchange, or exudation of water, by which the excited protoplasm brought about the purposeful response. The difference is greater than at first it seems to be, for Sachs' position involved if not the denial, at any rate the nonrecognition of the existence of anything of the nature of a nervous mechanism in the plant, a view to which BurdonSanderson had been led and on which he laid considerable stress. Sachs said, indeed, "we have no necessity to refer to the physiology of nerves in order to obtain greater clearness as to the phenomena of irritability in plants.' To Sachs the electrical phenomena observed by BurdonSanderson were the consequences of the disturbances of the equilibrium of the water in the tissues, rather than the accompaniments of the disturbance of the equilibrium of the protoplasm.

Burdon-Sanderson's researches were the last of the period to carry towards elucidation the theory of the sensitiveness of vegetable organisms. They helped perhaps more than any others to establish the identity of the protoplasm of animals and plants, and aided greatly to stimulate those inquiries into nutrition, which have been already alluded to.

Towards the latter part of the century valuable contributions to the general subject came from the pens of Stahl, Strasburger, Vöchting, Rothert, Noll, and Czapek, besides further memoirs from those already mentioned; on 
account of the number of both authors and papers it is impossible to discuss them here, but references will be made to the more important ones later.

\section{HELIOTROPISM}

The behaviour of different parts of plants with radial symmetry, when exposed to differences of illumination on two opposite sides, was observed in comparatively early times, and attempts to explain it were put forward by Dutrochet. The fact that roots and stems curve in opposite directions, the former away from, the latter towards, the direction of greatest intensity, was also known. The terms positive and negative heliotropism were first applied to these curvatures by Hofmeister in 1863 ; they were called heliotropism and apheliotropism by Darwin in I880.

In I870 Frank described a third movement effected under similar conditions, the assumption by organs of dorsiventral symmetry of a position across the incident rays, and gave it the name of transverse heliotropism, a term later replaced by diaheliotropism by Darwin in I880. Frank's view was not accepted at once, De Vries, Sachs, and other writers suggesting that the position is not taken up in consequence of the incidence of the light, but is the result of the working of other forces, such as the weight of the organ acting in opposition to positive heliotropism.

The subject of transverse heliotropism was the subject of considerable investigation between $\mathrm{I} 870$ and $\mathrm{I} 880$. Frank showed in 1870 that it is exhibited not only by leaves which have an anatomically dorsiventral symmetry, but also by certain stems, which, though anatomically radial, are physiologically bilaterally symmetrical. Shoots of Lysimachia nummularia, Polygonum aviculare, and several other plants which grow erect in darkness, run along the ground when light is admitted to them. In I873 he showed that branches of the thallus of Marchantia become narrow 
and channelled on their upper edges under the same conditions. Vöchting observed the same peculiarity of growth under the two conditions by the peduncles of species of Erodium and Taraxacum; while Viesner, in I880, saw the runners of Fragaria and Nepeta exhibit the same behaviour. Rauwenhoff, in $\mathrm{I} 878$, showed that in many plants the lateral branches which grow obliquely in the light point vertically upwards in darkness. Frank's results were confirmed and their accuracy established by the observations of F. Darwin in 1880 , and by those of Pfeffer in I88I. F. Darwin studied the positions of leaves while rotating on a klinostat and found they are diaheliotropic. Vöchting, in I888, and Krabbe, in I889, adduced further evidence in support of Frank's views.

The so-called mid-day sleep of plants, investigated in I875 by Pfeffer, and studied by Wiesner almost at the same time, was also examined by Darwin in I880. He gave it the name of paraheliotropism.

The interpretation of the movements of heliotropic curvature was essayed by the older observers, with little appreciation of their real meaning in the life of the plant. True, Dutrochet in 1824 held that the action of light is not a directly mechanical one, but really an inducing cause of the curvature, but his ideas were obscured by the theories of others. The retarding influence of light on growth, advanced as an explanation by de Candolle, involving a partial etiolation of the shaded side, was accepted for some time, despite its inadequacy to explain the curvature of negative heliotropism. After Frank's researches a better view replaced it, and investigations, carried out in Sachs' laboratory after I874, completely demonstrated the insufficiency of the old ideas. The first experiments,those of Müller-Thurgau,-showed that negatively heliotropic roots grow more rapidly in darkness than in light. Even more conclusive researches on the subject were GREEN 
carried out by Francis Darwin in I880. Early in the course of these investigations Sachs emphasized the theory that heliotropic and geotropic curvatures are evidence of the possession of irritability, and of purposeful response to stimulation on the part of the curving organs.

Frank's hypothesis thus attained general acceptance and was the subject of much critical examination during the remaining years of the century. It received strong support from the researches of Pfeffer in I877, to which reference has already been made; it was aided by those of Wiesner in 1878 , and was emphasized by F. Darwin in I880. Further evidence was forthcoming when N. J. C. Müller noted in I872 that certain seedlings of cress are positively heliotropic in weak light, and negatively heliotropic when a particular intensity is exceeded. Stahl showed in I880, and Berthold in I882, that certain Algae behave in the same manner. Oltmanns, in 1892 and 1897 , observed a similar reversal of response to light in the case of Phycomyces, which is positive in dim but negative in bright light. Oltmanns' experiments showed that with light of a particular intermediate intensity no response to the stimulus is manifested. It is clear that in this case we must be dealing with interaction between the protoplasm and the light, and not with any mechanical interference with growth. Other researches dealing with various aspects of the problem were published by Vöchting in I888, and by Krabbe in I889.

By this long series of researches the phenomena were shown to be purposeful and not merely mechanical, and it became possible to study them from the point of view of the adaptation of organisms to their surroundings. The conception that the heliotropic curvatures indicate perception and response was followed by the discovery that the region of the plant by which the stimulus is received is not identical with that by which the curvature is effected. 
This was first shown by Charles Darwin in 1880 in the case of young seedlings.

Hofmeister found, in I863, that the region of curvature is the most actively growing zone of the axis. MüllerThurgau, in 1876 , and Wiesner, in 1878 , came to similar conclusions, though they did not altogether agree as to the position of the maximum points.

In Darwin's work he brought to notice for the first time the extraordinary degree of sensitiveness which particular organs possess; certain seedlings bending their stems towards a light which was not sufficiently intense to cause them to cast a shadow on a piece of white paper held behind them. He showed, too, how greatly the degree of sensitiveness varies in different cases.

The way in which light sets up stimulation has been the subject of some controversy. Sachs, in 1873 , and MüllerThurgau, in 1876 , concluded that the prime factor is the direction of the rays, or the angle of their incidence upon the plant, while Darwin attributed it to the difference of intensity of the illumination received by the opposite sides of the organ. Wiesner regarded both factors as co-operating. Oltmanns' researches in 1897 showed that intensity is very important.

The particular rays concerned in stimulation excited much attention, but no accurate views were obtained till Wiesner took up the question. In his important memoir of 1878 , Die heliotropischen Erscheinungen, he showed that all the rays of the visible spectrum except the yellow cause heliotropic curvature, but that those which produce the greatest effect include the violet and the ultra-violet. He constructed a curve showing the relative influence of the different rays, and ascertained that while the maximum lies there a second crest of the curve can be detected in the infra-red region. The rays of this part of the spectrum are effective after passing through a solution of iodine in 
carbon disulphide, which is absolutely opaque to the rays of the visible spectrum.

Wiesner examined also the dependence of the effect upon the intensity of the illumination, and determined the upper, lower, and optimum degrees of the latter. He said that its lower limit coincides with the lower limit of light-intensity which causes the stoppage of growth in length, while its upper limit is only occasionally the same as that which affects the latter process. He found, too, that the relative efficiency of the several rays is not the same for all plants.

In 1876 Kraus showed that the yellow and blue rays have almost equal effects on the stalks of the perithecial heads of Claviceps. Brefeld confirmed this observation in I88I. Sachs stated in $\mathrm{I} 88 \mathrm{2}$ that he found the exciting rays extend from the ultra-violet to the blue.

The position assumed by the various organs of the plant was examined by Frank in 1870 and by Sachs in 1873 . They agreed that the final result of the stimulation is that plants take up a definite position which has been called a fixed light position. Wiesner showed that this position is determined in the case of most leaves by the direction of the incidence of the brightest diffuse daylight and not by that of direct sunlight. In I880 Darwin ascribed the attainment of that position to a modification of the movement of circumnutation. Indeed, the view that this movement is universal in all growing organs and serves as a basis for the movements of curvature under the various conditions of stimulation which such organs encounter is the main thesis of the Power of Movement in Plants, published in that year. This hypothesis met with considerable opposition from Wiesner.

The influence of direct sunlight in causing certain plants to take up a fixed light-position was shown by Stahl in I88I in the case of the so-called Compass plants.

Certain investigations into some of the less conspicuous 
features of heliotropic curvature, which have a bearing on the general phenomena of irritability, will be noticed later.

The influence of light upon organisms which are free to move is very similar to the heliotropic influences affecting fixed plants. This phenomenon, to which the name phototaxis was given by Strasburger in I878, was observed by Braun in $185 \mathrm{I}$, but little attention was given to it till some years later. Cohn found in I867 that the rays concerned are those of high refrangibility; an observation confirmed by Strasburger in I878. The general effect of light on the movements of locomotion was noticed by Hofmeister in I867, in the course of his study of the behaviour of the Myxomycetes; and Famintzin showed in I867 and I868, that a similar effect is produced by light on certain Oscillatoriae. Baranetzky confirmed Hofmeister's observations in 1883 . In the same year Engelmann found that this susceptibility is shared by certain Bacteria, $B$. photometricum especially being quiescent in darkness, but commencing to move after a short latent period when illuminated.

The nature of the phototactic movement was studied by Strasburger in 1878 ; in the paper alluded to he says that certain zoospores place their axes parallel to the direction of the incident rays, a statement confirmed by Stahl in I88o. Strasburger further pointed out that the influence is not confined to the visible spectrum, but that it is excited also by the rays of the infra-red, thus showing a correspondence between the phototactic stimulation of freely moving organisms and the stimulation leading to heliotropic curvatures as established by Wiesner.

\section{GEOTROPISII}

The introduction of this term is due to Frank, who applied it to the phenomena of curvature under the influence of the attraction of the earth, which had long been observed 
and to some extent studied by earlier writers. The tendency of roots to grow downwards, and of stems to grow upwards were named by him positive and negative geotropism respectively. He added to our knowledge of the directive influence of gravitation by describing the behaviour of certain radial organs, such as rhizomes, which grow parallel to the surface of the soil, and to this tendency he applied the term transverse geotropism, which was replaced by the name diageotropism by C. Darwin in I880. Darwin's terminology, geotropism and apogeotropism, for positive and negative geotropism are now in common use. The writers who examined and discussed the phenomena of heliotropism also concerned themselves with these curvatures and demonstrated the co-existence of the two kinds in most plants, pointing out as well their similarity. Allusion may be made especially to the researches of Wiesner and Darwin in this direction. The latter writer added greatly to our knowledge of this form of irritability. Elfving and Stahl may also be mentioned in this connexion.

Frank attributed to the possession of transverse geotropism the plagiotropic position assumed by dorsiventral organs such as leaves, but his views met with considerable opposition from De Vries, who claimed that the assumption of their position should preferably be regarded as due to a co-operation of many causes, negative geotropism acting concurrently with light, the latter not only causing heliotropic curvature but epinastic growth.

The explanations that were advanced to explain the curvatures underwent a change about I868 and 1870 , when Frank revived the theory of response to stimulation which had been advanced by Dutrochet in I824 and recognized by Treviranus in 1838 , but which had fallen into the background. The views which had supplanted it were based upon purely mechanical considerations. Knight had held still earlier, in I806, that the curvatures are due to 
the distribution of materials of differing specific gravity in the plant; that the downward growth of roots is purely plastic, while the upward curving of a stem placed horizontally is due to the nutrient sap sinking to the under side and so causing more rapid growth of that region. Hofmeister, who wrote in I859 and I863, restated the old hypothesis of Knight, with little modification, though he advanced no actual evidence. He explained the greater growth of the upper side of a horizontally placed curving root by an accumulation there of the less dense nutritive material which favoured the growth of that side, while he attributed the curving of a stem similarly placed, to the pull of the stretched turgid pith on the tissues of the lower side made yielding by excess of water settled there. In I872 Ciesielski, and in I875 Traube, suggested that the explanation must be looked for in the tensions due to mass attraction and in the thickening of the walls due to more favourable nutrition.

These mechanical conceptions failed to give any even plausible explanation of the curvatures. Frank's remarkable memoirs formed a starting-point for the views now held, and directed research into a new direction. In I873 some experiments of Sachs afforded confirmation of Frank's suggestions. He showed that if stems are laid horizontally on soil till curvature has begun-usually from thirty minutes to two hours-and then are placed vertically, they continue to curve in the original direction for two or three hours. By repeated experiments on these lines he showed that the problem is one of response to a stimulus administered to the plant, and that removal of that stimulus does not at once cause the action of the plant to cease.

Sachs, in 1879 , helped very materially the practical study of the attraction of gravitation as the stimulus by the introduction of the Klinostat, an instrument which has been of such great value in the investigation of so many 
phenomena of stimulation. By means of it has been made possible the equal distribution of either the geotropic or heliotropic stimulus over a cylindrical receptive organ - a result which has the same effect as the elimination of the reception of stimulation.

Sachs' results were confirmed and greatly extended by Charles Darwin in I88o. In the same year Elfving added considerably to the instances of diageotropism then known. On the basis of these researches Darwin suggested in I880 that plants possess a sense of direction or a faculty of what has since become known as gravi-perception, a suggestion endorsed by Pfeffer the next year; it was supported by Vöchting's observations in I882, that the geotropic movements of the peduncle of the poppy vary during its life, and show a definite purposefulness in its adaptation to the different needs which accompany it at different times in its life.

The recognition that we are concerned with stimulation and response has led in this case, as in that of heliotropism, to a differentiation of the sensory from the motor mechanism. Ciesielski showed, in 1872 , that the geotropic curvature of a root can take place only so long as it has an uninjured growing-point. Darwin, following the same line of research, determined in I880 that the tip is especially the sensitive region of the root, or what we may call the region of perception as distinguished from the part which moves, which we may term the motor area. He originally relied on amputation of the tip, taking off a piece about $2 \mathrm{~mm}$. long. Roots so treated remained uncurved when placed horizontally. When he allowed uninjured roots to remain in that position for some time, and then removed the tip, he found they curved, whatever position they were placed in. He claimed therefore that geotropic induction is localized in the root-tip.

Darwin's views were immediately vehemently opposed 
by Sachs, who objected to both his experiments and conclusions, insisting that the removal of the root apex is too drastic treatment and causes various irregular curvatures. $\mathrm{He}$ insisted, therefore, that conclusions drawn from such experiments must be valueless. Detlefsen, in I882, supported Sachs in his objections and joined him in denying that roots with amputated tips have lost their power of curvature when placed horizontally. Wiesner, in I884, supported Sachs up to a certain point, but admitted that amputation diminishes subsequent geotropic curvature, as did Molisch in I883.

The controversy on this point became very acute, but events have proved that Darwin was right in his conclusions. Experimental evidence of some weight was furnished in 1894 by Czapek, by his classical experiment of causing young roots to grow into small glass slippershaped tubes, bent at a right angle at about $2 \mathrm{~mm}$. from the pointed apex. He brought about in this way a natural bend in the root, the tip only being diverted through an angle of $90^{\circ}$ from the rest of the axis. In Czapek's experiments the root so treated underwent no geotropic curvature so long as the tip was directed downwards, though, of course, the rest of the axis was horizontal.

F. Darwin's demonstration by a similar method that the cotyledon of Setaria and Sorghum is the region sensitive to gravitation was made in $\mathbf{I} 899$.

The method of response was shown to be different for growing and for adult organs. In the case of the former Hofmeister showed, in I863, that no curvature can be observed except in the actively growing zones, and that the curve is due to difference of growth upon the opposite sides. Sachs claimed, in 1865 , that increased growth of the convex side brings about the curvature in all cases. Darwin gave a similar localization. A more exact delimitation of the area of most active curvature was given 
by Czapek in 1898 ; he found that the geotropic bending begins just behind the percipient apex. A similar localization for response to contact stimulation was determined by McDougal in 1897 .

In adult organs whose growth has ceased other mechanisms were found. Sachs showed in 1865 that the adult pulvini or motile organs of periodically motile compound leaves can execute geotropic curvatures under appropriate conditions, the mechanism being modifications of turgor and not of growth. Sachs found also that when haulms of grasses in which growth has ceased, are placed horizontally, growth recommences under the stimulus of gravitation, being measurable along the under sides of the swollen nodes.

The researches so far discussed left untouched a point of considerable importance, viz. the nature of the stimulus. We have no conception of the manner in which gravitation produces its effect, nor what its attraction really is, but it seems probable that in some way the effect of weight upon the living substance of the sensitive cells may bring about the stimulation. From I886 onwards, researches were directed to this question. In that year Berthold suggested that the primary effect of gravity, as regards stimulation, may depend on the passive sinking of the heavier parts. Noll, in I892, argued in a similar way that Knight's experiment on the action of centrifugal force involves the presence somewhere within the sensitive structure of bodies possessing weight, or at any rate that the protoplasm must be able to distinguish between varying pressures on different sides of the cell. In Igoo Noll suggested more definitely that a perceptive apparatus of some such nature must exist in the ectoplasm. He thought it might consist of vesicles of sensitive plasma filled with cell sap and containing a small heavy particle in the fluid. In the same year Nermec and Haberlandt, at about the same time, called attention to the 
existence of movable starch grains in the cells of the perceptive zone of the root-tip, and attributed the stimulation to the alteration in their position relatively to the cell walls as the root is displaced from the vertical direction. This theory, known as the statolith theory, has since the century closed made its way into greater favour, if not general acceptance.

Czapek showed in $\mathrm{I} 898$, that during and following the sensory excitation, the processes of stimulation are accompanied by complex chemical changes which precede the visible change in growth. These may be consequences of the internal disturbance produced by the falling statoliths. Czapek showed also that the perception of the stimulus and the manifestations of the reaction are differently affected by external conditions.

\section{Contact Perception}

The possession of this form of sensitiveness had, prior to $\mathrm{r} 860$, been observed and investigated principally in connexion with the climbing of various plants by means of tendrils, which were considered to be sharply separated from twining stems by the manifestation of contact perception. Von Mohl, somewhat in advance of his contemporaries, claimed that the latter possess a certain irritability of this kind, but the earlier writers of our period, especially Darwin and De Vries, failed to find evidence of it. The trend of thought during the later years of the century was in favour of the view that the behaviour of stem twiners is rather a response to geotropic stimulation, combined with circumnutatory movement. It was ascribed, in I873, by De Vries to arrest of the latter movement as the twiner comes into contact with its support, a view which had previously been suggested by Darwin in I865. In I88 I Schwendener suggested that the process is due to circumnutation combined with antidromous torsion, while 
Baranetzky a year later held that asymmetric circumnutation will explain it.

The ordinary regular movement of circumnutation, depending on rhythmic and coordinated variation of turgor, failed to satisfy the minds of investigators as an explanation of many of the observed phenomena of tendril twining, but there was no general agreement as to what modifications of the circumnutatory processes are brought about. Sachs held that the curvature is due to a disturbance of the growth of the tendril in consequence of the stimulation, both concave and convex sides growing, but at different rates. De Vries, writing in 1873 , suggested that the stimulus of contact produces an increase of turgor in the cells of the side which becomes convex, causing a stretching of that side, which is followed and fixed by growth. The old view of Knight, that there is an actual contraction of the concave side, was reasserted by Darwin in 1865 ; he held that the rapidity with which the curvature sets in in certain cases forbids the idea of growth as its cause. Careful measurements which he made gave in many instances no evidence that the convex side had grown. Earlier measurements made by both De Vries and Sachs were somewhat conflicting, and led those authors to the views already attributed to them. In 1896 McDougal found that contraction is certainly shown by the tendrils of Passiflora gracilis, but that its occurrence is not universal. He suggested that the movement is due to a diminution of turgidity on the concave side and to the curve being rendered permanent by subsequent growth, a view which has much in common with that of De Vries. The latest researches of the century on the subject, which were not published till I903, were those of Fitting, which were carried out by means of microscopic measurements of the distances of lines marked along the sides which became respectively convex and concave in response to the contact stimulus. 
Fitting observed that the changes in these distances set in with very great rapidity, the elongation of the convex side more than doubling its length in an hour, a rate of increase which was more than twenty times that of an unstimulated tendril. The markings on the concave side showed a slight contraction of that side amounting to about I per cent. per hour. Fitting concluded that these results are attributable to growth changes only.

The mechanism of the extension of the convex side of a tendril which accompanies growth has been the subject of a certain speculation. In $1887-9$ Wortmann claimed to have shown that the cell membranes of the concave side of the organ are thickened and their rigidity increased by the protoplasm, and that consequently the turgor of the region stretches most strongly the thinner membranes of the convex side. Kohl, in I894, suggested different degrees of elasticity of the cell walls in different directions, and hence unequal extension under uniform turgor. Noll attributed the change to a direct influence of the protoplasm on the cell walls of the convex side, whereby they become more plastic and extensible. These views, to which we shall return later, differ rather strikingly from those held by De Vries, according to which the action of the protoplasm in all such cases causes local modifications of the turgor of the cells and does not work directly upon the cell wall.

On the general question of the behaviour of tendrils and other climbing organs, the most notable investigations of our whole period were those of Charles Darwin, the results of which appeared in his Climbing Plants, in I865. Among the most striking discoveries he made may be noted the extreme delicacy of perception which some tendrils display. A single touch on the concave side of a tendril of Passiflora gracilis caused a rapid curvature, which resulted in two minutes in the formation of a helix. A loop of soft thread weighing about half a gramme, placed three times on the tip, caused 
curvature in half a minute. Perhaps a more extraordinary observation was that the tendrils of Echinocystis lobata and Passiflora gracilis are able to discriminate between the con tacts made by falling raindrops and those of solid bodies refusing to bend to the former. This remarkable pheno menon, at first appearing to indicate a rudimentary con sciousness on the part of the plant, was subsequently investi gated by Pfeffer, who, in I885, repeated the experiments and added to them by dropping on the tendrils water in which a very fine powder was suspended. The repeated impact of these solid particles induced reaction, but no the water alone. Pfeffer advanced as an explanation o this behaviour the view that statical pressure alone doe not act as a stimulus. He said, "in order that a stimulu may be effective, definite points of limited extent in th sensitive region of the tendril must be affected by push or a pull of sufficient intensity, simultaneously o. in adequately rapid succession.'

Darwin stated that the tendrils of Echinocystis refuse to climb round the stem of the plant, becoming straight anc non-sensitive when they approach it. Pfeffer combated this, however, attributing the absence of coiling under sucl circumstances to the smoothness and slenderness of th tendrils, together with their movements.

Darwin showed in the course of his researches that th fixation of many tendrils is often followed by hypertro phic growth. This was confirmed by many subsequen writers. The discs developed on the tips of the tendrils o species of Ampelopsis and Vitis, and the thickening of th woody portion of the petioles of Solanum may be cited a instances. More recently the hooks of Uncaria wer described by Treub, while Ewart added, in I898, a furthe example in the pulvinus of the leaflet of Dalbergia, th woody cylinder of which becomes in a week double th thickness of that of an unattached organ. 
We have already seen that roots manifest both heliotropic and geotropic sensitiveness. Their endowment with contact irritability as well was first observed by Sachs in I873, when he described a curvature resulting from their coming into contact with particles of soil. The root bent in such a way that the stimulated side became concave. This curvature can be explained on purely mechanical principles. It follows a pressure upon the part of the root which is the seat of more or less active growth and is the result of the inhibition or diminution of growth at the part so touched, the other side of the root continuing to grow and so becoming convex. The effect is thus more akin to the result of an injury than to that of a stimulus. In 1880 Darwin observed what Wiesner later called the Darwinian curvature, which is a definite result of stimulation, the tip being diverted away from the obstacle touching it by a bending of the axis at a point higher up. Detlefsen, in 1882 , and Burgerstein, in I883, opposed Darwin's explanation of the movement as a response to contact stimulation, claiming that it is preferably to be regarded as traumatic, for injury of the same part by cutting, branding, or treatment with caustics, produces the same effect, though often giving rise to more irregular movements. The criticism does not appear to be very destructive, as it seems quite possible that the differences between slight contact and severe injury, chemical or mechanical, may be only of degree and not of kind.

Darwin's investigations showed clearly that there is a sensitive area, and a motor one, which differ in position, and that the movement is the result of stimulation and not of direct mechanical injury of the tissues. The explanation which Darwin gave of the greater growth of the convex side has been accepted generally, but a detailed study of its mechanism was carried out in 1896 by McDougal. To this point we shall return in connexion with the general 
questions of sensitiveness and response to stimulation later.

The behaviour of the leaves of Mimosa and other sensitive plants has been shown to be affected by various influences, among which contact stimulation must be included. Others are disturbance caused by shaking, and modifications of the tonic action of light. The mechanism of the pulvinus which is concerned in the movement was investigated by Pfeffer in $\mathbf{1 8 7 3}$. He showed that the stimulus of contact with some portion of the leaf blade, or some other part of the plant, causes a change in the turgid tissue of the lower half of the pulvinus, bringing about a diminution of its turgor, water passing from the cells in to the intercellular spaces. The result is a different condition of equilibrium of the tissue tensions in the pulvinus and the weight of the leaf then causes it to fall. The original position and its accompanying equilibrium of strain is reproduced as the turgor gradually returns. Vines put forward in 1878 the view that the disturbance of turgor and consequent movement are aided by an active contraction of the cells on the lower side of the pulvinus, and Gardiner, as the result of independent investigations, supported him in I887. Pfeffer, however, did not accept the view, though in the latest edition of his Pfanzenphysiologie he said it is uncertain.

The movements of the stamens of the Cynareae, of Berberis and other flowers, received little notice. In I86r-3 they were investigated by Cohn, who held that their movement is produced by a change in the shape of the filaments without any escape of water. He compared the contracting cells to muscle fibres. Unger put forward similar views in I862-3. Hofmeister opposed the muscular hypothesis in $I 867$ and attributed the movement to the properties of the cell wall. In I873 Pfeffer claimed that the movement has as its cause a change similar to that in the pulvinus of Mimosa. 
More specialized examples of the power of appreciating contact stimulation are afforded by the so-called insectivorous plants, of which but little was known up to I860, but which attracted much attention after that date. They were shown to possess a very specialized apparatus for nutrition, associated with very delicate sensitiveness in more than one direction. Many writers gave careful attention to their biological peculiarities, of whom Nitschke and C. Darwin added most to our knowledge. The work of Nitschke, which was confined to Drosera, was published in I860, and was the first to appear after the memoir by Roth, which was published in 1782 . Nitschke gave an account of the movements of the tentacles and described the method of their propagation, which was a very satisfactory piece of work for the time. The subject then fell into neglect and was only brought to the front again by the more elaborate researches of Darwin, published in I875. Darwin did not confine himself to Drosera, but investigated all the then known insectivorous plants, and made clear the bearing of their behaviour on their nutritive processes, and the close correspondence of the latter with gastric and intestinal digestion in mammalian animals, while he showed that not only movement but secretion and chemical change follow stimulation. He demonstrated further their possession of chemotropic as well as tactical perception.

In the case of Drosera, to which a large part of his memoir was devoted, Darwin gave a full description of the nature of the movement of the tentacles; the relation of this movement to the area of stimulation in any given case ; the distribution of the sensory areas ; and the conduction of the stimulus from tentacle to tentacle; pointing out the co-ordination of all; to the end that the digestion and absorption of nitrogenous food material may be secured. He showed that the result of contact stimulation alone 
differs from that of the combination of the absorption of digested material with such tactile impulses, so that the active mechanism of the leaf is not called into full play unless useful results are secured. He described the changes in the interior of the cells of the tentacles which are the accompaniment and sign of stimulation, the mysterious churning of protoplasm and sap to which he gave the name aggregation.

One of the most remarkable hypotheses which may be found in his work is the view that the heads of the tentacles exercise a definite influence upon the process of the conduction of impulses, being not only seats of sensation, but in a somewhat rudimentary fashion co-ordinators of the transmission in such a way as to suggest a kind of reflex action. Another very interesting discovery was that like certain tendrils, the tentacles can discriminate between contact with a solid body and the shock received by the impact of drops of rain, failing to curve under the stimulus of the latter. The researches of Pfeffer made ten years later upon this point in connexion with the behaviour of tendrils have already been alluded to. He showed that both phenomena admit of the same explanation.

In I877 Batalin claimed that the movement effected by the tentacle is a growth curvature. Correns supported him in I892; he killed a stimulated and curving tentacle by immersion in boiling water and found that its curvature remained permanent.

In I882 Schimper published the result of some researches on the condition of the cells of the tentacles during and after stimulation. He showed that after strong excitation a precipitate falls in the cell sap, due to the formation of some chemical secretion by the protoplasm. This was observed aiso by Goebel in I893, and was by him termed granulation. Schimper distinguished between this precipitation and the churning movement of aggregation, 
which he said is a vital rather than a chemical process. The changes in the cells were scrutinized very minutely in 1896 and 1899 by Miss Huie, and in 1899 by Rosenberg. Both observers agreed that, as a result of their activity, the protoplasm and nuclei diminish in amount while an increase in the volume of the cell sap becomes apparent.

In the same memoir to which allusion has been made Darwin discussed very completely the mechanisms of Dionaea muscipula, the leaves of which after contact stimulation close after the manner of a pair of hinges. He showed them to possess chemotropic as well as tactile sensitiveness, though the latter is the more evident. The leaves agree with those of Drosera in responding to stimulation by secretion as well as by movement. Darwin was able to make out a differentiation between the two forms of irritability similar to that noticed in the case of Drosera. The sensitive area for the motor effects he determined to be the three large hairs on each lobe of the leaf, mechanical excitation of which does not call into play the secretory activity of the glands. The general surface of the leaf appreciates chemical stimulation, which is always followed by secretion and; when sufficiently prolonged; by closure also. Munk found, in 1876 , that the sensitiveness is not confined to the large hairs, though these manifest it most strongly. In 1877 Batalin found that the closure of the leaf is effected by variation of turgor in a strip of tissue on each side of the midrib and parallel with it, the midrib itself being unaffected. The vital character of the changes and the electrical disturbance associated with them were investigated by BurdonSanderson in I873, I877, I882, and I888. He showed the electrical variations to be essentially the same as those associated with the stimulation of muscle. Kunkel made a similar observation in 1878 with regard to electrical changes following the stimulation of the leaf of Mimosa.

Darwin showed that Pinguicula vulgaris, among the less H h 2 
known insectivorous plants, exhibits sensitiveness to contact and to chemical stimulation. The edges of the leaves curl over towards the centre and pour out a secretion resembling that of Drosera when an insect crawls upon their upper margins. A similar differentiation to that of Dionaea is observable. Darwin found that a mechanical stimulus causes the infolding of the leaf-edge, while stimulation by a drop of solution of ammonium carbonate causes only an outpouring of the viscid digestive juice.

The possession of contact irritability was shown by many observers to be possessed by the lowlier plants. Mention may be made of observations by Wortmann in I887, Errera in I884, De Bary in I886, Ward in I888, Büsgen in I893, Borge in I895, and Goebel in I9oo, which show it to be shared by both fungi and algae.

An observation made by Frank in 1872 may be mentioned here. The petioles of various aquatic plants, whose leaves normally float on the surface of the water, show a curious modification of their growth as the height of the water varies, elongating as much as is necessary to save the leaf surface from submersion. This seems to be a form of irritability, showing response to the strain of traction. There is, however, some doubt about this interpretation, as Frank found that the increased growth can be induced by covering the leaf with a thin film of water, avoiding any strain.

\section{Chemotropism and Chemotaxis}

The tentacles of Drosera, the leaves of Pinguicula, and those of Dionaea were observed by Darwin in 1875 to respond to stimulation caused by placing on their surfaces certain chemical substances, such as carbonate of ammonia. The completion of the movements and the secretion of a true digestive juice was found to be largely influenced by the absorption of some of the products of protein decomposition. The power of appreciating chemical stimulation 
was found to be differentiated from the contact irritability, the differentiation being possibly most complete in Pinguicula. Darwin found that mechanical stimulation of the leaves of the latter caused them to curl over at their edges but did not affect the secretion. The application of carbonate of ammonia caused secretion but not movement. The perceptive organs for the stimulus of contact in Dionaea were found to be the large hairs upon the leaf-blades, those for the appreciation of chemical substances the small glandular hairs scattered all over the surface.

Darwin's observations were not quite the earliest indicating sensitiveness to chemical excitation. Pfeffer showed in 1873 that the application of chloroform vapour causes curvature of the pulvinus of Mimosa. This, however, may be a local effect upon the protoplasm and need not indicate a sensory mechanism. After Darwin's work appeared, examples of the possession of this form of sensitiveness by plants multiplied considerably. In I88I Engelmann described the effect of oxygen in causing movement of Bacterium termo, and De Bary showed that chemical stimuli aid in bringing together the sexual structures in Saprolegnia. Pfeffer's proof that solutions of malic acid and of sugar lead the antherozoids of ferns and mosses respectively to the open necks of the archegonia dates from I883; in I884 Molisch and De Bary independently showed that sensitiveness of this kind is manifested in the approximation of the pollen-tube to the ovule, while Stahl and Pfeffer separately described the behaviour of various Myxomycetes under the attraction or repulsion of such chemical substances as nitre, glycerin, sugar, and extract of tan. Two years later Berthold showed that the oöblastema filaments of Dudresnaya respond to chemical stimulation when they fuse; in I888 Overton, and in I890 Haberlandt, proved that similar sensitiveness guides the approximation and subsequent fusion of the filaments of Spirogyra. In I 889 
Molisch showed that roots curve towards free oxygen but away from carbon dioxide, while pollen-tubes tend to avoid the former. In I894 Miyoshi published some extended researches upon the same question, giving many instances of sensitiveness of various fungi to different stimulating substances. He showed that the penetration of a parasite into its host is mainly due to chemotactic stimulation. $\mathrm{He}$ also gave a more complete account of the behaviour of the pollen tube in its progress from the stigma to the ovule, and showed that cane sugar secreted by the micropyle plays an important part in the guiding process. Correns showed, in I896, that both chloroform and ammonia cause curvature of tendrils. In Igoo Stahl published further researches on the Myxomycetes, in which he showed that variations in the concentration of the solutions of the various stimulants are appreciated and responded to.

\section{OTHER KINDS OF SENSITIVENESS}

During the last twenty years of the century many other forms of irritability were discovered. The power of appreciating differences of temperature, associated so long ago with the opening and closing of flowers was found to be capable of causing curvatures. In Wiesner's work on heliotropism he showed that the infra-red rays act in the same way as those of the visible spectrum. This form of irritability was named thermotropism by Van Tieghem. Wortmann found in 1883 that seedlings of cress and of maize, and the sporangiophores of certain Phycomycetes curve towards a hot plate which is giving off heat-rays only; in I 884 Barthelémy saw that roots of Hyacinths act in the same way, while the leaves of the plant curve away from a heat source. In I 890 Vöchting showed the occurrence of positive thermotropism in the peduncle of Anemone.

Curvature of roots under the influence of moisture, which 
had been observed and to a certain extent explained by Knight as long ago as I8II, was made the subject of very careful research by Sachs in 1872 . It was further investigated by Darwin in I880, and the sensitiveness was located in the root apex, as had been other perceptive powers. Wiesner and Detlefsen both opposed Darwin's view, but Molisch confirmed it fully in I883. Pfeffer, some ten years later, came to the conclusion that not only is the apex the sensitive area, but that the irritability is confined to it. If the apex is uniformly wet on all sides, no curvature of the growing zone occurs. Molisch failed to find this kind of sensitiveness in the stem. Wortmann showed, in I88I, that the sporangiophores of the Mucorini grow away from moisture. Hydrotropic irritability was observed in 1883 in the rhizoids of Marchantia by Molisch, and in 1894 by Miyoshi in pollen-tubes.

Curvature under the influence of injury was first examined by Darwin in 1880 in his studies of the effect produced by amputating root-tips, and was studied at some length by Spalding in I894. It has been called traumotropism. Massart, in I889, found that concentrated solutions of various salts affect several free-swimming organisms, independently of their chemical nature; he introduced the term tonotaxis for this peculiarity. Pfeffer wrote of the phenomenon as osmotaxis, as did Rothert subsequently. In I883 Jönsson discovered that plants are able to execute curvatures in response to the movement of the water in which they live. He called this kind of irritability rheotropism. Elfving in I882, Müller in I883, and Brunchorst in I884, noticed that the radicles of certain seedlings are variously affected by the passage of an electric current, the response being in some cases positive, in others negative. To this property the term galvanotropism was applied. But little attention was paid to it up to the end of the century. 
The power of appreciating and responding to vibration was demonstrated by several observers; it was called seismotropism by Pfeffer. It was first spoken of by Prillieux in I868, when he showed that if a shoot is struck repeatedly but gently near its apex, the latter slowly curves over towards the opposite side, so that the side which is struck becomes convex. Blows administered to the shoot low down cause a curvature towards the stimulated side. Pfeffer showed, in I885, that this kind of sensitiveness is exhibited by tendrils, motile pulvini, and certain leaves (Biophytum sensitivum). The mechanism of perception is still uncertain, while the resulting movements are usually those of variation and not of growth curvature.

\section{GENERAL CONSIDERATIONS AS TO IRRITABILITy}

The true nature of irritability appears to have been first hinted at by Frank in I870, but was only slowly developed. The great accumulation of evidence that we have traced through the next decade served to establish it firmly in the current opinion of the time, and in 1879 we find Sachs saying that the living material of plants is internally differentiated in such a way that different parts are supplied with specific energies resembling those of the sensory nerves of animals. The coexistence of various forms of sensitiveness in the same organ was shown first by Sachs, then by Müller in 1876 , and again later by Wiesner. Heliotropic curvature occurs in a plant rotating on a klinostat so as to eliminate its natural geotropism. Not only their coexistence, but their power of independent manifestation was shown by Noll in I892, when he found that during marked heliotropic excitation the manifestation of geotropic sensibility is inhibited.

As we have seen, detailed observations of the manifestation of the various kinds of irritability or forms of sensitive- 
ness have revealed a complicated mechanism associated with them, proving that they play an important part in modifying the ordinary phenomena of life, in causing purposeful movements and in adjusting structure to varying conditions of environment.

In rapidly reviewing the progress of knowledge of these various kinds of sensitiveness, we have passed somewhat lightly over many features of general interest.

Up to the end of the century comparatively little was determined, except in a very general way, as to the sensory zones, or areas of perception of stimuli. Their existence was proved by many observers, but their localization and particularly their character were not very closely examined. The most complete instance afforded was the root-tip, to which Darwin attributed, as we have seen, the possession of such varied perceptive powers. The root-tip was studied more recently by McDougal, who in I896 determined it to be indebted for its sensitiveness to a mass of periblem in the shape of an inverted cup which extends axially for a distance of $\mathrm{I}-2 \mathrm{~mm}$., and reaches approximately to the forward edge of the motor zone. The bottom of the cup is formed by the punctum vegetationis. Lessstudied parts are the tips of certain cotyledons, certain epidermal outgrowths of leaves, special portions near the tips of tendrils, certain pulvini, portions of the general surface of leaves and stems, to which we have already referred. The only fact that was conclusively shown is that they exhibit no histological differentiation by which at present they can be identified. Noll suggested that the perceptive region of the protoplasm is the denser ectoplasm which is relatively stable in its position in the cells.

More extended observations, ranging over almost the whole period under review, were made upon the mechanism of movement or curvature, and the other results which follow the reception of various stimuli. Some of these, of 
special character, have been referred to already, but certain questions still claim attention.

The cause of curvature in growing organs was investigated by many botanists, who studied it as it occurs in response to various forms of stimulation. At the commencement of the period under review the older views of Knight were again advanced and extended by Hofmeister. He explained the geotropic curvature of roots as a plastic bending of the organ caused by its weight, and he advanced an ingenious theory to account for the upward curving of a stem. He said that when an apogeotropic organ is placed horizontally, the resistance of the tissue of the lower side to curvature decreases because the cells become water-logged as the fluid in the shoot settles to that side, and their walls increase in extensibility; in this condition they yield more readily than the upper ones to the longitudinal stretching by the turgid pith. He suggested that in coenocytic structures the cause of curving is, in like manner, a strain on the convex side, but in these plants its seat is the common cell wall, whose cuticle is passive and resistant to the more active growth of the inner layers.

This view was not overthrown till the appearance of Frank's work; it met with support, though with certain modifications, from Sachs in I865. Frank, however, brought out the idea that these curvatures are vital phenomena, associated with changes in the environment, and so diverted thought and research into a different direction. The old mechanical views henceforward gave way to biological theories. Frank himself attributed the curvatures to alteration of growth set up by the organism; he supposed the distribution of longitudinal growth to be made unequal, and showed that such a hypothesis can account for all geotropic curvatures, whether positive, negative, or transverse, and that con- 
sequently one explanation is sufficient for all three. In I87I Sachs carried the idea a little further, and while he showed that the convex side grows faster and the concave one more slowly than the normal rate in an uncurved stem, he advanced the view that this growth depends on variation of the turgor of the cells, increased cell pressure being the first result. Ciesielski, in the same year, observed that the changes in the motor zones of curving roots consist chiefly of a greatly exaggerated increase of size in all directions of the cells of the cortex of the convex side, together with a decreased growth combined with a compression of the cells of the concave side. In the next year he observed that these latter cells become more fully stored with protoplasm than the cells of the convex side.

In I879 De Vries pressed further Sachs' theory of varying turgor in the several regions, and said that the growthcurvatures of multicellular organs are due to increased cell pressure on the convex side, this being set up in consequence of the formation of a larger quantity of osmotic substances in the cell sap of the tissues. Kraus showed, however, in I882 that these substances are not present in excess in such cells.

In I880 Darwin put forward the view that these movements of curvature are all brought about through a modification of the universal natural rhythm of circumnutation, in obedience to the stimuli received in each case.

Wiesner, in his Heliotropische Erscheinungen (I880), said that the increase of osmotic pressure in the convex side is associated with an increased ductility of the membranes of the same part, and suggested also that the concave tissues are more perfectly elastic than the ductile cell walls of the convex side. This view of a modified ductility of the cell wall was supported by Strasburger in $\mathbf{1 8 8 2}$.

The influence of varying turgor on the change gradually lost hold of current opinion, as the proofs of modi- 
fications of the properties of the cell membranes accumulated, but the activity of the protoplasm in causing them maintained its ground. In I887 Wortmann stated that in the curving of coenocytes there is clearly visible an accumulation of protoplasm on the concave side, leading to a thickening of the membrane there. The unequal thickening of the membrane causes the structure to yield unsymmetrically to the internal pressure and so curvature results. The cause is thus rather a.retardation of the rate of growth of the concave than an acceleration of that of the convex side. Wortmann further claimed that in multicellular curving organs there is an actual migration of the protoplasm to the cells of the concave side where it accumulates, so that the membranes of the cells of that side are on the whole thicker than those of the other. There is consequently practically a repetition of the conditions found in the coenocyte. The curvature is there also to be regarded as due to the retardation of growth on the concave side.

Wortmann's conclusions were opposed at once by Elfving, who showed in 1888 that his views fail to explain geotropic curvature, for the geotropic stimulus causes increased growth whether allowed to cause curvature or not. He made his measurements on plants rotating on a klinostat.

Noll, in I888, argued that the proximate cause of the curvature is really an increase in the extensibility of the tissues on the convex side rather than an interference with the growth on the concave side. In his own experiments he failed to confirm Wortmann's observation of an accumulation of the protoplasm on the concave wall of the curving coenocyte. Noll advanced further evidence to the same effect in 1895 .

McDougal investigated the mechanism of the curvature of tendrils in 1896 . He found that the curvature round a support does not accelerate the growth of the convex 
side, but that on the other hand there is an actual contraction of the tissues of the concave side, while the subsequent coiling of the free portion is due to directly contrary behaviour. The region of maximum growth of the tendril of Passiflora lies between its middle and its tip, and never coincides with the sensory zone. He found curvature attended by an accumulation of protoplasm in the cells of the concave side, and attributed the action of the tendril to changes in those cells. These changes consist of an increase in the permeability of the protoplasts with consequent extrusion of water into the intercellular spaces, causing thus a release of the stretching tension that has been exerted on the walls of the vascular, cortical, and epidermal tissues, which then recoil elastically.

McDougal, during the next year, published his researches on the curvature of roots under the influence of contact or of a traumatic stimulus, in the course of which he made very careful measurements of the dimensions of all the cells of the curving area. He came to the conclusion that the curvature of roots is due to excessive active elongation of the internal layers of the cortex of the side which becomes convex, an elongation brought about by the stretching of the longer membranes. The latter process further causes the walls to become thinner, while as a later effect of compression on the growth of the concave side, the membranes there increase in thickness. Converse changes in the radial diameters of the cells of the two sides accompany those in the longitudinal direction.

Fitting's views, based on the study of tendrils already alluded to, were that the increased growth-curvature of the convex side far exceeds the contraction of the concave side, and that the neutral zone is consequently near the latter. The greater part of the change is thus due to greater growth on the convex side.

The mechanism of the rapid fall of the leaf of Mimosa 
was shown by Pfeffer to be a passage of the water fror the cells of the lower side of the pulvinus to the inter cellular spaces. That this is caused by a modification the permeability of the protoplasm and not by any activ contraction as was supposed by Cohn in 1876 , was advance by Vines in I886; he based his opinion on Darwin observation that loss of turgidity is an accompaniment aggregation in the cells of the tentacles of Drosera as the curve.

Kraus observed, in I879 and I880, that both heliotrop and geotropic stimulation cause curious changes in th normal metabolism of the different parts of the plant; 1 was able to notice an increased production of reducin sugar in the cells of the lower side of a shoot placed hor zontally before the curvature had begun; this diminishe again during the period of curving. Variations in th quantity of free acid on the two sides were also notice These changes are also shown by stems which from the age are not able to curve. As they occur before the bendin commences it is clear they are due to the action of th stimulus.

Researches have already been described which show tha response to stimulation does not always take the form movement or curvature. Some curious effects of the in fluence of a unilateral light on the constitution of plant call for notice. In 1876 Leitgeb showed that it induce the permanent dorsiventrality of the germ filaments 0 protonemata growing from the spores of certain Marchan tiaceae. Pick found in 1882 that twigs of Biota orientali develop dorsiventral structure under the same conditions Czapek, in I898, showed that Marchantia gemmae, rota ting on a klinostat for two to three months, gave ris to weakly plants of radial structure. In I886 Vöchtin showed that the dorsiventrality of the flowers of Epilobiun angustifolium, Hemerocallis fulva, and Clarkia pulchella 
whose primordia are radially arranged, is induced by the action of gravity.

The mechanism of the transmission of stimulation was investigated by Pfeffer in I873. He showed that it can travel over chloroformed parts of stems, and hence he sought to explain it by the pulsation of water in the tissues. When a stem of Mimosa is cut, a stimulus is exercised only if the section goes as deep as the vascular cylinder and a drop of water escapes. Then the leaves are gradually affected as the disturbance of the hydrostatic equilibrium passes on. Hence he held that the transmission of the stimulus is due to movements and changes of pressure in the water in the vascular bundles. Ziegler, in 1874 , and Batalin, in 1877 , supported the view that the vessels form the path for the transmission of stimuli. With the demonstration of the continuity of the protoplasm through the cell walls of contiguous cells by Gardiner and by Russow in I883, the probability of a transmission resembling that of a nervous impulse in animals was at once realized. This hypothesis did not, however, at once meet with acceptance. In I890 Haberlandt reaffirmed Pfeffer's view that dead regions of both stem and leaf retain conductivity after being killed, In 1896 he advanced the view that in Mimosa the conduction is due to the tannin tubes (Schlauchzellen) of the phloem, which transmit positive or negative pressure waves to the pulvini. These mechanical explanations seem, however, insufficient to account for the rapidity with which a normal response occurs, and in I896 McDougal showed that variations of hydrostatic pressure, whether positive or negative, when artificially produced do not constitute a stimulus in Mimosa.

In I888 Oliver suggested that the path in Masdevallia is a sheath of thin-walled parenchyma accompanying the xylem. Czapek held that the path of transmission is not the vascular tissue, but the fundamental parenchyma, as 
did Rothert also. At the end of the century Némec claime to have demonstrated the existence of special conductin fibrils in the protoplasm of the cells of stimulated roots This still awaits confirmation.

The rapidity of transmission was found to vary con siderably in different cases. Rothert showed, in 1896 that heliotropic stimulation travels at the rate of $\mathrm{I}-2 \mathrm{~mm}$ in five minutes; Czapek, in I898, that geotropic stimulation progresses at about the same rate; while Fitting, at th close of the century, found that the contact stimulation of certain tendrils travels $18 \mathrm{~mm}$. in the same time.

The intensity of the stimulus necessary to cause a respons was first investigated by Charles Darwin, who showed that in many cases the sensitiveness of vegetable protoplasm is a acute as that of the sense organs of the animal body, anc that in some it even exceeds theirs. Darwin showed hor greatly it varies in different cases, and ascertained that in most cases repeated excitation causes a summation of th influences, or a cumulative effect.

Besides Darwin, references may be made to Musset, whe showed, in 1890 , that bright moonlight is capable of inducing heliotropic curvature, and to Figdor, who proved in I89. that the hypocotyl of cress, and that of Linaria bienni respond to an intensity equal to .003 of a standard candle Wiesner showed, in the same year, that the most sensitive plants he tested reacted to a light which did not affec chloride of silver paper. Czapek determined, in I895, tha sensitive radicles curve slightly in response to a centrifuga force which is equal to $\cdot 00 \mathrm{~g}$.

The sensitiveness of plants to different forms of stimulation was shown to vary considerably under changes of the environ. ment. An old observation made by Dutrochet, that it is not manifested in the absence of oxygen, was confirmed by Kabsch in I862, and by Darwin in I875. Its depen. dence on temperature was first shown by Sachs in 1863 
Sachs showed also, in I863, that deprivation of light causes the disappearance of the power of appreciating stimulation, the plant passing into a state of rigor. He gave the name phototomus to the normal condition depending on normal illumination. Bert, in I870, confirmed the observation that various organs which contain chlorophyll lose their sensitiveness in darkness. In I870 Frank proved that cold stops geotropic curvature if the temperature is low enough to check growth. Conversely, Sachs showed in I874 that high temperatures cause protoplasm to pass into rigor. Loss of motility was brought about in Mimosa by heating it to $50^{\circ} \mathrm{C}$. in moist air. Darwin found the leaves of Drosera paralysed at $55^{\circ} \mathrm{C}$. It seems probable that the temperature in these cases affects the motor rather than the sensitive mechanism. In I873 Pfeffer showed that the irritability of Mimosa is diminished by keeping it at a low temperature. In I878 Wiesner noticed that stems of Galium and radial shoots of Cornus are heliotropically positive to feeble illumination but react negatively when the light is strong. Vöchting made the same observation in I882 with regard to the peduncles of Erodium and Taraxacum. The manifestation of response to stimulation varies during the life of the plant as its needs change.

Sachs showed that age influences the response of the shoots of Tropaeolum and the roots of Hedera, both of which are positively heliotropic when young and negatively so when older. Oltmanns' researches on the relation of intensity of light to the direction of heliotropic response and its change as the illumination increases have already been referred to (p. 466). Goebel, in I883, suggested that the geotropic change in rhizomes when they put out long upright shoots is caused by age, and he correlated it with the change from a bare rhizome to a leafy shoot. Wiesner showed in 1882 that there is a change in heliotropic reaction from positive to negative in the peduncle of Helianthemum after fertilization has been effected. HofGREEN 
meister showed the same thing as early as 1867 in th case of Linaria when the fruit is formed.

In 1874 Sachs showed that a change in the mode of respons to geotropic stimulation takes place when the main roo is cut out of a root system. One of the lateral branche which has been growing at an angle of about $60^{\circ}$ change its direction and grows vertically downwards.

The latent period or induction period elapsing between the reception of a stimulus and the consequent respons received little attention till towards the end of the century In I875 Pfeffer found that the heliotropic curvature of th pulvini of Lourea vespertilionis commences one minute afte they have been illuminated. Darwin investigated many cases of the phenomenon up to I880. A more detaile examination was made by Wiesner in $\mathrm{I} 878$. He foun that an hour's exposure to unilateral light produced no effect of curvature on the epicotyls of Phaseolus, but $\mathrm{i}$ they were then transferred to darkness a well-markec bending was observable after a further interval of two hours. This delay of the response, followed by its appear ance after the removal of the stimulus, Wiesner callec photomechanical induction. The length of exposure neces sary to bring it into evidence is about one-third the tim usually elapsing between the reception of the stimulus anc the appropriate response when conditions remain constant Wiesner made some observations on the length of this normal interval, which he determined to be twenty-five minutes in the case of cress, and thirty-five minutes in tha of vetch seedlings. The induction period varies greatly in length. In I897 Ewart showed it to be one or two seconds after strong sunlight in the case of the leaflets of Mimosa Oltmanns found the sporangiophores of Phycomyces react in from one to three minutes; Czapek, a year later, determined that geotropic reaction requires twenty to thirty minutes.

We have seen that Wiesner showed that when stimulation is once received it produces its effect even if the stimulation 
is removed before the latter is manifested. Another very similar phenomenon is the prolonged maintenance of the movement or response after the actual stimulation has ceased. This is generally spoken of as the after effect. Attention was first called to it by Sachs in 1873, when he found that a negatively geotropic stem placed horizontally till a curvature began, and then placed vertically, continued to curve against its apogeotropic tendency for one to three hours. The observation was confirmed by Wiesner and by Müller in I876. Vines, two years later, noticed an after effect of tonic stimulation of light. He kept a leaf of Secale in the dark, but exposed it at intervals to light for an hour at a time. Its growth was retarded during the exposures, and when it was returned to darkness the retardation persisted for at least another hour. Darwin published many instances of after effect in I88o.

An interesting case of the production of an induced rhythmic movement as an after effect of prolonged rhythmical geotropic stimulation was recorded by F. Darwin and Pertz in I8g2.

An important contribution to our knowledge of after effects was made by Rothert in I896, when he showed that they are not stopped by the removal of the sensory area. Once started, the sensory impulses move along to the curving zone and the subsequent injury does not arrest them. The period of stimulation necessary to secure this after effect varies with the nature of the stimulus. Rothert found the interval in the case of heliotropism to be a very short one. Similar observations on geotropic stimulation had been made earlier by Ciesielski and by Darwin.

Rothert's experiment shows that the maintenance of the movement is not due to passive continuance of the irritation of the sensitive organ, but that its explanation must be sought in the sluggish response of the protoplasm of the curving region. Wortmann, in 1887 , called attention to the slow accumulation of protoplasm in the cells of the 
side becoming concave which leads gradually to a difference in the thickness of the cell walls. As the latter takes time to develop, the process goes on after the removal of the stimulus, which in fact produces its primary effect in the migration of the protoplasm.

The vital theory of irritability received support from the discovery that plants are capable of showing fatigue. In I86I Cohn found that the excitability of the stamens of the Cynareae is temporarily inhibited by stimulation but soon returns. This was also observed by Bert in 1870 . In I873 Pfeffer showed that the continued application of mechanical shocks to Mimosa does not prevent its return to its original position, but after such treatment it becomes for a time incapable of responding to further mechanical stimulation. It seems to be due to inhibition of perception, as other forms of stimulation provoke responsive movements. The motor mechanism seems intact. BurdonSanderson found a similar capability of inducing fatigue in the sensitive hairs of the leaf of Dionaea in I882. After a single stimulation the sensitiveness of Mimosa pulvini is inhibited for a short time during the return movement. In I885 Pfeffer found that he could set up fatigue in the leaflets of Oxalis, but not so readily, for they continue capable of receiving stimulation during the return movement.

The vital theory receives support further from observations which have been made upon the behaviour of plants when exposed to anaesthetics. Bert showed in 1870 that the motility of the leaves of Mimosa is inhibited by chloroform, as did Pfeffer in 1873 . Haeckel, in 1873 and 1874 , showed the same thing in the case of irritable stamens and stigmas. He found that I per cent. solution of morphia inhibits the stamens of Berberis. Darwin found ether inhibit the sensory hairs of Dionaea in 1875. Kabsch found chloroform arrest the movements of the lateral leaflets of Hedysarum. 


\section{GENERAL CONCLUSION}

THE survey which we have taken in these pages of the general course of research in the different regions of the vegetable kingdom during the latter half of the nineteenth century has now illustrated the vast change that came over botanical speculation and opinion under the influence of the work of Darwin, and to a less extent of that of Hofmeister and his successors. The general trend of thought turned, after the appearance of the Origin of Species, in the direction of Physiology, and found in its study the clue to what had before escaped explanation in the various fields of research. Perhaps because this subject was almost entirely a new one, the records of what was done seem more voluminous than might have been expected. Though no doubt much appeared that was crude and ill-digested and proved to be but ephemeral, most of the researches remain as substantial contributions to knowledge, as monuments of untiring energy and patience, and as work affording points of departure that in the new century will lead, indeed have already led, to results of even greater importance.

Early in the period under examination, a notable advance was made under the influence of the new point of view, to which so far little allusion has been made in these pages. Many statements had gone forth to the world which were based on little more than the opinion of one or other of the leading men of earlier times, and these had been accepted as fundamental facts, to doubt which savoured of heresy. In the earlier years of our period there was the same tendency to accept statements upon similar authority, without sufficient examination of the evidence on which 
such affirmations rested. We may instance Naegeli's theory of growth by intussusception based upon his hypothesis of the micellar constitution of all organized structures, which was not only accepted as demonstrated for starch grains and cell walls, but was by many held to be applicable to the living substance itself. There was a little later Boussingault's statement that carbon dioxide is absorbed by the cell wall of the epidermis, and does not enter the plant through the stomata; similarly there was a general acceptance of Sachs' view that starch is the culmination of the early photosynthetic processes. Indeed throughout the history of the science, repeated instances of the undue weight attached to the dicta of particular workers meet us at almost every turn. The advance that began in those early years was an important one in the direction of freedom of thought. There was a revolt against authority as such, and the statements of the older writers not only ceased to bind the opinions of the younger men, but actually challenged criticism and investigation. The time of speculation and hypothesis passed away and the new era of philosophical inquiry and rigid experimentation took its place. Not that either speculation or hypothesis failed to take a place in investigation and research, but they lost their dominance; they were put forward not as final explanations of events and circumstances not fully understood, but as suggestions which were to be rigidly examined and discussed, which were indeed only meant to be the basis of experiment and research.

The effect of this spirit of free inquiry has appeared over and over again in these pages; the old inexactitude gradually vanished, and the researches of the later years of the century yielded knowledge which was at once farther reaching and based upon more satisfactory foundations.

Allusion has already been made to the great development of the biological sciences during the period which has 
engaged our thoughts, and it is hardly necessary to divell further on this feature of the time. But it may be recalled for a moment to point out that we have been thereby furnished with not only one, but many points of departure from which lines of investigation are spreading out widely during the new century. Cytology and oecology have attracted many followers, and both anatomy and physiology have received copious illustration from their work. Still greater importance may be attached to the development of vegetable pathology, for it possesses not only scientific interest, but is likely to lead to results of very great economic value. Regarded side by side with the same subject in the animal kingdom, its achievements certainly seem extremely small, but several directions for its development are indicated. A few experiments were directed in the closing years of the century to the fascinating problem of securing immunity from disease, though most of the work on this subject, small as it is, has been done since rgoo. Bacteria as the source of disease in plants have begun to be scrutinized, though very little accurate information has been forthcoming. The development of this section remains as a problem for the new century.

The application of research in vegetable physiology to the problems of agriculture we have seen was a feature of the whole period under review. At its close those problems were as insistent as at any time during its progress. Though, as we have seen, many new facts were ascertained, they gave rise themselves to further inquiry and new questions continually came to the front. Among the latter, good results have already been obtained by the study of the problems of heredity, hybridization, variation, and kindred subjects, and botanical questions are competing in interest with those of zoology.

Besides these developments, certain other features of great interest made themselves evident during our period. 
Prior to I860 there was a considerable degree of isolation of the sciences, and their interdependence was only dimly recognized. Botanical research played its part in breaking down this isolation by showing how important for the solution of the problems presented by the living plant is the application of physical and chemical principles to the phenomena of its life. The study of the distribution of plants in space and in time showed further the interrelationship of botany and geology, while a knowledge of the latter science proved to be imperative in the discussion of the relations of the plant with the soil, which influence so greatly the industry of agriculture. The period we are reviewing saw much advance made in the direction of securing the co-operation of the followers of all the sciences in common investigation and research. These new aspects of inquiry proved to be of more than scientific interest, for they afforded a broader outlook than the earlier years presented. The study of the fungi and bacteria particularly illustrate this point; though their life histories were studied with great completeness, the aim of the investigators ceased to be the mere determination of systematic position or even phylogenetic affinity; it extended to economic importance, the study of the phenomena attending their lives and the influence of such phenomena for good or evil on the community at large. The development of our knowledge of fermentation and the more complete methods of its study, which came into vogue during the later years of the century, have already been alluded to.

Though the great changes we have pointed out as occurring in the progress of investigation can be traced directly or indirectly to the influence of the work of Darwin, we may well summarize the account of the activities of our period by brief allusion to the more important of them. Perhaps the most striking result attained is the discovery of the identity of the living substance of both plants and 
animals. There is one protoplasm, and though the needs of different organisms demand very varied ways of supporting it, and though they call for different degrees of development of its fundamental properties and powers, its essential features are always the same. Its supplies of food, its manner of nutrition, its relations to supply, distribution, and expenditure of energy, and its power of appreciating its relations with its surroundings, are at the bottom characteristic of all apparently different cases.

Though this stands out as a great result of the century's work, many stages of its discovery may be thought worthy of individual emphasis. The researches on the metabolism of the plant made by Sachs in the early years of our period, continued by Boussingault, Winogradsky, Lawes and Gilbert, Hellriegel and Wilfarth form very conspicuous contributions to knowledge. The physical investigations of Pfeffer and his pupils cleared up many obscure points in the mechanical working of the plant. The demonstration of the sensitivity of plants stands out as a remarkable achievement and brings into great prominence the names of Frank, Viesner, and the Darwins.

The wonderful advance in anatomical research presents similar achievements. The establishment of the cell theory, the elucidation of the law of the alternation of generations, the discoveries connected with the nucleus with their influence upon the problems of descent and heredity, were all features of the period under review. The combined influence of all these factors upon the principles of classification and the problems of taxonomy led to profound discontent with the schemes of the older morphologists, and affirmed without fear of contradiction that phylogeny is the true key to classification.

Another feature of the period was the spread of exploration as well as of minute examination of structure and function. It was not only spread, but systematized, and its results 
studied in the light of related problems. There resulted a vast increase in our acquaintance with the characters of the vegetation of the globe, which in its turn threw light upon the history of the world in ages long gone by. The revival of the study of the fossils under the influence of Williamson, of Renault, and of their pupils and successors served largely to illustrate these larger questions as well as to throw light upon the descent of vegetable forms.

Thus the outlook of the new century becomes bright and hopeful. There is no lack of problems, for the old ones have not received full explanation, and such results as have been achieved have been most fertile in suggesting other and supplementary lines of inquiry. Nor does there seem any likelihood of a lack of either workers or enthusiasm. In all European and most American countries research has assumed an almost national importance, and its economic value is beginning to be properly appreciated, while the spirit of enthusiasm is spreading beyond the older borders to the remoter regions of Asia and Africa. The work carried out so far from the older centres promises to vie in completeness, thoroughness, and importance with that of the European schools. 


\section{BIBLIOGRAPHY}

(The figures between brackets after the authors' names are the numbers of the pages on which reference is made to the several papers.)

ACQUa (386). Ann. Ist. Bot. Roma, vi (1894).

ACTON (306). Proc. Roy. Soc., xlvii (1890).

AEBy (349). Landw. Versuchsst., I 896.

Altmann (172). Studien über die Zelle, Leipzig, I886; Die Elementarorganismen, Leipzig, I890.

ARChangeli (237). Nuovo Giorn. Bot. Italiano, viii (1876).

AschofF (362). Landw. Jahrb., I8go.

Askenasy (443). Verhandl. d. naturhist.-med. Vereins zu Heidelberg, 1878 and 1880 .

(185). Ber. d. deut. bot. Ges., I 890.

(275). Verhandl. d. naturhist.-med. Vereins Heidelberg, I 895.

ATKINSON (58). Amer. Naturalist, 1896.

Atwater (346). Amer. Chem. Journ., vi and viii.

BACH (303). Compt. Rend., I 893.

- (353). Compt. Rend., cxxii (I897).

BAEyer (30i). Ber. d. deut. chem. Ges., i870.

Baillon (90). Ann. Sci. Nat., sér. 4, xiv (1860).

Balfour, Bayley (I07, I28). Brit. Assoc. Reports, Glasgow, I90I. Pres. Address to Sec. K.

Balland (390). Compt. Rend., I888.

BARANETZKY (265). Bot. Zeit., I872.

- Abhandl. d. naturf. Ges. zu Halle, 1873.

- (257). Bot. Zeit., xxxi (1873).

(375). Die stärkeumbildenden Fermente. I 878.

(442, 448). Mém. de l'Acad. Imp. de Saint-Pétersbourg, I 879.

$(446,469,476)$. Mém. de l'Acad. Imp. de Saint-Pétersbourg, xxxi (I883).

BARBer, C. A. (I4I). Ann. of Bot., iii (I889) and v (I89I).

BARThélemy (283). Ann. Sci. Nat., ix (1868), xix (1874).

Compt. Rend., 1877 .

Compt. Rend., xcviii (I884). 
DE BARY (239). Ann. Sci. Nat., Bot., sér. 4, ix (1858).

- (229). Bot. Zeit., I 875.

- (435). Die Erscheinung der Symbiose, 1879.

Morphol. u. Physiol. d. Pilze, I88I.

- (436). Vgl. Morph. u. Biol. d. Pilze, Leipzig, 1884. $(405,484)$. Bot. Zeit., 1886.

DE BARY und WORONIN (230). Abhandl. d. Senckenb. naturf. Ges., xii (I 88I).

Batalin (450). Bot. Zeit., I871.

- (454). Flora, 1871 ; ib., 1873.

$-(482,483,495)$. Flora, 1877 .

BaUMANN (333). Landw. Versuchsst., I887.

BÉchamp (407). Compt. Rend., lix (1864).

BecQuerel (32I). La Lumière, I 868.

BEIJERINCK (347). Bot. Zeit., I 888.

- $(289,433)$. Bot. Zeit., 1890.

- (408). Centralbl. f. Bakt., 1890.

- (331). Centralbl. f. Bakt., I90I.

BeLAJEFF (240). Bot. Zeit., 1885.

- (237). Bot. Centralbl., I 892.

- (99, I2I). Ber. d. deut. bot. Ges., ix (189I) and xi (1893).

Belzung $(382,388)$. Ann. Sci. Nat., Bot., sér. 7, v (1887).

- (393). Journ. de Bot., 1891.

BeNECKE (362) : Ber. d. deut. bot. Ges., I 894 ; Jahrb. f. wiss. Bot.,

I 895 ; Bot. Zeit., I896, I898.

VAN BENEDEN (180). Arch. de Biologie, iv (1883).

Benson, M. (103). Trans. Linn. Soc. Bot. iii (1894).

BERGGREN : Bot. Zeit., I881.

- (237). Lund's Univer. Årsskrift, xvi (1881).

Bernard, Claude (406, 409, 4I2). Compt. Rend., xxviii (1849).

BERT $(497,500)$. Mém. de l'Acad. de Bordeaux, 1870.

Berthelot (407). Compt. Rend., l (1860).

- (325). Compt. Rend., I876, I877, I 885, I887, 1892.

(353). Compt. Rend., cxxviii (1899).

Berthelot et ANDRÉ (351). Compt. Rend., 1884.

BERTHOLD. Mittheil. d. zool. Stat. zu Neapel, I88o.

- (466). Jahrb. f. wiss. Bot., xiii (1882).

- (168, 172, 474). Studien über Protoplasmamechanik, Leipzig. 1886.

Bertrand (162). Ann. Sci. Nat., Bot., sér. 5, xx (1874).

— Arch. bot. du Nord de la France, 1885.

- (239). Arch. bot. du Nord de la France, 1885, 1886. 
Bertrand (367). Compt. Rend., cxxiv (1897).

- (145). Ann. of Bot., I 899 .

Bertrand et Renault (I50). Arch. bot. du Nord de la France, I886.

BIEDERMANN (358). Landw. Versuchsst., 1867.

BIFFEN (4I3). Ann. of Bot., I 899.

Binney (134). Palaeontogr. Soc., I 868.

- (I4I). Palaeontogr. Soc., xxi (1868), xxiv (I871), xxv (1872), xxix (1875).

BiNZ $(383,386)$. Flora, 1892.

BIRNER und LUCANUS (36I). Landw. Versuchsst., I 866.

Blackman, F. F. (285, 320). Phil. Trans., clxxxvi B (1895).

Blackman, V. H. (102, 106). Phil. Trans., cxc (1898).

BоEнм (45I). Sitzb. d. k. k. Akad. Wiss. in Wien, 1856.

- (269). Sitzb. d. k. k. Akad. Wiss. in Wien, 1865 .

- $(364,380,428)$. Sitzb. d. k. k. Akad. Wiss. in Wien, 1875 .

Landw. Versuchsst., 1877 .

(272). Warum steigt der Saft in den Bäumen? Wien, I878.

(272). Ann. d. Sci. Nat., Bot., 1878 .

$(285,306)$. Bot. Zeit., I 883 .

(273). Ber. d. deut. bot. Ges., I889.

BOKORNY (308). Bot. Centralbl., I 888.

Bonnier (I I3). Ann. Sci. Nat., Bot., sér. 7, ix (1889) ; Rev. Gén. de Bot., i ( 1889$)$.

- (435). Compt. Rend., cxiii (189I).

Rev. Gén. de Bot., I893.

Bonnier et Mangin (266). Ann. d. Sci. Nat., Bot., I884.

- (318). Ann. d. Sci. Nat., Bot., I886.

BORGE (484). Bot. Centralbl., I895.

BORNET (I13). Ann. Sci. Nat., Bot., xvii (1873).

Bornet et Flahault (227). Ann. Sci. Nat., Bot., sér. 7, v (1887). Bornet et Thuret (228). Ann. Sci. Nat., Bot., I867.

Borodin (452). Bull. de l'Acad. de Saint-Pétersbourg, I 867.

- (421). Sur la respiration des plantes, I875. Bot. Jahresb., 1876 .

$(353,355,42$ I $)$. Bot. Zeit., 1878 .

Bouchut (4II). Compt. Rend., xci (1880).

Bourquelot (408). Bull. de la Soc. Mycol. de France, ix (1893).

- (404). Compt. Rend. Soc. Biol., I893.

- (407). Journ. Pharm. et Chim., I 895.

BOURQUELOT et HÉRISSEY (408). Compt. Rend,, cxvi-cxxxi ( $1893-1900)$. 
Bourquelot et Hérissey (402). Bull. de la Soc. Mycol. de France, $x$ (1895).

- (406). Compt. Rend., cxxvii (1898); Bull. de la Soc. Mycol. de France, xv (1899).

- - (406). Compt. Rend., cxxix (1899), cxxx, cxxxi (1900). Boussingault (34I). Compt. Rend., I859.

- (362). Chimie agricole, I860.

- (323). Agronomie, $2^{\ominus}$ éd., 1860, 1861.

- (291). Ann. Sci. Nat., Bot., I864, I869.

- $(282,321)$. Agron. Chim. agric., iv (1868).

Bower (225). Quart. Journ. Mic. Sci., xxi (1881), xxii (1882).

- (73). Phil. Trans., I 884.

- (239). Phil. Trans., 1885.

- (237). Ann. of Bot., I 888 .

- $(55,59)$. Ann. of Bot., iv (1890).

- (1 20). Ann. of Bot., v (1890).

- (89). Proc. Roy. Soc., I891.

- (120, 234). Studies in the morphology of spore-producing members. I. Phil. Trans., clxxxv B (I894). II. Dulau and Co., I 896. III. Phil. Trans., clxxxix B (1897). IV. Phil. Trans., cxcii B (1899). V. Phil. Trans., cxcvi B (1903).

- $(68,86$, 1 19). Ann. of Bot., viii (1894).

Brasse $(375,402)$. Compt. Rend., 1884 .

Braun (90). Das Individuum der Pflanze. Berlin, 1853.

- (238). Monatsber. d. k. Akad. Wiss. Berlin, 1870.

- (340). Sitzber. d. bot. Vereins d. Prov. Brandenburg, 1874.

- (49). Monatsber. d. k. Akad. Wiss. Berlin, 1875.

Bréal (328, 346). Ann. Agronom., 1892.

BREBNER (236). Ann. of Bot., x (1896).

BREFELD (232, 468). Bot. Unters. üb. Schimmelpilze. Leipzig, I $872-81$.

- (231). Flora, 1873 .

- (427). Landw. Jahrb., 1876.

- (449). Unters. a. d. Gesammtgeb. d. Mykologie, I889.

BRoNGNiART (137). Recherches sur les graines fossiles silicifiées. Paris, $188 \mathrm{I}$.

Brosig (257). Die Lehre von der Wurzelkraft, 1876 . BroughtoN (423). Phil. Trans., 1870.

Brown, H. T. (268, 310, 322). Brit. Assoc. Reports. Dover, 1899. Brown and Escombe (405). Proc. Roy. Soc., 1898. - $(287,310,322,379)$. Phil. Trans., cxciii (I900).

- (3II). Proc. Roy. Soc., I902. 
Brown and MORrIS (404). Journ. Chem. Soc., xlvii (1885).

- $(390,402)$. Journ. Chem. Soc., 1890.

- $(307,310,375,380)$. Journ. Chem. Soc., 1893.

BRUCHMANN. Ueber Wurzeln von Lycopodium und Isoëtes. Jena, I874.

- $(238,240)$. Jenaische Zeitsch. f. Naturwissenschaften, I874. (239). Bot. Centralbl., xxi (1885).

- (239). Ueber die Prothallien u. s. w. der Lycopodien. Gotha, I898.

BRÜCKE (167). Sitzber. d. k. k. Akad. Wiss, in Wien, xliv (1861).

BRUNCHORST (487). Ber. d. deut. bot. Ges., I 884.

- (345). Ber. d. deut. bot. Ges., 1885 .

Brunton and MacFadyen (4I I). Proc. Roy. Soc., xlvi (I889).

Buchner (429). Ber. d. deut. chem. Ges., I 896.

Buchtien (241). Bibliotheca botanica, Cassel, viii (1887).

BÜRGERSTEIN (259). Einfluss äusserer Bedingungen auf die

Transpiration. Wien, 1876.

- (259). Sitzber. d. k. k. Akad. Wiss. in Wien, I $876,1878$.

- (455). Oesterreich. Bot. Zeitsch., I90I.

BÜSGEN (439). Bot. Zeit., I883.

- (484). Bot. Zeit., I893.

BüTSCHLI (172). Verhandl. der deut. zool. Ges. zu Leipzig, I891.

(172). Verhandl. des naturhist.-medic. Vereins zu Heidelberg, iv (1889, I890).

(168). Unters. uiber die mikrosk. Schäume u. d. Protoplasma. Leipzig, 1882.

Bunbury (139). Quart. Journ. Geol. Soc., xvii (I 86I).

Burdon-SANDERSON (462, 483). Reports Brit. Assoc., 1873.

Proc. Roy. Soc., xxv (1877).

- $(440,462,483)$. Phil. Trans., I882, 1888.

BurEaU (162). Bull. Soc. Bot. de France, 1872 .

Campbell, D. H. (238). Ann. of Bot., ii (1888).

- (240). Ber. d. deut. bot. Ges., 1890.

- (236). Ann. of Bot., v (1892).

- (237). Bull. Torrey Bot. Club, 1893.

- (236). Ann. of Bot., viii (1894).

- (1 19, 236). Brit. Assoc. Rep., Oxford, IS94.

- (120). Mosses and Ferns, I 895.

- (93). Proc. Calif. Acad. Sci., 1897.

- (93). Ann. of Bot., xii (1898).

- (223). Ann. of Bot., xii (1898), xiv (1900).

Camus (413). Compt. Rend. Soc. Biol., 1897. 
CANBy (439). Gardener's Monthly, Philadelphia, I 868.

CApus (35I). Ann. Agronom., 1886.

CARRUTHERS (I 34, I42). Seeman's Journ. of Bot., v (I867).

- (I44). Monthly Micros. Journ., I869.

- (I 50). Trans. Linn. Soc., xxvi (1870).

- (I39). Quart. Journ. Geol. Soc., xxviii (I 872 ).

— (I 40). Monthly Micros. Journ., viii (1872).

Caspary (90). Ann. Sci. Nat., sér. 4, xiv (1860); Flora, I862.

- (220). Monatsber. d. k. Akad. Wiss, zu Berlin, I862.

Celakowsky (47). Sitzb. d. k. böhm. Ges. Wiss. Prag, I868.

- (48). Sitzb. d. k. böhm. Ges. Wiss. Prag, I874.

-_- (96). Flora, 1874; Bot. Zeit., 1875.

- (97). Sitzb. d. k. böhm. Ges. Wiss. Prag, 1875.

- (54). Sitzb. d. k. böhm. Ges. Wiss. Prag, I 877.

- (96). Ann. Sci. Nat., Bot., I 877 .

- (90). Flora, 1879.

- (90). Abhandl. k. böhm. Ges. Wiss., Ser.6, xi (1882); Ser. 7, iv (1890).

- (85). Flora, 1885 .

- (90). Bot. Jahrb. f. Systematik (Engler), xxiv (1897).

Chamberlain (IO2). Bot. Gazette, xxvii (I899).

Chatin (223). De la Feuille. Paris, I874.

Chauveaud. Compt. Rend., cxiv (1892).

Chittenden (4Io). Journ. of Physiology, xv (I894).

ChitTenden and Osborne (395). Amer. Chem. Journ., I891.

CHODAT et BOUBIER (I 74, 255). Journ. de Bot., I 898.

Cienkowski (I68). Jahrb. f. wiss. Bot., iii (I863).

Ciesielski (47 I, 472, 49I). Cohn's Beiträge, I87 I, I872.

Clautriau (389). Étud. chim. du glycogène chez les Champignons. Bruxelles, I 895 .

CoHN (454). Verhandl. d. Schl. Ges. für vaterländ. Cultur, 1859.

- $(480,500)$. Ibid., I86I.

- (408). Zeitschr. f. wiss. Zoologie von Siebold u. Kölliker, I 863.

- (469). Bot. Zeit., I867.

- (II4). Hedwigia, I872.

- (438). Beiträge z. Biol. d. Pfianzen, I 875.

- (494). Deutsche Rundschau, ix (1876).

COPELAND $(254,444)$. Einfl. d. Temperatur u. d. Lichtes auf den Turgor. Diss., Halle, I896.

- (277). Bot. Gazette, I 902.

CORRENS (433). Ber. d. deut. bot. Ges., I 889.

- (386). Jahrb. f. wiss. Bot., I89I. 
CORRENS $(296,482)$. Flora, 1892.

- (I 86). Zimmermann's Beitr. z. Morph. u. Physiol., I 893.

- (486). Bot. Zeit., liv (I 896).

- (105). Ber. d. deut. bot. Ges., xvii (1899).

CRAMER (94). Bildungsabweichungen bei einigen wichtigeren

Pflanzenfamilien, u. s. w. Zürich, I869.

- (185). Unters. ü. d. verticillirten Siphoneen, I890.

CRATO (303). Ber. d. deut. bot. Ges., I 892.

Crouan (440). Quoted by Delpino, Ult. osservaz. sulla Dicogamia, I 868-9.

CUISINIER (407). Monit. scientif., I 886.

Cunningham (398). Quart. Journ. Mic. Sci., I880.

Curtius und Reinke (309). Ber. d. deut. bot. Ges., I 897.

CZAPEK (496). Jahrb. f. wiss. Bot., I 895.

- $(254,360)$. Jahrb. f. wiss. Bot., I 896.

- (377). Sitzb. d. k. k. Akad. Wiss. in Wien, math.-nat. Cl., I 897.

- $(474,475,494,496)$. Jahrb. f. wiss. Bot., I 898.

- (406). Ber. d. deut. bot. Ges., I 899.

Jahrb. f. wiss. Bot., I 900.

- Ber. d. deut. bot. Ges., I90I, I902, 1903.

- (29I). Ber. d. deut. bot. Ges., I902.

DANGEARD (239). Le Botaniste, sér. 2, I89I.

DARWIN, C. Climbing Plants, I865.

- (438). Insectivorous plants, 1875 .

$(446,461)$. The power of movement in plants, 1880 .

DARWIN, F. (439). Journ. Linn. Soc., xvii (I 878 ).

- $(465,466)$. Arb. d. bot. Inst. in Würzburg, ii (1880).

- (465). Journ. Linn. Soc., London, xviii (1881).

- Journ. Linn. Soc., xix (1882).

- (445). Brit. Assoc. Rep. Cardiff, Pres. Address to Section D,

- 1891 .

(262). Phil. Trans., I898.

(473). Annals of Botany, I 899.

DARWin, F., and PerTz (499). Annals of Bot., vi (I892).

(289). Proc. Camb. Phil. Soc., I 896.

David (222). Ueber die Milchzellen der Euphorbiaceen. Diss.,

Breslau, I 872 .

Dawson, J. W. (I43). Quart. Journ. Geol. Soc., xxii (I 866).

Dawson, M. (348). Phil. Trans., cxcii B (I 899), and cxciii B (1900).

Dehérain (266). Ann. Sci. Nat., Bot., I 896.

- (342). Annales Agronomiques, viii and xii.

DEHÉRAIN et MOISSAN (422). Ann. Sci. Nat., Bot., 1874.

GREEN

$\mathrm{K} \mathrm{k}$ 
Denis (393). Mémoire sur le Sang. Paris, 1859.

DetLEFSEN $(473,479,487)$. Arb. d. bot. Instit. in Würzburg, ii (I 882).

- (321). Arb. d. bot. Inst. in Würzburg, I888.

DetMer (257). Beiträge z. Theorie d. Wurzeldruckes, 1877.

- (457). Bot. Zeit., I 882 .

Devaux (427). Compt. Rend., cxxviii (1899).

DipPEL (225). Bot. Zeit., I862, I 863.

- $(220,222)$. Verhandl. d. Bataafsch. Genootschap u. s. w., Rotterdam, xii (1865).

Dixon (182). Ann. of Bot., viii (I 894).

Dixon and Joly (275). Proc. Roy. Soc., I894; Phil. Trans., 1895.

DODEL (IOI). Festschrift (Naegeli u. Kölliker), I89I. - (383). Flora, 1892.

DöLL (85). Beitr. in Jahresber. des Mannheimer Vereins für Naturkunde, I87o.

DONATH (407). Ber. d. deut. chem. Ges., I875.

DOUliot (197, 201). Ann. Sci. Nat., Bot., sér. 7, xi (1890).

DREChSEL (396). Journ. f. prakt. Chemie, 1879.

DRUde (442). Nova Acta d. k. Leop.-Carol. Akad., Halle, I88I.

Dubois (437). Compt. Rend., I 890.

DUChartRe (447). Compt. Rend., I866.

Duclaux $(335,402)$. Chim. biol, , 1883 .

Dunstan and Henry (409). Proc. Roy. Soc., I goo.

Duval-Jouve (162). On the French species of Equisetum. Paris, 1863.

EBerdT (265). Die Transpiration der Pflanzen, I 889.

- (382). Jahrb. f. wiss. Bot., xxii (1892).

Effront (406). Compt. Rend, cxxv (1897).

EICHLER (71). Entwickelungsgeschichte der Blätter, I86I.

- (85). Blüthendiagramme, I $875-8$.

- (97). Blüthendiagramme, ii (1878).

- (9I). Monatsber. d. k. Akad. d. Wiss. Berlin, I88I.

ElFviNG (296). Arb. d. bot. Inst. in Würzburg, I880.

- (472). Acta Soc. Scient. Fennica, Helsingfors, xii, I 880.

$-(272,487)$. Bot. Zeit., I 882 .

EMmerling (35I, 352). Landw. Versuchsst., i 880.

ENGelmann $(289,297,298,485)$. Bot. Zeit., I88I.

- (469). Pflüger's Archiv, xxx (1883).

(316). Bot. Zeit., I884.

- (298). Bot. Zeit., I888. 
ERIKSSON (344). Studier öfver Leguminosernas rotknölar. Lund, 1874 .

- (197). Jahrb. f. wiss. Bot., I878.

ERLENMEYeR (302). Ber. d. deut. chem. Ges., I877.

ERRERA (389). Bull. Acad. Roy. Bruxelles, I 882 et I 884.

- (484). Bot. Zeit., I884.

- (389). Compt. Rend., I885.

EWART (106). Trans. Liverpool Biol. Soc., ix (1895).

- $(297,298)$. Journ. Linn. Soc., xxxi (1896).

- $(299,498)$. Ann. of Bot., 1897.

(478). Ann. du Jard. bot. de Buitenzorg, I 898 .

Faivre (373). Compt. Rend., I879.

FALKENBERG (217). Vergl. Unters, ï. d. Bau d. Vegetationsorgane. Stuttgart, 1876 .

FAMiNTZiN $(296,452,469)$. Jahrb. f. wiss. Bot., I 867-8.

- (387). Verhandl. d. naturhist.-med. Vereins in Heidelberg, I 869.

- (197). Bot. Zeit., 1875, I876.

(240). Mélanges biologiques (Saint-Pétersbourg), ix (1876).

- (107). Mém. Acad. Imp. Sci. Saint - Pétersbourg, xxvi

(1879).

Fanintzin et Baranetzky (I12). Ann. Sci. Nat., Bot., sér. 5 (I867).

Fankhauser (I 15, 239). Bot. Zeit., I 873 .

FARLOW (5 I). Quart. Journ. Micr. Sci., I874.

Farmer (240). Proc. Roy. Soc., xlv (I889); Ann. of Bot., v (I 89o).

- (236). Ann. of Bot., vi (1892).

(I8I, 233). Ann. of Bot., ix (1895).

FARMER and FrEEMAN (235). Ann. of Bot., xiii (1899).

FarMer and Willians (227). Phil. Trans., cxc B (1898).

Feistmantel (140). Abh. k. Böhm. Ges. Wiss., vii (1889).

FELLNER (232). Jahresb. d. Akad. d. naturwiss. Vereins in Graz, 1875 .

FIGDOR (496). Sitzb. d. k. k. Akad. d. Wiss. in Wien, I893.

Fischer (100). Jenaische Zeitsch. Naturwiss., xiv (1880).

- (221). Siebröhrensystem der Cucurbitaceen, I884.

(377). Jahrb. f. wiss. Bot., I89o.

FitTing (477). Ber. d. deut. bot. Ges., I902.

- (476). Jahrb. f. wiss. Bot., xxxviii (1903), xxxix (1903).

FlahaUlT (197). Ann. Sci. Nat., Bot., sér. 6, vi (1878).

FLemming (181). Quart. Journ. Micr. Sci., I882 ; Archiv f. micr., Anat., xviii. 
Flemming (181). Zellsubstanz, Kern- und Zelltheilung. Leipzig, 1882 .

FleUry (412). Ann. de Chim. et de Phys., I 865.

Flot (2II). Ann. Sci. Nat., Bot., sér. 7, xviii (1893).

Focke (105). Die Pflanzen-Mischlinge, I881.

Fontaine (I 52). Monogr. U. S. Geol. Surv., xv (1889).

FrANK (224). Bot. Zeit., xxii (I864).

- (446, 460, 469). Beiträge zur Pflanzenphysiologie. Leipzig, I 868 .

- $(456,460,464,490)$. Die natiirliche wagerechte Richtung von Pflanzentheilen. Leipzig, i870. Cohn's Beiträge z. Biol., 1872.

- (452). Jahrb. f. wiss Bot., 1872 .

- (464). Bot. Zeit., I 873 .

- (344). Bot. Zeit., I879.

- $(327,436)$. Ber. d. deut. bot. Ges., 1885-92. Landw. Jahrb., I 888.

— $(347,349)$. Die Pilz-Symbiose der Leguminosen. Berlin, I89o. (80). Lehrbuch d. Botanik, I892.

Frank und OtTo (356). Ber. d. deut. bot. Ges., viii (I89o).

Frankland, P. and G. (337). Phil. Trans., 1890.

FRÉMY (I87, 283, 288). Compt. Rend., xIviii (I859).

- (293). Compt. Rend., I860.

- (294). Ber, d. deut. chem. Ges., I 877.

FrIEDRICH (447). Bot. Zeit., I897.

Fromman (169). Unters, uiber die Anatomie des Rüickenmarks. Jena, I 867 .

- (I76). Protoplasma der Pflanzenzellen, 1880.

Ganong (I08). Bot. Gaz., xxv (1898).

GARDiner (I76). Proc. Roy. Soc., xxxv (I883), xxxvi (I884);

Quart. Journ. Mic. Sci., xxii (1882), xxiii (1883).

Phil. Trans., I 883 .

- (438). Proc. Roy. Soc., I 886.

- (480). Ann. of Bot., i (1887).

- $(177,405)$. Proc. Roy. Soc., lxii (I897).

- (177). Proc. Roy. Soc., I900.

Gardiner and Hill (I75, I78). Phil. Trans., cxciv B (I90I).

Gaucher (377). Ann. Sci. Nat., Bot., I900.

Gautier (353). Cours de Chimie, I 872.

- (294). Bull. Soc. Chim., I876.

- (294). Compt. Rend., I879.

- $(354,365)$. Chimie Biologique, Paris, 1892. 
Gautier et Drouin (328). Compt. Rend., 1891.

GEDULD (407). Wochenschrift für Brauerei, viii (I89I).

GÉrard (218). Ann. Sci. Nat., Bot., sér. 6, xi (1881).

- (4I3). Compt. Rend., cxxiv (I897).

Gerber (428). Ann. Sci. Nat., Bot., sér. 8, iv.

Gerland (302). Ann. d. Chem. u. Phys., I 87 I.

Geyler (225). Jahrb. f. wiss. Bot., vi (1867).

Gibson, Harvey (240). Ann. of Bot., vii (1893), viii (1894).

xi (1897).

GIRARD (390). Compt. Rend., I 889.

GODLEWSKI (300, 31 I, 319, 374). Flora, I873.

- $(285,287)$. Arb. d. bot. Inst. in Wïrzburg, I 873 .

- (274). Jahrb. f. wiss. Bot., I 884.

- (448). Anzeiger d. Akad. d. Wiss, zu Krakau, 1889.

- (370). Ibid., I895.

- (351). Ibid., I 897 .

Goebel $(68,86,96,234,239,241)$. Beiträge z. Entwick. d. Sporangien. Bot. Zeit., I880, I 881 .

(72, 223). Bot. Zeit., I 880, I882.

$(85)$. Schenck's Handbuch der Botanik, Bd. iii, I $\$ 84$.

(482). Pflanzenbiol. Schilderungen, II, I893.

- $(79,87)$. Science Progress, I 895 .

Goedechens (359). Ann. d. Chemie u. Pharmacie. See Wolff,

Aschenanal. v. landw. Producten, pt. I, I87 I, p. I 30.

GoepPert und Stenzel (148). Palaeontogr., I 88I.

Golden, Katherine (447). Bot. Gazette, xix (1894).

GoldsMith, Sophie (2I8). Beitr. z. Entwickelungsgesch. d.

Fibrovasalmassen im Stengel u.s. w. Inaug.-Diss., Zürich, I876.

V. Gorup-Besanez $(374,401)$. Ber. d. deut. chem. Ges., I874.

- (4Io). Sitzb. d. phys.-med. Soc. zu Erlangen, I 874.

v. Gorup-Besanez und IVill (437). Ber. d. deut. chem. Ges..

I876; Sitzb. d. phys.-med. Soc. zu Erlangen, I876.

Grahali (250). Phil. Trans., I862 ; Ann. d. Phys. u. Chemie, 1863.

Grandeau et Bouton (360). Compt. Rend., lxxxiv (1877).

GRAND'EuRY (14I). Flore carbonifère du Dép. de la Loire, 1877 .

- (149). Mém. sav. étrangers Acad. sci., xxiv (1877).

_- (142). Bassin houiller du Gard. Saint-Étienne, I89o.

Green, Reynolds (397). Proc. Roy. Soc., I886.

- $(405,410)$. Phil. Trans., clxxviii B (1887).

- (404). Ann. of Bot., I 888.

- (410, 412). Proc. Roy. Soc., xlviii (1890). 
Green, Reynolds (410). Ann. of Botany, i 892.

- (106, 388, 404, 407, 433). Phil. Trans., clxxxv B (1894).

- (74). A Manual of Botany, I895.

- (453). Phil. Trans. B, I897.

Green, Reynolds, and Jackson (413). Proc. Roy. Soc., lxxvii (1905).

GriessmeYer (403). Liebig's Annalen, I 871 .

GRIS (295). Ann. Sci. Nat., Bot., I 857.

GRUSS (403). Jahrb. f. wiss. Bot., I 894 .

- (405). Chem. Centralbl., I 896.

Guignard (100, ror, 107). Ann. Sci. Nat., Bot., sér. 6, xii and xiii (I88I-2).

- (102). Ann. Sci. Nat., Bot., sér. 7, ii (1885).

- (408). Coinpt. Rend., cx, cxi (1890).

- (408). Journ. de Bot., iv (1890, I893, I894).

- (I8I). Compt. Rend., I89I.

- (IOI). Journ. de Bot., xv (I90I).

HABERLANDT (222). Sitzb. d. k. k. Akad. Wiss. in Wien, lxxii (1875). - (259). Wiss. prakt. Unters. a. d. Geb. d. Pflanzenbaues, ii, I877.

- (377). Sitzb. d. k. k. Akad. Wiss. in Wien, math.-nat. Cl., i, I883.

— Jahrb. f. wiss. Bot., I 886.

- Ber. d. deut. bot. Ges., I 886.

- (262). Flora, I887.

- (297). Function u. Lage d. Zellkernes, I 887.

- (185). Oestr. Bot. Ztg., iii (I889).

- (495). Das reizleitende Gewebesystem d. Sinnpflanze, I89o.

- (485). Sitzb. d. k. k. Akad. Wiss. in Wien, I89o.

- (402). Ber. d. deut. bot. Ges., I 890.

- $(449,495)$. Physiol. Anat., I 896.

- (474). Ber. d. deut. bot. Ges., I 900 and I 902 .

HaEckel (167). Die Radiolarien. Berlin, I 862.

HAHN (4I I). Ber. d. deut. chem. Ges., xxxi (I898).

HAMPE $(332,432)$. Versuchsst., I865, I866, I 867.

Hansen, A. (365). Die Farbstoffe des Chlorophylls. Darmstadt, I 889.

Hansteen $(379,403)$. Flora, I 894.

- (352). Ber. d. deut. bot. Ges., I 896.

- (356). Jahrb. f. wiss. Bot., I 899.

Hanstern (373). Jahrb. f. wiss. Bot., I 860.

- (222). Die Milchsaftgefässe. Berlin, I 864 .

- (237). Jahrb. f. wiss. Bot., iv (1 866). 
Hanstein (237). Pilulariae glob. generatio cum Marsilia comparata. Bonn, I866.

- (I95). Die Scheitelzellgruppe im Vegetationspunkt der Phanerogamen. Bonn, I 868.

- (107). Bot. Abhandl. Bonn, I870.

(168). Sitzber. d. niederrh. Gesellsch., Bonn, 1870.

(168). Das Protoplasma als Träger der Lebensverrichtungen. Heidelberg, I 88 o.

(168, I7I). Bot. Abhandl. Bonn, iv (1882).

HARPER (229, 23I). Ber. d. deut. bot. Ges., I895.

HARTIG (39I). Bot. Zeit., I 855.

- (269). Bot. Zeit., I86I.

- (98). Karsten's Bot. Untersuch., iii (1866).

- (435). Bot. Jahresb., I 875 .

HARTOG (230). Quart. Journ. Mic. Sci., I887.

- (230). Ann. of Botany, x (1896).

HASSAK (289). Unters. a. d. bot. Inst. zu Tübingen, 1888.

HEER (I 50, I 5 I). Bot. Jahrbuch f. Systematik u. s. w., i (I 88I) ;

Flora fossilis arctica, I 868-83.

Hegelmaier (240). Bot. Zeit., I874.

- (238). Bot. Zeit., I 875 .

- (I08). Bot. Zeit., lv (I897).

Heidenhain (180). Archiv f. Micr. Anat, xliii (1894).

Heinricher (435). Beitr. zur Biol. d. Pfl., I 895.

- (435). Jahrb. f. wiss. Bot., I 897 onwards.

HeitzmanN (169). Sitzb. d. k. k. Akad. Wiss. in Wien, lxvii (1873). HellRiegel (361). Beitr. z. d. naturw. Grundlagen d. Ackerbaues. Braunschweig, I 883 .

Heliriegel und Wilfarth (342). Versuchsst., I 887.

- (342). Unters. ü. d. Stickstoffnahrung der Gramineen u. Leguminosen. Berlin, 1888 .

HeræuS (340, 369). Zeit. f. Hygiene, 1886.

Hérail (217). Ann. Sci. Nat., Bot., sér. 7, ii (1885).

HICK (I75). Brit. Assoc. Reports, I883 ; Journ. of Bot., I 884.

- (I77). Journ. of Botany, I885.

HILDEBRANDT (I05). Corresp.-Blatt naturhist. Ver. Bonn, I867.

Hiltner (349). Landw. Versuchsst., 1896.

- (349). Centralbl. f. Bakt., ii (1 899).

HiraSÉ (99, I2I). Journ. Coll. Sci. Imp. Univ. Tokyo, viii ( I 195$)$. HöHNEL, voN $(265,267)$. Ueb. d. neg. Druck der Gefässluft. Wien, I 876.

(221). Sitzb. d. k. k. Akad. Wiss, in Wien, 1877. 
HÖHNEL, VON (260). Transp. d. forstl. Gewächse, I879.

- (272). Jahrb. f. wiss. Bot., I 879 .

— Forsch. a. d. Geb. d. Agrikulturphysik, 1881.

HOFMEISTER (272). Ber. d. k. sächs. Ges. der Wissenschaften, 1857.

- $(444,47$ I). Jahrb. f. wiss. Bot., 1859.

- Ber. d. k. sächs. Ges. d. Wiss., 1860.

- (235). Abhandl. d. k. sächs. Ges. d. Wiss., ii.

- $(257,444)$. Flora, I 862 .

- $(444,464,473,490)$. Jahrb. f. wiss. Bot., iii (1 863 ).

- $(184,469,480)$. Die Lehre der Pflanzenzelle. Leipzig, i 867.

- $(223,47 \mathrm{I})$. Allgemeine Morphologie der Gewebe. Leipzig, 1868.

Holland (440). Quart. Mag. of the High Wycombe Nat. Hist. Soc., 1868.

HOLLE (235). Bot. Zeit., I 875 .

Hooker (225). Trans. Linn. Soc., dxiv (1862).

-_ (437). Brit. Assoc. Reports, 1874.

Hoppe-SEYler (393). Med.-chem. Unters., I 867.

- $(289,294)$. Zeit. physiol. Chem., 1879, I880, 1881 .

Hovelacque (I45). Mém. Soc. Linn. Normandie, i (I892).

Hueppe $(369,370)$. Biol. Centralbl., i 887 .

Huie, Miss $(438,483)$. Q. J. M. S., xxxix (1896) and xlii (1899).

Huisgen (97). Unters. iib. die Entwickelung der Placenten. Bonn, i 873 .

IkENo (99, I2 I). Bot. Mag., Tokyo, x (1896); Bot. Centralbl., lxix ( 1897 ).

JANCZEWSKI (23I). Bot. Zeit., xxix (1871).

- (227). Ann. Sci. Nat., Bot., xvi (1872).

- $(196,217,223)$. Ann. Sci. Nat., Bot., sér. 5, xx (I874).

- (240). Mém. de la Soc. Nat. des Sci. de Cherbourg, xix (1876).

Études comparées sur les tubes cribreux. Cherbourg, I881.

- (449). Ann. Sci. Nat., Bot., 1885.

JANSE (274). Jahrb. f. wiss. Bot., 1887.

- (254). Verh. d. Akad. d. Wiss. zu Amsterdam, 1888.

JEFFREY (IOS). Ann. of Botany, ix (1895).

- (236). Trans. Canad. Inst., 1896-7.

- (241). Mem. Boston Soc. Nat. History, v (1899).

- (212). Trans. Canad. Inst., vi (I900).

- (122, 213). Phil. Trans., cxcv B (1903).

Jensen. Bot. Centralbl., lvi (1893). 
JöNSSON (487). Ber. d. deut. bot. Ges., I883.

Johannsen (408). Ann. Sci. Nat., Bot., 1887.

Johnson, D. S. (238). Ann. of Bot., xii (I898).

Johnson, T. (I02). Ann. of Bot., iii (1889).

JONKMANN (236). Bot. Zeit., 1878.

- (236). Dissert., Utrecht, I 879.

Joulie (327). Bull. Soc. d. Agriculteurs de France, 1886.

JUEL (I09). Bot. Centralbl., lxxiv (I898).

Junelle (266). Rev. Gén. de Bot., I 889, I890.

JURANYI (239). Jot. Zeit., I 87 I.

- (237). Ueber die Entwickelung der Sporangien u. Sporen von Salvinia natans. Berlin, 1873.

KABSCH $(455,496)$. Bot. Zeit., I 861, I 862.

- (I 87). Jahrb. f. wiss. Bot., iii (I863).

KAMIENSKi (436). Bot. Zeit., I88I.

Kaufmann (93). Bull. Soc. Nat. Moscon, xli (1869).

Kayser $(307,376)$. Landw. Versuchsst., I883.

KEAN (405). Bot. Gazette, I 890.

KEIM (307). Zeitsch. anal. Chem., I 891 .

KidsTON (142). Trans. Bot. Soc., Edinburgh, 1883.

- (146). Trans. Roy. Soc., Edinburgh, xxxix (1897).

KienitZ-GerLoff (232). Bot. Zeit., I874, I875.

- (233.) Bot. Zeit., I878.

- (240). Bot. Zeit., 1881.

- (177). Bot. Zeit., I891.

Kinoshita (352). Bull. of the College of Agriculture, Tokio, I 895 .

KJELDAHL $(402,407)$. Meddelelser Carlsberg Laborat., I 878.

KJELMANN (456). Bot. Zeit., I875.

KLEBS (185). Unters. bot. Inst. zu Tübingen, I 886.

- $(62,228,449)$. Die Bedingungen der Fortpflanzung einiger Algen u. Pilzen, I 896.

- (60). Brit. Assoc. Rep., Bristol, I898.

KLEIN (180). Quart. Journ. MIic. Sci., xviii (I878), xix (I879).

KLEMM (453). Jahrb. f. wiss. Bot., I895.

KNOP (358). Landw. Versuchsst., I859, I 864.

- $(361,398)$. Landw. Versuchsst., I 860.

KNOP und WOLFF (432). Landw. Versuchsst., 1865.

KNY (236). Jahrb. f. wiss. Bot., viii (I 872).

- (344). Sitzungsb. d. bot. Vereins d. Prov. Brandenburg, 1878.

- 1 bid., I 88 I. 
KNY (29I). Ber. d. deut. bot. Ges., I 897.

KосH, L. (435). Entwicklungsgesch. d. Orobancheen. Heidelberg, 1887.

- (201, 435). Jahrb. f. wiss. Bot., 1889, 1891, 1893.

KöNig (359). Chemie d. menschl. Nahr.- u. Genussmittel, I889.

Koningsberger (383). Arch. Néerland. des Sci. exactes et nat., xxvi (1893).

KöPPEN (454). Wärme und Pflanzenwachsthum, I870.

KöRnECKE (105). Sitzber. d. niederrhein. Ges., Bonn (1872). KOHL. Jahrb. f. wiss. Bot., xv (I884).

- (273). Bot. Zeit., I 885.

- (265). Transpiration der Pflanzen, 1886.

- (477). Mechanik der Reizkrümmungen. Marburg, I894.

- (264). Bot. Beiblatt zur Leopoldina, 1895.

- (298). Ber. d. deut. bot. Ges., 1897.

Kolkwitz (186). Fünfstück's Beiträge z. wiss. Bot., I 897 .

KONRAD (294). Flora, I 872.

Kosmann $(375,402,407)$. Bull. Soc. Chim. de Paris, 1877.

Kossel (409). Zeit. physiol. Chem., I898-1900.

Kossowitsch (328). Bot. Zeit., 1894 .

KrabBE (214). Sitzber. k. Akad. d. Wiss. Berlin, 1882.

- (185). Jahrb. f. wiss. Bot., 1887 .

- (466). Jahrb. f. wiss. Bot., xx (1889).

KRAUCH $(375,402)$. Landw. Versuchsst., I879.

KRAUS $(444,448)$. Bot. Zeit., I 867-7x.

- $(444,449)$. Jahrb. f. wiss. Bot., vii (1 869, I 870).

- (293). Unters. ü. Chlorophyllfarbstoffe, 1872 .

$-(451,468)$. Bot. Zeit., 1876.

- (494). Ueber die Wasservertheilung in d. Pflanze. Halle, I 879, I 880 .

- (447). Sitzb. d. naturf. Ges. zu Halle, 1880.

- (49I). Abhandl. d. naturf. Ges. zu Halle, xv (I882).

- (377). Sitzb. d. naturf. Ges. zu Halle, I \$94.

Kreussler (310, 31 I, 318, 320). Landw. Jahrb., I 885, I 887, I 888, I 890.

Kreuz. Sitzb. d. k. k. Akad. Wiss. in Wien, 1875.

- (225). Ibid., lxxvi (1877).

KREUZHAGE und WOLFF (362). Landw. Versuchsst., I 884.

- Landw. Jahrb., I887.

KRUKENBERG (4I I). Kühne's Untersuchungen, I 882 .

KÜHNE (167). Unters. über das Protoplasma u. die Contractilität. Leipzig, 1864 . 
KÜHNE (389). Lehrb. physiolog. Chem., I 868.

- (409). Verhandl. d. naturhist.-med. Ver. Heidelberg, 18761886.

KüHnemann (390). Ber. d. deut. chem. Ges., I 875.

Kundig (236). Hedwigia, vii (1888).

KUNZ (399). Arch. Pharm., I 886-I 888.

LachManN (236). Ann. Soc. Bot. Lyon, I889.

LANG (62). Proc. Roy. Soc., lx (1896).

- (60). Science Progress, I 898.

- (239). Brit. Assoc. Reports, I 898 ; Ann. of Bot., xiii (1 899).

LASKOWSKY (423). Landw. Versuchsst., I 874.

LAURent (350). Ann. de l'Inst. Pasteur, I889.

- (353). Bull. de l'Acad. roy. de Belgique, I890, I89I.

Laurent et Marchal (356). Bull. de l'Acad. roy. de Belgique, 1903.

Laurent, Marchal, et Carpiaux $(350,351)$. Bull. de l'Acad. roy. de Belgique, 1896 .

LAWES and Gilbert (350). Journ. Roy. Agr. Soc. England, I862.

- Trans. Chem. Soc., 1885.

- (346). Phil. Trans., I 888.

Lawes, Gilbert, and Pugh (324). Phil. Trans., I86I.

LeChartier et Bellamy (427). Compt. Rend., I 869, I 872 , 1874.

LeConte (377). Ann. Sci. Nat., Bot., 1889.

LeitGeB (233). Sitzb. d. k. k. Akad. d. Wiss, in Wien, lvii (1868).

- (223). Bot. Zeit., I87 I.

- (232). Unters. ü. d. Lebermoose, I 874-82.

- (227). Sitzber. d. k. k. Akad. d. Wiss. in Wien, lxxvii (1878).

- (185). Bau u. Entwickelung d. Sporenhäute, 1884.

- (26I). Mitth. d. bot. Inst. zu Graz, I886.

Lendner (449). Ann. Sci. Nat., Bot., I 897.

- LePley (390). Compt. Rend., I882.

LeYDHeCKer (362). Landw. Versuchsst., I865, 1866.

Liebig (358). Ann. d. Chem. u. Pharm., I 858.

- (359). Die Chemie in Anwend. auf Agric. u. Physiol., 1876.

Lignier (I50). Mém. Soc. Linn. Normandie, xviii (I894).

LippMANN (399). Ber. d. deut. chem. Ges., I 887.

LOEW (416). The active albumin in plants. Pharm. Journ., Oct. 22, 1892 .

- (364). U. S. Depart. of Agriculture, Bulletin I8, 1899.

- (4I7). Science, N. S., xi (1900).

Lommel (312). Poggendorf's Annalen, i 87 I.

LoTSY (109). Ann. Jard. Bot. Buitenzorg, ii (1 899). 
DE LuCA (427). Ann. Sci. Nat., Bot., I 878.

LÜDTKE (392). Jahrb. f. wiss. Bot., 1890.

LUERSSEN (236). Bot. Zeit., xxxi (1873), xxxiii (1875).

LUTz (354). Compt. Rend. du Congrès des Soc. sav., 1899.

Macallum (365). Proc. Roy. Soc., l (1891).

— Quart. Journ. Mic. Sci., xxxviii (1895).

- (362). Proc. Roy. Soc., lxiii (1 898).

- (363). Journ. of Physiology, xxxii (1904).

MacDoügal (495). Botanical Gazette, I 896.

-- $(476,489,492)$. Ann. of Bot., xxxix (1896).

- (474). Bot. Gazette, 1897.

- (493). The curvature of roots : thesis presented to the faculty of Purdue University, I 897.

Macmillan (447). Amer. Naturalist, 1 S91.

McNab (277). Trans. Bot. Soc. Edinburgh, $187 \mathrm{I}$.

MAGNus (93). Bot. Zeit., I 869.

- (436). Jahrb. f. wiss. Bot., 1900.

MaLiniak (356). Rev. de Bot., xii (1900).

Mangin (217). Ann. Sci. Nat., Bot., sér. 6, xvi (1882).

- (106). Bull. Soc. Bot. de France, xxxiii (1 886).

- (284). Compt. Rend., I887, I885.

- (284). Ann. de la Science Agronomique Fr. et Étr., 1888.

- (1 89,365$)$. Journ. de Bot., I \$92-3.

- (320). Compt. Rend., I 896.

MARTin (171). Arch. de physiol. norm. et pathol., I882.

- (410). Journ. of Physiology, v, vi (1884, 1885).

Martin, S. (395). Proc. Roy. Soc., xlii (1887).

Massart (487). Arch. de Biologie, I 889.

Mattirolo (113). Nuovo giorn. bot. Ital., I 88 I.

MaYer, AD. (350). Landw. Versuchsst., 1874.

- (423). Landw. Versuchsst., 1875.

MAZÉ (347). Ann. de l'Inst. Pasteur, I 897.

- (333). Ann. de l'Inst. Pasteur, I 900.

Merget (283). Compt. Rend., I877, I 878.

MetTenius(236). Abhandl. d.k.sächs. Ges. d. Wissensch., ix(1864). - (239). Bot. Zeit., 1867 .

MeYer, AR. $(292,306,307,375,3$ So, 382, 390). Bot. Zeit., I881-86.

- (292). Das Chlorophyllkorn, 1883 .

- (386). Ber. d. deut. bot. Ges., I\$91.

— $\left(383,3 S_{5}, 403\right)$. Unters. ï. d. Stärkekörner. Jena, I 895. Micheli (452). Arch. d. sci. de la Bibl. Univ. de Genève, I 876. Mifscher (ISo). In Hoppe-Seyler's Physiol. Chemie, I 871. 


\section{Bibliography}

Mikosch (295). Sitzber. d. k. k. Akad. Wiss. in Wien, I 878.

- (220). Sitzber. d. k. k. Akad. Wiss. in Wien, Ixxxiv (188I).

-- (388). Unters. über d. Bau d. Stärkekörner, I887.

Millardet (22I). Mém. Soc. des Sci. Nat. de Cherbourg, xi (I 865).

- $(238)$. Le prothallium mâle des Cryptogames vasculaires. Strasbourg, I 869 .

- $(448,453,456)$. Mém. de la Soc. d. Sci. Nat. de Strasbourg, vi (1869).

Mivoshi (486, 487). Bot. Zeit., I 894 ; Flora, I894.

Möller, A. (II3). Ueber die Cultur flechtenbild. Ascomyceten ohne Algen, I 887 .

VON MoHL (260). Bot. Zeit., 1856.

(90, 224). Bot. Zeit., I87 I.

(92, 225). Vermischte Schriften.

Molisch $(351,473)$. Ber. d. deut. bot. Ges., i (1883).

— Sitzber. d.k. k. Akad. Wiss. in Wien, math.-nat. Cl., Ixxxviii (I883), Abt. I.

(485). Ibid., I884.

(333). Ibid., 1887.

(486). Ibid., I889.

( 365,366$)$. Die Pflanze in ihren Beziehungen zum Eisen. Jena, 1892 .

- $(362,364,433)$. Sitzber. d. k. k. Akad. Wiss. in Wien, 1893 , I 895, I 896.

Moll (300). Landw. Jahrb., I877.

LE MONNIER (104). Journ. de Bot., i (1887).

Montemartini (320). Quoted by Lopriore. Jahrb. f. wiss. Bot.,

I 895.

MORGEN (374). Bot. Zeit., I 877.

Morot (217, 221). Ann. Sci. Nat., Bot., sér. 6, xx (1884).

MÜller, Carl (236). Ber. d. deut. bot. Ges., I 893 .

MIÜLler, H. (I05). Die Befruchtung der Blumen (I873).

MÜller O. (227). Ber. d. deut. bot. Ges., i (1883).

MÜlLER, N. J. C. $(283)$. Jahrb. f. wiss. Bot., I 870 .

- (315). Bot. Unters., Heidelberg, 1871 .

(466). Ibid., I 872, Bd. i, p. 57.

MÜller-Thurgau $(465,467)$. Flora, 1876 .

- (307). Landw. Jahrb., I882.

MUNK (483). Die elektrischen und Bewegungserscheinungen am Blatte von Dionaea, I876.

Muntz (4I2). Ann. de Chim. et de Phys., 1871.

- (333). Chem. Trade Journ., I89o, p. I 56 
MUNTZ (350). Ann. de la science agrionom., I 896.

MURBECK (109). Bot. Zeit., lix (1901).

v. Musculus (403). Compt. Rend., I86o, 1862.

v. Musculus und GRÜBer (404). Compt. Rend., I 878.

Musset (496). Compt. Rend., I89o.

MUSSI (4II). L'Orosi, Nov. I8go.

NAEGELI $(279,385)$. Die Stärkekörner. Zürich, 1858.

- (433). Bot. Mitt., I 879 .

- (398). Sitzber. d. k. Akad. in München, 1879.

- (382). Bot. Zeit., I881.

- (433). Unters. ü. nied. Pilze. München und Leipzig, I882.

- (82). Die phys.-mech. Abstammungslehre, I884.

NAEGELI und Leitgeb (209, 216). Beiträge z. wiss. Bot., I867.

NAEGEli und Schwendener $(66,168,223,444)$. Das Mikroskop.

Leipzig, 1867.

NAGAMATZ (314). Beiträge zur Kenntniss der Chlorophyllfunktion. Diss., Würzburg, I886.

NAwASChin (103). Bull. Acad. Imp. Sci. Saint-Pétersbourg, ix (1898), xiii (1892); Bot. Centralbl., liv (1893), lxiii (1895), lxxviii (1899).

NĚMEC (474). Ber. d. deut. bot. Ges., I 900 and I90I.

- (496). Die Reizleitung und die reizleitenden Structuren, I90I .

NEUMAYR (140). Erdgeschichte. Leipzig, I887.

NEUMEISTER (409). Zeitsch. f, Biol., I 887-94.

Newcombe (406). Ann. of Bot., xiii (1899).

Nitschke (438). Bot. Zeit., I860, I86I.

NOBBE $(361,362)$. Landw. Versuchsstat., 1862.

NobBe und Hiltner $(347,349)$. Ibid., li and lii (1899).

Nobbe, Schmid, Hiltner, und HotTer (349). Ibid., xxxix (1892).

NOLL (I85, 384). Unters. ï. d. Wachsthum d. Zellmembran, I887.

- (384). Abhandl. d. Senckenberg. naturf. Ges., 1887.

- (492). Arb. d. bot. Inst. zu Würzburg, I 888.

- $(474,488)$. Heterogene Induction, 1892.

$-(477,492)$. Flora, 1895 .

- (474). Jahrb. f. wiss. Bot., xxxiv (1900).

O'Brien, Miss (396). Ann. of Bot.; 1895.

Oersted (90). Videns. Meddelelser Nat. Foren. Copenhagen, I 864 .

Oliver (227). Ann. of Bot., i (1887).

Oliver and ScotT (138, 148). Phil. Trans., cxcvii B (1904).

Olivier (197, 222). Ann. Sci. Nat., Bot,, sér.6, xi (1881). 
Oltmanns (466). Flora, 1892. $(466,498)$. Flora, 1897.

Osborne, T., and pupils $(395,396)$. Amer. Journ. of Physiology and Journ. of Amer. Chem. Soc., 1894 and onwards.

O'Sullivan (403). Journ. Chem. Soc., 1872 and 1879.

O'Sullivan and Tompson (407). Journ. Chem. Soc., lvii (189o).

Oudemans (208). Abhandl. d. k. Acad. Wiss. zu Amsterdam, math.-phys. Klasse, ix (1861).

Overton (485). Ber. d. deut. bot. Ges., 1888.

- (61). Ann. of Bot., vii (1893).

- (254). Vierteljahrssch. d. Naturf.-Ges. Zürich, 1899.

Pagnioul (351). Ann. Agronom., 1879.

- (350). Compt. Rend., cxi (1890).

Palladin (450). Rev. Gén. de Bot., I893.

Pappenheim (268). Bot. Centralbl., I 892.

PARKIN (390). Ann. of Bot., 1900.

Parlatore (90). Opuscula botanica, 1864 .

PASTEur (433). Compt. Rend., I860-2.

- (426). Compt. Rend., I861.

- (430). Jahrb. d. Chem., I86I.

PAYER (85). Organogénie de la Fleur, I 857.

PEDERSEN (454). Arb. d. bot. Inst. in Würzburg, I874.

Petermann (349). Bull. de l'Acad. roy. de Belgique, 1893.

Petersen (217, 221). Engler's Jahrb. f. Systematik, iii (1882).

Petit (366). Ber. d. deut. bot. Ges., I 893.

PFEFFER (284). Arb. d. bot. Instit. in Würzburg, i.

- (239). Botan. Abhandl. u. s. w., Bonn, 1871.

- $(355,376,391)$. Jahrb. f. wiss. Bot., 1872.

- (374). Monatsber. d. Akad. Wiss. Berlin, 1873.

- $(454,480,495)$. Physiol. Unters., I873.

- (495). Jahrb. f. wiss. Bot., ix (1873).

- (453). Die periodischen Bewegungen der Blattorgane, 1875 .

- $(252,257,360,378,438)$. Osmotische Untersuchungen, 1877 .

- (428). Landw. Jahrb., 1878.

- (291, 472). Pflanzenphysiologie, 1881.

- (485). Ber. d. deut. bot. Ges., 1883.

- (485). Unters. a. d. bot. Inst. zu Tübingen, i (1884).

- $(253,428,478)$. Unters. a. d. bot. Inst. zu Tübingen, 1885, 1886.

- (168). Bot. Zeit., 1886.

- Unters. a. d. bot. Inst. zu Tübingen, 1888.

— Oxydationsvorgänge, I889.

- $(254,480)$. Zur Kenntniss d. Plasmahaut u. d. Vacuolen, 1890. 
Pfeffer (I 7I). Abhandl. d. math.-phys. Klasse d. k. sächs. Ges. der Wiss., xvi (1890).

- ( 185$)$. Studien zur Energetik, I 892.

- $(186,254)$. Druck- u. Arbeitsleistungen, I 893 .

(447). Die Reizbarkeit d. Pflanzen, 1893.

Pfeiffer und Franke (349). Landw. Versuchsst., IS96, I 897.

Pfitzer (215, 240). Jahrb. f. wiss. Bot., vi (1867).

- (277). Jahrb. f. wiss. Bot., 1877 .

Pfitzner (I7I). Archiv f. micr. Anat., xxii (I883).

PFLÜGER (414, 424). Arch. f. d. ges. Physiol., x (1875).

Phillips (228). Ann. of Bot., ix ( I 895), x (1896), xi ( (1897), xii ( 1898).

Pick $(222,494)$. Bot. Centralbl., xi (1882).

Pierce (435). Ann. of Bot., I 894.

PITRA (435). Bot. Zeit., I861.

Pitsch (333). Landw. Jahrb., I887-96.

Poirault (237). Mém. de l'Acad. imp. des Sci. de Saint-Pétersbourg, xxxvii (1890).

- (235). Journ. de Bot., I 892.

- (235). Ann. Sci. Nat., Bot., sér. 7, xviii (1 893).

Pollacci (308). Atti d. Istit. Bot. Pavia, I900, 1902.

Portes (408). Journ. de Pharm. et Chim., 1877.

PоTONiÉ (I22). Lehrbuch der Pflanzenpalaeontologie, I897.

PotTevin (409). Compt. Rend., I900.

PRANTL $(447,450)$. Arb. d. bot. Inst. in Würzburg, I873.

- (237). Unters. z. Morph. d. Gefässkrypt., Leipzig, i (1875) and ii (188I).

- $(236,237)$. Bot. Zeit., $1877,1879$.

- (237). Die Schizæaceen. Leipzig, I 881.

- (235). Ber. d. deut. bot. Ges., I 883 .

Prazmowski (347). Bot. Centralbl., I 888.

- (347). Landw. Versuchsst., I 890.

Prillieux (488). Ann. des Sci. Nat., Bot., I 868.

Pringsheim (47). Monatsb. d. k. Akad. Wiss. Berlin, I 856.

- (47). Jahrb. f. wiss. Bot., i, ii (I 858).

- (237). Jahrb. f. wiss. Bot., I 863 .

- (227). Jahrb. f. wiss. Bot., iii (I864).

- $(291,292,294,3$ I 4). Monatsber. d. k. Akad. Wiss. Berlin, I 874 .

- $(5 \mathrm{I}, 233)$. Ibid., 1876.

- (52). Jahrb. f. wiss. Bot., xi (1877).

- (52). Jahrb. f. wiss. Bot., 1878 .

- (294). Monatsb. d. k. Akad. Wiss. Berlin, I 879.

- (45I). Jahrb. f. wiss. Bot., I879. 


\section{Bibliography}

PRINGSheIM (302). Jahrb. f. wiss. Bot., xii (I880).

- (302). Quart. Journ. Mic. Sci., I882.

PuRiewitsch (329). Ber. d. deut. bot. Ges., I 895.

$(379,403)$. Ber. d. deut. bot. Ges., 1896.

RAdlKofer (i62). Brit. Assoc. Reports, Norwich, i 868.

(163). Festrede, München, I883.

v. RAUMeR (439). Bot. Zeit., I 878.

- $(364,365)$. Landw. Versuchsst., 1883.

RAUWENHOFF (449, 465). Ann. Sci. Nat., Bot., sér. 7, v (1878).

- (236). Bot. Zeit., I 879; Arch. Néerland. d. Sci. exactes et nat., xxiv (1890).

ReEss (445). Bot. Zeit., I 868.

- (II3). Monatsb. d. k. Akad. d. Wiss, zu Berlin, I891.

REESS und WILl (439). Bot. Zeit., I 875.

REID (253). Journ, of Physiology, 1890.

REINHARDT (I 86). Festschrift für Schwendener, Berlin, I891.

REINKE (227). Zeitsch. gesammt. Naturwiss., Halle, xxxix (I 872$)$.

- (447). Bot. Zeit., I 876 .

(170). Archiv f. die ges. Physiologie, xxvii (1882).

(292). Ber. d. bot. Ges., 1883.

(433). Unters. aus d. bot. Inst. d. Univ. Göttingen, iii ( 1883 ).

(317). Bot. Zeit., I884. Ibid., I886.

(296). Sitzber. d. k. Akad. Wiss. Berlin, I893.

(I80). Archiv f. micr. Anat., xliii, xliv (I894).

(416). Jahrb. f. wiss. Bot., 1897.

ReINke und BraunMÚller. Ber. d. deut. bot. Ges., I 899.

REINKE und RODEwald (170, 389). Studien über das Protoplasma, Unters. aus dem bot. Inst. d. Univ. Göttingen, iii (1881). ReNault (135, 143). Compt. Rend., Ixx (1870).

— (135, I49). Ann. Sci. Nat., Bot., sér. 6, i (1875).

(136). Ann. Sci. Nat., Bot., sér. 6, iii (1876).

(149, I 50). Nouv. Arch. du Muséum, sér. 2, ii (1879).

(144). Cours de Botanique fossile, 1881-85.

(147). Compt. Rend., xciv (1882).

(142). Mém. de la Soc. d'Hist. Nat. de Saône-et-Loire (1885).

Renault et Bertrand (136). Arch. Bot. du Nord de la France, 1886.

Renault et Grand'Eury (135). Acad. Sci., lxxviii (1874). —_ (145). Mém. prés. par divers savants à l'Acad. des Sciences, xxii (1875). 
Renault et Zeiller (136). Bull. de la Soc. de l'Industrie Minérale, 1888-90.

RENDLE (391). Ann, of Bot., ii (1888).

RitThausen (393). Die Eiweisskörper der Getreidearten u. s. w., I 872.

- (394). Pflüger's Archiv, I877 and 1879.

Rosenberg (439). Physiol. Cytol., I 899.

Rostafinski und Woronin (228). Bot. Zeit., I877.

Rostowzew (235). Bot. Centralbl., I 892.

Rothert (230). Sitzungsb. d. Krakauer Akad., math.-nat. Classe, xvii (1887).

- (230). Cohn's Beiträge z. Biol., I 888.

- $(496,499)$. Ibid., I 896.

(487). Flora, I9oI.

Russow (200, 235, 236, 238, 240). Vergleichende Unters. uib. d. Leitbündel-Kryptogamen. Mém. de l'Acad.imp. des Sciences de Saint-Pétersbourg, sér. 7, xix (1872).

- (175). Ann. Sci. Nat., Bot., sér. 6, xiv (1882).

- $(175$, I76). Sitzber. d. naturf. Ges. Dorpat, I882, I883.

(233). Schrift. naturf. Ges. Dorpat, I887.

Sablon, Leclerc DU (233). Ann. Sci. Nat., Bot., sér. 7, ii (I885).

- (210, 218). Ann. Sci. Nat., Bot., sér. 7, xi (1890).

- (413). Rev. Gén. de Bot., I895.

- (404). Compt. Rend., cxxvii (1898).

SACCHAROFF (366). Eisen als das thätige Prinzip der Enzyme u. d. lebendigen Substanz. Jena, I902.

SACHS (435). Bot. Zeit., I853.

- $(296,373,376)$. Sitzb. d. k. k. Akad. d. Wiss. in Wien, 1859.

- $(25 \mathrm{I}, 258)$. Versuchsst., I 859 , I 860.

- (350). Jahresb. d. Agr.-Chem., I860-I.

- $(25 \mathrm{I})$. Bot. Zeit., I860.

- (454). Jahrb. f. wiss. Bot., I 860.

(296). Flora, 1862.

— (497). Vorïbergehende Starrezustände periodisch beweglicher und reizbarer Pflanzenorgane, I863.

- Jahrb. f. wiss. Bot., I863.

$-(455,497)$. Flora, I863.

- $(447,448,455)$. Bot. Zeit., I863.

- $(374,451)$. Bot. Zeit., I864.

- (296). Flora, I 864 .

- $(256,360,490)$. Experimental-Physiologie, I 865.

- (442). Arb. d. bot. Inst. in Wü̈rzburg, 1871 . 
SACHS $(442,448)$. Arb. d. bot. Inst. in Wiurzburg, I 872.

- (445). Lehrbuch, 1873 .

- (445). Arb. d. bot. Inst. in Würzburg, i (1873).

- $(467,468,471,499)$. Flora, 1873. Arb. d. bot. Inst. in Würzburg, i (1874).

- $(193,270,277$.$) Arb. d. bot. Inst. in Würzburg, ii (1878).$

- $(220,270,445,466,471)$. Arb. d. bot. Inst. in Würzburg, ii (1879).

- (415). Über Stoff und Form der Pflanzenorgane. Arb. d. bot. Inst. in Wuirzburg, ii (1880), p. 452 ; ii (1882), p. 689.

— Vorlesungen über Pflanzenphysiologie, Würzburg, I 882.

- (309), Arb. d. bot. Inst. in Wiirzburg, I884.

- (415). Flora, I893.

SACHSSE (302). Chem. u. Physiol. d. Farbstoffe u.s. w., I 877.

- (288): Agriculturchemie, 1888.

SADEBECK (236). Die Entwickelung des Farnblattes, I874.

- (241). Jahrb. f. wiss. Bot., 1878.

Sali-Horstimar $(360,364,365)$. Vers. und Resultate üb.d. Nahrung d. Pflanze. Braunschweig, 1856.

SALTER $(385,403)$. Contributions to a fuller knowledge of starch grains, 1896. Thesis for D.Sc. Lond., 1896.

Sanio (215). Jahrb. f. wiss. Bot., I860; Bot. Zeit., I860.

- (221). Jahrb. f. wiss. Bot., ii (1863).

- (194). Bot. Zeit., 1863.

- (215). Bot. Zeit., I864.

- (188). Jahrb. f. wiss. Bot., ix (1873).

DE SAPORTA (1 50). Paléontologie française, sér. 2, ii (1875).

SAPOSCHNIKOFF (321). Ber. d. deut. bot. Ges., I 889, I890, I891, 1893.

- (355). Bot. Centralbl., 1895.

SARGANT, E. (104). Ann. of Bot., xiv (1900).

Sснаснт (99, I0I). Entwickelungsgeschichte des Pflanzenembryos. Amsterdam, 1850.

SCHAEFFER (262). Jahrb. f. wiss. Bot., I888.

SCHAFFNER (106). Bot. Gazette, xxiii (1897).

SCHELLENBERG (262). Bot. Zeit., I896.

Scrienk (144). Bot. Zeit., xxxiv (1876).

- (14I). Pflanzliche Versteinerungen. Berlin, I883.

- (220). Schimper's Bot. Mittheil. a. d. Tropen, Heft v (1893).

SCHIMPER, A. F. W. (304, 380). Bot. Zeit., I 880.

(386). Bot. Zeit., I881.

- $(437,438,440,482)$. Bot. Zeit., 1882.

- $(385)$. Bot. Zeit., I 883 . 
SCHIMPER, A. F. W. (306, 307, 377). Bot. Zeit., 1885 .

$-(353,356)$. Bot. Zeit., I 888.

$-(363,364)$. Flora, I 890 .

Schimper, W. P. (14I). Paléontologie végétale, i 869-74.

Schleiden (94). Ann. Sci. Nat., Bot., sér. 2, xii (1839).

SCHLicht (436). Landw. Jahrb., i 889.

Schloesing (332, 350). Compt. Rend., 1874.

SCHloesing and Laurent (346). Compt. Rend., 1890.

- (328). Compt. Rend., I 891, 1892.

Ann. de l'Inst. Pasteur, I 892.

Schloesing et Muntz (335). Compt. Rend., i 879.

Schualhausen (222). Mém. de l'Acad. Imp, de Saint-Pétersbourg, xxiv (1 877 ).

SchMidT (222). Bot. Zeit., I882.

SchmiedeberG $(365,394)$. Zeit. f. physiol. Chem., 1877.

Schmitz (215). Sitzber. d. naturf. Ges. zu Halle, 1874.

- (227). Sitzber. d. naturf. Ges. zu Halle, I 877.

- $(102,179,228,230)$. Sitzber.d. niederrhein. Ges. in Bonn, 1879.

- (170, 179, I83). Sitzber. d. niederrhein. Ges. Bonn, I880.

SchneEgans (409). Pharm. Centralbl., I 896.

Schneider (169, I73). Zoolog. Anzeiger, I861; Arbeiten des Zool. Inst. Wien, ix (1891).

Schützenberger (412). Les Fermentations. Paris, I876.

Schultze, Max (I66). Das Protoplasma der Rhizopoden und der Pflanzenzellen. Leipzig, I863.

Schultz-LuPiTz (342). Landw. Jahrb., I88I.

Schulze, E. (397). Landw. Versuchsst., I 882.

- Landw. Jahrb., I894.

- (410). Zeitsch. physiol. Chem., I 897.

ScHUNCK (365). Proc. Roy. Soc., 1 (1891).

SCHUNCK und MARCHLEWSKi (294). Liebig's Annal, cclxxxiv (I 895).

SchWARZ (I68, I70, I80). Die morph. u. chem. Zusammensetzung des Protoplasmas. Cohn's Beiträge, v (I887-I892).

SCHWENDENER (112,435). Naegeli's Beiträge zur wiss. Bot., I 860, I 862, I 868 .

- $(2 \mathrm{I} 8,445)$. Das mechan. Princip im Bau d. Monocotylen, I 874 .

- Mechanische Theorie der Blattstellung. Leipzig, I878.

- (26I, 475). Monatsber. d. k. Akad. d. Wiss. zu Berlin, 1881. Gesammelte bot. Mitth., i (I88I).

— Jahrb. f. wiss. Bot., xiii (1 882).

SCHWENDENER $(268,274)$. Sitzber. d. k. Akad. Wiss. Berlin, I 892. 


\section{Bibliography}

SCHWENDENER (275). Ibid., I 893.

SCHWERE (IOI). Flora, lxxxii (I896).

ScotT, D. H. (222). Quart. Journ. Mic. Sci., I 882.

- (6I). Brit. Assoc. Rep., Presidential Address to Section K, Liverpool, I 896.

- (224). Ann. of Bot., xi, I 897.

- (144, I46). Phil. Trans., clxxxix B (I897).

- (123). Phil. Trans., cxciv B (IgoI).

ScotT, J. (438). Gardener's Chronicle, I863.

ScotT and BREBNER (221). Ann. of Bot., iii (I889), vii (1893).

Shorey (397). Cited in Rev. Gén. de Bot., xiv, I902, p. 283.

Sigmund (4I3). Sitzb. d. k. k. Akad. d. Wiss. in Wien, I 890 , I 89I.

SOLEREDER (163). Systematische Anatomie der Dicotyledonen, I 899 (Eng. Ed., I907).

Solms-LaUbach (107). Bot. Zeit., 1878.

- (239). Ann. du Jard. bot. de Buitenzorg, iv (1884).

- (I50). Ann. of Bot., v (I89I).

- (I45). Bot. Zeit., I 892.

- (I 44). Jahrb. d. k. k. geol. Reichsanstalt, Wien, I895.

(I48). Bot. Zeit., I 897 .

Solms-Laubach et Capellini (150). Mém. Acad. Sci. Inst.

Bologna, sér. 5, ii ( 1892 ).

SORAUER (443). Bot. Zeit., I873.

SOROKINE (35I). Bot. Jahresber., I 875 .

SPALding (487). Bot. Centralbl., I893; Ann. of Bot., I 894.

STAHL (22I). Bot. Zeit, I 873.

- (233). Bot. Zeit., I876.

(II3, 23I). Beiträge zur Entwickelungsgeschichte der Flechten, 1877 .

- $(222,452,466,469)$. Bot. Zeit., xxxviii (1880).

(468). Jenaische Zeitsch., I 88 I.

- (449). Jenaische Zeitsch., xvi (I883).

- (470). Ber. d. deut. bot. Ges., I884. Bot. Zeit., 1884.

- (285). Bot. Zeit., I 894 .

- (264). Bot. Zeit., I 897 .

STANGE (254). Bot. Zeit., I $\$ 92$.

STEBLER $(443,447)$. Jahrb. f. wiss. Bot., 1878 .

STEINBRINCK (276). Ber. d. deut. bot. Ges., I 894.

Stenzel (9o). Nov. Act. d. deutsch. Akad. d. Naturf., xxxviii ( 1876$)$.

StoklaSA (399). Sitzber. d. k. k. Akad. d. Wiss. in Wien, I 896. STrasburger (232). Jahrb. f. wiss. Bot., vii (1868). 
Strasburger (9I, 198). Die Coniferen u. die Gnetaceen. Jena, I 872 .

- $(239-40)$. Bot. Zeit., 1873 .

- (237). Ueber Azolla. Jena, 1873.

- (166, 170). Jenaische Zeitsch., ix (1876).

- (98). Jenaische Zeitsch., xi (1877).

_-_ (108, 456, 469). Jenaische Zeitsch., xii (1878).

- (91, 100, 102, 108). Die Angiospermen u. die Gymnospermen. Jena, I 879.

- (100, 179). Jenaische Sitzber., 1879.

- $(184,191,384,444,491)$. Bau und Wachsthum der Zellhäute. I 882 .

- $(268,274,377)$. Bau u. Verrichtungen d. Leitungsbahnen. (Histol. Beitr., iii) Jena, I891.

(6I). Ann. of Bot., viii (I894).

(6I). Jahrb. f. wiss. Bot., I 897 .

- (192). Jahrb. f. wiss. Bot., xxxi (1898).

STUR (141, 142). Abh. d.k. k. geol. Reichsanst. zu Wien, viii (1877). - (14I, I44). Sitzber. d. k. k. Akad. d. Wiss. in Wien, math.naturw. Classe, lxxxiii (I88I).

- (146). Ibid., Ixxxviii (I883).

SUZUKI (352). Bull. of the Coll. of Agriculture, Tokio, I 898.

TACKE (327). Landw. Jahrb., I889.

TAmmes (453). Landw. Jahrb., I90o.

TANGL (1 76). Jahrb. f. wiss. Bot., xii (1880).

Thoné (408). Bot. Zeit., i 865 .

Thompson, D'Arcy (1 45). Trans. Edinburgh Geol. Soc., iii (1 880). van Tiegheir (9I). Ann. Sci. Nat., Bot., sér. 5, ix (1869).

- (208). Ann. Sci. Nat., Bot., sér. 5, xiii (1870).

- (106). Ann. Sci. Nat., Bot., sér. 5 (1871).

- (97). Recherches sur la structure du pistil, I87I.

- (225). Ann. Sci. Nat., Bot., 1872.

- (433). Ann. Sci. Nat., Bot., xvii (1873).

- (433). Compt. Rend., Ixxxiv (1877).

- (141). Compt. Rend., Ixxxix (I879).

- $(236)$. Bull. Soc. Bot. de France, 1883 .

-_- $(266,407)$. Bull. Soc. Bot. de France, 1886 .

- $(210,211,241)$. Journ. de Bot., iv (1890).

vaN Tieghem and Douliot $(210,217)$. Ann. Sci. Nat., Bot., sér. 7, iii ( I 886).

(197). Ann. Sci. Nat., Bot., sér. 7, viii (1889).

TimiriazeFF (293, 312). Bot. Zeit., 1869.

- 13ot. Jahresb.. I875. 
Timiriazeff, Ann. de Chim. et Phys., I877.

Bot. Zeit., I885.

Compt. Rend., 1890.

$(292,294,312,321)$. Croonian Lect., Proc. Roy. Soc., I903.

Tischutkin (437). Arb. d. St. Petersb. naturf. Ges., 1891.

TöpleR (398). Landw. Versuchsst., I 861.

ToLLENS. Handb. d. Kohlenhydrate, I 895.

Traube (250). Archiv f. Anat. u. Physiol., 1867.

- $(250,47 \mathrm{I})$. Bot. Zeit., 1875 .

Treat, Mrs. (438). American Naturalist, 1873.

Trécul (222). Baillon's Adansonia, vii-ix.

Tretjakow (Io8). Ber. d. deut. bot. Ges., xiii (1895).

Treub (I 3 ). Bot. Zeit., xxxi (I 873).

-- (197). Le méristème primitif de la racine. Leyden, I876.

- (240). Musée bot. de Leide, ii (I877).

- (107). Natuurkund.Verhandel.koninkl. Akad., Deel xxi (1879).

- (223). Ann. du Jardin bot. de Buitenzorg, I882.

— (239). Ibid., iv, v, vii, viii (I 884-90).

- (I03). Ibid., x (IS9I).

- (354). Ibid., I 895 .

(I09). Ibid., xv (1898).

Treub et Mellink (100). Archives Néerlandaises, 1880.

TsCHIRCH (294). Unters. ü. d. Chlorophyll, I 884.

TSCHISTIAKOW (240). Nuov. Giorn. bot. Ital, v (I873).

- (236). Ann. Sci. Nat., Bot., sér. 5, xix (I874).

UNGER (480). Bot. Zeit., I 862.

Usher and Priestley (29I). Proc. Roy'. Soc., Igo6.

VAIZEY (233). Ann. of Bot., i (1887).

- (56). Ann. of Bot., iv (IS9o).

Van'T Hoff (252). Ber. d. deut. chem. Ges., I 894.

VELTEN (169). Flora, I873; Sitzb. d. k. k. Akad. d. IIiss. in IVien, lxxiii, lxxiv (1876).

(456). Flora, I 876.

VERWORN (417, 425). General Physiology (Eng. Trans., 1899).

Vesque (100). Ann. Sci. Nat. Bot., sér. 6, vi (1878).

- $(259,267)$. Ibid., I880.

$(273,277)$. Ibid., 1883 .

VINES (437). Journ. Linn. Soc., I 877.

- $(450,480,499)$. Arb. d. bot. Inst. in Würzburg, ii (I 878$)$.

- (394). Journ, of Physiology, iii (I 8Eo).

$(265,302,447)$. Physiology of Plants, 1886.

- (120). Ann. of Botany, ii (I888).

$-(346,347)$. lbid., 1889 . 
ViNES (375). Ann. of Bot., I89I.

- (437). Ann. of Bot., I 897 onwards.

(83). Science Progress, 1898.

Vöchting, Organbildung im Pflanzenreich, I878.

- $(445,465,472,497)$. Die Bewegungen der Blüthen und Früchte. Bonn, I882.

- (416). Jahrb. f. wiss Bot., I885 and 1900.

- (494). Jahrb. f. wiss Bot., I 886.

- $(465,466)$. Bot. Zeit., I 888.

- (486). Jahrb. f. wiss. Bot., ii (I890).

- (449). Jahrb. f. wiss. Bot., I894.

VOGL (I88). Sitzb. d. k. k. Akad. d. Wiss. in Wien, xlviii (I863). DE VRIES (454). Arch. Néerlandaises, I 870.

- (214). Flora, lv (I872).

- $(456,470)$. Arb. d. bot. Inst. in Würzburg, i (1 872); ib., i (1873).

- (446). Arb. d. bot. Inst. in Wiirzburg, 1874 .

- $(254,443)$. Unters. ii. d. mechan. Ursachen d. Zellstreckung, I 877.

- $(450,491)$. Bot. Zeit., I879.

- (254). Jahrb. f. wiss. Bot., I884.

- (174). Jahrb. f. wiss. Bot., xvi (1885).

- (438). Bot. Zeit., I886.

- (105). Compt. Rend., cxxix (1899).

WAGER (230). Ann. of Bot., iv (1889).

- (179). Ann. of Bot., v (1891).

- (23I). Ann. of Bot., vi (I 892), vii (I893), x (I896), xii (I898).

WAGNER (332). Versuchsst., I 868.

WAKKLR (392, 398). Jahrb. f. wiss. Bot., 1888.

WVALDNER (233). Die Entwickelung der Sporogone u.s. w. Leipzig, 1887.

WARD, MARShall (IOO). Journ. Linn. Soc. Bot., xvii (I880).

— Quart. Journ. Mic. Sci., I 884 .

- (344). Phil. Trans., I 887.

- $(405,484)$. Ann. of Botany, I 888.

- (453). Phil. Trans., B, I894.

- (436). Brit. Assoc. Reports, I899.

Ward, Marshall, and Dunlop (408). Ann. of Bot., 1887.

WARINGTon (334). Journ. Chem. Soc., I878, I879, I 884, I891.

WARMING (93). Hanstein's Bot. Abhandl., ii (I873).

- (438). Soc. d'Hist. Nat. de Copenhague, I 873 .

- $(98$, I00). Ann. Sci. Nat., sér. 6, v (1877).

W'́ebier (99, I2 I). Bot. Gaz., xxiv (I897). 
WebBer (I05). Bull. 22 of U.S. Department of Agriculture (1900). WEBer (309). Arb. d. bot. Inst. in Würzburg, ii (1878).

Weber und Stenzel (147). Beiträge z. Kenntniss der Medullosae.

Chemnitz, I896.

WEIsS, J. E. (217, 221). Flora, lxiii (I880); Bot. Centralbl., xv (1883).

- (141, I42). Abh. z. geol. Specialkarte von Preussen, v (I884). IVENT (175). Jahrb. f. wiss. Bot., xix (I888).

WERMINSKI (392). Ber. d. deut. bot. Ges., I886.

Westermaier (222). Sitzb. d. k. Akad. Wiss. zu Berlin, 1882.

- $(254,273)$. Ber. d. deut. bot. Ges., 1883 .

DE Wevre (439). Ann. Sci. Nat., Bot., I 895.

WeYL (394). Zeitsch. f. physiol. Chem., I 877.

- (394). Ber. d. deut. chem. Ges., I880.

Wieland (150). Amer. Journ. of Sci., I899.

Wieler $(254,258)$. Cohn's Beiträge z. Biol., I 893 .

Wiesner (188). Sitzb. d. k. k. Akad. d. Wiss. in Wien, ii (1864).

- (296). Festschr. d. zool.-bot. Ges. in Wien, 1876.

$(265,267)$. Sitzb. d. k. k. Akad. d. Wiss. in Wien, 1876 .

(296). Entstehung d. Chlorophylls, I 877 .

$(465,466,467)$. Denksch. d. k. k. Akad. Wiss. in Wien, xxxix (1878), xliii (1880).

(284). Sitzb. d. k. k. Akad. d. Wiss. in Wien, 1879.

(491). Heliotropische Erscheinungen, I880.

13ot. Zeit., I 880 .

(446). Bewegungsvermögen, I88I.

(447). Sitzb. d. k. k. Akad. d. Wiss. in Wien, 1883.

(473). Ibid., lxxxix (1884).

(473). Ber. d. deut. bot. Ges., ii (1884).

(184). Sitzb. d. k. k. Akad. d. Wiss. in Wien, xciii (1886).

(451, 496). Ibid., I893.

WIESNER and MOLISCH $(285,288)$. Ibid., I 889 .

WILHELM (22I). Beitr. z. Kenntniss d. Siebröhrenapparates.

Leipzig, 1880.

IVILLE (227). Ber. d. deut. bot. Ges., iii (1885).

- (185). Entwickelungsgeschichte d. Pollenkörner, I 886.

Williams (227). Ann. of Bot., xi (1897); xii (1898).

Willianison (134). Phil. Trans., I868-93.

Williamson and ScotT (138). Phil. Trans., I893-5.

WinOGRADSKY (370). Bot. Zeit, I887.

- $(337,370)$. Ann. de l'Inst. Pasteur, I890-I.

Arch. d. Sci. biol. de l'Inst. imp. à Saint-Pétersbourg, I 892.

Compt. Rend., I893, I894. 
Winogradsky (329). Arch. d. Sci. biol. de l'Inst. de méd. exp. Saint-Pétersbourg, I895.

Centralbl. f. Bakt., I 896.

Winogradsky et OMeliansky (339). Archives des Sciences Biologiques, I 899.

VAN VVisselingh (192). Jahrb. f. wiss. Bot., xxxi (1898).

IVCLFF $(358,368)$. Versuchsst., I 864,1865, I 868.

- $(332)$. Versuchsst., 1867.

- $(359,360)$. Aschenanal. v. landw. Produkten, i (1871), ii (1880).

V. WOLKOFF und MAYER (422). Landw. Jahrb., i 874.

Woronin (343). Mém. de l'Acad. d. Sciences de Saint-Pétersbourg, I 866 .

- Ann. Sci. Nat., I 867.

WORSDELl. Ann. of Bot., x ( 1896 ), xii ( 1898 ).

WORTMANN $(422,423)$. Arb. d. bot. Inst. in Würzburg, I 880.

- (487). Bot. Zeit., I88I.

- (447). Bot. Zeit., I882.

- (486). Bot. Zeit., I883.

- (477). Ber. d. deut. bot. Ges., I 887.

- $($ I $85,375,477,484)$. Bot. Zeit., I887, I888, I889, I890.

- (375). Bot. Zeit., I 890.

IVÜRTz (376, 410). Compt. Rend., xc, xci (1880).

WÜRTZ et Bouchut (4I0). La Papaine. Paris, I879; Compt. Rend., lxxxix (1879).

ZACHARIAS (227). Bot. Zeit., I 887 .

- (179). Bot. Zeit., I890, I893.

- (185). Flora, lxxiv (1891).

ZALESKI (356). Ber. d. deut. bot. Ges., I9OI.

ZEILlér (139). Ann. Mines, Mém., sér. 8, ii (1882).

- (146). Ann. Sci. Nat., Bot., sér. 6, xix (1884).

- (136, I48). Flore fossile du Bassin houiller et permien d'Autun et d'Épinac, Part I (1890).

- ( I 43). Mém. de la Soc. géol. de France, 1893.

— (I40). Compt. Rend., I895.

- (140). Compt. Rend., I896.

Ziegenbein (422). Jahrb. f. wiss. Bot., I893.

ZimMERMANN (456). Arb. d. bot. Inst. in Würzburg, 1882.

- (185). Die Pflanzenzelle, I887.

- (29I, 398). Beitr. z. Morph. u. Phys., i (I 893).

ZiNGer (I03). Flora, $S_{5}$ (1898).

ZölLER (396). Ber. d. deut. chem. Cies., I88o. 


\section{INDEX}

Absorption, law of, $35 \delta$.

- of gases, theories of, 281 .

- selective, 359 .

Achromatin, I80.

Aerobic, 428 .

After effect, 499 .

Albumins, 394, 395 .

Aldrovanda, 440.

Alethopteris, $136,146,147$.

Aleurone grains, 39 1.

- layer, 402.

Amitosis, I8I.

Anabolic, 43I.

Anachoropteris, 149 .

Anaerotic, 428 .

Anetra, 233.

Angiopteris, 236 .

Annual rings, cause of, 214 .

Anmularia, I 42 .

Antheridium of Gymnosperms, 99 .

Antherozoids of Gymnosperıns, 99; I 21 .

Anticlinal, I93.

Antiphyt, 48 .

Antipodal cells, 100.

Apheliotropism, ${ }^{6} 4$.

Apogamy, 51, 108 .

Apogeotropism, $4 \%$.

Apospory, 5 I.

Apostrophe, $45^{2}$.

Archaeocalamites, $\mathrm{I}_{41}, \mathrm{I}_{42} 2$.

Archesporium, $24^{1}$.

Arthrodendron, I4I.

Arthropitys, 143.

Artificial cells of Traube, 250 .

Asparagin, 397.

Assimilation, nature of, $4^{\mathrm{I}} 4$.

Astely, 210.

Asterophyllites, I 43.

Astromyelon, 142.

Auxanometer, 443 .

Azolla, 237 .

Bacteria, palaeozoic, I4 I

Bacterio-purpurin, $29 \AA$.
Bacteroids, 345 .

Basichromatin, I 80 .

Bennettites, I 50.

Betain, 397 .

Betulase, 408.

Biogen, 418 , 425 .

Bioplasts, 172 .

Bordered pits, 220.

Botrychium, 235.

Botryopteris, I35, I49.

Bowmanites, 143 .

Bromelin, 4I I.

Bruckmannia, I 42 .

Calamodendron, 143 .

Calamopitys, I $4 \mathrm{I}$.

Calamostachys, I 42 .

Cane-sugar, 307 .

Carbohydrates of leaf, 307 .

- estimation of, 309 .

Carotin, 298.

Caroubinase, 406.

Caseins, 394.

Catabolic: see Katabolic.

Caulome, 66, 67 .

Cell-wall, composition of, 187 .

- formation of, 192.

- hypothesis of structure of, 182 , $18_{3}, \mathrm{I} 84$.

Celluloses, I $8 \%$.

Centrosome, I $8 \mathrm{I}$.

Chalazogamy, 103 .

Chara, 227.

Cheirostrobus, I 44.

Chemotaxis, 484 .

Chemotropism, $4_{4} 4$.

Chitin in cell-walls, 192.

Chlorophyll apparatus, 289 .

- energy relations of, $3 \mathrm{I} 2$.

- screen theory of, $3^{1} 4$.

Chlorophyllan, 294.

Chloroplast, 36 .

- structure of, 292.

Chlorovaporization, 266.

Cholesterin, 398 . 
Cholin, 399.

Chromatin, 180.

Cingularia, $\mathbf{1}_{4} 2$.

Circumnutation, 445 .

Cladosiphonic stele, 122, 214.

Cladoxylon, I 48.

$\mathrm{CO}_{2}$, optimum percentage of, 379 .

Collema, 23 I.

Combustion, physiological, $4^{2} 3$.

Compass plants, 468 .

Cone, theories of, 90.

Conidia, 50.

Contact perception, 475 .

Cordaiteae, 149 .

Cork, 221.

Cradina, $4 \mathrm{II}$.

Curvature, mechanism of, 490 .

Cytase, $4^{\circ} 4$.

Dadoxylon, I 34 .

Danaea, 236.

Derived albumins, 395 .

Dermatosomes, 184 .

Diageotropism, 470.

Diaheliotropism, 464 .

Dialystely, 2 I 0.

Diastase, $374,40 \mathrm{I}, 403$.

Differentiation of leaf, Frank's theory of, so.

Diffusion of gases through small apertures, 287 .

Dionaea, 439, 483, 484 .

Drosera, $438,4^{81}, 4^{84}$.

Drosophyllum, 439 .

Ectoplasm, I 73 .

Elaborated sap, 372 .

Elaioplasts, 398 .

Electrical changes, $4^{6} 3$.

Embryo, I07.

Embryophyta siphonogama, II 8, I 25.

- soidogama, I IS, I25.

Emulsin, 408 .

Enchylema, I68, I 70.

Endistem, 200.

Endocarpon, 23I.

Endodermis, 208.

Endoplasm, I 73 .

Energy, solar, utilization of, 32 r.

Engelmann's test for oxygen, 316 .

Enzymes, 401.

- localization of, 403 .

Epiblema, 197.

Epinasty, 446.
Epipodium, 74.

Epistrophe, 452.

Equisetum, 240.

Erepsin, 409.

Ergot, 23 I.

Etiolation, 448.

Etiolin, 295.

Eusporangiatae, 117 .

Existem, 200.

Exodermis, 222.

Fat, digestion of, $4^{1} 2$.

Ferment glucosique, 407 .

Fermentation, 426 .

Fertilization, nature of, 34, 102.

- double, 103.

- of Fucus, 227.

Filiform apparatus, 99, 10 I.

Filtration, vital, 253 .

Flower, morphology of primitive, 87 .

Foliar base, 7 1,73 .

Formaldehyde in leaves, 308.

Fragmentation, I8I.

Fungi, classification of, 229.

Galvanotropism, 487 .

Gamostely, 210.

Gaseous interchanges, $28 \mathrm{I}$.

Gasometer (Timiriazeff's), 315 .

Gaultherase, 408 .

Gelatines, 394, 396.

Genera plantarum, 123.

Genlisea, 44I.

Geotropism, 469 .

Ginkgo, I 50.

Gliadin, 396.

Globulins, 393 .

Glossopteris, I39.

Glucase, 407 .

Glucosides, 399 .

Gluten-fibrin, 396 .

Glutenin, 396 .

Glycin, 397 .

Glycogen, 389 .

Gonidia, 50.

Granulation, 482 .

Gravi-perception, 472.

Growth, grand period of, $44^{2}$.

- rhythm of, 447 .

Hadrom, 219.

Hadromase, 406.

Haematoporphyrin, 294.

Haustoria in embryo-sac, 102. 
Heliotropism, 464 .

Helminthostachys, 235.

Heterangium, 138, I47, I48.

Heterostylism, 105.

Histogenetic layers, 194, I 95.

Hordein, 396.

Humus, 33I, 332.

Hyaloplasm, I68.

Hydrocyanic acid, occurrence of, 354 .

Hydroplastids, 392.

Hydrotropism, 487 .

Hymenophyllizm, 237.

Hypochlorin, 294.

Hypoderma, 205.

Hyponasty, 447 .

Hypopodinm, 74 .

Idioplasm, 33 .

Induction period, 498 .

Intussusception, $33,36,183,185$.

Inulase, 404 .

Inulin, $307,3^{89}$.

Invertase, 406.

Isoëtes, $24^{\circ}$.

Kaloxylon, 147 .

Karyokinesis, I8I.

- in myxomycetes, 230.

Katabolic, 4I9, 43I.

Kaulfussia, 236.

Kern, 386.

Kleberschicht, 402 .

Klinostat, $47 \mathrm{I}$.

Lactase, 407 .

Lagenostoma, 138, I49.

Latent period, 498.

Laticiferous tissue, 222.

Leaf, anatomy of, 223.

- conception of, 70 .

Leaflets, movements of, 455 .

Lecithin, 398.

Lenticels, 222.

Lepidodendron, 144.

Lepidostrobus, 146.

Leptom, 2 I 9.

Leptosporangiatae, I I 7 .

Leucin, 397.

Lichens, nature of, II 2, 229, 23 I, 435 .

Light, influence of, 452 .

Linin, I 80.

Liorhizeae Dicotyleae, 128.
Lipase, $4 \mathrm{I} 2$.

Liverworts, 232.

Lophophyllum, 150.

Lotase, 409.

Luminous bacteria, 289.

Lycopodium, 238, 240.

Lyginodendron, I3S, $\mathrm{I}_{47}, \mathrm{I}_{4} 8$.

Nacrostachya, I 37 .

Maltase, 407.

Marattia, 236 .

Marsilia, 237,238 .

Medullosa, I 48 .

Melizitase, 408.

Meristele, 2 I I.

Mesistem (of Russow), 200.

Mesozoic flora, I 5 I.

Mestom, 2 I 9 .

Metabiosis, 434, 436 .

Metamorphosis, progressive, 66 .

Micellae, I 83 .

Microsomata, I 7 I, I9I.

Middle lamella, I88.

Mitosis, I8I.

Moss, structure of, 233 .

Mucilage, 390.

Mycoplasm, 347.

Mycorrhiza, $43^{6}$.

Miyelopteris, I 47.

Myeloxylon, $136,147,1_{4} 8$.

Myosins, 394.

Myrosin, 408.

Negative pressure, 267 .

Nematophycus, I 40.

Nepenthes, 437 .

Neuropteris, I36, 146, I47.

Nitrification, 334 .

Nitrogen, fixation of, by bacteria, 325.

Nuclear division, I8I,

Nuclein, 181 .

Nucleinic acid, I8I.

Nucleolus, I 81 .

Nucleus, I 78 , I 79 .

- of starch grain, 386 .

Nutation, 445 .

- undulating, 447.

Nyctitropic, 453 .

Oecology, 2 I.

Oedematin, I 80.

Ophioglossum, 235, 236 .

Orthotropic, 445. 
Osmotaxis, $4^{87}$.

Osmotic pressure, range of, 254 .

Ovule, morphology of, 93 .

- development of, 98 .

Oxalate, calcic, formation of, 353 .

Oxychromatin, 180.

Pacytheca, I4I.

Palaeostachya, $\mathbf{1}_{42}$.

Papain, 4 IO.

Papaw tree, enzyme of, 376 .

Paraheliotropism, 45I, 465 .

Parasitism, 435.

Parthenogenesis, I09.

Pecopterideae, I 49.

Pectoses, I87, I 89 .

Pepsin, 409.

Pericambium, 2 I 6.

Periclinal, 193 .

Pericycle, 216.

Periderm, 215.

Perimedullary zone of Flot, 2 I I.

Peristem, 200.

Phleoterma, 2 I I.

Phloem, internal, 220.

Photo-epinasty, 457 .

Photomechanical induction, $49^{8}$.

Photosynthesis, theories of, 301 .

- inhibition of, 32 I.

Phototaxis, 469 .

Phototonus, 457 .

Phyllocyanin, 293.

Phylloglossum, 239 .

Phyllome, 66, 67 .

Phyllopodium, 73.

Phylloporphyrin, 294.

Phyllosiphonic stele, I 22,2 I 4.

Phylloxanthin, 293.

- iron in, 365 .

Phyto-actinometer, 322.

Pilularia, 237,238 .

Pinguicula, $44^{\circ}, 4^{8} 3,4^{8} 4$.

Pinites, $5_{52}^{2}$.

Pitcher plants, $43 \%$.

Placenta, morphology of, 97 .

Plagiotropic, 445.

Plasma membranes, $174,252,255$.

Plasmolysis, $25+$.

Plastids, independent action of, 297 .

Pollen tube, homologies of, $9^{8}$.

- nuclei in, 98 .

- growth of, Io6.

Polyembryony, 108.

Polystely, 210.
Poroxyleae, 136, I 50.

Pothocites, $\mathbf{I}^{2}$.

Protein, theories of construction of, 35 I, 353 .

Protein, labile, 416, 418 .

Proteoclasis, 409.

Proteosomes, $4 \mathrm{I} 7$.

Prothallus of Angiosperms, IOI.

- of Gymnosperms, I02.

- of Pteridophyta, 235.

Protophyllin, 295.

Protophyt, 48 .

Protopitys, 148 .

Protoplasm, 167 .

- continuity of, 75 .

Protostelic, 213.

Prototaxites, I 40.

Psilotum, 239.

Pulvini, mechanism of, 4 So.

Pyrrol, 294.

Rachiopteris, I47.

Raffinase, 408.

Rand, 385 .

Rectipetality, 445.

Reduction divisions, 61, 182 .

Reserve materials, 379 .

Resin ducts, 225 .

Respiration, 4I9; intramolecular. 426.

Respiratory quotient, $42 \mathrm{I}$.

Rhamnase, 408.

Rheotropism, $4^{8} ;$.

Rhythm, 448, 453, 454.

Riccia, $23^{2}$.

Root-pressure, ${ }_{2} 56$.

- periodicity of, 257 .

Roots, corrosive action of, 25.5 .

- lateral, 223 .

- sensitiveness of, 479 .

- selective power of, 247 .

Rotation, movement of, $45^{6}$.

Salvinia, 237 .

Saprophytes, 435 .

Sarracenia, 437 .

Schizostely, 2 I I.

Schleimschicht, 33 .

Seismotropism, $4^{88}$.

Selaginella, 239, 240.

Seminase, 406.

Sieve-tubes in Algae, $22 \%$.

Sigillaria, I 35, I45. 146.

Siphonostely, 213. 
Spectrophore, 317 .

Spencerites, 146.

Sphaerotheca, 231.

Sphagnum, 233.

Sphenophyllum, 135, 143.

Sphenopteris, I 47.

Spongioles, 249 .

Sporangiophore, 68,88 .

Sporogenous tissue, sterilization of, 56,69 .

Sporophylls, nature of, 86 .

- strobiloid origin of, 86 .

Sporophyte, intercalation of, 55,56 , 62.

Stamen, homologies of, 92 .

- irritability of, 480,500 .

Starch-forming corpuscles, $3^{8} \mathbf{r}$, 384 .

Starch-grain, crystalline structure of, 388 .

- lamination of, 385 .

Statoliths, 474,475 .

Stele theory, 208 .

Stem, junction with root, $2 \mathrm{I} S$.

Stimuli, transmission of, 495 .

Stomata, 259.

Stratification, 184 .

Striation, 184 .

Snlphur bacteria, 370.

Symbiosis, 341, 343, 349: 435.

Synergidae, 101.

Tannase, 409 .

Tendrils, 476 .

Tensions, 444.

Thallome, 67 .

Thermotonus, 457 .

Thermotropism, 486 .

Thickening ring of Sanio, 194.
Thickening, abnormal secondary, $215,221$.

Thinnfeldia, 146.

Thyloses, 187 .

Tissue, transfusion, 224.

- systems of, 219.

- classification of, 204.

Tmesipteris, 239.

Tonoplasts, 174 .

Tonotaxis, 487 .

Tracheids, 220.

Translocation, 373,376 .

Transpiration, $2 j 8$.

- path of current, 269.

- functions of, 268.

Traumotropism, 487 .

Trehalase, 408 .

Trichomanes, 237 .

Trichome, 67 .

Trypsin, 409 .

Ulodendron, 145.

Utricularia, 79, $44^{\circ}$.

Vertebraria, $\mathrm{I}_{4} \mathrm{O}$.

Vitellins, 394, 396.

Volkmannia, $\mathrm{I}_{43}$.

Water, resistance of to tensile stress, 275.

- culture, $36 \mathrm{I}$.

IVilliamsonia, 150 .

Xanthophyll, 293, 29\$.

Xenia, I04.

Zein, 396.

Zygopteris, 136, 149.

Zymase, 429. 


\section{OXFORD}

PRINTED AT THE CLARENDON PRESS

BY HORACE HART, M.A.

PRINTER TO THE UNIVERSITY 


\section{OXFORD UNIVERSITY PRESS}

\section{PUBLICATIONS IN NATURAL SCIENCE}

AND MATHEMATICS 



\section{Botany}

Series of Botanical Translations, under the general editorship of Professor I. BAYLEY BaLFour

Royal 8vo, unless otherwise specified. The prices are for copies with morocco back and copies in cloth respectively.

Jost's Lectures on Plant Physiology. Authorized English translation by R. J. Harver Gibsos. 24s. net and 21s. net.

Schimper's Geography of Plants, authorized English translation by W. R. Frsher, revised by P. Groosr and I. Bayley Balfour. With

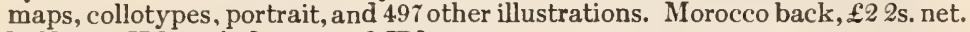
Pfeffer's Physiology of Plants, a treatise upon the Metabolism and Sources of Energy in Plants. Second fully revised Edition, translated and edited by A. J. Ewart. Vol. I, £1 6s. net and £1 3s. net. Vol. II, 16s. net and 14s. net. Vol. III completing the work, $£ 11 \mathrm{~s}$. net and 18s. net.

Goebel's Organography of Plants. Authorized English Edition

by I. Bayley Balfour. Part I, General. 12s. net and 10s. net. Part II, Special. 24s. net and 21s. net.

Goebel's Outlines of Classification and Special Morphology of

Plants. Translated by H. E. F. Garnsey, and revised by I. Bayley

Balfour. Morocco back, £2 2 s. net (a few copies only remain).

Sachs's History of Botany (1530-1860). Translated by H.E.F.

Garnsey, revised by I. B. Balfour. 2nd impression. Cr. 8vo, cloth, 10s. net.

A History of Botany, 1860-1900: a continuation of Sachs's

History. By J. Rervolds Greex. Crown 8vo. 9s. 6d. net.

De Bary's Comparative Anatomy of the Vegetative Organs of the Phanerogams and Ferns. Translated by F. O. Bower and D. H. ScoTt. £1 4s. net and $£ 1$ s. net.

De Bary's Comparative Morphology and Biology of Fungi, Mycetozoa and Bacteria. Translated by H. E. F. Garssey, revised by I. Bayley Balfour, $£ 14$ s. net and $£ 11$ s. net.

De Bary's Lectures on Bacteria. Second edition. Translated by H. E. F. Garnsey, revised by I. Bayley Balfour. Crown 8vo, clotl, 5s. net. Solms-Laubach's Introduction to Fossil Botany. Translated by H. E. F. Garssey, revised by I. Baylezy Balfour. 17s. net and 15 s. net. Fischer's Bacteria, translated by A. Coppex Joses. Cloth, 7s. 6d, net. Iinuth's Handbook of Floral Pollination, based upon Hermann Müller's work, The Fertilization of Flowers by Insects, translated by J. R. Aissworti Davis. Vol. I, 21s. net and 18s. net. Vol. II, 35̃s. net and 31s. 6d. net. Vol. III, 31s. 6d. net and 28s. net.

Solereder's Anatomy of the Dicotyledons. Translated by L. A. Boodle and F. E. Frtтsch. Revised by D. H. Scott. Two volumes, 27s. 6d. net each and 24 s. net each.

Warming's Oecology of Plants. English edition by P. Groosr and I. B. Batrour. 10s. net and 8s. 6d. net.

On the Physics and Physiology of Protoplasmic Streaming in Plants. Ву A. J. Ешавт. With 17 illustrations. 8s. 6d. net. List of British Plants. By G. C. Druce. Crown 8vo, paper covers.

2s. 6d. net; cloth interleaved, 3s. 6d. net. 
Floral Mechanism : Diagrams and Descriptions of Common Flowers. By A. H. Church. Royal 4to. Part I, Types I-XII (Jan. to April). With coloured plates and numerous other figures. 21s. net.

Index Kewensis; an enumeration of the Genera and Species of Flowering Plants from the time of Linnaeus to the year 1885. Edited by Sir J. D. Hooker and B. D. JAckson, 2 vols. 4to, morocco back, $£ 10$ 10s. net.

Supplement I (1886-1895), can be ordered from Mr. Frowde, price with the Index $£ 1213 \mathrm{~s}$. net; it is not sold separately. Supplement II (1896-1900), 28s. net. Or Fasc. I, 12s. net; Fasc. II, 12s. net. Supplement III (1901-1905), 28s. net.

Annals of Botany. Edited by I. Bayley Balfour, D. H. Scotr, J. B. Farmer, and R. Thaxter ; assisted by other Botanists. Royal 8vo, morocco back, with many plates and illustrations in the text. Subscription price for each four parts, 30s., with 1s. $6 \mathrm{~d}$. for foreign postage.

Vol. I, Nos. 1-4. Sold only as part of a complete set.

Vol. II, Nos.5-8. Sold only as part of a complete set.

Vol. III, Nos. 9-12. £2 12s. 6d. Vol. IV, Nos. 13-16. £2 5s.

Vol. V, Nos. 17-20. £2 10s. Vol. VI, Nos. 21-24. £2 4s.

Vol. VII, Nos. 25-28. £2 10s.

Vol. VIII, Nos. 29-32. £2 10s.

Vol. IX, Nos. 33-36. £2 15s.

Vol. X, Nos. 37-40. Vol. XI, Nos. 41-44.

Vol. XII, Nos. 45-48. Vol. XIII, Nos. 49-52.

Vol. XIV, Nos. 53-56. Vol. XV, Nos. 57-60.

Vol. XVI, Nos. 61-6i, including a Life of Sir William Hooker, with a photogravure portrait.

Vol. XVII, Nos. 65-68. Vol. XVIII, Nos. 69-72.

Vol. XIX, Nos. 73-76. Vol. XX, Nos. $77-80$.

Vol. XXI, Nos. 81-84. Vol. XXII, Nos. 85-88.

Vol. XXIII, Nos. 89-92. Vol. XXIV, Nos. 93-96.

(The price of a volume is $£ 216$ s. unless stated.)

Indexes to the Annals of Botany. Prepared by T. G. Hrtu, under the direction of the Editors. Royal 8vo. (1) Vols. I-X. (2) Vols. XI-XX. Each, paper covers, 5s. to subscribers; to non-subscribers, 9s. ; morocco back, to subscribers, $6 \mathrm{~s}$.; to non-subscribers, $10 \mathrm{~s}$. $6 \mathrm{~d}$.

Reprint: Life of Sir WILLIAM Hooken, with portrait, 3s. 6d. net.

'The Flora of Berkshire; with short Biographies of the Berkshire Botanists. By G. C. Druce. Crown 8vo. 16s. net.

'The Herbarium of the University of Oxford. By the same. Crown 8vo. $6 \mathrm{~d}$.

'The Dillenian Herbaria. By G. C. Druce. Edited with Introduction by S. H. Vines. Crown 8ro. 12s. 6d. net.

Studies in Forestry. By J. Nisbet. Crown 8vo. 6s. net.

Forest 'l'erminology (French-German-English). By W. R. Fisuer. [In the press.]

'The Physical Properties of Soil. By R. Waringron. 8ro. 6s.

School Gardening. By P. Eufond and S. Heaton. Crown sro, illustrated. 2s. net.

A School Garden Note-Book. By Percr Elfond and S. Heatox. Crown 8vo. 9d. net. 


\section{Biology}

Essays on Erolution. By E. B. Pourtos. 8vo. 12s. net. Physiological Histology. By G. Mans. 8vo. 15s. net. Experimental Embryology. By J. W.Jenkissos. 8vo. 12s.6d. net. Adler's Alternating Generations; a Biological Study of Oak Galls and Gall Flies. Translated and edited by C. R. Srastox. With coloure. illustrations of 42 Species. Crown 8vo. 10s. 6d. net.

The Birds of Oxfordshire. By O. V. Apurs. 8vo. 7s. 6d. net.

The Harlequin Fly : its Structure and Life-History. By L. C. Mrall. and A. R. HAsmond. With one hundred and thirty illustrations. 8vo. is. 6d. A Naturalistin'Tasmania. By G. W. Sмгтн. 8vo, illustrated. 7s. 6d. net. Müller's Vocal Organs of the Passeres, translated by F. J. BeLr, and edited by A. H. Garrod. With plates. 4to. îs. $6 \mathrm{~d}$.

A Glossary of Greek Birds. Bу D’Arсу W. Thомтson. 8vo. 10s. net. The Order Oligochaeta, a Monograph, Structural and Systematic. By F. E. Beddard. With illustrations. Demy 4to. £2 2s. net.

Memoirs on the Physiology of Nerve, of Muscle, and of the Electrical Organ. Edited by Sir J. Burnon-Sanderson. Medium 8vo. £l 1s.

Ecker's Anatomy of the Frog. Translated, with Additions, by G. Haslas. Medium 8vo. 21 ls.

Weismann's Essays upon Heredity. Authorized Translation. Crown 8vo. Vol. I. Ed. E. B. Pourtos, S. Schöntand, and A. E. Shiplex. Ed. 2. 7s. 6d. Vol. II. Ed. E. B. Pourtox and A. E. Shipley. 5s.

Catalogue of Eastern and Australian Lepidoptera Heterocera in the Oxford University Museum. By Colonel C. SwiNhoE. Part I : 8vo, with eight plates, £1 ls. Part II : by Col. C. Swrshoe, Lord Waisingham and J. H. Durrant. With eight plates, £2 $2 \mathrm{~s}$.

African Mimetic Butterflies. By H. Eutringhasr. With ten coloured plates and a map. Royal 4to. £2 10s. net.

Forms of Animal Life, a manual of comparative Anatomy. By G. Rolurston. Second edition. Medium 8vo. £1 16s.

Rolleston's Scientific Papers and Addresses. Edited by W. TurNer. With biographical sketch by E. B. Truor. 2 vols. 8vo. $£ 14 \mathrm{~s}$.

Nature and Man. By Sir E. RaY Lankester (being the Romanes Lecture, 1905). 8vo, paper covers. Third impression. 2s. net.

An Introduction to the Study of Biology. By J. W. Kirkatdr and I. M. Drusmoxo. Crown 8vo, illustrated. 6s. 6d.

Lectures on the Method of Science. Edited by T. B. Strona 8 vo. 7s. 6d. net.

Rivers and Canals. By L. F. Vernon-Harcourt. 2 vols. 8vo. 31s. $6 \mathrm{~d}$ 


\section{Medicine and Hygiene}

Quarterly Journal of Medicine. Edited by WuLuas OsLER, J. Rose Bradford, R. Hutchison, A. E. Garrod, H. D. Rolieston, and W. HALE White. 8s. 6d. net per number. Annual Subscription, 25 s. Vol. I (Nos. 1-4), Vol. II (Nos. 5-8), Vol. III (Nos. 9-12), 35s. net each.

Studies in the Medicine of Ancient India. By A. F. R. Hoerní.. 8vo. Part I : Osteology. Illustrated. 10s.6d.

Surgical Instruments in Greek and Roman 'Times. By J. S. MiLNE. With illustrations. 8vo. 14s. net.

English Medicine in Anglo-Saxon 'Times: the Fitz-Patrick Lectures for 1903. By J. F. PAYNE. 8vo, with 23 illustrations. 8s. 6d. net. 'The Study of Medicine in the British Isles : Fitz-Patrick Lectures, 1905-6. By Norman Moore. 8vo, with 13 Collotype plates. 10s. 6d. net.

The Last Days of Charles II. By Raysond Crawrurd. Medium 8 vo, illustrated. 5s. net.

An Alabama Student and other Biographical Essays. By WiLLras Osser. 8vo, with portraits and other illustrations. 7s. 6d. net.

'Two Oxford Physiologists (Lower and Mayow). By Fraxcis Goтсн. Svo. 1s. net.

Criminal Responsibility. By Charres Mercier. 8ro. 7s. 6d. net. The Construction of Healthy Dwellings. By Sir D. Gatros. Second edition. 8vo. 10s. $6 \mathrm{~d}$.

Healthy Hospitals. By the same, with illustrations. 8vo. 10s.6d. A System of Physical Education: Theoretical and Practical. By A. Maclaren. New edition, by W. Maclaren. Crown 8vo. 8s. 6d. net. Pathological Series in the Oxford Museum. By Sir H. W. AcLAND. 8vo. 2s. 6d. Epidemic Influenza. By F. A. Dixey. Medium 8vo. is. 6d. Scarlatina. By D. A. Gresswel. Medium 8vo. 10s. $6 \mathrm{~d}$. Surgical Aspect of Traumatic Insanity. By H. A. Powell. 8vo. 2s. 6d.

\section{The Oxford Medical Publications} PUBLISHED BY

\section{HENRY FROWDE AND HODDER \& STOUGHTON}

(A complete list may be had on application.)

'The Collected Writings of the Right Hon. Lord Lister, O.M., F.R.S. In two volumes. Demy 4to. 42s. net.

'The History of Medicine. By Prof. Max Neuberger. Translated by ERnfest Prayfair. In 2 volumes. Crown 4 to. Vol. I now ready. 25 s. net. Practical Pathology. By G. Siss Woodnead. Fourth edition. Illustrated by over 240 microscopical drawings in colour. Demy 8vo. 31s.6d.n. Clinical Pathology in General Practice. By T. J. Horder. Demy 8ro. 7s. 6d. net.

A System of Medicine. Edited by Wirliam Oster, F.R.S., and Thomas McCrae. In seven 8vo volumes of about 900 pages each illustrated. Price to subscribers for the seven volumes 24 s. net each volume; to non-subscribers, single volumes, 30s. net. 
A System of Diet and Dietetics. From the scientific and practical standpoint. Edited by G. A. Sutherland. Crown 4to. 30s. net. A System of Operative Surgery. Edited by F. F. Burghard. Now ready, complete in four vols. Cr. 4 to. $£ 6$ net the set, or $36 \mathrm{~s}$. net each vol. Fevers in the'Tropics. By Leonarn Rogers, I. M.S. Cr. 4to. Ed. 2. 30s.n. Heart Diseases. By Jasies Mackenzie. 2nd ed. Cr. 4to. 25s. net.

Heart Diseases_Graphic Methods. Ву Jонм HAY. 7s. 6d, net. 'Text-book of Anatomy. Edited by D. J. Cunninghas, F.R.S. Third edition. Royal 8vo. 31s. 6d. net.

Manual of Practical Anatomy. By D. J. Cunningham, F.R.S. Fourth edition. In two volumes. Crown 8vo. 10s. 6d. net each.

Manual of Surgery. By Alexis Thosson and Alexander Miles. Third edition. Two vols. Crown 8vo. 10s. 6d. net each.

Manual of Operative Surgery. By H. J. Waring. Third edition. 521 Illustrations, including 30 in colour. Crown 8 vo. 12s. 6d. net.

Operations of General Practice. By Edren M. Corner and Henry Irvisg Pincues. Third edition. Demy 8vo. 15s. net.

Fractures and their 'Treatment. By J. Hogarth Pringle. Royal 8 vo. 15 s. net.

A Handbook of the Surgery of Children. By Prof. E. Kermisson. Translated by J. Keоgh Murpuy. 8vo. 20s. net.

Emergencies of General Practice. By P. Sargent and A. E. Russell. Demy 8vo. 15s. net.

Infectious Diseases. By C. B. Ker. Crown 4to. 20s. net.

Manual of Bacteriology. By Robert Muir and James Ritchie. Fifth edition, thoroughly revised. With nearly 200 illustrations in the text and 20 figures in colour. Crown $8 \mathrm{vo}$. 10s. 6d. net.

A Laboratory Handbook of Bacteriology. By R. Asez. Translated by M. H. Gornos, from the Tenth (German) Edition. Cr. 8vo. 5s. net. Functional Nervous Disorders in Childhood. By Leovard G. Guthrie. Second impression. Crown 8vo. 7s. 6d. net.

Common Disorders and Diseases of Childhood. By G. D. Stir L. Demy 8vo. Second Impression. 15s. net.

The Blood in Health and Disease. By R. J. M. Buchanan. Demy 8vo. 12s. 6d. net.

Sprains and Allied Injuries of Joints. By R. H. A. Whrтelocke. Demy 8vo. Second edition. Ts. 6d. net.

Medical Inspection of Schools. By A. H. Ноgarth. Cr. 8vo. 6s. n. Introduction to Practical Chemistry. By A. M. KeLLas. Demy 8vo. 3s. 6d. net.

Practical Inorganic Chemistry. ByA. M. Keldas. Demy8vo. 5s.n. Outlines of Zoology. By J. Автнur Thosson. Fifth Ed. Revised and Enlarged. Crown 8vo. 12s. 6d. net.

\section{IN PREPARATION}

The Surgery of the Skull and Brain. By L. Bathe Rawling. 


\section{Oxford Medical Manuals}

Edited by J. Keogh Murphy. Crown 8vo. 5s, net each volume.

Diseases of the Larynx. By H. Barwell. Treatment of Disease in Children. By G. A. Sutherland. Surgical Emergencies. By P. Sargent. Skin Affections in Childhood. By H. G. Adasson. Heart Disease. By F. J. Poynton. Practical Anaesthetics. By H. E. G. Boyre. Diseases of the Ear. By Hunter Tod. Diseases of the Nose. By E. B. WagGetт. Diseases of the Eye. By M. S. MAyov. Gunshot Wounds. By Major C. G. Spexcer. Infant Feeding. By J. S. Fowler. Aseptic Surgery. By C. B. Lockwood. Gallstones, their Complications and 'Treatment. By A. w.

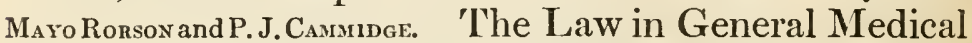
Practice. Ву S. Аткгмson. Glandular Enlargements. Ву A. Eduunds.

\section{Geology}

The Face of the Earth (Das Antlitz der Erde). By Eduard Suess. Translated by Hertha B. C. Sollas, under the direction of W. J. Sollas ; with a preface by Professor Suess. Royal 8vo. In five volumes.

Vol. I, with 6 maps and 48 illustrations. 25s. net.

Vol. II, with 3 maps and 4.2 illustrations. 25s. net.

Vol. III (= III $\mathrm{i}$ of the German edition), with 7 maps and 23 illustrations. Iss. net.

Vol. IV (=III ii of the German edition), with 55 illustrations. 25s, net.

Fossils of the British Islands, Stratigraphically and Zoologically arranged. Part I, Palaeozoic. By R. Etheridae. 4to. \&l 10s.

Martini Lister Historia sive Synopsis Methodica Conchyliorum. Editio Tertia. Recensuit et indice locupletissimo instruxit L. W. Diwwy's. 1823. With numerous plates. 52s. 6d. net.

First Lessons in Modern Geology. By A. H. GreEN, edited by J. F. BlakE. With 42 illustrations. Crown 8vo. 3s. 6d.

Geology of Oxford and Thames. By J. Pnimurs. 8vo. £l ls. Vesuvius. By the same. Crown 8vo. 10s. 6d.

Geology. By Sir J. Presswicr. Royal 8ro. Vol. I. Chemical and Physical. £1 5s. Vol. II. Stratigraphical and Physical. With a geological map of Europe. £1 16s. Geological Map (separately), 5s.

Physics of Earthquake Phenomena. By C. G. Ккотт. 8ro, with numerous diagrams. 14s. net. 


\section{Astronomy}

Astronomy in the Old Testament. By G. Schiaparelu. Authorized English translation. Crown 8vo. 3s. 6d. net.

A Handbook of Descriptive Astronomy. By G. F. Chasibers. Fourth edition. In three vols. 8vo. 28s. net, or separately, Vol. I. Sun, Planets, and Comets, 15s. net. Vol. II. Instruments and Practical Astronomy, 15s. net. Vol. III. The Starry Heavens. 10s. 6d. net.

The Story of the Comets. By G. F. Chamrbers. 8vo, with many illustrations. Second Edition. 6s. net.

Bradley's Miscellaneous Works. 4to. 17s. net.

A Cycle of Celestial Objects, observed, reduced, and discussed by W. H. Sмrтth ; revised and greatly enlarged by G. F. Сhasвers. 8vo. 6s. net. Astronomical Observations made at the University Observatory, Oxford, under the direction of C. Pritciard. Royal 8vo.

No. I. On observations of Saturn's Satellites. Paper covers, 3s. 6d.

No. II. A Photometric determination of the magnitudes of all Stars visible to the naked eye, from the Pole to $10^{\circ}$ south of the Equator, 8s. 6d. Nos. III and IV. Researches in Stellar Parallax by the aid of Photography. Part I, 7s. 6d. Part II, 4s. 6d.

Tables for Facilitating Computation of Star-Constants. By H. H. Turner. Second impression. 8vo. 2s. (published by Mr. Frowde). Halley's Comet. By H. H. Turner. 8vo. Ed. 2. Illustrated. Is. net. Halley's Comet, with notes on Comets in general. By G. F. Chambers. 8vo. Illustrated. 1s. net.

Celestial Ejectamenta : the first Halley Lecture, by Henry WiLde. 8vo. Illustrated. 1s. net.

\section{Chemistry}

Mathematical Crystallography. By H. Hirton. 8vo. 14s. net. Crystallography. A treatise on the Morphology of Crystals. By N. Story-M MSKelyne. Crown 8vo. 12s. 6d.

Fock's Introduction to Chemical Crystallography, translated by W. J. Pope; preface by N. Story-Maskelyne. Cr. 8vo. 5s. The Molecular Tactics of a Crystal. By Lord Kenvis. 8vo. 3s. 6d. Organic Chemistry of Nitrogen. By N.V.Sidgwcr. 8vo. 14s.net. Elementary Chemistry. Progressive Lessons in Experiment and Theory. By F. R. L. Wilson and G. W. Heduey. 8vo, with many diagrams. Part I. Second edition. 3s. Part II. Second edition. 5s.

Class Book of Chemistry. ByW.W. Frsher. Ed, 5. Cr.8vo. 4s. 6d. Exercises in Practical Chemistry. By A. G. Vernon Harcourt and H. G. Madan. Fifth edition. Crown 8vo. 10s. 6d.

$V$ an 't Hoff's Chemistry in Space, translated and edited by J. E. Marsh. Crown 8vo. 4s. 6d.

Original Papers in the Science of Chemistry. A list compiled by V. H. Velery. Third edition. Paper covers, ls.

Chemistry for Students. By A. W. Wiumasson. Fcap. 8vo. 8s. 6d. Tables of Qualitative Analysis. By H. G. Madan. 4to. 4s. 6d. 


\section{Pure and Applied Mathematics}

Introduction to the Algebra of Quantics. By E. B. Ециотт. 8 vo. 15s. net.

'Theory of Continuous Groups. By J. E. Camprelr. 8vo. 14s. net. 'Theory of Groups of Finite Order. By Haroud Hilton. 8 vo. 14 s. net.

Treatise on Infinitesimal Calculus. By Bartholosew Price.

Vol. I. Differential Calculus. [Out of print.]

Vol. II. Integral Calculus, Calculus of Variations, etc. [Out of print.]

Vol. III. Statics, including Attractions; Dynamics of a Material Particle. Second edition. 8 vo. 5 s.

Vol. IV. Dynamics of Material Systems. Second edition. 8vo. 5s.

The Collected Mathematical Papers of H. J. Stephen Smith, late Savilian Professor of Geometry in the University of Oxford. Edited by J. W. L. Glaisher. 2 vols. 4to. £3 3 s.

Rigaud's Correspondence of Scientific Men of the Seventeenth Century. 1841. 2 vols. 8vo. 18s. 6d.

\section{Elementary Books}

Responsions Papers in Stated Subjects (exclusive of Books), 1901-1906, with answers to Mathematical Questions and Introduction by C. A. Marcon and F. G. Brabant. Crown 8vo. 3s. 6d. net.

A School Course of Mathematics. By David Marr. Crown 8ro. 3s. $6 \mathrm{~d}$.

A Study of Mathematical Education, including the teaching of arithmetic. By Bexchara Branford. Crown 8vo. 4s. $6 \mathrm{~d}$.

School Algebra. By W. E. Paterson. Crown 8vo. Parts I (Ed.3) and II (Ed. 2), each, 2s. 6d. (with answers, each 3s.); together, 4s. (with answers, 5s.). Arithmetic. With or without answers. By R. Hargreaves. Crown 8 vo. 4s. $6 \mathrm{~d}$.

Elementary Plane Trigonometry. By R. C. J. Nrxox. Crown 8 vo. 7 s. $6 \mathrm{~d}$.

Book-keeping. By Sir R. G. C. Hasrlton and J. Bar... Feap 8vo. 2s. Ruled exercise book to the above, 1s. 6d. ; to preliminary course only, $4 \mathrm{~d}$.

Lectures on the Logic of Arithmetic. By M. E. Boole. Crown 8 vo. 2s. ; or interleaved with writing-paper, 3s.

Figures made Easy : a first Arithmetic Book. By Lewis Hexsley. Crown Sro. $6 \mathrm{~d}$. Answers, is.

The Scholar's Arithmetic. By the same. 2s. 6d. Answers, 1s. 6d.

The Scholar's Algebra. By the same. Crown 8vo. 2s. 6d.

A Text-Book of Algebra : with Answers. By W. S. Aldis. Cr. Sro. is. 6d. Elementary Mechanics of Solids and Fluids. By A. L. Setriy. Crown 8vo. 3s. $6 \mathrm{~d}$. 


\section{Geometry}

Geometry for Beginners : an easy introduction to Geometry for young learners. By G. M. Miscins. Extra fcap 8vo. 1s. 6d.

Elementary Geometry, on the plan recommended by the Mathematical Association.

Experimental and Theoretical Course of Geometry. By A. T. W Arren. With Examination Papers set on the new lines. Crown 8vo. With or without answers. Third edition with additions (1905). 2s.

Elementary Modern Geometry. Part I. Experimental and Theoretical. (Ch. I-IV) Triangles and Parallels. By H. G. WILLIs. Crown 8vo. 1905. 2s.

Euclid Revised, containing the essentials of the Elements of Plane Geometry as given by Euclid in his first six books, edited by R. C. J. Nixon. Third edition. Crown 8vo. 6s.

Sold separately as follows :-Book I, 1s.; Books I, II, 1s. 6d. ; Books I-IV, 3s.; Books V, VI, 3s. 6d.

Geometry in Space, containing parts of Euclid's Eleventh and Twelfth Books. By R. C. J. Nixos. Second edition. Crown 8vo. 3s.6d.

Geometrical Exercises from Nixon's Euclid Revised. With Solutions. By Alexander Larmor. Crown 8vo. 3s.6d.

'The 'Junior' Euclid. By S. W. Fins. Crown 8ro. Books I and II, 1s. 6d. Books III and IV, 2s.

Sequel to Elementary Geometry, with numerous examples. By J. W. Russel.. Cr. 8vo. 6s. Solutions (Key). Cr. 8vo. 10s. 6d. net. Obtainable only from the Secretary, Clarendon Press, Oxford.

Pure Geometry, an elementary treatise, with numerous examples. By J. W. Russelz. Crown 8vo. New and revised edition (1905). 9s. net.

Analytical Geometry, an elementary treatise by W. J. Johnstow. Crown 8vo. 6s.

Notes on Analytical Geometry. By A. Clemient Jones. Crown 8vo. 6s. net.

Cremona's Elements of Projective Geometry, translated by C. Leudesdorf. Second edition. 8vo. 12s. 6d.

Cremona's Graphical Statics, being two treatises on the Graphical Calculus and reciprocal figures in Graphical Statics, translated by T. H. BEARE. 8vo. 8s. $6 \mathrm{~d}$.

On the Traversing of Geometrical Figures. By J. Coor Wirsos. 8vo, with Addendum. 6s. 6d. net. Non-Euclidean Geometry. By J. L. Coornde. 8vo. 15s, net. 


\section{Physics}

Hermann von Helmholtz. By Leo Koentgsberger. Translateí by Frances A. Werby. With a Preface by Lord Kelvin. Royal 8vo, wit] 3 portraits. 16 s. net.

Modern Views on Matter, being the Romanes Lecture for 190: By Sir Oliver Lodge. New edition. 1s. net.

Treatise on Electricity and Magnetism. By J.CLerr Maxwel Third edition. Two vols. 8vo. £1 12s.

Notes on Recent Researches in Electricity and Mag netism. By Sir J. J. THоsson. 8vo. [Out of print.]

Maxwell's Elementary 'Treatise on Electricity. Edited b W. GaRNETT. 8vo. 7s. 6d.

Introduction to the Mathematical Theory of Electricit and Magnetism. ByW. T. A. Esrrage. 2nd ed. Crown 8vo. 7s. 6r

'The Measurement of Electrical Resistance. By W. A. Pric: 8vo. $6 \mathrm{~s}$.

'The Mathematical 'Theory of Electricity and Magnetisn

In two volumes. By H. W. WAtson and S. H. Burbury. 8vo. 6s. each.

Vol. I. Electrostatics. Vol. II. Magnetism and Electrodynamics.

The Application of Generalized Co-ordinates to the Kineti of a Material System. By the same. 8vo. 2s. 6d.

Lessons on Thermodynamics. By R. E. Bayses. [Out of print Elementary Treatise on Heat, with numerous Woodcuts ar Diagrams. By Balfour Stewart. Sixth edition, revised with Additions, $\mathrm{k}$ R. E. Baynes. Crown 8vo. 8s. $6 \mathrm{~d}$.

Practical Work in General Physics. By W. G. Woоцсомв Crown 8vo. 2s. each part.

Part I. General Physics. Out of print. Part II. Heat. Second Editio Revised. Part III. Light and Sound. Part IV. Magnetism \&I Electricity. Out of print.

The 'Theory of a Physical Balance. By J. Watrer. 8vo. 3s.6c A 'Treatise on the Kinetic 'Theory of Gases. By H.W. WArso Second edition. Crown 8vo. 4s. 6 d.

Acoustics. By W. F. Donkrn. Second edition. Crown 8vo. 7s. 6d. nr A 'Treatise on Statics with Applications to Physics. I G. M. Minchin.

Vol. I. Equilibrium of Coplanar Forces. Sixth edition. 8vo. 10s. 6d.

Vol. II. Non-Coplanar Forces. Fourth edition. 8vo. 16s.

Hydrostatics and Elementary Hydrokinetics. By the san Crown 8vo. 10s. 6d. 

Date Due Slip-This Book may be kept FOURTEEN DAYS

A fine of 2 Cents will be charged for each day the book is kept overtimc.

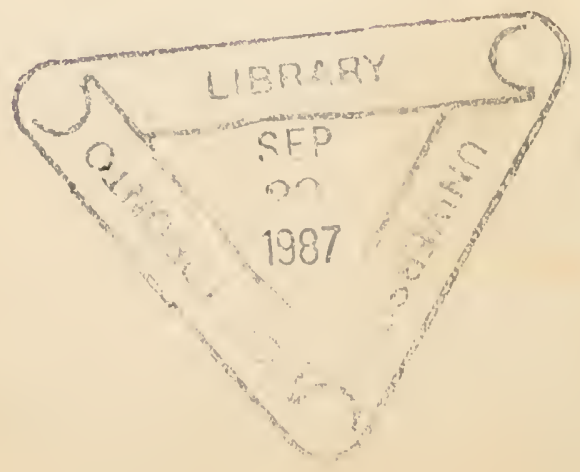




\section{PLEASE DO NOT REMOVE \\ CARDS OR SLIPS FROM THIS POCKET}

\section{UNIVERSITY OF TORONTO LIBRARY}

Gr een, Joseph Reynolds

A History of botany

QK
15
S14
C. 2
*BOTA 


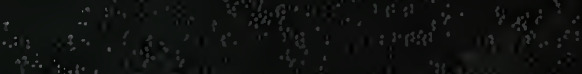

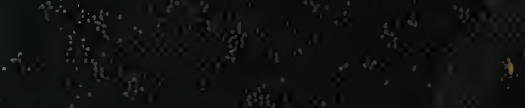

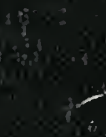

